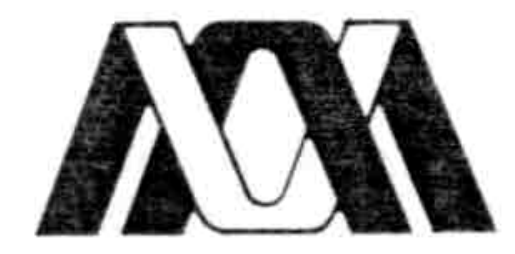

Casa abierta al tiempo

UNIVERSIDAD AUTÓNOMA METROPOLITANA

UNIDAD IZTAPALAPA

DIVISIÓN DE CIENCIAS SOCIALES Y HUMANIDADES

POSGRADO EN CIENCIAS ANTROPOLÓGICAS

Dinámicas jurídicas, construcción del derecho y procesos de disputa en una comunidad indigena de Oaxaca

Elisa Cruz Rueda

Tesis de Doctorado en Ciencias Antropológicas

Directora: Dra. Maria Teresa Sierra Camacho

Asesoras: Dra. Margarita del Carmen Zárate Vidal

Dra. Maria Victoria Chenaut González

México, D.F.

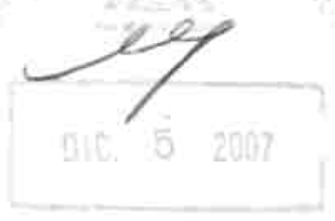




\section{DINÁMICAS JURÍDICAS, CONSTRUCCIÓN DEL DERECHO Y PROCESOS DE DISPUTA EN UNA COMUNIDAD INDÍGENA DE OAXACA}

\section{CONTENIDO}

AgRADECIMIENTOS

INTRODUCCIÓN

PARTE I

TRANSFORMACIÓN Y PROCESOS DE CAMBIO EN EL CAMPO JURÍDICO:

RELACIÓN ENTRE EL ESTADO Y LOS PUEBLOS INDÍGENAS

\section{CAPÍtUlo 1}

LA TENSIÓN EN LA RELACIÓN DEL ESTADO CON LOS PUEBLOS INDÍGENAS:

\section{CAPÍtulo 2}

LAS TENSIONES EN EL CAMPO JURÍDICO: LO TERRITORIAL

\section{PARTE II}

NIVELES LEGALES DEL CAMPO JURÍDICO Y SUS TENSIONES: EL CASO DE

TOTONTEPEC Y SAN MARCOS MÓCTUM

\section{CAPÍTULO 3}

LA RELACIÓN ENTRE EL DISTRITO, EL MUNICIPIO Y LA LOCALIDAD COMO

DEMARCACIONES TERRITORIALES DEL CAMPO JURÍDICO

\section{CAPÍtulo 4}

LA CUESTIÓN AGRARIA COMO ESTRUCTURADORA DEL DERECHO Y LA

AUTONOMÍA COMUNITARIA

PARTE III

LAS DINÁMICAS DEL CAMPO JURÍDICO Y LA CONFRONTACIÓN ENTRE INSTANCIAS

CAPÍtulo 5

EL SISTEMA JURÍDICO Y LA RESOLUCIÓN DE CONFLICTOS EN TOTONTEPEC

CAPÍtulo 6

LAS INSTANCIAS LEGALES Y EL SISTEMA JURÍDICO EN SAN MARCOS MÓCTUM

CONCLUSIONES FINALES 


\section{AGRADECIMIENTOS}

En la elaboración de este trabajo recibí el apoyo de muchas personas y organizaciones sin las cuales, seguramente no hubiera sido posible llevar a cabo la empresa que implica el proceso de investigación y elaboración de una tesis de doctorado.

En principio, quiero agradecer al Dr. Roberto Varela Velásquez (†) ya que fue el que me aplicó la primera entrevista para ingresar al programa de doctorado del Departamento de Antropología de la UAM-I. Con esto y con su muestra en los hechos de su apoyo para que pudiera ingresar al gremio de los antropólogos, me ofreció esta oportunidad pero además, la de reconocer en un gran pensador las virtudes de la calidez humana y del rigor académico y profesional.

Con la intervención del Dr. Roberto Varela tuve también el honor de contar con la dirección inicial del Dr. Esteban Krotz Heberle y posteriormente de la Dra. María Teresa Sierra. Por supuesto, lo que el Dr. Roberto Varela hizo por mí -como por muchos y muchas de mis compañeras -, sus gestiones, apoyos y atenciones, no hubieran sido posibles sin la intervención siempre profesional y diligente de la Sra. Socorro Flores, de la cual también, siempre he recibido su calidez humana y su disposición de ayuda y de estar siempre dispuesta, hasta donde su propias posibilidades le permitían, y constaté que siempre daba más de lo que le tocaba.

De igual forma quiero agradecer a la Dra. María Teresa Sierra Camacho, quien aceptó continuar dirigiendo mi trabajo de elaboración de tesis en una etapa que tal vez, lo más fácil hubiera sido empezar de cero. Sin embargo, gracias a su comprensión, tesón y compromiso humano, profesional y académico, pude llevar a mejor término esta obra de doctorado. Es importante agregar que gracias a la Dra. Sierra Camacho he podido afinar mi criterio antropológico, por su atención en invitarme a dos proyectos de investigación de los cuales he podido obtener 
herramientas teóricas y retroalimentación con otros colegas para dar forma a esta tesis de doctorado.

Agradezco a la Dra. María Victoria Chenaut González-Lelong y a la Dra. Margarita del Carmen Zárate Vidal por que a pesar de sus múltiples compromisos y trabajos aceptaron leer y dictaminar este trabajo, además de facilitarme sus comentarios, observaciones y correcciones puntuales y precisas, con lo cual ayudaron a mejorar en mucho el contenido y presentación de esta obra doctoral.

A mi colega antropóloga y amiga Dra. Artemia Fabre Zarandona, agradezco porque me dio su apoyo, cuando pensaba claudicar y dejar de lado este trabajo; leyó, analizó y me condujo en una parte importante para clarificar ideas y conceptos. También agradezco a mi amiga la Dra. María Teresa Valdivia Dounce, porque también me impulsó con sus comentarios y retroalimentación para perfeccionar mis planteamientos sobre el sistema normativo en comunidades mixes.

Reconozco también que sin el apoyo y confianza de las autoridades comunitarias visitadas, no hubiera sido posible obtener el corazón etnográfico de este trabajo. En este sentido, agradezco infinitamente a las autoridades y pobladores (hombres, mujeres, niños y niñas) de San Marcos Móctum y especialmente al Sr. Cipriano Gómez Gómez y su familia, a la Sra. Hipólita Bravo y a la Sra. Noemí Gómez Bravo (lidereza y poetisa mixe) y a las mujeres del grupo “Mujeres Olvidadas del Rincón Mixe” que me ofrecieron su apoyo, amistad y acompañamiento. También agradezco el apoyo y apertura de las autoridades de Totontepec, especialmente al Sr. Guillermo Gómez Reyes (†) (Alcalde Único Constitucional en el año 2004) y al Mtro. Lucio López Reyes (Presidente Municipal del año 2004).

Especialmente quiero agradecer a mi familia de origen y actual, sin las cuales definitivamente no hubiera iniciado y concluido esta tesis. Fundamentalmente quiero agradecer a mi papá el economista Mtro. Federico Cruz Castellanos (†) y mi mamá la socióloga Lic. Idalia Rueda Cadena, por el camino 
que me mostraron y que he decidido continuar, por el apoyo incondicional siempre oportuno de ella que me dio fortaleza y confianza para concluir; a mis hermanos Carlos Federico y Paulo Constantino por su presencia. De igual forma, quiero agradecer a mi esposo el Lic. Javier S. Balderas Castillo que nunca dudó de mi capacidad para terminar y que me ha ayudado infinitamente hasta donde ha podido para este fin; y a mi hijo Iyari Balderas Cruz, por su paciencia y presencia.

De igual forma me interesa subrayar la intervención de muchas personas, compañeros y amigos que me alentaron a continuar este proceso que marca un momento muy importante en mi vida, entre otros Dolores González Saravia, Amparo Sevilla y Martha Flores; a los indígenas, sus organizaciones, comunidades y pueblos, cuya realidad me impulsó a incorporarme a la antropología jurídica Seguramente me faltaron muchas personas y organizaciones, ante las cuales pido me disculpen por la grave omisión al no mencionarlas.

Finalmente el proceso de investigación, trabajo de campo, elaboración de diversos borradores hasta la obra que ahora se presenta no hubiera sido posible sin el apoyo financiero del Consejo Nacional para la Ciencia y la Tecnología (CONACYT), del que obtuve los recursos necesarios y oportunos para mis primeros estudios de antropología desde la especialización, durante la maestría y en el doctorado del Departamento de Antropología de la Universidad Autónoma Metropolitana Unidad Iztapalapa. También, es importante señalar que obtuve apoyo del CONACYT para participar en el proyecto de investigación "Interculturalidad, derecho y género en regiones indígenas: un enfoque comparativo", dirigido por la Dra. María Teresa Sierra Camacho; participación que me permitió abundar en mis conocimientos antropológicos y, afinar mis ideas y planteamientos para verterlos en mi tesis de doctorado. De este proyecto resultó un artículo como parte del libro: "Haciendo Justicia: Interlegalidad y género", coordinado por la Doctora Sierra Camacho (CIESAS-DF).

México, D.F. a 28 de septiembre de 2007 


\section{INTRODUCCIÓN}

A mi manera de actuar ya lo hice, si no hice bien ¿acaso no es válido?

Soy parte del juez porque él no puede venir aquí a esperar cuánta gente viene a pedir justicia.

Yo conozco a mi gente, quiénes son malos

¿Por qué ellos se fueron? ¿Por qué rebasaron?

Yo soy la justicia, soy la autoridad, porque la gente me nombró.

Ahora, ¿qué no es válido lo que yo hago aquí? ¿No tiene validez?

Si el juez hace así, que él venga y que escuche aquí la gente

porque ella me dio el lugar, el mando, y eso es la ley, lo que la gente decidió.

Si el juez no considera lo que yo estoy haciendo que él venga.

Aquí ya se hizo Justicia. No estamos como juguetes para hacer lo que la gente no conoce.

Yo me hago a un lado si te crees capaz.

¿Por qué el juez no me pidió información, si aquí está el asunto?

Guillermo Gómez Reyes

(Alcalde Único Constitucional de Totontepec)

Entrevista realizada el 20 de octubre de 2004

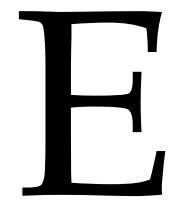

n esta tesis, me propongo estudiar el derecho vigente en comunidades mixes ${ }^{1}$ del municipio de Totontepec, en la Sierra Norte del estado de Oaxaca, tal como es construido y negociado por los actores sociales en sus dinámicas cotidianas y en su relación con el Estado. En especial, me propongo dar cuenta de qué manera comunidades tan pequeñas - como San Marcos Móctum- han conseguido construir sus sistemas normativos y sus propias regulaciones en un contexto histórico de tensiones y conflictos con unidades mayores - como la cabecera municipal de Totontepec- a las cuales se han encontrado históricamente subordinadas, participando en campos jurídicos heterogéneos hegemonizados por el Estado.

En el caso de Oaxaca, como en muchos otros estados del país con fuerte presencia indígena, la defensa del territorio comunal junto con el reconocimiento de los pueblos-cabeceras ha marcado en gran medida la conformación del orden jurídico regional y estatal, fomentando el localismo y el arraigo comunitario, más que las identidades étnicas regionales, y ha repercutido también en el tipo de

\footnotetext{
${ }^{1}$ Mixe o ayuuk ja'ay que en español significa gente de la palabra sagrada (Barabas y Bartolomé 2004:16). En adelante usaré ayuuk o mixe, indistintamente.
} 
relación corporativa y subordinada que se ha gestado con el Estado. Todos estos procesos han incidido en la conformación de los sistemas normativos de las comunidades indígenas entendidas como campos sociales semiautónomos. En las últimas décadas, se observan cambios importantes en la relación del Estado con los pueblos indígenas, especialmente marcados en las nuevas legislaciones que reconocen los derechos indígenas y un cierto margen de autonomía local y de manejo de recursos municipales que, si bien limitados, afectan las dinámicas del campo jurídico y político regional, y propician la redefinición del derecho vigente en las comunidades. De esta manera, la tesis pretende también mostrar en qué sentido dichos cambios dan cuenta de procesos generales de construcción de hegemonía y subalternidad, y ejercicio del poder ${ }^{2}$ a través del derecho.

Retomo la propuesta planteada por Santos (1998) que sostiene que el derecho, en sentido amplio en las sociedades contemporáneas, está conformado por un universo policéntrico y dinámico en el que existen sistemas normativos distintos relacionados entre sí, pero con características propias. Bajo esta perspectiva, el objeto de estudio es documentar y analizar la manera en que dos comunidades indígenas del mismo grupo etnolingüístico, como cabecera municipal y como agencia, construyen y negocian su derecho indígena para distinguirse como campos sociales semiautónomos (Moore 1990, véase CAPÍtUlO 1 de esta tesis) y con ello confrontar el ejercicio de poder y control de comunidades mayores o incluso del Estado mexicano, frente a los cuales se encuentran históricamente subordinadas.

Por lo anterior, el derecho como producto social y cultural se convierte en un referente clave para comprender los procesos identitarios (v. gr. su mito de origen, quiénes son y quiénes no son parte de un grupo o comunidad) que definen a la comunidad en el contexto local y regional. Al mismo tiempo, el derecho revela

2 En este trabajo abundo sobre este término en el CAPÍtulo 3, apartado 3.3. En el caso de estudio además de esto mostraré cómo la aplicación del derecho indígena en una comunidad depende de distintos factores, entre otros, la mejor argumentación sobre casos ya dados. Quien tiene este conocimiento (del derecho y de la argumentación) tiene el poder de hacer que la asamblea y las autoridades dicten un resultado a favor o en contra. 
aspectos estructurales que conforman a una comunidad independiente y la insertan en las dinámicas de poder de la región y del estado. Así, el derecho se constituye como un referente clave en el ejercicio del poder local y para comprender los componentes del campo jurídico y político regional, objeto de mi investigación.

El interés personal de estudiar el derecho indígena tiene ya una historia larga, ${ }^{3}$ desde mis estudios de licenciatura en Derecho, y gracias a mi relación con organizaciones sociales y de derechos humanos, me enfoqué al seguimiento de la defensa de los derechos de los indígenas, sobre todo por detenciones extrajudiciales asociadas a conflictos por tierras.

Este acercamiento fue revelador de las ventajas del derecho como instrumento de defensa de derechos, pero también de sus limitaciones; de igual forma, el trabajo realizado con comunidades de Guerrero (con la organización “Luz de la Montaña”), de Veracruz (H. Ayuntamiento Constitucional de Playa Vicente, Veracruz, 1999) y de Oaxaca (Asamblea de Autoridades Mixes, Centro de Derechos Humanos Tepeyac del Istmo de Tehuantepec [Cruz 1994, 1995, 2004, 2005]), me permitió dar cuenta del uso del derecho del Estado por parte de organizaciones, comunidades y líderes indígenas para defender y enarbolar demandas, más que nada sobre tenencia de la tierra y derechos humanos en la

\footnotetext{
3 De esta manera, ya había realizado un estudio sobre el derecho indígena en una comunidad indígena del Bajo Mixe, San Juan Jaltepec de Candayoc, que constituyó mi trabajo de licenciatura en derecho (Cruz, 1994). De este caso, se derivaron por la Comisión Nacional de Derechos Humanos (CNDH 1991b) tanto la recomendación núm. 103/91 como la Memoria de la zona mixe en el estado de Oaxaca (1991a), que me motivaron a involucrarme con esta comunidad. Este trabajo lo realicé porque como estudiante de Derecho formaba parte de una organización estudiantil de Derechos Humanos llamada Taller Universitario de Derechos Humanos (TUDH), desde donde apoyábamos a la organización "Servicios del Pueblo Mixe" en talleres de capacitación jurídica. Esta organización indígena apoyó mi introducción a la comunidad, sin embargo, no contaba con las herramientas teóricas, metodológicas y analíticas para ir más allá de la descripción. Para continuar mi trabajo de indagación sobre los derechos y órdenes jurídicos indígenas, escogí a San Marcos Móctum (localizado en el extremo opuesto de la primera comunidad), pues poco antes de incorporarme al programa de maestría y doctorado de la Universidad Autónoma Metropolitana Unidad Iztapalapa UAM-I (1994) ya tenía una relación con algunos miembros de esta comunidad, a través de talleres sobre derechos humanos y con la organización de mujeres "Mujeres Olvidadas del Rincón Mixe" conformada por mujeres de la comunidad y dedicada a la capacitación y desarrollo de proyectos productivos.
} 
rama penal (conocidos como garantías individuales en el argot nacional). Sin embargo, al momento de tratar de estudiar las dinámicas internas y los usos del poder en las comunidades a la luz de lo aprendido en la Facultad de Derecho de la UNAM, es decir, a partir de códigos, leyes y normas del derecho positivo mexicano, también constaté las limitaciones de mi primera disciplina: era imposible entender el porqué al interior de una comunidad indígena se regulaban dinámicas y situaciones que el derecho del Estado no contemplaba, o bien, por qué se regulaban de formas distintas incluso hasta contradictorias $o$ en franca confrontación con ese derecho. Surgieron así una serie de interrogantes que han guiado gran parte de mis indagaciones: ¿Ante qué fenómeno social, económico o político me encontraba? ¿Cómo comprenderlo en su justa dimensión, si mi sola presencia era una alteración en las dinámicas internas? ¿Cómo saberlo? ¿Hasta dónde mi falta de comprensión de la diferencia cultural era un obstáculo para conocer lo jurídico en la comunidad? ${ }^{4}$ ¿Si esas comunidades tienen un margen de control interno, por qué recurren a la jurisdicción o justicia del Estado? Estas y otras preguntas surgieron y me plantearon la necesidad de acercarme con otra mirada a la defensa de los derechos indígenas. Podía percibir que el derecho no sólo eran normas, sino que incluye otros elementos que aparentemente no están considerados como parte del derecho positivo pero que evidentemente lo atraviesan y desde esta perspectiva conforman un campo jurídico (Santos 1995). Consideré que la antropología y especialmente la antropología política y jurídica me darían la posibilidad de ese acercamiento, además de darme nuevas herramientas para mi trabajo en la defensa de los derechos humanos de los indígenas, sus pueblos y organizaciones. El estudio de la antropología fue positivo

\footnotetext{
${ }^{4}$ En el caso del investigador que es oriundo de la sociedad a estudiar, no es garantía que el trabajo que realice exprese la cultura sin obstáculo o influencias externas algunas, pues la formación que recibió como antropólogo o abogado le da otra visión o comprensión de lo que observa, ya que sus conocimientos académicos los adquirió en una situación de subalternidad en la que los estados nacionales han impuesto una cultura nacional sobre las demás. Esto de acuerdo con Miguel A. Bartolomé (2001:48-51) quien hace referencia a la formación de profesionistas indígenas bajo la política indigenista y sus efectos en la investigación antropológica.
} 
porque amplió mi visión del derecho y de la relación de los pueblos indígenas con el Estado, ya que la perspectiva positivista del derecho dejaba fuera aspectos como las prácticas y usos del poder que finalmente son significativos para entender tanto las transformaciones de las comunidades indígenas, a su interior y en su relación con el Estado, como las del derecho.

De esta manera, el análisis contemporáneo del campo jurídico (Santos 1995) desde la especificidad de los pueblos y comunidades indígenas se torna especialmente relevante, debido a las actuales reivindicaciones sociales y políticas y a los cambios constitucionales para reconocer sus derechos. Por ello, cobra importancia sustancial la especificidad cultural y la historia de la relación del Estado con los pueblos indígenas.

Para entender justamente las transformaciones del derecho y las dinámicas del poder me centro en la tensión entre la cabecera municipal de Totontepec Villa de Morelos y San Marcos Móctum — como una de sus agencias- desde dos ejes principales de análisis: lo territorial —en su dimensión agraria y municipal—y la justicia y la jurisdicción.

El interés fundamental de este trabajo es mostrar cómo las normas jurídicas - sistema normativo - en una comunidad indígena tienen un arraigo en su historia y cultura, exponer cómo el sistema jurídico indígena producto de ese arraigo histórico y cultural, permite la inserción y/o adecuación entre elementos culturales diversos ${ }^{5}$ y cómo ese derecho indígena se ha gestado en relación con el derecho del Estado.

\footnotetext{
${ }^{5}$ Como parte de los procesos de transformación cultural existe una memoria colectiva que subsiste y se expresa en la lengua y en las formas de organización política, social y religiosa, que a decir de Artemia Fabre (2005:57): “No obstante lo violento de la conquista y la evangelización que trató a lo largo de la conquista misma y la Colonia, borrar y transformar la cultura y por ende las formas de organización política, social y religiosa, sabemos que parte de esa memoria colectiva, de ese pasado quedó en aquellos ámbitos más privados: en el individuo, en la familia donde el resguardo y continuidad de los valores individuales, familiares y su relación con los dioses y protectores se mantuvo intacto, en algunos lugares alejados de las grandes ciudades, en otros, encontramos, elementos ciertamente interconectados ya con la memoria católica, creando así, las expresiones católicas indígenas, las cuales tienen referentes de las expresiones religiosas mesoamericanas".
} 
De esta manera, las comunidades indígenas desde la época colonial a la fecha han pasado por procesos de transformación, adecuación y resistencia, creando formas diversas de relación entre el sistema normativo indígena y el derecho estatal; formas de relación que presentan particularidades coyunturales según las regiones y grupos étnicos (Bartolomé 1997; Sierra 2004a; Fabre 2005).

El campo jurídico en el que se relacionan distintos derechos, como es el indígena y el del Estado, no es uniforme en tanto los sistemas jurídicos que lo conforman se relacionan entre sí y están articulados bajo la égida del derecho estatal, que constituye el sistema jurídico hegemónico, que históricamente se ha impuesto a otros ordenamientos jurídicos como los sistemas jurídicos indígenas. En esta investigación, me he propuesto documentar desde el espacio local cómo se construye y negocia esta relación entre sistemas jurídicos en diferentes niveles de análisis. El campo jurídico en la región de estudio comprende distintos niveles legales y políticos: la federación, el estado de Oaxaca, la cabecera del municipio de Totontepec Villa de Morelos y sus agencias, en particular la agencia de Móctum. La circunscripción territorial del campo jurídico en el caso de estudio se ubica — sin considerar el nivel de la federación - en una zona indígena, porque ahí es posible ver la imbricación de sistemas legales y la hegemonía del Estado y cómo influyen en las transformaciones del derecho y las dinámicas del poder, esta zona se ubica en la región mixe (Sierra Norte) del estado de Oaxaca, concretamente se trata del municipio de Totontepec. Es importante advertir que el nivel federal lo enuncio como parte del contexto y que únicamente me aboco al campo jurídico en los niveles estatal, municipal-regional y de la agencia. Indudablemente lo federal es importante porque enmarca la conflictividad de la tenencia de la tierra y de la relación de las cabeceras municipales y sus agencias.

Asímismo, para facilitar este estudio, como ya mencioné, se han escogido dos ejes fundamentales de análisis: lo territorial y la jurisdicción y la justicia, ya que son elementos recurrentes para comprender la problemática jurídica de la mayoría de las regiones indígenas de Oaxaca. De esta manera, a partir de estos ejes 
se puede explicar y mostrar sincrónica y diacrónicamente la relación del poder y los usos del derecho en el campo jurídico.

Se parte de la premisa que la justicia y la jurisdicción son la expresión más concreta para abordar el estudio de lo jurídico, y el ámbito donde se puede apreciar con mayor nitidez la lógica cultural que determina las normas, su justiciabilidad, la adecuación o imbricación de sistemas jurídicos y por ende la interlegalidad. Esto es así porque la justicia y la jurisdicción conforman el espacio de elaboración de normas y su aplicación — para la resolución de disputas y conflictos, pero también para la regulación de las relaciones inter e intracomunitarias-. En este espacio se puede apreciar el uso del poder y del derecho por distintos actores (autoridades indígenas, comuneros, agentes del Estado); el entrecruce de sistemas legales en las prácticas y discurso; los conflictos que son relevantes para la comunidad, así como los valores y motivaciones (culturales, económicas, sociales e históricas) que determinan la decisión de los actores.

Para comprender y explicar esa jurisdicción, la lógica de la justicia, la construcción del derecho en la comunidad y las dinámicas del poder en los distintos niveles del campo jurídico, se parte de lo agrario —una dimensión de los territorial - como eje de análisis fundamental que ha estructurado las relaciones y conflictos entre el Estado y las comunidades, y entre las cabeceras municipales y sus agencias.

De igual forma, lo agrario — como dimensión de lo territorial (véase CAPÍtulo 2) - explica la conformación de los asentamientos humanos (comunidades) en la Sierra Norte de Oaxaca, con anterioridad a la época colonial, y fundamentalmente que las disputas por la tierra y el territorio, así como la supremacía entre poblados antiguos y poblados nuevos, constituyen referentes estructurales que dan fundamento a la comunalidad, entendida ésta como ideología organizativa de muchas comunidades indígenas de Oaxaca. Por tanto, 
desde una perspectiva histórica lo agrario se establece como una arena de tensión entre cabeceras y agencias.

Por lo anterior, se puede afirmar que existe un componente histórico y cultural que hace que comunidades indígenas como poblados antiguos o viejos, a través de periodos temporales amplios - desde la época prehispánica, pasando por la Colonia hasta nuestros días-, insistan en ser vistas como unidades con relativa autonomía frente a unidades mayores. De esta manera, el proceso jurídico histórico de distribución de la tierra (lo agrario) en México, y particularmente en Oaxaca y en la región mixe, ha provocado, en muchos casos, que comunidades indígenas pertenecientes a un grupo etnolingüístico común (Barabas y Bartolomé 1999a:15-16) se disputen el control de la tierra, ${ }^{6}$ generando conflictos que involucran a varias generaciones. Esto en parte es así porque los campesinos, en su mayoría indígenas, posteriormente a la Revolución Mexicana fueron "beneficiados" por el Estado con el reparto agrario a través de la constitución jurídica de ejidos y bienes comunales. A esto se agrega que el cacicazgo rural, apoyado en la institución municipal, fue uno de los bastiones que garantizó el control del Estado sobre la masa campesina e indígena, a través de ese reparto agrario.

En el contexto oaxaqueño, lo agrario —como la imposición de reglas sobre el uso de la tierra por parte del Estado- constituye efectivamente una dimensión central del conflicto entre cabeceras y agencias, éstas últimas reclaman derechos primordiales a la tierra mientras aquéllas niegan esos derechos en aras de mantener una situación de sujeción.

\footnotetext{
${ }^{6}$ Los trabajos de Romero Frizzi $(1996,2005)$ a través de la etnohistoria nos dan cuenta de estos conflictos por las tierras desde la Colonia a la fecha y cómo la conformación arbitraria de los pueblos desde esa época ha impactado en la configuración territorial y por ende en la permanencia de los conflictos.
} 
En cuanto a las disputas sobre el territorio, la hegemonía y predominio de un pueblo sobre otro, es interesante lo que Viola König (1993) cita respecto al mapa antiguo de Santa María Tiltepec, quien también disputaba tierras a Totontepec: ${ }^{7}$

[Schmieder] menciona el mapa en relación con la descripción del problema de que las pequeñas rancherías que pertenecían a un poblado mayor, con el tiempo siempre se iban independizando de su "asentamiento original". Eso llegó a tal punto, que algunos "pueblos viejos" fueron empujados a una posición defensiva: perdían tierras en favor de los pueblos nuevos, que anteriormente habían sido contados entre sus propias rancherías.

En esas disputas, el Estado y los poderes regionales han contribuido sensiblemente al imponer a comunidades, que tradicionalmente se consideraron a sí mismas como independientes, la subordinación a la jurisdicción de otro pueblo del mismo u otro grupo etnolingüístico. ${ }^{8}$ En este escenario las comunidades se valen de los canales legales que el Estado les ofrece, pero también han recurrido con mayor frecuencia a otras instancias cuando las nacionales son poco eficaces para garantizar el respeto de sus derechos. ${ }^{9}$

Con lo anterior surgen las siguientes preguntas: ¿Hasta dónde los elementos históricos y culturales influyen en la conformación del derecho en una comunidad? ¿Cómo se expresan las dinámicas y relación del Estado con los pueblos indígenas en esa construcción del derecho indígena / sistema normativo / derecho en la comunidad? ¿Cómo estas dinámicas y estos procesos legitiman la existencia de

\footnotetext{
${ }^{7}$ La referencia a este mapa me interesa porque Tiltepec es una de las agencias de Totontepec con la que colindan sus terrenos comunales, y muestra cómo la disputa por el territorio ha sido un tema recurrente desde antes de la Colonia española.

8 Por ejemplo, en el centro y norte de la República Mexicana no es raro ver cabeceras municipales dominadas por los llamados chabochis, yoris o "blancos" en regiones indígenas de wixas, raramuris y guarijíos o yoremes. Cfr. Valdivia 2001, 2002 y 2003.

${ }_{9}^{9}$ En el caso de Móctum y Totontepec, la historia de tensión entre agencia y cabecera da cuenta del proceso de disputa, de imposición e imbricación de jurisdicciones, así como de los intentos de Móctum por conservar sus límites y distinguirse de Totontepec. En la actualidad las tensiones se mantienen en la arena de la aplicación de jurisdicciones, pero también involucran otros aspectos culturales como el hallazgo en la década de 1970 de vestigios arqueológicos en terrenos de Móctum que Totontepec si bien no reclama como propios, sí quiere beneficiarse de ellos.
} 
Móctum y Totontepec como campos sociales semiautónomos y a la vez contenidos en el campo social del Estado?

En el nivel local, cabría hacerse las siguientes preguntas: ¿Cómo el proceso de conformación comunitaria tiene impacto en la construcción de su derecho? ¿Cómo se expresa en el derecho la transición por la que pasa una comunidad sojuzgada después que consigue tener márgenes de autonomía relativa? ¿Cómo se pueden apreciar los referentes culturales que intervienen en un conflicto y su resolución, así como los cambios estructurales en una comunidad estudiando su derecho interno? Son éstas algunas preguntas que se plantean y se responden en este trabajo

Sin duda, el estado de Oaxaca es un caso paradigmático que muestra la complejidad del estudio del campo jurídico y su relación con la tenencia de la tierra, por su composición pluricultural de 16 grupos etnolingüísticos (Barabas y Bartolomé 1999b), 570 municipios, la mayoría de ellos comunidades con conflictos agrarios que datan de mucho antes de la Colonia española, y otros detonados a partir de ésta, que persisten en la actualidad. Entre los conflictos más trascendentes están los de límites territoriales entre municipios, y entre cabeceras y agencias. Estas disputas han sido redimensionadas en épocas recientes debido a contiendas electorales y al movimiento de reivindicación de derechos de los pueblos indígenas, y están determinados por la correlación de fuerzas, usos de poder y acceso a recursos económicos (estatales y federales) entre cabeceras municipales - muchas de ellas gobernadas por mestizos o indígenas descaracterizados- ${ }^{10} \mathrm{y}$ sus agencias. En el caso de análisis se abunda sobre este concepto en el que se menciona a Totontepec como un poblado mixe descaracterizado, es decir, que en un inicio fue mayoritariamente mixe pero con el paso del tiempo y debido a su ubicación geográfica estableció relaciones de parentesco con personas de otros grupos étnicos como los zapotecos de la sierra y los mestizos, aunado a un

\footnotetext{
10 Sobre este concepto abundo en el CAPítulo 3 cuando me refiero al ejemplo de la cabecera de Totontepec.
} 
incremento de sus ingresos económicos y por tanto de sus niveles de vida, marcó una distancia entre los pobladores de Totontepec y sus agencias dejando de considerarse a sí mismos como ayuuk aunque hablan o entienden el idioma, o tienen relaciones de parentesco con familias de algunas agencias. Esta situación determina las dinámicas y usos del poder y del derecho (estatal e indígena), así como las tensiones entre cabecera y agencias, y al interior de ellas. Es decir, el estudio del campo jurídico da cuenta de una constante en la relación del derecho estatal y el derecho en la comunidad y, a la vez, se revelan dos tensiones: la que existe en esa relación y la tensión cabecera-agencias. Finalmente, el espacio de lo agrario marca una arena clave de conflicto fundamentalmente por la separación territorial, la tenencia de la tierra y la relativa independencia en el control de recursos económicos, humanos y naturales, tanto de cabeceras municipales como de sus agencias. El caso de estudio se inserta en esta problemática.

En esta tensión marcada por la separación territorial, el control por los recursos y el acceso al poder, que caracteriza la relación de Totontepec con Móctum, es relevante el papel de la religión como elemento de distinción identitaria. De esta manera, el uso instrumental del derecho estatal fue reforzado con la conversión religiosa para establecer una "frontera" clara entre los "invasores y los legítimos propietarios o dueños de las tierras de Móctum", es decir, entre la cabecera y la agencia. De alguna forma esto influyó en que la mayoría de la población de Móctum se convirtiera al adventismo, lo cual les dio un sentido de ser diferentes. A la larga esto facilitó el reconocimiento de Móctum como comunidad con terrenos aparte de la cabecera. La religión, en este caso - que no abordaré, ya que su estudio excede los propósitos de este trabajo-, funcionó como un espacio de disidencia y una bandera político-ideológica (Fabre 1985,11 2005; Garma 1987).

11 Artemia Fabre en su tesis de licenciatura trabaja la religión como un uso político en el faccionalismo político, y cómo la disidencia religiosa fortalece la lucha por el poder. El caso que trabaja es disidencias justamente entre católicos y protestantes. Hay bibliografía que habla sobre la disidencia religiosa que permite justamente no sólo una disidencia político-religiosa, sino también marcar procesos de transformación interna: social, familiar, económica. 
La complejidad que plantea el estudio del campo jurídico revela que el derecho en la comunidad o el derecho indígena sufre cambios importantes dados en la relación de los pueblos indígenas entre sí, con la Colonia española y especialmente con el Estado mexicano. El Estado en particular ha sido definitorio por su fuerte presencia en regiones indígenas a través del control corporativista y centralista que ejerció sobre las mismas, y fundamentalmente a través de la reforma agraria y el municipio, como principales bases del caciquismo rural. ${ }^{12}$ De esta manera el derecho en la comunidad se formula y reformula, se reconfigura en sus usos y espacios, se redimensiona desde la historia pasada hasta la actualidad. Pese a esto, la cultura es referencia constante que da un sentido de formar parte de una totalidad e identidad comunes y explica el continuo histórico (sincrónico y diacrónico) entre el derecho actual (contemporáneo) en la comunidad y la región de la que forma parte. Sin embargo, debe advertirse que este continuo histórico y cultural que se reconoce no es inmutable ya que la cultura como totalidad ${ }^{13}$ cambia y se modifica por las dinámicas del poder y los usos del derecho, y a la vez éstos son transformados por la cultura e historia indígena.

La cultura es lo que relaciona a las comunidades indígenas mixes o ayuuk con un pasado común, y que las hace reconocerse como parte de una entidad mayor: el pueblo mixe, a pesar de las distancias geográficas y las diferencias dialectales e identidades comunitarias que puedan darse entre ellas. Finalmente, el reconocimiento a una pertenencia étnica común da cierta lógica a las confrontaciones y los conflictos en la región y, aunque no los evita, el conocimiento de sus antecedentes históricos y contexto cultural puede contribuir a su mejor resolución.

\footnotetext{
12 Indudablemente se podrían agregar otros aspectos como el económico, sin embargo, considero que lo agrario ha sido de tal importancia en la conformación del Estado mexicano contemporáneo, que en la transición de ser parte de la Colonia española a ser un Estado independiente, la tierra fue el recurso primario con el que contó en sus orígenes y en el que cimentó su economía.

13 Según Edward Burnett Taylor, CULTURA "es el todo complejo que incluye conocimiento, creencia, arte, moral, derecho, costumbre y cualesquiera otras capacidades y hábitos adquiridos por el hombre como miembro de una sociedad" (Carrithers 2000:138).
} 


\section{Intención y aportes}

Uno de los objetivos de esta obra es aportar al debate antropológico y jurídico argumentos teóricos y datos etnográficos concretos sobre la existencia de órdenes jurídicos indígenas con sus propias especificidades, pero imbricados al derecho estatal.

A lo anterior se agrega el dar cuenta de cómo desde el estudio de una sociedad tan pequeña, como Móctum y la cabecera de Totontepec, se pueden comprender sociedades o niveles de organización más complejos como el Estado. Esta perspectiva es uno de los puntos nodales de la antropología social de acuerdo con Roberto Varela (2002:69), más cuando aquéllas como campos sociales semiautónomos (Moore 1990) están inmersas e interconectadas con el Estado.

De esta manera, en el proceso de construcción de las normas en una comunidad indígena, participan tanto los referentes propios de ésta como los del Estado — sobre todo legales-, que, si bien son impuestos, suelen ser apropiados y retraducidos a las necesidades e intereses locales. En este sentido, mi mirada de abogada me permitió comprender el interés de Móctum en construir su Reglamento Interno más allá de lo que la Ley Agraria exigía, y el sentido en que dichas normas se alejaban o contradecían las normas oficiales. Pero la mirada antropológica me permitió también comprender los usos y sentidos de las normas en el contexto de una relación histórica de tensión que ha mantenido Móctum con su cabecera, Totontepec.

Estudiar los sistemas normativos desde dos disciplinas distintas revela el dinamismo cultural en el que se desarrolla y construye un derecho distinto pero imbricado con el derecho estatal. En esto radica lo relevante del caso de la relación entre Móctum y Totontepec - como de otras comunidades mixes y de otros pueblos indígenas-. La construcción de un derecho propio pero imbricado con el derecho positivo sólo puede ser entendido tomando en cuenta tanto la visión antropológica como la jurídica, de donde se puede concluir que tal construcción se debe a la apropiación de elementos jurídicos positivistas que incorporan 
autoridades y usuarios indígenas a su cultura y a los cuales dan un uso diferente al que da el derecho estatal, lo que expresa una dimensión de la interlegalidad. La apropiación y reconfiguración de los usos del derecho que las comunidades indígenas hacen frente al Estado, o bien que las autoridades indígenas hacen para hacer justicia en las comunidades, se puede apreciar en la invocación de la ley estatal para sustentar y explicar algunas sanciones o actitudes de las autoridades o los particulares al interior de la comunidad (la violación o el homicidio); el uso y apropiación cultural de instituciones municipales como la agencia de policía para la gestión de recursos ante instituciones federales y estatales, y la opción religiosa invocada como un derecho humano. Así, la combinación del enfoque antropológico y jurídico, es decir, los aportes teóricos que dan el derecho y la antropología sirven para dar cuenta de la realidad plural, jurídica y cultural que caracteriza al universo normativo en las comunidades indígenas.

\section{Proceso de investigación}

En un principio entre 1998 y 2000, el trabajo de campo lo realice en Móctum como centro de mi investigación, en visitas de una a tres semanas, durante dos años. Ante la necesidad de comprender los procesos jurídicos, considerando el contexto regional, posteriormente desarrollé un trabajo de campo en la cabecera municipal de Totontepec, y recorrí la mayoría de las agencias de su jurisdicción (2004-2005). Me interesaba conocer las formas de hacer justicia en los diferentes espacios, así como comprender como se veían las tensiones entre comunidades desde diferentes lugares. Los datos que obtuve en el trabajo de campo en Móctum fueron a través de la observación (además de estar en asambleas, realicé talleres y me involucré en la cotidianidad de la gente en la comunidad) y las entrevistas a autoridades, líderes y personas involucradas en disputas; confrontándolos con la consulta de varias fuentes, sobre todo bibliográficas $y$ de otros documentos $\mathrm{o}$ escritos mecanografiados así como expedientes agrarios. La mayor parte de este trabajo de campo lo registré en varios cuadernos, cintas fotográficas y cintas auditivas o 
casetes, cuyo contenido transcribí. En el año 2000 suspendí la investigación de campo para sistematizar y seleccionar los datos recabados, sin embargo, como se ha mencionado, tenía más datos de la comunidad-agencia que de la cabecera por lo que a fines de 2005 regresé para complementar los datos de la justicia en Totontepec. Se visitaron cinco agencias (incluyendo a Móctum), en todas fui bien recibida, en gran medida porque don Cipriano (persona reconocida, líder de Móctum) fungió como intermediador para establecer las entrevistas y es persona conocida, aunque también por esta circunstancia y al saberse de distintas religiones supongo que su sola presencia influyó en las entrevistas. También las autoridades de las agencias me proporcionaron información general, sin embargo, fue muy poco lo relacionado a la impartición de justicia, pues decían los agentes o alcaldes que el secretario no estaba. Por ejemplo, en el caso de Santigo Amatepec me dijeron que con mucho gusto me daban copias de actas o que me mostraban documentos, pero que el secretario no estaba, que vivía en México y que no sabían para cuándo regresaba, pero que si yo volvía en un mes tal vez lo encontraba, pero no era seguro. Con esto intente abarcar una dimensión regional de lo municipal, a través de entrevistas con el Alcalde Único Constitucional de la cabecera, así como con autoridades de las agencias, logrando revisar 30 casos en aquélla y 10 en las demás. Desde 2004 he elaborado varios borradores para dar forma a la obra que se presenta.

\section{Estructura del trabajo}

Para exponer los resultados de la investigación sobre las transformaciones del derecho, las dinámicas del poder y el análisis del campo jurídico tal como se expresa en la disputa entre cabeceras y agencias por el control territorial en la región mixe de Oaxaca, este trabajo se divide en tres partes.

La primera parte, Transformación y procesos de cambio en el campo jurídico, incluye dos CAPítulos: 1) La tensión en la relación del Estado con los pueblos indígenas: Alteridad y derecho y 2) Las tensiones en el campo jurídico: Lo territorial. En 
CAPítulo 1 expongo los referentes teóricos y conceptos centrales de la tesis como son: pluralismo jurídico, interlegalidad, el derecho indígena y la lógica jurídica en el sistema jurídico indígena, campo jurídico y niveles legales. A partir de estos conceptos, explico las imbricaciones y distinciones entre el sistema jurídico positivista y el indígena y las influencia del derecho estatal en las dinámicas locales. En el CAPítulo 2 planteo los elementos del contexto histórico y político de conformación de las comunidades, para explicar cómo y porqué la ideología del comunitarismo tiene arraigo entre los mixes, así como el contexto político del caciquismo en la región y su influencia en el ejercicio del poder local municipal, todo ello enmarca el caso de disputa que se analiza. De igual forma en este segundo capítulo, explico los ejes centrales de análisis (lo territorial, la justicia y la jurisdicción) a partir de los cuales abordo el estudio del campo jurídico, y se explica cómo desde ellos se puede apreciar la relación del Estado con los pueblos indígenas, las tensiones que lo caracterizan, cómo se presentan en el campo jurídico en el municipio de Totontepec y cómo éstas determinan las dinámicas y la práctica del derecho en las comunidades que lo conforman.

La segunda parte, Niveles legales del campo jurídico y sus tensiones: El caso de Totontepec y San Marcos Móctum, consta de dos CAPítulos: 3) La relación entre el distrito, el municipio y la localidad como demarcaciones Territoriales del Campo Jurídico y, 4) La cuestión agraria como estructuradora del derecho y la autonomía comunitaria. En el CAPÍTULO 3 me refiero a la relación entre el distrito, el municipio y la localidad como parte de una realidad cultural e identitaria, compartida pero diversificada entre los mixes, pues además de representar diferentes niveles de gobierno y contar con instancias jurídicas distintas, comparten elementos comunes, sobre todo por lo que toca a la cultura de los poblados que llamo niveles —en los que existen instancias de justicia-, lo cual no significa que no existan pugnas, disputas y diferencias. En el CAṔ́tulo 4, me refiero al ejercicio del poder local a nivel comunitario y cómo la cuestión agraria se constituye como elemento clave de ese ejercicio y de la construcción del derecho, es decir, los conflictos por la tierra y 
el territorio intercomunitario se constituyen como elementos fundamentales de reafirmación de las nuevas identidades. La vinculación étnico-identitaria, expuesta en términos generales en el capítulo anterior, la aplico ahora al caso concreto entre la cabecera y la agencia, cuya adscripción al mismo grupo etnolingüístico ha significado establecer más una relación de conflicto y disputa que de armonía, sobre todo por lo que se refiere al territorio en sus vertientes agraria y municipal.

En la tercera parte, Las dinámicas del campo jurídico y la confrontación entre instancias, se desarrolla el eje de la jurisdicción y la justicia para mostrar el sistema jurídico en Totontepec y Móctum (CAPítulos 5 y 6, respectivamente), así como la relación entre estos sistemas y con el derecho del Estado, es decir, ¿se puede decir que en esta zona indígena existe un campo jurídico conformado por el distrito, la cabecera municipal y sus agencias, o de campos jurídicos separados según el derecho en cada comunidad?; ¿se puede hablar de un derecho propio pese a la imbricación y a la interlegalidad? De esta manera, por lo que se refiere a las dinámicas del poder y del derecho y la formulación y aplicación de las normas me concreto al nivel local, es decir, al derecho en la cabecera de Totontepec y especialmente en la comunidad-agencia de Móctum, consideradas en relación estrecha. Por lo que toca a la justicia en Totontepec, me concreté a entrevistar al Alcalde Único Constitucional y a revisar casos, a partir de este trabajo doy cuenta de las motivaciones y la lógica que esta autoridad aplica para hacer justicia. En cuanto a Móctum, hago un estudio de su Reglamento Interno o Estatuto Comunal; de igual forma, hago una clasificación de asuntos y una breve historia para mostrar cómo se gesta una norma oral y la necesidad de ponerla por escrito. En el último capítulo, planteo las conclusiones generales.

Finalmente observé que para las autoridades de la cabecera y de las agencias visitadas es realmente muy delicado hablar de los asuntos que jurídicamente resuelven, por lo que agradezco la apertura que tuvieron para narrarme, explicarme y mostrarme las actas cuando las había y los asuntos que recordaban. También quiero agradecer a don Guillermo Gómez Reyes, Alcalde 
Único Constitucional quien me brindó todo su apoyo para realizar el capítulo correspondiente a Totontepec Villa de Morelos, y a don Cipriano Gómez Gómez por apoyarme en el recorrido a las agencias y en su comunidad, así como a las autoridades de San Marcos Móctum por todas las facilidades brindadas para realizar mi trabajo ahí. 


\section{PARTE I \\ TRANSFORMACIÓN Y PROCESOS DE CAMBIO EN EL CAMPO JURÍDICO: RELACIÓN ENTRE EL ESTADO Y LOS PUEBLOS INDÍGENAS}

\section{Introducción}

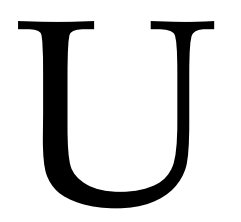

no de los conceptos centrales es el de campo jurídico que es visto como un conjunto de arenas de disputa en las que confluyen diversos aspectos culturales como lo político, lo cultural, lo social y lo económico, y es un punto de partida para comprender las dinámicas internas de las comunidades indígenas y su relación con el Estado mexicano. Éste, desde el campo jurídico, ha definido su relación con los pueblos indígenas estableciendo reglas para el acceso a la tierra, por ejemplo la Reforma Agraria hecha ley (Ley Federal de Reforma Agraria y después su contrarreforma en la Ley Agraria), el reconocimiento reciente de espacios de una justicia indígena en la Constitución Política de los Estados Unidos Mexicanos, y en las de varios estados del país. De igual forma, es a través del campo jurídico que se puede apreciar el uso estratégico del derecho del Estado para contestarlo por parte de indígenas y no indígenas, y lograr el reconocimiento de derechos antes negados, por ejemplo derechos colectivos de los pueblos indígenas como lo es la justicia y la consulta, o bien cuando se plantea como objetivo el reconocimiento de una demanda (como lo es la tenencia de la tierra y el control territorial). Justamente estos temas claves: los usos del derecho y del poder han sido documentados por la antropología jurídica, dando cuenta que ese uso estratégico del derecho es producto de la relación sincrónica y diacrónica que distintos sectores de la sociedad mexicana han tenido con el Estado, especialmente los pueblos indígenas, por sus procesos y dinámicas 
de confrontación interna. En muchos casos tales dinámicas tienen raíces en la época colonial, si bien se agudizaron posteriormente en la época independiente.

Por la relación que el Estado mexicano ha establecido con los indígenas y sus pueblos, por el uso que hacen del derecho estatal y por la exigencia de sus derechos - como el derecho a tener su propio derecho-, el campo jurídico sólo puede ser entendido como parte de un contexto histórico y cultural específico, y en una demarcación territorial concreta. En este sentido, el concepto de pluralismo jurídico nos ayuda a entender no sólo el fenómeno de diversidad de formas de derecho (Santos 1995), sino además el de la diversidad cultural. Bajo esta perspectiva es que trabajo la relación del Estado mexicano con los pueblos indígenas.

En este trabajo abordo el estudio del pluralismo jurídico concibiendo la conformación del derecho en zonas indígenas a partir de la imbricación y de la interrelación (interlegalidad) entre el derecho estatal y el derecho indígena. ${ }^{14}$ Precisamente el postulado de la interlegalidad presupone la existencia de sistemas jurídicos distintos, que pueden compartir algunos elementos y características, y diferir en otros y que al mismo tiempo se influyen y modifican mutuamente.

El poder es uno de los conceptos nodales que da cierto dinamismo al campo jurídico ya que se presenta en todas las relaciones entre personas, grupos, instituciones y niveles legales, en sus acuerdos y desacuerdos, en sus encuentros y desencuentros. El poder, como Adams $(1978,1983)$ lo definió, es la capacidad para lograr que alguien haga lo que nosotros queremos, debido al control que tenemos sobre aspectos culturalmente relevantes y significativos en una sociedad determinada. El poder y su uso no es exclusivo del ámbito del derecho, sin embargo, en las dinámicas de éste se puede percibir su presencia a través del estudio de los conflictos y su resolución, y cómo se presentan valores y principios

\footnotetext{
${ }_{14}$ Mi trabajo sigue la línea de investigación de otras antropólogas como Laura Nader (1998), Jane F. Collier (1995), Victoria Chenaut y María Teresa Sierra (1995) y abogados indígenas como Adelfo Regino Montes (1998), quienes han puesto de relieve la heterogeneidad del país con respecto a la esfera del derecho y han documentado la existencia de órdenes jurídicos diferentes del derecho estatal mexicano.
} 
culturales, es decir, "lo jurídico no tiene solamente que ver con la distribución del poder y la forma establecida para ejercerlo, sino también con los valores aceptados como tales en y por una colectividad específica" (Krotz 1995:349). Por consiguiente, donde hay diferencias culturales puede haber diferentes órdenes jurídicos o derechos, es decir, el derecho se presenta en el Estado pero también puede presentarse en otros niveles y formas de organización política o social (Mair 1998:112) o de integración social (Varela 2002:102). Por último, la relación del derecho con el poder está dada por que aquél puede ser un vehículo de dominación pero también de contestación al Estado de sectores subalternos (Lazarus-Black e Hirsch 1994; Mallon 2003).

De esta manera, el estudio del campo jurídico tiene especial relevancia si se considera que la relación que el Estado mexicano ha establecido con las comunidades indígenas, por lo menos durante los siglos XIX y $\mathrm{XX}$, ha pasado en gran medida por la imposición de normas y leyes, definidas especialmente desde la legislación federal, sobre todo en lo que tiene que ver con la materia agraria y municipal. ${ }^{15}$ El espacio municipal como ámbito de administración políticoterritorial, pero sobre todo como nivel de gobierno, representa un espacio de control y de ejercicio de poder. La tierra, como fuente de riqueza fundamental y como la expresión territorial de la delimitación del poder político del Estado, ha sido uno de los aspectos junto con el municipio, a través de los cuales éste ha ejercido control de la población rural, sobre todo de los campesinos y de los indígenas. De igual forma, mucho antes de la constitución del Estado mexicano - y una vez instaurado éste-, los pueblos indígenas han sido afectados en la posesión y propiedad de sus tierras, como se expone más adelante.

\footnotetext{
${ }^{15}$ Por ejemplo, antes la Ley Federal de Reforma Agraria y ahora la Ley Agraria y los artículos de la Constitución Federal en materia indígena - antes el $4^{\circ}$ y ahora el $2^{\circ}$ Constitucionales - Por lo que toca a la materia municipal en la reforma constitucional en materia indígena (2002) se incluyó una reforma al ARTículo 115 Constitucional, que se refiere al municipio. Así como el reconocimiento local en el estado de Oaxaca de los llamados Usos y Costumbres para la elección de autoridades (cfr. Código de Instituciones y Procedimientos Penales del Estado de Oaxaca, reformado en 1997).
} 
Históricamente, el Estado ha establecido una relación con los pueblos indígenas de desconocimiento de sus derechos y de afectación de sus tierras, lo cual cruza los distintos niveles de gobierno: la federación, el estado y el municipio. Es apenas en los últimos veinte años que la relación del Estado con los pueblos indígenas se ha transformado, lo que ha llevado al reconocimiento de ciertos derechos a los indígenas, sus comunidades y pueblos. El estudio de la relación actual entre los pueblos indígenas y el Estado, particularmente la dificultad de establecer mecanismos de reconocimiento a sus derechos, implica abordar la complejidad de la relación pero también las dinámicas internas de las comunidades indígenas para acomodarse, acoplarse y hacer frente a los nuevos tiempos. En este trabajo me refiero a esas manifestaciones y particularidades.

A través de dos ejes principales de análisis, $1^{\circ}$ lo territorial (que involucra la dimensión agraria y la municipal) y $2^{\circ}$ la justicia y la jurisdicción (vistas como un mismo eje analítico), se expone la problemática general de la coexistencia de sistemas jurídicos diversos, con especial énfasis en las tensiones que se generan en el campo jurídico. Como se mencionó en la introducción de este trabajo, esos ejes de análisis son aspectos recurrentes en las dinámicas comunitarias e intercomunitarias en el estado de Oaxaca. Desde estos ejes se puede explicar y mostrar, sincrónica y diacrónicamente, la relación del poder y sus usos, en general, en el campo jurídico.

En los dos capítulos de esta primera parte se exponen los principales conceptos teóricos utilizados en este trabajo. Para ello, se plantea cómo desde el campo jurídico se puede apreciar la relación y las tensiones del Estado con los pueblos indígenas, cómo esas tensiones se expresan en el sistema jurídico indígena y cómo éstas determinan las dinámicas en comunidades indígenas y su derecho. Tales planteamientos resultan fundamentales para comprender las formas concretas que tiene el derecho en esta parte de la región mixe que comprende el municipio de Totontepec concretamente en la cabecera municipal, y la agencia de policía de Móctum. 


\section{CAPÍTULO 1 \\ La Tensión en la Relación del ESTADO CON lOS PUEBlos IndígenAS. Alteridad y DeReCHO}

\section{Introducción}

$\mathrm{T}$ al cual está dado el derecho positivo, tanto en su contenido normativo como en los aspectos históricos que le han dado origen y sustento, se puede apreciar una negación sistemática de la alteridad, es decir, de la otredad y la diversidad cultural. Así, en el derecho mexicano se expone una visión etnocéntrica sobre "el otro", como campesino, comunidad, ejido, pueblo indígena, grupo indígena, comunidad indígena, municipio con población mayoritariamente indígena. La perspectiva antropológica permite cuestionar el reconocimiento de derechos desde esa visión etnocéntrica dando herramientas conceptuales para que ese "otro" se exprese desde su alteridad. En este sentido Krotz (2002a:60) señala:

La alteridad tiene un precio elevado: no es posible sin el etnocentrismo. "El etnocentrismo es el estado natural de la humanidad", y es el que posibilita el contacto entre culturas, la pregunta antropológica. Es la forma y la condición para poder concebir al otro como otro, en el sentido descrito. Entre el grupo propio y el extraño existe, entonces, una relación similar a la que se da entre lo conocido y lo desconocido en el acto de adquirir conocimiento, donde lo desconocido, la mayoría de las veces, sólo se puede alcanzar desde lo conocido.

Por ello, la negación de la alteridad implica negarse al conocimiento de la cultura propia, es decir, desconocer las realidades históricas de nuestras sociedades. En oposición a ello, surge la necesidad de reconocer la existencia de la diversidad cultural. 
En este primer capítulo se exponen los conceptos centrales utilizados a lo largo de la tesis, los cuales son referentes importantes para explicar las tensiones entre la negación y el reconocimiento de derechos a los pueblos indígenas, sobre todo, el derecho a tener un derecho propio, y cómo la relación estructural dada en un ámbito macro entre el Estado, la sociedad mexicana y los pueblos indígenas se observa también a nivel micro de las comunidades indígenas, con ciertas particularidades. Esto es fundamental para comprender la configuración de los sistemas jurídicos mexicano e indígena como parte del campo del derecho, entendido como un universo policéntrico, es decir, conformado por una diversidad de sistemas jurídicos interrelacionados.

En lo siguiente, me refiero a los conceptos centrales que han guiado el desarrollo de la investigación, y que son fundamentales para comprender las dinámicas del campo jurídico en la región mixe de Totontepec.

\subsection{El pluralismo jurídico y la interlegalidad}

El pluralismo jurídico es uno de los conceptos centrales de la antropología jurídica y se refiere a la coexistencia de sistemas jurídicos diversos dentro de un mismo campo social, lo cual cuestiona la visión etnocéntrica del derecho occidental que ha sido construido como el único y legítimo referente del Derecho por el positivismo jurídico (Fitzpatrick 1998), concepción que vino a consolidar la empresa colonial. El cuestionamiento a la centralidad del derecho estatal ha sido uno de los focos de atención de los estudios antropológicos del derecho, interesados en dar cuenta de la vigencia de otros sistemas jurídicos dentro de los estados nacionales. Una vertiente inicial de los estudios del pluralismo jurídico, llamada por Merry (1988) como pluralismo jurídico clásico, mostró cómo sistemas jurídicos de poblaciones colonizadas fueron subordinados, negados, o bien refuncionalizados por los colonizadores para sus fines de dominación. De esta manera en los países con pasado colonial, como es el caso de México, donde los pueblos nativos lograron subsistir, el derecho estatal se enfrenta hoy en día a sistemas jurídicos vigentes, a 
un derecho indígena que no se logró eliminar a pesar de los sistemáticos esfuerzos por homogeneizar a la nación e integrarla en un solo y único marco legal. Es por esto que el concepto de pluralismo jurídico es, sin duda, un concepto muy productivo para documentar el carácter plural de las sociedades y la vigencia de otros derechos. Debates actuales revelan que el pluralismo jurídico no es solamente una característica de sociedades con pasado colonial, sino una propiedad de las sociedades contemporáneas estructuradas por una diversidad de sistemas jurídicos interconectados, como lo señala Santos (1991).

El nuevo pluralismo, a diferencia del pluralismo clásico que tendía a destacar a los sistemas jurídicos como entidades independientes, se preocupa por dar cuenta de la interacción, imbricación y mutua influencia entre los distintos órdenes jurídicos, lo que plantea la problemática de la interlegalidad (Santos 1995). Mientras el pluralismo jurídico tradicional caracterizó a la investigación antropológica en un momento histórico en el que imperaban en el mundo los territorios colonizados, concretamente en África, el nuevo pluralismo jurídico se enfoca a una situación histórica actual, en la que los pueblos (países, estados, naciones) son independientes y soberanos, pero que a su interior existen pueblos con culturas diversas que no se han reconocido cabalmente. ${ }^{16}$ Tales conceptualizaciones han sido claves en el desarrollo de la antropología jurídica latinoamericana y especialmente centrales en los estudios sobre el derecho indígena en su relación con el derecho del estado (cfr. Sierra 1995; Chenaut 1999;

\footnotetext{
16 En su estudio sobre el pluralismo jurídico y la interlegalidad Santos (1995:272-273) ejemplifica cómo cada orden jurídico tiene una tradición histórica y cultural distinta, con ello expone una clasificación y estudio de las familias jurídico-legales así como de sus "lazos de parentesco", señalando diversos criterios para agrupar los sistemas jurídicos, entre los que se pueden mencionar las fuentes de la ley, la raza, la ideología, las "características sustantivas de la ley", modelos del pensamiento legal, etc., criterios que rompen la clasificación tradicional de las familias o tradiciones jurídicas o legales occidentales: Ius Civile (romano-canónica), socialista, y del Common Law. Y bien podríamos hablar de cuatro, cuando de la tradición jurídica del Common Law derivamos el Derecho Anglosajón y el Angloescandinavo. Tales derivaciones nos expresan y plantean la pluralidad de sistemas jurídicos existentes en el mundo (pluralismo jurídico internacional), e incluso al interior de una nación o país (pluralismo jurídico interno).
} 
Sánchez 1992, 1998; Correas 1994), y también para legitimar el reclamo de los pueblos indígenas a tener un derecho propio.

El abordaje que la antropología jurídica ha hecho sobre el pluralismo jurídico es importante para comprender la relación del derecho estatal y del derecho indígena en el contexto de sociedades con pasado colonial como las nuestras.

En torno a la definición del pluralismo jurídico se han desarrollado varios debates centrados tanto en la definición de lo legal como en la existencia o no de órdenes jurídicos separados. Sobre esto Sierra (2006:61) señala:

Sobre la definición de lo legal: sí es posible considerar que cualquier sistema normativo constituye o no derecho, o sólo aquel que tiene determinadas características, como el hecho de tener autoridades que lo hagan exigible, sancionable y eficaz (Hoekema 1998, Correas 2003). Sobre la existencia o no de órdenes jurídicos separados; de acuerdo a Sally Merry (1988) el pluralismo jurídico obliga a pensar en la interpenetración y mutua constitución de los ordenamientos jurídicos cuestionando por tanto las visiones dualistas sobre los sistemas normativos; Benda Beckman por su parte cuestiona que este reconocimiento de la interpenetración de los ordenes jurídicos en las prácticas impida pensar los sistemas en su especificidad normativa [...] En este sentido define pluralismo analíticamente como la coexistencia de dos o más grupos de concepciones normativas dentro del mismo proceso, o de procesos agregados de estructuración; pero también la coexistencia del mismo elemento normativo en más de un contexto.

De este debate me interesa destacar tres posturas respecto al tipo de relación entre sistemas jurídicos: una que reconoce la existencia de diversos sistemas jurídicos independientes entre sí pero coexistiendo en un mismo territorio (Correas 1994); otra plantea la relación de esos sistemas jurídicos en una mutua constitución de legalidades (Sierra 1995, 2004b); y una última que establece la relación de sistemas jurídicos como dos miradas distintas sobre un mismo objeto - por ejemplo una disputa-, sobre el cual cada sistema jurídico tiene principios y procedimientos 
diferentes para darle solución. ${ }^{17}$ Tales posiciones delinean caminos diferentes para abordar el estudio del derecho en comunidades indígenas, lo que tiene consecuencia en la definición del objeto de estudio. En este trabajo comparto tanto la visión del pluralismo jurídico como interacción y mutua constitución de legalidades, como la propuesta analítica más normativa que busca reconstruir las miradas distintas sobre la norma, en torno a casos de disputas, tal como se verá en los capítulos analíticos; considero que estas dos posiciones son complementarias para el análisis. De esta manera podemos decir, de acuerdo con Santos (1991), que el planteamiento central del pluralismo jurídico es ver al derecho como un universo policéntrico de órdenes jurídicos o formas diversas de derecho interconectados y sobrepuestos (interlegalidad), y pueden abordarse según su escala, $^{18}$ su proyección ${ }^{19}$ y su simbología. ${ }^{20}$ Sobre estos mecanismos Santos (1991:223-224) señala:

[los] desarrollos socio-jurídicos revelan pues, la existencia de tres espacios jurídicos diferentes a los que corresponden tres formas diferentes de derecho: el derecho local, el derecho nacional y el derecho mundial. Es poco satisfactorio distinguir estas formas de derecho con base en el objeto de regulación pues, a veces, regulan o parecen regular el mismo tipo de acción social. En mi entender, lo que distingue a estas formas de derecho es el

17 Esther Sánchez señala: "Para mí el concepto de interlegalidad no es que la legalidad de un sistema toca el territorio de otro espacio social y entonces es en esa intersección que se da la interlegalidad. No. La interlegalidad para mí es que frente a un mismo objeto, se utilizan dos principios y dos procedimientos que provienen de dos sociedades que son portadoras de estos y por decirlo así... también son aportadoras para encontrar una salida a un asunto" (comunicación personal del 21 de octubre de 2005).

18 "La escala es el primer gran mecanismo de representación / distorsión de la realidad. La escala es 'la relación entre la distancia en el mapa y la correspondiente distancia en el terreno' y, como tal, implica una decisión sobre el grado de pormenorización de la representación. Los mapas de grande escala tienen un grado más elevado de promenorización que los mapas de pequeña escala" (Santos 1991:217).

19 "Es precisamente a través de la proyección como las superficies curvas de la tierra son transformadas en superficies planas en los mapas" (Santos 1991:218). "Cada período histórico o tradición cultural selecciona un punto fijo que funciona como centro de los mapas en uso, un espacio físico simbólico al que es atribuida una posición privilegiada y a partir de la cual se distribuyen organizadamente los restantes espacios" (Santos 1991:219).

20 "La simbolización es el tercer gran mecanismo de representación / distorsión cartográfica de la realidad. Se trata de los símbolos gráficos usados para señalar los elementos y las características de la realidad espacial seleccionados" (Santos 1991:220) 
tamaño de la escala con que regulan la acción social. El derecho local es una legalidad de grande escala; el derecho nacional estatal es una legalidad de mediana escala; el derecho mundial es una legalidad de pequeña escala. [...] Los diferentes órdenes jurídicos operan así en escalas diferentes $y$, con eso, traducen objetos empíricos eventualmente iguales en objetos jurídicos distintos [...]

De esta manera, la propuesta de Santos resulta muy atractiva para pensar la relación entre los sistemas jurídicos y la construcción del campo jurídico como la conjunción de órdenes policéntricos vinculados entre sí en diferentes escalas. Por ello, el estudio del pluralismo jurídico va más allá de postular la existencia de sistemas normativos diversos, o de formas distintas de derecho, implica también abordar su dinamismo y su complejidad en el contexto histórico de la relación entre los pueblos indígenas y el Estado, así como considerar la situación actual de esa relación y su impacto en la conformación del campo jurídico.

Para este trabajo, he optado por el concepto de pluralismo jurídico entendido como sistemas jurídicos relacionados entre sí en un mismo campo social, ya que permite documentar el sentido en que el sistema normativo vigente en las comunidades indígenas se construye en relación estrecha con el sistema jurídico del estado. Esta relación se puede observar en las mutuas influencias entre sistemas jurídicos, por ejemplo, cuando el alcalde municipal -que en la comunidad es la autoridad principal para hacer justicia - utiliza la formalidad del derecho positivo para darle fuerza a un acuerdo entre partes (véase CAPÍTULO 4 de esta tesis), pero también en las tensiones que surgen al definir determinadas conductas como graves o leves según cada sistema jurídico; por ejemplo, cuando el sistema jurídico mexicano define algunas conductas como delitos graves o leves, y no corresponde con valoraciones propias del sistema jurídico indígena sobre esas mismas conductas (véanse CAPÍTUlos 5 y 6). Para dar cuenta de esas diferencias, imbricaciones y una mutua constitución de legalidades, los conceptos de pluralismo jurídico e interlegalidad son de gran utilidad porque obligan a observar 
al derecho en su multiplicidad de manifestaciones (según niveles y ámbitos), en su relación con el poder, los usos de la legalidad y el discurso de los derechos.

Para el desarrollo de la tesis retomo los conceptos teóricos y analíticos utilizados y producidos en el seno de la antropología jurídica en general y en particular de la antropología jurídica mexicana. Esta obra antropológica se caracteriza por los estudios del derecho en contextos étnicos diversos con lo que se da un peso relativo a la diferencia étnica y cultural, y el énfasis en el estudio del pluralismo jurídico y la interlegalidad.

La interlegalidad puede ser entendida como la imbricación de sistemas legales y lógicas jurídicas en espacios sociales determinados (Santos 1995), vistos éstos como campos sociales semiautónomos (Moore 1990). Pero también como las distintas maneras de entender un objeto, utilizando por ejemplo principios axiológicos y procedimientos que provienen de sociedades distintas. Indudablemente el lugar, desde el que se trata de entender el objeto o resolver la disputa o el conflicto, determina la preponderancia y aplicación de un sistema y la lógica cultural que lo configura sobre otro. La interlegalidad es un concepto clave del trabajo que desarrollo, ya que permite insistir en el aspecto de interrelación y poder entre legalidades.

Para comprender y definir el campo de lo jurídico, básicamente son relevantes las obras de Leopold Pospíšil (1965), quien en su planteamiento del campo jurídico desde la antropología postuló la existencia de distintos niveles legales, y que en cada nivel podían observarse distintos tipos de autoridad y distintas dinámicas del uso del poder y del uso del derecho, dando cuenta de la especificidad y distinción del campo jurídico de otros campos — la religión o las costumbres - y su integración en niveles; pero mi base teórica está fundada en los trabajos de Boaventura de Sousa Santos $(1991,1995)$ sobre el pluralismo jurídico y la interlegalidad y en Comaroff y Roberts (1981) sobre los paradigmas antropológicos en el estudio del derecho: el normativo y el procesual. Comaroff y Roberts (1981) en sus estudios entre los tswana en Sudáfrica criticaron la dicotomía 
entre la visión procesual y normativa que han orientado la investigación en la antropológica-jurídica, insistiendo en la necesidad de considerar las normas y sus procesos en el estudio del derecho. De igual forma el trabajo de Moore (1990) es particularmente sustancial para mi trabajo, ya que subraya la dimensión sincrónica del cambio legal en su estudio sobre la costumbre jurídica en Kilimanjaro, es decir, da cuenta que la costumbre jurídica y la tradición no son inamovibles y pese a esto se pueden apreciar elementos culturales que distinguen entre sí a los sistemas legales que coexisten en un espacio determinado. La obra de Lazarus-Black e Hirsch (1994) centran su análisis en el uso del derecho y el poder para contestar al Estado y muestran cómo los actores hacen un uso estratégico del derecho, lo que a nivel latinoamericano fue constatado poco antes y llamado "uso alternativo del derecho" y "derecho alternativo" por los fundadores del Instituto Latinoamericano de Servicios Legales Alternativos (ILSA, la revista El otro derecho, es un ejemplo). ${ }^{21}$ Todos estos autores han sido centrales en el desarrollo de la presente investigación, ya que ofrecen los referentes analíticos para comprender la construcción del derecho tal como se expresa en los espacios comunitarios y municipales de la investigación, en su particularidad y en sus mutuas interrelaciones.

En cuanto a la antropología jurídica mexicana, y para definir los parámetros teóricos de este trabajo de tesis, se consideran fundamentalmente los trabajos realizado por Rodolfo Stavenhagen y Diego Iturralde (1990) sobre la relación entre el derecho positivo y la costumbre indígena, el de María Teresa Sierra y Victoria Chenaut (2002) sobre los usos del derecho y la interlegalidad en distintos niveles legales y el de Esteban Krotz (2002a, b), quien aborda el estudio del derecho en comunidades indígenas desde la interculturalidad y la reflexión filosófica de la

\footnotetext{
${ }^{21}$ Numerosas publicaciones realizadas por más de 30 años constatan esto, por ejemplo, la revista $E l$ Otro Derecho (cfr. <http://www.ilsa.org.co/>). También el libro: Pluralismo Jurídico y Alternatividad Judicial. "Si alguna edición de nuestra revista hace honor a su nombre, El Otro Derecho, es este número doble dedicado a los temas del pluralismo jurídico y la alternatividad judicial. Coincide, en este sentido, con el propósito y, si se quiere, con la definición política, en su acepción más amplia, que ha tenido ILSA desde su fundación [en 1978]: encontrar lo jurídico alternativo como una dimensión imprescindible de una genuina transformación social" (cfr. http:// www.ilsa.org.co/recherche.php3?recherche=Pluralismo).
} 
alteridad y el derecho, finalmente todos ellos han aplicado los conceptos de pluralismo jurídico y derecho indígena al caso de los pueblos indígenas frente al Estado mexicano y su derecho.

\subsection{Influencia del derecho estatal en las dinámicas locales y el sistema jurídico indígena como parte de un campo social semiautónomo}

La relación que el Estado establece con los pueblos indígenas tiene su origen en la Conquista española y en la Colonia, ya que los pueblos indios fueron sujetos a la jurisdicción colonial después de la Conquista, y en esa medida usaron las leyes coloniales para reclamar sus tierras. Así, esa relación histórica se resume en la dominación y el despojo en contra de los pueblos indígenas sobre sus tierras y territorios, lo que es posible documentar en los distintos periodos de formación del Estado en México, donde el aspecto de lo territorial adquiere especial relevancia. De esta manera, el derecho estatal tiene sus fundamentos en el derecho colonial y posteriormente republicano, en el que se legitima jurídicamente la dominación y el despojo (Medina Cervantes 1987; González Galván 1995). Destacan en especial las Bulas Alejandrinas (Inter Caetera), ${ }^{22}$ las instituciones del derecho romano relacionadas con la propiedad, ${ }^{23}$ las reducciones, encomiendas, ${ }^{24}$ la república de

22 En 1493, Alejandro VI mandó despachar sucesivamente cuatro bulas de indudables consecuencias para el futuro del Nuevo Mundo. Dos de ellas son conocidas con el nombre de Inter Caetera, la tercera con el de Eximiae Devotionis, y bajo el título de Dudum Siquidem la cuarta. En la primera se hacían dos concesiones fundamentales en favor de los Reyes Católicos: en primer lugar, la donación de tierras descubiertas y por descubrir en el mar océano por la parte de occidente "hacia las Indias", siempre que no perteneciesen a ningún príncipe cristiano. En segundo lugar, la concesión de privilegios espirituales $\mathrm{u}$ obligación de "adoctrinar a los indígenas y habitantes dichos en la fe católica e imponerlos en las buenas costumbres".

(http://es.encarta.msn.com/encyclopedia_761586289_2/Bulas_Alejandrinas.html) [consulta 15 de mayo 2006]. De estos documentos es de destacarse la manera en que se distribuyeron tierras entre los grandes imperios del momento, a partir del principio del derecho de Conquista.

${ }^{23}$ Como el derecho de Conquista, la prescriptio y la usucapio. La primera se define como el derecho que se pierde sobre un bien inmueble por que no se han ejercido derechos de propiedad sobre él (uso y disfrute). El segundo es la contraparte de la prescriptio, es decir, la adquisición de derechos sobre un bien inmueble por el uso y disfrute que se ha hecho de él por cinco años (si es de buena fe) y 10 años (si ha sido de mala fe).

${ }^{24}$ Las reducciones de indios eran núcleos de población en la que se debían reasentar los indios en la América española, separados de las ciudades donde vivían los españoles. La encomienda es una institución característica de la colonización española en América y Filipinas, que, jurídicamente era 
indios y los municipios, utilizados por los españoles para tener mejor control de los pobladores de estas tierras; por lo que toca al México independiente, tenemos las Leyes de Reforma y Desamortización y la Reforma Agraria fundamentalmente (Chávez Chávez 1984), a la cual me he referido anteriormente.

Actualmente la intervención del Estado mexicano en regiones indígenas se ha hecho a través de la aplicación del derecho positivo, fundamentalmente en las esferas agraria, municipal, electoral y de procuración e impartición de justicia, que de maneras distintas mencionan los derechos indígenas, aunque los márgenes para su ejercicio son limitados. Ejemplo emblemático de esto fue la Ley Federal de Reforma Agraria, a través de la cual los agentes del Estado relacionados con el sector agrario - la Secretaría de la Reforma Agraria (SRA), las promotorías y comisiones agrarias mixtas - influyeron en las dinámicas internas de ejidos y bienes comunales (indígenas o no). Tal influencia quedó constatada con la entrada en vigor de la "nueva Ley Agraria" (en 1992), que generó en ejidatarios y comuneros dudas de hasta dónde podían realizar asambleas o elaborar su reglamento interno sin la intervención de un promotor de la Secretaría, o bien, si era correcto o no nombrar autoridades sin su intervención, o resolver conflictos interparcelarios al interior del núcleo agrario. ${ }^{25}$ Esto constata la hegemonía del Estado, así como el papel que juegan sus órganos de autoridad y funcionarios (Secretaría de la Reforma Agraria, Procuraduría Agraria y Tribunales) a los cuales

un derecho otorgado por el monarca en favor de un súbdito español (encomendero), con el objeto de que éste percibiera los tributos o los trabajos que los súbditos indígenas debían pagar a la monarquía. A cambio, el encomendero debía cuidar del bienestar de los indígenas en lo espiritual y en lo terrenal, asegurando su mantenimiento y su protección, así como su adoctrinamiento cristiano [consulta 15 de mayo 2006] http://es.wikipedia.org/wiki/Reducciones_de_indios).

${ }^{25}$ Mi experiencia personal como abogada agraria me permite constatar esta situación. En 1992 (cuando entraron en vigor las reformas a la Constitución en materia agraria, la llamada contrarreforma agraria), participé en el curso de capacitación para abogados agrarios de la Procuraduría Agraria (PA). Después de ese curso, se me asignó como abogada agraria en la Delegación Oaxaca de esa institución, posteriormente fui jefa de la Residencia de la PA en Matías Romero, Oaxaca, donde me tocó atender asuntos de esa zona que abarcaba los límites con Tuxtepec, incluyendo los Chimalapas hasta Tehuantepec. En Tuxtepec y Tehuantepec también hay Residencias de la PA. 
los núcleos agrarios buscan para resolver sus conflictos, pero también los confrontan.

Un ejemplo más es el de la reforma municipal que jurídicamente ha consistido en reformas a la Constitución Política de los Estados Unidos Mexicanos (CPEUM) con las que se otorgan mayores atribuciones al municipio y que a nivel administrativo y sobre todo práctico implican mayor transferencia de facultades y recursos (1993). El impacto de esto en el estado de Oaxaca se expresa en las tensiones entre cabeceras y agencias, concretamente por la distribución y administración de los recursos económicos de los ramos 28 y 33 destinados al municipio y que se asignan a las cabeceras.

Las pugnas entre cabeceras y agencias se pueden apreciar en la mayoría de los municipios de la República Mexicana pero son particularmente especiales y recurrentes en Oaxaca. Esto se explica fundamentalmente por la diversidad de municipios y pueblos que existen en esta entidad; por la existencia de un comunitarismo arraigado - donde las identidades locales tienen mayor peso que las identidades regionales y étnicas-, así como por la existencia de un sistema de usos y costumbres reconocido legalmente para la elección de autoridades, volviéndose una nueva arena de disputa política e interpartidista. ${ }^{26}$

En materia de procuración e impartición de justicia, el reconocimiento en la llamada Ley Indígena de Oaxaca (1998) ${ }^{27}$ de las facultades de resolver conflictos o

\footnotetext{
${ }^{26}$ Es decir, los usos y costumbres en Oaxaca han sido reconocidos en la esfera jurídico-electoral para la elección de autoridades por asamblea, y en materia de justicia de manera muy limitada a los casos considerados menores o no graves. Es una nueva arena política interpartidista porque aun cuando es la asamblea la que elige a las autoridades municipales, los partidos políticos todavía influyen a través de sus comités de partido y sus simpatizantes. Ejemplo de esto es el conflicto poselectoral en el municipio zapoteca de Guevea de Humbolt en la Sierra del Istmo de Tehuantepec, donde la comunidad en Asamblea General solicitó al anterior presidente municipal (miembro del PRI) entregar los bienes muebles e inmuebles del ayuntamiento ya que había terminado su periodo. No aceptó argumentando que la elección de las autoridades que lo sustituyeron debía ser por el sistema de partidos políticos, es decir, como a él lo habían elegido, sin embargo, durante su periodo el Congreso del Estado aprobó que el municipio de Guevea eligiera a sus autoridades municipales según lo establecido en el libro IV del Código Estatal de Procedimientos Electorales (sobre el sistema de usos y costumbres).

${ }^{27}$ Ley publicada en el Extra del Periódico Oficial del Estado de Oaxaca, el viernes 19 de junio de 1998.
} 
asuntos menores (o de menor cuantía) plantea a las autoridades locales, agentes municipales y cabildos la posibilidad de ejercer con mayor seguridad el ejercicio de sus atribuciones (que venían haciendo de cualquier forma), lo que también plantea nuevos espacios de conflicto entre comunidades del mismo pueblo, donde unas son cabeceras y otras agencias. De esta manera, los casos que no se resuelven en la agencia y pasan a la cabecera representan en algún sentido un cuestionamiento a la capacidad de control de la autoridad comunitaria, más cuando el usuario indígena pasa a la instancia de la cabecera municipal sin pasar por la instancia de la comunidad. O bien, cuando los pobladores de la comunidad-cabecera no toman en cuenta la justicia del alcalde municipal y pasan a las autoridades del Estado en el distrito. La manera como se da este impacto se muestra en los CAPítulos 5 y 6, sobre la forma de hacer justicia comunitaria y las formas de establecer normas jurídicas en Totontepec y San Marcos Móctum.

De igual forma, a nivel federal la actual reforma constitucional en materia indígena (ARTíCULO $2^{\circ}$ de la CPEUM) ha impactado a las comunidades en tanto sus miembros que se ven involucrados en una disputa, suelen incorporar en su discurso el recurso de la Ley Indígena del estado de Oaxaca o la reforma a la Constitución Federal (2002), aun sin conocer realmente su contenido. La influencia del derecho estatal en las comunidades indígenas se revela también en las acciones de capacitación que realizan agentes oficiales; por ejemplo, representantes de la Procuraduría de Justicia del Estado y la Comisión Estatal de Derechos Humanos capacitan a las autoridades indígenas sobre lo que deben de hacer para no excederse en sus funciones, de lo contrario pueden ser acusadas de abuso de autoridad. En esta capacitación se suele mencionar sobre todo el Código Penal y de Procedimientos Penales del Estado de Oaxaca así como la Ley Indígena. Esta introducción de información, conceptos y concepciones jurídicas positivistas, indudablemente, influyen en las maneras de resolver conflictos y en la idea que las autoridades indígenas tienen del derecho y la justicia. 
Esta forma de interacción, coexistencia y mutua constitución de legalidades —interlegalidad - (Santos 1995; Sierra 2004a) da cuenta de una diversidad de sistemas jurídicos que interactúan a través de diversas instancias y procedimientos.

El campo jurídico es interlegal de acuerdo a la concepción de que el derecho puede ser múltiple y diverso (Santos 1995), es decir, policéntrico, dándose una interconexión entre el derecho del Estado y un conjunto o variedad de órdenes jurídicos. En este sentido y de acuerdo con Santos el campo jurídico en sociedades contemporáneas y en el sistema mundial como un todo, tiene las siguientes características: “a) es un terreno más complejo y rico que el asumido por la teoría política liberal, b) tal campo jurídico es una constelación de diferentes legalidades e ilegalidades operando en tiempo-espacio local, nacional y transnacional, c) finalmente la ley es una regulación con potencial tanto represivo como emancipatorio" (Santos 1995:111). Esto es, que el uso del derecho del Estado así como otros sistemas jurídicos pueden ser utilizados para confrontar y contestar un status quo. Por lo que el derecho del Estado puede ser usado para la movilización social o como un espacio donde los pueblos indígenas y otros grupos subordinados logren, por ejemplo, el reconocimiento de derechos (Lazarus-Black e Hirsch 1994).

El sistema jurídico mexicano —o derecho positivo-, como parte del campo del derecho, interactúa y se interrelaciona con otros sistemas jurídicos: en lo municipal y en lo local (comunitario o regional). Podemos afirmar que el sistema jurídico indígena como parte de un campo social semiautónomo tiene características propias, sin embargo, al ser abarcado por el Estado como un campo social más amplio, está influenciado por el sistema jurídico oficial. Desde la concepción centralista del derecho positivo, el derecho indígena no es un sistema jurídico con características propias, más bien es visto como un nivel legal del sistema jurídico mexicano, donde éste le señala sus atribuciones y límites.

De esta manera el sistema jurídico indígena es invisibilizado, pues desde el derecho del Estado no se reconoce como un verdadero sistema de derecho con 
especificidades propias, dada la historia de subalternidad ${ }^{28}$ de los pueblos indígenas. El derecho indígena es un sistema jurídico que se encuentra imbricado, entrelazado e influenciado por el sistema jurídico positivo, ya que muchas de las instituciones de éste — como las municipales, agrarias, electorales, de procuración e impartición de justicia - han sido impuestas y reapropiadas por los pueblos indígenas incorporándolas a sus formas y estructuras de organización. Pese a esto el sistema jurídico indígena tiene particularidades propias (como se verá en los casos de Totontepec y Móctum) con distintos niveles, instancias legales y autoridades. Es decir, el sistema jurídico indígena es el resultado de la historia y cultura de cada pueblo y comunidad indígena en su contexto regional y estatal. Por ello, el sistema jurídico mexicano y el sistema jurídico indígena representan realidades distintas, imbricadas entre sí. El primero abarca e influye de manera determinante al segundo, y de alguna forma lo reconoce, como lo vemos en la incorporación de nuevas leyes al marco jurídico mexicano (Convenio 169 de la OIT y el ARTículo $2^{\circ}$ Constitucional, Constitución del Estado de Oaxaca y Ley Indígena

\footnotetext{
${ }^{28}$ Los llamados enfoques de la subalternidad, particularmente significativos en el análisis de la descolonización de la India, se proponen documentar la centralidad de los sectores mayoritarios, su autonomía relativa, limitada pero importante. Retomo este planteamiento para señalar que los indígenas como sujetos subalternos no están inermes a los dictados de la clase dominante o al margen del diseño de un modelo de Estado. Desde esta perspectiva las comunidades indígenas son campos sociales semiautónomos, es decir, con relativa autonomía, por tanto, existe una historia no oficial donde los campesinos - en su mayoría indígenas-, desde sus proyectos comunitarios locales y regionales y desde su oposición a los proyectos hegemónicos, ayudaron a "profundizar el proyecto nacional" (Tutino 2003: 32, en la Presentación a la obra de Mallón 2003).
} 
del mismo), ${ }^{29}$ pero también los indígenas hacen uso cotidiano del derecho positivo para resolver sus controversias (cfr. Sierra 2004a). ${ }^{30}$

Al estar considerado como parte del campo social del Estado mexicano el sistema jurídico indígena puede ser visto como un sistema que ayuda a mantener el orden social en los espacios locales. De esta manera, el sistema jurídico indígena cobra especial interés para analizar el sentido en que pueblos colonizados consiguen ejercer un control sobre sus dinámicas internas en su propio contexto territorial, histórico y cultural sin perder de vista su relación con el Estado. Esta idea es más clara a partir del concepto de campo social semiautónomo que Sally Falk Moore (1990) acuñó para explicar el derecho consuetudinario de los chagga en Kilimanjaro.

Según Moore, la noción de campo social semiautónomo se define como la posibilidad que tienen los chagga (a través de distintos espacios, instancias y mecanismos: los grupos patrilineales localizados, las asociaciones de irrigación y los consejos de ancianos del distrito) de controlar importantes recursos materiales y humanos que pueden ser delimitados y regulados creando normas jurídicas y

29 En este sentido, Yuri Escalante (2002:62-63) señala: “En resumidas cuentas, los sistemas normativos tal como han sido incorporados en la Carta Magna aparecen como una institución virtual, todavía no configurada en sus rasgos esenciales y dependiendo de unas leyes o bien de unos jueces y tribunales que validarán, positiva o negativamente, sus determinaciones [...] la reforma reconoce sistemas normativos pero no instaura un sistema plural de derecho. O sea, avala la existencia o creación de instancias indígenas de justicia (lo cual en teoría se podría realizar sin reforma constitucional), pero de ninguna manera reconoce la pluralidad jurídica. Acepta que existe diversidad y alteridad, pero esta no pone en duda los pilares del positivismo. La pluriculturalidad de hecho, en este caso, todavía no es la pluriculturalidad de derecho, aunque como dijimos al inicio, los sistemas indígenas por lo menos podrían tener legalidad".

${ }^{30}$ En el trabajo coordinado por Teresa Sierra Camacho (2004 $\left.{ }^{\mathrm{a}}: 17\right)$ señala que "un análisis general de las regiones estudiadas muestra diferencias importantes con relación a los alcances de la justicia indígena y su relación con el Estado. Si bien en todas las regiones el Estado ha conseguido imponer una estructura legal, su impacto es diferenciado. El control estatal a través de instituciones y funcionarios es mucho más hegemónico en la región nahua de Cuetzalan en la Sierra Norte de Puebla y en el municipio de Coyutla, en la Sierra Totonaca de Papanta, que en la región tzotzil de Zinacantán, en Los Altos de Chiapas, donde el Estado no tiene el control de la justicia y la gestión municipal, lo que hace que prevalezca una jurisdicción indígena de gran fuerza en la zona. En un lugar intermedio encontramos a las comunidades mixes de Oaxaca donde la presencia del Estado es continuamente negociada, dado que existe además una mayor autonomía para la gestión municipal, constitucionalmente reconocida, y debido también a las divisiones entre cabeceras y agencias municipales". 
aplicarlas para ese fin. ${ }^{31}$ En el caso de los pueblos y comunidades indígenas en México, y particularmente en Oaxaca, estamos también ante campos sociales semiautónomos con reglas y dinámicas propias, es decir, sistemas jurídicos que se encuentran acotados por un campo social más amplio que es el del Estado mexicano, en el que están insertos. Por ejemplo, las autoridades indígenas a nivel local en la cabecera o en las agencias son presionadas por la presencia de las instituciones municipales y del estado de Oaxaca — como la Comisión Estatal de Derechos Humanos-, 32 así como por la intervención de los agentes de las diversas dependencias o instituciones estatales o federales, en particular, las que se encargan de la procuración y administración de justicia, sin por ello perder el control sobre asuntos que son relevantes para las propias comunidades.

Esa posibilidad de control sobre los recursos, a través de diversos mecanismos, instancias y espacios, se sintetizan en un conjunto de normas que integran el sistema jurídico (ya sea mexicano o indígena) que regulan las actividades y acción humana. A este conjunto de normas se denomina derecho, es decir, se trata de "un cuerpo de procedimientos regulados y normas consideradas justiciables en un grupo dado, las cuales contribuyen a la creación y prevención de disputas tanto como a su establecimiento, a través de un discurso argumentativo acompañado de la amenaza de la fuerza" (Santos 1995:112). Las normas justiciables se dan sobre los aspectos, recursos y/o relaciones que son consideradas relevantes

31 Cfr. Moore (1190:64, 88): “En el periodo colonial muchas de las negociaciones recursosdistribución, reglas-acciones, reglas-administración, reglas-imposición y disputas-actividades establecidas entre los chagga, tuvieron lugar dentro de los distritos, los grupos patriliniales localizados, las asociaciones de irrigación y los consejos de ancianos del distrito y algunos en los mercados de mujeres. Cada uno de estos dominios sociales relativamente autónomos controlan importantes recursos materiales y humanos los cuales pueden ser distribuidos y regulados". (Traducción libre de Elisa Cruz Rueda).

32 Hasta el 2005 que se hizo esta investigación, la Comisión Oaxaqueña de Derechos Humanos tenía como práctica hablar vía telefónica con las autoridades de las comunidades indígenas ante una queja por su forma de actuar en la resolución de conflictos internos, principalmente cuando había una denuncia o queja o cuando una persona estaba encarcelada, el visitador de la Comisión pedía a la autoridad indígena que lo dejara en libertad argumentando que en caso contrario la autoridad indígena podría tener problemas con el Ministerio Público por privación ilegal de la libertad. 
por la comunidad. La justiciabilidad es definida por Boaventura de Sousa Santos (1995:126) como:

[La justiciabilidad se define] "como las características de aquellas normas las cuales se consideran adecuadas a ser aplicadas por un órgano judicial en algún procedimiento definitivo". Por órgano judicial se entiende como: "una autoridad definitiva relacionada con un tipo de casuística, verbigracia, la aplicación de principios a casos individuales de conflicto entre partes". 33

El concepto de justiciabilidad es útil para definir la justicia en las comunidades indígenas a través de la aplicación de normas jurídicas de acuerdo al caso concreto (el individuo o la persona) y a las circunstancias (sus condiciones materiales y su relación con la comunidad) para resolver conflictos y lograr acuerdos. A esta aplicación de normas al caso concreto subyace el sentido de justicia, es decir, los valores, intereses y principios que cada sociedad o pueblo tiene, así como la lógica o la forma de cómo debe hacerse para lograrlo. Estos aspectos relevantes para la comunidad, que determinan el sentido de la justicia (en la resolución de conflictos, disputas y atención de asuntos) y los límites del campo jurídico, se denominan principios generales del derecho (cfr. Cruz 2005); ${ }^{34}$ por ejemplo, en el caso del alcalde de Totontepec al hacer justicia se pueden observar los tipos de casos que son relevantes; la confrontación con el sistema jurídico del Estado y los criterios y principios fundados en la comunalidad, que lo orientan a una determinada resolución. Estos principios son criterios que la conducta humana debe seguir en cierta situación - deber ser - que emanan, por un lado, del devenir histórico de la

33 El subrayado y la traducción son mías. [...] "as the characteristics of those rules "which are considered fit to be applied by a judicial organ in some definite procedure'. By 'judicial organ' Kantorowicz means 'a definite authority concerned with a kind of 'casuistry', to wit, the application of principles to individual cases of conflict between parties'."

34 Me refiero a los principios generales del derecho según la definición de Adame (1998:2541-2542), "los principios más generales de ética social, derecho natural o axiología jurídica, descubiertos por la razón humana, fundados en la naturaleza racional y libre del hombre, los cuales constituyen el fundamento de todo sistema jurídico posible o actual". Es importante advertir que ese concepto se deriva de la tradición jurídica occidental por demás criticada por las organizaciones e intelectuales indígenas, por ser fundamentalmente individualista y contraria al principio de colectividad. 
comunidad-cabecera en su relación con cada una de las comunidades-agencias que integran el municipio y por otro, de la relación de estas unidades o conglomerados humanos con el pueblo indígena o grupo etnolingüístico del que forman parte. El principio fundante en el que descansa este cuerpo de principios éticos y axiológicos en el caso de las comunidades indígenas de Oaxaca, y en concreto de las que se estudian, es el de la comunalidad.

\subsection{El derecho indígena ${ }^{35}$}

El concepto de derecho indígena ha adquirido una gran relevancia en los últimos años como parte de los procesos de emergencia étnica y revalorización de las identidades. Tal proceso coincidió con el desarrollo de estudios antropológicos sobre el derecho consuetudinario indígena desde fines de la década de 1980, en México y en América Latina. En esta dirección ha sido clave el trabajo pionero de Rodolfo Stavenhagen quien impulsó el desarrollo de estudios sobre el tema, con el interés de comprender la particularidad de este derecho y sus diversas relaciones

\footnotetext{
35 El estudio y conceptualización del derecho indígena se ha dado desde enfoques diversos, entre los que destaca el planteamiento del llamado derecho consuetudinario indígena, o la "costumbre jurídica" o los "usos y costumbres", expresiones que como señala Magdalena Gómez (1997:25) implican subordinación del derecho indígena al derecho nacional predominantemente unicista y homogeneizador de la diversidad. Por su parte, Sierra (2005:5) destaca las circunstancias en que el derecho indígena es construido y transformado: "De esta manera lo que llamamos derecho indígena es el resultado de múltiples procesos de transacción, negociación y resistencia, y en gran medida ha sido moldeado por las relaciones de dominación y tensión con los sistemas jurídicos dominantes: del colonizador, primero, del derecho estatal nacional, posteriormente, y hoy en día del derecho internacional".
} 
con el derecho estatal. De esta manera el libro Entre la ley y la costumbre: el derecho consuetudinario indígena en América Latina (Stavenhagen e Iturralde 1990) constituye un hito en los estudios sobre el tema, sobre todo por la visión relacional que impulsan y el énfasis en plantear su vínculo con la problemática de los derechos humanos de los pueblos indígenas. La intención de esa obra fue entender las situaciones de conflicto entre el derecho estatal y el derecho consuetudinario o costumbre jurídica, entendiendo a ésta "como un intento de las sociedades subordinadas por adaptar y reinterpretar las normas positivas estatales de acuerdo a sus propias estructuras, valores, intereses y necesidades". ${ }^{36}$ Esto es, el trabajo Entre la ley y la costumbre da cuenta "de un proceso dinámico y a veces contradictorio, de cambio legal y jurídico en situaciones de pluralismo legal" (Stavenhagen 1990:39). Por lo que podemos decir, que el término derecho consuetudinario indígena fue aplicado al caso latinoamericano y mexicano, destacando la base histórica colonial a la que fueron sometidos los pueblos del continente americano (al igual que los pueblos africanos), bajo condiciones que los colocó en grado de desventaja, lo que se puede percibir hasta nuestros días en la relación derecho estatal-sistemas jurídicos indígenas.

La utilidad del concepto de derecho consuetudinario radica en que el término refiere a la costumbre como fuente del derecho, pero también porque el derecho consuetudinario es fundamentalmente un conjunto de:

[...] costumbres reconocidas y compartidas por una colectividad (comunidad, pueblo, tribu, grupo étnico o religioso, etcétera), a diferencia de leyes escritas que emanan de una autoridad política constituida, y cuya aplicación está en manos de esta autoridad, generalmente el Estado. La diferencia fundamental, entonces, sería que el derecho positivo está vinculado al poder estatal, en tanto que el derecho consuetudinario es propio de

36 Sierra (1993:18) define como costumbre jurídica: “me refiero aquí a ciertas prácticas y procedimientos que suelen ser recurrentes en la resolución de las disputas entre los vecinos de una comunidad, o grupo étnico, y a los principios o normas que el grupo valora ante un determinado hecho" o bien "costumbre jurídica o de carácter jurídico para referirnos a las prácticas de carácter prescriptivo cuya violación es susceptible de generar una sanción" (1992:98). 
sociedades que carecen de Estado, o simplemente opera sin referencia al Estado. (Stavenhagen 1990:30)

De esta manera el derecho consuetudinario indígena revela asimismo que las comunidades indígenas han debido construir y renovar su derecho en contextos de colonialismo y subordinación ante el Estado, respuesta que no todas las comunidades han conseguido dar de la misma manera. En caso de los mixes, en Oaxaca, como en la mayoría de las comunidades de Oaxaca, el vínculo comunitario ha sido un elemento clave en la construcción del derecho propio y su defensa. Finalmente, hay una acepción más del concepto derecho indígena como sistema jurídico que comprende una serie de atributos y facultades - derechos subjetivos - individuales y colectivos (implicados e imbricados mutuamente) como: el derecho a la cultura (ética de la cultura del individuo y de la entidad colectiva) (Villoro 1999:113), el derecho al desarrollo, el derecho al territorio, el ejercicio de autoridad, el derecho al derecho propio y el derecho a la justicia que “combina tanto la posibilidad de la autorregulación de un pueblo [...] como el derecho a tener acceso a la justicia del Estado" (Iturralde 1997:181). Tal definición ayuda a comprender la fuerza que tiene el derecho para las comunidades y pueblos indígenas.

De esta manera, desde el punto de vista normativo positivista el derecho indígena se define como el "conjunto de las normas eficaces en comunidades que contienen, en grado variable, elementos culturales" que las distinguen de las sociedades de los estados nacionales en los que viven, de acuerdo con el ARTícUlO 1 inciso b) del Convenio 169 de la OIT. ${ }^{37}$ Pero visto desde una dimensión antropológica, el derecho incluye las prácticas a través de las cuales se dirimen las disputas y se reconstituyen las relaciones sociales.

\footnotetext{
37 Por su parte, Óscar Correas (1994:16) define el derecho indígena como "el conjunto de las normas eficaces en comunidades que contienen, en grado variable, elementos culturales indígenas", independientemente de los errores de formulación de esta definición pues se incluye en ella el objeto a definirse (indígena), nos parece importante por ser formulada por un abogado que ha trabajado desde una concepción de pluralismo jurídico clásico, lo sistemas normativos indígenas en México - pues postula que éstos son independientes y separados del sistema jurídico del Estado.
} 


\subsubsection{El derecho indígena frente al derecho estatal}

El sistema jurídico indígena ha sido históricamente negado e invisibilizado por el Estado, a pesar de ello, las comunidades han conseguido reproducirlo adecuando sus principios normativos. La fuerza del derecho indígena para renovarse es lo que ha permitido su vigencia y ser reconocido, aún en sus marcos limitados, como parte del campo jurídico con particularidades históricas y culturales, así como con distintos niveles e instancias legales y autoridades.

En cuanto a esas particularidades históricas y étnico-culturales del derecho y del campo jurídico en zonas indígenas, es atinada la vinculación que hace Stavenhagen (1990:27-28) del derecho con la cultura de un pueblo:

[...] junto con la lengua, el derecho constituye un elemento básico de la identidad étnica de un pueblo, nación o comunidad, [por tanto] cuando un pueblo ha perdido la vigencia de su derecho tradicional ha perdido también una parte esencial de su identidad étnica, de su identidad como pueblo, aun cuando conserve otras características no menos importantes para su identidad, [de esta manera] el derecho consuetudinario es considerado generalmente como una parte integral de la estructura social y la cultura de un pueblo, por lo que su estudio es un elemento fundamental para el mejor conocimiento de las culturas indígenas del continente [americano].

Como lo apunta María Teresa Sierra (1992:98), el derecho indígena se refiere a “normas no codificadas ni escritas, se trataría por lo tanto, de un derecho oral, que va de lo particular a lo general; en este sentido es un derecho situacional y sustantivo: existe el delito mientras se cometan trasgresiones que se tipifican como tales", es decir, se basa en acontecimientos o situaciones que expresan los valores y asuntos relevantes de una sociedad y que lo perfilan y, a la vez, definen las faltas, derechos y obligaciones. ${ }^{38}$

\footnotetext{
38 En el derecho estatal es a la inversa, existe la norma que describe una conducta como prohibida o permitida, el delito existe en tanto que hay una norma que señala que una conducta lo es, por ejemplo, el delito de homicidio se da cuando una persona priva a otra de la vida, si no existiera esa norma, el homicidio no sería delito, según la lógica jurídico positivista.
} 
El derecho indígena, siendo oral y situacional, comprende las causas y las circunstancias que subyacen en un acontecimiento o situación. Por ejemplo, la norma de matar a un brujo, por que se tiene la certeza de que está atentando contra la integridad y la vida de otras personas por realizar brujería (Gómez Rivera 1990:382), ${ }^{39}$ no está por escrito pero responde a una circunstancia y realidad concreta que se modifica y cambia con el tiempo y el contacto con el campo social del Estado. Este ejemplo es clave para comprender que el derecho es un fenómeno social, parte de la cultura de un pueblo, que la realidad es cambiante y que una norma oral es más flexible a ese cambio que una norma escrita.

El derecho indígena puede ser también escrito, sin que ello signifique que se vuelva estático o que deja de ser parte de la cultura de un pueblo indígena, y por tanto seguir siendo flexible y dinámico. En este sentido, la norma escrita puede ser una guía ${ }^{40}$ de pautas de conducta, que no se sobreponen a la valoración de la persona o individuo y de las circunstancias que rodean cada caso. Algunas organizaciones han decidido escribir lo que consideran su derecho propio, para darle un uso particular. Tal es, por ejemplo, lo que sucede en Oaxaca con los estatutos y reglamentos en materia agraria elaborados por las comunidades, en los que han incorporado distintas normas que tienen que ver con la dinámica interna de las comunidades indígenas (Zapata 2004).

El sistema jurídico indígena o el derecho indígena es una manifestación del campo jurídico y como tal comparte las características del derecho como "un cuerpo de procedimientos regulados y normas consideradas justiciables en un grupo dado, las cuales contribuyen a la creación y prevención de disputas tanto como a su establecimiento, a través de un discurso argumentativo acompañado de

\footnotetext{
39 En el derecho estatal la brujería no es un delito (no existe norma que se refiera a él), pero sí el homicidio, circunstancia que expresa una discriminación a la lógica indígena sobre la definición del bien jurídicamente tutelado y las acciones que atentan contre el mismo.

40 Puede ser una guía de casos o acuerdos de asamblea como lo es el reglamento escrito de San Marcos Móctum y el de la Policía Comunitaria de la Costa y Montaña de Guerrero, confrontados estos ordenamientos jurídicos con la realidad de las dinámicas jurídicas locales existen muchos casos que no se plasman pero que existen o se han dado.
} 
la amenaza de la fuerza" (Santos 1995:112), que incluye instituciones, procedimientos y autoridades para aplicarlo y hacerlo eficaz, esto también se aplica al derecho indígena. El derecho indígena tiene particularidades propias como las ya apuntadas pero también, como señala Valdivia (2001:68-69), se puede encontrar una visión del mundo expresada en la forma de regular los asuntos públicos y privados y que se encamina a la protección de la costumbre comunitaria — con arraigo histórico y étnico-cultural—, y a la reproducción y continuidad de la comunidad. De esta manera, el derecho indígena se define como un conjunto de normas jurídicas (que establecen derechos y obligaciones), cuya observancia y aplicación está garantizada por un poder público. Tal poder público — fundado en el principio de la comunalidad - se ejerce a través de un cuerpo institucionalizado de autoridades designadas por la comunidad sobre las cuales delega facultades de decisión, resolución y ejecución, para lo cual existen procedimientos. Este derecho está en constante relación con el derecho del Estado por lo que se llega a un punto "en el que es difícil e inútil tratar de distinguir cuándo una norma es estrictamente nativa o no lo es, ya que el conjunto de normas vigentes es lo que da sentido al sistema jurídico indio" (Valdivia 2001:70).

\subsubsection{La lógica jurídica en el sistema jurídico indígena, la comunidad y la comunalidad}

Con la Conquista española y posteriormente con la Colonia se promovieron procesos de concentración y reorganización de los pueblos indígenas (Gerhard 1986; Medina Hernández 1995). En la época de independencia se imponen disposiciones jurídicas que buscaron desarticular a las comunidades, lo que en la actualidad trae como consecuencia que los pueblos indígenas no cuenten con una estructura interna compacta ni centralizada, es decir, que no tengan una representación política que encabece o incorpore a las distintas comunidades de

una etnia. De igual forma, vale advertir que los pueblos prehispánicos no 
compartían las mismas estructuras organizativas ni tampoco todos eran compactos, homogéneos y uniformes:

la organización socioeconómica española inicial, como las encomiendas (las concesiones del tributo y trabajo de los indios a los españoles) y los repartimientos (tierras que iban a ser distribuidas), así como las parroquias rurales, las municipalidades y las jurisdicciones, fueron construidos sobre una forma de organización náhuatl anterior a la Conquista, el altépetl o "Estado étnico". Tales unidades, según Lockhart, quien basó su estudio en fuentes nahuas, eran asentamientos de personas que reflejaban la existencia y reproducción de la "microetnicidad".

[...] Es interesante resaltar que la constante fragmentación étnica choca con las definiciones modernas de grupos étnicos compactos (Barth, 1969, Smith, 1986) que entraña la evolución histórica de un grupo unificado que tiene en su poder un solo territorio. En vez de ello, como lo ha revelado Lockhart, dentro de la misma región lingüística y territorio, cada complejo altépetl tenía su propio carácter étnico que competía y era económicamente interdependiente con los demás. (Gutiérrez Chong 2001:65)

Lo anterior es útil para entender que la fragmentación de pueblos en comunidades, en algunos casos, se remonta hasta antes de la Conquista y la Colonia. De igual forma da pie para definir a la comunidad indígena como un conglomerado humano con características etnolingüísticas - que lo asocian con otros con los que comparte elementos comunes - , y que ocupa un espacio territorial determinado. Como se expondrá más adelante, en el caso de Oaxaca los pueblos indígenas son grupos etnolingüísticos que abarcan conglomerados humanos o comunidades diversificadas y complejas. Esta complejidad responde a procesos históricos de definición cultural interna y territorial, pero también por el estatus jurídico que el derecho positivo les señala.

El concepto de grupo etnolingüístico lo retomo del planteamiento de Barabas y Bartolomé (1999b), quienes lo manejan haciendo énfasis en la complejidad que los pueblos indígenas como grupo humano tienen a su interior, y las dificultades que existen para definirlos aplicando exclusivamente el criterio 
lingüístico. Concluyendo que no puede afirmarse categóricamente o concluirse que un grupo etnolingüístico es uniforme y homogéneo, ya que las personas y comunidades que lo componen comparten una cultura aunque no poseen necesariamente una identidad colectiva, "la que por lo general es resultado de la acción de un aparato político estatal" (Barabas y Bartolomé 1999:15; Bartolomé 2005:102). Por lo tanto, se puede dar cuenta de una vigencia de nociones de una indentificación compartida, mas no de una filiación global abarcativa, basada en una comunidad de comunicación y de intereses. Por ello, la pertenencia a un mismo grupo etnolingüístico no excluye la disparidad de intereses ni incluye una necesaria identidad generalizada, de esta manera diversos estudios etnográficos (cfr. Bartolomé 2005; Maldonado y Cortés 1999) demuestran que tal identificación colectiva no se expresa necesariamente en términos de solidaridad, sino más bien en términos de conflicto, que se establece como una forma de relación. Ejemplo de esto es el caso que se aborda en este estudio, en la tesión entre la cabecera municipal de Totontepec Villa de Morelos con una de sus agencias de policía, San Marcos Móctum, ambos poblados considerados comunidades pertenecientes al grupo etnolingüístico mixe.

De esta manera, en el caso del grupo etnolingüístico mixe se compone por más de 200 comunidades, entre las cuales existen diferencias por la división municipal y agraria. Mientras unas comunidades son cabeceras de distrito y/o cabeceras municipales, otras son agencias de policía o agencias municipales y las comunidades más pequeñas son rancherías. De igual forma, de estas comunidades unas son ejidos y otras son bienes comunales - ambas categorías jurídicas se refieren a la propiedad social de la tierra-, pero también existen comunidades en las que sus habitantes tienen pequeñas propiedades o propiedad privada sobre la tierra. Estas particularidades, históricas y jurídico positivistas, determinan e influyen en la conformación, construcción y dinamismo del derecho en cada comunidad, distinguiéndose manifestaciones diversas del derecho, aun cuando esas comunidades formen parte del mismo grupo etnolingüístico. Por esto mismo, 
el derecho que se expresa en cada comunidad comparte elementos y características comunes o, como veremos más adelante, principios generales.

Son muchas las razones por las cuales los pueblos indígenas se encuentran fragmentados, dando como resultado un fenómeno de pluralismo cultural al interior de las comunidades indígenas. Sin embargo, los pueblos indígenas siguen existiendo y las comunidades se reconocen como parte de ellos, unidos por la cultura -lengua y el sentido o significado de las prácticas e instituciones, tradiciones, usos y costumbres -, elemento fundamental que los distingue entre sí. De esta manera, los sujetos colectivos operantes son las comunidades. ${ }^{41}$

La comunidad como grupo humano, como forma de vida colectiva y como lugar de origen y de destino, es el centro de la vida, cotidianidad y acción humana, y de la dinámica de los indígenas y sus pueblos. De esta manera, el conjunto de argumentaciones, sobre su importancia como centro que rige la acción humana y los recursos, es lo que en Oaxaca se ha llamado comunalidad (Regino 2002; Martínez Luna 2003), que más que un concepto es una forma de pensamiento y una actitud en torno a la comunidad. En este sentido, la comunalidad es a la vez el principio de unidad básica y central de cualquier conducta, proyecto, meta o fin en torno a la comunidad, es decir, es "la actitud humana hacia lo común" (Regino 2002:7). En palabras de Jaime Martínez Luna (2003:52), intelectual indígena zapoteco de la Sierra:

${ }^{41}$ El pueblo indígena es el grupo humano o sociedad asentada en algunas partes o regiones del territorio de un estado. Su característica fundamental es descender de pueblos históricos (poblaciones precolombinas y precoloniales), que habitaron ese territorio con anterioridad al establecimiento de las actuales fronteras internacionales e interestatales, hecho por el que se les llama o conoce, también, como pueblos originarios (ARTículo $1^{\circ}$ del Convenio 169 de la Organización Internacional del Trabajo, OIT). Esa herencia cultural se expresa en el control, uso y ejercicio de sus propias costumbres y tradiciones, así como por la existencia de instituciones propias como la lengua, el derecho, la organización social y económica, las relaciones de parentesco, etc., que distinguen al pueblo indígena del resto de la población de un estado, aunque se puede apropiar de algunos elementos culturales de ésta. El pueblo indígena puede estar asentado en el territorio de uno o varios estados, ocupando regiones geográficas continuas o compactas, o bien fragmentadas o discontinuas, por ejemplo: los huicholes de Jalisco, Nayarit y Durango; los amuzgos de Oaxaca y Guerrero; los mixtecos de Puebla y Oaxaca. 
La comunalidad como tal es el pensamiento sustantivo de la educación regional y extrarregional y son acuerdos comunes en un territorio propio. Es la suma de valores de intercambio hacia adentro y al exterior; integra a la individualidad pero es algo más que la suma de individualidades. Comunalidad es autoridad y es poder en tanto decisión consensual. Se enfrenta al poder externo en campos diversos de confrontación: en la educación, en la tecnología, en la religión o en la fiesta. Es concepto integrador de instancias que se alcanzan a reproducir incluso en ámbitos urbanos.

El planteamiento arriba expuesto pretende subrayar las bondades del sistema comunitario para contestar la postura y pretensiones del Estado de invisibilizar el derecho indígena, que lo coloca como un nivel jurídico del derecho positivo, sin reconocer sus particularidades. También la argumentación de la comunalidad pretende confrontar la definición que desde el Estado y su derecho se hace sobre lo qué es o debe ser el sistema jurídico indígena. El planteamiento de la comunalidad constituye un referente discursivo ideológico con fuerte poder retórico que busca establecer límites a la ingerencia del Estado en las comunidades y regiones indígenas, y a su afán de hacer un reconocimiento parcial y unilateral de lo que es el sistema jurídico indígena, reduciendo los márgenes de potestad y jurisdicción de las autoridades indígenas y finalmente limitando el ejercicio del poder comunitario. De igual forma, la respuesta de la comunalidad es también el resultado de esa ingerencia del Estado y el control que ha ejercido en zonas indígenas, propiciando o reforzando la fragmentación comunitaria a través del establecimiento del municipio con la consecuente imposición de fronteras administrativas.

De acuerdo con el planteamiento de la comunalidad, la exteriorización de la voluntad individual de formar parte de la comunidad, de manera constante y permanente, es uno de los criterios que orientan la conducta humana en muchas comunidades indígenas, como es el caso de las comunidades mixes. ${ }^{42}$ Las

42 Teresa Valdivia Dounce señala que tales principios generales del derecho, así como el principio fundante del derecho que es la comunalidad, se reconocen y pueden apreciar en la mayoría de las comunidades mixes. Esto pudo ella constatarlo en su trabajo de campo en los 19 municipios mixes, 
conductas individuales se orientan por el interés común, lo que no significa que el individuo no encuentre también ámbitos de realización individual. Las dinámicas contemporáneas en las que están insertas las comunidades indígenas como parte de procesos globales, sin embargo, están impactado a la cohesión comunitaria fomentando la migración, la conversión religiosa, ${ }^{43}$ así como el cuestionamiento a los cargos comunitarios, lo cual ha implicado un constante esfuerzo por redefinir la comunalidad y los criterios de pertenencia. De ahí que el término de comunero se aplica no sólo a los que detentan o hacen uso de la tierra sino a los que participan de la cotidianidad de la comunidad, los trabajos colectivos, la asignación de cargos y servicios, las fiestas, el aprovechamiento de los servicios urbanos, de salud, vivienda, transporte, educación. Quien de esta manera externa su voluntad constante y permanente de ser considerado como parte de la colectividad forma parte de ella, aceptando la obligatoridad de sus normas y la legitimidad de las autoridades encargadas de aplicar el derecho; por lo que las personas que se consideran como sujetos de derecho son, en primer lugar, los que han nacido y vivido en la comunidad, y los que se integran a ella siendo mayores de edad, la mayoría de las veces por contraer matrimonio con alguna persona oriunda de la comunidad. Pero también quienes aun viviendo fuera de ella mantienen sus vínculos a través de cooperaciones y muchas veces regresando a cumplir sus cargos.

En resumen, esta voluntad de formar parte de la comunidad se externa

que cristalizó en su obra Normas jurídicas en los sistemas de cargos mixes. Zonas, alta y media (materiales etnográficos) (2003) y Valdivia 2002.

43 En el caso de la cabecera del municipio de Totontepec, aunque es mayoritariamente católica existen otros grupos religiosos como los adventistas y en menor número los pentecostales. Tanto los adventistas como los pentecostales han aceptado realizar cargos considerados religiosos. En el caso de Móctum (agencia de policía de Totontepec) la mayoría son adventistas, pero tanto éstos como los católicos participan de los cargos civiles dejando de lado los religiosos, también los hombres mayores que han pasado por todos los cargos tanto de una como de otra religión sesionan para discutir o dar su opinión a la autoridad en turno, sobre determinados asuntos o casos. Sin embargo, son más los casos en los que la conversión religiosa provoca más conflicto, trastocando la estructura indígena por lo que toca al sistema de cargo como a otros aspectos como el uso de la tierra y los rituales en torno a ella. Sobre los conflictos religiosos Fabre (2005) aborda el estudio de un caso en la zona zapoteca de la Sierra, precisamente vecina a la zona del municipio de Totontepec. 
desde que el individuo vive, convive y desarrolla su vida cotidiana en ella, acepta sus normas o cuando se le asignan servicios y cargos (como el tequio o ser topil o encargado de la tienda comunitaria).

Hablar de la comunalidad como fundamento de los principios generales del derecho idealiza la conducta humana en sociedad, pero esto también se da en el caso de los principios generales del derecho del Estado. Sin embargo, esto no significa soslayar el estudio de las desigualdades o dar cuenta de las contradicciones o conflictos al interior de un sistema. En este sentido y por lo que se refiere al sistema de cargos indígena, Velásquez (1999:300) señala "si bien se trata de un sistema [los cargos] que tiende a mantener la reciprocidad, no por ello nivela las diferencias sociales; por el contrario, legitima roles diferenciados y estratos sociales" lo que Cancian $(1965,1990)$ ya había constatado en el caso de Zinacantán.

De esta manera, la propuesta sobre ideología de la armonía de Laura Nader (1998) forma parte de mi marco teórico para explicar los localismos arraigados y la comunalidad como recurso argumentativo que contesta al Estado. Si bien el planteamiento de la ideología armónica no es un concepto elaborado desde la intelectualidad indígena, sí tiene como base un trabajo serio y extenso en una comunidad del rincón zapoteco, región vecina a donde se encuentra Móctum. El trabajo de Nader nos ayuda a constatar cómo los indígenas desde sus comunidades conciben sus sistemas normativos, cómo los justifican, sobre qué lógica o argumentos se erigen. El planteamiento de la comunalidad coincide con la propuesta de Laura Nader en torno a la "ideología de la armonía" para referirse al discurso usado por las autoridades indígenas para mantener un cierto control sobre sus asuntos internos evitando al mismo tiempo la intromisión del Estado. Nader documenta, de esta manera, cómo las comunidades zapotecas han buscado mantener el control social y cultural de las dinámicas internas del pueblo, entre 
ellas la justicia, a través una ideología unificante que promueve la legitimidad del actuar de las autoridades y la lealtad de los vecinos. ${ }^{44}$

Como fundamento histórico de estos principios, la comunalidad hace énfasis en las cualidades de un sistema jurídico distinto al derecho del Estado. Además, como antes se ha apuntado, es un discurso que idealiza a la comunidad - sus formas de organización y control-, para contestar y confrontar la hegemonía del derecho del Estado.

Otra vertiente del discurso de la comunalidad ha sido elaborada por dirigentes indígenas mixes como Adelfo Regino, quien plantea la existencia de un derecho indígena igualmente válido que el derecho del Estado. Para dar cuenta de ello expone sus características retomando parámetros del derecho positivo, como la generalidad, la abstracción, la formulación y la definición de un deber ser a la manera del sistema jurídico mexicano. Ejemplo de esto y de cómo la comunalidad es la base fundante de los principios generales del sistema jurídico en comunidades mixes (como Totontepec y Móctum), Adelfo Regino (1996:149-150) desarrolla lo que es la justicia preventiva -evitar que se comentan faltas o errores en la conducta de las personas que dañen a otros o a la comunidad-dentro de lo que él llama derecho mixe; esa justicia preventiva se logra a través de las conductas, instituciones y normas que están de acuerdo o "mantienen el orden social y natural, y que ayudan a lograr la reproducción y la convivencia armónica". Este autor menciona tres principios del derecho mixe que concuerdan con el estudiado en Totontepec y Móctum: 1) que la conducta humana esté de acuerdo con "el orden social y natural", 2) que la conducta humana en este sentido contribuya a mantener y preservar ese orden (respeto a la autoridad, por ejemplo), y 3) que ayuden a lograr la reproducción y la convivencia armónica (aceptar y ejercer servicios y cargos sin remuneración).

44 Esto es claro en el caso de San Marcos Móctum, cuando el apoyo al acusado en un futuro próximo, así como su estadía en la comunidad, se condicionan a cambio de que acepte su error, respete a la autoridad y a los acuerdos de la asamblea. También la imagen de unidad que se quiere dar hacia afuera a personas ajenas a la comunidad se expresa, por ejemplo, cuando se reconocen propiedades particulares pero al exterior se dice: "la tierra es comunal" $\mathrm{y}$ "es de todos". 
De igual forma agrega otros principios: "los principios o valores primordiales que se defienden en nuestras comunidades $-\mathrm{y}$ que, por ende, nuestras normas comunitarias protegen - serían la vida, la unidad del pueblo, la igualdad de derechos entre todos y el aseguramiento de la propiedad de las tierras comunales" (Regino 1996:151). Estos principios remiten a los conceptos de comunalidad, justicia y sentido de justicia ya expuestos (Velásquez 1999; Valdivia 2002; Martínez Luna 2003), pero también se relacionan con los conceptos de jurisdicción (o ejercicio de la autoridad para la resolución de conflictos) y la territorialidad. Por un lado, el ejercicio del poder político de la autoridad para conocer asuntos, resolverlos y ejecutar decisiones, es decir, la jurisdicción se da en un ámbito espacial integrado por la propiedad comunal, esto es, la territorialidad. Este ejercicio del poder político de la autoridad como jurisdicción busca "dar a cada quien lo que es suyo", es decir, mantener cierta igualdad de derechos, lograr el respeto a la vida y la salvaguarda de la propiedad comunal, como espacio físico del ejercicio del poder comunitario, depositado o delegado en la autoridad. Lo relevante del trabajo de Regino es que, con los mismos argumentos y principios que definen y dan validez al sistema jurídico mexicano, demuestra que el sistema jurídico indígena también es válido y es un Derecho. La desventaja de este tipo de definiciones es que no dan cuenta del dinamismo del campo jurídico, de los usos del derecho y del poder al interior de las comunidades y plantean una visión idealizada de las comunidades.

En un sentido similar al planteado por Regino, Valdivia (2003) elaboró un catálogo de sistemas de cargos en 17 de los 19 municipios de la región mixe, en donde da cuenta de principios generales del sistema de cargos y la imbricación del sistema civil municipal y el sistema religioso; lo que marca una aportación a la conceptualización del derecho mixe. En este trabajo no me propongo documentar el derecho mixe, más bien me refiero a las manifestaciones y construcciones del derecho en dos comunidades mixes, como unidades centrales de análisis en el caso de estudio: San Marcos Móctum y Totontepec Villa de Morelos, estas comunidades 
pertenecen al grupo etnolingüístico mixe de la zona alta, tienen características comunes como el uso del idioma y bienes comunales o propiedad colectiva, como forma de tenencia de la tierra. Entre las diferencias se cuentan aspectos como el sistema de cargos, el número de habitantes de cada una. Así, mientras Totontepec es cabecera municipal y cuenta con aproximadamente tres mil habitantes y su sistema de cargos es cívico-religioso, Móctum está subordinada a ella por ser una de sus agencias de policía, contando con aproximadamente doscientos cincuenta habitantes y un sistema de cargos en el que se han separado los servicios religiosos de los civiles. Además del vínculo que implica la división municipal, estas comunidades están relacionadas por un conflicto por tierras que se remonta hasta antes de la llegada de los españoles y un conflicto municipal por recursos.

Finalmente como se ha apuntado, el concepto de comunalidad ayuda a comprender los elementos comunes entre estas comunidades, sus diferencias y divergencias, sobre todo en su forma de hacer justicia; pero también es útil para explicar las disputas y conflictos municipal y por la tierra - reforzado por el sentimiento localista tan arraigado que motiva a los habitantes de una comunidad a tener como referente primordial y central a ésta y no al grupo etnolingüístico en su totalidad

\subsection{Niveles legales y jerarquías del campo jurídico}

El estudio de las dinámicas del campo jurídico en lo local se ubica en la región mixe y se configura e integra por la confluencia e interconexión de tres niveles legales: ${ }^{5}$ las instancias jurídicas de las agencias (municipales y de policía) y en

\footnotetext{
45 El concepto de niveles legales ha sido desarrollado por la antropología jurídica para dar cuenta de las diferentes instancias y jerarquías en las que se insertan los sistemas jurídicos en campos sociales particulares. El concepto fue propuesto inicialmente por Leopold Pospísil para referirse a la jerarquía y relación entre sistemas jurídicos vigentes en una misma sociedad, tal como lo analizó para el caso de los kakaupu de Nueva Guinea (citado en Sierra y Chenaut 2002). Más adelante el concepto ha sido retomado por diferentes estudiosos para documentar las relaciones complejas entre órdenes jurídicos diversos en contextos de pluralidades normativas. El concepto ha sido aplicado al estudio de comunidades indígenas en México por Laura Nader (1998) en los estudios ya mencionados sobre los zapotecos de Villa Alta, por Jane Collier (1995) en su estudio sobre los procesos legales zinacantecos, por Sierra entre los nahuas en la Sierra Norte de Puebla (1995, 2004b),
} 
particular de Móctum, las instancias municipales de Totontepec Villa de Morelos como centro de poder que abarca al conjunto de las agencias, y las instancias jurídicas del distrito judicial como centro de poder del Estado, representado por la cabecera de Santiago Zacatepec, que comprende 17 de los 19 municipios mixes del estado de Oaxaca. En cada uno de estos niveles legales se hace patente la interlegalidad, es decir, la confluencia del derecho del estado y el derecho indígena. Sin embargo, la presencia del Estado y su derecho es más evidente o exclusiva conforme el campo social es más amplio — según sus límites territoriales, y sus recursos humanos y materiales-. En el nivel del Distrito Judicial —donde las autoridades indígenas tienen poco margen de actuación-, se relegan los valores culturales y circunstancias reales, que determinan la resolución de un caso en una comunidad y sus lógicas jurídicas, debido a la imposición del derecho positivo como referente de legalidad. Es decir, prevalece en los hechos una negación del pluralismo jurídico y de la interlegalidad, circunstancia que no cambia con la llamada Ley Indígena de Oaxaca (1998), como se mostrará posteriormente.

Finalmente en la cabecera municipal de Totontepec Villa de Morelos - como campo social semiautónomo- se observa un cierto control de las dinámicas jurídicas y políticas en relación con sus agencias municipales y de policía, por la territorialidad y recursos que abarca, pero a su vez se encuentra subordinado a las dinámicas jerárquicas del Estado mexicano del cual forma parte. Por ello el sistema jurídico indígena si bien revela en sus dinámicas la historia y cultura del grupo étnico, expresa asimismo las regulaciones que el Estado ha impuesto. Esto también significa que este sistema jurídico no es uniforme en sus contenidos y dinámicas. Se pueden apreciar en él la presencia de órdenes jurídicos diversos — formas diferentes de lograr lo justo y de concebir lo justiciable—, que operan en un mismo espacio y de manera distinta según el nivel legal en el que nos

y por Victoria Chenaut (1999) en la región totonaca de la Sierra de Papantla, Veracruz, entre otros trabajos. 
encontremos - por ejemplo, el uso de la ley del Estado que las autoridades indígenas hacen según cada nivel legal, ya sea la cabecera o las agencias.

En resumen, el campo jurídico se define por reglas y conductas (agencia humana), procesos de disputa y conflicto, y usos de poder en distintos niveles legales y arenas. En general, tanto el campo jurídico como sus niveles, instancias y autoridades, las analizo desde los dos ejes planteados al principio: lo territorial (lo agrario y lo municipal) y, la justicia y la jurisdicción. En cierto sentido, podemos decir que el estudio del pluralismo y la interlegalidad es un acercamiento a la alteridad y al conocimiento del "otro", desde una concepción diversificada del derecho, es decir, de la existencia de "otros" derechos distintos y a la vez semejantes al derecho positivo o del Estado.

Finalmente como se mencionó en la introducción, con el estudio de este caso y bajo la perspectiva apuntada, se vuelve comprensible la complejidad jurídicosocial de los pueblos indígenas. Aunque el estudio se centra en el caso mixe, es un buen ejemplo de la relación del Estado con los pueblos indígenas, lo que es más claro en el siguiente capítulo en el que se expondrán elementos del contexto territorial (agrario y municipal) centrales para comprender las particularidades del campo jurídico en la región de estudio. 


\section{CAPÍtUlo 2}

\section{Las Tensiones en el Campo JuRídico: LO TERRITORIAL}

\section{Introducción}

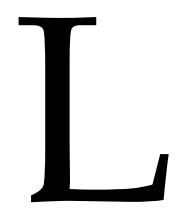

a comunidad es un concepto central en esta tesis, diversos autores (cfr. Lisbona 2005) se han ocupado en definirla, algunas veces como unidad territorial, otras como colectividad extraterritorial, moral o cultural, o bien, como un imaginario colectivo (cfr. Pérez Ruiz 2005:92-95) en constante transformación.

Concuerdo con Maya Lorena Pérez Ruiz (2005:94), cuando se refiere a la comunidad como "una unidad de pertenencia y organización social asociada[s] real o simbólicamente a un territorio y una historia comunes, y en la cual coexisten el cambio y el conflicto junto al interés por la reproducción y la continuidad, por lo cual es un espacio social contradictorio y dinámico". Por tanto, la comunidad no debe entenderse romántica ni ahistóricamente como en la que prevalece la igualdad y la equidad, por el contrario, la comunidad es producto de una gran diversidad de factores que impulsan la solidaridad entre sus miembros, y las decisiones y acciones en las que se involucran relaciones de poder, de clase y estatus, y las diferencias religiosas y políticas.

En este segundo capítulo se explica, desde una perspectiva histórica, la importancia que lo territorial ha tenido para la configuración de las comunidades en Oaxaca y la comprensión de los conflictos comunitarios que finalmente determinan el derecho en lo local. El abordaje de lo territorial se hace en sus aspectos agrario y municipal, que delimitan el espacio para el ejercicio de la jurisdicción y la justicia, así como del control y del poder comunitario delegado en 
las autoridades indígenas encargadas de hacer justicia. Lo territorial definido desde el derecho del Estado se centra fundamentalmente en lo agrario y lo municipal, porque es a través de las leyes en estas materias que el Estado marca su relación con los pueblos indígenas, define y establece a los sujetos de derecho, a las autoridades municipales y agrarias; destina recursos federales y estatales; señala las funciones de los núcleos agrarios y de los ayuntamientos; lo que no descarta que los pueblos indígenas han adoptado a las instituciones agrarias y municipales para refuncionalizarlas según sus requerimientos y necesidades. Es decir, el derecho positivo ha establecido límites tanto territoriales a las comunidades indígenas -cabeceras o agencias, o ejidos o comunidades- como a las potestades de sus autoridades a través de la legislación agraria y municipal. Finalmente lo territorial tiene importancia central porque es el espacio simbólico en el que los pueblos indígenas reproducen y recrean su cultura y, a la vez, es el espacio físico del ejercicio de su control y de su poder político, lo que delimita las dinámicas y expresiones de lo que el Estado reconoce como sistema normativo indígena.

Es pertinente distinguir entre el concepto de tierra y el de territorio. La tierra se entiende como una porción material —o espacio físico- del territorio, en la cual se pueden realizar diversas actividades humanas. El territorio es un concepto que abarca a la tierra, pero que incluye a otros elementos y atributos, como el espacio físico pero también el poder y por consiguiente el control de los recursos humanos y materiales (como los biológicos y minerales del suelo y subsuelo). ${ }^{46}$ De esta manera, el concepto de territorio involucra un agregado de elementos políticos, económicos, sociales y culturales que le dan un valor distinto al que tiene una porción del espacio físico (tierra), lo que da como resultado la posibilidad del ejercicio de poder de quien tiene su posesión y control (individuo o conglomerado humano). Los atributos del territorio que le dan un valor determinado dependen de la historia y cultura de un pueblo.

\footnotetext{
46 En el derecho mexicano el territorio incluye el espacio marítimo, aéreo, el suelo, el subsuelo y es un elemento central del Estado, sobre todo del ejercicio de su poder político.
} 
Así Arcos (2007) define el territorio indígena como:

el horizonte espacial en el que colectividades étnicas se despliegan y plasman su historia, sus anhelos de futuro, representaciones y sus relaciones de poder. Giménez (2000) lo define como el espacio apropiado y valorado por el grupo social para asegurar su reproducción y satisfacción de sus necesidades vitales, ya sean materiales o simbólicas; como lugar de inscripción de una historia o una tradición colectiva, la tierra de los antepasados, el recinto sagrado, repertorio de geosímbolos, bien ambiental, patrimonio valorizado, solar nativo, paisaje natural y símbolo metonímico de la comunidad

De esta manera, la cuestión territorial constituye un referente central para comprender las dinámicas jurídicas y políticas que han marcado la relación del Estado con las comunidades indígenas y de éstas entre sí. Por esta razón, tal como lo he señalado, analizo el campo jurídico desde el ejemplo y contexto del estado de Oaxaca, concretamente por lo que se refiere a las dinámicas del derecho y sus expresiones en lo local (municipio y comunidad). En este sentido la territorialidad, marca un punto de confluencia de muchos aspectos (económicos, políticos, sociales, culturales), dentro de los cuales destaco el aspecto agrario y municipal porque su comprensión histórica es clave para entender los conflictos en las regiones indígenas de Oaxaca. Es decir, en estos ámbitos, y a través del estudio de los conflictos intercomunitarios por la tierra y por los recursos - como aspectos recurrentes en las zonas indígenas de Oaxaca-, se puede observar con mayor claridad los usos del derecho y del poder así como las dinámicas que determinan la construcción del derecho.

Lo agrario y lo municipal son dos aspectos íntimamente relacionados, mientras lo agrario determina los límites territoriales entre poblados o comunidades de un mismo pueblo indígena, lo municipal remite a un nivel de gobierno con determinadas facultades de administración de recursos y ejercicio de poder en una demarcación territorial que puede incluir uno o más núcleos ejidales o comunales (demarcaciones territoriales agrarias), lo cual resulta ser referente central de tensiones. Por ejemplo, en un municipio pueden existir más de un 
núcleo agrario, a su vez algunos de ellos, pueden tener el carácter jurídico de cabecera municipal, agencia municipal o de policía. En el estado de Oaxaca existen 570 municipios algunos de los cuales se dividen a su vez en agencias municipales y de policía. Muchas de las veces el ámbito territorial coincide con los límites territoriales de la comunidad o núcleo agrario. En el caso del municipio de Totontepec Villa de Morelos —en adelante Totontepec-, la cabecera municipal está en la comunidad de Totontepec - cuya tenencia de la tierra es bienes comunales- . No obstante el municipio abarca diez agencias cada una de las cuales es un núcleo agrario. Estas características, que una comunidad puede tener, muestran que lo municipal también impone un orden de jerarquías en el que la comunidad indígena, señalada como cabecera, es centro de poder y control político frente a las otras comunidades que son agencias o rancherías. Así, en la Ley Municipal para el Estado de Oaxaca se señala esta distinción: en primer lugar la asignación del Ayuntamiento como gobierno del Municipio, que radica en la comunidad con mayor población (no menor de 15 mil habitantes - ARTícUlo 9). En segundo lugar el requisito para tener la categoría de agencia municipal o de policía (si la comunidad cuenta con una población no menor de 10 mil habitantes, para la primera, o de 5 mil, para la segunda: ARTículo 10). La categoría de agencias será asignada por el Ayuntamiento - radicado en la cabecera municipal- y con aprobación del Congreso Estatal (ARTículo 11). Las autoridades de las agencias son auxiliares del Ayuntamiento. Para el caso de las funciones y atribuciones de las agencias de policía y municipales son las mismas para ambas, la diferencia radica en la asignación de recursos que se realiza tomando como un criterio fundamental el número de habitantes - Ley de Coordinación Fiscal y el Ramo 33 del Presupuesto de Egresos de la Federación y Ley de Hacienda Municipal del Estado de Oaxaca- Finalmente se establece la posibilidad que el Presidente Municipal asigne a los agentes y que el ayuntamiento pueda remover de su cargo a los agentes municipales y de policía (ARTículOs 67 y 68). 
De esta manera, los límites territoriales que separan las tierras ocupadas por comunidades distintas, aunque pertenecientes a un mismo pueblo indígena, dan relativa independencia y control de los recursos económicos, humanos y naturales, y representan también el espacio físico del campo jurídico. De ahí que lo agrario y lo municipal son dos aspectos de disputas centrales y recurrentes entre comunidades en el estado de Oaxaca, constituyéndose además como elementos fundamentales del campo jurídico.

En resumen, lo territorial tiene tal importancia que si no se comprenden los aspectos agrario y municipal, no se podrán entender las tensiones entre comunidades de una misma jurisdicción municipal que las ha llevado a conflictos históricos y a reproducir y construir niveles locales de cierta "autonomía" y comunitarismo. Por ello, lo agrario y lo municipal, como dimensiones de lo territorial, resultan claves para dar cuenta de la manera en que el Estado ha impuesto su regulación y ha contribuido al desarrollo de los conflictos entre cabeceras y agencias, al mismo tiempo que la ley del Estado ha sido usada por los propios vecinos de las comunidades y sus autoridades para reclamar sus derechos y autonomía.

Aunque la disputa por los recursos o partidas presupuestales, primero, como exigencia de los estados a la federación y, posteriormente, de las cabeceras municipales a los gobiernos estatales, se ha presentado en otros estados de la República Mexicana, el caso de Oaxaca presenta especificidades particulares que han sido determinantes en la exigencia y reconocimiento de derechos sobre todo de los indígenas frente al Estado. En esta parte de la tesis mostraré esas especificidades que hacen tan interesante el caso oaxaqueño.

\section{Lo territorial, las disputas y la construcción del derecho}

Uno de los puntos de tensión entre cabeceras y agencias es que éstas no son reconocidas como un nivel de gobierno independiente y, más bien, se señalan a las agencias como auxiliares de la cabeceras, lo que trae como consecuencia que el 
acceso a los recursos económicos estatales y federales se mediatice por el gobierno municipal de la cabecera. Por otro lado, los poderes de gobierno y administración de recursos se concentran en la cabecera, además que en el sistema de elección de autoridades por usos y costumbres, las comunidades-agencias en el caso del municipio de Totontepec como de otros municipios tradicionalmente no han participado en la elección del cabildo municipal (presidente, síndico, regidores, alcalde y tesorero). Esto se debe a distintas razones, en el caso de estudio, las comunidades con categoría de agencia aceptan que este derecho es exclusivo de los pobladores de la comunidad-cabecera, ya que consideran que participar en ese proceso de elección les implicaría ceder en su relativa independencia, permitiendo que a su vez la cabecera se involucre en sus asuntos internos, o en última instancia les significa realizar doble cargo — los de la agencia y los de la cabecera-, sin posibilidad de un receso. Detrás de esto se puede percibir cierta justificación a partir del planteamiento mismo del comunalismo y del discurso de los usos y costumbres.

Lo anterior también se explica porque en el caso de Totontepec existe un antecedente histórico donde se constata que las comunidades tenían que hacer cargos en la cabecera municipal (véase expediente Núm. 229 del año 1775, Archivo Histórico del Poder Judicial), actualmente, como se apuntó anteriormente. ${ }^{47}$

De esta manera, a nivel municipal y comunitario son comunes dos tipos de disputas: por límites de tierras y por el control municipal. Esto muestra el entrecruzamiento de los aspectos municipal y agrario que, como se ha mencionado, se debe a que una comunidad indígena puede tener el doble carácter de ser comunidad-cabecera y, además, comunidad agraria - bienes comunales o ejidales-, o viceversa de comunidad-agencia y comunidad agraria.

\footnotetext{
47 Contrario a esto, en Tlahuitoltepec - comunidad cabecera mixe cercana a Totontepec-, sus agencias han establecido reglas de tal manera que al participar en la elección del cabildo municipal (votar y ser votado) resultan más beneficios que carga a sus pobladores. Cabe agregar que estas agencias no tienen carácter de núcleos agrarios aparte del núcleo de la cabecera en donde radica el gobierno o ayuntamiento.
} 
Por lo anterior cabría preguntarse: ¿Cómo lo agrario y lo municipal son puntos de y en tensión del campo jurídico? ¿Cómo se ha valido el Estado mexicano de estos aspectos para controlar las zonas indígenas? ¿Por qué se ha privilegiando a unos poblados o comunidades sobre otras en la constitución de municipios? ¿Cómo ha impactado en la relación cabeceras-agencia esa selección? Y, ¿cómo lo territorial representa espacios de poder comunitario?

Por la importancia que el territorio tiene en los siguientes apartados, presentaré los antecedentes de la configuración territorial y su relación con lo agrario y lo municipal, con la finalidad de plantear el contexto del conflicto entre cabeceras y agencias, concretamente entre Totontepec y San Marcos Móctum (en adelante Móctum). Estos antecedentes son necesarios para comprender la dinámica del conflicto contemporáneo en donde la disputa por la tierra y los linderos agrarios, así como el ordenamiento y control municipal han resultado ser aspectos claves y estructurales en la construcción de la relación del Estado con los pueblos indígenas, pero también en las propias definiciones del campo jurídico local y regional.

De esta manera, lo expuesto en este capítulo permite introducir las particularidades de lo territorial en el municipio de Totontepec — parte de la zona alta de la región mixe (CAPítulos 3 y 4) - y al estudio del campo jurídico en esas comunidades (CAPÍtULOS 5 y 6).

\subsection{El contexto histórico de la territorialidad}

Dos autores especialistas en Oaxaca, Chance (1998) y Bailón (1999), desde enfoques diferentes han documentado la relación comunidad-municipio-estado en Oaxaca a través de la historia. El primero se refiere específicamente a la historia de los pueblos de la Sierra Sur y la conformación de sus asentamientos —antes y después de la Colonia-, el segundo se concentra en la conformación del municipio como centro de control político del Estado, sobre todo en Oaxaca. A estos trabajos me referiré para posteriormente exponer el caso del caciquismo en el distrito Mixe 
como un intento de superar los localismos entre los ayuuk, tratando de unificar a sus comunidades y donde lo agrario y lo municipal tienen relevancia. Esto con la finalidad de explicar la conformación histórica de la comunidad como centro de la disputa entre cabeceras y agencias, particularmente en Oaxaca, así como el entrecruzamiento entre lo agrario y lo municipal en la configuración de los localismos o las identidades locales.

Las disputas entre cabeceras y agencias corresponden a la propia conformación social, económica e histórica de los pueblos de Oaxaca. Por un lado, se constata que los pueblos de la Sierra no tenían una organización centralizada como los que estaban asentados en los Valles, sin embargo, a la llegada de los españoles sufrieron cambios fundamentales sobre sus sistemas de organización, lo que propició posteriormente su desmembramiento y división en comunidades. De acuerdo a Chance (1998) antes de la Conquista los pueblos de la Sierra vivían diseminados y tenían una estructura de organización poco desarrollada, debido a la baja productividad de las tierras que también propiciaba el cambio de los asentamientos y su heterogeneidad. ${ }^{48}$ De igual forma, este autor agrega que durante la época de la Conquista, el distrito de Villa Alta (zona donde se ubica la disputa entre Totontepec y Móctum) comprendía pueblos chinantecos, zapotecos y mixes de la Sierra Juárez que antes de la intrusión española tenían pugnas bélicas. Esto revela como desde antes de la Colonia las comunidades de la zona, donde se ubican Totontepec y Móctum, tenían ciertas características, lo que facilita comprender la importancia de la comunidad para la definición de la pertenencia al pueblo indígena y, en definitiva, los conflictos que atravesaban la región, lo cual puede suponerse llevó a fomentar el localismo, es decir, advertir el porqué las identidades locales se sobreponen a la identidad étnica. De esta manera, dado que

48 “5. A diferencia de las más desarrolladas ciudades-estado en el Valle de México y en el de Oaxaca, no todas las comunidades de la Sierra contaban con un gobierno individual y jerarquías sacerdotales. 6. Las jerarquías sociales eran mucho más simples en la Sierra que en el Valle de Oaxaca y en la Mixteca. 7. Finalmente, es evidente que los caciques de la región poseían relativamente pocas tierras $\mathrm{u}$ otras formas de riqueza como para distinguirse de los plebeyos, con las posibles excepciones de las dinastías de Choapan y Xaltepec" (Chance 1998:33). 
el sistema de organización descansaba en el grupo consanguíneo en cada uno de éstos se fundaba un nuevo asentamiento (poblado o ranchería) independiente de los demás. 49

\subsection{La base comunitaria y localismos en la Sierra Juárez}

Chance se refiere a los antecedentes prehispánicos del comunitarismo, entre los poblados de la Sierra, dados por su sistema de organización consanguínea, lo que permite explicar de alguna manera cómo el sentido de comunalidad en la Sierra tiene un antecedente histórico que se retoma en la actualidad para contestar la hegemonía del derecho estatal.

Por su parte Bailón Corres (1999) plantea que los localismos proliferaron por el desmembramiento que sufrieron los pueblos en su organización central, una vez instaurada la Colonia española en todo el estado de Oaxaca. De acuerdo con Bailón, este desmembramiento se debió a la manera cómo fueron sometidos los pueblos indígenas durante el periodo de Conquista y la Colonia y, posteriormente, al papel central que se da al municipio para constituirse como el principal aparato de dominación política en el estado de Oaxaca.50 Sin embargo, sostiene que pese a ser prácticamente diezmados por el sistema colonial de congregación forzosa, los

49 "Ya habíamos dicho que en la época de la Conquista, los patrones de asentamiento eran muy dispersos. Citando a Burgoa, Beals afirmó que las agrupaciones de asentamiento de las rancherías aborígenes correspondían a los grupos sanguíneos. De acuerdo con su opinión, el 'pueblo mixe' [pueblo de indios o altepetl como organización que concentra varios asentamientos] fue introducido por los españoles, y en la década de los 1930, distinguió tres tipos de pueblos: los centralizados (Totontepec, Metaltepec, Zacatepec, Atitlán y Juquila); los de centro vacante (Tlahuitoltepec, Cacalotepec y Ayutla) y los asentamientos dispersos (Mixistlán)" (Chance 1998:131).

50 En este sentido el autor señala que el ámbito territorial del municipio "siempre ha sido un espacio de negociación y conflicto entre los detentadores del sistema regional de dominio, y la sociedad local. Le ha dado forma y contenido al sistema político en la entidad, ya que su desarrollo como institución de poder local ha ido aparejado con el del propio estado y el de las élites que lo han dirigido" (Bailón 1999:243). "[...] así como para el Estado nacional el nivel de gobierno y representación que existen en la entidad federativa es fundamental para la reproducción territorial, del sistema político, en el nivel de un estado federado concreto, el municipio no sólo es la base para la organización territorial del mismo, sino un aparato de dominación política fundamental. [...] Si en el caso de México esto último es cierto, lo es aún más en el de Oaxaca. El municipio ha sido y es el principal aparato de poder regional en el sistema político oaxaqueño, lo mismo que la principal forma de manifestar la identidad y la cohesión social en la región" (Bailón 1999:27-28). 
pueblos indígenas pudieron reconstituirse política, económica y socialmente (Bailón 1999:38).

Las propias contradicciones internas del sistema de repúblicas [de indios], asociadas al interés del dominio español de debilitar a los pueblos, llevan al aceleramiento de una recomposición étnica que tiende a un mayor localismo. Muchos pueblos sujetos buscan su autonomía frente a las cabeceras. Progresivamente se da la pulverización y la división de los antiguos territorios indios para formar otros. (Bailón 1999:41)

Pero además de lo apuntado por Bailón, es importante considerar otro tipo de procesos que determinaron lo que podríamos llamar el localismo de la época colonial y posteriormente el comunitarismo. Tales procesos están relacionados con la forma en que se conformaron los asentamientos humanos en la Sierra (Chance 1998), y al hecho que algunos poblados prevalecieron sobre otros en el control, ocupación y distribución del territorio serrano, entre otras cosas, por los caminos trazados desde la Colonia, el aumento de población y la migración que desplazaron a unos poblados por otros - como se deriva del trabajo de Viola König (1993).

Por lo que se refiere a la época del México independiente, se dio el mayor embate contra las comunidades indígenas, principalmente, a sus estructuras de organización desarrolladas con cierto margen de autonomía durante la época colonial, teniendo un primer obstáculo en las reformas federalistas, que enarbolaban, entre otras, la bandera de la igualdad y la ciudadanía (es decir, terminar con la separación y distinción entre repúblicas, y entre indios y españoles, fundamentalmente). Sin embargo, esto trajo consigo la oposición y resistencia de las comunidades por la pérdida de control político que esas reformas les representaban, por lo que en el caso oaxaqueño, los diputados del congreso local 
de 1825 tuvieron que establecer una normatividad que reconociera el poder local que se ejercía desde las múltiples comunidades. ${ }^{51}$

\subsection{La comunidad: Unidad básica de organización}

En la conformación actual del municipio oaxaqueño como aparato de dominación política, la corriente federalista oaxaqueña de principios del siglo XIX no tuvo otra vía que la de reconocer la autonomía de las comunidades, para poder nombrar a sus autoridades locales.

Por decreto de la legislatura se reducen las exigencias para que un asentamiento tenga autoridades reconocidas por el gobierno así, se manda que los pueblos y rancherías menores puedan instalar autoridades locales. Los que alcanzaran 200 habitantes tendrían posibilidad de nombrar un alcalde y dos regidores, y los de menor población sólo regidor. Pocos años más tarde, ya promulgada la Constitución de 1857, desaparece la discriminación entre pueblos con ayuntamiento y pueblos con república, que se había pensado llevaría poco a poco al ensanchamiento de los primeros, mediante uniones y concentraciones en detrimento de los segundos. Las poblaciones menores de 500 habitantes tenian derecho a designar también, anualmente en votación popular directa a dirigentes denominados agentes municipales. Si la población no tenía 200 habitantes nombraba dos agentes (Bailón 1999:144).

Es decir, que las comunidades indígenas con "posibilidades" de ser cabeceras municipales o entidades políticas son asentamientos provenientes del sistema de república de indios. De esta manera, lo apuntado por Bailón revela que tales medidas legislativas permitieron que asentamientos, comunidades, con población mayoritariamente indígena se convirtieran en municipio, lo que da la oportunidad a la creación de municipios gobernados por indígenas.

51 "[El] ayuntamiento [es] el modelo a seguir, pero también aceptan que se mantenga la forma de repúblicas indígenas en las poblaciones menores de 3000 habitantes. Incluso les otorgan el derecho de integrar esta forma de gobierno en los pueblos con comarcas hasta de 500 pobladores" (Bailón 1999:125). “Al igual que los ayuntamientos, o las repúblicas tenían obligaciones que cumplir con los gobiernos estatal y nacional” (Bailón 1999:127). 
Pero también el análisis hecho por Bailón, muestra la contradicción del proceso histórico de formación del Estado mexicano, lo que en parte explica que los indígenas como actores subalternos no están al margen de la conformación político-territorial del estado de Oaxaca pues son claves para ese proceso y referentes centrales de la distribución territorial oaxaqueña. Esto se vuelve más claro en el siguiente momento histórico.

\subsection{La comunidad como unidad político-territorial: El reparto agrario}

La relación entre el espacio territorial y el poder local que se ejerce desde el municipio se consolida, más adelante, en el México posrevolucionario a partir de que el gobierno municipal (ayuntamiento) funciona como centro de operación caciquil y como intermediario entre el gobierno y los pueblos demandantes de tierra. En esta intermediación los ejidatarios sin tierra a diferencia de los comuneros — con posesión antiquísima - son más fácilmente controlables — lo que no significa que aquéllos no lo fueran también-y serán considerados aliados subordinados, dado que la mayor parte del reparto agrario (1915) en los primeros años se realizó a través de dotaciones, mecanismo que garantizaba una mayor lealtad de los grupos beneficiados, que se alían a los nuevos gobiernos en su lucha contra los hacendados. Por su parte, los campesinos comuneros que solicitan no la dotación de tierras sino el reconocimiento sobre las que tienen en posesión desde tiempos inmemoriales, los coloca en otro tipo de relación con los gobiernos revolucionarios desde 1915 (cfr. Bailón 1999:186). Así, la lealtad política hacia el partido en el poder del campesinado beneficiado con el reparto agrario, les garantizaba a éstos el acceso a la tierra o el reconocimiento y protección de la propiedad de las tierras que ya tenían títulos virreinales. El papel del ayuntamiento es funcionar como garante de estas lealtades utilizando la reivindicación agraria como oferta política:

Se forma así de nueva cuenta una tríada de articulación de una sección fundamental con la sociedad local hacia la sociedad nacional y regional: a) la relacionada con la posesión de sus centenarios bienes, representados por la comunidad y el ejido mediante sus comisariados 
respectivos; b) la representación politica al crearse un sistema electoral de un partido dominante. Los pueblos, alejados antes de la lucha de fórmulas, aceptan el emblema del partido oficial a cambio de independencia interna [...] y c) la del ayuntamiento, que mantiene sus procedimientos plebiscitarios internos para su elección. Este órgano de autoridad local es fundamental para entender el sistema político actual en el Estado. Las reformas electorales de 1995 y 1997 reconocen la fortaleza de las autonomías comunitarias. (Bailón 1999:189)

De esta manera la legislación municipal se construye y establece sobre una organización comunitaria preexistente, en este sentido la Constitución Política del Estado de Oaxaca de 1922 opone un obstáculo a la comunidad como eje central de autonomía de los pueblos, ya que proliferaban los asentamientos que querían la categoría de municipios aunque tenían poca población, por lo que se establecieron criterios económicos y poblacionales para poner límites a la creación de nuevos municipios. Así, los asentamientos con 2000 ó más habitantes podían llegar a ser municipios o cabeceras municipales, mientras los que tuvieran hasta 200 habitantes serían considerados agencias municipales, y agencias de policía los restantes. Esta medida de contención a la proliferación de municipios sería, a mi modo de ver, la actualización de las disputas por la autonomía de asentamientos-comunidades que en la Colonia habían sido adscritos a la jurisdicción de otros poblados, algunos de estos con anterioridad habían sido rancherías pero con el tiempo crecieron (cfr. Viola König 1993).

Lo que hizo la medida constitucional [de 1922] fue evitar en lo sucesivo la creación de nuevas municipalidades. Al reagruparse las agencias municipales y de policía (que antes tenían autonomía) dentro de los municipios se impedía la expansión municipal [...] [Pese a esto y a la creciente lucha partidaria] la comunidad indígena aún es la base no sólo de la organización económica local, de las formas de explotación económica y extracción de excedentes, sino también un elemento determinante en la constitución y reproducción del poder político. (Bailón 1999:191, 242) 
El proceso histórico por el cual se entrecruzan el municipio y la cuestión agraria hace patente que la construcción del Estado mexicano ha pasado por una serie de contradicciones, que expresan la disputa y la correlación de fuerzas entre los distintos sectores interesados en ello. Así, en los distintos momentos de la historia de México hubo una insistencia por parte de los detentadores del poder político regional por socavar la autonomía (relativa o subordinada) que las comunidades indígenas tenían, sobre todo en el estado de Oaxaca, pero en este nivel las fuerzas sociales de campesinos e indígenas obligan a las élites en el poder a establecer mecanismos constitucionales legales que fortalecieran a los pueblos: "Así, al mismo tiempo que con las leyes de desamortización los gobiernos estatales buscaron la desaparición de las formas de posesión comunitaria, las disposiciones sobre autoridades locales fortalecieron el vigor de los pueblos para defenderse" (Bailón 1999:145). Ante esto, y a decir de Recondo (2002), el Estado mexicano posrevolucionario establece un modo original de integración política que pasaba sobre todo por lazos clientelistas a través de caciques locales y regionales, de los cuales los caciques mixes son un ejemplo paradigmático del caciquismo indígena. ${ }^{52}$

52 De igual forma Recondo (2002:82) pone como ejemplo paradigmático de caciquismo indígena el de los mixes, dado que el cacicazgo de Luis Rodríguez reposaba en la presencia de líderes o caciques menores en cada uno de los municipios: "Tal fue el caso de Lucio Jiménez en Tlahuitoltepec, de Luis Rodríguez en Puxmetacán y también de Samuel Alcántara en Totontepec. Estos hombres eran una réplica de su jefe [con el que tenían conflictos por el ejercicio del poder] y al mismo tiempo, aquéllos le eran indispensables como intermediarios, ya que representaban una amenaza constante para el poder absoluto del gran cacique. Luis Rodríguez y Lucio Jiménez [...] Las relaciones que mantenían con Luis Rodríguez fluctuaban incesantemente entre la colaboración y la rivalidad. La actitud de Lucio Jiménez, de Tlahuitoltepec, en este sentido fue significativa: él estableció por largo tiempo una alianza con el cacique de Zacatepec, pero de la misma manera, se le describe como un defensor de su comunidad frente a los abusos de Luis Rodríguez; a quien confrontó en su momento por que la explotación impuesta se volvía excesiva. Nosotros reconocemos la doble función del cacique, en la defensa de los intereses de la comunidad frente al poder central, del cual era un operador local. De esta manera, el cacique es una pieza clave en la cadena de mediación que va del líder comunitario al presidente de la República, él encarna a nivel local y regional la presencia del Estado-PRI en las periferias geográficas y culturales del país" (traducción libre por Elisa Cruz Rueda). Planteamiento que concuerda con el de Bartra (1976), además que subraya las interconexiones locales entre el gran cacique con las comunidades que quería controlar, en un vasto territorio como es el de la región mixe. 
La articulación con las comunidades rurales se hacía sobre la base de una serie de intermediarios (los caciques). Ellos constituían la clave del voto del pacto clientelista que el Estado modernizador reunía de las comunidades, sobre todo garantizándoles un margen de autonomía suficiente para reproducir sus diferencias institucionales y culturales en nombre de la ley. (cfr. Recondo 2002, traducción de Elisa Cruz Rueda)

El caso de Totontepec y Móctum es particularmente interesante por la presencia de Samuel Alcántara como cacique menor (en la cabecera del municipio de Totontepec) que garantizaba el control político de Luis Rodríguez, oriundo de Santiago Zacatepec comunidad-cabecera donde finalmente quedaría asentada la cabecera del distrito Mixe.

\subsection{El caciquismo y la creación del distrito Mixe}

Lo antes expuesto nos ofrece elementos para comprender cómo la comunidad se coloca en el centro de los proyectos políticos en el estado de Oaxaca. Por lo que se refiere a la región mixe, y para explicar cómo lo agrario y lo municipal se cruzan y determinan la configuración de la comunidad como unidad central en la disputa por el poder, es obligado referirnos a los dos principales caciques ayuuk que surgieron de la Revolución Mexicana (Recondo 2002:82-88): el coronel Daniel Martínez de Ayutla y Luis Rodríguez de Zacatepec y su relación con la creación del distrito Mixe como un proyecto político de aglutinamiento de las comunidades mixes por encima del comunitarismo prevaleciente entre ellas. En este sentido, Nahmad (1965:93) comenta:

Ambos lucharon por desarrollar, impulsar este rincón del estado de Oaxaca e integrarlo a la vida nacional [...] Su lucha fue ardua para lograr vencer la apatía de sus pueblos, su aislamiento y su indiferencia de tantos siglos [...] Intentaron desde el principio comunicar, por todos lo medios modernos, la región mixe, solicitaron los servicios médicos y sanitarios [...] lo más importante que lograron fue la integración politica de los pueblos mixes unificados en torno de sus dirigentes. Beals y Barahona describen de una manera precisa y 
profunda este fenómeno observado en épocas distintas, el primero habla del coronel Daniel Martínez y el segundo de la personalidad de Luis Rodríguez.

Fueron varios los aspectos en los que estos caciques se confrontaron pero el central fue fundamentalmente el control político de la región a través del distrito Mixe. De acuerdo con Bailón Corres (1999:141), las divisiones territoriales por distritos políticos durante el siglo XIX tenían como función la administración territorial del estado de Oaxaca y fundamentalmente servían para un mejor control y mediación política durante el Porfiriato. La eficacia de este tipo de división administrativa territorial fue tal que, como se ha mencionado, posterior a la Revolución y ya en 1938 se decreta la constitución del distrito Mixe, con sede en el pueblo de Santiago Zacatepec, de donde era oriundo Luis Rodríguez. Se cuenta que entre el coronel Daniel Martínez (también cacique, pero oriundo de Ayutla) y Luis Rodríguez se disputaban la cabecera del distrito Mixe, ganando el primero sobre el segundo, según lo apunta Nahmad (1965:98):

La lucha por el control de la región entre el coronel y don Luis se inició muy tempranamente. En nuestros días ya no perdura esa lucha, pero aun sin líderes en la actualidad hay aspectos dramáticos en los choques que se libran entre los pueblos mismos. [...] Porque al poco andar desde 1938, ya son muchos los poblados que secundan al movimiento de avance cuyo abanico da frutos ramificados con origen en Zacatepec. Pero necesitan organizarse ahora para intercambiar ideas, darse ayuda cabal, reunir fuerzas diseminadas y transmitirse datos del esfuerzo propio e individual a fin de que se torne en colectivo y superior.

De esta manera, la contienda por el poder político en la región llevó a la división de los pueblos en tres bandos, los que estaban con el coronel Daniel Martínez, los que estaban con Luis Rodríguez y los neutrales. Pero tal divisionismo no era del todo uniforme o monolítico pues, según Nahmad (1965:100), existían entonces Municipios divididos internamente, entre los que cuenta a Totontepec y a Cacalotepec (éste último pasó por un conflicto por tierras con una de sus agencias, San Isidro 
Huayapan, semejante al de Totontepec con Móctum, como secuela de este conflicto Huayapan se volvió parte del municipio de Alotepec).

De lo expuesto por Bailón y Nahmad podemos decir que el municipio (como aparato de dominación política y de mediatización fundamentalmente en los siglos XIX y XX) para los mixes significó la cuna del caciquismo, constituido como parte de una estructura de mediación, que sustenta y atraviesa al Estado mexicano. Así, es posible comprender que el caciquismo en México cumple una función de control político, pero que también sólo funciona en un tiempo y espacio determinados, pudiendo volverse un obstáculo al control de dominio político del Estado sea a nivel local, municipal, estatal o nacional. Bartra (1976:29) lo expone con mayor claridad cuando señala:

Muchos de los caciques que controlan vastas regiones del agro mexicano tienen su origen en el proceso de reforma agraria, del cual fueron promotores y del cual obtuvieron su poder mediante una compleja red de compadrazgo, amistades, deudas, favores y amenazas que les permiten controlar a las comunidades campesinas. En su origen, todo sistema de cacicazgo implica una estructura de mediación, en la que el cacique consigue el poder mediante el apoyo que logra de la comunidad a la que representa; pero el poder que le otorga la comunidad es ejercido de acuerdo a intereses ajenos a ésta. Ahora bien, con el tiempo este sistema se anquilosa: el cacique ha sabido convertir su poder en riqueza y ejerce de manera despótica y arbitraria su dominio. A partir de ese momento deja de ser útil al sistema, y se encuentra con la oposición del sistema formal de poder: el presidente municipal, con una parte del partido oficial detrás, los representantes del gobierno federal, etc. Se entabla una lucha en la cual el sistema oficial construye paulatinamente una nueva estructura de mediación, pues requiere de cierto apoyo de la comunidad para liquidar al cacique.

Como se ha postulado hasta ahora el municipio fue un ámbito de control caciquil que reforzó el control del Estado sobre la población rural, y al igual que en la definición del poblado que sería la cabecera del distrito Mixe, los cacicazgos 
influyeron en la constitución y definición de las comunidades-cabeceras ${ }^{53}$ municipales; por ello, no es mera casualidad observar que uno de los caciques menores más importantes de la región mixe haya sido de Totontepec, emparentado con personas de Villa Alta, y que haya quedado como cabecera municipal.

Hoy en día el caciquismo regional ha sido contenido, aunque subsisten liderazgos comunitarios. En gran parte la contención se ha debido fundamentalmente a tres circunstancias: a una mayor intervención en la región del gobierno (federal y estatal), a las dinámicas de globalización en que se encuentra el Estado mexicano que trastocan las estructuras de organización de las comunidades indígenas y al desarrollo de organizaciones sociales regionales (con un discurso proétnico y de derechos humanos).

\subsection{El distrito judicial Mixe}

Para dimensionar el espacio de control y de ejercicio de poder que se disputaban el coronel Martínez y Luis Rodríguez, así como los caciques menores, no está por demás agregar que los mixes ocupan $4668.55 \mathrm{~km}^{2}$ que los coloca en la tercera posición en extensión territorial y el quinto en número de hablantes de la lengua (Pardo 1994:575) en el estado de Oaxaca, antecediéndoles los zapotecos, mixtecos, mazatecos y chinantecos (Barabas, Bartolomé y Maldonado 2004:16), respectivamente. Distintos tipos de hábitat se encuentran dentro de su territorio, desde las cumbres más altas del estado hasta altitudes casi a nivel del mar.

En el año 2000, Totontepec contaba con una población total de 5626 de los cuales 4641 de 5 años o más eran hablantes del mixe (Censo efectuado por el INEGI, ${ }^{54}$ en el II Conteo de Población y Vivienda de 2005). De igual forma se da

\footnotetext{
${ }^{53}$ En la constitución de las comunidades-cabeceras influyen otros factores como el auge económico determinado muchas veces por las vías de comunicación. De esta manera, Totontepec ha sido desde la Colonia paso obligado para llegar al distrito de Choapan, la zona de Tuxtepec y para Villa Alta, a diferencia de sus agencias que están más alejadas de estos puntos.

54 XII Censo General de Población y Vivienda, México, 2000. Cfr. <http://www.inegi.gob.mx> y $<$ http://www.e-local.gob.mx/work/templates/enciclo/oaxaca/index.html $>$
} 
cuenta de una población total de 4780 y de 4305 de población (de 5 años o más) hablantes de una lengua indígena. ${ }^{55}$

En la TABLA 1 (Censo de Población 2000) se puede observar la disminución (por migraciones y decesos) en la población del municipio de 5 años o más hablantes de una lengua indígena, así como la existencia de otros idiomas en el municipio de Totontepec además del mixe, esto se explica, porque justamente Totontepec es uno de los municipios de frontera del distrito Mixe que colinda con los chinantecos y zapotecos de la sierra.

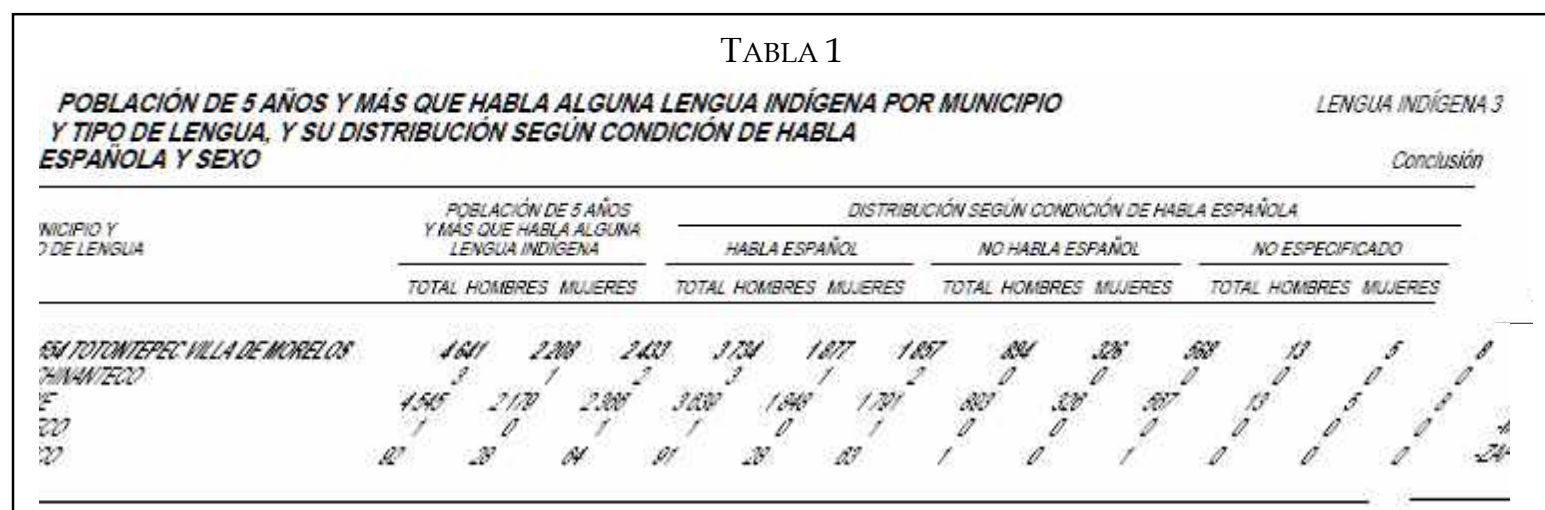

Fuente: INEGI. XII Censo General de Población y Vivienda, México, 2000

Por lo que respecta a los hablantes del mixe, en el estado de Oaxaca se cuenta con 105443 hablantes del mixe de los cuales 82.8\% se encuentra en el distrito Mixe (Barabas, Bartolomé y Maldonado 2004:42).

La TABLA 2 muestra la población hablante de lengua indígena en el distrito Mixe (Censo de 2000). La existencia de población hablante de otros idiomas distintos al mixe se debe a la migración de personas de otras regiones hacia este distrito, pero también a que, como se ha mencionado, el distrito Mixe colinda con los zapotecos del valle, de la sierra y del istmo, así como con los mazatecos y los chinantecos (véase MAPA 3 en CAṔ́tULO 3).

\footnotetext{
${ }^{55}$ Cfr. http://www.inegi.gob.mx/est/contenidos/espanol/sistemas/conteo2005/localidad/iter/default.asp
} 


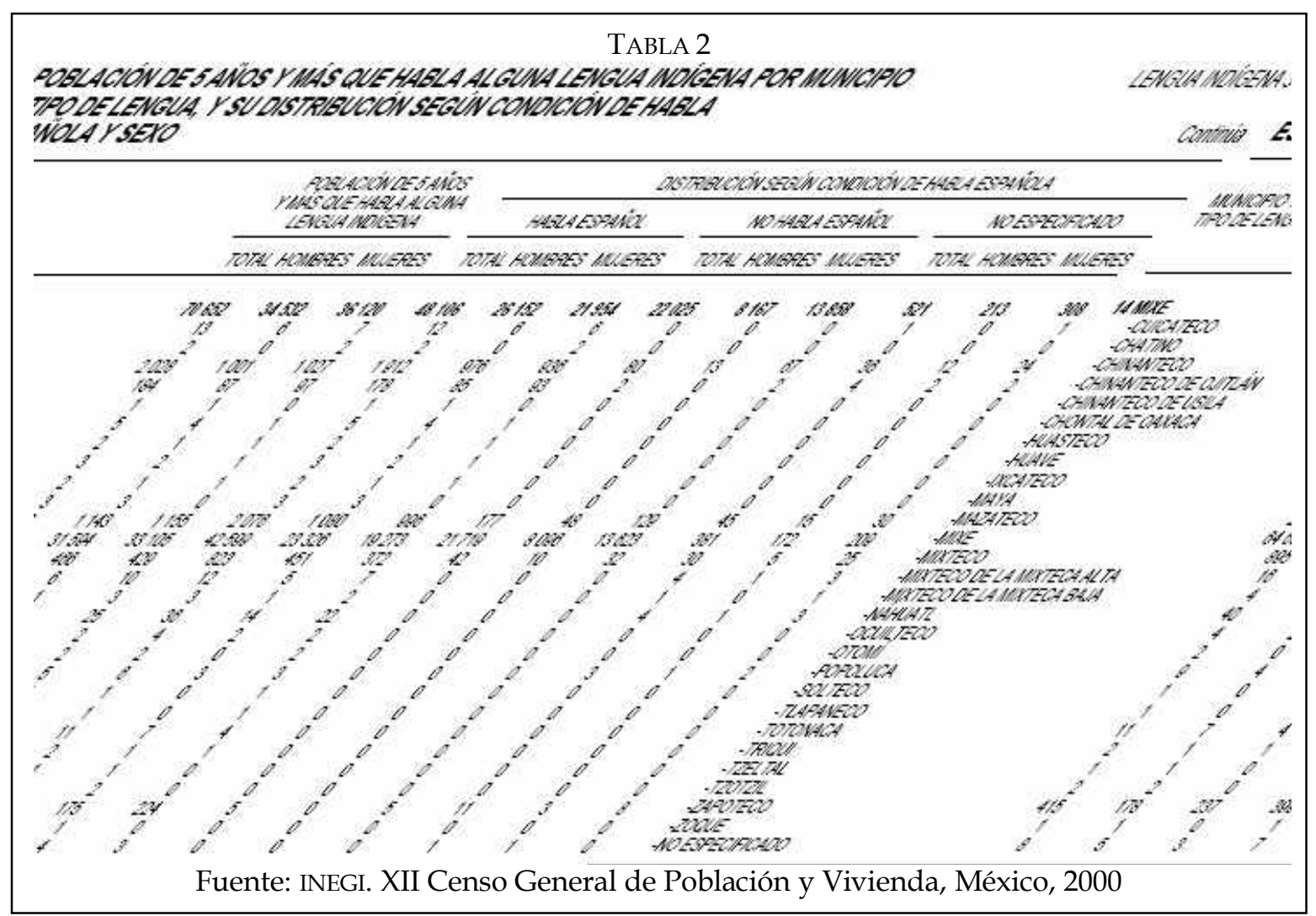

El distrito judicial Mixe ${ }^{56}$ se funda en $1938,{ }^{57}$ tiene su cabecera (o sede) en Santiago Zacatepec donde se encuentra el Registro Civil (que atiende a cinco municipios y algunas agencias), el Ministerio Público y un Juzgado Mixto de primera instancia. ${ }^{58}$ El distrito Mixe comprende a la mayoría de los municipios

56 "para la primera instancia federal, la República se divide en distritos, al frente de los cuales se coloca por lo menos un juzgado, pudiendo haber más, como en la ciudad de México, donde hay 29. El número de distritos judiciales federales y de juzgados varía prácticamente año con año y su número y territorio es determinado por la Ley Orgánica del Poder Judicial Federal, en sus ArTículos 72 y 73. Por lo que se refiere a la administración de justicia estatal, algunas entidades designan con el nombre de distrito judicial al territorio donde tiene competencia un juez de primera instancia; en otros, a ese mismo espacio territorial se le denomina partido judicial, como en el caso del Distrito Federal" (Soberanes 1987:1173).

57 Decreto Núm. 203. Se erige la región mixe del estado, con el nombre de Distrito Mixe (ARTículos $1^{\circ}, 2^{\circ}$ y $\left.3^{\circ}\right)$.

58 En 1982 se modifica la circunscripción territorial del distrito Mixe, y se acuerda que se establezca en Santiago Zacatepec el $1^{\circ}$ Juzgado Mixto de primera instancia y un $2^{\circ}$ Juzgado Mixto de primera instancia en María Lombardo, para atender a las agencias o comunidades mixes de la zona baja, sobre todo las del municipio de Cotzocon. 
mixes, y el resto están en los distritos de San Carlos Yautepec y Juchitán, ${ }^{59}$ por lo que podemos decir que la región mixe está integrada por los municipios y comunidades con población que habla el idioma ayuuk / mixe y que en su mayoría se encuentran en el distrito Mixe.

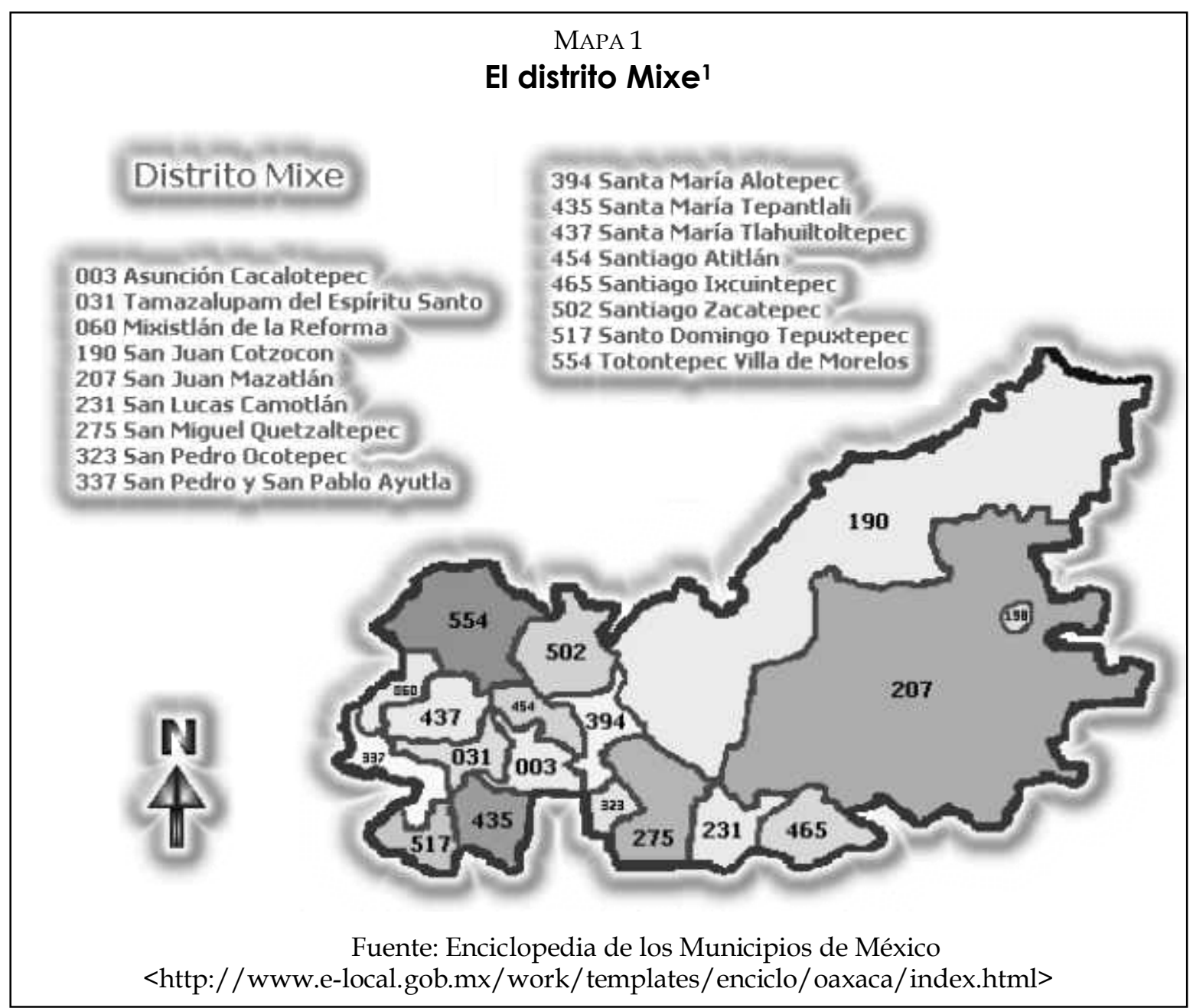

Otro dato que es importante considerar es la presencia de distintas religiones en el distrito Mixe, así como en el municipio de Totontepec. La TABLA 3 (Censo de Población 2000, pues en el de 2005 no se tomó esta variable) muestra que

\footnotetext{
59 María Luisa Acevedo y Teresa Pardo (s/f) señalan que la mayoría de los municipios mixes se concentraron en una misma unidad política y administrativa "agrupándose bajo el recién creado distrito Mixe 18 de los 19 municipios de este grupo con excepción de San Juan Guichicovi que se mantuvo en el distrito de Juchitán. En 1953, se separa San Juan Juquila Mixes y se anexa de nuevo a Yautepec. En la actualidad, está integrado por 17 municipios quedando fuera de los límites de esta jefatura distrital una importante porción del área lingüística de este grupo ubicada hacia el extremo sur y hacia el oriente". Totontepec y Móctum quedaron dentro del distrito Mixe.
} 
la religión católica es mayoritaria seguida por las pentecostales y neopentecostales, la adventista.

\begin{tabular}{|c|c|c|c|c|c|c|c|c|c|c|c|}
\hline \multicolumn{10}{|c|}{$\begin{array}{l}\text { POBLACIÓN DE } 5 \text { AÑOS Y MÁS POR MUNICIPIO, SEXO Y RELIGIÓN, Y SU DISTRIBUCIÓN } \\
\text { SEGÚN GRUPOS QUINQUENALES DE EDAD }\end{array}$} & \multicolumn{2}{|c|}{$\begin{array}{l}\text { RELIGIÓN } 1 \\
\text { Continúa }\end{array}$} \\
\hline \multirow{2}{*}{$\begin{array}{l}\text { MUNICIPIO, SEXO } \\
\text { YRELIGION }\end{array}$} & \multirow{2}{*}{$\begin{array}{l}\text { POBLACIÓN } \\
\text { DE } 5 \text { ANQS } \\
\text { YMAS }\end{array}$} & \multicolumn{10}{|c|}{ DISTRIBUCIÓN SEGÚN GRUPOS QUINQUENALES DE EDAD } \\
\hline & & $\begin{array}{r}5 \cdot 8 \\
\text { ANOS }\end{array}$ & $\begin{array}{l}10,14 \\
\text { ANOS }\end{array}$ & $\begin{array}{l}15 ; \cdot 18 \\
\text { ANOS }\end{array}$ & $\begin{array}{l}20 ; .24 \\
\text { ANOS }\end{array}$ & $\begin{array}{l}25,29 \\
\text { ANOS }\end{array}$ & $\begin{array}{l}30,34 \\
\text { ANOS }\end{array}$ & $\begin{array}{l}35.39 \\
\text { ANOS }\end{array}$ & $\begin{array}{l}40 ; .44 \\
\text { ANOS }\end{array}$ & $\begin{array}{l}45.49 \\
\text { ANOS }\end{array}$ & $\begin{array}{l}\text { 5OYYUAS } \\
\text { ANOS }\end{array}$ \\
\hline 14 MIXE & 85722 & 15165 & 14293 & 10316 & 7411 & 5972 & 5257 & 4976 & 4259 & 4030 & 14043 \\
\hline CATÓLICA & 67418 & 11538 & 11137 & 8122 & 5775 & 4729 & 4158 & 3056 & 3397 & 3230 & 11378 \\
\hline PROTESTANTES Y EVANGÉLICAS & 8741 & 1651 & 1521 & 1002 & 758 & 577 & $52 B$ & 505 & 445 & 380 & 1374 \\
\hline $\begin{array}{l}\text {-HISTORICAS } \\
\text {.PENTECOSTALESY }\end{array}$ & 1825 & 278 & 252 & 215 & 160 & 108 & 67 & 88 & 88 & 83 & 278 \\
\hline $\begin{array}{l}\text { NEOPENTECOSTALES } \\
\text {-IGLESIA DEL DIOS VIVO, } \\
\text { COLUIANAY APOYO DE LA }\end{array}$ & 5447 & 1043 & 868 & 623 & 472 & 381 & 338 & 326 & 272 & 236 & 808 \\
\hline VERDAD, LA LUZ DEL MUNDO & 368 & 76 & 67 & 30 & 28 & 21 & 22 & 14 & 18 & 12 & 78 \\
\hline OTRAS EVANGELICAS & 1303 & 253 & 234 & 134 & 88 & 87 & 101 & 77 & 71 & 49 & 200 \\
\hline $\begin{array}{l}\text { BíBLICAS NO EVANGELICAS } \\
\text { ADVENTISTAS DEL. }\end{array}$ & 5022 & 886 & 845 & 633 & 463 & 338 & 278 & 270 & 234 & 244 & 853 \\
\hline $\begin{array}{l}\text { SEPTIMO DIA } \\
\text {-IGLESIA DE JESUCRISTOO DE } \\
\text { LOS SANTOS DE LOS ULTIMOS }\end{array}$ & 3807 & 650 & 811 & 435 & 328 & 252 & 200 & 183 & 144 & 186 & 830 \\
\hline DIAS (MORMONES) & 27 & 4 & 8 & 2 & 2 & 0 & 1 & 4 & 1 & 0 & 5 \\
\hline TESTIGOS DE JEHOVÁ & 1388 & 212 & 228 & 186 & 135 & 86 & 75 & 73 & 88 & 78 & 218 \\
\hline OTRAS RELLGIONES & 35 & 4 & 4 & 5 & 5 & 4 & 0 & 2 & 5 & 1 & 5 \\
\hline SIN RELLGON & 3881 & 698 & 871 & 486 & 363 & 286 & $260^{\circ}$ & 213 & 160 & 158 & 368 \\
\hline NO ESPECIFCADO & 845 & 408 & 115 & 68 & 47 & 28 & 35 & 30 & 18 & 17 & 78 \\
\hline
\end{tabular}

Fuente: INEGI. XII Censo General de Población y Vivienda, México, 2000

Dado que en la tensión entre Totontepec y Móctum se presenta el elemento de la religión como un factor que refuerza la postura de oposición de la agenciacomunidad al poder central de la cabecera, también son importantes los datos sobre la presencia de distintas religiones en el municipio. En este caso, la religión mayoritaria es la católica seguida por los pentecostales y neopentecostales y la adventista. 
TABLA 4

\begin{tabular}{|c|c|c|c|c|c|c|c|c|c|c|c|c|}
\hline $\begin{array}{l}\text { OBLA } \\
\text { GUNC }\end{array}$ & $\begin{array}{l}\text { ISPORA } \\
\angle E S D E E\end{array}$ & $\begin{array}{l}W O \\
A D\end{array}$ & $S E$ & YREL & $O N$, & D/S & 300 & & & & & sint $s$ \\
\hline \multirow{2}{*}{$3 . S E P O$} & \multirow{2}{*}{ 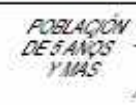 } & \multicolumn{10}{|c|}{ 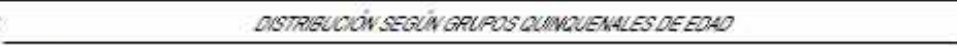 } & \multirow{2}{*}{ YAREXY } \\
\hline & & AWES & ADES & Astos & Anos & 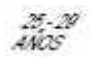 & ANCS & Aivos & AHOS & AW & SOYMOSS & \\
\hline
\end{tabular}

554 TOTONTEPEC VILLA DE MORELOS

CATOLICA

PROTESTANTES Y EVANGÉLICAS

$\begin{array}{rrr}4895 & 811 & 808 \\ 2724 & 411 & 437 \\ 43 & 4 & 5\end{array}$

PENTECOSTALESY

NEOPENTECOSTALES

BIBLLCASNO EVANGELICAS

ADVENTISTAS DEL.

SEPTIIIO DIA

.TESTIGOS DE JEHOVÁ

SIN RELIGION

NOESPECFICADO

$\begin{array}{rrrrrrrrrrr}48 & 4 & 5 & 8 & 2 & 3 & 4 & 1 & 2 & 2 & 14 \\ 1811 & 348 & 323 & 228 & 168 & 132 & 108 & 110 & 80 & 72 & 343 \\ 1868 & 338 & 317 & 221 & 164 & 128 & 108 & 105 & 78 & 72 & 340 \\ 43 & 10 & 8 & 7 & 4 & 4 & 3 & 5 & 1 & 0 & 3 \\ 94 & 12 & 20 & 8 & 7 & 5 & 7 & 7 & 8 & 6 & 18 \\ 120 & 38 & 23 & 11 & 5 & 8 & 10 & 3 & 2 & 3 & 18\end{array}$

Fuente: INEGI. XII Censo General de Población y Vivienda, México, 2000

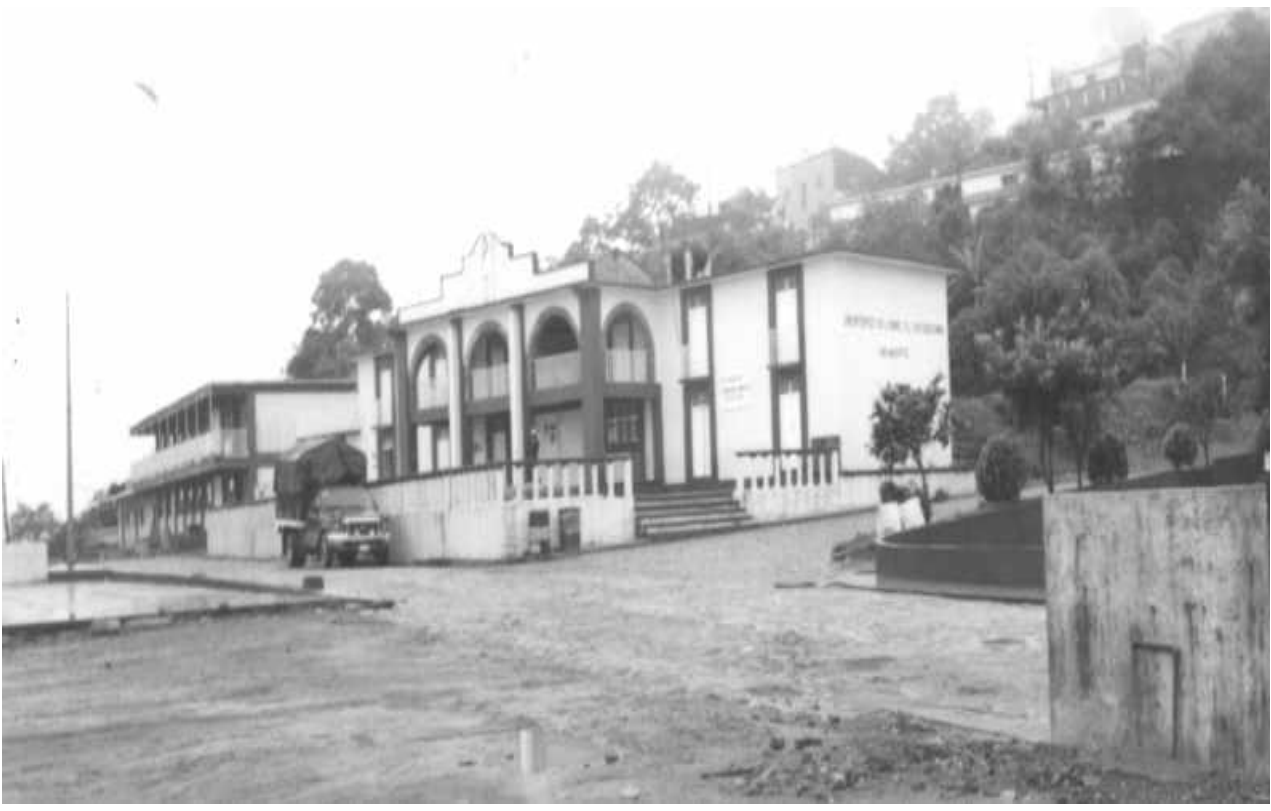

Oficinas del Ayuntamiento de la cabecera-comunidad de Santiago Zacatepec, del Registro Civil, del Ministerio Público y del Juzgado

De acuerdo a la división por altitud de la región mixe, tenemos que la distribución de los 19 municipios mixes es: a) la zona alta, con altitudes superiores a los 1800 metros sobre el nivel del mar (msnm) donde se localizan Tlahuitoltepec, Ayutla, Cacalotepec, Tepantlali, Tepuxtepec, Totontepec, Tamazulapam y Mixistlán; b) la zona media, entre los 1300 y $1800 \mathrm{msnm}$, en la que se sitúan Ocotepec, Atitlán, Alotepec, Juquila Mixes (distrito de San Carlos Yautepec), 
Camotlán, Zacatepec, Cotzocón, Quetzaltepec e Ixcuintepec y c) la zona baja entre los 35 y 1000 msnm: Mazatlán y Guichicovi (Distrito de Juchitán). La región mixe abarca los municipios y comunidades que se consideran mixes, por tener población mayoritariamente hablante del idioma ayuuk, estén o no comprendidos en el distrito Mixe.

Sin embargo, la división geográfica de la región mixe por zonas según la altitud no da cuenta de la división climática y ecológica, pues la geografía es escabrosa y accidentada, encontrando varios climas (en una misma época del año) en un espacio geográfico reducido como es la división municipal.

Por ejemplo, el municipio de Totontepec se localiza a una altitud de 1840 metros sobre el nivel del mar (INEGI, 2001) en la zona alta (con clima frío todo el año), Móctum (agencia de policía de Totontepec) a poco menos altura se encuentra en esta zona. Sin embargo, parte de las tierras de ambas comunidades se ubican en la zona media y otro tanto de Móctum en la zona baja. ${ }^{60}$

De esta forma, la sinuosidad de la geografía y la diversidad de ecosistemas de la región se han asociado a la diversidad cultural entre los mixes, como lo explican Nahmad (1990) y Maldonado y Cortés (1999).61 Para estos autores, la geografía agreste y la diversidad de ecosistemas han influido en la concepción de la comunidad como espacio de definición de la identidad, pues la topografía ha favorecido el aislamiento entre comunidades, relativamente cercanas entre sí y a veces pertenecientes a un mismo municipio, lo que permite plantear que en

60 Circunstancias como éstas plantea Beulink (1979:66): “En virtud de que no puede medirse toda la zona [región] mixe por el mismo rasero en cuanto a su topografía, ni a su economía ni cultura, nos parece conveniente dividir la zona [región] en tres partes [zonas] globales".

61 "Los antropólogos hemos caracterizado las diferencias por los nichos ecológicos donde viven [los mixes]: los de la zona alta, la media y la baja, confiriendo al ambiente y al hábitat ser un determinante en la diferenciación. Sin duda que el tema que habremos de trabajar en los próximos años arrojará más luz sobre lo que aglutina y lo que diferencia. La hipótesis central de nuestras investigaciones en este campo es que entre los mixes como en toda la civilización mesoamericana la diferencia es lo relevante y el sistema total está basado en una civilización poliétnica, en contra de los proyectos modernos de integridad y hegemonía" (Nahmad 1990:38). 
territorio ayuuk se diversifican las formas de "ser" mixe particularizando la identidad en la comunidad, lo que propicia diferencias intercomunitarias. ${ }^{62}$

Pese al arraigo de la identidad comunitaria sobre la del conjunto de comunidades (territorio mixe), la importancia de la unidad étnica sigue siendo un discurso de referencia, pues el reconocimiento de una lengua común, así como la historia de origen que comparten los mixes, superan las diferencias intercomunitarias por lo que entre ellos y en determinados contextos — sobre todo de oposición al exterior o a la hegemonía estatal— se reconocen como hermanos. ${ }^{63}$

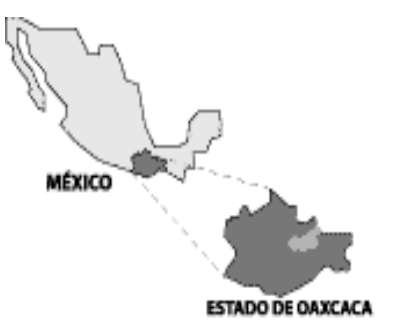

\section{MAPA 2 \\ El territorio (región) Mixe ${ }^{64}$}

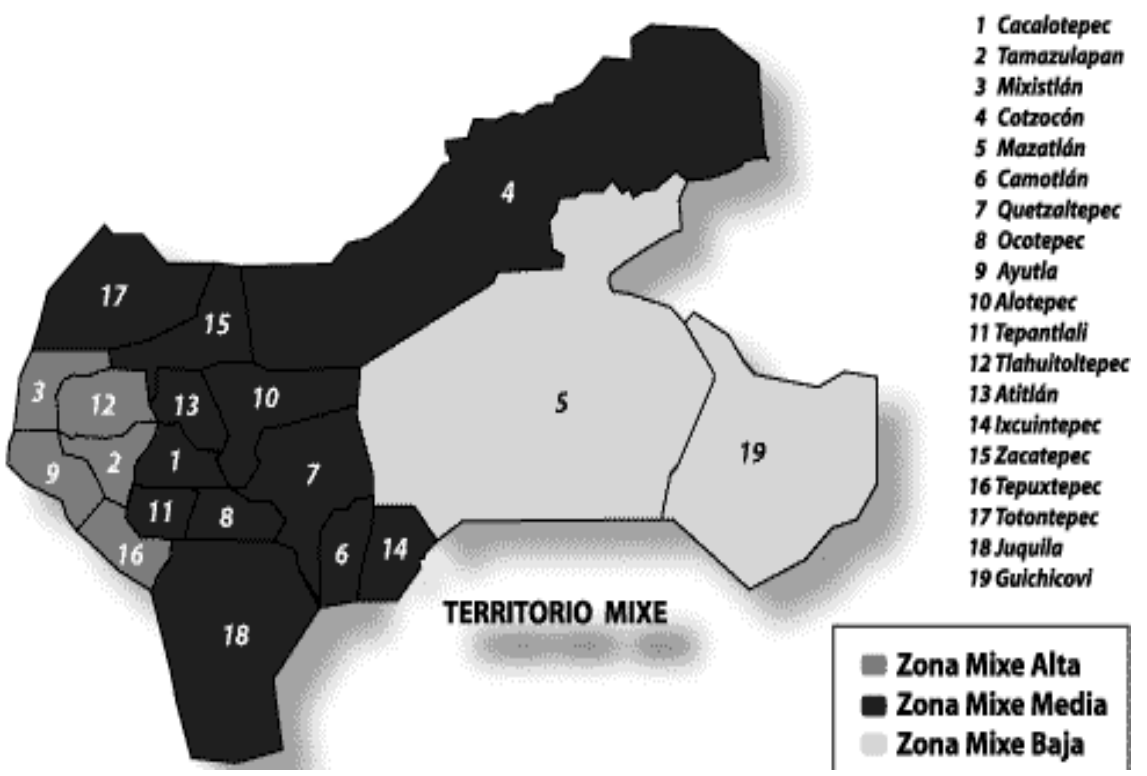

62 “Pero en el de los mixes construir su autonomía con base en el territorio étnico significaría desconocer las diferencias ancestrales entre los mixes de la parte baja (San Juan Guichicovi) y el resto, las cuales han generado no sólo importantes variantes dialectales sino articulaciones diferenciadas a sistemas interéticos regionales" (Maldonado, 1988:375).

63 Noemí Gómez Bravo (2004:33-35) narra a propósito del conflicto entre Móctum y Totontepec: "Para enfrentarse los dos pueblos se armaron con lanzas de madera, tal vez cuidando de no lastimarse, ya que tenían la misma sangre mixe, y entregar lo más pronto a la muerte unos a otros".

${ }^{64}$ Es importante aclarar que en este mapa aparece Totontepec como parte de la zona media, sin embargo, los propios habitantes de la zona se identifican con la zona alta, además de que en entrevista con maestros indígenas señalan que la variante dialectal de Totontepec es más apegada a la zona alta que a la media. Por esta circunstancia en este trabajo ubico mi trabajo en la zona alta. <http://www.redindigena.net/ser/pueblomixe/localizacion.html> 


\subsection{El comunalismo y los cacicazgos}

Como se ha apuntado, Luis Rodríguez tuvo mucha influencia en varias zonas de la región mixe, sobre todo en la zona alta donde se encuentra Totontepec y Móctum. El caso de Móctum frente a la cabecera de Totontepec Villa de Morelos y ante el distrito es un ejemplo de la relación cacicazgo-municipio, pero también lo es el de San Francisco Jayacaxtepec (otra agencia de Totontepec colindante con Móctum) que, según apunta Floriberto Díaz (1994:557), ${ }^{65}$ tuvo que sufrir sobre sus tierras, los embates del caciquismo:

Para tener sojuzgados a los pueblos, Luis Rodríguez se alió a caciques menores de la misma región y con otros grandes caciques fuera de ella como el caso de su relación estrecha con Samuel Alcántara de Totontepec, a través del cual entró en tratos con el cacique terrateniente de Santa Gertrudis, Oax., Hamilton, concesionario de la Ford en Oaxaca, para explotar yacimientos mineros de El Niño Perdido en terrenos de San Francisco Jayacaxtepec [municipio de Totontepec y colindante de Móctum], que de una forma ilegal pasaron a ser de Zacatepec por su riqueza potencial a futuro.

Con lo anterior, Floriberto Díaz responsabiliza a Luis Rodríguez (oriundo de Zacatepec e impulsor de la creación del distrito Mixe) de ataques contra Alotepec, y de ser causante de la división entre el municipio de Asunción Cacalotepec y su agencia San Isidro Huayapam (también mixes), que consiguió cambiarse al municipio de Alotepec, aunque sus terrenos pertenecen a los bienes comunales de Cacalotepec. Otro ejemplo de comunidad mixe que ha sufrido la política agraria del Estado es el de San Juan Jaltepec de Candayoc, en la zona baja de la región mixe, cuyos habitantes sufrieron el despojo de sus tierras por parte de un cacique mestizo. 66

${ }^{65}$ Antropólogo indígena fundador de la Asamblea de Autoridades Mixes, la Academia de Derechos Humanos de esa Asamblea y de Servicios del Pueblo Mixe, falleció en 1994.

66 También sobre este caso y la recomendación de la Comisión Nacional de Derechos Humanos véase mi trabajo de tesis de licenciatura (Cruz 1994). De igual forma Móctum sufrió el ejercicio del poder de Luis Rodríguez, como lo narra don Cipriano Gómez uno de los líderes morales de Móctum oriundo de Totontepec: "En los años cincuenta Luis Rodríguez castigó a Jareta y la bajó a Agencia de Policía" E.- ¿Por qué lo hizo? "No sé, tal vez se oponían a él. Luis Rodríguez y Daniel 
La cuestión agraria del reparto de tierra y el control territorial y político, que representan el cacicazgo y el municipio, se relacionan configurando la situación actual de los pueblos indígenas y el Estado mexicano. La vigencia de un comunalismo muy arraigado en el estado de Oaxaca también se explica por que la mayoría de los territorios indígenas están bajo la figura de bienes comunales (reconocimiento y titulación de bienes comunales o restitución), y pocas bajo el régimen ejidal (dotación) (Arellanes 1999:26; Nahmad 2003). ${ }^{67}$ Esta circunstancia da mayor independencia a las comunidades frente al Estado que a los ejidos. Por un lado, los bienes comunales son terrenos de pueblos cuya posesión sobre la tierra se tituló desde la época colonial a través de títulos primordiales. Por otro, los ejidos eran el resultado de la dotación a partir de la expropiación de fincas y haciendas que el Estado hacía a favor de un grupo de campesinos sin tierra - o peones antes acacillados en haciendas - por medio de un decreto. ${ }^{68}$ Esta distinción marca diferencias entre los campesinos comuneros y los campesinos ejidatarios frente al Estado mexicano, pues mientras los últimos dependían de la resolución directa de éste, los comuneros gozaban del uso de la tierra con mucha antelación amparados en ese hecho, es decir, por el uso y disfrute que habían hecho por mucho tiempo de las tierras que ocupaban, o bien, en títulos dados por la Corona española, llamados títulos primordiales.

Martínez estaban confrontados por la carretera, cada quien pedía que pasara por su pueblo. Daniel Martínez mandó a deshacer una camioneta para llevarla a Ayutla y ahí armarla nuevamente. Cuando algunos de Totontepec nos invadieron no tenían líderes, pero eran más familiares Alcántara que de otros. Fueron como 100 los invasores pero muchos dieron a medias los terrenos, a otros del mismo pueblo de Totontepec" (entrevista del 22 julio de 2004).

${ }^{67}$ De acuerdo con Nahmad (2003), sólo en los municipios de Cotzocón, Mazatlán y Guichicovi existen asentamientos con terrenos ejidales y propiedad privada. De estos municipios sólo Mazatlán tiene los tres tipos de tenencia de la tierra y Guichicovi no cuenta con terrenos comunales, sólo ejidales y pequeña propiedad.

68 Según lo documenta Arellanes (1999), dada la situación del México pre y posrevolucionario, en las primeras décadas de la Revolución Mexicana, la política agraria se enfocó hacia la expropiación de haciendas y ranchos y a la dotación ejidal (1999:128, 131-132, 228, 246), acción que no fue fácil dado los intereses de hacendados y finqueros que con ello se veían afectados: "Además de los conflictos generados por las formas de manejar y decidir los repartos de tierra, otro aspecto que incidió negativamente fue la política agraria estatal ligada a la relación subordinada con el poder central por un lado, y por el otro, los compromisos que el gobernador mantuvo con la vallistocracia [sic] quien en ocasiones trató de suspender las actividades de la Delegación Agraria". 
Pese a la ventaja que representaba que los pueblos indígenas contaran con títulos primordiales, en muchos casos esto no fue suficiente para hacer frente a intereses de personas con poder político y económico, según lo apunta Arellanes (1999:228). ${ }^{69}$ En los inicios del reparto agrario, el reconocimiento hecho sobre la posesión y el usufructo sobre la tierra fue un derecho a medias, por lo que los comuneros beneficiados de esta manera estaban en una situación de desventaja frente a las propiedades privadas (latifundios), ya que al no reconocérseles la propiedad, la población o núcleo agrario con bienes comunales, no podía ejercer sus derechos como propietario - entre otras, defender jurídicamente la tierra que ocupa-, pues sólo se les reconocía la posesión de la tierra que trabajaban.

El caso de Móctum está inserto en la historia de afectación de la tierra a los indígenas por parte del Estado mexicano, ${ }^{70}$ aunque sólo se perciben algunas de sus consecuencias. Este pueblo fue sujeto de la política de reparto agrario contemporánea (implementada en el periodo 1971-1992 en toda la República Mexicana), resultando el reconocimiento de sus tierras por Resolución Presidencial en 1975, la cual se ejecuta hasta los umbrales del XXI; es decir, se les reconoce a los pobladores la propiedad y la posesión física de sus tierras casi veinte años después de la Resolución Presidencial. Tal hecho no es tan dramático como el de otros pueblos indígenas del país ${ }^{71}$ que han luchado por recuperar sus territorios, pero

${ }^{69}$ De igual forma: “Cabe aclarar que en términos técnicos la restitución y la confirmación de tierras comunales no formaron parte del proceso de Reforma Agraria, se reivindicó muy poca de la tierra usurpada y cuando se llega a confirmar - acción que secularmente han buscado las comunidadestoda la acción gubernamental se reduce a expedir documentos sobre terrenos usufructuados por los campesinos acreditados como comuneros" (Arellanes 1999:246). Es decir, los núcleos de población con títulos primordiales no siempre fueron beneficiados por la extensión territorial que indicaban dichos títulos, pues según lo que apunta Arellanes, en estos casos sólo se les dieron documentos que amparaban los terrenos que efectivamente ocupaban (usufructuaban) y el resto se dejaban sin protección.

70 Esto se puede confrontar con Medina Cervantes (1987), González Galván (1995), Durand (1994), Florescano (1997), entre otros.

71 Como los huicholes (wixas) de Nayarit, Durango y Jalisco (Arcos 1998), los zoques de Chimalapas (entre Oaxaca y Chiapas) y los huaves (ikoods) (Bailón Vázquez 2001; Hernández y Lizama 1996) de San Francisco del Mar, Oaxaca. Sobre los huaves y concretamente sobre los procesos judiciales por la recuperación de su territorio, se recomienda consultar los informes del Centro de Derechos Humanos Tepeyac del Istmo de Tehuantepec, A.C. De igual forma se puede confrontar con los títulos primordiales que muchos de estos pueblos indígenas tenían, y que al momento de la 
para Móctum y Totontepec como para otros pueblos en Oaxaca se trata de una constante en la reivindicación de las identidades locales, en el ejercicio del poder y en el control de recursos asentados en sus territorios.

Finalmente la cuestión agraria marca la relación de Totontepec como cabecera municipal con sus agencias y fundamentalmente con Móctum: primero porque ambos poblados reconocen que éste último fue el poblado original de donde salieron pobladores hacia el lugar que ahora ocupa Totontepec, lo que significó para Móctum perder parte de sus terrenos, pues su extensión territorial era mayor que ahora. Segundo, porque es en el espacio territorial de cada comunidad donde se desarrolla la vida comunitaria de ambos poblados (las relaciones entre individuos y organizaciones), y se ejerce el poder y el control sobre los recursos que abarca.

Por lo anterior, lo agrario como dimensión de lo territorial se constituye en un elemento estructural para comprender la relación entre Móctum y Totontepec, sus dinámicas jurídicas y la construcción del derecho. Lo agrario constituye de hecho un referente central para analizar no sólo las dinámicas comunitarias sino también la relación agencias-cabeceras municipales a nivel regional, tal como lo revela el caso de Totontepec. Así como sucede con Móctum, Totontepec tiene conflictos de linderos (por lo menos hasta el año 2004 cuando se realizaron trabajos de PROCEDE) ${ }^{72}$ con cuatro más de sus diez agencias, lo cual revela las tensiones persistentes que han caracterizado al campo jurídico municipal, obstaculizando el desarrollo de cualquier política pública y las posibilidades de una jurisdicción municipal con legitimidad. Tal escenario es referente para comprender las dinámicas políticas y jurídicas en esta zona de la región mixe.

Reforma Agraria fueron recogidos por la dependencia correspondiente (Secretaría de la Reforma Agraria) y entregados directamente al Archivo General de la Nación.

72 Programa Certificación de Tierras Ejidales y Solares Urbanos en su versión para comunidades: PROCOM. 
El planteamiento de Viola König (1993) 73 , sobre el mapa antiguo de Santa María Tiltepec (que es también agencia de Totontepec y sus terrenos comunales son colindantes), es revelador porque da cuenta de cómo la tierra y sobre todo los límites territoriales no están fijos para siempre, no son inamovibles o inmutables y que, más bien, lo que sucede, por lo menos en esta zona de la región mixe, es que se recomponen de acuerdo a factores que no están al alcance de las comunidades cambiar, como la migración, por ejemplo.

En la actualidad, y como se ha expuesto en los antecedentes históricos, en las disputas territoriales el Estado y los poderes regionales han contribuido sensiblemente al imponer a comunidades, que tradicionalmente se consideraron a sí mismas como independientes, la subordinación a la jurisdicción de otro pueblo del mismo grupo etnolingüístico o de otro.

Por lo que toca al caso de Totontepec y Móctum, según los pobladores de esta comunidad y a la historia oral que narran, hace mucho tiempo hubo una epidemia que obligó a algunos a irse hacia las tierras que ahora ocupa Totontepec que para entonces ya estaban pobladas pero con menos gente que en Móctum. De esta manera podemos señalar de acuerdo con König (1993), y de manera hipotética, que Móctum fue el pueblo grande y Totontepec una ranchería que después se convertiría en la cabecera municipal, desplazando a Móctum. Por lo que el fenómeno de asentamientos-poblados por cada grupo consanguíneo (cfr. Chance 1998) es determinante en la constitución de Totontepec como comunidad aparte de Móctum mucho antes de la llegada de los españoles (cfr. Gómez Bravo 2004) e influye en la relación actual entre ambos poblados.

Hasta aquí se ha explicado la territorialidad y la relación entre lo agrario y lo municipal como sus dimensiones centrales en la relación del Estado y las comunidades indígenas. También se ha hecho referencia a cómo este aspecto se ha desarrollado en el estado de Oaxaca y ha sido una base fundamental en la construcción del comunalismo como base y unidad fundamental de la

\footnotetext{
${ }^{73} \mathrm{Al}$ referirse al trabajo de Schmieder, véase introducción general de esta tesis.
} 
organización regional y política de un pueblo.

Finalmente el derecho que se construye desde las comunidades es el referente de la regulación interna, pero también da cuenta de un proceso de negociación y tensión en el que se ha construido, tanto en su relación con el Estado como en su relación con los poderes caciquiles regionales.

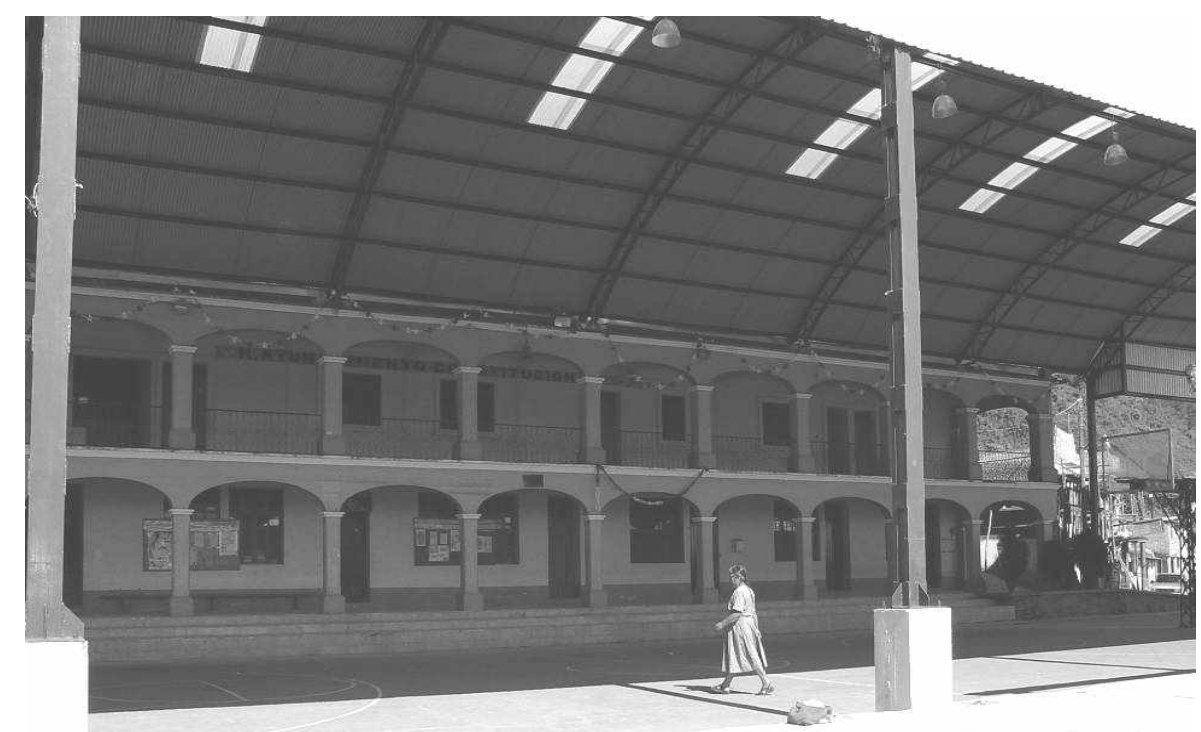

Edificio del Ayuntamiento municipal de la cabecera-comunidad de Totontepec

En capítulos posteriores, profundizaré en la relación de tensión entre Totontepec y Móctum a partir de la reconstrucción particular del conflicto agrario entre ambas comunidades, y la incidencia de las dinámicas municipales en el desarrollo del conflicto entre la cabecera y la agencia. Esto será fundamental para observar como en el marco de estas tensiones se afirma la diferencia comunitaria y se construye una negociación propia que pone en juego tanto referentes culturales como normativos, sustento del derecho en la comunidad, redefinida continuamente en su relación con el derecho estatal. 


\section{PARTE II}

\section{Niveles legales del Campo JuRídico y Sus Tensiones: EL CASO DE TOTONTEPEC Y SAN MARCOS MÓCTUM}

\section{Introducción}

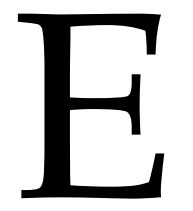

n la primera parte se expuso el sentido en que las dinámicas municipales y la cuestión agraria —como dimensiones de lo territorial — han marcado el contexto histórico y político característico del caso oaxaqueño. Ahora en esta segunda parte se analizan las instancias jurídicas de Totontepec Villa de Morelos (Totontepec) y San Marcos Móctum (en adelante Móctum) como niveles legales del campo jurídico regional, considerando sus tensiones en el ámbito territorial.

El contexto planteado en el capítulo anterior da la pauta para observar cómo se desarrollan y se muestran, a nivel de la región mixe y concretamente del municipio de Totontepec, las disputas por la tierra y el control político municipal y cómo éstas determinan las dinámicas del campo jurídico regional y local. El desarrollo de esta segunda parte se hace en los siguientes dos capítulos: CAPÍTULO 3. La relación entre el distrito, el municipio y la localidad como demarcaciones territoriales del campo jurídico y, CAPÍTULO 4. La cuestión agraria como estructuradora del derecho y la autonomía comunitaria. Posteriormente, en la tercera parte, se aborda el eje de la jurisdicción y la justicia, para lo cual es fundamental comprender cómo el contexto del reordenamiento territorial y político - lo agrario y lo municipal — se ha desarrollado en el estado de Oaxaca, y se presenta en el nivel regional del municipio de Totontepec Villa de Morelos.

Para compenetrarnos en la comprensión de las tensiones en el campo jurídico, retomo los conceptos definidos en la primera parte del trabajo. En el 
CAPÍTULO 1, se definió el campo jurídico como un espacio estructurador de reglas y arenas en donde confluyen diversos sistemas jurídicos, de los cuales nos interesan destacar el derecho positivo mexicano y el indígena, que a su vez están organizados por jerarquías y niveles legales, éstos como instancias de justicia, manejo y resolución de conflictos, así como normas y valores. El proceso de conformación de estos niveles legales, como parte del campo jurídico en regiones indígenas, tiene que ver con las historias particulares de los pueblos indígenas en cada región en su relación con el Estado mexicano. De esta manera, Sierra (2004a:16) plantea:

En el caso de México a diferencia de otros países latinoamericanos con presencia indígena, estas instancias o niveles revelan el papel fundamental del Estado mexicano en la conformación del orden jurídico regional [lo que en este trabajo denomino campo jurídico], y en la construcción de su hegemonía política y jurídica. Revelan asimismo que esta relación no es homogénea y adquiere formas particulares de acuerdo con las diferentes regiones. Es en el marco de estas instancias que encontramos las prácticas de una justicia indígena, sobre todo en sus niveles locales, práctica que sin embargo el Estado ha desconocido.

A esta cita se puede agregar que el sistema jurídico indígena es invisibilizado dependiendo de la influencia y fuerza del Estado. Esta hegemonía se expresa desde el derecho positivo como la concepción de las instancias de justicia de la comunidad o del municipio no como ámbitos de expresión del derecho indígena, sino como parte del sistema jurídico mexicano.

Como se expuso en el primer capítulo, desde el derecho positivo las instancias de la justicia comunitaria están subordinadas a él y no son vistas ni reconocidas como parte de un sistema jurídico con particularidades históricas y culturales propias. En estos términos y de acuerdo con el postulado de la interlegalidad, se puede hablar de un derecho indígena en relación de subalternidad con el derecho estatal. Esta falta de visibilización de las instancias de justicia comunitaria, y por tanto del derecho indígena, es un obstáculo para su 
comprensión, lo que se agrega al hecho de que al estar imbricado con el derecho estatal, los estudiosos de la antropología jurídica no podamos identificar si estamos frente a un derecho indígena o frente a normas del derecho estatal aplicadas de cierta manera por autoridades y usuarios indígenas. Pese a esto, puede afirmarse que se trata de su derecho o derecho propio, porque son normas, discursos y prácticas reapropiadas y aplicadas por sus autoridades, invocadas por ellos y eficaces para resolver sus conflictos internos e intercomunitarios.

Los conceptos de campo jurídico, derecho indígena e interlegalidad, aplicados a la relación de los pueblos indígenas con el Estado mexicano, hacen comprensibles las influencias del derecho positivo sobre las prácticas de hacer justicia en las comunidades indígenas, tal como sucede entre los mixes o ayuuk del estado de Oaxaca.

De la misma manera se retoma lo planteado en el CAṔ́tULO 2 respecto a la creación del distrito Mixe $-\mathrm{y}$ sus instancias judiciales, como niveles legales del derecho positivo - como un espacio de control del Estado mexicano, pero también como una instancia del derecho indígena. En este sentido, coincido con Sierra y Chenaut (2002:157) cuando plantean la necesidad de reconocer el peso del Estado y su derecho en la conformación del campo jurídico indígena.

Es decir, abogar por el pluralismo jurídico no debe significar dejar de lado el papel central del poder y del poder del estado, así como la manera en que los ordenamientos jurídicos se construyen mutuamente. La imagen del pluralismo jurídico puede involucrar una idea de convivencia armónica de los sistemas de regulación, cuando en realidad hay jerarquías que atraviesan los campos sociales semitautónomos, como es el caso del derecho del estado. Se evita de esta manera caer en visiones dualistas, que conciban un campo donde interactúan sistemas jurídicos que se tocan, pero no se influencian.

Por lo anterior, se asume que el derecho indígena está en constante relación y mutua determinación con el derecho del Estado. Para efectos analíticos, en el caso de estudio, llamo derecho indígena al derecho que se va construyendo desde los espacios locales en las comunidades, para distinguirlo del derecho estatal, sin 
eludir la situación de subalternidad e imbricación entre los órdenes jurídicos. El derecho indígena remite también a otros aspectos vinculados con las matrices culturales que lo han gestado y que definen los valores y marcos referenciales inscritos y reproducidos en las normas.

La creación del Distrito Judicial Mixe (1938) tuvo el propósito de cohesionar a las comunidades mixes subordinándolas al centro de poder distrital. El distrito Mixe ha significado dar visibilidad a uno de los grupos etnolingüísticos del estado de Oaxaca con mayor número de habitantes, dado que está compuesto por comunidades mixes ${ }^{74}$ a diferencia de otros distritos culturalmente heterogéneos como el de Juchitán que comprende comunidades zapotecas, mixes, huaves, algunos mixtecos - ubicados en el Bajo Mixe- y zoques.

La creación del distrito Mixe ${ }^{75}$ plantea la posibilidad de construir un proyecto político de cohesión de las localidades mixes respetando el arraigado sentido de comunalidad, según lo pretendían el coronel Daniel Martínez y Luis Rodríguez, caciques de la región.

Finalmente en el caso que se estudia, Móctum, como sucede con la mayoría de las comunidades indígenas oaxaqueñas con el estatus de agencias municipales, está subordinada a la cabecera municipal de Totontepec, con la que históricamente mantiene una relación de tensión por los motivos antes expuestos. Estos aspectos están entrecruzados con elementos culturales como el comunitarismo de ambos poblados y la descaracterización (amestización, véase punto 3.3) de la cabecera, aunque ambas pertenecen al Distrito Judicial Mixe y se reconocen como mixes.

74 El distrito de Villa Alta es colindante del distrito Mixe y particularmente del municipio de Totontepec, también tiene población mayoritariamente zapoteca de la Sierra, sin embargo, no tiene el nombre de la etnia, es decir "Villa Alta Zapoteco", como es el caso del nombre completo "Zacatepec Mixe" del distrito Mixe. Dentro del distrito Mixe, se destaca la conformación de diferentes campos sociales semiautónomos en diferentes escalas: la municipal y la comunitaria, es decir, el municipio de Totontepec y las 10 agencias que lo conforman.

75 Con esto, distingo entre el distrito Mixe y la región mixe. El primero es un ámbito jurídico, el segundo es un ámbito cultural. El primero está constituido por 17 municipios, el segundo abarca los 19 municipios mixes, así como localidades mixes adscritas a municipios no mixes existentes en Oaxaca, como la agencia municipal de El Paraíso en el municipio de Tehuantepec. 
Destaca en particular el conflicto agrario que llevó al reconocimiento de los límites territoriales de Móctum y con ello su categoría de comunidad agraria independiente de Totontepec. Junto con este hecho se han desarrollado otros procesos que marcan las tensiones entre cabeceras y agencias: Entre ellos es de notar la conversión religiosa de la mayoría de los miembros de Móctum al adventismo (1968-1969), que incide también en la distinción y separación de Móctum de Totontepec, y que la llevan a redefinir sus marcos normativos y su identidad sin que esto signifique romper con los lazos que vinculan a Móctum política, cultural y administrativamente con la cabecera municipal.

De esta manera las disputas históricas que han marcado la relación de San Marcos Móctum con Totontepec, como cabecera municipal, dan cuenta de los procesos internos que viven las comunidades por mantener ciertos márgenes de autonomía y distinción ante las unidades mayores. Dichas rivalidades inciden también en los sistemas normativos y la construcción de las identidades locales.

Ninguna de las culturas indígenas de México puede ser considerada como sistemas internamente homogéneos, sino como vastos conjuntos que exhiben grandes diferencias no sólo entre sí sino también dentro de sí. Quizás una de las tantas enseñanzas que nos pueden ofrecer estas formaciones culturales es que se encuentran basadas en la diversidad y no en la homogeneidad. No hay en realidad formas estándar de ser nahua, maya o chinanteco; cada una de esas denominaciones designa a conjuntos formados por grupos sociales heterogéneos, aunque de hecho sean depositarios de tradiciones lingüísticas y culturales comunes. (Bartolomé 1997:59)

Como lo menciona Barabas y Bartolomé (1999a, b) y Bartolomé (1997), los grupos etnolingüísticos no son homogéneos y uniformes, por el contrario manifiestan diversidad interna al grado de que la aplicación del criterio lingüístico como indicador exclusivo de lo étnico "puede llegar a forzar la convivencia de gente que puede no tener mayor vinculación entre sí que una lengua, de la que incluso hablen variantes que no sean inteligibles" (Bartolomé 1998:14). De esta manera en el caso de los mixes como grupo etnolingüístico heterogéneo, no se puede hablar 
de un ser mixe sino de distintas maneras de ser mixe, lo cual necesariamente impacta las prácticas jurídicas comunitarias.

Pese a lo anterior se puede afirmar la vigencia de una cultura común ${ }^{76}$ entre los ordenamientos comunitarios, pero no así la existencia del derecho mixe aplicable a todas las comunidades y municipios mixes, ya que en este grupo etnolingüístico existe una diversidad cultural (modos de vestirse, variedades dialectales) que se puede observar en la organización segmentarizada (Bartolomé 1997:60): Los comunitarismos y las identidades propias de cada comunidad, determinados por procesos históricos distintos, el contacto con otras culturas como la zapoteca de la Sierra y la zapoteca del Istmo, por la historia de conformación territorial y por las condiciones geográficas de la región. Estas historias locales son el producto de procesos históricos de instauración colonial que no afectaron de la misma manera y al mismo tiempo a los distintos sectores de un mismo grupo etnolingüístico. Como lo señala Bartolomé (1997:60), la organización segmentarizada es producto de estos procesos diversificados y distintos por los que pasaron todos los grupos etnolingüísticos:

A pesar del riesgo de reiterar las generalizaciones, se podría destacar que las sociedades nativas actuales contenidas dentro del Estado mexicano exhiben características que las podrían tipificar como sociedades polisegmentarizadas, es decir integradas por segmentos politicos primarios. [... Por] estar configuradas por segmentos políticos primarios, representados por comunidades independientes, funcionalmente equivalentes y con escasos mecanismos propios que favorezcan su integración política [...] Incluso la mayoría de los mecanismos integradores provienen del sistema administrativo estatal dentro del cual están incluidas (municipios, agencias) [...] la segmentarización contemporánea deriva también del hecho de que distintos sectores de un grupo padecieron diferentes procesos históricos de instauración colonial, que influyeron en la configuración sectorial de un mismo grupo etnolingüístico.

76 A pesar de las transformaciones culturales visibles, existe un sentido de identidad étnica que unifica a las comunidades y municipios mixes. 
Esta segmentarización es justamente lo que se puede observar entre los mixes, pese a lo cual, como señala Bartolomé (1997:60), no se puede negar la existencia de "una identidad global potencial que subyace a estas formaciones segmentarizadas, que constituye el aspecto latente de su identidad y que puede dar lugar al resurgimiento de formas de identificación abarcativas". Esto es importante para el caso de estudio enfocado a un municipio de la zona alta de la región, ya que la comprensión del campo jurídico mixe implica considerar la existencia de esa identidad abarcativa y a la vez de la diversidad cultural interna del grupo etnolingüístico. Siguiendo esta misma línea de reflexión podemos decir que el reconocimiento de la heterogeneidad ecológica y cultural de los mixes no niega la vigencia de una matriz cultural común entre los ordenamientos jurídicos comunitarios. 


\section{CAPÍTULO 3}

\section{LA RELACIÓN ENTRE El DISTRITO, EL MUNICIPIO Y LA LOCALIDAD COMO DEMARCACIONES TERRITORIALES DEL CAMPO JURÍDICO}

\section{Introducción}

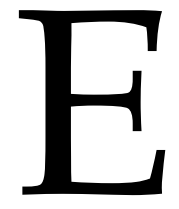

n este capítulo expongo cómo los espacios del distrito, el municipio y la localidad a pesar de representar diferentes niveles de gobierno y contar con instancias jurídicas distintas, comparten elementos comunes, sobre todo por lo que toca a la cultura compartida por los poblados en los que se encuentran esos niveles e instancias. Con esto, pretendo abordar la parte cultural que unifica a las comunidades y municipios que se encuentran en el distrito Mixe, si bien ésta se monta sobre una gran diversidad que caracteriza a la región y que se debe, entre otras razones, a las condiciones geográficas y climáticas la incorporación de "nuevas religiones" así como a la vecindad con otros pueblos indígenas (como se muestra en el MAPA 3)..$^{77}$

Sin embargo, es de advertirse que en el caso de Totontepec ha existido una insistencia, por parte de algunas familias y grupos, de distinguirse en grado de superioridad sobre la población del resto del municipio, es decir, de las agencias de policía y municipales.

\footnotetext{
77 En este mapa se pueden observar las fronteras étnicas de la región mixe (que es el territorio que abarca a las comunidades con población mayoritariamente mixe, estén dentro o fuera del distrito Mixe). En los distritos de Yautepec y Tehuantepec también hay comunidades mixes (como agencias o cabeceras municipales).
} 


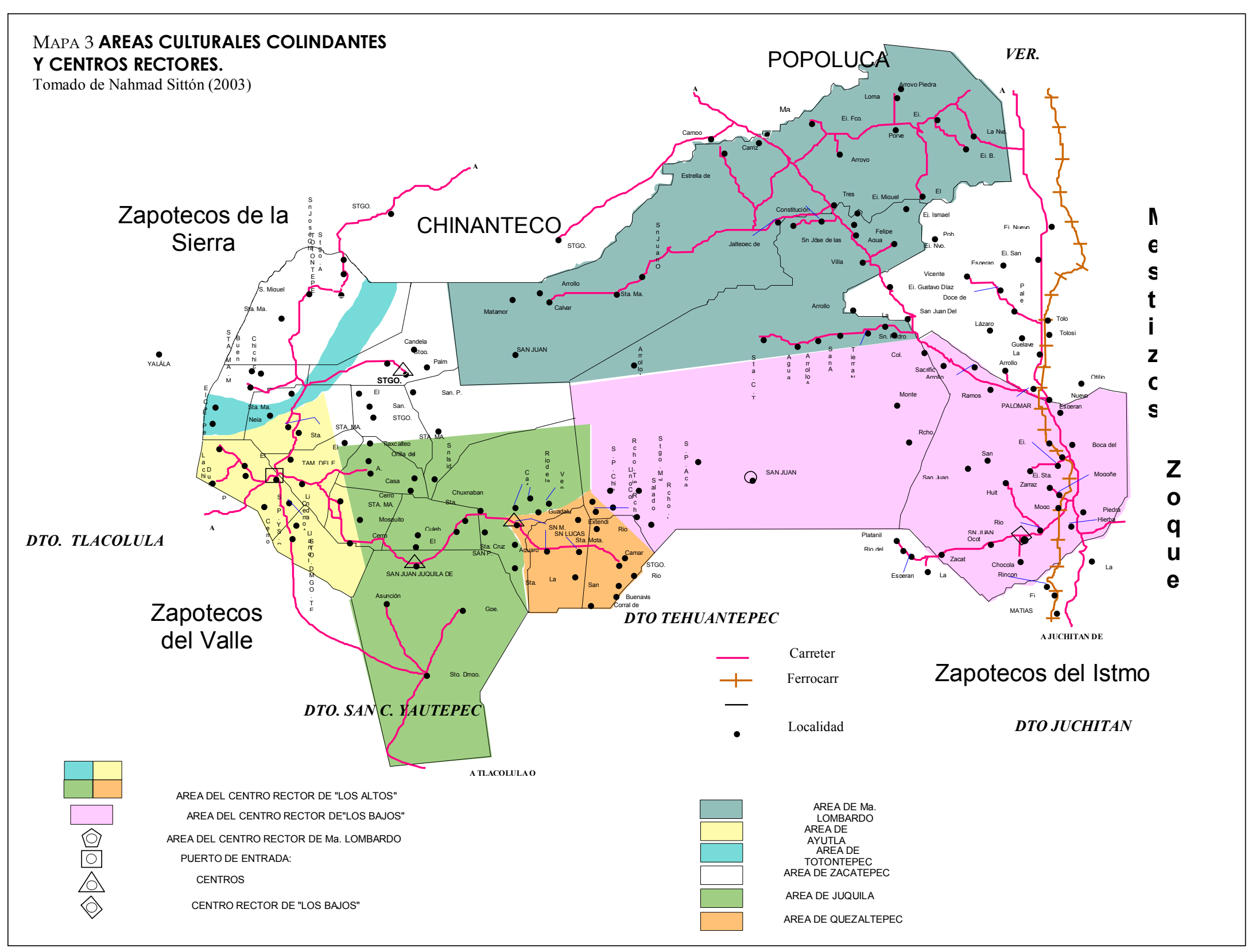


Esa forma de distinguirse es resultado de un proceso cuyo origen se remonta hasta la Colonia y que es calificado por algunos estudiosos de los mixes (Kuroda 1993; Acevedo y Pardo s/f) como descaracterización o amestización de la población de la cabecera, lo que ha marcado la relación y tensiones entre ésta y las agencias del municipio de Totontepec, y que pude percibir sobre todo en las relaciones políticas y económicas desarrolladas entre los pobladores de cabecera y agencia y, entre las autoridades de agencias y cabecera. Esto, sin embargo, no lo constaté en la forma de hacer justicia, aunque sí fue evidente que por lo menos en 2004 no hubo casos que llegaran de las agencias de Móctum y Huitepec (agencia que encabezó la reivindicación de derechos sobre los recursos municipales), lo que no significa que en años anteriores no haya sido así.

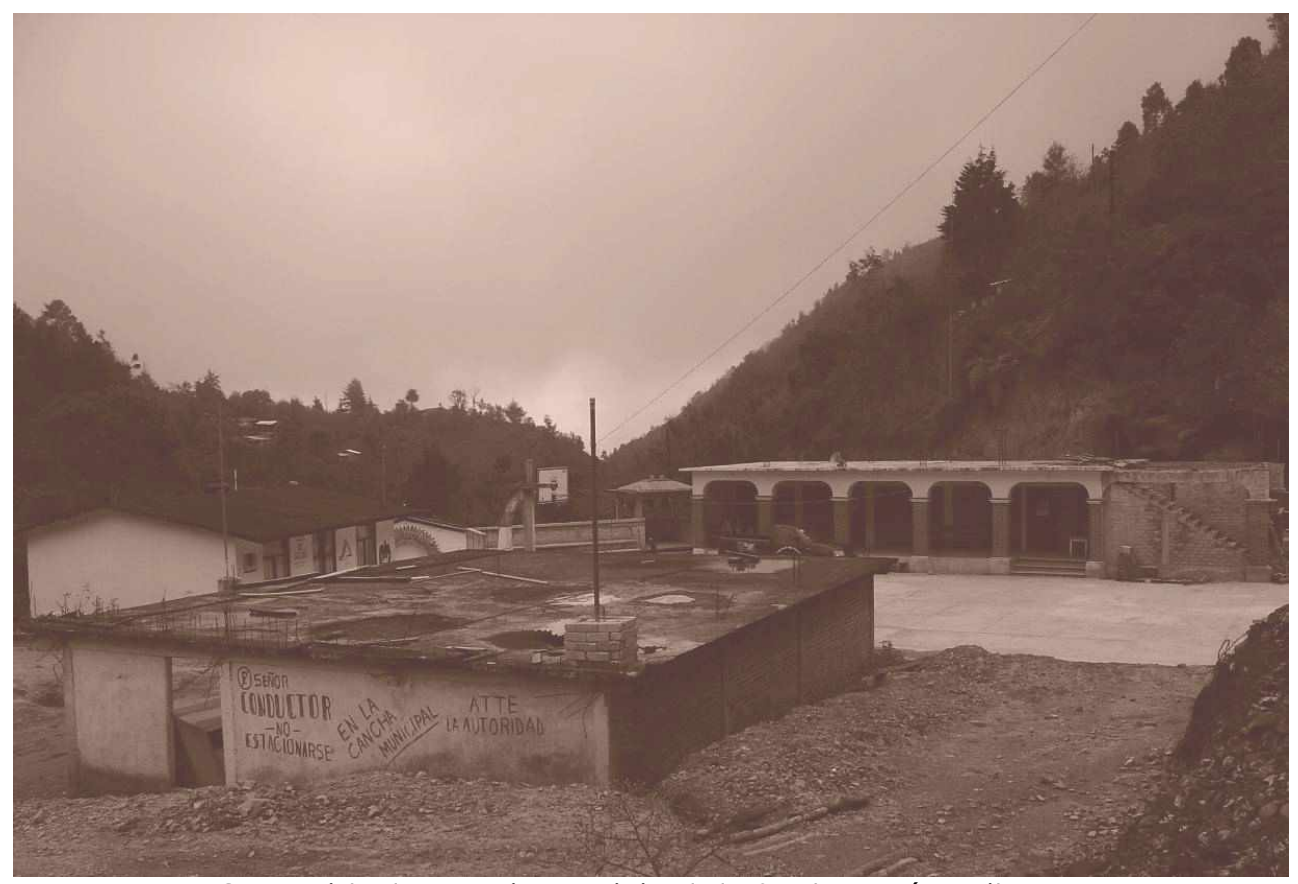

Comunidad-agencia municipal de Santa María Huitepec

De esta manera, el distrito Mixe, el municipio de Totontepec y sus agencias comparten tres aspectos en común: 1) Son parte de la jerarquía jurídico política del Estado mexicano, y sus instancias de justicia a su vez son niveles legales del campo jurídico, en este campo, y concretamente en el estudio del derecho en Totontepec y Móctum, se puede observar la interrelación del sistema jurídico indígena y del sistema jurídico mexicano. 2) Son espacios de poder relacionados entre sí por la 
territorialidad, y por la jurisdicción y la justicia. 3) Son espacios en los que se pueden apreciar ciertos elementos culturales comunes entre los mixes.

\subsection{Aspecto cultural en la relación de los campos sociales}

Los elementos culturales comunes entre los mixes también son determinantes en la relación entre los niveles legales del campo jurídico en la zona mixe de referencia. Esto es así porque por encima de los comunitarismos, entre las comunidades y municipios mixes se reconocen elementos culturales comunes que conforman una pertenencia identitaria. De igual forma, ese aspecto étnico-cultural marca la relación entre el distrito Mixe, los municipios que abarca y las localidades que constituyen la demarcación territorial del campo jurídico mixe.

De acuerdo con Bartolomé (1997), el aspecto étnico cultural está dado por las afinidades culturales objetivas y subjetivas que comparten los mixes, ${ }^{78}$ pero más allá de estas afinidades, las identidades se construyen en cada zona y en cada comunidad según sus circunstancias geográficas, históricas y de contacto cultural con otros grupos etnolingüísticos. Las particularidades culturales, que pueden acercar o separan a las comunidades entre sí y con el Estado, son importantes para definir los usos del poder y el derecho. Un acercamiento inicial a dichas particularidades permite comprender la dinámica de la relación entre sistemas legales.

\subsubsection{El comunitarismo y el sentido de unidad étnica}

Pese al sentido de identidad local (comunitarismo), entre los mixes prevalece el reconocimiento de una ascendencia o un pasado común, como referente que nutre una identidad étnica ${ }^{79}$ compartida, aunque el criterio de adscripción a la

\footnotetext{
78 Tanto las afinidades objetivas como subjetivas pueden variar según la historia y desarrollo actual de cada comunidad, por lo que referirse a ellas como elementos de definición de la identidad étnica puede ser una opción poco eficaz. Véase el pie 81.

79 De acuerdo con Stavenhagen (1992:57), los criterios que definen a la identidad pueden ser subjetivos u objetivos, siendo éstos los mismos atributos compartidos por los miembros de una etnia que los distinguen de otros grupos semejantes (lengua, vestido, música, religión); se
} 
comunidad y a la identidad local son puestos en primer término antes que la adscripción al territorio o región mixe. En este sentido, tenemos que

[...] El mecanismo para establecer una ascendencia común entre los que aseveran tener una identidad étnica común no es, como ocurre con los grupos de parentesco, una genealogía que establece vínculos con un antepasado común. Las vinculaciones con los antepasados apicales, los predecesores de un grupo étnico, se establecen a través de narrativas de origen, migración y especialmente sufrimiento a manos de otros. (Keyes 2000:204)

De acuerdo con esta cita, la vinculación con un antepasado épico, predecesor de los mixes (Beulink 1979:19, 25) se expresa en los cuentos, historias o leyendas (narrativa) de cada comunidad mixe que los vincula al antepasado común Cong Hoy y al cerro del Zempoaltépetl, cerro de los veinte picos o las veinte divinidades (Aguilar 1992; Barabas y Bartolomé 1984), así como una forma de explicar su origen que se expresa en cuentos e historias sobre los cerros, el agua y la culebra, que giran en torno al antepasado épico pero que toman características locales o de la historia de cada comunidad. 80

diferencian de los criterios subjetivos, pues éstos se refieren a la conciencia individual de pertenencia e identificación con el grupo (identidad), la internacionalización de los valores y símbolos compartidos con otros miembros del grupo; y las creencias comunes relativas a los orígenes, etcétera. La autoidentificación o autoadscripción se refiere al criterio subjetivo el cual no es posible sin la existencia de la comunidad. Sin embargo, es importante subrayar los riesgos de la distinción entre lo subjetivo y lo objetivo pues tanto unos como otros no son inamovibles. Por ello, es que las identidades étnicas se construyen de acuerdo a un contexto particular y en relación al Estado. Esto es claro en el caso de Totontepec cuando se define como poblado descaracterizado, lo cual no sólo depende de la pérdida de determinados rasgos, sino de cómo los pobladores se conciben a sí mismos haciendo distinciones frente a personas pertenecientes como ellos, a un mismo grupo etnolingüística.

80 Estas características las hace patente Miller (1956:16) en su trabajo, al recopilar los cuentos e historias mixes del poblado de San Lucas Camotlán, Oaxaca (la ubicación de este poblado es en la zona alta de la región mixe). De igual forma estas características se constantan en un trabajo más reciente y de mayor envergadura coordinado por Elisa Ramírez (1982), pues abarca varios pueblos mixes. 


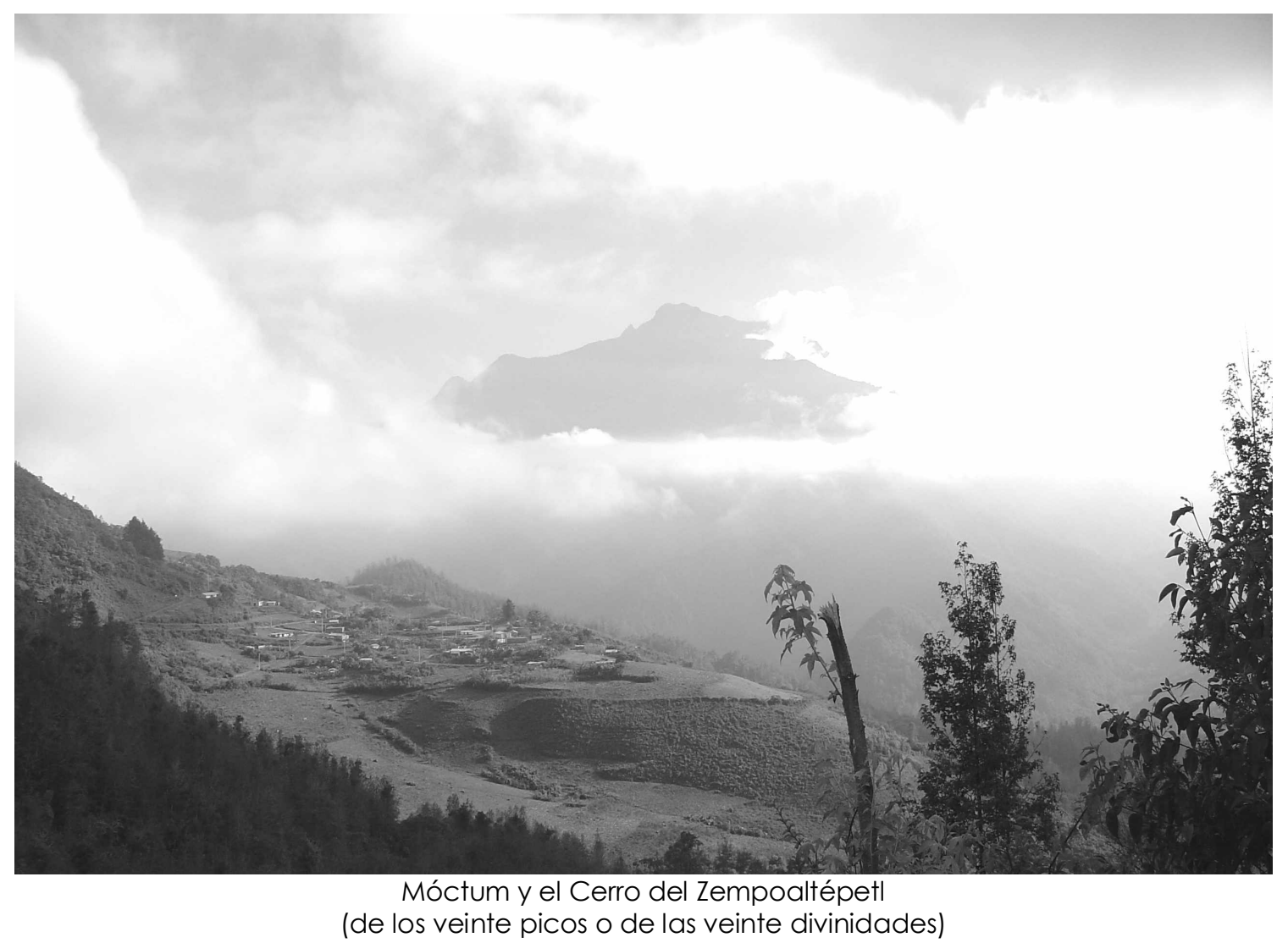

Según lo anterior, la referencia cultural distingue a los mixes de otros pueblos y los identifica entre sí, subrayando que las identidades comunitarias varían, pero que existe una constante de reconocerse entre sí — básicamente y no exclusivamente- por la lengua y un pasado común.

Sin embargo, en el caso de los Mixes, a pesar de la diversificación dialectal, había un concepto manejado por todas las comunidades de pertenecer al pueblo Ayuuk. Es decir, existe una categoría social y cultural que los define como una entidad mayor que la estrictamente comunitaria. Este elemento también los distingue de los pueblos chinantecos, zapotecos, serranos, istmeños y vallistas o los mestizos (gente de razón) del entorno de la frontera geográfica. (Nahmad 1990:35-36)

Por lo anterior las comunidades que forman parte del pueblo mixe tienen distintas formas de apropiarse de elementos culturales ajenos y de recrear los propios, es decir, la identidad como la cultura se construyen y no son permanentes, lo cual 
supone que los conflictos relevantes y básicos también serán definidos y entendidos de distintas maneras en cada comunidad indígena mixe.

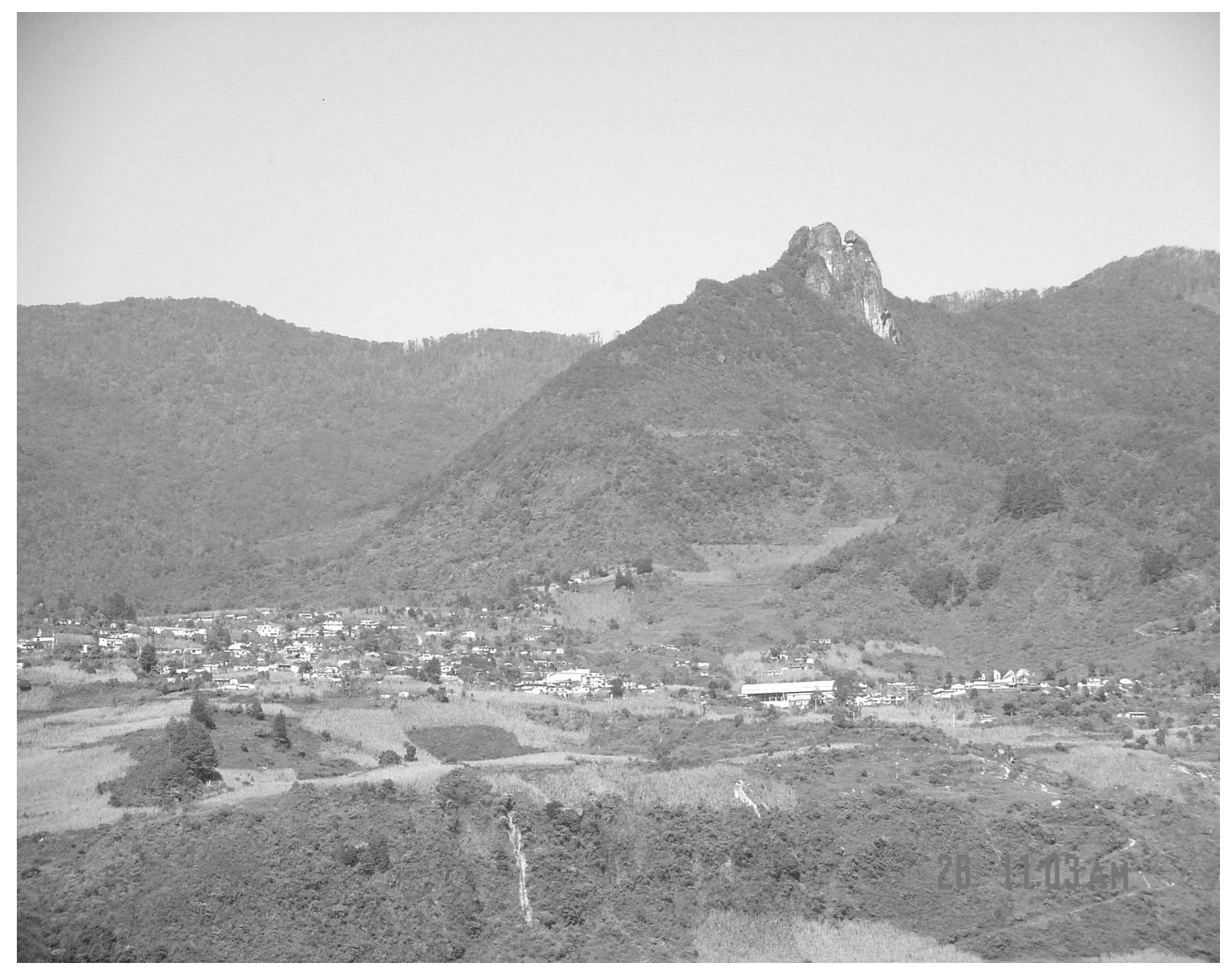

Vista de la cabecera-comunidad de Totontepec

\subsubsection{Totontepec y Móctum: Un ejemplo de diversidad cultural entre los mixes}

Como lo plantee en el capítulo anterior, entre los mixes existe un comunitarismo muy arraigado, es decir, la adscripción a una comunidad tiene más peso que la adscripción a la etnia. Sin embargo, de acuerdo con Maldonado y Cortés (1999:101), los mixes o ayuuk (o ayouk en la variante lingüista de Móctum) se reconocen entre sí como tales, fundamentalmente por el uso de la lengua y su adscripción a una comunidad. Los habitantes de Móctum como de Totontepec no son la excepción, en el primer caso se autodenominan ayoukta pronunciación local 
de ayuuk — como se denominan en el primero-, lo que coincide con el planteamiento de Maldonado y Cortés (1999:101) sobre comunidad como territorio cultural entre los mixes:

La pertenencia a alguna comunidad es un referente básico, concibiendo a la comunidad como un territorio en el que se establecen relaciones entre familias y fuerzas sobrenaturales. En cada comunidad, el tipo de pronunciación, de vestido, de alimentación, la forma de las casas, etcétera, conforman el referente particular distintivo frente a otras comunidades ayuuk. La comunidad es el ámbito de definición específica de la identidad ayuuk. Lo ayuuk adquiere formas de expresión comunitaria diferenciales y que son percibidas por los pueblos vecinos.

Tanto en Móctum como en Totontepec, y otras de sus agencias que visité, no percibí elementos objetivos comunes a los mixes, como el vestuario tradicional (sólo pocas personas lo usan, principalmente mujeres) o la religión, pues existe una penetración acelerada de otras religiones distintas a la católica, sobre todo en las agencias y poco menos en la cabecera municipal de Totontepec, sin embargo, el uso de la lengua mixe es fuerte y arraigado, así como de costumbres de solidaridad individual y colectiva como el tequio o la mano vuelta. Finalmente, en el caso de estudio, la lengua, la referencia a formas de organización (CAPÍTULOS 6 y 7) y a un pasado común, más que la religión o que el vestuario, son el referente cultural más importante por el cual los mixes se identifican y autoidentifican, como lo plantean Maldonado y Cortés (1999:101):

El referente fundamental de identidad entre los ayuuk es la lengua, sobre todo en el caso de los pueblos de la parte Baja, donde la aculturación zapoteca es amplia. Por lo mismo, la diferenciación principal con los zapotecos es a través del idioma. Se puede compartir con ellos el vestido (en el caso del Istmo), la música [en el caso de la Sierra, donde están ubicados Totontepec y Móctum], las formas del goce festivo o la vocación comunal, pero la autodistinción primordial es la lengua. 
Además de la autoadscripción a la comunidad como unidad étnica fundamental de identificación entre los mixes, existe también una presunción de ascendencia común, que hace que sobre ese comunalismo las localidades mixes se identifiquen como parte de un todo, es decir, la etnia o pueblo.

Ejemplo de lo anterior es la narrativa a la que se refiere Beulink (1979) que expresa el vínculo a un pasado y a antepasados comunes, y que también existe en Totontepec y Móctum — comunidad donde subsisten dichas creencias a pesar de ser mayoritariamente adventista- En estos lugares se cuenta que antes abundaban enormes culebras que vivían en el agua — símbolo primordial de los mixes, pues se menciona al hermano Culebro del rey Cong Hoy- y animales salvajes que ahora es difícil encontrar (leones, changos). En el caso de Totontepec en el año 2004, se adoptó un escudo — que se ubica en las oficinas del cabildo municipal - en donde se representan entre otras cosas, el cerro de La Mitra (que le da nombre a Totontepec: Anyukojm) y Cong Hoy, el líder histórico de los mixes.

Este escudo es un emblema que en Totontepec representa la adscripción de la comunidad al grupo etnolingüístico mixe y reivindica la identificación de esta localidad con otras localidades mixes. En cuanto a la simbología del escudo en Totontepec:

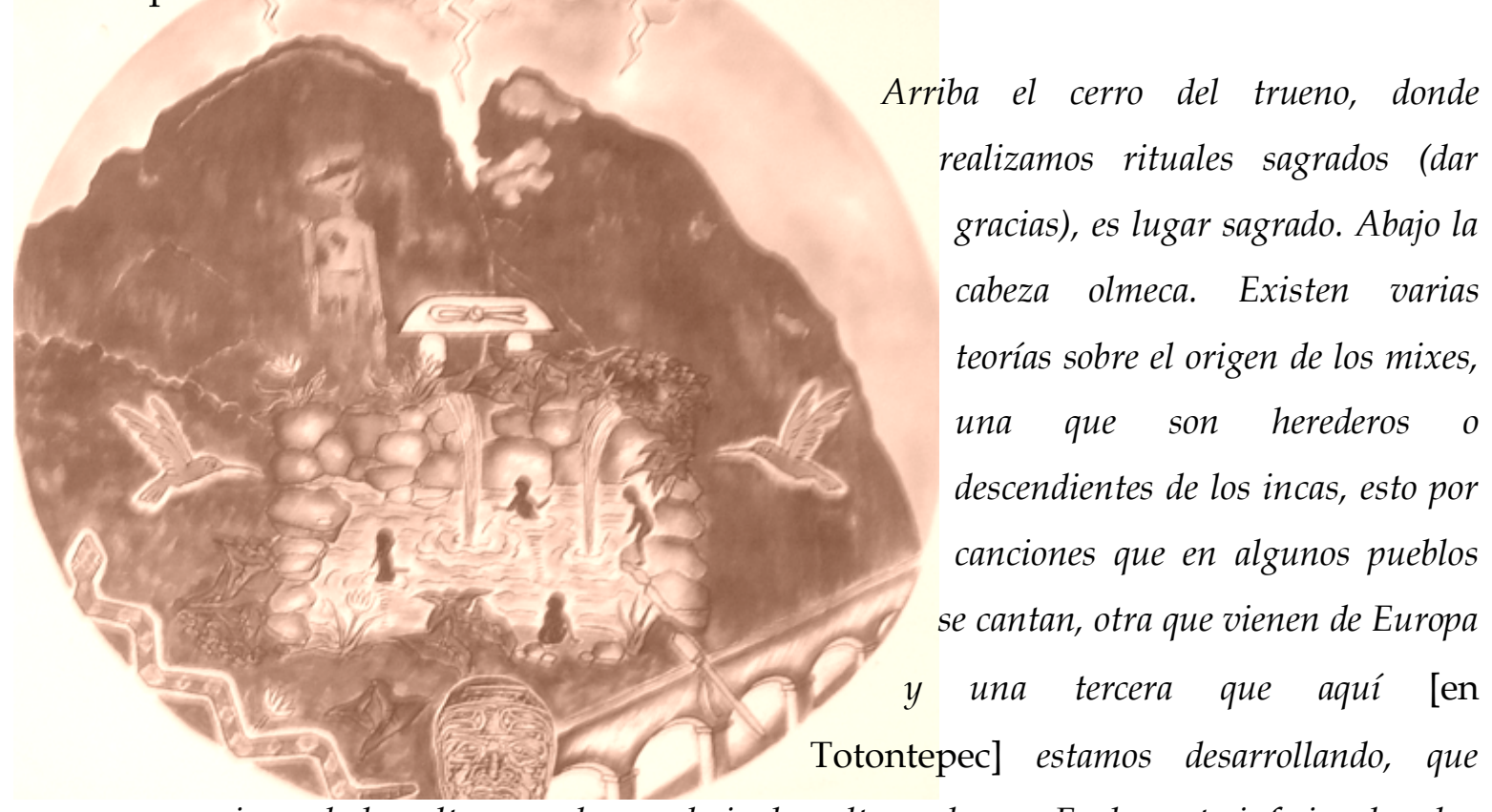
provenimos de la cultura madre, es decir, la cultura olmeca. En la parte inferior derecha, 
están los arcos del palacio municipal, es decir, la casa del pueblo, sobre éste está el bastón de mando que representa la autoridad, yo digo que es la autoridad como justicia no como dominio. De lado inferior izquierdo una víbora, que en las culturas mesoamericanas representa la sabiduría. En la historia del rey Cong Hoy se dice que de dos huevos nació, de uno nació y del otro su hermano el Culebro. En el centro se ve el nacimiento (manantial) de agua, donde juegan los niños (hijos de la peña), simboliza cuando los primeros que llegaron, al ver el nacimiento del agua decidieron quedarse. Por arriba del manantial, dos piedras sosteniendo una laja, representa el trono de Cong Hoy (en él aparece el listón de los que eran los guerreros). Cada pueblo o comunidad mixe se atribuye algo de Cong Hoy, que aquí comió, que aquí durmió. Se dice que aquí en Totontepec tenía a su ejército. (Entrevista realizada el 24 de julio de 2004, al presidente municipal Lucio López Reyes).

En la reivindicación étnica que se expresa con este escudo, indudablemente ha influido el discurso sobre derechos indígenas a nivel nacional e internacional, sobre todo porque el presidente municipal en turno - quien describió el escudoes maestro y participó en el Consejo Consultivo de la Comisión para el Desarrollo de los Pueblos Indígenas (CDI), donde coincidió con el líder mixe Adelfo Regino de Servicios del Pueblo Mixe (SER), ${ }^{81}$ lo que sin duda influirá en la manera en que la cabecera municipal se relacione en adelante con las agencias y en la percepción de éstas sobre las pretensiones de superioridad de los pobladores de Totontepec, aunque seguramente la descaracterización no se revertirá a corto plazo.

De igual forma, se observa que la revitalización de las identidades étnicas ha impactado en la relación de la cabecera frente a sus agencias. Desde 1993 se

\footnotetext{
${ }^{81}$ En <http://www.laneta.apc.org/rci/organinteg/mixe.html> “SERVICIOS DEL PUEBLO MIXE, A.C., es un Organismo Civil compuesto por indígenas mixes y de otros pueblos de Oaxaca. Desde la constitución de SER, se fijó como objetivo promover la unidad del Pueblo Mixe como una estrategia para lograr el desarrollo integral autónomo en el marco de nuestra cultura y con respeto a la naturaleza. Como antecedente podemos mencionar que nuestra tarea de organización se inició en 1979 con la fundación de CODREMI (Comité de Defensa de los Recursos Humanos, Culturales y Naturales de la Región Mixe) y, a lo largo de 18 años de actividades, nuestra estructura organizativa y nuestros temas concretos de acción prioritaria han ido evolucionando de manera paralela a las transformaciones que se están dando en la realidad mixe en relación con el resto de la sociedad mexicana y, obviamente, con el resto del mundo".
} 
establecieron en la Ley Orgánica Municipal del Estado de Oaxaca, ${ }^{82}$ una serie de atributos y facultades al municipio, entre las que está contemplada la de crear Consejos de Participación Ciudadana, uno de ellos congrega a los agentes municipales y de policía de Totontepec, por lo menos desde hace diez años. Sin embargo, es hasta el 2004 que la cabecera municipal pone a discusión el presupuesto municipal, que antes se había dado. Según la versión del presidente municipal, fue por iniciativa propia del cabildo, según algunos agentes municipales entrevistados, fue por la presión que hicieron para obtener mayores recursos municipales. ${ }^{83}$

\subsection{Totontepec Villa de Morelos y San Marcos Móctum: Las identidades compartidas}

Como se ha mencionado, entre los mixes como entre comunidades de otros pueblos indígenas la vigencia de elementos culturales, así como de antecedentes históricos comunes, constituyen referentes de una identidad étnica unificada pero no por ello inalterable e inamovible. Las identidades son construcciones dinámicas por lo que de acuerdo con Miguel Bartolomé (1997:43, 47):

resulta necesario destacar que la identidad es un concepto polisémico que alude a fenómenos múltiples, ya que no hay un ser sino formas del ser [y destaca que] la continuidad de la identidad de los grupos étnicos se manifiesta precisamente a través de las discontinuidades que hacen a las sociedades reelaborar su propia imagen. La historia identitara de una

\footnotetext{
82 De 1993. El ARTículo 36 de la Ley Orgánica Municipal del Estado de Oaxaca establece: “El Presidente Municipal tiene a su cargo, la representación política del ayuntamiento y la ejecución de sus resoluciones con las siguientes facultades y obligaciones: [...] Fracción XII. Promover y vigilar la organización e integración de los Consejos de Participación Ciudadana en los programas de Desarrollo Municipal”. En http://www.e-local.gob.mx/wb2/ELOCAL/ELOC_Ley_Organica_Municipal_15 [consultado en febrero 2007]:

${ }^{83}$ Este tipo de procesos de reivindicación al interior del municipio, donde las agencias exigen mayores recursos para obras, se inserta en un proceso de reforma municipal y del Estado mexicano que lleva más de 20 años. Las reformas de 1983 y 1999 al ArTículo 115 Constitucional enmarcan este tipo de disputas. Lo cual no ha sido una dádiva del Estado o un proceso difundido por él, más bien ha sido el resultado de las luchas y reivindicaciones del movimiento indígena que datan de más de 20 años atrás y que han convergido con las demandas del movimiento municipalista por el reconocimiento del poder local.
} 
sociedad aparece así como un vasto conjunto de diferentes imágenes especulares de sí misma, aunque generalmente orientadas hacia un modelo que pretende definirla.

De esta manera, entre Totontepec y Móctum existen aspectos de vinculación pero también de distinción. En la narrativa de Móctum sobre su origen se pueden percibir elementos de identidad que lo relacionan con Totontepec como comunidad mixe, pero que también la distinguen de él.

En lo que a la cuestión histórica se refiere, Noemí Gómez Bravo (2004) —mixe, oriunda de Móctum_, basándose en entrevistas realizadas a personas ancianas de su comunidad, así como en investigaciones recientes sobre un sitio arqueológico en tierras de Móctum, señala que este poblado en la época prehispánica, mucho antes de la llegada de los españoles, era considerablemente más grande que Totontepec, que surgió a raíz de que un grupo de pobladores de Móctum iban en busca de mejores tierras (autoridades de Totontepec que pude entrevistar coinciden con esta versión). Este hecho histórico de cómo poblados mayores y antiguos son desplazados en su importancia y control por poblados que iniciaban como rancherías es explicado por König (1993) y en la siguiente cita por Gómez Bravo (2004 16-43): ${ }^{84}$

Móctum no perteneció desde siempre a Totontepec, ni éste fue superior a aquél; los ancianos han ido pasando la palabra a sus descendientes en la que sostiene que Móctum surgió antes que Totontepec y que las tierras totontepecanas de ahora son parte de las que le pertenecieron a aquel pueblo en su época de máximo esplendor.

Antropólogos y arqueólogos, que estuvieron en Móctum hace seis años, realizaron una investigación sobre la existencia de un centro ceremonial antiguo en el lugar, sin embargo, no comunicaron a los pobladores de esta comunidad acerca de sus resultados.

Juntando estos acontecimientos con la silenciosa presencia de cuatro montículos en ruinas que rodean el enorme patio donde se ubica la escuela de Móctum, sin temor a la aventura, se

84 Noemí Gómez Bravo es adventista y pese a su religión que prohíbe muchas de las creencias y prácticas religiosas mixes -como los sacrificios de animales - se ha preocupado por la recuperación de la historia de su pueblo, San Marcos Móctum. 
puede deducir que la piedra de la mujer con metate se relaciona con el nombre del lugar: Moctun, "trabajadores del maíz", en tanto que la segunda piedra la del hombre con bolas de oro, muy probablemente correspondía con el de un jugador de pelota pues la plazuela (centro ceremonial de Móctum) parece un campo de juego de pelota.

La anterior cita puede ser un indicio de que si bien el criterio de adscripción a la comunidad y a la identidad local es puesto en primer lugar antes que la adscripción al territorio o región mixe, se construye un sentido de pertenencia común al pueblo mixe.

\subsubsection{El caciquismo regional y el sistema jurídico en zona indígena}

Entre los mixes existe un sentido de identidad común, pese a esto, el arraigo a la comunidad de origen es primordial. Ante esta aparente paradoja, han existido -como se expuso en el CAPÍTULO 2- intentos de unificación política impulsados por personajes mixes que resultaron de la Revolución Mexicana que se caracterizaron como caciques en la región, y el caso del municipio de Totontepec no fue ajeno a esto. Así el caciquismo regional es clave para comprender las dinámicas políticas y jurídicas en Móctum y Totontepec y punto de referencia de la lucha que los habitantes del primer poblado - como comunidad agraria de facto en ese entonces y como agencia de policía - dieron para recuperar su tierra frente a caciques de Totontepec - la cabecera municipal_-, a quienes identificaron con los Alcántara. ${ }^{85}$ Este hecho fue en su momento denunciado por la Asamblea de

${ }^{85}$ Lo que se puede confirmar en el expediente agrario núm. 276/807 (“Confirmación y Titulación de Terrenos Comunales de San Marcos Móctum, Municipio de Totontepec, Distrito Mixe, Oaxaca", en el Archivo General de la SRA-Oaxaca), donde se desprende la lista de los "posesionarios" que no eran de Móctum. Es importante destacar que si bien el conflicto se puede ubicar claramente con algunas personas y no con todo el pueblo de Totontepec, las dinámicas económicas y sociales de éste influyeron para que muchos de sus pobladores se vieran involucrados. Tales dinámicas estàn relacionadas con la insuficiencia de tierra y con las relaciones de aparcería y arrendamiento sobre la misma, lo que marca desigualdades económicas y sociales entre los pobladores de Totontepec. Fueron pocos los caciques, sin embargo, éstos a su vez arrendaban o tenían algún acuerdo o convenio con sus paisanos para el pago de sus deudas sobre el uso de las tierras de Móctum. Por ello, no es de sorprender que cuando San Marcos Móctum quiere recuperar sus tierras (que había perdido por deudas económicas con comerciantes y caciques de Totontepec), los directamente afectados son los caciques pero también, indirectamente, los aparceros y arrendatarios. Sobre las 
Autoridades Mixes (ASAM). ${ }^{86}$ Finalmente el cacicazgo pierde fuerza, en lo que influye sin duda las dinámicas económica y política de la región como el nuevo plano organizativo impulsado por asociaciones de derechos indígenas y de reivindicación étnica. Con esto y en el marco de la emergencia y auge de los derechos humanos (como discurso y como derechos exigibles por los indígenas al Estado - aunque para entonces todavía no se daban las discusiones y reformas constitucionales en estas materias-) ${ }^{87}$ se logra de alguna manera que el Gobierno del Estado de Oaxaca interviniera de otra manera en el conflicto entre los dos poblados, y se evidenciara que el cacicazgo regional no podía ser sostenido, pues si en su momento cumplía un papel de mediación y control del Estado, ahora ante el discurso proétnico de participación comunitaria directa ${ }^{88}$ (por ejemplo, la elección de autoridades por usos y costumbres) representa un obstáculo a la participación social y política "democrática". De esta manera, ante el caciquismo ejercido desde la cabecera-comunidad de Totontepec, Móctum había perdido la posesión de muchas de sus tierras, sin embargo, con el proceso de Reforma Agraria que se extiende hasta finales del siglo $\mathrm{XX}$, se da la oportunidad de que eso cambie. El hecho de que Móctum tuviera sus documentos agrarios derivados de un procedimiento federal le dio de alguna manera un margen de seguridad jurídica, sin embargo, eso no significó que el conflicto agrario fuera atendido desde el principio a su favor, ya que la Resolución Presidencial data de 1975 y el finiquito agrario se da en su última etapa hasta 1996. Confluyeron un conjunto de circunstancias que obligaron al Gobierno del Estado de Oaxaca a iniciar un proceso

condiciones económicas y sociales de Totontepec en este periodo, nos remitimos a la obra de Martha Romer (1982).

86 Organización indígena impulsada por Servicios del Pueblo Mixe que congrega a autoridades de comunidades de la región mixe. Tiene como una de sus funciones realizar actividades conjuntas sobre proyectos productivos y acciones políticas, como la capacitación en derechos humanos, derechos de los pueblos indígenas y derechos de las mujeres.

$87 \mathrm{Si}$ bien la lucha por los derechos humanos tiene unos veinte años de trayectoria (desde las décadas de 1970-1980 a la fecha), el uso que de ellos han hecho los indígenas y sus pueblos es relativamente reciente, hecho que he podido constatar en mi práctica profesional independiente y gubernamental (con el Departamento de Derechos Humanos de la Arquidiócesis de México y la Procuraduría Agraria, entre otros espacios).

${ }^{88}$ Véanse las reformas constitucionales al ARTículo 115, sobre todo las de 1983 y 1999. 
que llevaría varios años para intervenir de manera diferente y anular el poder caciquil, construyendo nuevas intermediaciones como los liderazgos comunitarios en sustitución de los liderazgos regionales, como lo fueron el coronel Daniel Martínez y Luis Rodríguez.

Lo anterior es el contexto en el que se ubica la relación de Totontepec y Móctum -el caciquismo, la reforma municipal y el comunitarismo-, dado que en estas comunidades se entrecruzan las categorías político-administrativas y lo agrario, lo que resulta central para mi estudio. Esto es comprensible, si se toma en cuenta que la condición agraria de Móctum corresponde a una regulación federal que le da mayor margen de control de sus dinámicas internas, aún más que el de ser agencia de policía, ya que el nombramiento de los representantes agrarios de la comunidad no depende de la ratificación del ayuntamiento municipal y el ejercicio de sus facultades no está subordinado a él, a diferencia del agente municipal o de policía, que jurídicamente son considerados como autoridades auxiliares. Sin embargo, es de advertirse que la categoría de agencia municipal (o de policía) plantea la posibilidad de obtener recursos económicos, mientras que este aspecto está un tanto reducido para la categoría agraria. ${ }^{89}$

\subsubsection{El campo social semiautónomo de la cabecera municipal de Totontepec Villa de Morelos}

Considero importante presentar algunos datos generales de Totontepec y Móctum, antes de referirme al eje de lo territorial en sus dimensiones agraria y municipal.

El poblado de Totontepec está comprendido entre la latitud norte $17^{\circ} 15^{\prime}$ y la longitud oeste $96^{\circ} 02^{\prime}$, a una altura de $1840 \mathrm{msnm}$. Según el INEGI, cuenta con una población total de 5626 habitantes (2 726 hombres y 2900 mujeres). ${ }^{90}$ El municipio

${ }^{89}$ La doble condición de agencia y comunidad agraria la desarrollaré a profundidad en el CAPíTULO 4.

${ }^{90}$ En el señalamiento o placa de entrada al poblado, se indican tres mil habitantes (en el año 2000) 
(cabecera y diez agencias) cuenta con una población total de 98831 habitantes, de los cuales 48544 son hombres y 50287 , mujeres. ${ }^{91}$

TABLA 5

\section{Agencias de Totontepec Villa de Morelos}

\begin{tabular}{|l|l|}
\hline \multicolumn{1}{|c|}{ Agencias municipales $^{\mathbf{9 2}}$} & \multicolumn{1}{|c|}{ Agencias de policía } \\
\hline 1. San Francisco Jayacaxtepec & 1. San José Chinantequilla \\
2. Santiago Amatepec & 2. San Marcos Móctum \\
3. Santiago Tepitongo & 3. Santa María Asunción Ocotepec \\
& 4. Santa María Huitepec \\
& 5. Santa María Tiltepec \\
& 6. San Miguel Metepec \\
\hline
\end{tabular}

En la cabecera municipal se ubica una oficina de correos y de telégrafo, ${ }^{93}$ una clínica de salud (IMSS) que brinda servicio a las comunidades-agencias;

${ }^{91}$ Son 10 agencias las que integran el municipio siendo las más grandes en extensión territorial y en población San Francisco Jayacaxtepec y Santa María Huitepec y, la más pequeña, San Marcos Móctum. Por otro lado, para llegar a la cifra de 98 mil habitantes, cada agencia tendría que tener en promedio más de 8 mil habitantes. Sin embargo, de las visitas hechas a cada agencia así como de la información obtenida de las autoridades, las agencias no superan los mil habitantes. Por ejemplo, la población de Móctum no es superior a 250 habitantes, así como la de Amatepec y Metepec. Por su parte Huitepec cuenta con cerca de 800 habitantes, mientras Tepitongo tiene 600, lo que resulta un desfase o desequilibrio inexplicable en la distribución de la población, ya que la mayor concentración de población estaría en Jayacaxtepec (que es le menos comunicada de todas las agencias, pues no tiene camino de terracería para entrar, aunque sí vereda, no cuenta con médico de planta, a diferencia de Totontepec) y Tiltepec cuyo camino es muy accidentado y se observa con infraestructura mínima (clínica sin médico), no hay mercado y los puestos de venta se colocan esporádicamente por comerciantes de otros lugares. Tal vez, una razón del porqué los números no concuerdan se debe a que las autoridades en el conteo que yo hice no consideran a los migrantes, aunque insistí mucho en este aspecto. Otra razón puede ser los topes de población que se han impuesto desde la legislación estatal para considerar a un poblado como cabecera municipal o agencia (municipal y de policía) (cfr. Bailón Corres 1999; véase CAPítulo 2 de esta tesis).

92 Según me informaron las autoridades de las agencias, la diferencia radica en que las municipales cuentan con alcalde, síndico, regidores, agente y topiles, y las agencias de policía sólo cuentan con agente, secretario y topiles. Qué agencias son municipales o de policía, depende de la cantidad de población (cfr. Ley Orgánica Municipal del Estado de Oaxaca, ARTículo 10). 
planteles de educación preescolar, primaria, secundaria (pública y privada de los salesianos), telesecundaria y preparatoria (Colegio de Bachilleres de Oaxaca, COBAO), un albergue de lo que antes era el Instituto Nacional Indigenista (INI) y una biblioteca pública integrante del Sistema Nacional de Bibliotecas Públicas. En la biblioteca se resguardan los libros del СОВАО - mientras se construye un local propio- y es surtida de libros por la Comisión Nacional para la Cultura y las Artes (CONACULTA), la biblioteca, y la oficina del comisariado de bienes comunales de este poblado se encuentran en el edificio del Ayuntamiento. También a las afueras del pueblo (llegando de Ayutla), existe un campamento de la Secretaría de Comunicaciones y Transportes (SCT). Existen dos templos, uno católico (dos hectáreas aproximadamente, pues se incluye la escuela salesiana) y uno adventista (50 por 50 metros). Desde el punto de vista agrario $^{94}$ y de acuerdo con la Resolución Presidencial del 17 de diciembre de 1980, cuenta con 6 846-22-40 hectáreas de terrenos (seis mil ochocientos cuarenta y seis hectáreas veintidós áreas y 40 centiáreas) bajo el régimen de tenencia comunal y 427 comuneros. ${ }^{95}$ Todas las

\footnotetext{
${ }^{93}$ Los datos se recabaron entre 1995 - fecha en la que todavía no iniciaba mi investigación pero me encontraba en la zona impartiendo talleres de capacitación jurídica - y 1999, para 2004 la oficina de correos y telégrafos estaba cerrada. Según el alcalde "tal vez como ya hay dos casetas de teléfono, no se utiliza tanto el correo". En 2004 existían dos casetas telefónicas dando servicio. El albergue del Instituto Nacional Indigenista (INI) pasó a Educación Indígena del Gobierno del Estado; también, actualmente se está terminando de construir la Escuela de Educación Musical.

${ }_{94}$ Desde el punto de vista jurídico agrario, el ARTículo 27 de la Constitución Política de los Estados Unidos Mexicanos divide la tenencia o tipos de propiedad de la tierra en tres: social, privada y pública. En la primera se clasifican los núcleos agrarios, ejidos y bienes comunales, éste último es el caso de Totontepec y Móctum.

95 Seguramente este dato ha cambiado pues a partir de las reformas al ARTículo 27 de 1992, se empezó a fomentar entre las comunidades el Programa de Certificación de Parcelas y Titulación de Solares Urbanos (PROCEDE) que para el caso de las comunidades agrarias tomó el nombre de Programa de Certificación de Terrenos Comunales (PROCOM). Este programa implica la corrección o confirmación de medidas entre las que se indican en la Resolución Presidencial y las que existen en el terreno. También tal remedición de los límites territoriales de las comunidades implica el ajuste de las mediciones según la nueva configuración territorial, debido a que muchas comunidades y ejidos cambiaron sus límites o mojoneras por conflictos agrarios entre ellas. Así, por ejemplo, en 1998 Móctum que es colindante de Totontepec regularizó sus tierras con el Programa de Certificación de Derechos Comunales (PROCOM) lo que dio como resultado una diferencia de más, muy pequeña con respecto a lo que se indica en la Resolución Presidencial, pero que según los técnicos esto se atribuye a que los aparatos con los que actualmente se hacen las mediciones son más exactos que los que existieron hace 20 ó 30 años.
} 
comunidades-agencias que se encuentran en este municipio tienen el régimen de bienes comunales de tenencia de la tierra.

\subsubsection{El campo social semiautónomo de San Marcos Móctum, agencia de policía 96}

El camino que viene de Totontepec (véase MAPA 4) llega hasta el centro de la comunidad, en donde se ubican frente a frente el templo católico y el edificio de la agencia de policía, mediando la casa de salud y la cancha de basketball. ${ }^{97}$ Cuenta también con escuela primaria (con dos aulas, parcela escolar y dos maestros) y preescolar, panteón, templo adventista, casa de los maestros. Cuenta con un teléfono satelital por parte de Telecomunicaciones de México (TELECOM). ${ }^{98}$

En enero del año 2000 se contaban 31 familias que efectivamente viven en Móctum. No se distingue que el pueblo se divida por familias (a manera de barrios), cada cual se ha acomodado donde ha podido, sin embargo, la residencia y el sistema de parentesco coincide con los datos proporcionados por Martha Romer (1982:43) en su estudio sobre los mixes de la cabecera.

Cada familia en promedio se integra con ocho a diez miembros, pero existen más pequeñas, lo que da un total de 250 habitantes (entre hombres, mujeres y niños). Se cuentan 59 comuneros, en algunas familias el padre y los hijos o hijas, a partir de los dieciséis años, son comuneros-ciudadanos.

Aunque desde 1968, cuenta con luz eléctrica (monofásica) que proviene de Santa María Ocotepec - lo que para 2004 se modifica, véase CAPÍTULO 6 - para las casas, la escuela, la agencia y los dos templos; no hay alumbrado público para

\footnotetext{
96 San Marcos Móctum está a una altitud menor que Totontepec y cuenta con tierras "bajas" de clima templado y semitropical, el clima es frío en el lugar donde se encuentra el asentamiento humano o poblado (caserío), sobre todo en época de lluvia y en invierno (aunque menos que en Totontepec).

${ }_{97}$ Esta distribución de los edificios es común en las agencias, es decir, el edificio de la agencia se ubica frente a la iglesia mediando la cancha.

${ }_{98} \mathrm{El}$ costo por llamada es de entre $\$ 3.20$ y $\$ 4.20$ el minuto. Este costo para algunos en Móctum es excesivo por lo que prefieren ir a Totontepec a hablar pues ahí el minuto cuesta 3 pesos y si se recibe la llamada es menos caro, aunque cuando se va la luz el servicio telefónico se suspende y los de Totontepec o de otras agencias van a Móctum.
} 
alumbrar las veredas, la cancha o el patio de la escuela. En la noche para trasladarse de un lugar a otro se utilizan linternas ("foco"). ${ }^{99}$

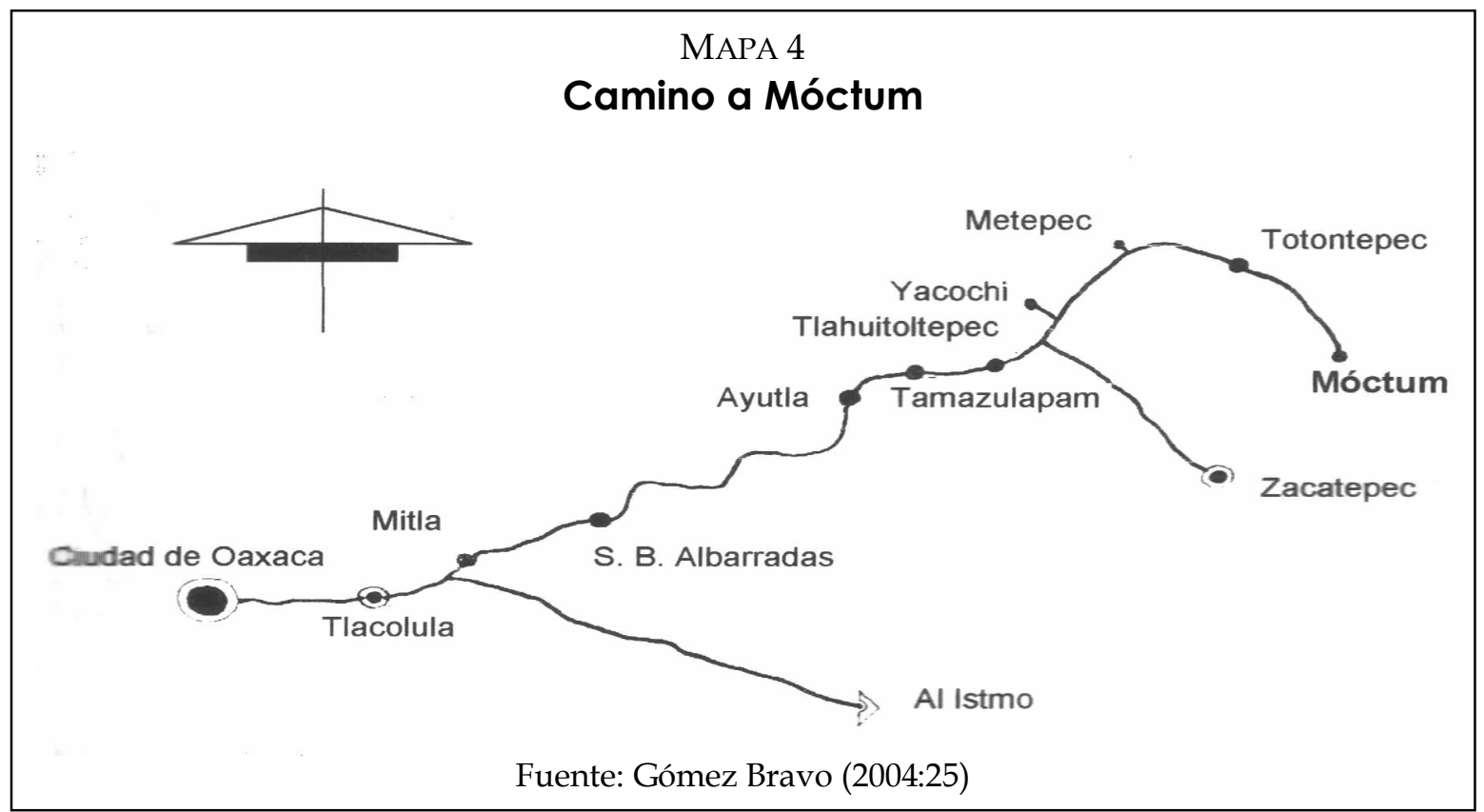

Además del río que hace colindancia con Santa María Ocotepec no existen manantiales y los habitantes de Móctum se proveen del agua que se filtra del cerro por las piedras y que llega a depósitos artesanales (hechos por ellos) o naturales (a diferencia de Totontepec que cuenta con agua potable). De esta manera, al interior de los Bienes Comunales de Móctum no se reconocen pequeñas propiedades o propiedades privadas. Sin embargo, tal situación jurídica no coincide con la situación de hecho, en la que los pobladores reconocen y respetan otros tipos de propiedad sobre la tierra (como también es el caso de Totontepec).

\footnotetext{
99 Para el año 2004 se empezó a gestionar la luz eléctrica trifásica que viene de Totontepec, esto por parte del municipio o ayuntamiento municipal y en coordinación con las autoridades de la agencia de Móctum. Para 2005 se empezaron los trabajos de postes y cableado. En 2006 ya se contaba con luz eléctrica. En 2005 gestionaron el agua potable ante el ayuntamiento de Totontepec -y por negociaciones para que los pobladores de la cabecera tuvieran paso sobre tierras de Móctum para llegar a sus trabajaderos o ranchos, lo que antes no podían hacer debido al conflicto agrario entre los dos poblados - . En 2007, Móctum todavía no cuenta con sistema de agua potable.
} 
Existen dos lugares que les dicen "el chorro", en cada uno colocaron un tubo donde cae la mayor cantidad de agua, uno sirve para que las mujeres se bañen y laven ropa y trastos, el otro es para que los hombres se bañen.

El sistema de canalización del agua es a través de mangueras que se colocan en los lugares del cerro cercano a la comunidad donde se estanca el agua. Estos depósitos se encuentran en la entrada de la comunidad, pero existe un depósito de agua de dos mil litros en el otro extremo de la comunidad que no sirve de mucho "porque no llega a llenarse", pues se localiza en un punto por arriba del lugar donde llega agua y no cuenta con bomba. Las mangueras miden aproximadamente quinientos metros de largo y van desde estos lugares hasta las casas.

Para trasladarse de un lugar a otro dentro y fuera de la comunidad se va a pie o en bestia (sobre todo para trabajar la milpa).

Las casas se comunican por pequeñas veredas, para cruzar de un extremo a otro del poblado se pasa por la escuela, el molino de nixtamal, el templo católico, la cancha y la casa de salud, todas viendo hacia la agencia (y ésta dando la espalda a Anyukojm o cerro de La Mitra donde se encuentra Totontepec). Este espacio carece de árboles y siempre se mantiene limpio.

Móctum cuenta con 520 hectáreas (según su Resolución Presidencial de 1975 y 525 hectáreas según los resultados del Programa de Certificación de Derechos Comunales PROCECOM o PROCEDE para los ejidos), aproximadamente 500 son de temporal y el resto son peñascos. Estas hectáreas de tierras se dividen entre las que ocupan el poblado (caserío, agencia de policía, escuela, iglesia y templo) o asentamiento humano; las tierras de uso común utilizadas para pastar el ganado, recoger leña y donde también se encuentran los trabajaderos o ranchos; la parcela escolar además del espacio que ocupan las dos aulas de la escuela y la Unidad Agrícola Industrial de la Mujer (UAIM).

En términos jurídicos y agrarios (según la Ley Agraria de 1992), las tierras de Móctum como las de Totontepec pertenecen en propiedad al núcleo agrario respectivo (el conjunto de comuneros o comuneras legalmente reconocidos) y los 
comuneros y comuneras, en lo individual, son poseedores, no propietarios. Sobre este y otros datos, que den una idea clara sobre la cabecera y sobre la agencia, abundaré en los siguientes capítulos, sobre todo en el relativo al eje de lo territorial y la PARTE III sobre la justicia.

\subsection{La descaracterización étnica en la configuración municipal como una tensión en el campo jurídico}

El concepto de descaracterización étnica lo utilizo a propósito del ejemplo de la cabecera de Totontepec como un poblado mixe descaracterizado, es decir, que en un inicio fueron mayoritariamente mixes pero con el paso del tiempo y debido a su ubicación geográfica establecieron relaciones de parentesco con personas de otros grupos étnicos como los zapotecos de la sierra y los mestizos. Esto, aunado a un incremento de sus ingresos económicos y por tanto de sus niveles de vida, marcó una distancia entre los pobladores de Totontepec y sus agencias dejando de considerarse a sí mismos como ayuuk aunque hablen o entiendan el idioma, o tengan relaciones de parentesco con familias de algunas agencias. De igual forma, esta descaracterización puede entenderse como la pérdida de características objetivas (como la lengua, el vestido, las costumbres) consideradas como propias del grupo etnolingüístico del que forma parte la población descaracterizada. Finalmente es importante apuntar que la reivindicación cultural indígena que Totontepec ha hecho, es relativamente reciente, comparada con procesos como el de Tlahuitoltepec de donde era oriundo Floriberto Díaz Gómez, fundador de Servicios del Pueblo Mixe, la Asamblea de Autoridades Mixes (ASAM) y la Academia de Derechos Humanos Indígenas de la Asamblea de Autoridades Mixes (ADHIASAM).

Para comprender la situación de subalternidad de comunidades como Totontepec y Móctum y su relación de tensión como cabecera y agencia, retomo la propuesta de Florencia Mallon (2003) en su análisis sobre la relación de tensión entre centros de poder económicos y políticos, generalmente cabeceras municipales 
y las comunidades subordinadas, hecho recurrente en la historia de las regiones indígenas del país, no solamente en Oaxaca, tal como lo documenta en su estudio sobre la Sierra Norte de Puebla. El concepto de subalternidad que Mallon utiliza es importante para poder explicar cómo comunidades indígenas en la época de la Independencia de México lograron de una u otra manera responder a partir de un proyecto comunitario a la presión y exigencias de cabeceras municipales, generalmente gobernadas por mestizos, pese a esto, no eran completamente marginales de los acontecimientos sociales y políticos de la Revolución de Independencia y del proyecto de Nación que se estaba gestando.

Tal planteamiento permite ilustrar la situación de los caciques mixes de la Sierra y de las comunidades que controlaban, y que el concepto de subalternidad explica cómo participaban de una u otra manera en sostener ese poder caciquil y posteriormente desarticularlo. Estos caciques eran líderes y mantenían su hegemonía a través de los caciques menores, por ejemplo, atendían y gestionaban las necesidades de las comunidades, pero también ejercían represión sobre ellas. De esta manera, el concepto de subalternidad permite explicar cómo Móctum y el resto de las nueve agencias no están inermes ante las imposiciones de la cabecera o del Estado, ya que desde sus circunstancias comunitarias o regionales pueden influir en las políticas oficiales.

Por otro lado, Nader (1998) propone el concepto de ideología de la armonía en su estudio sobre la comunidad de Talea de Castro - comunidad zapoteca de la Sierra Juárez de Oaxaca-, para explicar cómo esta cabecera municipal hace frente a la hegemonía jurídico-legal del Estado. La propuesta de Nader tiene dos acepciones: Por un lado, remite a un discurso que busca construir una visión de no conflicto al interior de las comunidades reivindicando la relación armónica entre autoridades y vecinos como una manera de evitar la intromisión del Estado. Por el otro, se puede entender como la forma en que las comunidades indígenas conciben su forma de hacer justicia o sentido de la justicia, buscando el acuerdo. Es decir, con este concepto Nader busca comprender el control social y cultural de las dinámicas 
internas del pueblo, basado en el establecimiento y desarrollo de mecanismos que permitan mantener la lealtad local e inculcar una ideología unificante $y$, a la vez promueve la legitimidad del actuar de las autoridades. ${ }^{100}$

Finalmente, tanto el concepto de la ideología de la armonía de Nader (1998) como el de subalternidad utilizado por Mallon (2003) aplicados al caso de Totontepec y Móctum son útiles para pensar que las comunidades si bien no están aisladas, no solamente se encuentran subordinadas a los poderes estatales o caciquiles de la región, sino que son capaces de generar sus propias respuestas a los modelos impuestos, ${ }^{101}$ y hacer uso de la legalidad misma del Estado para reclamar sus derechos. Tales aspectos resultan centrales para comprender las tensiones en el campo jurídico municipal y el papel de las élites políticas.

\subsubsection{Tensión entre cabecera y agencia: Totontepec como pueblo descaracterizado}

Como lo mencioné en la primera parte de este trabajo, lo agrario y lo municipal constituyen dos espacios de control del Estado mexicano sobre la población rural. Sin embargo, la demarcación territorial es un punto de tensión en la relación entre comunidades agrarias que son a la vez cabeceras municipales o agencias, ambas como categorías político-administrativas determinan la amplitud del control sobre recursos humanos, económicos, políticos y sociales, fundamentalmente porque su constitución y ejercicio de facultades como entidades de derecho público implica un número determinado de población y una superficie o demarcación territorial.

El control que ha significado el municipio como categoría políticoadministrativa y centro de poder así como los antecedentes históricos de

\footnotetext{
100 Esto se desarrollará más adelante para el caso del sistema normativo o derecho en San Marcos Móctum y Totontepec (PARTE III).

101 El uso del discurso dominante a nivel comunitario y regional, para la acumulación o reproducción del poder local ha sido estudiado por María Teresa Sierra (1987) y la relación entre discurso, cultura y poder en un estudio más amplio (Sierra 1992). Si bien no pretendo realizar un estudio que se centre en los usos del discurso dominante, es importante esta última referencia, en tanto da cuenta de la presencia del Estado y de otras influencias (como los derechos humanos) en las prácticas y discursos de las autoridades indígenas al momento de dirimir disputas.
} 
Totontepec y los procesos migratorios que lo han impactado (Romer 1982) han propiciado que sea considerado como un pueblo indígena descaracterizado. La descaracterización es el resultado de la confluencia de factores económicos y étnico-culturales que hacen que un grupo deje de considerarse a sí mismo, o por otros, como parte del grupo étnico originario.

He señalado que en el caso de Oaxaca es recurrente que las comunidades indígenas estén subordinadas a las cabeceras municipales y que muchas de éstas son gobernadas por indígenas o, en otros casos, por indígenas étnicamente descaracterizados (Barabas 1998:352). ${ }^{102}$ De igual forma, he planteado que el comunitarismo arraigado entre los mixes sienta sus bases desde la época colonial, e incluso prehispánica, lo que se consolida con la Reforma Agraria de 1915-1917. En este proceso ha incidido también la orografía y climas variados de la región mixe. El comunitarismo puede ser interpretado como una tendencia localista que más que unificar divide y marca distancias entre las distintas localidades, sin embargo, también puede ser interpretado como las luchas por el control y la reafirmación de autonomías locales. El proceso de descaracterización étnica, por el que ha pasado Totontepec, se explica por la influencia española tan cercana en la instauración de Villa Alta como primer enclave colonial en la Sierra, en una situación geográfica como municipio de frontera entre los mixes y otros grupos etnolingüísticos como los chinantecos y los zapotecos de la Sierra, particularmente con la cabecera del distrito de Villa Alta; ${ }^{103}$ otros factores son el económico, el aumento de población y

102 Barabas señala (1998:352) “De los 570 municipios, 431 (75 por ciento) tienen índices de marginalidad altos y muy altos, y de ellos 400 son municipios rurales, habitados principalmente por indígenas. Con frecuencia las cabeceras municipales son asiento de la población no indígena, o indígena étnicamente descaracterizada, que controla el ayuntamiento, pero también existen numerosas cabeceras municipales con ayuntamientos indígenas".

103 Distrito mayoritariamente zapoteco. Chance (1998:24) apunta sobre esta vecindad entre Totontepec y Villa Alta: "El área comprendida dentro de la alcaldía mayor de Villa Alta en la época de la Colonia corresponde actualmente a los distritos de Villa Alta y Choapan, la parte occidental adyacente del distrito Mixe, y una gran porción oriental del distrito de Ixtlán". "Establecida como puesto de avance en la montaña, a unas veinte leguas de Antequera (como se le llamaba entonces a la ciudad de Oaxaca en el Valle Central) Villa Alta estaba ubicada inicialmente en tierras que pertenecían a Totontepec, un pueblo mixe grande y poderoso justo al este del territorio zapoteco. El 
la migración, factores todos estos que determinan la amestización de sus pobladores y las pretensiones de las élites económicas y políticas de distinguirse como superiores sobre el resto de la población mixe del municipio, que de alguna manera se reproduce por el resto de los pobladores de la cabecera.

De esta manera, el poblado de Totontepec se distingue de los poblados mixes que conforman el municipio porque los niveles de vida son más elevados que los que tienen las agencias, debido a que desde la década de 1950 se ha incorporado a la economía nacional "exportando" mano de obra, de acuerdo con Martha Romer (1982). ${ }^{104}$ Esto ha significado incluso modificaciones en las relaciones sociales y políticas al interior de la comunidad de Totontepec. El aumento en los ingresos económicos ha influido en la participación en el sistema de cargos y en la acumulación de capital y de bienes, estableciéndose distinciones muy claras entre los pobladores de la cabecera (entre los barrios centrales y los periféricos o "nuevos"), lo que influyó a la larga en la distinción de la cabecera frente a las agencias, cuyos pobladores contaban con menos posibilidades de acceder al mercado de mano de obra del exterior del municipio o de la región mixe.

propósito del cuartel era poner fin a las guerras en la región, ya que los zapotecos y los mixes continuaban combatiendo entre ellos y contra los españoles" (Chance 1998: 39).

104 Martha Romer (1982:71) documenta la migración de los habitantes de Totontepec desde 1945, situación alentada por el gobernador en turno al anunciar a los presidentes municipales sobre las contrataciones de braceros para los Estados Unidos. "La búsqueda de fuentes de empleo ha sido siempre en la zona mixe una necesidad de sobrevivencia para la gran mayoría de la población. Mientras duraba su conocimiento limitado de las posibilidades de trabajo que había en el país, el monolingüismo y falta de contactos fuera de sus comunidades, se dirigían a las tierras calientes de Veracruz, funcionando como reserva de mano de obra barata para las fincas cafetaleras. Pero desde que algunos conocieron la ciudad de Oaxaca, partes de los Estados Unidos, y la Ciudad de México, la alternativa más interesante desde el punto de vista económico, es decir, la capital." (Romer 1982:75-76). Los factores que han determinado la migración, sobre todo hacia la ciudad de Oaxaca, a la ciudad de México y a Estados Unidos, son de carácter económico: la tierra pobre, agotada e insuficiente, el crecimiento demográfico que causa la fragmentación de las parcelas y aumenta la presión sobre la tierra, baja productividad por falta de tecnología más moderna y de crédito, frecuente pérdida de cosechas. A éstos antes se agregaba otros de tipo ritual que descapitalizaban a la comunidad, como la mayordomía, y la penetración del mundo exterior por el rompimiento del aislamiento, gracias a los caminos y al transporte terrestre. 
Tal proceso de descaracterización de la población de la cabecera municipal de Totontepec lo confirma María Luisa Acevedo y Teresa Pardo (s/f) que plantean:

En la región mixe, Totontepec está considerado como el pueblo más "amestizado" del distrito mixe. Este calificativo, en gran medida, se le atribuye por ser un área de frontera entre la región mixe y el área zapoteca de Villa Alta; sin embargo, también corresponde a la fisonomía de algunos de sus pobladores y al desenvolvimiento socioeconómico alcanzado.

En efecto si se compara la población de Totontepec y la de las agencias, el desenvolvimiento económico, sobre todo, la fisonomía de la población y el uso del español son notables.

La condición de amestización resulta ser también un elemento fundamental que marca la relación de las agencias frente a la cabecera de Totontepec y es un punto sensible de tensión del campo jurídico en esta zona indígena, que va más allá de la cuestión administrativa del municipio o de la tenencia de la tierra. Así, en algunas agencias pude escuchar algunas expresiones de inconformidad sobre la manera como son tratadas las autoridades y pobladores cuando van a Totontepec:

A principios del año se constituye el Consejo Municipal, ahí yo expuse [agente de policía de Santa María Huitepec] que Totontepec era como el papá que está muy bien vestido y sus agencias están muy trascuaches [sic]. El municipio tiene viáticos para viajar y hacer sus gestiones, nosotros como agencias [dirigiéndose a don Cipriano, ex autoridad de Móctum], no.

[A lo anterior pregunté al agente, “¿por qué la cabecera se comporta así?”]. “Ha de ser porque desde la Conquista los españoles tuvieron su base ahí y la mezcla de sangre, como son cabecera se sienten prepotentes y superiores. Esto hace que ellos han criado [sic] lo que es el egoísmo. Nuestra raza mixe, descansa en el egoísmo. Ellos en eso se han destacado. Cuando llega un recurso concentran y acaparan, como es una tradición que ellos tienen, tienen un patrón. Por eso es difícil que las comunidades se desarrollen. Cuando uno va [a la cabecera] la tensión es fría. También otras expresiones como: "nos tratan menos, como si no valiéramos", o bien, "cuando se necesita cambiar un cheque (que se entrega a 
propósito del PROCAMPO, por ejemplo) los comerciantes de Totontepec lo hacen siempre y cuando se gaste la mitad en su establecimiento, por lo que nos regresamos a nuestra comunidad con la mitad de lo que señalaba el cheque".105 (Entrevista al agente de policía de Sta. María Huitepec, 29 de octubre de 2004)

La reflexión anterior da cuenta de las versiones locales en torno a la tensión de las agencias con la cabecera de Totontepec, y del rencor que guardan los vecinos ante la ventaja que tiene la cabecera. Estamos efectivamente ante un cuadro de relaciones interétnicas similar al que observamos en otras regiones del país, que reproduce una situación colonial de subordinación.

Finalmente no podemos decir que la descaracterización sea común a la mayoría de la población de la cabecera pues también aquí se dan desigualdades económicas y no todos tienen tierras propias para trabajar, sin embargo, sí lo podemos afirmar de las élites políticas y económicas que han marcado la pauta en la relación de la cabecera municipal con las agencias. Esto es una explicación de lo que desde la perspectiva de los habitantes de Móctum fue la dominación y el menosprecio, así como las múltiples vejaciones que sufrieron durante el conflicto agrario frente a algunos habitantes, comerciantes y autoridades de Totontepec, tal como lo revela el expediente agrario. De igual forma, la descaracterización se puede comprender, como lo he apuntado, por la influencia tan cercana de Villa Alta (con población zapoteca y cabecera de distrito que abarca comunidades de la Sierra con población mayoritariamente de este grupo étnico; entre los mixes se comparte la idea de que los zapotecas los ven con menosprecio).

105 A lo arriba expuesto se agregan quejas sobre el servicio de salud de la clínica del IMSs, que es atendida por una enfermera oriunda de Totontepec, entre otras cosas por maltratos y mala atención de este personal en varias agencias ("nos trata peor que a animales", y por supuestas esterilizaciones y control natal forzados - implantaciones de dispositivos intrauterinos - , o bien sin respetar el derecho a la consulta y al consentimiento previo e informado, "en Móctum no, porque no nos dejamos" (Noemí Gómez Bravo). Sobre esto último, según Noemí Gómez Bravo, los pobladores de las agencias prefieren no denunciar por temor a represalias, por ejemplo que se les niegue el servicio de salud cuando llegue haber una emergencia (sobre todo por los niños, niñas y mujeres embarazadas); que se les quite del programa PROGRESA (Programa de Combate a la Pobreza), o bien, como la enfermera es totontepecana, que las autoridades del municipio estén a su favor y los denunciantes resulten más perjudicados con una multa o con la cárcel. 
También esta relación de subordinación y menosprecio, así como la descaracterización con la cual se ha calificado a Totontepec, la muestra Laviada Iñigo (1978:102-103) cuando señala:

Por haber sido fundada por los españoles en el siglo XVI los habitantes de Villa Alta se consideran la única "gente de razón" - de raza y cultura europeas - en las sierras del norte de Oaxaca, a pesar de la incomunicación y de estar rodeados por el mundo indígena. David Alcántara, blanco y rubio, es el hombre más rico del pueblo. Despacha en su gran tienda comercial, compra gran parte de la producción de café de la zona y es dueño del hotel. Además pertenece a una familia de abolengo en su pueblo y en Totontepec mixe.

Cita que coincide con lo arriba apuntado de que Villa Alta como primer enclave español en la sierra, se funda en terrenos de Totontepec (cfr. Chance 1998), Kuroda (1993) confirma que posteriormente la amestización de Totontepec se dio por la llegada de personas de distintos lugares, sobre todo de Villa Alta de donde llegan los Alcántara, personas notablemente mestizas por sus rasgos fisonómicos aunque manejan el idioma mixe - Samuel Alcántara, cacique de Totontepec, fue uno de ellos-. Con la cita se puede comprender cómo la comunidad-cabecera de Totontepec es controlada por élites amestizadas que en realidad nunca fueron o se asumieron como indígenas - lo que es bastante común en regiones indígenas - y que se valieron de su ascendencia y control económico para ejercer un poder autoritario caciquil. Sin embargo, pude observar que el uso del recurso de la reivindicación indígena es usualmente usado públicamente sobre todo en eventos en la ciudad de Oaxaca por los miembros de esas élites, lo que en el municipio y ante los pobladores de las agencias no hacen, tal vez, porque eso los colocaría en un rango de igualdad con el resto de la población mixe del municipio, por lo que - especulando un poco - las transacciones comerciales y mercantiles se verían "afectadas" ya que finalmente al ser todos indígenas, los comerciantes totontepecanos tendrían que ser "más comprensivos" con sus paisanos "de raza" respecto a las deudas y al canje de cheques que llegan de la federación (PROCAMPO), 
por ejemplo dar el total de la cantidad que indican sin condicionar que los campesinos compren en sus establecimientos, o que se vuelva práctica común que los presidentes municipales convoquen a las agencias informando la cantidad de recursos y la forma de asignarlos, así como las políticas públicas y de gobierno. De igual forma, esta reivindicación étnica construye una identidad común cohesiva entre Móctum y Totontepec como de otras comunidades indígenas para contestar al Estado, en sus pretenciones de imponer su derecho. Esta imposición ha ocasionado que en el terreno de la práctica, por ejemplo se violenten derechos de indígenas sujetos a procesos penales (cfr. Informe de la Oficina del Alto Comisionado de Naciones Unidas para los Derechos Humanos en México 2007), como la negación de derechos colectivos, como el derecho a tener un derecho propio, como se expondrá en la PARTE III de esta tesis. 


\section{CONCLUSIÓN}

Los elementos que comparten los mixes y que los hacen reconocerse en una identidad común apuntados en este capítulo, contribuyen a la configuración territorial y cultural del municipio mixe de Totontepec. Con esto he querido destacar cómo comunidades tan pequeñas como Móctum no están subordinadas de forma pasiva a unidades mayores como la cabecera municipal del municipio de Totontepec, sino que pueden participar activamente en las dinámicas del municipio en una condición subalterna pero no marginal. Tal condición de subalternidad se hace especialmente evidente en el análisis de la cuestión agraria y la jurisdicción municipal.

Por la característica de amestización de Totontepec y por su condición de centro de control político, se encuentra en una jerarquía superior, lo que aunado a las pretensiones de supremacía de sus pobladores - según las narraciones de las autoridades de las agencias visitadas-, ha sido el origen de muchas injusticias infringidas al resto de la población del municipio. Esto se puede apreciar sobre todo en asuntos que corresponden al establecimiento de límites territoriales, considerados en la jerga jurídica como parte del "reparto agrario". Pese a esto, no pude constatar que tal amestización se refleje en la lógica de la manera de hacer justicia tanto en la cabecera como en las agencias. Lo que sí pude observar es la identidad que persiste, tan arraigada en la comunidad, pues tanto las autoridades como los pobladores de las comunidades-agencia como Móctum y Huitepec -que también ha tenido disputas con la cabecera - han cuidado de no enviar sus asuntos o que los usuarios indígenas lleguen al ayuntamiento.

De manera retrospectiva, podemos afirmar que prevaleció una situación de colonialismo interno (cfr. González Casanova 1978; Stavenhagen 1982), cuando Móctum todavía no conseguía el reconocimiento legal como comunidad agraria, dándose una situación de subordinación de tal impacto que lo mantuvieron sujeto 
a las dinámicas (políticas, económicas y religiosas) que le dictaba la cabecera. ${ }^{106}$ Tal situación se ve alterada por el cambio de correlación de fuerzas, cuando Móctum obtiene el reconocimiento legal como comunidad agraria independiente (1975) y la mayoría de la población se convierte al adventismo.

Lo agrario es un elemento central de las dinámicas internas, porque ha sido una forma de organización y de relación impuesta por el Estado pero también porque representa el espacio de reproducción cultural y económica de una comunidad, y le señala sus límites territoriales en el ejercicio de la justicia y la jurisdicción, así como del poder político y del control. Esta situación ubica a la comunidad como ente semiautónomo, en el sentido propuesto por Moore (1990:64, 88), a diferencia de su categoría de agencia de policía que remite a un campo político-administrativo más reducido que aquél, al estar subordinada a la cabecera, pero que a la vez esa subalternidad le permite negociar con ella y participar en los rumbos del municipio. Tal es, por ejemplo, lo que sucede con el Consejo de Planeación y Desarrollo Municipal a través del cual representantes de las agencias y las cabeceras anualmente acuerdan sobre las partidas municipales, que por lo menos en 2004 lo empezó a impulsar la presidencia municipal, por exigencia misma de las reformas legales estatales. La participación ciudadana y, en este caso, la participación de las agencias ha sido un punto de convergencia del movimiento municipalista y del movimiento indígena que por lo menos en los últimos 20 años, han logrado que el gobierno local sea visibilizado en la legislación y discursos nacionales. Sin embargo, aunque en las leyes se han establecido esas reglas de participación, el caso de Totontepec muestra que tales cambios legislativos no

\footnotetext{
106 Esta tesis es importante en tanto explica cómo en el caso de Totontepec, desde su posición de cabecera municipal descaracterizada, ejerce un poder que propicia la desigualdad y el paternalismo, negando los pequeños márgenes de relativa autonomía que sus agencias tienen. Pese a que me remito a esta teoría, es importante advertir que una de las críticas que se ha hecho a la tesis del colonialismo interno en México es que hace pensar que las estructuras del colonialismo no han cambiado, y por tanto tampoco la situación de coloniaje sobre los indios, por tanto no se toman en cuenta los procesos de cambio o aculturación implicados en el contacto cultural, que conocemos como difusión, asimilación e intercambio cultural (Isabel y Ricardo Pozas 1985:30- 31; Stavenhagen 1992:66).
} 
representan en la práctica trasformaciones inmediatas, y esto se debe en parte a los propios procesos histórico-culturales de cada región y, en su caso, de cada pueblo indígena.

Por otro lado, tal vez ahora que se ha dado por terminado el conflicto agrario entre Totontepec y Móctum, los habitantes de este poblado han recurrido con más frecuencia a la justicia de la cabecera - pero no tanto como los pobladores de otras agencias -, tal vez porque la ven como un recurso más en la resolución de disputas, o porque observan que las autoridades de Totontepec se han acercado a las de Móctum para negociar la entrada de luz y de agua potable, a cambio de la introducción de un camino en terrenos de Móctum para facilitar el tránsito de personas de Totontepec a las zonas de cultivo más alejadas (CAPítUlo 6). Tal hecho tiene una gran significación porque implica un giro en las lealtades comunitarias ante Totontepec que al parecer ya no es visto como el adversario al que debe oponerse o ante el cual es necesario distinguirse.

Finalmente a pesar de la amestización que ha marcado la relación de la cabecera con sus agencias, se puede apreciar la intención de algunos gobernantes que han llegado recientemente al gobierno municipal. En este sentido es importante mencionar que en 2004, Totontepec ha dado impulso a varios proyectos regionales junto con Servicios del Pueblo Mixe, convocando a sus agencias y siendo sede de eventos relacionados con la revaloración cultural y la variación dialectal, entre otros. Esto quizá puede impactar el proceso de descaracterización y las pretensiones de superioridad de la comunidad-cabecera sobre las comunidades-agencias, y que por lo menos en el discurso se empiecen a sentar las bases que generen un cambio en esa relación. Se trata, sin embargo, de un proceso a largo plazo, que no significa que las élites cambien su ideología de supremacía (de racismo y discriminación) ante el resto de los pobladores mixes del municipio, ni que Totontepec deje de ser centro rector dentro de su demarcación municipal y de una microregión, pues además es sede de parroquia y de la iglesia adventista para los mixes, chinantecos y zapotecos de la Sierra. 
La historia de la relación de Totontepec con sus agencias / comunidades, como es el caso de Móctum, revela una compleja red de tensiones que han marcado el campo jurídico en la región y especialmente el sistema normativo de los mixes de esta parte de la zona. Esta complejidad es comprensible cuando nos remitimos al proceso histórico de la configuración territorial y municipal que abordaré en el capítulo siguiente, en el análisis del conflicto territorial y municipal, entre cabecera y agencia. La actitud de algunos pobladores de la cabecera que asume formas de racismo no necesariamente es la exaltación de una raza sobre otra como podría ser el caso entre personas o grupos con características físicas distintas pues según el lugar y el momento histórico el racismo cambia, lo que en palabras de Alicia Castellanos (2000:12) quedaría explicado así: Es cierto que en nuestras sociedades el racismo de hoy no puede disociarse de su imaginario colonial. La representación del indio y del negro, como toda representación social, tiene un anclaje en la memoria de relaciones sociales preexistentes y funciona como referente en los procesos de clasificación y categorización. [...] Es decir, representaciones y prácticas cambian en el tiempo y en el espacio pero a partir de un sustrato anterior que revela la persistencia de ciertos estereotipos. Lo anterior es más claro en el caso de Totontepec frente a las agencias si tomamos en cuenta su pasado colonial en el que se obligaba a los pobladores de las agencias a hacer cargos en la cabecera (cfr. Expediente colonial que se expone en el siguiente capítulo); y por su amestización étnica y su auge económico dados por la relación de parentesco con personas que llegaron de otras regiones y por los procesos migratorios que impactan a este poblado mucho antes que a los demás del municipio. 


\section{CAPÍTULO 4}

\section{LA CUESTIÓN AGRARIA COMO ESTRUCTURADORA DEL DERECHO Y LA AUTONOMÍA COMUNITARIA}

\section{Introducción}

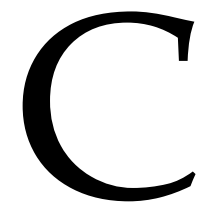

omo se ha señalado, el eje de lo territorial, en sus dimensiones agraria y municipal, es central en la determinación de las dinámicas del campo jurídico en la zona indígena que comprende el municipio de Totontepec Villa de Morelos (en adelante Totontepec), así como en la relación de tensión entre la comunidad-cabecera con la mayor parte de sus agencias. El punto de tensión se ubica en la dimensión agraria como limitación del ejercicio del poder y de control y en la dimensión municipal, por la distribución de recursos públicos fundamentalmente económicos. Esto se comprende por las siguientes razones: 1) porque los terrenos comunales de la cabecera-comunidad colindan con los terrenos de cuatro agencias municipales que a la vez son comunidades agrarias, y 2) porque los recursos estatales y federales se concentran en la cabecera municipal. En este capítulo me concreto a abordar la cuestión agraria y la municipal, como punto de tensión en la relación de Totontepec con San Marcos Móctum (en adelante Móctum).

En el CAPÍTULO 2 me referí a las disputas por el territorio, fundamentalmente por la historia de conformación de los asentamientos humanos en la Sierra, lo que dio supremacía a un pueblo "nuevo" - que antes era una ranchería - sobre otro que era el pueblo original, de acuerdo con Viola König (1993). Estos antecedentes históricos y el aumento de población, entre otros, determinaron la creación de comunidades-municipios y, por tanto, la distinción entre comunidades-cabeceras y 
comunidades-agencias (Bailón Corres 1999). ${ }^{107}$ La supremacía territorial y política, conformada a través del tiempo, conlleva mayor control de recursos humanos y económicos, marcando la disputa actual por la distribución de partidas presupuestales estatales y federales entre cabeceras y agencias.

Para este trabajo se define lo territorial desde dos aspectos: lo económico, como factor fundamental de supervivencia que se identifica con la definición agraria de la tierra; y el político-administrativo como ámbito de poder y control que se identifica con las figuras de estado, municipio y agencia. Cuando me refiero a lo territorial lo hago desde la concurrencia de estas dimensiones, donde cada una tiene cierta importancia pero se comprende en función de las demás.

A lo anterior se agrega que la tierra como espacio de subsistencia y lo territorial como ámbito político-cultural son aspectos de suma importancia para los indígenas y sus pueblos. En el caso de los mixes queda constatado, porque la tierra es considerada el patrimonio fundamental de la comunidad que determina en gran medida su vida, además de que la agricultura, según Nahmad (2003:71), sigue siendo la principal actividad de la que obtienen los recursos básicos de subsistencia. Por ello, la tierra es entre los mixe, como entre la mayoría de las comunidades indígenas, el principal motivo de confrontaciones comunitarias que muchas de las veces han sido violentas (Nahmad 2003). ${ }^{108}$

\footnotetext{
107 A Bailón Corres como a Viola König los cito en el CApítulo 2 como parte de esta argumentación. La constitución de poblados cabecera es complejo, porque concurren factores, económicos, sociales, históricos, culturales, poblacionales. De esta manera, pese a los límites jurídicos que se establecieron en Oaxaca para la creación de nuevos municipios - algunos no los cumplen-, o bien se observan agencias municipales económicamente más desarrolladas o con mayor extensión territorial en relación a la cabecera municipal, como son los casos de municipios indígenas como Santa María Huatulco y San Pedro Mixtepec. Del primero sus agencias - descaracterizadas - como La Crucecita, donde se ubica el complejo turístico, es más próspera económicamente y con mucho más población. De San Pedro Mixtepec sus agencias - también descaracterizadas - Bajos de Chila y Puerto Escondido, son mucho más desarrolladas que su cabecera.

108 En este sentido Nahmad (2003:71) señala: "Las 234 localidades que integran el grupo mixe tienen dividido el territorio en 234 grandes fracciones que dan forma física a la comunidad. El territorio determina así la configuración geográfica de cada localidad y esto, a su vez, determina ciertos aspectos del etnocentrismo de cada lugar, por pequeño que sea. La cohesión de la comunidad está basada en la propiedad de la tierra. Es por esto que la tierra pertenece a la comunidad o, por decirlo de otra manera, a los miembros nativos de la localidad, quienes tienen esa tierra para trabajarla y
} 
La cuestión agraria marca una arena de conflicto porque remite a la separación territorial primaria entre comunidades; es decir, se puede observar que el ámbito territorial entre agencias y de éstas con la cabecera está dado por la demarcación que corresponde al núcleo agrario o comunidad - una agencia no puede ir más allá de este límite espacial-. Como ya se explicó, en capítulos anteriores, la cabecera como las agencias son a la vez comunidades agrarias, es decir, constituidas con determinado número de tierras por una Resolución Presidencial. Esta demarcación territorial establece las dinámicas de su relación y las tensiones entre ellas, fija límites a su relativa independencia y a su ejercicio de poder y de control sobre los recursos humanos, naturales, biológicos y económicos. De igual forma, marca límites a la aplicación del derecho, el ejercicio del gobierno y la justicia facultades que en términos jurídicos constitucionales dan forma al espacio político administrativo del municipio (ARTículo 115 Constitucional). Este doble carácter del territorio, como espacio de subsistencia (lo agrario) y de ejercicio de poder político-administrativo (lo municipal), lo hace ser un elemento vital para la comunidad-agencia, pero también para la comunidad-cabecera y para el municipio en su conjunto, como base fundamental en la definición y control de sus dinámicas internas y por tanto de las reglas comunitarias que se establecen para ese fin, es decir, del derecho propio.

Por tanto, la cuestión agraria y la organización municipal son un punto central de la tensión entre cabecera y agencias. Esta situación incide asimismo en las relaciones políticas y jurídicas que establecen entre sí la comunidad-cabecera y las comunidades-agencias. Pese a que en la primera se encuentra el poder político municipal - reconocido jurídicamente por el Estado-, no puede intervenir en la vida interna de las agencias-comunidades, ya que se enfrenta al discurso de la comunalidad ${ }^{109}$ sustentado en la figura agraria de bienes comunales con su propia

obtener sus frutos. Solamente podrá ser explotada por miembros de esa localidad y nunca podrá ser vendida a un miembro ajeno a ella".

109 Véase CAPítulo 1 apartado 1.3.3. De igual forma y como se expuso en el Capítulo 2, en el caso de los mixes, lo territorial marca identidades locales o comunitarias, que en el caso de estudio se 
territorialidad reconocida jurídicamente por el Estado (segundo párrafo de la fracción VII del ARTículo 27 Constitucional). Sin embargo, lo municipal y lo agrario también representan dos vías de control político del Estado. Como se explicó en el CAPítulo 2, el reparto agrario, realizado por la Secretaría de la Reforma Agraria mediado por el caciquismo, fue un instrumento de control sobre la población rural y por tanto indígena, apoyado muchas veces desde el municipio, tal fue el caso de Luis Rodríguez y otros caciques menores. Dada la estrecha relación entre el poder municipal y el conflicto agrario, en este trabajo se presentan como un eje de análisis de la tensión entre Totontepec y Móctum. ${ }^{110}$

Como punto de tensión entre los ámbitos municipal y agrario, lo territorial es un aspecto que influye en la relación de las localidades - agencias y cabeceras y sus instancias de justicia como niveles del campo jurídico en esta zona. Desde esta perspectiva el municipio puede ser visto en dos ángulos o dimensiones legales. Por un lado como categoría de nivel de gobierno (dentro del esquema federal planteado en la Constitución Federal ARTículos 40 y 115). Por otro, al ser gobernada por indígenas y estar ubicada en una región indígena, la cabecera municipal - como representación del municipio - es a la vez una instancia de impartición de justicia "propia", muchas veces considerada como el último nivel de jurisdicción reconocido por el Estado, vinculado al distrito Mixe (donde el Ministerio Público y el Juez no son indígenas). Dichas instancias son también usadas por los vecinos de las comunidades indígenas sobre todo para asuntos de

profundizan por el proceso de conversión religiosa. Cabe aclarar que en esta tesis no se desarrolla un estudio a profundidad sobre la religión y la conversión religiosa, sin embargo, es un dato importante que revela un punto de tensión entre la cabecera y la agencia, y que en su momento fue utilizado por ésta como recurso de distinción para reforzar el proceso de reivindicación o recuperación de la tierra.

${ }^{110}$ En mi visita a aquellas agencias que colindan con los terrenos comunales de Totontepec, pude constatar que, al igual que en Móctum, existe un malestar porque - según algunas autoridades e informantes - ese pueblo ha obtenido más tierra de la que realmente le pertenece ya sea porque se vale de canales oficiales estatales, tomando por sorpresa a las autoridades de las comunidades, o bien, porque gente de ahí han llegado a ser funcionarios del gobierno, según sus palabras: "los funcionarios de la Secretaría [de la Reforma Agraria] o de asuntos agrarios son los mismos con los que tenemos conflicto". Por su parte Noemí Gómez (2004:16, 46 y 49) menciona que el problema del conflicto agrario entre Móctum y Totontepec, en realidad no era con todo el pueblo, sino con algunas personas de ese lugar, con poder económico y político. 
mayor gravedad o cuando la instancia de la cabecera municipal no es favorable o es evidentemente adversa a los intereses de un usuario. Por ejemplo, Móctum prefirió acudir al Ministerio Público y al Juez radicados en Zacatepec (cabecera del distrito Mixe), dado que el conflicto de tierras - a principios de la década de 1980 - había llegado a tal punto, que las autoridades municipales en turno de la cabecera de Totontepec apoyaban a sus paisanos invasores de tierras de Móctum. También se puede constatar el uso de instancias legales indígenas y/o estatales en casos donde una de las partes involucradas está emparentada con las autoridades comunitarias de la agencia y/o la cabecera es entonces cuando se ve al distrito ${ }^{111}$ como la única instancia posible de justicia.

Para comprender la relación entre la dimensión agraria y la municipal, expongo a continuación el marco general de lo municipal en el estado de Oaxaca y su relación con lo agrario. Posteriormente analizo las etapas del conflicto y su expresión actual a través de los expedientes, tanto civil - de la época colonialcomo del agrario entorno al reconocimiento de bienes comunales de Móctum en la época actual. En estos expedientes se exponen los vaivenes del conflicto con Totontepec a través de diversos escritos y documentos presentados por los representantes de ambos poblados. Por último, analizo un caso concreto sobre la confrontación de la cabecera municipal de Totontepec y las agencias por la distribución de recursos federales, como parte de la dimensión municipal de lo territorial.

Finalmente, y como lo señalé anteriormente, la relación entre Móctum y Totontepec es representativa de una problemática recurrente en el estado de

${ }^{111}$ Lo que es muy recurrente en zonas indígenas como lo muestra Sierra $(1995,2004)$ y Vallejo (2004) en sus trabajos sobre la justicia en la Sierra Norte de Puebla, y las condiciones por las cuales pasan los usuarios indígenas - entre ellos las mujeres indígenas - para acceder a ella. Recurrir a instancias extraterritoriales con legitimidad para impartir justicia, también es una práctica de los no indígenas cuando se acude a la Comisión Interamericana o a la Corte Interamericana de Derechos Humanos para dirimir cuestiones electorales internas o violación directa a los derechos humanos como desapariciones forzosas o torturas. Los niveles legales en un campo jurídico y la relación entre mapas legales es lo que muestra Santos $(1991,1995)$ en sus diversos trabajos. Véase también el libro colectivo editado por Sierra (2004) donde se da cuenta de los usos del derecho en distintos niveles legales en diferentes regiones indígenas de México. 
Oaxaca, por lo que a través de su estudio se puede comprender una dinámica general característica de la relación del Estado con los pueblos indígenas y la complejidad de la misma.

\subsection{Lo municipal como punto de tensión en el campo jurídico}

La disputa entre cabeceras municipales y sus agencias por la distribución de los recursos que provienen de la federación y del estado está íntimamente relacionada con la reconfiguración territorial que marca la relación histórica entre poblados. En el caso de estudio fueron varios los factores que propiciaron esa reconfiguración, entre otros: las vías de comunicación como los caminos que impactaron en el desarrollo de unos poblados sobre otros, la migración por mejores tierras, las epidemias y el aumento o disminución de la población; todo esto influyó en la expansión de pequeños poblados antes rancherías, que a la larga se constituyeron como centro del poder municipal.

De igual forma la disputa por los recursos asignados al municipio no se comprende si no se toma en cuenta el papel de éste en la estructura del Estado y del sistema político mexicano (Bailón Corres 1999). De esta manera, por setenta años el gobierno nacional "tradicionalmente" controló a la población municipal a través del ayuntamiento y fundamentalmente de grupos no corporativizados en el partido oficial (Partido Revolucionario Institucional PRI), reforzándose este control en las zonas rurales con los comités de ese partido y el comisariado de bienes comunales y ejidales ${ }^{112}$ - garantizando su control a través de la Confederación Nacional Campesina.

112 “[P]odríamos decir que el gobierno nacional controla a la población municipal usando el ayuntamiento. Este control es ejercido principalmente sobre aquellos sectores de la población que no pertenecen a alguna organización corporativa del PRI. Bajo esta línea caen todas aquellas nuevas organizaciones que han venido surgiendo con el proceso de cambio socioeconómico (pequeños comerciantes, artesanos, profesionistas liberales, etcétera). En los municipios rurales este control es reforzado con dos instrumentos: el partido oficial (el PRI), y las autoridades campesinas (comisariado ejidal y comunal) [...] En los municipios rurales y semiurbanos las autoridades campesinas son el instrumento para controlar aquellos campesinos que han recibido su parcela ejidal o comunal" (Díaz Montes 1992:35). 
Sin embargo, el control político del municipio se ha visto transformado por los cambios que ha sufrido la sociedad, especialmente agudizados con las políticas neoliberales de las últimas décadas, dando lugar a la emergencia de grupos sociales y políticos que cuestionan la estructura y funcionamiento del municipio, dado que está inserto en el modelo de Estado centralista y autoritario. De esta manera, aunque la lucha por la supremacía municipal viene desde la época posrevolucionaria (Bailón Corres 1999), la lucha política por alcanzar el control del ayuntamiento municipal tiene su antecedente desde mediados de la década de 1970 cuando la mayoría de los grupos de izquierda empezaron a abandonar su posición antielectoral (Díaz Montes 1992:7) y los grupos controlados por el partido oficial, a través de sus distintas corporaciones obreras y campesinas, empiezan a cuestionar el sistema oficial de participación política (el corporativismo fundamentalmente). Fausto Díaz Montes (1992:8) lo expresa así:

Por varias décadas el control político del área rural permaneció incuestionado. Algunos de los factores que contribuyeron a esta estabilidad fueron: a) que el Estado tenía tierras para distribuir a los campesinos pobres; b) que en la mayoría de las comunidades rurales las organizaciones campesinas, controladas por el PRI, eran relativamente fuertes, tomando en cuenta su tamaño y sus recursos políticos; y c) que las comunidades en las cuales el PRI no tenía una organización campesina para ejercer su control, se mantuvieron políticamente marginadas y fueron controladas a través de los gobiernos locales ayudados por intermediarios políticos [por ejemplo, los cacicazgos como se dio en el caso mixe]. Sin embargo, en las últimas dos décadas el sector rural ha llegado a ser una fuente de inestabilidad, porque aquellas comunidades que antes estaban aisladas han comenzado a participar en el sistema político. Asimismo, aquellas comunidades previamente controladas han empezado a cuestionar los patrones tradicionales de dominación.

La anterior cita muestra de alguna manera el papel que tuvo el municipio bajo el control de caciques locales, lo que fue el caso de la región mixe y específicamente de Totontepec, pues como se verá más adelante, la mayoría de las agencias de este municipio se quejaban de las formas y mecanismos que la población de la cabecera 
utilizó para hacerse de más tierras a costa de las comunidades colindantes, y de la intervención de la familia Alcántara, relacionada con caciques como Samuel Alcántara, para el control municipal.

En este contexto se reconoce jurídicamente el sistema de usos y costumbres (1992-1998)113 como una arena de elección de autoridades municipales, que enmarca la disputa actual entre cabeceras municipales y sus agencias (Martínez Martínez 2006).

En el caso concreto de la relación de Totontepec con sus diez agencias, fundamentalmente con Móctum, la comunidad-cabecera está perdiendo su característica de instrumento de control del Estado (por lo menos como venía siendo durante los últimos setenta años que gobernó el Partido Revolucionario Institucional), sobre todo por la difusión y mayor acceso a la información sobre derechos humanos y los derechos que las agencias tienen para acceder a los recursos municipales y al ejercicio del gobierno local (como se verá en el CAPítULO 6). La centralidad del municipio - y sobre todo de la cabecera municipal - como instrumento de control del Estado se ve cuestionada en la década de 1980-1990 por el surgimiento de nuevos actores políticos, sobre todo organizaciones civiles o sociales proétnicas y proderechos humanos que objetan las formas tradicionales de relación entre los gobernados con las instituciones oficiales como el ayuntamiento, el gobierno estatal y el gobierno federal. Esto justamente es uno de los campos de acción de la Escuela Municipalista de Oaxaca ${ }^{114}$ que introduce un nuevo discurso; el discurso de los derechos humanos. Esa relación entre gobernados y las

\footnotetext{
${ }^{113}$ A propósito de las comunidades indígenas véase el ARTículo 25 de la Constitución del Estado de Oaxaca (1990) y el Código de Instituciones Políticas y Procedimientos Electorales (1992) adicionados en 1995. En 1998 se reforman y adicionan distintos artículos de la Constitución del Estado en materia indígena, cfr. López Bárcenas 2007.

114 Esta escuela se enfoca al estudio del municipio y, por tanto, del fenómeno de conflicto cabeceras municipales y agencias desde dos perspectivas: la legal y la de la reforma del Estado, haciendo uso de los conceptos de poder local, autonomía municipal, autonomía indígena y autonomía comunitaria. La perspectiva legal de esta escuela parte del análisis y reflexión sobre las ventajas y desventajas de la ley estatal, en cuanto a la asignación de recursos, la legislación sobre elección de autoridades por sistema de partidos o por sistema de usos y costumbres y el debate sobre el nuevo federalismo.
} 
instituciones de Gobierno del Estado se expresa, de acuerdo con un documento producto de la Escuela Municipalista de Oaxaca, de la siguiente manera (García Arreola et al. 2004:24):

Las acciones de las autoridades municipales se ven limitadas por los pocos recursos que envía la federación, mismos que han generado, entre los ayuntamientos indígenas y no indígenas, una cultura de improductividad, repetición de esquemas y vicios federales y estatales, tales como el centralismo y el presidencialismo. En la mayoría de los ayuntamientos no se distribuyen equitativamente y con justicia social los recursos económicos, concentrándose tanto en la cabecera municipal como en los ayuntamientos.

Además el asistencialismo motivado por la federación hacia los estados y municipios ha traído como consecuencia efectos inversos a los pretendidos. En el caso de Oaxaca los ayuntamientos viven a expensas de los recursos federales y no generan alternativas de producción e inversión comunitarias propias

Es decir, pese a las reformas de 1983 al ARTículo 115 Constitucional que dan capacidad a los municipios de obtener ingresos y ejercer nuevas capacidades de servicio público, continúa la intervención del Estado a través de los gobiernos estatales y las legislaturas locales y federales, lo que genera cierta dependencia en el ejercicio del presupuesto y en el gobierno municipal en la planeación del desarrollo. Esto se expresa claramente en el procedimiento de planeación, aprobación y asignación del presupuesto. A nivel estatal el presupuesto se analiza y aprueba por el Consejo de Planeación y Desarrollo Estatal (COPLADE) presidido por el Ejecutivo estatal, donde se discute y aprueba el presupuesto de cada uno de los municipios del estado, este presupuesto pasa al Congreso del Estado para ser aprobado y publicado en el Diario Oficial donde aparecen "etiquetados" los presupuestos para los municipios. El presupuesto aprobado y asignado se redistribuye por el Ejecutivo estatal a través de la Secretaría de Finanzas, es aquí donde la pugna cabecera y agencias tiene su origen, porque desde el gobierno estatal los presupuestos asignados a pesar de estar "etiquetados" desde la 
federación, no son respetados (pues se "recortan" o coartan), lo que a su vez provoca que a nivel de los municipios muchas veces los ayuntamientos tampoco respeten las partidas que corresponden a las agencias, lo que en el caso de Totontepec se puede apreciar y se abordará en el CAPítULO 6.

\section{Comunalismo y poder local en el marco del municipio}

En el contexto del estado de Oaxaca con una gran diversidad cultural así como de realidades económicas, políticas, jurídicas y sociales, que fomentan los arraigos locales, la comunidad se sitúa como el referente principal para la difusión de proyectos de diversa índole, que van desde los productivos para la subsistencia hasta los de capacitación en derechos humanos. En este panorama se encuadra la propuesta del comunitarismo o la comunalidad planteado por intelectuales indígenas de varias regiones del estado de Oaxaca (véase CAPítulo 2). En esta perspectiva, se concibe a las comunidades como un pilar del municipio indígena y, unidad común existente en los municipios oaxaqueños (García Arreola et al. 2004:37):

Es en la comunidad donde se sustentan sus formas de sobrevivencia y de búsqueda de sus caminos propios (autonomía), de permanencia de sus instituciones, entre otros. Esto es tan fuerte en varios municipios que existe la tendencia e inquietud de lograr que la comunidad indígena sea un ámbito más de gobierno [cuarto nivel de gobierno] además, es ahí [en la comunidad] donde la población oaxaqueña día a día ve, palpa, oye, dialoga, conoce y vive el ámbito más inmediato y cercano de gobierno.

Esta necesidad de reconocer la importancia política de la comunidad frente al municipio radica fundamentalmente en que la referencia a éste da una idea de totalidad, homogeneidad e indivisibilidad, lo que encubre la existencia de la comunidad y le quita su especificidad y peso político. Al hablar del municipio por lo regular se suele tener en mente exclusivamente a la comunidad-cabecera, sin considerar al resto de comunidades o poblados que conviven en el territorio municipal. Por ello, la reivindicación de la comunidad, como un ámbito de 
gobierno, pretende justamente darle visibilidad, mostrar la diversidad y dinamismo cultural que representa y darle el peso político que le corresponde.

Tal planteamiento se encuentra también en la base de apuestas políticas en torno a la autonomía que tuvieron gran difusión en los últimos tiempos. En el caso de los mixes después de la creación del distrito Mixe y de la confrontación entre Daniel Martínez y Luis Rodríguez - caciques de la región-, los intentos por unificar a las comunidades mixes, no sólo territorialmente sino política y económicamente, se continuaron posteriormente con otro tipo de líderes. A diferencia de los caciques, los nuevos líderes provienen de las comunidades y son miembros activos de organizaciones indígenas, y muchos de ellos también se han formado profesionalmente. Tal es el caso de Floriberto Díaz, antropólogo oriundo de Tlahuiltoltepec, impulsor de la Asamblea de Autoridades Mixes (ASAM) y de la Academia de Derechos Indígenas de esa Asamblea, y Adelfo Regino (2002) abogado oriundo de Alotepec de la organización Servicios del Pueblo Mixe (SER), también fundada por Floriberto Díaz. Esto se constata con la siguiente cita de una entrevista que realizó Hernández Díaz (2001:179).

[...] la ASAM nunca tuvo representantes ni dirigente como comúnmente se conoce, sino que siguiendo la tradición indígena se pretendió que hubiera una dirección colegiada y esa dirección la iban a tener las autoridades mixes. La intención básica que se tuvo para construir la ASAM fue la búsqueda de la unidad del pueblo mixe como punto fundamental para resolver los demás problemas que se tienen o que tenían en ese entonces dentro de las comunidades, y desde entonces otro de los objetivos era hacer una planeación integral de la vida mixe, es decir, cultura, educación, derechos, servicios públicos, etcétera [...] así fue como se estuvo trabajando durante los años 1985 y 1986 y, en 1988, se constituyó judicialmente la asociación civil, que hoy le llamamos Servicios del Pueblo Mixe (Miembro de Ser, A. C. Yalálag, Oaxaca). [Las negras son mías]

Los argumentos de esos intelectuales indígenas sobre la autonomía hacen énfasis en la necesidad de partir y considerar a la comunidad como unidad básica de autonomías más amplias como la municipal o la regional, y más aún como una 
forma de autonomía distinta a aquéllas con lo que acuñan el concepto de comunalidad.

Por lo anterior, es comprensible que, en los pueblos de donde provienen estos líderes, el proceso de participación comunitaria y municipal involucre a la comunidad-cabecera y a las comunidades-agencias. De esta manera la reivindicación proétnica y los procesos políticos, impulsados por organizaciones como Servicios del Pueblo Mixe y la Asamblea de Autoridades Mixes, han influido en los procesos locales de municipios como Alotepec y Tlahuitoltepec. ${ }^{115}$ En estos municipios se han podido establecer mecanismos de participación política con sus agencias que garantizan la distribución de recursos económicos y que los cargos de representación política y, por tanto, el control y el poder municipal se puedan distribuir entre las comunidades que conforman el municipio.

De esta manera, la autonomía comunitaria y municipal es una expresión de las dinámicas que se dan en las regiones y municipios indígenas en Oaxaca, que revelan una gran fragmentación de las unidades políticas. Esta fragmentación debe comprenderse en su justa dimensión dependiendo del desarrollo histórico de cada región o localidad. Según se ha documentado (Chance 1998; König 1993), la fragmentación pudo ser un rasgo que proviene desde la Conquista y la Colonia española.

Finalmente, en esta reivindicación de la comunidad se dignifica ${ }^{116}$ el papel de las autoridades locales comunitarias (agentes municipales y de policía), como verdaderas autoridades y no como autoridades auxiliares ${ }^{117}$ como se establece en la

115 Esto se confirma en entrevista con María Teresa Valdivia quien realizó una investigación en 17 de los 19 municipios mixes del estado de Oaxaca.

116 Con este término me refiero a reconocer la importancia de las autoridades de las agencias, aceptando que al ejercer el poder local de ejercicio de justicia y gobierno, también son capaces de administrar recursos y que deben de hacerlo para optimizar el desarrollo del municipio en su conjunto.

117 Luis de la Cruz López (1998:14-15) señala que: “Conforme a la Ley Orgánica Municipal de casi cualquier entidad federativa, las autoridades auxiliares dependen directamente del ayuntamiento o del presidente municipal, no obstante, tienen relación prácticamente con toda la administración municipal. También frecuentemente sostienen relaciones con diversas dependencias y organismos estatales y federales, sin que haya un marco de referencia legal o reglamentario que establezca con 
legislación municipal oaxaqueña, que las subordina a las autoridades de la cabecera municipal, lo que en términos prácticos también les representa una disminución en sus márgenes de ejercicio, aunque en la práctica van más allá de ser auxiliares ejerciendo en muchos casos verdaderas facultades de gobierno o de ejercicio de la justicia como es el caso de las agencias de Totontepec. El señalamiento de autoridades auxiliares, por un lado, cuestiona el ejercicio del poder (aplicación del derecho y control de las dinámicas internas) que hace la autoridad en las agencias-comunidades. Por otro, bajo la figura de auxiliares, los recursos destinados por el gobierno estatal o la federación, de por sí reducidos, se concentran en la cabecera y no llegan directamente a la comunidades-agencias. El planteamiento final de la Escuela Municipalista de Oaxaca es que la legislación municipal es insuficiente, reducida y ambigua, por tanto, es necesario "librar una lucha legislativa" para lograr que la comunidad sea vista como un ámbito de gobierno dentro del marco municipal (García Arreola et al. 2004:27). Lucha legislativa que en el caso de Totontepec pasó al terreno de la disputa y la confrontación directa, por la cual las autoridades de las agencias hicieron uso de las instancias del Estado para exigir a la cabecera mejor distribución de los recursos municipales.

Lo anterior es una expresión de cómo actualmente la disputa cabecera municipal-agencias en el estado de Oaxaca se ve influida y reavivada por lo que sucede en el contexto nacional, que por un lado, se expresa en el debate sobre federalismo, ${ }^{118}$ y las disposiciones establecidas a nivel estatal y federal

claridad las formas y modos en que debe darse esa relación, ni los alcances y límites que puede tener la actuación de esta autoridad [...] Las personas que desempeñan este cargo son auxiliares del ayuntamiento $y$, en general, de los funcionarios municipales que laboran en las oficinas del palacio municipal, para los trámites y procedimientos gubernamentales que requieran en su ámbito territorial. Algunos de ellos tienen funciones específicas, pero en las comunidades más alejadas, generalmente tienen que prestar múltiples servicios como auxiliares de: La jefatura o dirección de policía, cuando se refiere a un policía auxiliar o agente municipal encargado de velar por el orden en las comunidades rurales alejadas".

118 Entre otras cosas se debate sobre la construcción de una nueva relación entre la federación con los estados y los municipios, la definición de esta relación depende de los distintos actores involucrados: si esto significa ampliar los márgenes de autonomía local sobre la base de la 
(Constitución Política Federal, Constitución Política Local y Leyes Municipales) sobre gobierno y administración pública municipal; por otro, la aplicación de la legislación electoral y sus efectos a nivel local, concretamente sobre los municipios de usos y costumbres para elegir a sus autoridades municipales. De igual forma, los datos expuestos son significativos como parte del contexto para comprender la disputa entre Totontepec y Móctum, y proporcionan elementos para situar el caso en el contexto estatal y nacional. En el contexto municipal y frente a las demás agencias, la disputa territorial de Móctum frente a Totontepec es un caso típico que sirve de ejemplo - entre otros-, y que constituye un fenómeno recurrente en la relación de los municipios frente a los gobiernos estatales y la federación.

La inequidad, en la distribución de los recursos y en la participación del control y el poder político municipal, tiene que ver por un lado con criterios presupuestales que para las comunidades-agencias, e incluso para las comunidades-cabeceras, son impositivos y ajenos a las realidades locales, y no corresponden a las necesidades culturales y materiales de infraestructura y desarrollo. Por otro, esta inequidad también tiene que ver con los procesos históricos y políticos de cada localidad y región indígena. En el caso de estudio, veremos cómo en 2004 en el municipio de Totontepec -como conjunto de agencias-comunidades y cabecera - se establecieron acuerdos para una mejor distribución de recursos económicos, lo que no evitó la generación de nuevos conflictos.

transferencia de facultades, competencias y recursos; qué implica cada uno de ellos y en todo caso cómo debe darse ese proceso de transferencia. En este tenor, en el Tercer Congreso de la Red de Investigadores sobre Gobierno Local y Municipio IGLOM (febrero de 2004) se expuso entre los reclamos de los municipios mexicanos el que se les reconozca como un orden de gobierno, con soberanía y facultad para legislar, el derecho de asociarse con municipios de otros estados, mediando la aprobación de las legislaturas de los estados; que se suprima la obligación de formar el Consejo Municipal de Desarrollo Social, que es el que determina las prioridades en la distribución del ramo 33, que éste se convierta en parte del presupuesto municipal para que el Ayuntamiento pueda administrarlos de manera autónoma. Sobre una visión más local de las implicaciones federales en esta materia, véase el artículo de Víctor Leonel Juan Martínez "Reforma municipal, ¿fortalecimiento o violación de la autonomía?”, en: En Marcha, pp. 4-6, Núm. 50, 2003. 


\subsection{El conflicto agrario y su relación con las dinámicas comunitarias: El expediente agrario}

Ya que lo agrario es un componente fundamental del campo jurídico que se estudia, en este apartado abordo la reconstrucción del conflicto por la tierra entre Móctum y Totontepec desde: 1) El expediente civil (Núm. 229 del año 1775) de la época colonial donde Móctum acusa a Totontepec de invasión de terrenos. 2) El expediente agrario de Confirmación de Bienes Comunales de Móctum (Núm. $276 \ldots / 807 \mathrm{TC}$ ), del que recojo la visión de las partes y actores que participaron en él. El expediente civil del año 1775 está integrado de varios documentos en los que se puede apreciar el desarrollo del litigio y sus antecedentes, en torno a una supuesta deuda que los de Totontepec querían liquidar con la invasión de terrenos. El expediente agrario es un conjunto de documentos que se fueron agregando en torno a la tramitación de la acción agraria de confirmación y titulación de bienes comunales a favor de Móctum, de acuerdo con la anterior Ley Federal de Reforma Agraria de 1971, ante la Delegación de la Secretaría de Reforma Agraria en Oaxaca.

Como se mencionó en la introducción de esta tesis, los expedientes agrarios, debido a la naturaleza del marco jurídico que definía a la materia agraria antes de 1992, se distinguen de los que se encuentran en las instancias jurisdiccionales como los juzgados de paz o los actuales tribunales agrarios, o incluso se diferencian de los que se originan en las instancias administrativas de procuración de justicia como el Ministerio Público. Esta diferencia radica fundamentalmente en que los tecnicismos y la lógica legal en el derecho agrario, como derecho social, es distinta a la manejada en las ramas del derecho privado y público; por esta circunstancia se puede decir que el procedimiento agrario es atípico, lo que se observa de alguna manera en el expediente, ya que se integra de distintos documentos en los que destacan los escritos hechos por los actores en conflicto o partes en disputa (Móctum y Totontepec), quienes son ajenos al manejo de ese lenguaje, no tanto al uso del derecho del Estado. De igual forma, en el expediente agrario constan, por escrito, los hechos narrados por funcionarios, topógrafos y agrónomos 
comisionados para visitar a las comunidades, realizando trabajos de inspección sobre las condiciones de los terrenos en disputa, objetos de la acción agraria o solicitud agraria, circunstancia que los ubica en un nivel más cercano a las prácticas de los actores aunque tenían conocimiento amplio del marco jurídico agrario.

Por lo anterior coincido con Chenaut (1999) sobre la importancia de los expedientes judiciales como unidad de análisis clave de los procesos jurídicos. De acuerdo al marco jurídico agrario anterior a las reformas de 1992, la Secretaría de la Reforma Agraria (SRA), a través de sus Delegaciones Agrarias, hacía cumplir el mandato constitucional de reparto agrario, tramitando o ejecutando las acciones agrarias que se establecían para ese fin, haciendo constar este proceso en documentos, escritos de las partes y actas de comparecencia ante la Secretaría que se registraban en expedientes agrarios.

De esta manera el expediente agrario de Móctum ${ }^{119}$ es importante porque en los documentos elaborados por los pobladores y autoridades de este pueblo, se hace constar un conjunto de hechos que permiten apreciar los encuentros y desencuentros, que configuran el conflicto central entre Móctum y Totontepec. De igual forma, se puede observar cómo el Estado a través de la Secretaría de la Reforma Agraria construye categorías sobre esos actores (Chenaut 1999). Por ejemplo, Móctum pasa de ser comunidad de hecho (ARTículo 27 Constitucional anterior a las reformas de 1992) al de comunidad legalmente reconocida -cambiando su estatus legal-. Este cambio de estatus se puede interpretar de la lectura del primer párrafo de la fracción VII del anterior ARTículo 27 Constitucional que se aplicó al procedimiento agrario de Móctum (1973-1990):

VII. Los núcleos de población, que de hecho [por que existen sin papeles virreinales o posteriores a la Colonia] o por derecho [títulos primordiales u otro documento] que guarden

\footnotetext{
119 Por lo que toca al análisis del expediente agrario de Totontepec, no me centro en él por que se refiere a un proceso particular e independiente de Móctum (aunque indudablemente siendo su colindante, lo involucra). Leí y revisé el expediente pero no encontré mayores referencias al conflicto con Móctum que las que ya había encontrado en el expediente de éste.
} 
el estado comunal, tendrá capacidad para disfrutar en común las tierras, bosques y aguas que les pertenezcan o que se les hayan restituido o restituyeren. [El subrayado es mío]

En el segundo párrafo del mismo artículo se señala el procedimiento agrario para legalizar la condición de comunidad de hecho (reconocer de acuerdo a la ley del Estado una situación existente, que concluye con la entrega final de los documentos que prueban la propiedad colectiva) o resolver las controversias entre dos o más núcleos agrarios:

Son de jurisdicción federal todas las cuestiones que, por límites de terrenos comunales, cualquiera que sea el origen de éstos, se hallen pendientes o se susciten entre dos o más núcleos de población. El Ejecutivo Federal se abocará al conocimiento de dichas cuestiones y propondrá a los interesados la resolución definitiva de las mismas. ${ }^{120}$

De acuerdo con este último precepto o artículo constitucional y con su ley reglamentaria (Ley Federal de Reforma Agraria), los procedimientos de dotación de ejido, restitución y confirmación de terrenos comunales se llevaban a cabo por el Ejecutivo Federal a través de la Secretaría de la Reforma Agraria (SRA). Así, los pobladores de Móctum para hacer frente a la situación de subordinación con Totontepec que les era adversa, aprovecharon la reforma agraria, buscando el reconocimiento de sus tierras comunales. Con este proceso agrario de confirmación y titulación de bienes comunales que acompaña este conflicto agrario durante el siglo XX, los habitantes de Móctum se valieron del Estado para conseguir la legitimidad necesaria que les permitió hacer frente a poderes caciquiles del municipio, negociar su distinción de la cabecera y, ejercer poder y control sobre sus dinámicas comunitarias. Al mismo tiempo el Estado se valió de ese reconocimiento legal, concretamente de la legislación agraria, para construir su hegemonía y reproducir la condición subalterna de Móctum, que al ser reconocida legalmente por el Estado como comunidad agraria, entra a formar parte del orden jurídico

120 Este ARTículo 27 Constitucional es anterior a las reformas de 1992 que cancelan el reparto agrario. 
oficial. Se entiende entonces al derecho estatal en su doble función, como reproductor de hegemonía y de resistencia (Lazarus-Black e Hirsch 1994).

El análisis del expediente agrario es fuente de amplias posibilidades pero también con limitaciones, por ejemplo, es imposible determinar una pauta cultural a través de un expediente judicial sin conocer previamente el contexto del pueblo de que se trata, y mucho menos las motivaciones y aspiraciones de los actores involucrados. Por ello, resulta necesario complementar el análisis del expediente con la observación de las prácticas sociales y la reconstrucción del contexto social y cultural en que se insertan.

El conflicto agrario entre Móctum y Totontepec tiene antecedentes remotos en la Colonia e incluso antes de la Conquista española, etapas en las que se documentan conflictos por la tierra no sólo entre Móctum y Totontepec, sino también con otros pueblos que ahora son agencias como Tiltepec y Tepitongo, (Chance 1998 y Gómez Bravo 2004; Archivo Histórico del Poder Judicial e Oaxaca). De acuerdo con estos datos los pueblos de esta región han recurrido desde tiempo atrás a la jurisdicción del Estado para dirimir sus disputas y el conflicto por la tierra, y sobre todo por los límites territoriales, lo que ha sido una constante que ha definido la relación entre la cabecera municipal y sus agencias colindantes en sus terrenos, especialmente con Móctum. De esta manera, la constitución de Móctum como comunidad agraria indígena independiente de Totontepec, es decir, con el reconocimiento legal del Estado mexicano de que las tierras que posee son propiedad colectiva o social, le ha dado un margen de ejercicio de independencia y autodeterminación relativa que le permitió romper un círculo de dominación ejercido fundamentalmente por personas con poder económico y político de Totontepec.

\subsubsection{Etapas del conflicto entre Totontepec y Móctum}

Son tres etapas históricas del conflicto entre Totontepec y Móctum. La primera se sitúa en la época prehispánica donde el primer poblado se separa de Móctum. De 
esta etapa no se cuenta con referencias documentales se trata más bien de leyendas que son parte de la historia oral de la comunidad (cfr. Gómez Bravo 2004). ${ }^{121}$ Sin embargo, ya que se carece de documentos de la época, los datos de las entrevistas son valiosos y válidos para la reconstrucción histórica y para la definición del origen de la disputa. Una segunda etapa es la época colonial donde a través de un expediente judicial (del Archivo Histórico del Poder Judicial de Oaxaca) se tienen datos del conflicto entre ambos pueblos, y se puede leer que Totontepec era un pueblo con mayor categoría administrativa, ante el cual otros pueblos tenían que ir a cumplir servicios a la iglesia católica, por ejemplo, limpiarla. La tercera y última etapa se sitúa en la época moderna siglos XX y XXI; los datos de esta época son los que se encuentran en el expediente agrario de la Secretaría de la Reforma Agraria (Núm. 276.../807 TC) y los que se recogieron en el trabajo de campo en ambas comunidades.

Para el análisis del conflicto entre Totontepec y Móctum, me baso en la propuesta de Nader (1978), en la que señala las etapas que deben considerarse en el desarrollo de una disputa:

a) La prehistoria de la disputa. El estado de la relación y el origen de la disputa que se explica y se reconstruye a partir de la historia oral y el expediente colonial de Móctum contra Totontepec.

b) La disputa misma y su resolución, por acuerdo entre partes o arbitraje (adjudicación), tiene dos momento: la resolución dada en la época colonial y la que resultó en la época moderna por la tramitación de Móctum para ser reconocida como comunidad agraria con terrenos propios.

c) Consecuencias sociales del acuerdo al que se llegó. Fundamentalmente se deriva del trabajo de campo y las entrevistas.

Con esta propuesta planteada desde la perspectiva procesual, pretendo dar cuenta no sólo del desarrollo del conflicto sino de las relaciones de poder, los

${ }^{121}$ Las narraciones que se recuperan de los habitantes de Móctum son aparentemente leyendas simples. Sin embargo, es una historia oral que explica el origen de la disputa con Totontepec, lo que éstos como lo veremos más adelante lo confirman. 
encuentros y desencuentros que subyacen a los usos del derecho por las partes litigantes (Móctum y Totontepec), sus estrategias y las motivaciones que los determinan a tomar una u otra decisión.

\subsubsection{La prehistoria de la disputa: Época prehispánica y colonial}

Los datos que se tienen de esta etapa del conflicto son narraciones orales transmitidas de padres a hijos. Pese a la ausencia de datos que consten en documentos históricos se puede hacer una confrontación entre los hechos que se relatan en la narrativa oral, con lo que consta por escrito en los expedientes.

Como veremos, del expediente de la Colonia se desprende que la confrontación por la tierra fue un punto de tensión permanente entre Totontepec y Móctum, pues ya se había dado con anterioridad — en la época prehispánica - una solución acordada entre los dos pueblos estableciendo límites territoriales con un monolito o mojonera llamado la Piedra Agujerada (se puede ver el plano definitivo de Móctum en la carpeta agraria básica en el Archivo de la SRA). Sin embargo, la controversia trasciende de la época prehispánica a la colonial, quedando documentado de nueva cuenta el conflicto por la tierra en el Archivo Histórico del Poder Judicial del Estado de Oaxaca.

Para situar a Móctum y Totontepec en la historia, es importante tomar en cuenta que en 1548 Móctum formaba parte de Santa María Ocotepec (otra agencia de Totontepec); para 1648, Móctum junto con Jareta, Metepec y Jayacaxtepec (actualmente agencias de Totontepec), haciendo uso del derecho indiano o colonial, fueron reconocidos como pueblos independientes, esto de acuerdo con Chance (1998:132):122

Otro de los grandes asentamientos en la época de la Conquista fue Santa María Ocotepec (distinto a San Pedro Ocotepec en el distrito de Nejapa), el cual tenía once estancias en

\footnotetext{
122 Martínez Gracida (1883:837) ubica a Móctum en la jurisdicción del municipio de Totontepec. Según Noemí Gómez Bravo (2004), Móctum en 1914 era cabecera municipal, sin embargo, este dato es resultado de las entrevistas y no consta en ningún documento oficial.
} 
1548, incluyendo Ayutustepec (que deja de mencionarse después), Móctum, Jayacaxtepec y quizás Jareta y Metepec. Ocotepec, Jayacaxtepec y Móctum formaron una unidad hasta 1648 cuando se les reconoció como pueblos independientes y reclamaron tierras separadas.

La serie de conflictos que dan lugar a la resolución colonial, que le da independencia a Móctum junto con esos pueblos, explica actualmente su necesidad de distinguirse y marcar su independencia frente a Totontepec.

Lo que me interesa con lo antes apuntado, y concretamente con esta cita de Chance, es dar cuenta de cómo la reivindicación de Móctum de ser considerada una comunidad aparte en 1648, así como otros conflictos por la tierra que se dan en 1754 y 1755, resurge en un nuevo contexto y en una nueva situación, que significó para sus habitantes aplicar nuevas estrategias.

\section{La narrativa oral y la perspectiva de Móctum sobre el conflicto}

Desde la perspectiva de los habitantes de Móctum, el conflicto tiene sus antecedentes mucho antes de la época colonial. En ese entonces, Móctum era un pueblo grandioso no sólo por su actividad económica y por lo que representaba como centro ceremonial para los mixes, sino por su extensión territorial. Sin embargo, a través del tiempo Móctum fue perdiendo territorio, los hechos principales que explican este desenlace son: La separación de un grupo de pobladores de Móctum que se fueron a vivir hacia lo que ahora es Totontepec; la disputa entre mujeres de los dos pueblos por una jícara que tuvo como desenlace la entrega de un terreno propiedad de Móctum; la disminución de la población debido a enfermedades y epidemias fue otro factor que propició que los pueblos vecinos, sobre todo Totontepec, entraran a sus tierras a trabajar, y lo más reciente, la pérdida de un mantelito de hilos de oro utilizado en la liturgia católica. Todos estos aspectos son resaltados por los habitantes de Móctum para reconstruir la historia del conflicto, así como su separación y distinción de Totontepec.

Según esta versión, Móctum fue atacado por una epidemia, por lo que un grupo de los pocos habitantes que quedaron buscaron un mejor lugar hacia tierras 
altas cerca de lo que ahora es La Mitra - el pico del cerro que tiene la forma de una mitra y que en lengua ayuuk le da el nombre a Totontepec (cerro del Rayo o del Trueno).

Las personas que entrevisté de Totontepec coinciden en esa versión y señalan que Móctum hace mucho tiempo fue el primer pueblo de donde salieron - según cuentan las historias - ${ }^{123}$ Cuando los pasados llegaron a poblar bajo La Mitra o el cerro del Rayo, se encontraron con unos niños jugando en el manantial que ahora se encuentra cerca del edificio del ayuntamiento. Tal hecho se inmortaliza en el símbolo del escudo municipal (CAPÍtULO 3).

En esta leyenda se cuenta que después de la primera epidemia mermó la población de Móctum, pero con el tiempo se repobló. Sin embargo, poco antes de la llegada de los españoles, en el año 1500, hubo diferencias entre Móctum y Totontepec, supuestamente por un pleito entre mujeres que lavaban en el río, según narra Gómez Bravo (2004:33-38). Las mujeres de Móctum prestaron una jícara muy bonita a las mujeres de Totontepec, desafortunadamente, en un descuido ésta se rompió, lo que devino en una guerra. Para dar fin a esta confrontación bélica, los dos pueblos fijaron como centro de la disputa sus límites territoriales (colindancias), la mojonera Piedra Agujerada ubicada a la entrada de Móctum, como testimonio de esa contienda. Esto resulta similar al proceso que König (1993) menciona de grandes núcleos de población o asentamientos humanos desplazados en su preeminencia y control por otros que antes eran sus rancherías.

${ }^{123}$ En la Enciclopedia de los Municipios de México. Estado de Oaxaca. Por lo que toca a los orígenes del municipio de Totontepec, se apunta: "El pueblo de Totontepec tiene más de 600 años de existencia, su primer sitio de asentamiento fue el llano, según una leyenda muy antigua contada por el Señor Fortino Cruz Reyes, en ese lugar los niños tenían un maleficio que los mataba, esto fue motivo de gran preocupación de los guías y dirigentes del pueblo, por lo que mandaron expediciones en búsqueda de tierras más saludables, encontrando así los dominios del cerro del Rayo, quien por medio de su alma, indicó el lugar donde debería estar ahora, esto tuvo que ser antes de la llegada de los Españoles". Los créditos de esta información según se expone en la ficha, son del H. Ayuntamiento de Totontepec Villa de Morelos. $<$ http://www.elocal.gob.mx/work/templates/enciclo/oaxaca/municipios/20554a.htm> 
Con la llegada de los españoles, la zona sufrió otras epidemias ${ }^{124}$ lo que de nuevo afectó la población de Móctum. Esto fue atribuido a la maldición de un cura que no simpatizaba con las costumbres y tradiciones mixes; primero llegó a la fiesta de Ocotepec Viejo donde prácticamente lo amenazaron de muerte, al irse de este lugar el cura maldijo al pueblo provocando una epidemia (Gómez Bravo 2004:36-37):

El sacerdote se levantó muy de madrugada y pasó al altar donde había un Cristo con cuerpecito de madera, se lo guardó bajo el vestido y se fue sin hacer ruido hasta la salida de Ocotepec Viejo. Antes de agarrar rumbo a Móctum, el cura se quitó sus zapatos y los sacudió bien fuerte como señal de maldición [... pero en Móctum] ya todos sabían de su pensamiento hacia las costumbres mixes y decidieron cerrar las puertas de la iglesia y de sus casas [...] volvió a quitarse los zapatos y los sacudió fuerte en señal de maldición para Móctum. [...] De esa manera se fueron quedando poquitos en Móctum, hasta que sólo hubo ocho familias, según aseguran los ancianos que se acuerdan de estos acontecimientos y de que esas familias acordaron aceptar la llegada de personas que quisieran poblar el lugar. En ese tiempo llegó José María Ruiz para avecindarse en Móctum aunque era de Totontepec; y así siguieron llegando otras personas.

Este hecho, apuntado por Gómez Bravo, es importante porque posteriormente en el siglo XX (1980-1983), los de Totontepec plantearían que dada la epidemia que sufrió Móctum en tiempos inmemoriales, nadie ocupaba los terrenos por lo que sus abuelos y después sus padres entraron a trabajar, testimonios como éstos quedaron vertidos en el expediente agrario ${ }^{125}$ como se mostrará más adelante.

Con las disputas prehispánicas por la tierra y las epidemias, como lo apunta Gómez Bravo (2004), Móctum pierde una extensión considerable de sus terrenos. Posteriormente con el devenir del tiempo, se provocaron otros conflictos y se lograron convenios sobre el usufructo de la tierra entre Totontepec con los pueblos

${ }^{124}$ Cfr. Münch (1996) y Chance (1998:111-112) se refieren a las epidemias que azotaron en esta época a la Sierra como una de las razones en la disminución de la población indígena.

${ }^{125}$ Cfr. Expediente Núm. 276.../807 TC. 
circundantes (ahora agencias de este municipio); de esto queda constancia también en diversos expedientes judiciales del ramo civil del Juzgado de Villa Alta (ahora integrado al Archivo Histórico del Poder Judicial del Estado de Oaxaca).

\section{El expediente colonial: Móctum vs. Totontepec}

La existencia de acuerdos por escrito en el Archivo Judicial entre Pueblos Indígenas de la zona demuestra que estos pueblos indígenas, como muchos otros del estado de Oaxaca, recurrieron desde un principio a la justicia de indias o española (con fundamento en las Leyes de Indias), para dirimir sus controversias por tierras. Ejemplo de esto son los siguientes expedientes, organizados cronológicamente:

Núm. 20 del año 1583, con el resumen “Testimonio de Convenio Celebrado para la posesión de tierras, entre los pueblos de Ocotepec, Jayacaxtepec y Móctum".

Núm. 138 del año 1583, "Acuerdo Celebrado entre pueblos de Totontepec, Amatepec, Móctum y Tiltepec, sobre la forma de abastecer de leña, zacate y otros".

Núm. 46 del año 1694, "Diligencias hechas para que los naturales y especialmente los del pueblo mixe ocurran a reparar las casas de los vecinos de Villa Alta según Real Provisión".

Núm. 229 del año 1755,126 “Los principales y el común del pueblo de Móctum contra los del Pueblo de Totontepec sobre tierras".

\footnotetext{
126 Seguramente esta real provisión tiene que ver con lo que apunta Chance (1998:65): “En los siglos XVII y XVIII, Villa Alta no era un lugar muy distinto de cómo fue en años anteriores. Aunque se estableció como un asentamiento permanente, siguió siendo una avanzada pequeña y aislada que todavía dependía económicamente de los indígenas de la provincia". Sobre su característica étnica apunta: "A lo largo de todo el periodo colonial -y hasta hoy día - Villa Alta era la única comunidad hispánica situada en una vasta región indígena. No hay información precisa disponible sobre la composición étnica y racial de la villa en los siglos XVI y XVII, pero existen algunos registros fragmentados de finales del periodo colonial. Éstos muestran - como lo confirma una visita actual a la región - que la mayoría de los no indígenas de la alcaldía mayor vivían en Villa Alta" (Chance 1998: 69-70).
} 
Núm. 482 del año 1793, “Convenio celebrado entre el común del pueblo de Móctum y el de Jayacaxtepec sobre tierras".

La anterior relación de expedientes forma parte del índice del juzgado de Villa Alta del ramo civil; en este índice se localizó el expediente que corresponde a la disputa entre Móctum y Totontepec, con el número progresivo 229 del año 1755, con el resumen: "Los principales y el común del pueblo de Móctum contra los del Pueblo de Totontepec sobre tierras". En este expediente se puede observar que los principales de Móctum en 1755 eran el Alcalde, Alguacil Mayor y Regidor (Lorenzo Domingo, Joachin Ruiz y Nicolás Antonio, respectivamente), quienes recurrieron al juzgado de Villa Alta para denunciar que personas de Santa María Asunción Totontepec (como se llamaba entonces el actual Totontepec Villa de Morelos) estaban invadiendo sus terrenos (expediente Núm. 229 de 1755:8):

El común, y naturales del pueblo y cabecera de la Santa María Asunción de Totontepeque [sic], así mismo de esta jurisdicción; nos colindantes, se nos han introducido en nuestras tierras, por la varda que confinamos con ellos, cortando maderas, pastando sus ganados, y sembrando sementeras cada y cuando los hacen desde el Pasaje nombrado en nuestro idioma Mixe: Acazoachim hasta Omanonacooam y comprenden los pasajes siguientes: yocomnicom que actualmente tiene sembrado Marcos de Alcantara, y Pedro Vasques Ale y toxcocuim, que así mismo tienen sembrado sujetos de otro pueblo que no conocemos.

Para respaldar su denuncia, los principales de Móctum presentaron un título de fecha 12 del mes de septiembre de 1543, expedido por un juez de composiciones de tierra (arreglo sobre la posesión de las tierras de los pueblos). Básicamente es un acta en la que se hace constar las posesiones y se deslindan o separan los terrenos que corresponde a los de Móctum, de los que eran de otros pueblos, entre ellos Totontepec. ${ }^{127}$

Los representantes de Totontepec (Alcalde, Alguacil Mayor y Regidor), en esa época, alegaban que los vecinos de este pueblo no estaban invadiendo terrenos

${ }^{127}$ Este acto de posesión y deslinde fue realizado por el señor corregidor Gonzalo Díaz de Bargan. 
de Móctum, dado que esos terrenos eran suyos. Para respaldar esto, los principales de Totontepec argumentaron que los de Móctum habían perdido esos terrenos porque en una ocasión pidieron prestados ornamentos y otros utensilios para las celebraciones litúrgicas de la iglesia católica, los cuales ya no regresaron por lo que a cambio cedieron sus tierras.

Entre las diligencias o actos que se llevaron a cabo, para determinar si los de Totontepec habían invadido o no, se presentan testimonios de distintas personas, incluso de pueblos vecinos como Jayacaxtepec y Ocotepec así como una carta del cura que radicaba en Totontepec, don Joseph Manuel Lazarte. Todas estas personas coincidieron que la iglesia de Totontepec nunca prestó ornamentos y demás bienes necesarios y que, al contrario, cuando Móctum "en 1754 pidió prestado a Totontepeque [sic] una copa de oro, incensario y demás, para celebrar su fiesta, se los negaron estos" (Sebastián Diego, testigo con traductor, expediente Núm. 229 de 1755:71-75). Se presenta también un testimonio (con preguntas dirigidas) de que previo a esta disputa se habían sucedido otras, pero que entre los pueblos llegaron a un arreglo (expediente Núm. 229 de 1755:70):

Los pagos nombrados Acazoachum, Lucomcoch y Toxcocuim [ilegible] y que de mucho tiempo a esta parte no lo asen [no lo utilizan] por impedirlo, los de Totontepeque.

A la tercera [pregunta]: dice, saber por haberlo oído a los ancianos, de su pueblo, que habiéndose dividido, por iguales partes, la tierra nombrada Azoon, se puso por término divisorio, una mojonera, nombrada Azonaham, que las que quedaron de parte de arriba, hacia el poniente les [correspondieron] a los de Totontepeque, y las de la parte de abajo, para el Oriente, a los de Ocotepeque y Mohootom [Móctum]

El expediente se integra fundamentalmente por este tipo de testimonios en los que testigos exponen lo que saben de la disputa por tierras entre Totontepec y Móctum (mencionando otros pueblos). Debido a la antigüedad del expediente, el último documento que se puede leer es la carta del sacerdote dirigida al juez de la jurisdicción de Villa Alta. No hay sentencia, pero seguramente se dio la razón a 
Móctum, sobre todo porque Totontepec no pudo presentar un documento jurisdiccional (de un juez) similar al presentado por Móctum, ni testigos que contradijeran el dicho de los testigos a favor de Móctum. Es decir, de los documentos que el expediente contiene se deduce que el incensario o artículo parecido, utilizado para la celebración litúrgica católica, nunca se había dado o prestado por Totontepec a Móctum.

En resumen, lo anterior es un respaldo documental de la historia oral narrada de padres a hijos. De esa narrativa, confrontada con los expedientes judiciales como documentos históricos, se desprende que la disputa por la tierra fue un punto de tensión permanente entre Totontepec y Móctum. De esta manera, en la primera etapa se había acordado entre los dos pueblos desde antes de la Conquista española una solución para fijar los límites territoriales entre ambos con "la piedra agujerada".

En la segunda etapa esa controversia trasciende de la época prehispánica a la colonial por unos utensilios religiosos, quedando documentada de nueva cuenta el conflicto por la tierra en el Archivo Histórico del Poder Judicial del Estado de Oaxaca.

Por último, en la tercera etapa parece que la historia se repite y nuevamente Móctum pide prestado un ornamento religioso, por el cual los de Totontepec justifican la invasión de tierras. En el siguiente subapartado, se analiza el expediente agrario donde se hace constar el origen del conflicto.

\subsubsection{La disputa, su resolución y consecuencias: Época moderna}

Los datos que se tienen sobre esta etapa son la narrativa oral de los habitantes de ambos poblados que constan en los documentos del expediente agrario. Del análisis de estos datos se observa que la disputa entre los poblados se actualiza, es decir, en cada etapa el conflicto resurge de otra manera y con elementos distintos, pese a esto, se puede reconocer que finalmente el punto de tensión medular es por la supremacía de un poblado sobre otro, el sentido de identidad y pertenencia 
comunitaria, y el ejercicio del control relativo que el pueblo desplazado (Móctum) tiene frente a esa dominación desde su condición subalterna.

De acuerdo con las entrevistas hechas en Móctum y confrontadas con los datos del expediente agrario formado con la Reforma Agraria en el siglo XX, la disputa resurge debido a la pérdida de un mantelito de hilo de oro que el mayordomo o encargado de la iglesia católica de Móctum había pedido prestado a la iglesia católica de Totontepec para realizar la ceremonia de casamiento de unas personas de Móctum. Desafortunadamente, el mantelito se quemó al caerse una vela sobre él, perdiéndose irremediablemente. Este descuido se atribuye al encargado de la iglesia el día 25 de abril de 1914, día de la fiesta de San Marcos patrón del pueblo. Esta deuda no fue negada por los pobladores de Móctum,128 pero con el paso del tiempo se volvió una deuda impagable - ya que los de Totontepec aumentaban el precio del mantelito, por sus atributos, por ejemplo, que era de oro puro, que sólo se conseguía en Roma, que el tejido era único-. Esto constituyó el argumento central por el cual Totontepec ocupó terrenos de Móctum en 1914 entre otros motivos, lo que aunado, según cuentan los habitantes de este poblado, al maltrato y menosprecio de las autoridades y grupos de poder de la cabecera, y a los gastos de la fiesta, de las mayordomías y de cargos en la iglesia motivó que a la larga - en la década de 1970 - la mayoría de los pobladores se convierta al adventismo, pues lo necesario para esos eventos lo vendían los comerciantes de Totontepec. Desde entonces, los de Totontepec usaron las tierras de Móctum por más de 85 años. ${ }^{129}$

Según relatan algunos habitantes de Móctum, el pueblo no tenía suficiente dinero ni bienes para comprar otro mantelito o pagarlo. Otros dicen que los de Totontepec no aceptaron que se les diera otro a cambio: "que fuéramos a México a

${ }^{128}$ Cfr. Gómez Bravo (2004:39-40).

129 "Ochenta y cinco años pasaron y Móctum no podía recuperar sus tierras, los del acuerdo caciques de Totón [sic], no sólo sembraban en ellas sino hasta en los patios de las casas de los de Móctum. Sintiéndose dueños del lugar, hasta lo cosechado guardaban los del grupo de caciques de Totón [sic] dentro de las casas de los de Móctum". Testimonio recopilado por Gómez Bravo (2004:40). 
comprar otro"; incluso se dice que las autoridades municipales de Totontepec hablaban de ir a Roma para preguntar cómo tenía que ser el mantelito. Cuentan que el cura de Totontepec dijo que el mantelito no lo iba a ocupar el Ayuntamiento sino la Iglesia y que cualquier mantelito estaba bien, lo que sin embargo, no era la opinión de las autoridades municipales.

Al verse reducidos en la cantidad de tierras que podían utilizar pagando o dando a cambio parte o la totalidad de su cosecha (a medias), los de Móctum pedían prestado o fiado a los comerciantes de Totontepec para subsistir y realizar las fiestas católicas -ahondando la dependencia-. Lo que se realizaba por convicción o fe se volvió una obligación, ya que eran intimidados con la amenaza de que si no realizaban las fiestas católicas en Móctum se enfermarían o morirían. Así muchos de Móctum fueron obligados a ser mayordomos y se endeudaban aún más por los gastos que tenían que hacer para la fiesta del santo patrón. Ante esto algunos tuvieron que empeñar sus terrenos a los de Totontepec, o bien cuando no pagaban a tiempo un préstamo o alguna mercancía (café o medicinas) no les regresaban la tierra que habían dejando en prenda o empeño. Sobre esta forma de pago, que empezó a ser vista por los de Móctum como excesiva, Gómez Bravo (2004:40) apunta:

Cada 25 de abril, fecha en que se celebraba a San Marcos, el grupo de caciques de Totontepec se invitaba solo a la comida y al tepache que preparaba el pueblo de Móctum, como si este lugar fuera su rancho.

Móctum llegó a no contar con ningún pedazo de tierra porque el grupo de caciques de Totontepec lo había despojado de ella. Los pobladores de Móctum tenían que pedir permiso para trabajar la tierra, porque de lo contrario podían perder su rozo o resultar multados por el grupo de caciques de Totontepec.

Esta situación resultó del acuerdo entre Totontepec y Móctum, que ante la deuda aceptó que los de aquel poblado usaran por un tiempo sus tierras a cambio del mantelito perdido - acuerdo que no quedó por escrito-. Sin embargo, cuando los 
pobladores de Móctum consideraron pagada la deuda, los de Totontepec les recordaban el incidente y la deuda, argumentando que ésta todavía no se saldaba.

La pérdida de las tierras agravó la situación de Móctum porque su población estaba prácticamente diezmada por las diversas enfermedades que padecieron, por lo que eran pocos los que podían ocuparlas y defenderlas, lo que propicia que pobladores de Totontepec entraran a los terrenos de Móctum para utilizarlos. ${ }^{130}$ Esto coincide con lo que el grupo de Totontepec alegó para justificar su posesión sobre tierras de Móctum según el escrito que se presenta a continuación y que consta en el expediente agrario Núm. 276.../807 TC: 312.

25 de septiembre de 1984. Totontepec Villa de Morelos.

Acta de investigación.

Arnulfo Carrasco Puga, Jefe de la Promotoría Agraria en Ayutla Mixe.

Octavio Molina Maldonado Pte. Del Comisariado de Bienes Comunales.

Delfino Alcántara Gómez y Vicente Nuñez Reyes, representantes del grupo denominado 28 de noviembre, que tienen en posesión terrenos comunal en la comunidad de San Marcos Móctum; Delfino Reyes Villegas, Lucio Villegas Cabrera, Filemón Alcántara Reyes, Daniel Hernándes Reyes, José Alcántara Gómez, Layra Alcántara Gómez, Rebeca Bernal Alcántara, estos últimos campesinos que usufructúan terreno en San Marcos Móctum; con el objeto de dar cumplimiento a la orden 005010 de fecha 30 de agosto de 1984.

El Comisariado de Bienes Comunales y los dirigentes del grupo manifiestan que la posesión que tienen en la Jurisdicción de San Marcos Móctum, data de tiempo inmemorial de más de cien años dicha posesión la han venido heredando de padres a hijos hasta esta fecha.

Que saben por referencia que en la Comunidad de San Marcos Móctum, hace más de cien años hubo una epidemia en la cual casi se acabó la población por lo tanto desde esa época sus abuelos se posesionaron de distintas fracciones de terreno, las cuales hasta esta fecha

130 Según don Cipriano Gómez, se cuenta en el pueblo que no había niños pues éstos morían de diversas enfermedades; actualmente muchos de los habitantes adultos de Móctum con edades entre 40 y 60 años, son de otros pueblos, los más jóvenes nacieron aquí pero sus padres llegaron de otras comunidades del municipio o bien de la región, por ejemplo de Tepitongo, Huitepec, Ocotepec, Totontepec, Tlahuitoltepec (otro municipio mixe). 
usufructúan, que ellos ignoran porque en estas fechas están tratando de despojarlos de dichas fracciones que siempre han vivido en paz en dicha comunidad; siguen manifestando que todos los usufructuarios de dicho terreno no quieren problemas con la comunidad de San Marcos Móctum, pero que únicamente le respeten íntegra la posesión que usufructúan actualmente.

De lo anterior se puede entender que en la perspectiva de los de Totontepec, los habitantes de Móctum no eran los originarios poseedores de las tierras que ocupaban. De esta manera, después de perder el uso de sus tierras Móctum vio, en la Reforma Agraria de la década de 1970, la posibilidad de legalizar sus terrenos con la intervención del Departamento de Asuntos Agrarios y Colonización (19501970), y con ello recuperarlos. Mientras se tramitaba el expediente agrario, el grupo de posesionarios-invasores de Totontepec, haciendo uso de la ley, intentaron esgrimir el argumento del mantelito como defensa legal, recordando el suceso. Decían que las tierras que tenían en usufructo las habían adquirido de sus padres de tiempo inmemorial, o las habían comprado directamente por lo que eran legítimos poseedores, y más aún pequeños propietarios. En los escritos enviados por Móctum y Totontepec a las autoridades de la Secretaría de la Reforma Agraria y del Ministerio Público de Zacatepec no se hace mención del mantelito, sin embargo, es algo que los de Móctum guardan en su memoria como el argumento central de los de Totontepec para quedarse con sus tierras. De acuerdo con Gómez Bravo (2004) en las diversas reuniones que se llevaron a cabo entre estos pueblos con la intervención de algún funcionario de la Secretaría de la Reforma Agraria, lo del mantelito salía a relucir aunque en las minutas de reunión o acuerdos no se mencionaba, por lo que la disputa aunque se centró en la posesión sobre los terrenos, en realidad era la contestación o confrontación de Móctum a los abusos y atropellos de ese grupo y, a lo que Totontepec como centro de poder representaba tal como se puede leer en diversos escritos, por ejemplo:

Los que suscribimos, comuneros de Totontepec Villa de Morelos, Mixe, Oax., con posesión de terrenos en San Marcos Móctum, perteneciente a este Municipio, nos dirigimos ante 
usted por su muy digno y merecido cargo que desempeña, con el objeto de hacer formal denuncia en contra de nuestros vecinos comuneros de la población que se menciona, ya que a partir del transcurso de la segunda semana del mes de Octubre próximo pasado del presente año, se encuentran invadiendo y destruyendo plantas de café y otros árboles frutales en los terrenos que son de nuestra legítima posesión, desde hace aproximadamente ochenta y noventa años, aunque en realidad estos hechos se han venido registrando continuamente, aclaramos que los terrenos que mencionamos se encuentran ubicados dentro de la Jurisdicción [sic] de la comunidad que hemos mencionado, pero en tiempos anteriores no recordamos haber tenido problemas de este tipo por constarles a ellos de que algunos los tenemos por compras y otros por herencia de nuestros padres, de acuerdo a los convenios que realizaron nuestros antepasados de entre ambas comunidades, si bien existe la Ley de la Reforma Agraria [sic] la que ellos dicen los ampara por haberse declarado los terrenos de San Marcos Móctum como comunales, también la misma Ley confirma el respeto mutuo de las posesiones y pequeñas propiedades abocándonos a los ARTículos 72 fracción 6 y 7 de la misma, tampoco podemos tolerar los serios delitos que están cometiendo éstos [sic] campesinos para acarrearse derechos de posesión sobre estos terrenos, ya que la mala actitud de éstos se viene registrando y agravándose más desde el año de 1982 y en el transcurso del presente año, pues en forma violenta y abusiva están infringiendo los ARTíCULOS 387 y 389 del Código Penal Vigente en nuestro Estado manifestamos nuestros respetos por todas las disposiciones de la Ley Agraria y sí es aplicable en todos los términos, agregamos que en ninguno de los dos poblados existen terratenientes o latifundistas para que éstos [sic] vecinos nos consideren como alguno de estos afortunados. [Escrito de fecha de 28 de octubre de 1983, dirigido al gobernador del Estado por el grupo de poseedores de Totontepec. Expediente Núm. 276.../807 TC:312. El subrayado es mío]

En este párrafo se puede apreciar cómo las personas de Totontepec, que se ostentan como poseedores y propietarios, hacen uso de la ley del Estado invocando artículos y leyes; sin embargo, aceptan que sus terrenos se encuentran en la jurisdicción de Móctum, alegando que los pobladores de éste habían respetado sus posesiones durante mucho tiempo, por lo que consideran que los de Móctum al entrar en sus terrenos están cometiendo un delito. Pese a esto, los invasores no 
tenían papeles para justificar su presencia en terrenos de Móctum ni tampoco pudieron probar su derecho de propiedad sobre ellos.

Como el ejemplo anterior, existen una serie de escritos y argumentos que tanto los comuneros de Móctum como el grupo de Totontepec esgrimieron para que se les diera la razón, los cuales constan en el expediente agrario (Núm. 276.../807 TC) que se encuentra en el Registro Agrario de la Secretaría de la Reforma Agraria en Oaxaca, con los que se puede reconstruir el desarrollo del conflicto.

Al iniciar el expediente, se establece que no hay conflictos con otros pueblos (6 de diciembre de 1972), sin embargo, con posterioridad se hace constar por parte del personal de la Secretaría que existe conflicto de límites. Esto seguramente se debió a que la primera versión que tuvo la Secretaría de la Reforma Agraria llegó de personas que consideraban que no había conflicto, y no tanto porque los topógrafos de la SRA hayan realizado alguna inspección ocular o en el terreno. De igual forma, se pueden apreciar una serie de documentos que narran determinados hechos que dan una idea de la magnitud del conflicto; así en 1983 Móctum denunció una serie de atropellos en su contra, como la quema de sembradíos y casas por parte de algunas personas de Totontepec (cfr. Expediente agrario). De igual manera y tal como lo narra Gómez Bravo (2004),131 el grado de confrontación había pasado de la argumentación a la violencia física, pues los de Móctum sintiéndose respaldados entraron a los terrenos invadidos y los empezaron a

131 “A todos los jóvenes y señores de mayor edad se los llevaron hasta la cárcel de Totón [sic]. Algunos estaban golpeados [...] Las mujeres, que se quedaron en la comunidad de Móctum, recibieron el apoyo de los profesores (dos) que trabajaban en la escuela de esta comunidad, elaboraron un documento que el profesor Alfredo fue a entregar a la Asamblea de Autoridades Mixes (ASAM). Un enviado de ASAM acudió el día domingo a las 11 de la noche a Móctum bajo un aguacerazo, relámpagos y truenos, donde se elaboró una denuncia con las firmas de las mujeres de este pueblo [...] Los profesores indígenas presentaron la denuncia ante el Procurador General de Justicia del Estado de Oaxaca [...] Cuando se presentó el Agente del Ministerio Público de Oaxaca, acompañado de los cuatro judiciales, ante el presidente municipal de Totontepec, César Elí Alcántara López, a éste no le quedó más remedio que liberar a los detenidos". "El conflicto agrario continuó y cada vez que los de Móctum buscaban una solución, el grupo de caciques de Totontepec, para buscar que toda la gente de ese municipio los apoyara, recordaban el asunto del mantelito quemado" (Gómez Bravo 2004:47-48). 
trabajar, pues sabían que su condición de comunidad de hecho había cambiado con la Resolución Presidencial de 1975 donde se les reconocía como comunidad legalmente constituida y, por tanto, se les reconocía también la propiedad colectiva de la tierra. ${ }^{132}$ De esta manera, lo que comenzó como un conflicto entre un grupo de personas de Totontepec con Móctum, poco a poco involucró a la mayoría de ambos pueblos, ${ }^{133}$ ya que sus autoridades agrarias y municipales sentían que sus intereses estaban siendo afectados con la reivindicación de Móctum sobre sus terrenos. ${ }^{134}$

La mayoría de los que se encontraban trabajando en los terrenos estaban involucrados con la familia Alcántara ${ }^{135}$-emparentados con Samuel Alcántara anterior cacique (véase CAPÍtulo 3) -, sea porque miembros de esta familia

132 Según narra don Cipriano Gómez - líder de la religión adventista en Móctum - , él encabezó el trabajo de siembra en las tierras invadidas argumentando que la Resolución Presidencial le daba la razón a Móctum. Don Cipriano fue uno de mis informantes, es originario de Totontepec y cumplió cargos en este pueblo. En Móctum fue Agente y Presidente del Comisariado de Bienes Comunales, y ha ocupado otros cargos menores. Otros informantes fueron las propias autoridades en turno y pasadas y Noemí Gómez Bravo, hija de don Cipriano y líder del grupo de "Mujeres Olvidadas del Rincón Mixe", también las mujeres de este grupo me dieron datos relevantes sobre conflictos y su resolución ante la Agencia de Móctum, especialmente las que tenían cargos de Presidenta, Secretaria y Tesorera.

133 Esto se puede apreciar en el expediente agrario de Móctum, en las hojas 237 y 298 donde aparecen dos escritos, el primero suscrito por el grupo de poseedores y el segundo por el Comisariado de Bienes Comunales de Totontepec.

134 Cito textualmente parte de un escrito donde se hace constar, por un funcionario de la Secretaría de la Reforma Agraria, que la autoridad agraria de Totontepec (el presidente del Comisariado de Bienes Comunales) también era poseedor de terrenos de Móctum: “El día 18 de septiembre de 1984 el comisionado de la Promotoría Agraria en Ayutla Mixes, Armando Félix Valencia se reunió con representantes del Comisariado de Bienes Comunales de Totontepec Villa de Morelos, Mpio. del mismo nombre. (Informe de 25 de septiembre de 1984 dirigido al C. Arnulfo Carrasco Puga) [...] Según declaración del C. Presidente del Comisariado de Bienes Comunales, la Comunidad de Totontepec en sí no tiene ningún problema con los vecinos de San Marcos Móctum, y que están de acuerdo de participar en calidad de Autoridades Comunales en la solución que se pretenda dar al problema, siempre y cuando sea respetada la posesión de los comuneros de Totontepec que se encuentran enclavados dentro de los terrenos correspondientes a San Marcos Móctum, tomando en cuenta las opiniones y alegatos de dichas personas y que surgirán en una próxima reunión que tendrán con ellos. [...] Se anexa relación de comuneros de la población de Totontepec con o sin certificado de miembro de comunidad, mismos que se encuentran trabajando terrenos de la comunidad de San Marcos Móctum, de la cual hace constar el Presidente del Comisariado de Totontepec (que también es posesionario en terrenos de Móctum)" (Expediente Núm. 276.../807 TC: $30-301)$.

135 Expediente Agrario Núm. 276.../807 (General y Ejecución) “Confirmación y Titulación de Terrenos Comunales. San Marcos Móctum, Municipio de Totontepec, Distrito Mixe, Oaxaca". (CTBC-Móctum) Archivo General de la SRA-Oaxaca. 
usufructuaban directamente las tierras de Móctum o bien las daban a medias o por gozona a otros paisanos de Totontepec, por ello eran vistos por los habitantes de Móctum como caciques.

Como lo expuse en el capítulo anterior, la lucha que los habitantes de Móctum hicieron por recuperar su tierra se enmarca a finales del caciquismo indígena en la región. Como lo apuntan algunos autores (Nahmad 1965), los caciques jugaron un papel importante al promover el desarrollo, sin embargo, los efectos negativos y autoritarios también se hicieron sentir (Floriberto Díaz 1994).

De esta manera, para recuperar sus tierras, los de Móctum recurrieron al derecho del Estado como "vía pacífica"; aunque no querían confrontarse violentamente con los de Totontepec, tuvieron que empezar a trabajar las tierras ocupadas por éstos, es decir, ejercer la posesión como elemento legal -según la ley del Estado - fundamental para reclamar el derecho de propiedad sobre sus tierras. ${ }^{136}$ Esto derivó en una serie de confrontaciones entre las partes en disputa, donde los de Móctum eran denunciados por los del grupo de Totontepec ante el Ministerio Público de Zacatepec. El único escrito del expediente agrario que hace constar esto es el anteriormente citado, suscrito por el grupo de Totontepec ( 28 de octubre de 1983). Sin embargo, al no contar con documentos que acreditaran la propiedad o posesión sobre las tierras tal denuncia no prosperó, por lo que tomaron la decisión de hacerse justicia por propia mano (cfr. Gómez Bravo 2004).

Por lo anterior, después de que se publica la Resolución Presidencial de 1975, los pobladores de Móctum aprovechando su categoría de Agencia (pues todavía no habían nombrado autoridades o representantes agrarios) presentaron múltiples escritos dirigidos a las autoridades agrarias, así como denuncias penales dirigidas al juez mixto de lo civil y lo penal en materia común en el distrito de

\footnotetext{
136 Vale decir que la Ley Federal de Reforma Agraria (LFRA) y la legislación civil en la materia señalan que la posesión - uso de la tierra - es la prueba fundamental para exigir el derecho de propiedad.
} 
Santiago Zacatepec Mixe. Pese al uso de esta "vía pacífica", seguían siendo hostigados y encarcelados por las autoridades municipales de Totontepec. ${ }^{137}$

La información y asesoría, sobre los requisitos legales para hacer efectivo el derecho de posesión y posteriormente de propiedad sobre la tierra, la obtuvieron los de Móctum de la Asamblea de Autoridades Mixes (ASAM) y concretamente de Servicios del Pueblo Mixe, que contaba con abogados para apoyar el proceso de reivindicación de la tierra que los de Móctum encabezaban.

\section{El centro de la disputa}

El centro de la disputa entre Móctum y Totontepec es fundamentalmente la dominación de este centro de poder sobre Móctum, que se expresa en la disputa por la posesión de la tierra.

A continuación, la última fase del conflicto entre estos dos poblados la analizaré en tres momentos: 1) la intermediación de un tercero, 2) la negociación de las partes litigantes y 3) la imposición de una resolución final.

Conforme los funcionarios, topógrafos y agrónomos de la Secretaría de la Reforma Agraria (SRA) fueron avanzando en los trabajos de inspección y reconocimiento de linderos, los terrenos colindantes y los que estaban en disputa, las partes (grupo de Totontepec y comuneros de Móctum) se vieron en la necesidad de reconocer lo que jurídicamente (según la ley del Estado) podían o no podían hacer. Es decir, resultó que el número de hectáreas que decían los de Móctum que les habían invadido los de Totontepec no eran cien (lo que corresponde a casi la mitad de la totalidad de sus terrenos), sino mucho menos; de igual forma las tierras que decían los de Totontepec estar trabajando no todas estaban produciendo o bien estaban descuidadas desde hacía tiempo según los

\footnotetext{
137 Muchas de ellas tenían interés directo sobre las tierras de Móctum, como se desprende del expediente agrario de Móctum y del expediente Núm. 739-TC. “Confirmación y Titulación de Terrenos Comunales. Totontepec Villa de Morelos, Municipio mismo nombre (m/n), Distrito Mixe, Oaxaca". (СтвC-Totontepec) Archivo General de la SRA-Oaxaca. En éste se muestra además, cómo otros pueblos agencias y colindantes de este poblado tuvieron un problema similar al de Móctum con Totontepec.
} 
trabajos en campo realizados por los funcionarios de la SRA; por último resultó que eran 16 personas las que estaban invadiendo, de las cuales 11 estaban en la relación de comuneros de Totontepec, los otros cinco eran trabajadores a medias ${ }^{138}$ de aquéllos.

Con lo anterior se precisa que el papel de la Secretaría de la Reforma Agraria en el conflicto fue para investigar y aclarar las percepciones y argumentos de las partes con base en los datos obtenidos en campo. Al mismo tiempo con estos datos se convenció a cada uno de los poblados de lo que jurídicamente era posible hacer, con esto se estableció un espacio de negociación para que las partes plantearan sus propuestas. ${ }^{139}$

Pese a los sucesivos planteamientos de alternativas de solución, no se consiguió llegar a un acuerdo, por lo que la SRA tuvo que imponer una solución final, resolviendo a favor de Móctum.

Los de Móctum propusieron pagar los trabajos y construcciones que hubieran realizado el grupo de Totontepec y lograr que salieran de sus terrenos, lo cual fue respetado por la SRA y la Secretaría de Agricultura y Recursos Hidráulicos.

Es importante recordar que antes de las reformas al ARTículo 27 Constitucional en materia de tierras la SRA era juez y parte en el reparto agrario; determinaba quién debía ser favorecido, poniéndose de lado de uno u otro de los oponentes y emitiendo una resolución definitiva prácticamente inapelable. En este caso prevaleció la adjudicación más que una negociación. Esto es así, porque en el proceso agrario que se llevó a cabo para resolver el conflicto entre Móctum y Totontepec se dieron cuatro momentos: confrontación, negociación, mediación y adjudicación, que se repetían alternativamente, en una especie de espiral hacia arriba, dando la impresión de regresar al mismo punto pero en un nivel distinto de

\footnotetext{
138 Que trabajaban los terrenos de los poseedores-invasores a cambio de que la cosecha se repartiera a la mitad entre ambos.

139 Tanto las propuestas como la negociación se encuentran en el expediente. En este proceso tuvieron el asesoramiento y acompañamiento de Servicios del Pueblo Mixe, lo que consta en el expediente agrario y fue confirmado por don Cipriano Gómez y Adelfo Rodríguez Guzmán, ya que ambos fueron autoridades.
} 
intensidad. Aunque el resultado final fue aparentemente impuesto por la SRA ambas partes aceptaron la resolución, de no haber sido así el conflicto todavía existiría, como sucede con muchos otros conflictos agrarios en Oaxaca. Por tanto, fue una resolución por adjudicación negociada, es decir, la solución la "presenta" la SRA y la "impone", pero es negociada y aceptada por las partes.

\section{La resolución del conflicto}

Con los trabajos realizados por la SRA los representantes de Móctum y los invasores de Totontepec tuvieron que ceder en sus posiciones lo que baja el nivel de confrontación y cambia la arena de la disputa: pasan de la agresión física y la invasión de los terrenos al proceso legal ante la SRA. Así, pese a que los comuneros de Móctum se sabían dueños de sus terrenos no podían negar la posesión del grupo de Totontepec (según la ley del Estado a la que ambas partes habían recurrido y por tanto aceptado), es decir, reconocieron que los totontepecanos sí eran dueños de cafetales, platanares y varios árboles que cultivaron, pero que la dominación, menosprecio y denigración a que eran sometidos llegó a grados intolerables que los obligó a exigir que les regresaran sus tierras. ${ }^{140}$ Por su parte los de Totontepec no podían negar que los terrenos en disputa eran terrenos comunales de Móctum y no pequeñas propiedades, esta situación mantuvo a las partes en una serie de pláticas y negociaciones.

Fuera del expediente algunas personas de Totontepec sostenían que los verdaderamente originarios de esas tierras son ellos y que todos los demás (las agencias-comunidades) llegaron porque Totontepec les dio permiso o les prestó las tierras. De igual forma llaman a Móctum "barrio grande" que, según dicen, es la

\footnotetext{
${ }^{140}$ Fuera del expediente, la versión de los comuneros de Móctum era que la dominación de los de Totontepec llegó al extremo de que sus parcelas o trabajaderos ocupaban lo que ahora es el asentamiento humano, o zona urbana de la comunidad, las casas de los de Móctum eran usadas como bodegas para guardar maíz y café. "En las fiestas ellos se 'autoinvitaban' e 'invitaban' a sus amigos y parientes, además el mayordomo, cuando preparaba la fiesta todo lo tenía que comprar en Totón [sic], hasta las cocineras eran de allá' y si sobraba comida éstas se la llevaban por si el padre pide recalentado" (testimonio de una mujer de Móctum).
} 
traducción del nombre de Móctum al español, y a manera de menosprecio agregan que nadie de Móctum es "originario", pues todos sus pobladores vienen de distintos pueblos mixes. La aseveración de que los otros pueblos llegaron a poblar con el permiso de Totontepec, queda por demás refutada al confrontarla con las fuentes históricas (cfr. Gerhard 1986:378, 380; Chance 1998). De la misma manera, en los expedientes agrarios de otras agencias-comunidades se señala que los pueblos, que ahora integran el municipio de Totontepec, existían desde antes de la Colonia y que al momento de la reforma agraria del siglo XX exhibían y entregaban sus títulos primordiales para iniciar sus expedientes de confirmación de terrenos comunales (como Tepitongo, Tiltepec y Huitepec, los dos primeros colindantes de Totontepec en sus terrenos comunales).

Algunas propuestas que se presentaron entre Móctum y Totontepec con funcionarios de la SRA, ya en la etapa de resolución, fueron entre otras que los del grupo de Totontepec pagaran cierta cantidad de dinero por el usufructo de la tierra (es decir, como una especie de renta), sin embargo, el acuerdo sobre el monto no se logró. Otra propuesta fue que además del usufructo los del grupo de Totontepec debían pagar las cooperaciones que todos los comuneros de Móctum hacían por obras y tequios, lo que en definitiva no fue aceptado por los de Totontepec. Una propuesta más fue que los del grupo de Totontepec se integraran como comuneros a Móctum. Al parecer esta última propuesta pareció ser la más atractiva para las partes en conflicto dado que varias veces se reunieron para afinar detalles, sin embargo, finalmente, los de Totontepec no aceptaron. Por un lado, alegaban que ellos como comuneros y avecindados de su pueblo ya pagaban cuotas y que hacerlo en Móctum les traería más gastos que beneficios; por su parte, los de Móctum seguían aumentando requisitos, por ejemplo, que los del grupo de Totontepec construyeran sus casas en Móctum, esto es, que dejaran de ser comuneros de aquel pueblo (perdiendo sus derechos) y se convirtieran en comuneros de Móctum. 
Como lo he mencionado, el desarrollo del conflicto involucró a las autoridades agrarias y municipales de Totontepec, sobre todo porque al considerarse dueños y poseedores usufructuaban directa o indirectamente los terrenos en Móctum. El siguiente párrafo es alusivo de esto.

29 de noviembre de 1984.

El Comisariado de BC [sic] de Móctum Rogelio Martínez Jiménez, solicita al sub Delegado de BC en el Estado para que llame la atención del Síndico Municipal de Totontepec Vicente Vasquez Martinez a fin de que se le indique de que se abstenga de estar interviniendo en virtud de no ser de su competencia. [En este mismo oficio se señala que los CC. Aurora Rivera y Lucio Villegas están proponiendo al mejor postor las tierras que poseen en Móctum. Se solicita que se abstengan de proponer al mejor postor las tierras (expediente Núm. 276.../807 TC:319, 329, 330, 331). La denuncia en contra del Síndico de Totontepec la dirigen también al Gobierno del Estado. "Secretaría General de Gobierno. Lic. Gaspar Hernández Chávez, éste solicita informe al síndico en un plazo de 72 horas. 4 dic. 1984" expediente agrario Núm. 276.../807 TC:327]

A pesar de que en 1980 se ejecuta la Resolución Presidencial de 1975 a favor de Móctum (hecho que queda constatado en el Acta de Ejecución y Deslinde por la que se le reconoce formalmente la posesión y delimitación de sus tierras), es hasta mucho después (1996) que se logra un acuerdo ${ }^{141}$ sobre los terrenos en los que existían árboles y sembradíos de los de Totontepec, tal vez porque hasta el 10 de diciembre de 1991 la Secretaría de la Reforma Agraria tuvo listo el plano definitivo y casi un año después, el 9 de diciembre de 1992, hace entrega de la Carpeta

${ }^{141}$ La motivación del Acuerdo era que los posesionarios de Totontepec no querían dejar las tierras, pero como las habían trabajado tenían derechos de posesión y no de propiedad sobre ellas. Así para los pobladores de Móctum la alternativa (que seguramente ocasionó tensión al interior) era aceptarlos como comuneros o bien "indemnizarlos" (por decirlo de alguna manera) por los árboles sembrados. La indemnización acompaña a la expropiación, ambas jurídicamente hablando son acciones exclusivas del Estado (ARTículo 27 Constitucional). 
Básica ${ }^{142}$ a Móctum. Con esta Carpeta, Móctum tuvo todos los elementos para exigir jurídicamente que los de Totontepec se retiraran de sus terrenos $-\mathrm{o}$ bien cumplieran como comuneros en Móctum-. No obstante, aparece constancia de que en 1994 algunas personas, familiares de los primeros poseedores-invasores, todavía reclamaban derechos. ${ }^{143}$

Así anduvimos buscando y buscando soluciones, hasta que el gobierno dijo que se pagara los plantíos que tienen en nuestro rancho, para eso se solicitó la intervención del CECAFE [Consejo Estatal del Café], para que hiciera la inspección ocular y que evaluaran los precios de cada planta, la comunidad de Móctum consiguió a duras penas el dinero, fue

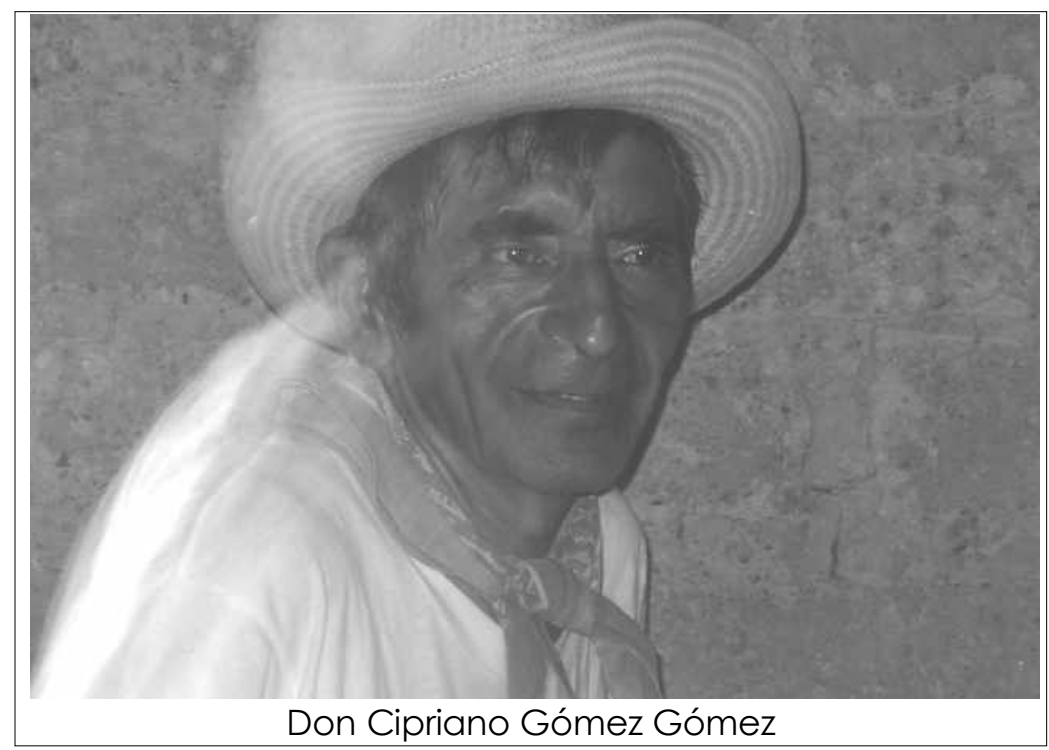

difícil para convencer a los de Totontepec que aceptaran la indemnización, ya que ellos le ponían un precio tan alto que el dinero que se había juntado lo querían como pago para una sola persona. Se pudo negociar porque nos

basamos en el avalú, hasta que se convencieron y aceptaron el dinero. Las dependencias institucionales que intervinieron fueron: Junta de Conciliación Agraria, Procuraduría Agraria, Reforma Agraria y la Delegación del Gobierno, junto con los comisariados de bienes comunales, Agentes de Policía y autoridades de Totontepec, dando vueltas buscando solución, jhasta que por fin se le da solución en mayo de 1996! ¡después de haber luchado durante 30 años! [Entrevista a don Cipriano Gómez Gómez 1997]

Como lo revela este testimonio, fue la tesón de los comuneros de Móctum y gracias al respaldo de su propuesta por distintas instituciones lo que permitió que

142 Integrada por la Resolución Presidencial (2 de septiembre de 1975), Acta de Ejecución y Deslinde (2 de agosto de 1980) y el Plano Definitivo (10 de diciembre de 1991).

143 Expediente de CTBC-Móctum. 
consiguieran el reconocimiento legal de los derechos sobre sus tierras (cfr. expediente Núm. 276.../807 TC). Después de un estudio solicitado por el entonces gobernador del estado de Oaxaca, resolvieron que la solución era que al grupo de poseedores invasores de Totontepec se les pagara por los árboles y construcciones hechas en los terrenos objeto del conflicto. Dicho pago resultó del esfuerzo de Móctum.

\section{Las consecuencias sociales}

Como se ha mencionado San Marcos Móctum es un pueblo mayoritariamente adventista, sus habitantes argumentan esta adopción en lugar del catolicismo por los gastos que les significaban la fiesta patronal y los malos tratos que recibían de algunos habitantes de Totontepec - mayoritariamente católicos-, sobre todo comerciantes y posesionarios/invasores de sus terrenos. Detrás de esto existe la contestación al poder central que representa Totontepec, recuérdese que éste es cabecera municipal pero también es el centro de la parroquia católica y adventista para distintos grupos etnolingüísticos.

De esta manera, el conflicto agrario de larga duración - porque se remonta a tiempos anteriores a la Conquista- como conflicto madre coincide con la penetración del adventismo en el siglo XX. Como se puede apreciar de la lectura del expediente civil en la Colonia y agrario en el siglo XX, en la disputa por la tierra se mantiene la insistencia entre comunidades de distinguirse entre sí, lo que es más claro en el caso del conflicto agrario cuando los de Totontepec admiten que las tierras que poseen están en jurisdicción de Móctum y no aceptan dejar de ser comuneros en su pueblo para convertirse en comuneros de éste último. Ante esto, la argumentación de los habitantes de Móctum a favor del adventismo se puede interpretar como una manera de contestación a la religión católica, representada en la zona por Totontepec.

Lo anterior es más claro si se considera la ideología comunitarista que exacerba la lucha por la prevalencia entre dos posturas: de resistencia al poder 
central y de imposición de éste. En esta lucha de poder la conversión religiosa facilitó y fortaleció a Móctum para señalar límites en su relación con la cabecera, sobre todo en un momento en el que no tenía su Resolución Presidencial y aun después de ésta ya que faltaba ejecutarla para darle plena validez.

Por esa convergencia entre el conflicto agrario madre y la conversión religiosa que reafirma la identificación de Móctum como una comunidad aparte de Totontepec, puedo afirmar que tal conversión fue una de las consecuencias sociales del conflicto, que influyó en el cambio en la estructura tradicional de la organización comunitaria (PARTE III). Otra consecuencia es la incorporación de Móctum al Programa de Certificación de Terrenos Comunales (PROCEDE o PROCOM), con esto los comuneros empiezan a recibir apoyos económicos, la relación con la cabecera cambia y Móctum agiliza la gestión de obras. De igual forma, al estar libre de la injerencia de Totontepec, los de Móctum empezaron a construir su derecho sobre nuevas bases, sin embargo, el conflicto agrario por ser reciente influye en el contenido y desarrollo de las normas internas y en la organización y dinámica comunitaria (CAPítulo 6). Por último, el finiquito del conflicto trajo como consecuencia que los pobladores de Móctum enfocaran sus esfuerzos en cuestiones relacionadas con su sobrevivencia y su devenir histórico, como obtener obras para la electrificación, el drenaje, el agua potable y, sobre todo, la protección del patrimonio cultural del pueblo mixe que yace en sus terrenos.

\subsection{Lo municipal como punto de tensión en la relación entre Móctum y Totontepec}

En el ámbito de la relación con el municipio de Totontepec, es relevante señalar que tradicionalmente las diez agencias no participan en la elección del cabildo municipal - el cual se realiza por usos y costumbres-, este derecho es exclusivo de los habitantes de la cabecera. De igual forma, las agencias escogen a sus autoridades internas por el mismo sistema, sin la injerencia de la cabecera, aunque la Ley Municipal del Estado de Oaxaca otorga al presidente municipal la facultad 
de asignar a los agentes, lo que indudablemente se plantea como un punto de conflicto entre cabeceras y agencias. ${ }^{144} \mathrm{El}$ hecho de que las agencias no participen en la elección por usos y costumbres del ayuntamiento y que, a su vez, los pobladores de la cabecera tampoco lo hagan para la elección de las autoridades de las agencias, tiene su explicación en los antecedentes históricos de Totontepec como pueblo de frontera con otros grupos etnolingüísticos y con Villa Alta como asentamiento colonial; también se explica por el comunitarismo arraigado entre los mixes y la descaracterización étnica de Totontepec sobre la cual las agencias perciben que sus habitantes, de una u otra forma, han tratado de distinguirse como superiores.

En cuanto a los recursos municipales en Totontepec, en diez años, por lo menos (desde 1990), se ha establecido y acordado, entre la cabecera y las agencias a insistencia y por reclamo de sus autoridades, que cada una haga una lista de obras y el Consejo Municipal, presidido por el presidente municipal -oriundo de Totontepec - , las aprueba o las rechaza, pudiendo las agencias reclamar, según el derecho estatal, ante el mismo ayuntamiento, sin posibilidad de ir hacia el Gobierno del Estado, de lo contrario se pone en riesgo la relación con el municipio para subsiguientes gestiones. En el siguiente apartado me refiero a los recursos municipales y a un ejemplo que ilustra cómo esa dinámica establecida entre la cabecera y sus agencias se ve cuestionada por éstas.

\section{Disputa por los recursos: Reivindicación de derechos de las agencias frente a la cabecera}

Para explicar el punto de tensión entre la comunidad-cabecera y las comunidadesagencias sobre los recursos económicos que llegan directamente a la cabecera municipal y que la comunidad-cabecera quiere seguir controlando, se expondrá en

\footnotetext{
${ }^{144}$ La forma como las comunidades-agencias o comunidades-cabeceras eligen a sus autoridades está reconocida por la Ley de Pueblos y Comunidades Indígenas del Estado de Oaxaca así como por el Código Estatal de Procedimientos Electorales, en el que se establece la posibilidad de cambiar las elecciones de sistema de partidos a sistema de usos y costumbres.
} 
primer lugar el tipo de recursos de que se trata, cómo se identifican, de dónde provienen y cómo se aplican, con ello, posteriormente me refiero al caso concreto de Totontepec y sus agencias.

\section{La hacienda municipal}

En el Artículo 115, fracción IV, de la Constitución Política de los Estados Unidos Mexicanos, se determina que los municipios son los responsables de administrar libremente su hacienda, la cual se integra por: patrimonio propio (bienes muebles e inmuebles que pertenecen al municipio), contribuciones e ingresos, participaciones federales (ramo 28), aportaciones federales (ramo 33) e ingresos extraordinarios.

De acuerdo con Jesús Campos (2000:154), en la actualidad las principales fuentes de recursos con que cuentan los municipios de México son las participaciones federales (ramo 28), las aportaciones federales (ramo 33), las participaciones estatales, los ingresos propios (principalmente la recaudación del impuesto predial y del agua), otros programas federales (establecidos en el ramo 20, por ejemplo, el Programa de Empleo Temporal y PROCAMPO), la posibilidad de contratar deuda pública y otras fuentes como pueden ser las provenientes de organismos de cooperación internacional, de hermanamientos con otras ciudades, o los recursos que llegan por medio de migrantes que radican en el extranjero.

De estos recursos nos interesan directamente los ramos federales etiquetados como 28 y 33 dado que son los que han generado en el estado de Oaxaca la mayor cantidad de confrontaciones entre cabeceras y agencias, pues son recursos que los municipios pueden manejar con relativa libertad, a diferencia de los demás que se fija de antemano su utilización.

\section{Participación y aportaciones federales}

Por un lado, las participaciones federales ${ }^{145}$-donde se ubica el ramo 28 provienen de los ingresos de los tres ámbitos de gobierno, y se concentran en el

145 De acuerdo con Campos Orozco (2000:168): “las participaciones federales que deben ser entregadas a los municipios por conducto de los gobiernos estatales son recursos que provienen de 
Fondo General de Participaciones, el cual se distribuye a las entidades federativas y están obligadas a entregar como mínimo $20 \%$ de lo que reciben de sus municipios (según su número de habitantes). Es decir, la federación, las entidades federativas y los municipios se distribuyen las participaciones o recaudación federal participable ${ }^{146}$ de acuerdo con lo establecido en el Sistema Nacional de Coordinación Fiscal. ${ }^{147}$ Esto implica que el uso o destino de los recursos, que haga cada uno de los tres ámbitos de gobierno sea libre y supervisado exclusivamente por la legislatura correspondiente.

Por otro lado, las aportaciones - como el ramo 33- son recursos federales con un mayor grado de descentralización, es decir, serán administradas y ejercidas por los gobiernos de las entidades federativas y, en su caso, los municipios que las reciban, conforme a sus propias leyes. Por tanto, al registrarlas como ingresos propios tienen mayor libertad de aplicación de acuerdo a las necesidades locales o comunitarias.

Jesús Campos apunta (2000:171) que:

la característica principal de las aportaciones consiste en que no son una distribución de la recaudación federal participable, como es el caso de las participaciones. Las aportaciones son recursos federales con un mayor grado de descentralización. Esto determina el hecho de que

varios fondos, a saber: Fondo General de Participaciones, Fondo de Fomento Municipal, Fondo por Coordinación en Derechos, Reserva de Contingencia, Fondo para Municipios Fronterizos o con Litoral, participaciones por los impuestos especiales sobre producción y servicios (IEPS), participaciones por la recaudación de la tenencia o uso de vehículos (ITUV), participaciones a municipios fronterizos o con litoral por el derecho adicional sobre la extracción de petróleo, participaciones a municipios con puentes de peaje y participaciones por la recaudación de pequeños contribuyentes [...] la distribución de los recursos a los municipios debe realizarse mediante criterios generales; esto significa que debe existir una fórmula aprobada por el Congreso local, con base en la cual se determinan los coeficientes y montos para cada municipio. Cada fondo o concepto participable tiene sus porcentajes específicos, su particularidad y complejidad que deben ser estudiados y analizados con detalle. Es importante que cada estado cuente con una ley estatal de coordinación fiscal y se pugne para que los ayuntamientos cuenten con facultades como organismos de coordinación fiscal".

146 Es la "bolsa grande" de recursos que se reparte entre la federación, los estados y los municipios. Está constituida por todos los impuestos, los derechos sobre la extracción de petróleo y minería, menos el total de devoluciones por los mismos conceptos (Campos 2000:162).

147 Constituido por un marco jurídico en el que se establecen los criterios de aportaciones (importe para la transferencia de recursos descentralizados), y sus adecuaciones operativas en los años subsecuentes. 
su destino sea etiquetado en lo general y supervisado por las entidades federativas, pero sancionado en última instancia por la Federación. 148

Lo que se puede observar de lo antes expuesto ${ }^{149}$ es que el ramo 33 son recursos federales que son administrados y ejercidos por el Gobierno de Oaxaca - por ejemplo- que distribuye, por tanto, a discreción a los municipios y que éstos, a la vez, disponen con libertad sin tener la obligación predeterminada de remitirlos a las agencias. Por su parte, la legislatura del estado de Oaxaca supervisa el uso y ejercicio del ramo 28.

Por la libertad que implica en su ejercicio estos dos ramos y la falta de una regulación que obligue a las entidades federativas, en este caso el Gobierno del Estado de Oaxaca, a distribuirlos a los municipios y que éstos lo distribuyan a sus agencias, es comprensible que las disputas por los recursos de este tipo sean recurrentes.

\section{La tensión entre Totontepec y sus agencias}

De acuerdo a los datos obtenidos durante mi trabajo de campo, las partidas municipales provocan - por lo menos desde hace diez años - importantes tensiones entre la comunidad-cabecera y las comunidades agencias, fundamentalmente por los ramos 28 y 33. Esta disputa llevó a la mayoría de las agencias a exigir ante el Gobierno del Estado de Oaxaca que la cabecera municipal informara sobre los montos de estos ramos y su distribución. Es de resaltar que en los escritos firmados en conjunto por los agentes, para este fin, se invocan artículos y leyes como es la Ley de Derechos de las Comunidades y Pueblos Indígenas del Estado de Oaxaca (o Ley Indígena de Oaxaca), así como el decreto

148 "La Federación transfiere [las aportaciones] a las haciendas públicas de los estados, Distrito Federal y, en su caso, de los municipios, condicionando su gasto a la consecución y cumplimiento de los objetivos que para cada tipo de aportación establece la ley de Coordinación Fiscal [...] se establece que las aportaciones serán administradas y ejercidas por los gobiernos de las entidades federativas y, en su caso, de los municipios que las reciban, conforme a sus propias leyes. Por tanto, deberán registrarlas como ingresos propios".

${ }^{149}$ La intención de lo anterior es comprender de dónde provienen los recursos distribuidos a los municipios, cuáles son esos mecanismos de distribución y cómo pueden ser utilizados por las cabeceras. La disposición sobre los recursos su administración y ejecución es lo que de alguna manera da una visión de los conflictos que esto puede generar y ha generado. 
correspondiente. Esto revela que la Ley Indígena como el conocimiento y uso de la misma genera tensión, y cómo leyes estatales son usadas para confrontar el poder de la comunidad-cabecera.

Existen convenios y acuerdos elaborados entre la cabecera de Totontepec y sus agencias (en reuniones de Consejo Municipal, en el que se reúnen representantes de todas las agencias y el presidente municipal) para establecer mecanismos de distribución de los recursos municipales: uno de ellos consiste en que las agencias se turnarían en la asignación del ramo 33, y otro acuerdo resultó de la disputa antes referida que llevó a un grupo de agencias del municipio a exigir cuentas sobre la distribución del ramo $28 .{ }^{150}$

El acuerdo, de que las agencias se turnaran en la repartición del ramo 33, es porque la asignación que le corresponde al municipio (en relación a su número de habitantes en conjunto cabecera / agencias) no es suficiente para ser distribuida entre las diez, incluyendo la cabecera. Tan sólo este año le tocó a cada una de las cinco agencias en turno para recibir los recursos del ramo (Móctum, Jareta, Huitepec, Tepitongo y Tiltepec), aproximadamente cuatrocientos mil pesos, lo que en total son dos millones de pesos, sin contar el ramo 28 y lo que le corresponde a la cabecera. Aunque las autoridades de la cabecera señalan que el reparto se hace de manera equitativa, existen dudas de algunas agencias, pues suponen que la cabecera se queda con más dinero, lo cierto es que la cabecera cada año recibe

150 En el escrito dirigido al presidente municipal con fecha 9 de febrero de 2004, suscrito por nueve agencias, excepto Móctum, se señala: "Los que suscribe [sic] CC. Agentes municipales y de policía del municipio de Totontepec Villa de Morelos, Mixe; conforme al decreto No. 108 de la LV legislatura constitucional del Estado libre y soberano de Oaxaca; nos dirigimos a usted con el debido respeto con el propósito de solicitar que a la brevedad posible nos haga saber de manera conjunta sobre el fondo municipal ramo 28 , así también como las demás obras a realizarse en las diferentes comunidades de su jurisdicción en el presente ejercicio. Hemos de agradecer que nos haga llegar la convocatoria para análisis y discusión de lo antes expuesto. Por lo anterior esperamos ser favorecidos y atendidos de acuerdo a la ley de derechos de los pueblos y comunidades indígenas en su artículo 59". Se señala copia para el Contador Mayor de Hacienda, al Delegado de Gobierno en la zona mixe-choapam y al expediente. Supongo que Móctum no participó en esto porque estaba en curso una negociación con la cabecera municipal para permitir abrir un camino para que los pobladores de Totontepec pudieran pasar a sus parcelas, a cambio de diversas obras como el alumbrado y el agua potable. Sin embargo, esto es una suposición personal que no pude corroborar con las autoridades de Móctum en turno. 
ramo 28 y 33, a diferencia de las agencias que como lo he mencionado no todos los años reciben ramo $33 .{ }^{151}$ La cabecera tiene una densidad de población superior a las agencias (cada una por separado) y, según datos de las autoridades en turno de las agencias visitadas (seis), las más pobladas no superan los mil habitantes, ${ }^{152}$ en cambio la cabecera tiene aproximadamente entre cinco mil y seis mil habitantes, de esta manera la cantidad o número de habitantes es un elemento que explica la diferencia en la asignación. Las necesidades en las agencias no obstante pueden ser mayores o más apremiantes para sus pobladores (como un médico de planta, refrigerador para medicinas, almacenaje e irrigación de agua potable, alumbrado público).

Como lo he expuesto, el ramo 33 debe ser comprobado según partidas previamente autorizadas, mientras el ramo 28 puede ser aplicado con mayor libertad a diversas necesidades ya que no está previamente etiquetado o asignado, además de que el sistema de comprobación no es tan estricto y complejo, por lo que algunos municipios lo aplican para pagar salarios a los empleados municipales. En el caso de Totontepec, los únicos que reciben alguna remuneración simbólica (no salarial) son la secretaria municipal y el tesorero. La característica del ramo 28 de alguna manera permite a los municipios disponer de estos recursos de la mejor manera, pero también no obliga a las cabeceras a repartirlo entre sus agencias, que como lo mencioné al principio ha generado reclamos por parte de éstas, que ahora piden que además del ramo 33 el ramo 28 también entre en la distribución entre cabecera y agencias.

\section{Obras municipales en Totontepec}

Podemos decir que "tradicionalmente" la posición de Totontepec frente a sus agencias ha sido inequitativa y desigual, que la descaracterización étnica, como lo

151 Según el Agente de Policía de Móctum (2004): “a cada una de las 4 agencia le tocó 460 mil pesos. A Totontepec todos los años le toca $40 \%$ del presupuesto general y a las agencias $60 \%$ para repartirse. Ese presupuesto es de los dos ramos, el 33 y el $28^{\prime \prime}$.

152 Sin embargo esta información debe tomarse con la debida reserva, pues la suma total de habitantes entre la cabecera y las agencias no concuerda con los totales del INEGI. Lo que es evidente es que la población de cada una de las agencias es menor a lA de la cabecera. 
he señalado, se expresa en la comunidad-cabecera sobre todo en la pretensión de sus pobladores de demostrar su superioridad o ubicarse por encima de las demás agencias.

Pese a lo anterior, en 2004, la presidencia municipal la ocupó un maestro muy relacionado con el movimiento de reivindicación étnica y de derechos humanos que, seguramente influenciado por líderes como Adelfo Regino (de Servicios de Pueblo Mixe) y por su propia formación profesional, trató de dar otro giro a la relación de la comunidad-cabecera con la comunidad-agencia. De esta manera, en entrevista (24 julio de 2004) el presidente municipal en turno argumentó que a diferencia de otros años él convocó a las agencias para ponerlas al tanto de las participaciones municipales y para constituir el Consejo Municipal con los agentes municipales y de policía y decidir las obras del año, ya que de acuerdo con el sistema de usos y costumbres, por lo menos en Totontepec, se nombran tres cabildos para que cada año se ocupen del cargo diferentes personas:

Este año lo que yo hice fue informar a cada una de las agencias lo que les toca para el ramo 33 , en los fondos 3 y 4 . Hasta se quedaron sorprendidos porque antes no era así, hasta se dieron cuenta que les estaban dando menos [en otras administraciones municipales de Totontepec]. Entonces ahora con las cinco agencias con las que estoy trabajando les dije claramente cuánto les toca. Ni modo, tal vez con otro presidente sea diferente. De las diez agencias que tiene Totontepec se turnaran por año, de lo contrario, si el presupuesto [sic] se dividiera entre las diez se pulverizaría, no alcanza para nada.

En esta misma entrevista aproveché para preguntar al presidente municipal sobre los ramos 33 y 28 , el primero lo explica como un recurso para abatir el rezago social aplicado a obras prioritarias como agua potable, electrificación, caminos, educación, salud y seguridad pública. ${ }^{153}$ El ramo 28, según palabras del entrevistado:

153 "Yo lo explico como un recurso [el ramo 33] para abatir el rezago social. El fondo 3 de este ramo es para obras prioritarias: agua potable, electrificación, caminos, educación y salud. El fondo 4 es un recurso para seguridad pública: uniformes de los policías, armas, ambulancias. Además de lo que se reparte del ramo 33 
Se puede utilizar en lo que sea siempre que se compruebe. Serían 40 mil para cada una de las diez agencias. Entonces con ese fondo, las cinco restantes que deben esperar para el próximo año no se quedan sin nada para éste. Así, con el ramo 33 se iniciaron varias obras en las agencias: en Santiago Jareta, la construcción de una Biblioteca; en San Francisco Jayacaxtepec, la carretera [la única manera de llegar es por vereda, los vehículos no llegan]; en Santa María Huitepec, un camino; en Metepec, una cocina comunitaria; y en Móctum, la luz trifásica.

Finalmente la tensión entre Totontepec y sus agencias no es reciente, si bien ha pasado por diferentes momentos. Hace quince años, cuando el problema agrario de Móctum estaba por finiquitarse, este pueblo se planteaba la posibilidad de cambiar de municipio (remunicipalización), aunque está en el corazón del territorio que abarca el municipio de Totontepec. También Santa María Huitepec (agencia municipal, colindante con Yacochi, agencia del municipio de Tlahuitoltepec) se planteó esa posibilidad (de acuerdo con sus autoridades del año 2004 y con información de don Cipriano) dado que desde entonces planteaban su inconformidad sobre la distribución de los recursos municipales y la actitud discriminatoria de la cabecera hacia las agencias.

\section{Móctum y su reivindicación de derechos frente a la cabecera}

Las autoridades de Móctum no participaron en la exigencia de las otras agencias por el ramo 28. Según la autoridad de Móctum, se enteró pero no tuvo tiempo de ir a las reuniones dado que su cargo es de tiempo completo y que debe pagar una deuda que contrajo al ir a Estados Unidos. De hecho estando allá tuvo que regresar cuando lo llamaron para hacer el cargo, por lo que no tuvo tiempo de ahorrar dólares. También según su información, Móctum ya no tiene problemas con la cabecera porque el conflicto agrario está finiquitado. Ahora el presidente municipal de

fondo 3, se reparte el fondo 4, pero no lo ocupamos para la policía sino para obras que nos beneficien. Tenemos problemas para la comprobación, pero estamos en eso para que el Estado lo reconozca. Así, por ejemplo, lo estamos usando para el Centro de Educación Musical. El Estado no puede comprender que nosotros vemos la enseñanza tradicional antes que la enseñanza formal. Así los niños primero aprenden a tocar y después aprenden las notas (leerlas). Entonces, este año le toca a cada una de las cinco agencias con las que trabajo $\$ 460603$ pesos". 
Totontepec los apoyó para conseguir la luz trifásica, porque antes con el conflicto agrario consiguieron luz monofásica y el tendido de luz (cableado) viene de Santa María Ocotepec.

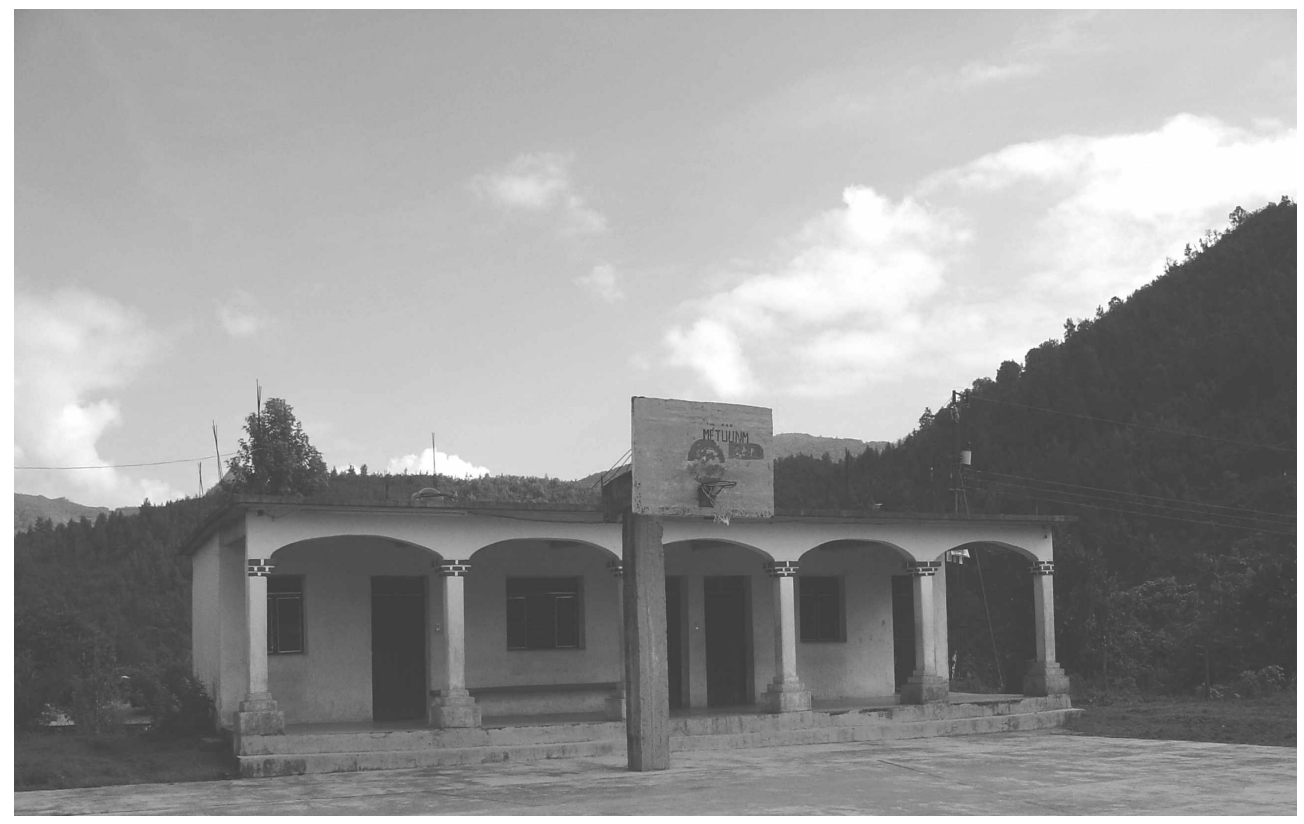

Edificio de la Agencia de Policía de San Marcos Móctum

De esta manera, aunque se repartieron los 460 mil pesos por concepto del ramo 33, y 40 mil por el ramo 28 entre las agencias, a Móctum "no le tocó", pues a esto se debía agregar otra cantidad para conseguir el millón de pesos que costó el cableado de la luz trifásica. Es decir, a Móctum le tocarían casi 500 mil pesos por concepto de esos dos ramos, el resto lo consiguió el presidente municipal en la Comisión Nacional para el Desarrollo de los Pueblos Indígenas (CDI).

Cuando pregunté en Móctum qué beneficios traería la luz trifásica, me respondieron "ahora sí el cableado se haría con orden y como debe ser". También ahora podrían usar molinos de nixtamal más potentes, y que serviría a futuro para el alumbrado público y para integrarse a la red de agua potable que viene de Totontepec, sin embargo, acordaron no desconectar la luz monofásica, porque saben que Totontepec tiene luz trifásica, "pero siempre se les va". Esto es significativo, si comparamos que Totontepec ya cuenta con todos estos servicios, es 
decir, el punto de referencia de Móctum para medir su desarrollo es Totontepec. ${ }^{154}$ Esta referencia del desarrollo al que aspiran las agencias, contrasta con la visión que tienen sobre las actitudes de discriminación de la cabecera. Como lo mencionaba al principio de este capítulo, la disputa por los recursos municipales, iniciada por otras agencias, se ve marcada por la descaracterización étnica y sobre todo por el control y el poder arraigados en la tradición caciquil de la cabecera, que se expresa en actitudes de discriminación hacia las agencias, lo que se entrecruza con la cuestión agraria.

Por último, al no haber participado Móctum en la disputa por los recursos municipales, también marca su postura de no tener mayores conflictos con la cabecera, sobre todo, porque previo a la movilización de las agencias "disidentes" ya habían negociado el cableado de la luz trifásica. Pero esta negociación no tuvo beneficios unilaterales, es decir, sólo para Móctum, porque éste tuvo que ceder terrenos suyos para que Totontepec abriera camino hacia las rancherías de sus comuneros, decisión que fue meditada con mucha cautela dado el antecedente del conflicto agrario. Presumo que de no haber existido la oferta del cableado de luz (con el argumento de un beneficio a largo plazo: en la red de agua potable, en molinos de nixtamal más potentes, o luz en las calles, Móctum no hubiera cedido a la construcción de ese camino. Esto, dado el antecedente de que durante el conflicto agrario con Totontepec, las autoridades en turno de este poblado hicieron lo posible para que Móctum quedara aislado y no tuviera camino que conectara al caserío con la cabecera y otras agencias, lo que le costó más caro al municipio y a

\footnotetext{
${ }^{154}$ La cuestión migratoria no es la excepción, pues según lo apuntan Acevedo y Pardo (s/f) los migrantes en Totontepec fueron el primer contacto hacia afuera aún antes de que llegara la carretera, también su aportación al municipio y su prestigio (según el nivel de ingresos promedio) es reconocido, por lo que algunos jóvenes de Móctum después de finiquitado el conflicto agrario migraron siguiendo ese patrón. Aunque en Móctum se reconoce la necesidad de crear fuentes de empleo y de la insuficiencia de la tierra para retener a los jóvenes, el modelo a seguir no se enfoca a atender estos problemas, lo que tiene que ver también con la falta de un plan de desarrollo municipal, que se explica por los antecedentes históricos del municipio, la política asistencialista de Estado aplicada a él y a las regiones rurales, y la estructura autoritaria y centralista del Estado mexicano en el cual está inserto.
} 
Santa María Ocotepec, agencia colindante de Móctum, porque al abrir la carretera tuvieron que rodear el poblado. Ahora, los pobladores de Santa María Ocotepec tienen que transitar por las veredas (empinadas y sinuosas) que atraviesan el poblado o caserío de Móctum para poder llegar a la cabecera, pues el camino de la carretera es más largo y sólo sirve para los vehículos.

Pese al comunitarismo y a las distancias entre las comunidades-agencias, éstas mantienen canales de comunicación que les permite informarse de lo que sucede en las agencias vecinas y conocer sucesos fuera del territorio municipal. De esta manera, otro ejemplo que revela la manera cómo estas comunidades se relacionan es precisamente el caso de Móctum cuando logra su electrificación gracias al tendido de luz proveniente de Santa María Ocotepec. Durante el conflicto agrario entre Móctum y Totontepec, las autoridades de Ocotepec cortaron la luz a Móctum, tal vez presionados por los caciques de Totontepec. Sin embargo, como la Secretaría de Comunicaciones y Transportes (SCT) estaba abriendo la carretera sobre terrenos de Móctum para llegar a Ocotepec, las autoridades de Móctum prohibieron a la SCT continuar los trabajos sobre sus terrenos, por lo que la carretera se suspendió. Fue entonces que las autoridades de Ocotepec llegaron a la agencia de Móctum a pedir que permitieran que los trabajos de la carretera continuaran, a lo cual cedieron bajo la condición de levantar un acta para hacer constar que Ocotepec "nunca más bajaría la palanca [de la luz]", de lo contrario, una vez terminada la carretera Móctum impediría el tránsito de vehículos y personas por sus terrenos.

Otro hecho lamentable, que ilustra las relaciones de poder entre la cabecera y sus agencias y el desarrollo de los canales de comunicación y de interlocución agencia/agencias y agencias/cabecera, fue la desaparición de dos maestras de preescolar cuyos cuerpos sin vida fueron encontrados posteriormente (los hechos sucedieron a mediados de 2004). Situación que además afectó el ritmo de mi trabajo de campo, pues la familia con la que me hospedé estaba preocupada por mis salidas de campo y las entrevistas, por ello, don Cipriano siempre estuvo 
acompañándome cuando se trataba de visitar otras agencias. Como el caso de las maestras fue tratado directamente por los agentes del Estado especializados en la procuración de justicia, se desarrolla en la PARTE III. 


\section{CONCLUSIONES}

La reivindicación territorial, como referente de subsistencia social y cultural y de ejercicio del poder, ha tenido y tendrá importancia fundamental en la relación del Estado con los pueblos indígenas, y en la relación de las unidades políticas que éstos conforman en el ámbito municipal y regional.

El caso de Totontepec Villa de Morelos es un ejemplo de cómo la dinámica estructural del Estado se reproduce en niveles de organización más simples como lo es la comunidad agraria y el ejido, o la agencia municipal y la cabecera. Pese a ser niveles simples de organización, como entidades semiautónomas insertas en una organización compleja como el Estado, se requiere que su análisis tome en cuenta antecedentes y circunstancias de distinta índole como lo histórico, lo social, lo cultural, lo económico y lo político.

En este caso tomé el ejemplo del conflicto agrario entre Móctum y Totontepec como la expresión de una relación más compleja, que tiene sus antecedentes mucho antes de la Colonia española y que trasciende en el tiempo para resurgir de otra manera sobre un mismo punto de tensión: el ejercicio y lucha por el poder y control, entre unidades céntricas y periféricas. Por la importancia que implica la tierra como demarcación territorial, se comprende que, al recuperarla, Móctum no sólo recuperó su fuente de subsistencia económica sino, sobre todo, la posibilidad del control de sus recursos y la determinación sobre sus dinámicas internas y sobre su futuro. Podemos decir que lo territorial para Totontepec, como comunidad agraria y con casi seis mil hectáreas de tierra, tiene la misma importancia. ${ }^{155}$

Para el análisis del conflicto agrario, que yo denomino conflicto madre, me basé en la propuesta de Nader (1978) sobre la historia de las disputas, si bien ella lo utiliza para los conflictos entre particulares, yo lo aplico al caso de un conflicto

155 Expediente Núm. 739-TC. 
colectivo en el que se ven confrontadas dos comunidades. Parto de que es un conflicto madre porque determinó la relación que posteriormente tendrían estos dos poblados, además de las reglas que en Móctum se establecerían para evitar nuevas invasiones en sus terrenos. De igual forma, este conflicto ha determinado que muchas veces los pobladores de Móctum piensen dos veces antes de llevar sus asuntos ante la cabecera, aunque no lo hacen con tanta frecuencia como otras agencias, no ha significado que dejen de hacerlo.

De igual forma, el caso de Totontepec y Móctum toma especial relevancia por las características étnicas de ambos, donde la población de la cabecera ha insistido en distinguirse del resto de las comunidades-agencias, adoptando actitudes racistas y discriminatorias que en los últimos años aparentemente se retraen para dar lugar a la reivindicación étnica del ser mixe. Por su parte, Móctum a pesar de la penetración adventista empieza a retomar su propia historia y herencia cultural que de alguna manera les permite mantener la identidad local y una cierta autonomía en el manejo de sus asuntos internos (CAPítulos 2 y 3). En este proceso sus habitantes han tomado medidas para resguardar los vestigios - piedras talladas - que han descubierto, pues han sabido de vecinos del mismo pueblo que las han sacado o vendido a personas de Totontepec (cfr. Gómez Bravo 2004). Tanto los habitantes de Móctum como algunos arqueólogos presumen que estos vestigios son de un centro ceremonial ubicado dentro de la demarcación territorial de Móctum. Una de esas medidas ha sido acordar en asamblea que la persona que encuentre una "piedra tallada" deberá entregarla al agente de policía para que éste la resguarde en la oficina del Comisariado de Bienes Comunales, también si algún miembro de Móctum observa a personas ajenas a la comunidad tomando fotos o revisando el lugar, deberá comunicarlo a la autoridad, lo que se ha vuelto una norma oral interna parte del "reglamento" como veremos más adelante.

Como veremos en la PARTE III de esta tesis, esa lucha y ejercicio del poder y el control se expresa en el sistema normativo interno de las comunidades sean 
cabecera o agencias. Concretamente me refiero a Móctum con la cual la cabecera ha tenido una relación peculiar, por su historia común y su cercanía geográfica.

El caso de Móctum, como el de otros pueblos y comunidades indígenas, refleja la manera en que ha debido luchar por ser reconocido en sus límites territoriales y políticos y en su identidad. Móctum, una comunidad pequeña subordinada a Totontepec también mixe, consiguió la titulación de sus tierras a las cuales tenían derecho históricamente. De esta manera han podido confrontar a los poderes regionales, y se vieron en la necesidad de construirse como comunidad aparte, en lo cual la conversión al adventismo jugó un papel fundamental, como lo veremos en el CAPÍtulo 5. En este proceso las autoridades de Móctum se han valido de diferentes estrategias entre las que sobresalen el recurrir a referentes de legalidad del Estado, como es el caso de la Ley Agraria.

La resolución del conflicto agrario, así como el surgimiento de otras fuentes económicas, está provocando hoy en día que la cuestión agraria pierda peso como estructuradora de las tensiones con la cabecera y del sistema jurídico comunitario y regional. Seguramente esto propiciará que las normas que se empiecen a formular tendrán que ver con otro tipo de asuntos, como es el hecho mismo de la migración, sin que pierda su importancia la tierra y el territorio como espacio de reproducción cultural y de aplicación del derecho. Como se verá en el CAPíTULO correspondiente a Móctum, la membresía de una persona que ha emigrado, el cumplimiento de los servicios y los cargos, y la salvaguarda de los vestigios arqueológicos - que en este capítulo se mencionó - apuntan como algunos de los asuntos que aparecen en lugar del conflicto por la tierra, pero que remiten a un problema de fondo que es la independencia de cada pueblo sobre su dinámica comunitaria y el control territorial al hacer justicia sobre determinados casos, por ejemplo.

Tal situación se vuelve significativa cuando se escuchan comentarios como que las autoridades actuales (de 2004) no son muy competentes, pero como ya no hay tanto que gestionar y sobre todo, el problema de la tierra ya está resuelto "lo que viene ya no es tan importante". Tal expresión conlleva una deslegitimación de 
la autoridad, ${ }^{156}$ pues las expectativas de la población, sobre el actuar y la importancia del quehacer del cargo de autoridad, han disminuido, lo que trae aparejado que los pobladores no lo tomen en cuenta o bien que se considere que pueden ser fácilmente manipulables por los más fuertes económica o políticamente.

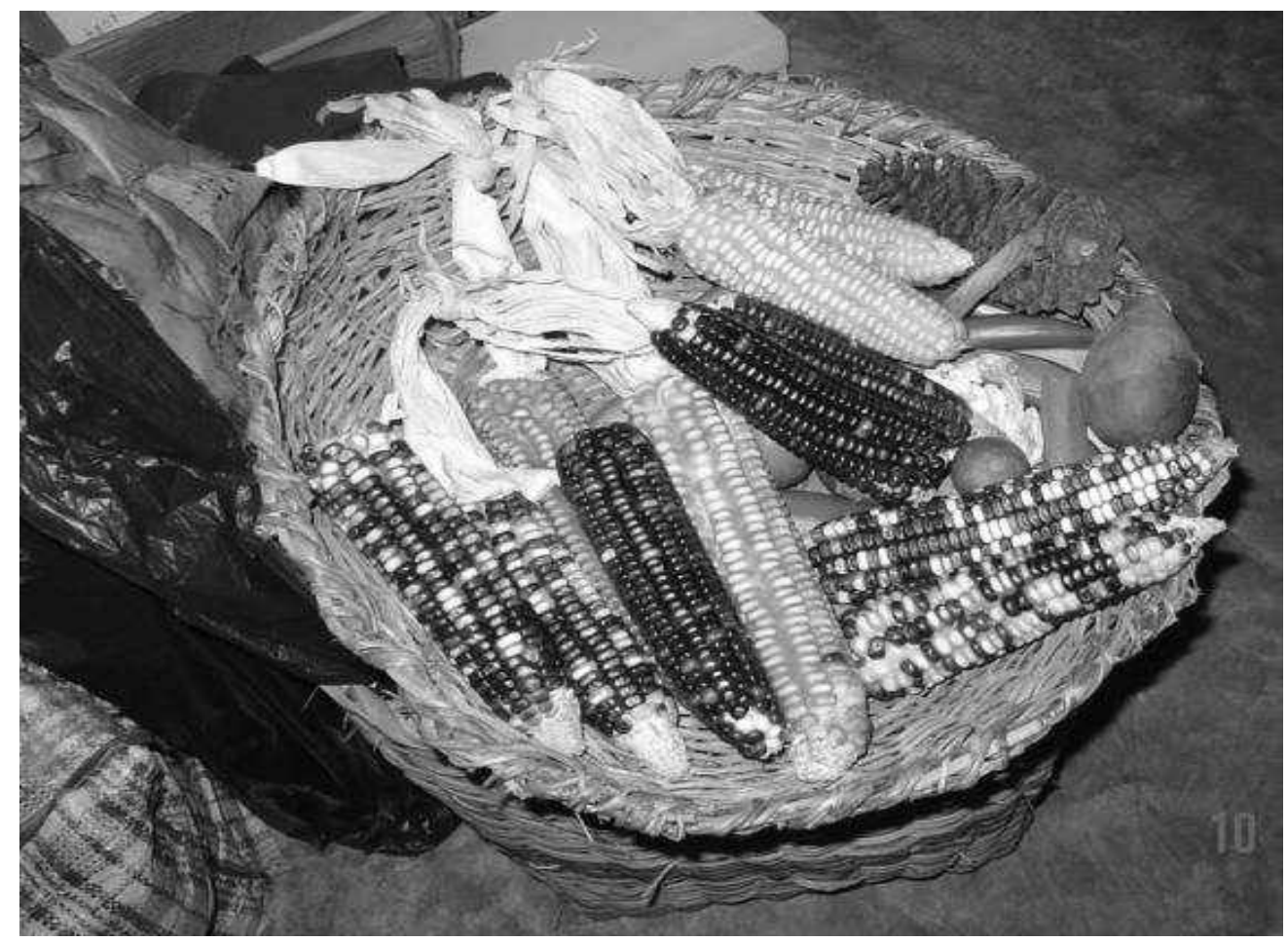

Maíces mixes

156 Según Swartz, Turner y Tuden (1994:105, 116): “La legitimidad deriva de valores que proceden del establecimiento de una conexión positiva entre la entidad o el proceso que tiene legitimidad y tales valores. Puede establecerse esta conexión de diferentes maneras [...] pero en todos los casos incluyen a un conjunto de expectativas en las mentes de quienes aceptan la legitimidad. Estas expectativas están en función de que la entidad o el proceso legítimos, bajo determinadas circunstancias, satisfagan ciertas obligaciones que deban cumplir quienes ven esto como legítimo [...] La legitimidad es un tipo de evaluación que imputa una conducta futura de tipo esperado y deseado". 


\section{PARTE III}

\section{LAS Dinámicas del CAMPO JURÍDICO Y LA CONFRONTACIÓN ENTRE INSTANCIAS}

\section{Introducción}

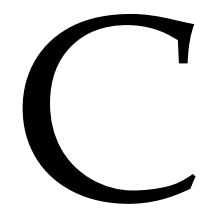

omo se mencionó en la parte anterior de este trabajo, se parte de la premisa de que la arena de conflicto, configurada por la confrontación agraria entre Móctum y Totontepec, es la base fundamental y el marco general que determina muchas de las dinámicas internas de cada poblado y de sus relaciones intracomunitarias. De esta manera, el conflicto agrario y lo agrario/municipal - expuestos en la segunda parte de esta tesis - definen la formulación y aplicación de determinadas normas internas y las dinámicas y relaciones con la cabecera, por ello lo denomino conflicto madre.

En los capítulos de esta tercera parte, el propósito es ir más allá de la presentación de una recopilación de normas orales o escritas, situándolas en su contexto cultural general, planteando cómo y porqué surgieron, qué relaciones de poder expresan y demostrando que su vigencia no está dada por su característica escrita $u$ oral, sino por su eficacia y adecuación a las necesidades y requerimientos de la comunidad y sus integrantes.

De esta manera la reconstrucción de las normas - a través de casos que narran los actores, y de las del Reglamento Comunitario o Estatuto Comunal en Móctum - como el proceso de resolución de disputas en ambas comunidades dan cuenta de la manera en que se actualizan y negocian localmente. Pero también revelan que estas comunidades son campos sociales semiautónomos y como tales son más propensas a recibir influencias del exterior que a influir de manera directa y contundente en los procesos de transformación del Estado. En este sentido, las 
influencias del sistema jurídico mexicano sobre el sistema jurídico indígena son diversas. Por un lado, la legalidad del Estado es parte del horizonte jurídico indígena lo cual es promovido por funcionarios y agentes del Estado, así como por actores externos que introducen el conocimiento de esas leyes - a través de cursos de capacitación o por los escritos oficiales o institucionales, que les dirigen a las autoridades indígenas-. De esta manera el discurso legal estatal ha sido incorporado en las dinámicas jurídicas de las comunidades, lo que sin duda ha propiciado cambios y transformaciones del derecho en la comunidad. Pero por otra parte, las comunidades no son simples receptoras de las normas del Estado sino que las usan y las adaptan a sus propias circunstancias e intereses, o bien resisten a ellas.

Justamente el campo de la reforma agraria es uno de los espacios que más ha influido en la promoción y apropiación de leyes y reglamentos para la defensa de la tierra y de la misma comunidad, al mismo tiempo es un referente para analizar el sentido en que las comunidades se han apropiado de ellos para defender sus límites y reclamar derechos. De ahí la elaboración de reglamentos internos o la ejecución de PROCEDE, por parte de la Procuraduría Agraria (para asesorar a los núcleos agrarios en conflictos internos e intercomunitarios), y la capacitación de las autoridades indígenas por parte de la Procuraduría de Justicia de Oaxaca o la Comisión de Derechos Humanos de Oaxaca. Las dos últimas instituciones son especialmente relevantes por lo que toca a la justicia, ya que por un lado, la Procuraduría de Justicia ha realizado talleres de capacitación para las autoridades municipales y de las agencias sobre los procedimientos para levantar denuncias o querellas, así como darles seguimiento; sobre "levantamiento de cadáver", llenado de formatos en caso de asesinatos, homicidios u otros asuntos considerados graves para el derecho positivo, y darles a conocer las hipótesis o supuestos sobre abuso de autoridad. Por otro lado, la Comisión de Derechos Humanos de Oaxaca se ha encargado de "reforzar" esa acción al llamar vía telefónica a las autoridades indígenas (por lo menos hasta 2005), para advertirles 
que su actuar puede ser considerado como abuso de autoridad cuando realizan acciones que no se sujetan al marco legal permitido, por lo que se les pide que reconsideren su trato hacia las personas que están sujetas a un proceso comunitario o interno de justicia.

También existen otros agentes del Estado que están presentes en la dinámica municipal y en el campo jurídico en esta zona indígena, como es el Consejo de Planeación Estatal (COPLADE) y la Delegación de Gobierno para la zona Mixe Alta, que intervinieron para asesorar y hacer aclaraciones a las agencias de Totontepec sobre las participaciones municipales del año 2004 — dicha Delegación de Gobierno también intervino en el conflicto agrario entre Móctum y Totontepec-. En este sentido, debe considerarse que las agencias inconformes con la asignación de recursos municipales acudieron al Instituto Estatal de Desarrollo Municipal de Oaxaca para solicitar asesoría, de lo que resultó un escrito en el que se invoca la Ley de Derechos de las Comunidades y Pueblos Indígenas de Oaxaca. Si bien la sola presencia de estos agentes del Estado marca pautas de conducta y discursos de las autoridades indígenas, también es cierto que el discurso de los derechos humanos y de los derechos de los pueblos indígenas, que agentes externos manejan, tiene una repercusión en las dinámicas comunitarias de hacer justicia. Esta introducción del derecho mexicano, a través de agentes externos como los del Estado, impacta aun cuando las autoridades y los usuarios indígenas no tengan conocimiento exacto de los artículos u ordenamientos legales que invocan, pues, como se observará tanto en Móctum (véase CAPítUlo 6) como en Totontepec basta con invocar la ley para provocar que la Asamblea desista en sus intentos de expulsión de un miembro, por ejemplo, en Móctum, el control sobre el conocimiento y la información dan poder a una persona sobre otras. Esta penetración e influencia del discurso de la legalidad provienen del sistema jurídico mexicano lo que resulta por la intervención no sólo de agentes del Estado, sino también por la presencia de los maestros rurales y por organizaciones proétnicas y 
de derechos humanos como Servicios del Pueblo Mixe (SER) y la Asamblea de Autoridades Mixes (ASAM).

\section{El sistema de cargos como parte del sistema jurídico indígena}

Otro aspecto que se destaca en los siguientes capítulos de esta tercera parte es el sistema de cargos como un referente central de la organización comunitaria tanto en Oaxaca como en otras regiones indígenas. De acuerdo con Medina Hernández (1995:7), el sistema de cargos actual plantea un panorama sumamente complejo sobre todo por lo que se refiere al planteamiento teórico dada "la conjugación y la confrontación entre el México profundo y la inercia irresistible de la globalización en que se sitúa ese otro polo de tensiones que constituye el Estado, corazón de lo que también Guillermo Bonfil llamaría el México imaginario".

En el debate sobre el origen y naturaleza del sistema de cargos, Medina Hernández (1995) ubica tres posturas: 1) la que lo vincula directamente a las sociedades mesoamericanas (Aguirre Beltrán 1991; Cancian 1990); 2) la que rechaza tal antigüedad situando el origen del sistema a finales del siglo XIX (Chance y Taylor 1987) con la imposición de la jerarquía civil colonial y cívico-religiosa después de la Independencia; y 3) la que conjuga las posturas anteriores considerándolas como fases de un desarrollo que tiene que ver con la dinámica misma de las comunidades estudiadas, reconociendo una variedad de situaciones, tanto en el tiempo como en el espacio.

Este trabajo se apega más a la tercera postura, pues si bien se puede observar y dar cuenta de un continuo histórico en el que la comunidad y el territorio como espacio que da independencia a un conglomerado humano, han sido y son el centro de disputas mucho antes de la Colonia, se pueden apreciar cambios e influencias que impactan el sistema de cargos y la organización comunitaria. De esta manera, la influencia del Estado a través de la reforma agraria es visible cuando se observan en el caso de Totontepec y Móctum la existencia de cargos civiles, religiosos y agrarios (véase CAPítULO 6). 
De esta manera, coincido con Medina Hernández (1995:10) cuando marca la complejidad del sistema de cargos actual y resalta su relación con la estructura agraria de origen prehispánico pero que es impactada por la estructura colonial y modificada por la Revolución Mexicana, en la introducción y el desarrollo de instituciones políticas complejas y representativas de las comunidades; y concretamente a consecuencia de la reforma agraria durante el periodo cardenista, periodo histórico en el que a decir de Medina "se darían las condiciones materiales y políticas para la reconstitución de numerosas comunidades indias". Por otro lado, concuerdo con el hecho de que el sistema de cargos lejos de nivelar las diferencias legitima el ejercicio de poder y mantiene las desigualdades socioeconómicas que existen al interior de la comunidad, por lo que su función no es la redistribución de la riqueza que en Totontepec fue constatado por Romer (1982) y por Cancian (1965), en Zinacantán, Chiapas.

Finalmente, de acuerdo a Medina, no se puede definir el sistema de cargos a partir de la promoción individual y de la jerarquía cívico-religiosa ya que el aspecto fundamental en el que descansa el sistema es la matriz comunitaria india expresada en el modo de vida campesino - el trabajo agrícola en torno al maíz-, que a decir de Medina permanece inalterable y tendría importancia fundamental para la reproducción del campesino indio y de su cultura mesoamericana. En este orden de ideas, Barabas (2004) argumenta que el sistema de cargos cívico-religioso es un componente central de los "usos y costumbres" indígenas, sin embargo, éstos son más amplios y diversos que aquéllos porque permean todos los campos de la vida social, la cosmovisión y el sistema normativo de la sociedad. Por su parte, Medina (1995:10) señala:

[L]o que llamamos el sistema de cargos, las instituciones politico-religiosas comunitarias, se inscribe en la matriz agraria de la comunidad, que posee su propia jerarquía y sus ciclos ceremoniales respectivos. Reducir la discusión a la promoción individual o a la jerarquía cívico-religiosa como estructura autónoma, pierde de vista no sólo la base profundamente agraria que la sustenta, sino también el complejo sistema de representaciones que rige su 
vida, y con ello se pierde la rica y sugerente perspectiva de la historia a largo plazo. Este planteamiento no ignora, desde luego, las nuevas situaciones que enfrentan las poblaciones indias: la reducción y desaparición del trabajo agrícola tradicional, de la milpa, y la organización de instituciones políticas y movimientos de reivindicación étnica, los que desarrollan su discurso a partir de una cosmovisión construida históricamente, en el curso de milenios, y que mantiene su vigencia y su coherencia en la mayor parte de las comunidades indias contemporáneas.

En este trabajo se retoma el sistema de cargos como una consecuencia de esas transformaciones históricas dadas en la región y en la comunidad, en su relación con la cabecera municipal. Por tanto, el sistema de cargos "es un centro neurológico de la comunidad indígena" (Barabas 2004:341), referente clave para observar los efectos de las tensiones entre niveles legales — por demarcaciones territoriales y jurisdiccionales - así como para dar cuenta de las normas que rigen a la comunidad, y de las dinámicas del poder y el uso del derecho vigente.

El tema del sistema de cargos en la relación de Totontepec y Móctum es fundamental pues, como se expuso en el capítulo anterior, uno de los argumentos de los pobladores de Móctum para convertirse en adventistas fue la dominación que grupos de poder de la cabecera ejercían a través de la asignación de las mayordomías y la celebración de las fiestas patronales. Pese a esto puede observarse el sistema tanto en Totontepec como en Móctum, con variaciones de fondo. En el primer caso, es una comunidad señalada como descaracterizada - pero mayoritariamente católica-, en la que el sistema de cargos ha funcionado para mantener el poder económico de algunos grupos (Romer 1982) y, en el segundo, la penetración del adventismo ha provocado que los cargos civiles se separen de los religiosos, sin que sus miembros dejen de realizar trabajos colectivos para la comunidad y de solidaridad entre familias.

De esta manera, como parte del sistema jurídico indígena tenemos a las normas que regulan el sistema de cargos, que defino como el conjunto de servicios que se dan a la comunidad a nivel personal y colectivo, los cuales son organizados 
en orden de importancia y de responsabilidades. En el caso de Móctum se distinguen los cargos que son de sello y los que no lo son, lo que revela otra introducción o influencia del sistema jurídico mexicano. El uso del sello también es importante en el caso de Totontepec, pues como lo expresa el alcalde del año 2004 "un escrito sin sello no vale". Como se podrá observar en los siguientes capítulos, el sello es un referente simbólico de autoridad.

Esos servicios deben ser cumplidos por hombres o mujeres para poder vivir en la comunidad, tener derecho a "ser tomados en cuenta" como parte de la misma, pero también significan obligaciones, como trabajar la tierra, entre otros. Aunque existen distinciones entre los cargos para hombres o para las mujeres, pues para los primeros existen pocas posibilidades de excusas aun cuando la esposa tenga un cargo, mientras que las mujeres pueden aplazar su cargo porque su esposo está en "funciones". Esto revela y marca la bilateralidad como una característica muy importante de los derechos, es decir, un derecho y su ejercicio siempre implican una responsabilidad y una obligación frente a otros (individuos o colectividades), lo que seguramente también ha sido una influencia del sistema jurídico mexicano sobre el sistema jurídico indígena, ya que según señalan varios autores los cargos más que derechos han significado deberes (Velásquez 1999; Valdivia 2001).

En el sistema de cargos se puede observar esa característica pero de forma distinta al derecho positivo. Este sistema forma parte del sistema jurídico indígena en las dos comunidades estudiadas y a la vez es parte medular de su organización política, pues confluyen un conjunto de normas que describen y señalan derechos y obligaciones, así como requisitos de ciudadanía y de membresía o de integración del individuo a la comunidad. De esta manera, el hecho de que un individuo entre al sistema de cargos implica adquirir el "lugar" o estatus de comunero y ciudadano $\mathrm{y}$, por tanto, tener derechos y obligaciones ante la comunidad. 


\section{CAPÍTULO 5}

\section{El SISTEMA JURÍDICO Y LA RESOLUCIÓN DE CONFLICTOS EN TOTONTEPEC}

\section{Introducción}

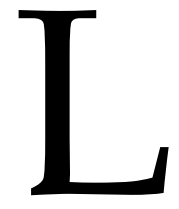

as instancias jurídicas de la cabecera de Totontepec constituyen uno de los niveles legales del campo jurídico dentro de la demarcación territorial del municipio. Como se mencionó en el CAPítulo 4, el poblado indígena mixe de Totontepec tiene una doble característica, es cabecera del municipio y es comunidad agraria, como tal es también centro de control político y religioso. Territorialmente la cabecera colinda por lo menos con cinco de las diez agencias que comprenden el municipio de Totontepec.

El análisis de esta parte se concreta a los casos que el alcalde municipal, como juez municipal, dirime y resuelve. ${ }^{157}$ La oficina del alcalde se encuentra en el palacio municipal del Ayuntamiento, donde también se ubican las oficinas del presidente y síndico municipales, así como una oficina del registro civil. ${ }^{158}$ Como se ha mencionado el municipio de Totontepec está integrado por agencias de policía y agencias municipales (véase CAPÍTULO 3 de esta tesis), éstas al igual que la cabecera tienen como autoridades al alcalde, síndico y agente, dos regidores, el comisariado de bienes comunales, mientras las agencias de policía sólo cuentan

157 De acuerdo con la información del agente municipal de Santiago Tepitongo las autoridades en esta agencia son: Alcalde Municipal, Síndico y Agente (con sus suplentes), 2 Regidores, Comisariado de Bienes Comunales y topiles. Los regidores se encargan de recoger las cooperaciones, por ejemplo, para el mantenimiento de la agencia. Al principio de la entrevista señaló que el actual alcalde no impartía justicia porque tenía que recibir un curso, sin embargo, cuando pude entrevistarlo me narró varios casos y me permitió sacar copias de varias actas de asuntos que había resuelto o enviado al municipio.

158 Para la elaboración de actas de acuerdo o convenios y demás documentos, el alcalde se auxilia de la secretaria que trabaja en la oficina del registro civil. 
con agente de policía y secretario. En este capítulo se presentan asuntos que llegaron de las agencias a la cabecera.

El objetivo de este capítulo es dar cuenta de las relaciones de poder que se dan en la aplicación y uso del derecho vigente en la comunidad. A través de la exposición de asuntos y casos que llegaron a la alcaldía del municipio, con esto, buscaré reconstruir algunos principios que caracterizan el sistema normativo indígena, así como los procesos para su resolución. De igual forma, pretendo reconstruir aspectos de la lógica cultural a través de las dos dimensiones de la justicia: como acto de autoridad y como valor cultural producto de un proceso histórico-social.

Este capítulo se compone de un apartado que se refiere fundamentalmente a la justicia y el derecho en las dinámicas locales y municipales. En este apartado se explica la relación entre justicia y derecho, subrayando que existen valores sociales distintos que sustentan al derecho positivo y al derecho indígena en la comunidad y a la vez reconociendo la existencia de una imbricación de sistemas. De esta manera, se retoma el concepto de principios jurídicos del derecho positivo para aplicarlo al caso concreto, con las salvedades apuntadas. Por ello, más que explicar un cuerpo de normas o un reglamento (como se verá en el caso de Móctum), se habla de principios generales del derecho en la comunidad, que se refieren a las dinámicas y procesos sociales que explican el sentido de justicia y justifican una resolución. De esta manera, los principios generales del derecho en Totontepec se desprenden de su historia como comunidad indígena descaracterizada, como núcleo agrario y como centro de poder religioso y político, que han marcado su relación con las comunidades-agencias que conforman el municipio. En general, y como se explicó en los capítulos anteriores, esas tensiones y disputas están relacionadas con la asignación de recursos económicos y el ejercicio del poder centralizado, aspectos que se han vuelto recurrentes en la mayoría de los municipios del estado de Oaxaca. Por ello, para comprender la especificidad de cada proceso, es necesario 
remitirse a los antecedentes históricos que marcan la relación entre la cabecera y las agencias que conforman cada municipio.

Los asuntos que se expondrán tanto de Totontepec como de Móctum son una muestra de aspectos sociales fundamentales y claves vinculados con la historia y la comunidad, y marcan la relación de ésta con el grupo etnolingüístico mixe. Así, en los siguientes apartados se puede apreciar que los sistemas normativos indígena y positivista se imbrican calificando el mismo objeto - de disputa o conflicto- de forma distinta (lo que es grave para el derecho mexicano, no es necesariamente grave para el derecho indígena), y por consecuencia proponen distintas alternativas para su solución. Del estudio hecho en Totontepec y Móctum se puede decir que, por ejemplo, para el sistema normativo indígena el encarcelamiento no es un fin del ejercicio de hacer justicia, tampoco es la justicia en sí, más bien es un medio o el primero de los mecanismos para lograrla. Si el encarcelamiento cumple el fin de calmar los ánimos y hacer que el culpable o el que cometió un error asuma su responsabilidad, se le deja en libertad para cumplir su parte en la resolución de un conflicto, de lo contrario se utilizan otros medios como la amonestación pública y la suspensión de derechos, hasta llegar a la expulsión. ${ }^{159}$

Para el derecho positivo mantener a alguien en la cárcel es el inicio del proceso de hacer justicia pero también es su culminación; el encarcelamiento implica la suspensión de derechos políticos y la restricción de derechos civiles,

159 En el caso de Móctum, como en otros poblados, en cuanto a la expulsión, la influencia que el campo social semiautónomo indígena recibe del campo social del Estado - y concretamente de su sistema jurídico positivista - ha dado sus frutos pues se ha convertido en un mecanismo menos frecuente. Pese a esto, en el caso de Móctum (CAPítulo 6) se podrá observar que la opción de la expulsión, por lo que se refiere a incumplimiento de obligaciones en y ante la comunidad, no es categórico o se aplica de manera que no exista otra opción para evitarla, pues para llegar a una decisión de tal magnitud se pasa por una serie de pasos de negociación en los que se da la posibilidad de que el culpable reconozca su error, por ejemplo, si no ha hecho cargos ni servicios que los pague en dinero. También es importante reconocer que se han dado casos donde la opción de reconocer el error y no ser expulsado está obstaculizada por una serie de circunstancias de tipo político, económico o religioso por las cuales la expulsión sea inevitable, o bien porque se trata de una lucha por el control y el poder entre grupos 
económicos y sociales - o garantías individuales- de una persona, principalmente el derecho a la libertad, al libre tránsito a votar y ser votado en elecciones políticas. Por su parte desde la perspectiva indígena, una expulsión deja en libertad al individuo con todos sus derechos civiles, sociales y políticos restringiéndole el acceso a la comunidad para ejercerlos, en algunos casos también lo restringe para integrarse a otras comunidades, si éstas solicitan al individuo o persona como requisito comprobar buena conducta en la comunidad de origen.

Finalmente los encuentros y desencuentros entre el sistema normativo mexicano y el indígena se deben al tipo de relación que el Estado ha impuesto entre ellos, llegando a un punto tal que se hace insostenible seguir hablando del derecho de los indígenas a tener su derecho, sin reconocer que se trata de sistemas jurídicos indígenas con particularidades propias, aun si éstos se imbrican con el derecho estatal.

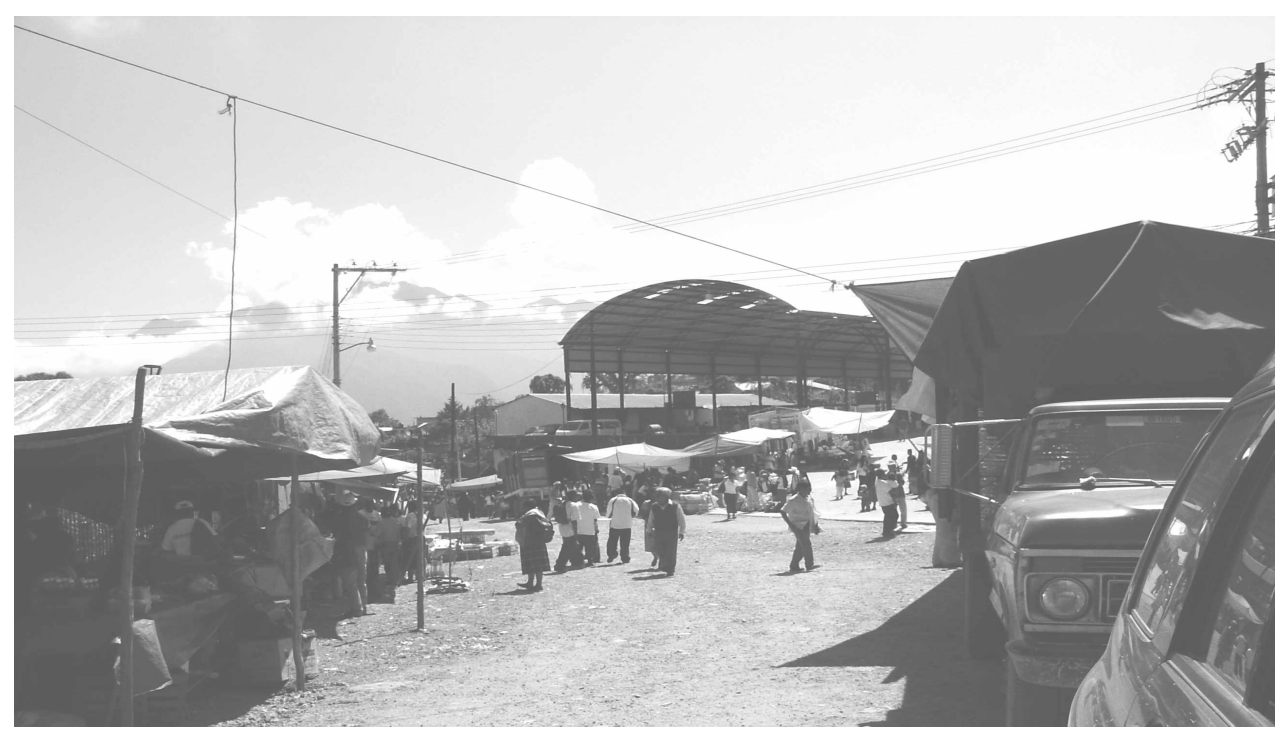

Día de mercado en Totontepec 


\subsection{La justicia y el derecho en las dinámicas locales y municipales}

Los principios generales del derecho - como se apuntó en la introducción de la tesis - están determinados social y culturalmente y orientan la conducta humana. En el caso de nuestro análisis, dichos principios emanan, por un lado, del devenir histórico de la comunidad-cabecera en su relación con cada una de las comunidades-agencias que integran el municipio, pero también en la relación de estas unidades con el pueblo indígena o grupo etnolingüístico del que forman parte. El principio fundante en el que descansa este cuerpo de principios éticos y axiológicos es el de la comunidad. De esta manera, esos principios generales del derecho son una combinación de valores éticos y morales de una sociedad, en este caso, de una sociedad indígena. La justicia, el sentido de justicia, los principios generales del derecho y las normas (orales o escritas) forman un sistema jurídicocultural, donde esos principios dan legitimidad sistémica al ejercicio de autoridad para hacer la justicia y a los acuerdos que se convierten en norma, y por tanto al derecho y al quehacer de las autoridades cuando se apegan a ellos. De esta manera, para comprender un elemento de ese sistema es necesario considerarlo en su relación con los otros, así la justicia y el sentido de justicia se entienden en su relación con los valores y principios culturales de un pueblo, y los principios jurídicos expresan esos valores dando legitimidad a la justicia y a las normas del derecho. Tal como se ha dicho anteriormente en la introducción de este capítulo, los principios generales del derecho son el resultado de un proceso complejo de dinámicas y de relaciones municipales: comunitarias e intercomunitarias. El contexto de este proceso se ha expuesto en los capítulos anteriores al plantear y explicar el caso oaxaqueño y al analizar el conflicto agrario entre Totontepec y Móctum y su desarrollo histórico pasando por la Reforma Agraria hasta nuestros días, época donde la arena de conflicto pasa al espacio municipal.

En el caso que se estudia, la relación de tensión entre cabecera y agencias está marcada por varios elementos culturales, históricos, políticos y económicos. En primer lugar el caciquismo ejercido desde la cabecera municipal, sostenido por 
una élite política y económica local dentro del poblado cabecera, y por un cacicazgo mayor radicado en el Distrito Judicial y representado por Luis Rodríguez. De igual forma es de destacarse la ideología de discriminación desarrollada por las élites de la cabecera, para distinguir de los habitantes de las agencias que componen el municipio. Esto se ha definido como una descaracterización, no sólo por ese afán de distinguirse como superiores sino porque los procesos de amestización han sido más profundos en Totontepec que en cualquier otro poblado de la zona (Nahmad 2003; Acevedo y Pardo s/f). Esta descaracterización étnica, económica y social ha significado que las agencias vean con recelo a la comunidad-cabecera, sobre todo a quienes detentan el poder político y económico, lo cual es justificado por las comunidades-agencias colindantes con los terrenos de Totontepec porque se sienten engañados con el establecimiento de los límites territoriales - sienten que fueron despojados de terrenos - , así como en la asignación de los recursos económicos municipales.

Seguramente estos elementos, así como la accesibilidad geográfica, fueron determinantes en la constitución de Totontepec como cabecera, condición que le ha permitido a sus habitantes lograr mejores niveles de vida, sobre todo por la migración, ya que los caminos trazados desde la Colonia marcaron de alguna manera las rutas migratorias actuales hacia el Papaloapam, la capital del estado, de la República Mexicana y a los Estados Unidos. De acuerdo con Romer (1982) la migración se presenta en Totontepec con mayor fuerza en la década de 1960, mientras en el caso de Móctum se presenta - según el testimonio de sus pobladores - a finales del siglo XX casi con 40 años de diferencia. Finalmente estos datos históricos y culturales son los que definen la dinámica de relación entre niveles legales del campo jurídico regional - tanto los poblados que abarcan el municipio y éste como totalidad - y el derecho que se construye y transforma en cada uno de ellos.

Como se mostrará en el discurso del alcalde municipal de Totontepec, así como en el del agente de policía de Móctum, el peso que se da a la comunidad 
como principio ideológico de cohesión y contrapeso del control del Estado es uno de los principios generales del derecho en Totontepec $\mathrm{y}$, a la vez, es un principio de unidad básica y central de cualquier conducta, proyecto, meta o fin en torno a la comunidad, lo que no quiere decir que los derechos individuales no sean reconocidos.

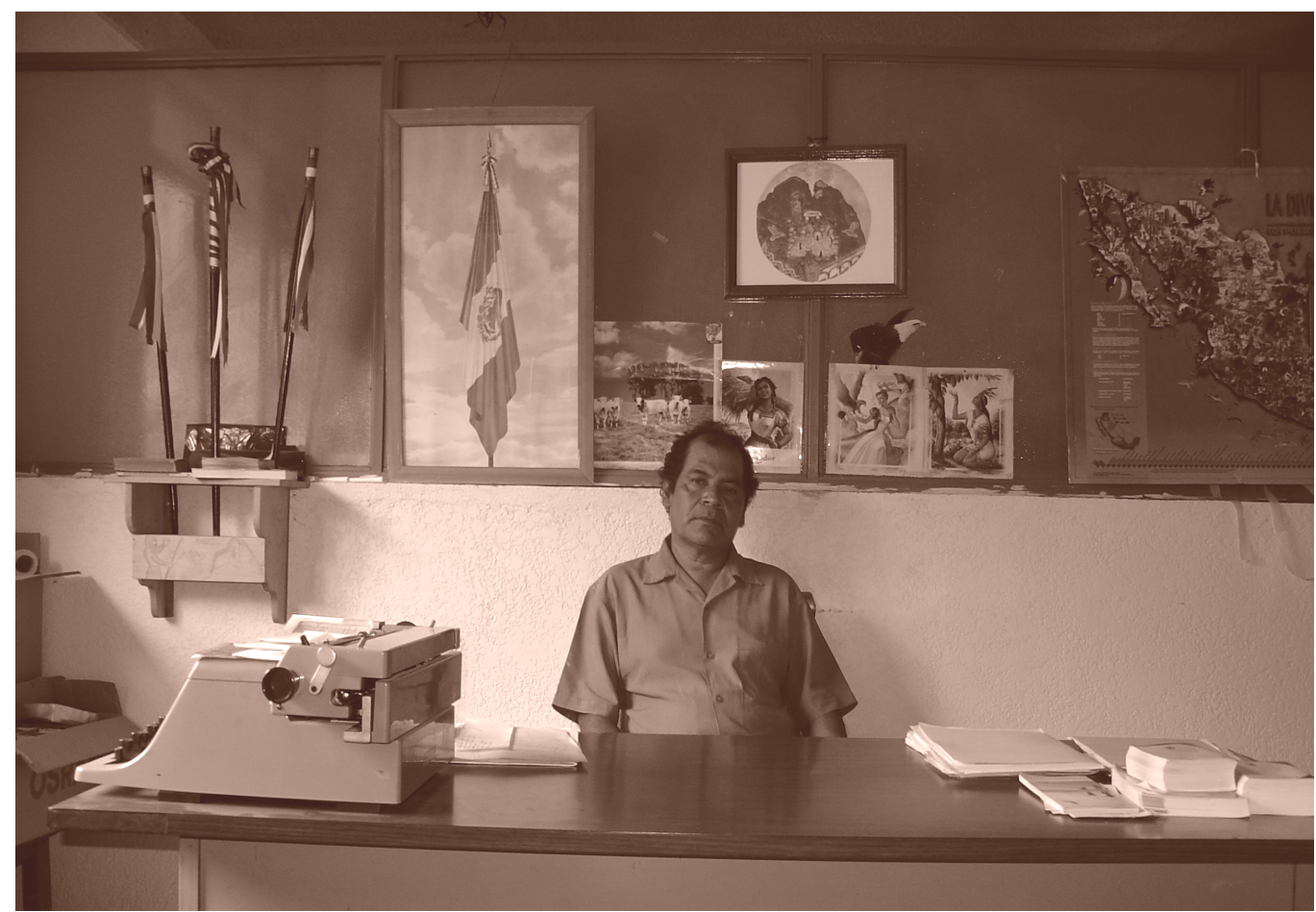

Don Guillermo Gómez Reyes

Alcalde Único Constitucional de Totontepec durante el año 2004

Los derechos individuales son reconocidos en su relación con la comunidad ya que ésta es el ámbito físico de su ejercicio. El individuo es reconocido con derechos cuando cumple sus obligaciones y deberes frente a la comunidad a partir de normas - generalmente orales - conocidas y aceptadas por todos pues emanan de acuerdos de asamblea y de la resolución de conflictos concretos. La aceptación de estas normas puede ser de manera directa o indirecta, la primera a través de la participación en las asambleas, la segunda por una aceptación tácita de la norma porque la conducta individual se ajusta a ella o bien, cuando se pudo cuestionar o rebatir no se hizo. De acuerdo con esto si la comunidad no existiera, los derechos individuales no podrían ejercerse. Por ello, tanto en Totontepec como en Móctum 
- como en muchas comunidades mixes - un individuo al incorporarse al sistema de cargos exterioriza su voluntad de formar parte de la comunidad por lo que acepta sus reglas sobre resolución de conflictos y participación comunitaria, pese a esto existen espacios para contra-argumentar la norma (véase el caso de expulsión en Móctum, CAPítulo 6) y establecer una nueva. Es por esto que puede decirse que el derecho vigente en Totontepec se construye a partir de casos concretos, considerando las circunstancias en que se ha dado una disputa, tomando en cuenta más a la persona en su relación con la comunidad, que el hecho o falta cometida - hecho documentado ampliamente por la antropología jurídica (cfr. Sierra 2004a, b). Como se mencionó en la introducción de esta tesis, a esta aplicación de normas al caso concreto subyace el sentido de justicia, es decir, los valores, intereses y principios que cada sociedad o pueblo tiene, así como la lógica o la forma de cómo debe hacerse para lograrlo. Estos aspectos, relevantes para la comunidad, que determinan el sentido de la justicia (en la resolución de conflictos, disputas y atención de asuntos) y los límites del campo jurídico se denominan principios generales del derecho (cfr. Cruz 2005).

En este capítulo y en el siguiente se puede observar, en el análisis de dos casos, que la relación individuo-comunidad es una relación compleja en la que se entrecruzan usos del poder y del derecho, por lo que los derechos colectivos indígenas o la comunalidad no se imponen hegemónicamente o arbitrariamente sobre el individuo, ya que hasta cierto punto éste también es valorado como parte de la misma.

Como se mencionó, la comunidad es el principio fundante del derecho en Totontepec y Móctum, que remite a principios como la obligatoriedad para realizar servicios, la reciprocidad y el prestigio - que no necesariamente es económico(Velásquez 2000). Se resalta de este planteamiento su carácter normativo, es decir, "el deber ser" o lo que se espera de un miembro de la comunidad. Postura que es comprensible porque la comunalidad es un ideal y una ideología que busca justificar ante el derecho del Estado, una situación o un orden de cosas, lo que no 
significa que los sistemas normativos indígenas - como el sistema normativo mexicano - estén exentos de las disputas por el poder y el control que se da al interior de las comunidades indígenas.

\subsubsection{La resolución de conflictos y disputas: Normas y criterios}

Para dar cuenta de lo que he llamado derecho vigente en Totontepec, así como de la lógica jurídica cultural que se expresa en los asuntos y conflictos relevantes, a continuación me refiero a ellos en dos vertientes: 1) los asuntos y conflictos que se presentan en la cabecera municipal y 2) los asuntos que llegan de las agencias a la cabecera, sobre todo de Móctum, ya que de alguna manera el conflicto agrario, que durante más de 40 años mantuvieron estos poblados, influye en las posturas que toman sus autoridades $\mathrm{y}$, por tanto, en el derecho.

En las entrevistas hechas a las autoridades de Móctum y Totontepec sobre los asuntos que resuelven, la respuesta fue inicialmente que "el pueblo es muy pacífico y no hay problemas", esto se puede entender en dos sentidos. Por un lado, que los asuntos que se presentan en el Municipio o la Agencia son pocos o tan comunes que para las autoridades no amerita llamarlos "problemas", "disputas" o "conflictos", pues hay casos que sí lo son - como el conflicto intercomunitario por la tierra o por el agua-. Podemos referirnos a la estrategia de presentar a la comunidad como "realmente pacífica", para justificar que agentes o autoridades del Estado, como la Comisión de Derechos Humanos de Oaxaca, la Procuraduría de Justicia o la Policía Judicial del Estado - o ministeriales - no intervengan en la dinámica comunitaria de hacer justicia. Esto es lo que finalmente Nader (1978, 1998) identifica como ideología armónica, pero también se observa esta ideología en el afán del Alcalde por lograr un acuerdo consensado entre las partes, logrando que éstas lo firmen para garantizar que el asunto efectivamente fue resuelto ante él y aceptado de manera pacífica y conciliatoria por las partes en disputa. Desde esta perspectiva el alcalde, después de corroborar que yo era estudiante sin relación con el trabajo que realiza la Comisión de Derechos Humanos de Oaxaca, expone el 
primer caso que trata sobre robo, en el que un niño le expuso que su bicicleta desapareció cuando fue a la tienda:

No se puede decir que fue un robo, porque tal vez la gente hace bromas, o los mismos chamacos de juego, aunque puede ser que sí sea un robo. Pues anuncio por el sonido si alguien vio una bicicleta que se extravió y esperaré que alguien avise si la vio. O si ya regresó a su dueño ya no me meto. Si fue broma de un chamaco se le llama la atención y se le dice a sus padres que lo corrijan. Pero si fue una persona grande lo encarcelamos siquiera un día. [Entrevista con el alcalde de Totontepec el 21 de julio de 2004]

Se puede observar que el alcalde tiene mucha cautela no sólo en exponer el caso sino en expresar su juicio o resolución sobre el mismo, sin conocer o tener más elementos o datos. También en su momento, parecía que quería seguir a tono con la idea de que "el pueblo es pacífico y no hay problemas".

Es importante apuntar que en la lógica que expresa el alcalde, en este caso el robo no puede pasarse por alto si es un niño o un adulto — sea lo que fuere que se haya hurtado-, en cambio es frecuente escuchar que el Ministerio Público (en zonas indígenas y no indígenas) no actúa en casos donde el monto (valor económico) de lo robado es, a su parecer, ínfimo.

\subsubsection{Asuntos que se presentan y resuelven en la cabecera municipal: Imbricación de sistemas legales}

En los siguientes asuntos se puede observar la influencia del derecho positivo en la forma de hacer justicia del alcalde municipal de Totontepec, visto desde una óptica legal positivista, es evidente que en algunos casos pesa el criterio del alcalde más que lo que dice la ley -el Código Penal-, ésta sólo se usa para legitimar o justificar una resolución determinada, por ejemplo, al meter a una persona a la cárcel si es más de una semana - según el Alcade - "podemos involucrarnos en abuso". El registro que el alcalde tiene de los casos son actas de acuerdo que se realizan y en las que se hace un resumen del caso y los acuerdos entre partes o compromisos del culpable. 
De acuerdo con las entrevistas realizadas al alcalde municipal de Totontepec (julio y agosto de 2004), los asuntos que se presentan son graves o leves, según el tiempo en que una persona deba estar en la cárcel, "de acuerdo con el Código Penal". Sin embargo, el Código Penal no señala esa característica. El Código Penal de Oaxaca y la Ley de Derechos de los Pueblos y las Comunidades Indígenas de Oaxaca enumeran los delitos graves y establece una restricción para que las autoridades indígenas no resuelvan sobre ese tipo de delitos, a nivel interno o comunitario. Pese a esto, las autoridades indígenas tienen su propia concepción de lo que se consideran asuntos graves en la comunidad, éstos son: chismes, robos de leña, de maíz, de ganado (el abigeato es un delito grave cfr. artículos del Código de Procedimientos Penales), disputas por terrenos, por daños en las siembras, riñas en las que haya heridos (los que pueden presentar distintas lesiones graves o leves).

TABLA 6

\begin{tabular}{|l|l|}
\hline \multicolumn{2}{|c|}{ Delitos graves según el Código de Procedimientos Penales de Oaxaca } \\
\hline \multicolumn{2}{|c|}{ Delitos } \\
\hline Abuso de autoridad & Abigeato \\
Ataque a las vías de comunicación & Delitos Electorales (previstos en el Código \\
Corrupción de menores & Penal Del Estado de Oaxaca) \\
Delito culposo de homicidio & Desaparición forzada de personas \\
Evasión de presos & Despojo \\
Homicidio & Extorsión \\
Lenosinio de menores & Infanticidio \\
Pornografía infantil & Lesiones \\
Rebelión & Parricidio \\
Violación & Robo calificado \\
& Secuestro \\
& Tortura (previsto en la Ley Estatal para \\
& Prevenir y Sancionar la Tortura) \\
\hline Definición según el ARTículo 23 bis: Son aquellas conductas o actos que afectan de \\
manera importante valores fundamentales de la sociedad
\end{tabular}


Según esta clasificación se puede observar en los siguientes ejemplos que existe una imbricación de sistemas que el alcalde utiliza como uno solo, sin distinguir si es o no el derecho de la comunidad o el derecho positivo - al igual que el agente de policía en Móctum, según veremos más adelante-. Por un lado el alcalde justifica su actuar con el Código Penal que es parte del sistema jurídico mexicano, y por otro hace una clasificación en la que incluye actos en los que la Ley de Derechos de los Pueblos y las Comunidades Indígenas de Oaxaca (o Ley Indígena) limita su participación. Es decir, no puede actuar haciendo justicia (como juez), pero interviene con esa calidad porque son casos que la gente le expone y le solicita una solución, ${ }^{160}$ por lo que frente al Código Penal justifica su intervención por un mandato que le dio la comunidad, y hace lo posible para que las partes en un conflicto lleguen a un acuerdo. En caso contrario y como último recurso, envía el caso a Zacatepec donde se encuentra el Ministerio Público y el Juez — pues espera que los daños causados por una conducta sean realmente pagados-, ya que al despachar un asunto al nivel del Distrito se limita la posibilidad de que exista realmente un arreglo que repare un daño, lo que también para el alcalde significa que su capacidad de resolución o de hacer justicia se pone en duda ante la comunidad que lo nombró. La justificación de su intervención como autoridad se da en dos sentidos, primero porque sabe que tiene un nombramiento que viene del

160 La Ley de Derechos de los Pueblos y Comunidades Indígenas de Oaxaca señala “ARTículo 38.- Las autoridades comunitarias de los pueblos y comunidades indígenas, procurarán y administrarán justicia aplicando sus sistemas normativos internos, en los casos y de acuerdo con las formalidades que se prescriben a continuación. / I.- Las autoridades comunitarias de los pueblos y comunidades indígenas ejercerán jurisdicción en los casos siguientes. / a) Tratándose de controversias en las cuales ambas partes sean indígenas, ya sea que pertenezcan a un mismo pueblo o a pueblos diferentes. / Cuando el conflicto de que se trate involucre como partes a indígenas y no indígenas, el infractor, tratándose de asunto penal, o el demandante si el asunto es de materia diversa a la penal, podrá elegir a la autoridad a la que someterá la controversia. b) Que la materia de las controversias verse sobre: delitos que estén sancionados en el Código Penal del Estado de Oaxaca, con pena económica o corporal que no exceda de dos años de prisión, en estos casos las autoridades comunitarias actuarán, a través de sus órganos competentes, como auxiliares del Ministerio Público o del Poder Judicial; tenencia individual de la tierra en la comunidad de referencia, faltas administrativas y de policía; atentados contra de las formas de organización, cultura, servicios comunitarios, trabajos y obras públicas; cuestiones del trato civil y familiar; incumplimiento del deber de las madres y padres de familia consistente en enviar a sus hijos e hijas a la escuela; y en general, todos aquellos casos en los que los ascendientes o los esposos y esposas no se conduzcan como buenos padres y madres de familia". El subrayado es mío. 
Estado, pero sobre todo porque la comunidad lo elegió en el cargo que se considera el mayor de todos. Es común que el discurso de la exaltación de la comunidad salga a relucir en la práctica de la justicia, por ejemplo, cuando el alcalde interviene en casos que le plantean sus paisanos de la cabecera y de las agencias argumenta "lo hago porque la comunidad me nombró".

Finalmente, la práctica del alcalde de levantar Actas de Acuerdo, si bien es una práctica del derecho positivo y exigida por el Estado, tiene la finalidad de evitar que las partes en conflicto crean que pueden seguir peleando. Como él apunta:

¿Sabe por qué se levanta el acta? Para detener el pleito, porque si uno no levanta, pues la gente se va y cree que puede seguir. En este caso regresaron y viven juntos [señalando un acta del caso de una pareja que quería separarse]. Tienen hijos, eso es lo que nos preocupa que tienen hijos, es por los niños buscamos que sigan juntos. Levantamos el acta y éste ya no le pega a su compañera [Entrevista con el alcalde de Totontepec el 22 de julio de 2004]

Posiblemente en el caso que apunta el alcalde, el hombre no dejó de golpear a su mujer pero, en su momento, la conciliación y el acuerdo plasmado en el acta sirvió como un elemento de presión para que el hombre reconociera su error. En cambio, el principio jurídico positivista plantea que un acto o actividad humana demuestra su existencia jurídicamente si está o consta por escrito, por tanto, la finalidad de levantar un acta en ambos sistemas jurídicos es completamente distinta.

A continuación se mostrarán los casos por los cuales las personas disputan, en general tratan sobre la posesión y explotación de terrenos, herencias, desacuerdos entre parejas, deudas económicas, lesiones, riñas, alteración del orden, incumplimiento de obligaciones ante la comunidad, infidelidad. Finalmente, el elemento común de estos asuntos es el sentido de la comunidad: 1) Porque el alcalde legitima su actuar por la designación y delegación del poder que la asamblea le ha dado para resolver conflictos y disputas, 2) porque las personas 
que acuden a él reconocen la validez de ese poder delegado, y 3) a cambio de esa designación y de ese poder el alcalde está obligado a responder a las peticiones de justicia y a hacer lo necesario para que se cumpla, sea que se trate de un asunto familiar o entre vecinos. Lo comunitario se vuelve más evidente cuando se trata de casos en los que está involucrada alguna instancia del Estado y las autoridades tratan de evitar su injerencia (inciso i del apartado 5.1.1.2).

Lo agreste de la geografía de la región y las distancias que deben recorrer los usuarios indígenas para acudir a la justicia del Estado en el Distrito, a veces los hacen desistir de ese intento. Sin embargo, no siempre es así por lo que una vez obtenido algún resultado, esas mismas condiciones se vuelven un obstáculo para hecer efectiva la justicia del Estado - de un juez penal o civil-, es decir que sus resoluciones sean realmente ejecutadas, más cuando en la perspectiva de la comunidad y de las autoridades indígenas sobrepasan los límites de su jurisdicción. Esto se podrá apreciar sobre todo en los casos (del apartado 5.1.1.1.) por uso y disfrute de terrenos comunales (inciso a.1); incumplimiento de obligaciones cívicas (como cumplir con los cargos, inciso e); por pensiones alimenticias (inciso f),

\section{a) Disputa sobre terrenos comunales}

Cuando dos personas se disputan un terreno para sembrar, el criterio es que la primera persona que empieza a trabajar - a limpiar o prepararlo - tiene el derecho sobre el producto. Para indagar quién fue primero, el alcalde se traslada al lugar para inspeccionar y preguntar a otros vecinos o personas que estén trabajando cerca: "Si alguien miente se investiga con testigos, cómo escucharon. Salen los chismes, si alguien vio podemos llamarlo como testigo". "Si se sabe [de los que disputan] que uno mintió es penado con la cárcel de 1 ó 2 días, si es grave [si alguien salió herido] se le multa". Como se ha argumentado y se expondrá en los casos que provienen de las agencias, ${ }^{161}$ las lesiones dependiendo de su tipo se

\footnotetext{
${ }^{161}$ Véase tABLa 6 en las que se señalan los delitos de acuerdo al Código Penal de Oaxaca.
} 
consideran un delito grave por el derecho estatal, por lo que no corresponde a la autoridad indígena resolverlos. El alcalde también menciona: "cuando mucho una semana podemos meter a alguien a la cárcel, si es más podemos involucrarnos en abuso", sin embargo, el Código Penal no señala ese plazo ni tampoco la Constitución Política del Estado de Oaxaca. ${ }^{162}$ Es decir, hay una conceptualización propia sobre lo que se consideran los límites de sus competencias legales aunque no necesariamente correspondan a lo escrito en la ley del estado. En lo siguiente me refiero a una serie de casos que se dirimieron ante el alcalde de Totontepec.

\section{a.1) Terrenos utilizados para una pista}

Para comprender el caso que a continuación se expone es importante remitirnos al tipo de tenencia de la tierra que tiene Totontepec como comunidad agraria, de acuerdo con el sistema jurídico mexicano. Las tierras de Totontepec son comunales y así se ostentan hacia el exterior, sin embargo, al interior se distinguen otros tipos de tenencia de la tierra, como la de propiedad privada que se encuentra dentro del asentamiento humano, es decir, donde está el pueblo propiamente dicho, los solares donde se encuentran las casas (a veces tienen patio), los edificios públicos, las escuelas, la iglesia católica, el templo adventista, los servicios públicos, como la biblioteca, el СОвАO, la oficina de telégrafos y correos, etcétera. Existen porciones de tierra o parcelas fuera del área del pueblo o asentamiento humano que son comunales y la gente las puede utilizar alternadamente un año y otro las deja para que se regenere el suelo; en otras porciones de tierra hay personas que han cultivado por mucho tiempo, donde tienen sembrados árboles frutales, sobre éstos

162 Constitución Política del Estado Libre y Soberano de Oaxaca. “ARTículo 7 (REFORMADO PRIMER PÁRRAFO, P.O. 25 DE SEPTIEMBRE DE 1999) Ninguna detención ante autoridad judicial, podrá exceder del plazo de setenta y dos horas, a partir de que el indiciado sea puesto a su disposición, sin que se justifique con un auto de formal prisión en el que se expresarán: el delito que se le impute al acusado; el lugar, tiempo y circunstancias de ejecución, así como los datos que arroje la averiguación previa, los que deberán ser bastantes para comprobar el cuerpo del delito y hacer probable la responsabilidad del indiciado [...] Si la detención es resultado de infracciones a los Reglamentos gubernativos y de policía, serán calificadas de inmediato, y, en su caso, sancionadas con multas no mayor a la retribución que el infractor perciba en un día de trabajo, la cual se permutará por arresto hasta de treinta y seis horas, si no fuere pagada" [El subrayado es mío] 
se reconoce que quien sembró es dueño. Pese a que existe un régimen de tenencia comunal o colectiva, al interior se reconocen también pequeñas propiedades que de acuerdo con el dicho del alcalde, desde que se dio la comunidad agraria, algunos pobladores se pusieron vivos y cercaron diciéndose dueños. También esto se puede explicar de acuerdo con Romer (1982) por las dinámicas internas de la comunidad sobre acumulación de la riqueza y del capital, donde se pueden distinguir diferentes extractos sociales.

El alcalde narra los antecedentes de un conflicto sobre terrenos que se utilizaron como pista de aterrizaje. Cuenta que hace muchos años los dueños de los terrenos los dieron para construir la pista, sin embargo, se utilizó poco "porque la gente ya no quiso porque está lejos, a un kilómetro", además por el mejoramiento del camino ya no se utiliza avioneta. Uno de los hijos de los que eran dueños cercó por muchos años el terreno y ahora lo reclama aunque no lo ha trabajado (sembrado). Sin embargo, en su momento los dueños donaron aproximadamente tres hectáreas cada uno al pueblo: "ya están viejitos, ya no viven aquí, sus hijos los llevaron a Oaxaca desde chiquitos, nadie de ellos viven acá".

El alcalde argumenta que el terreno pasó a ser comunal desde la década de 1950, y que los hijos de los que fueron dueños ya no viven en la comunidad, no hacen servicio ni dan cooperaciones, por lo que nadie en el pueblo "los reconoce que son de acá". Según el alcalde el terreno "va a pasar a la comunidad y va a servir para la gente que necesita terreno". Sin embargo, el hijo que reclama derechos sobre el terreno acudió con un licenciado, ante lo cual el alcalde señala: "El acuerdo del pueblo lo respetamos como una ley. Eso dice el pueblo y debemos obedecer".

Es importante advertir que el alcalde en su narración, por un lado, argumenta que los dueños donaron el terreno a la comunidad y por otro señala que los terrenos están ubicados en el área comunal y sólo los que están en el pueblo son propiedad porque son solares - son los espacios de terreno dentro del 
asentamiento humano que se destinan para la construcción de viviendas o donde se encuentran éstas:

Aquí en el centro sí hay propiedad porque son solares. Los terrenos de abajo es [sic] comunal. Anteriormente los que salieron más abusados agarraron y pusieron colindancias pero no tenían papel. Nada más respetamos la herencia, ésta no se puede vender, no se puede hacer papeles, sólo se puede prestar. Algunos han vendido pero después tienen problemas con otros de la familia.

El argumento revela cómo se busca justificar el discurso de la comunalidad de las tierras para oponerlo a los intereses de los particulares y eventualmente a la intervención del Estado por las gestiones del licenciado que el supuesto heredero contrató, ya que interpuso un amparo en contra de las autoridades municipales. Las autoridades municipales fueron requeridos por un juez federal para que le informaran si eran ciertos los hechos que reclamaba el supuesto heredero y determinar si otorgaba el amparo definitivo.

IV. ACTOS RECLAMADOS. De las autoridades responsables se reclama:

3. Reclamamos el Acta de Asamblea general de ciudadanos del municipio de Totontepec, levantada el dos de junio del dos mil dos, por las autoridades señaladas como responsables; de manera particular el punto número cinco del Orden del Día.

4. Reclamamos el Acta de Asamblea general de ciudadanos del municipio de Totontepec Villa de Morelos, Mixe, Oaxaca [...]

8. Reclamamos, los actos jurídicos que derivan de las asambleas referidas y que consiste en la privación del derecho de propiedad que detentamos como dueños de la fracción de terreno descrito. [Demanda de amparo y protección de la justicia de la Unión de 20 de abril de 2002]

Ante esto las autoridades municipales también fueron asesoradas por un licenciado para contestar negando los actos que el supuesto dueño reclamaba, es decir, que las autoridades municipales le habían expropiado. De esta respuesta se destaca que 
las autoridades indígenas del municipio se aprovechan de la lógica jurídicopositivista que no reconoce a la Asamblea como autoridad y que no tiene facultades para expropiar - de acuerdo con el marco jurídico mexicano- por no formar parte de la estructura del Estado. ${ }^{163}$ Ya que el amparo se solicita en base a las Actas de Asamblea, y no se presentan oficios firmados por las autoridades municipales, éstas "niegan los actos de desposesión, expropiación e invasión del terreno" -que en el sistema jurídico mexicano sólo pueden ser realizado por autoridades del Estado-. El argumento central de las autoridades municipales fue que la Asamblea comunal fue la que resolvió el conflicto sobre los terrenos y ellas no intervinieron en esa decisión. Podemos decir que esto es el punto de mayor confrontación entre sistemas distintos, marcado por el argumento comunalista y el uso estratégico y contestatario del derecho (Lazarus-Black e Hirsch 1994). Así, las autoridades indígenas a nivel interno o comunitario consideran a la Asamblea como la máxima autoridad, sin embargo, al ser requeridas por el Juez de Amparo no admiten que dentro del sistema jurídico indígena la Asamblea sí es autoridad, con lo que hacen un uso estratégico del derecho estatal ya que éste no reconoce a la Asamblea ciudadana y de comuneros como autoridad. Por lo que el juez federal negó la suspensión definitiva (amparo) de los actos reclamados por el supuesto heredero, pues el amparo sólo puede utilizarse en contra de actos de autoridades del Estado -incluidos o reconocidos dentro de su estructura.

Segundo.- Respecto de los actos reclamados consistentes en las actas de asamblea de dos de junio, siete de septiembre de dos mil tres, la falta de notificación de las convocatorias a las citadas asambleas, así como los actos jurídicos que se derivan de las mismas, es preciso destacar que para efectos del juicio de garantías, no son actos de autoridad, toda vez que la asamblea general de ciudadanos, no puede, con fundamento en la ley, emitir actos

\footnotetext{
163 Jurisprudencia: Novena época. Instancia: Pleno. Fuente: Semanario Judicial de la Federación y su Gaceta. Tomo V. Febrero de 1997. Tesis P. XXVII/97, página 118. “AUTORIDAD PARA EFECTOS DEL JUICIO DE AMPARO. LO SON AQUELLOS FUNCIONARIOS DE ORGANISMOS PÚBLICOS QUE CON FUNDAMENTO EN LA LEY EMITEN ACTOS UNILATERALES POR LOS QUE CREAN, MODIFICAN O EXTINGUEN SITUACIONES JURÍDICAS QUE AFECTAN LA ESFERA LEGAL DEL GOBERNADO" [Las mayúsculas son del texto]
} 
unilaterales a través de los cuales pueda crear, modificar o extinguir situaciones jurídicas que afecten la esfera jurídica de los aquí quejosos; por tanto, al no ser actos de autoridad, resulta improcedente el juicio de garantías respecto de los citados actos reclamados, y procede al respecto el sobreseimiento del juicio. [Considerando Segundo de la Sentencia del Juez Primero de Distrito en el Estado de Oaxaca, 23 de junio de 2004. El subrayado es mío]

Por lo tanto, desde la perspectiva del derecho positivo lo que hizo la Asamblea de ciudadanos de Totontepec es ilegal, aunque el Juez de Amparo no se pronuncia en ese sentido ni lo califica así pues únicamente se le solicitó el amparo. El heredero por su parte interpone el amparo contra actos que consideraba de una Autoridad, en este punto se puede observar el recurso de distintos referentes de legalidad y que aparentemente el usuario no puede distinguir que se encuentra ante sistemas jurídicos diferentes. De esta manera, con el argumento que esgrime el supuesto heredero, sin quererlo reconoce a la Asamblea como autoridad - porque así es reconocida al interior de la comunidad - e interpone un recurso que sólo procede contra autoridades del Estado. ${ }^{164}$

Lo anterior muestra cómo el derecho en la comunidad se gesta en una estrecha relación con el derecho positivo, sin que se diluya su especificidad. Por ello existen asuntos que pueden ser resueltos de formas distintas según cada ordenamiento jurídico. Esta imbricación muestra también que el derecho positivo (sus estructuras, instituciones, autoridades, dinámicas), por un lado, puede ser una amenaza al sistema jurídico indígena, pero también puede constituirse como una circunstancia que lo fortalece. Pese a esto, el ejemplo muestra que el derecho positivo puede ser usado por los usuarios y autoridades indígenas como el alcalde

164 Es importante decir que el tecnicismo que significa identificar a una Autoridad es básico en los cursos de Amparo de las facultades de Derecho. Argumento que para el heredero el sistema jurídico interno de su comunidad y el sistema positivo es uno y el mismo, porque muchas veces los particulares NO conocedores de esos tecnicismos exigen a los abogados que hagan milagros con los recursos jurídicos que el derecho mexicano da. Algunos abogados somos más honestos que otros y aclaramos a los clientes que lo que piden no es posible, pero otros profesionistas del derecho no lo son y sin mediar ninguna explicación presentan amparos en contra de personas o instituciones que en el derecho mexicano no son consideradas autoridades. 
y las otras autoridades municipales, y la Asamblea para reforzar el derecho vigente en la comunidad. Esto además fortalece las decisiones de las autoridades y de la comunidad, haciendo más relevante el principio de la comunalidad (CAPítUlo 2). Se revela además la ductibilidad del derecho y las distintas formas y maneras de resolución de conflictos. A nivel interno las autoridades podrían decir al supuesto heredero: el Juez de Distrito, nos dio la razón, aunque realmente desde la perspectiva del Estado no haya sido así - si se lee con detenimiento la sentencia del Juez de Amparo-, pues el supuesto heredero puede agotar otro tipo de instancias judiciales dentro del sistema jurídico positivista - no precisamente el amparo-, lo que mantiene abierta la arena de disputa.

\section{b) Un problema entre padre e hijo}

La manera de resolver un conflicto implica escuchar a todas las personas involucradas, lo que no significa que cualquiera pueda presenciar la discusión sobre el asunto. El alcalde narra el caso de un joven que cuando chico fue criado por su madre, pero llegó a la edad en que ella le dijo que fuera con su papá para que él lo mantuviera. Sin embargo, el padre no se hizo cargo y en cambio le ofreció darle su casa:

Entonces el papá le ofreció al niño la casa [donde vivía aquél] y regresó llorando [el niño] con su mamá, dejó la escuela ya no terminó y salió a buscar lo suyo, buscó, trabajó con la gente, hacía trabajos. Una vez, ya grande encontró a su papá, éste le volvió a decir que era su único hijo y que le iba a dejar la casa que era suya. [Narración del alcade sobre el caso, 24 de julio de 2004]

Al casarse el hijo, su padre le reiteró "si quieres hacemos de una vez el papel", y midieron, sin embargo, ahora el padre aunque admite que es verdad ya no quiere dejarle al hijo la casa "y trae a toda su gente de allá, a sus vecinos. Yo [el alcalde] les digo que éste es un problema entre padre e hijo y que ellos no tienen nada que ver". Finalmente el padre no cumplió con su palabra a pesar de que las medidas y colindancias de la casa quedaron en papeles que el comisariado hizo ante testigos 
(utilizando un machote sobre estipulaciones testamentarias con el sello de la Confederación Nacional Campesina) y firmados por el síndico, el comisariado y cuatro testigos, sin la firma del padre porque estaba ausente. Ante este incumplimiento el alcalde señala: “yo creo que como él es solo, se enojó con su hijo cuando se casó, quería que el hijo fuera como él [que se quedara solo]". Termina diciendo "Éste es el problema que tengo [recargando los codos en su escritorio tomando su cabeza con las manos y haciendo hacia atrás su cabello], todavía no tiene solución".

En este caso se puede observar el uso de documentos oficiales como el papel introducido a través de la Confederación Nacional Campesina que proporcionó los machotes al Comisariado de Bienes Comunales de Totontepec para que los comuneros realicen sus testamentos a tiempo, designando herederos y evitando conflictos entre los que se creen con derecho. En el caso que se expone no hay herederos confrontados y como señala el alcalde "es un problema entre padre e hijo". El hijo solicita que el padre cumpla con su palabra, desde la perspectiva del alcalde el padre debe cumplir porque dio su palabra al hijo cuando era pequeño, además de aceptar esto, admite que nunca quiso hacerse cargo de él cuando su madre no pudo mantenerlo. Sin embargo, la introducción de un papel oficial que representa la lógica jurídica del derecho positivo con un machote de testamento que requiere la firma del padre, refuerza su postura por encima de lo que por costumbre le corresponde como obligación, ya que establece el derecho del testador [padre] a cambiar en cualquier momento su voluntad antes de morir y que hasta que no se dé ese evento no puede ser obligado a ceder sus propiedades. Ante el dilema que plantea el tener en cuenta los dos referentes o sistemas jurídicos, el alcalde sólo espera que el padre recapacite y acepte dejarle al hijo la casa, es decir, cumpla con su palabra. Al no resolverse el caso según el alcalde "queda para que la autoridad del siguiente año le dé seguimiento", seguramente entonces la autoridad que quede pedirá al actual alcalde que le dé más información sobre el caso o un consejo, si el hijo así lo reclama. 


\section{c) El marido o la esposa}

Algunas veces, si el caso lo amerita el alcalde intenta que las partes involucradas en un conflicto se acerquen entre sí y lleguen a un acuerdo, sin necesidad de que él intervenga. Así, en un asunto familiar narra que una joven señora lo fue a buscar para plantearle que su marido ya no le daba para sus gastos y que "anda raro, ya no es lo mismo como antes, ya no platica, se ve muy raro, ya anda mal" y que en una ocasión que ella se enfermó y no podía moverse, él se fue con el pastor adventista y que gracias a su vecina se recuperó. Ante esto, el alcalde le dijo a la mujer que no citaría inmediatamente a su marido y más bien le pidió "tú haz un esfuerzo para que platiques con él, para que ya no esté enojado, tú puedes corregirte para que diga de una vez porqué está enojado". La señora regresó y le expuso al alcalde que ella ya había hecho su parte "para que él no diga que yo soy" y agregó que su hijo tiene un problema de la cabeza y su esposo no quiere hacerse cargo. Ante esto el alcalde mandó a traer al marido, y al llegar lo confrontó:

Esposo.- ¿Por qué me traes aquí?

Alcalde.- Te traigo para platicar, para saber qué pasa, ipor qué hay rencor, por qué tratas así a tu mujer?

Esposo.- Hay otras mujeres, ella es muy descuidada se le olvida lo que le pido.

Alcalde.-Pero tienes un hijo que tiene un problema de la cabeza.

Esposo.- Él ya está grande.

Después que el esposo plantea su versión del caso, pidió al alcalde que lo divorciara, ${ }^{165}$ pero aquél lo trató de convencer mostrándole su acta de matrimonio diciéndole: "no es tan fácil". Ya que el marido se aferró a su idea de no seguir casado porque "no es a la fuerza" y que podía romper el acta de matrimonio, el alcalde decidió encerrarlo 24 horas en la cárcel para que se calmara y recapacitara. Al ver que no logró su objetivo levantó el acta donde se señala que el marido quiere divorciarse "comprometiéndose a hacerse cargo de los gastos de su hijo",

165 El divorcio es un acto jurídico que en el campo jurídico positivista no lo puede realizar el alcalde, que corresponde al oficial del Registro Civil - si es voluntario y no hay hijos - o al Juez. 
sin embargo, emigró a Nueva York, por lo que ahora el alcalde busca que la casa que construyó se le quede a la señora y a su hijo:

Ya mandé un oficio con el comisariado pero ahí lo tiene no ha hecho nada. Pero ahí está el acta [en la que queda] que [el marido] no quiso un acuerdo, y que quiere el divorcio, tiene sello [mostrándome el acta señalando el sello]. El sello tiene importancia porque sino cualquiera lo puede hacer.

Finalmente se observa el papel del sello como referente simbólico de poder y oficialización, que ha sido apropiado por la autoridad indígena para dar y reconocer validez a los escritos que le llegan y que él elabora. De igual forma, de la lectura del Acta de Acuerdo se puede observar que a pesar de que el marido se compromete a hacerse cargo de los gastos de su hijo, el alcalde decide encarcelarlo porque insiste en divorciarse:

El alcalde decide detenerlo veinticuatro horas por no aceptar una solución favorable. No habiendo más por tratar se cierra la presente siendo las 18 hrs del día 23 de marzo del presente año. Firmando para constancia los que en ella intervinieron. DAMOS FE.

También se puede observar que el Acta - escrita en computadora y redactada entre el alcalde y la secretaria auxiliar del Registro Civil - comienza y termina con un lenguaje muy formal pero que la narración de los hechos y la redacción de los acuerdos es muy familiar, casi coloquial.

Al preguntarle al alcalde si al regresar el esposo de Nueva York podía obligarlo a dejar la casa para su esposa e hijo, respondió: "Nosotros ya salimos pero el acta queda", esto muestra el valor de lo escrito, como expresión de la oficialización del derecho vigente en la comunidad promovido por el derecho positivo. Aunque la norma oral sin duda es un elemento clave central de la regulación local, lo escrito es un referente del ejercicio de poder y de autoridad. La importancia de la norma oral queda resumida por las palabras del alcalde cuando 
se le preguntó si Totontepec tiene reglamento interno o estatuto comunal, respondió: "No, todo es por acuerdo, nada se escribe".

\section{d) ¿Diferencia de religión o disputas matrimoniales?}

Una joven pareja acudió con el alcalde a exponerle su deseo de separarse pues habían tenido una pelea. La disputa aparentemente fue porque la mujer golpeó al hijo de dos años de edad, al ver esto el esposo golpea a la mujer, como ambos están enojados y muy molestos, ella decide ir a caminar con el niño, sin embargo, se le hace tarde y se queda en casa de su hermana. Al día siguiente que regresa a la casa de su marido éste la corre. Cuando el alcalde les hace varias preguntas, resulta que la molestia fue porque la mujer se llevó al niño al templo adventista por lo que el marido, que es católico, se molestó, y también a la mujer le molesta que el marido lleve al hijo a la iglesia católica. Después de mucho platicar con el alcalde, éste les pide que no obliguen al niño a seguir una u otra religión, ya que ellos tuvieron la culpa al casarse sabiendo que tenían distinta fe y que si el uno no ha fallado como marido ni tampoco la otra como esposa que deben seguir juntos respetando su religión:

Alcalde.- Deberían de pensar antes de hacer un compromiso de matrimonio, porque eso no es para un rato sino para toda la vida. A donde hay fe debe ser de un lado. Ustedes hicieron mal desde un principio.

Marido.- Cuando nos casamos platicamos y llegamos a un acuerdo.

Alcalde.- Pues ahora deben hacer lo mismo. Ahora por la fe se están peleando y todavía falta más familia. ¿Por qué aceptaron así su religión? Es un problema que aceptaron y deben mantenerse; así como aceptaron deben aguantarse. No vamos a decir ahorita si el niño va a ser adventista o católico, él decidirá cuando sea mayor.

Finalmente la pareja decidió seguir juntos, quedando lo siguiente en el Acta de Acuerdo: 
PRIMERO.- Los dos reconocen su error.

SEGUNDO.- Deciden perdonarse y volver a empezar.

TERCERO.- Dejan en libertad al niño para que vaya al templo que él quiera sin que ninguno de los dos se enoje o lo obliguen.

CUARTO.- Cada uno respetará la religión del otro.

QUINTO.- Los dos se comprometen a respetar los acuerdos y el que no lo cumpla será sancionado por la autoridad correspondiente.

CONVENIO que se firma en presencia de la autoridad actuante. Enseguida sin haber más que tratar se da por terminada la misma, previa lectura y ratificación en todas y cada una de sus partes, firmando los que en ella intervinieron. Acta que se cierra y autoriza. DOY FE. [Acta de Acuerdo, 14 de junio de 2004]

Como se observa en este caso las dos partes acudieron con el alcalde para que él diera la solución a la controversia familiar sobre la preferencia religiosa que debe prevalecer. A pesar de que el alcalde es católico no benefició al marido en contra de la mujer, sin embargo, pudo entender que la disputa por la preferencia religiosa tenía como centro al hijo, por lo que dejó como posibilidad la opción religiosa del hijo, advirtiéndoles: "Por ahorita no podemos definir si el niño va a ser adventista o católico. Lo dejamos libre porque no puede ser a la fuerza".

Sin duda la opción religiosa se ha constituido, desde la introducción de religiones distintas a la católica, no sólo como un conflicto comunitario sino también como un nuevo aspecto en la dinámica familiar.

\section{e) El error y la reparación del daño: ¿Crimen y castigo?}

Al llegar un muchacho a la oficina del alcalde cruza con él unas palabras en mixe y le deja dinero, al irse éste comenta que el muchacho por jugar pesado con una muchacha le lastimó la espalda, por lo que lo mandó a llamar para confrontarlos. El muchacho no negó su responsabilidad, sin embargo, argumentaba que lo había hecho de broma y no de maldad, el alcalde le respondió: “Sí, pero ya hiciste el 
daño y debes responder por sus curaciones". El muchacho aceptó pagar a la muchacha los gastos necesarios para curarse, sin embargo, llegó un momento -en el transcurso del trabajo de campo- que el alcalde lo citó para que firmara un acta en la que aceptaba hacerse cargo de los gastos de la muchacha para curarse, a lo cual se negó argumentando que no estaba su papá, que no tenían dinero. El alcalde me explicó después que el muchacho estaba haciendo cargo como capillo, para atender a las bandas que vienen de otros pueblos a la fiesta patronal, lo que realmente implica una erogación de gastos muy fuerte.

El muchacho pudo pagar mil quinientos pesos por consultas, curaciones y traslados de la muchacha, pero se negó a seguir pagando y su papá confrontó al alcalde para que hiciera justicia:

Papá.- ¡Debes hacer justicia formal, debes ser neutral! Alcalde.- ¿Cuál neutral voy a hacer si tu hijo hizo daño?

Ante la negativa del muchacho y de su padre a pagar más gastos de la muchacha, el alcalde después me expresó que ella tenía derecho a ir con un abogado:

Yo no quiero hacer grandes las cosas, quiero que se arreglen. Pero ella tiene el derecho de conseguir un abogado. Ella es fuerte, trabaja, pero ya no puede por su espalda y no estamos hablando de eso. [Entrevista, 28 de julio de 2004]

En esta reflexión del alcalde es importante resaltar que en su preocupación está que la muchacha tiene derecho de ir con un abogado reconociendo que puede acudir a la instancia del Estado ante el Juez en el Distrito y, por tanto, que la instancia de la alcaldía no es la última. Esto tal vez representa como en las estrategias de disputar de usuarios y autoridades indígenas están presentes otras instancias como el sistema jurídico mexicano - en el cual están formados todos los abogados.

Es importante señalar también que, como bien argumenta el alcalde, la muchacha puede ir con un abogado, pues las lesiones de este tipo son consideradas 
graves (véase cuadro de delitos), si fuera éste el caso la denuncia la recibe el Ministerio Público (MP) para que posteriormente resuelva el juez - lo que le implicará a la muchacha ir a Zacatepec-. Sin embargo, es de destacarse que la preocupación del alcalde en este caso era que ya tenía redactada el Acta de Acuerdo, en la que el muchacho se hacía responsable de los gastos, pero estaba incompleta por su negativa a firmar, por lo que pidió mi opinión y por primera y única vez me atreví a dársela, pues en otras ocasiones me había quedado callada para no interferir en la dinámica interna de hacer justicia. Le sugerí que pusiera una nota al reverso del acta donde se dijera que no quería firmar y las razones de por qué, y que citara a los dos para dar por concluido el caso, pues la muchacha desde hacía mucho ya no iba a la Alcaldía a pedir que le pagaran gastos. Estuvo de acuerdo y dijo que así lo haría. Esta preocupación muestra el sentido en que los referentes legales se ponen en juego al momento de atender o resolver las disputas. Por un lado dar la palabra firmando un convenio, por otro que el compromiso por escrito sirva después como constancia de la justicia a nivel interno y ante las autoridades estatales lo que se comprende si se toma en cuenta que el sentido de la redacción y firma del Acta - según el alcalde- es evitar que las partes sigan el pleito, de lo contrario, y dentro de esta lógica, significa que la intervención del alcalde no sirvió o no fue efectiva, es decir, no fue capaz de hacer justicia.

En este caso se constata que más que acudir a la legalidad del Estado lo que se observa de nueva cuenta es el uso del discurso de la ley estatal como recurso de presión para solucionar controversias - como también se puede observar en otras regiones indígenas de México en donde se utiliza el recurso del sistema jurídico estatal como una amenaza o presión para lograr acuerdos (cfr. Sierra 1995).

\section{f) Cuestionamiento a la justicia comunitaria: ¿El abogado indígena o la mujer como cliente?}

El caso se trata de un asunto que el alcalde resolvió entre dos esposos y el amante de uno de ellos (con el que resultó un niño), logrando que firmaran los tres un acuerdo. En este acuerdo cada uno se comprometió a determinados actos, el 
esposo a perdonar y respetar a su esposa, la esposa a aceptar su equivocación, regresar y atender a su familia, el amante a dejar libre a la esposa y "no volver a interponerse en esa familia", el niño (hijo de la esposa y el amante) "queda libre de irse con quien se sienta mejor". Finalmente en el acta se estableció un castigo por los actos que los llevaron a hacer el Acuerdo y, también, para el caso de no cumplir lo que cada quien se comprometió:

Quinta.- la persona que no respete este acuerdo será castigado, y el ofendido tendrá derecho a denunciarlo, por lo que todos están comprometidos a cumplir lo acordado. Como castigo se les impuso al señor [esposo] y a la señora [esposa] una tonelada de cemento para el $H$. Ayuntamiento, el primero por emborracharse y golpear a su esposa, la segunda por irse de su casa y por dar el mal ejemplo a sus hijos.

Al señor [amante] se le impuso como multa la cantidad de \$1,000.00, por meterse con la familia y provocar los problemas de casados. Por no haber más asuntos que tratar se cierra la presente para constancia del acuerdo tomado, siendo las trece horas con treinta minutos del mismo día de su inicio, firmado de conformidad los que en ella intervinieron. DAMOS FE. [Fragmento del Acta de Acuerdo, 20 de marzo de 2004]

En la concepción del alcalde, los esposos pagaron igual sin importar que el marido había golpeado antes a su esposa y por esa causa se marchó, ya que al hacerlo la mujer también estaba cometiendo un error - lo que para el alcalde quedó constatado por el hijo que tuvo con el amante-. Tal vez si la mujer hubiera acudido con el alcalde antes de abandonar a su marido, la sanción hubiera sido otra, o bien, no la hubiera tratado de convencer de volver con el marido.

De igual forma la intención prioritaria del alcalde era mantener unida a la familia "original", aunque esto implicara que la "nueva" familia de los amantes se desintegrara. Finalmente esto da a suponer que no existe la posibilidad de separación si no es por acuerdo de los cónyuges o bien por causas muy graves, como el hecho de que el esposo no reconociera su error y continuara golpeando a la esposa, o que ésta no lo atendiera debidamente. 
Sin embargo, y a pesar de este acuerdo, la esposa - al parecer aconsejada por el amante - recurrió a un abogado oriundo de Totontepec, para solicitar el divorcio y una pensión. El esposo llegó con el alcalde para ponerlo al tanto de esto e informarle que la esposa y el amante le habían dicho que tenía que ir a Zacatepec a firmar el divorcio de lo contrario vendría por él la policía. Ante esto, el alcalde se indigna gravemente porque el esposo decidió ir a firmar, lo que tomó como un cuestionamiento a su trabajo de hacer justicia. En entrevista con el alcalde el 20 de octubre de 2004, expresó:

Nos sentimos defraudados. Hace 10 días [un domingo], llegó la señora pidiendo que escuchara al abogado porque tenía que decirme cuál fue la decisión del Juez y que su abogado llegaba el lunes.

El abogado de la mujer le explicó al alcalde que el dictamen del Juez fue que el esposo tenía que depositar $\$ 600.00$ cada mes en la alcaldía o en la sindicatura, y que ya no puede vivir en su casa "ya perdió todo el derecho". Ante esta explicación del abogado, el alcalde indignado le increpó y le dijo que él ya había hecho justicia y que la esposa y el amante la rebasaron, además de que el Juez debió pedirle información por que él fue electo como alcalde por la gente y eso es la Ley:

Yo me voy a quedar falso porque estoy vendiendo el sello. ¿Por qué me dice esto? jyo no necesito escucha!. A mi manera de actuar ya lo hice, si no hice bien ¿a caso no es válido? Soy parte del Juez porque él no puede venir aquí a esperar cuánta gente viene a pedir Justicia. Yo conozco a mi gente, quiénes son malos ¿Por qué ellos se fueron? ¿Por qué rebasaron? Yo soy la Justicia, soy la autoridad porque la gente me nombró. Ahora, ¿qué no es válido lo que yo hago aquí? ¿No tiene validez? Si el Juez hace así, que él venga y que escuche aquí la gente porque ella me dio el lugar, el mando, y eso es la ley, lo que la gente decidió. Si el Juez no considera lo que yo estoy haciendo que él venga. Aquí ya se hizo Justicia. No estamos como juguetes para hacer lo que la gente no conoce. Yo me hago a un lado si te crees capaz ¿Por qué el Juez no me pidió información, si aquí está el asunto? [Entrevista con el alcalde, 20 de octubre de 2004] 
Viendo el enojo del alcalde el abogado señaló que no era su intención ofender sólo quería exponer lo que el Juez de Zacatepec había ordenado, y la esposa pedía perdón porque no había pensado que el problema se iba a hacer más grande. Finalmente el alcalde les informó su decisión de pasar el asunto al cabildo y en caso de que no se resolviera ahí, pasaría a la Asamblea.

En el cabildo, solicitó la ayuda de los otros integrantes, el presidente municipal le confirmó que su manera de hacer justicia había sido la correcta: "Porque si la gente se va a hacer justicia a otra parte ¿qué vamos a hacer nosotros?". Primero se había resuelto que como la esposa no era de Totontepec sino de otra comunidad - agencia de Totontepec - " ya no tenía derecho a agarrar agua, ni leña, piedra, tierra, ya no puede ir a la clínica. Que haga lo que quiera".

Sin embargo, se decidió que lo que había hecho la esposa quedaba como un "mal antecedente" de su conducta aunque el alcalde dijo "de todas formas va a perder sus derechos porque no es de aquí".

Es relevante, en este caso, que el abogado indígena - por ser oriundo de Totontepec - no recibió castigo ni amonestación alguna, sólo el regaño del alcalde, tal vez por que es hijo de un comerciante importante de la cabecera-comunidad, aunque tampoco ha hecho servicios ni cargos - según me informó el alcalde - . Tal vez no sabía hasta dónde llegaría la reacción del alcalde, lo cierto es que su calidad de indígena y oriundo de la comunidad cabecera, así como su formación profesional lo hacen ser un intermediario o agente de cambio que legitima el aparato legal del Estado por encima de las resoluciones de la autoridad indígena. La actitud del abogado revela su falta de respeto a las formas de hacer justicia ya que con su intervención pasó por alto la autoridad de su pueblo, poniendo en riesgo los derechos de la esposa en la comunidad.

Con este caso también se pone de relieve que seguramente la mujer no estuvo conforme con la justicia del alcalde y que realmente lo que quería era separarse de su esposo. Los usos del poder y la relación y tensión entre las instancias comunitarias de justicia y las del Estado - como son claros cuando las 
autoridades municipales consideran a la mujer como la única responsable de violentar o cuestionar la decisión del alcalde, a pesar de que ella no hubiera acudido a la instancia del Distrito sin la ayuda del abogado. Si bien los usuarios indígenas consideran al Juez del Distrito como una instancia donde puedan dirimir sus conflictos, saben que tienen que cumplir requisitos distintos de los que se cumplen a nivel de la comunidad. El abogado utilizó de acuerdo a sus intereses el derecho del Estado para continuar una disputa a nivel del Distrito Judicial, por lo cual seguramente recibiría un pago. ${ }^{166}$ La mujer vio en el uso del sistema normativo estatal la posibilidad de exigir otros derechos, como a separarse de un hombre que la golpeaba y recibir una pensión para sus hijos.

Las dinámicas en los usos del derecho y el ejercicio del poder también son claras al considerar que la mujer no es oriunda de Totontepec - según lo expone el alcalde-, por lo que seguramente siempre dudó de un acuerdo favorable para ella en la instancia municipal, por ello recurre al abogado, que además de ser totontepecano es de una familia importante del poblado-cabecera.

Como parte de este caso es de destacarse la indignación del alcalde sobre la postura del Juez de Distrito de no tomarlo en cuenta, no entendía porqué si él es Auxiliar del Juez y si existía un acuerdo por escrito con las firmas y el sello de la Alcaldía de Totontepec, el Juez en el Distrito no lo había considerado. Ante esto, le expliqué al alcalde que seguramente el abogado no había puesto en antecedentes al Juez de Zacatepec (cabecera del Distrito), porque si hubiera sido así no le hubiera dado la razón a la señora, pues en el Acta (que firmó ella, su marido y el amante)

166 También se muestra con este caso que no se puede ver el ejercicio profesional de un abogado indígena con romanticismo y esperar que actúe siempre respetando o aplicando el sistema normativo indígena. Cfr. Bartolomé (2001) y Capítulo 3 punto 3.1.1 de este trabajo. En un trabajo realizado como consultora en materia indígena para el Alto Comisionado para los Derechos Humanos de la ONU, me tocó trabajar con abogados indígenas - así los contrataron-, fue interesante escuchar sus reflexiones sorbre su profesión, frases como: "yo sólo hago lo que el cliente pide y si eso lo logro con el derecho positivo está bien, pues el derecho de la comunidad sólo ahí se conoce y muchas veces no da lo que el cliente quiere". Esto muestra que si bien los abogados son indígenas de nacimiento, el estudiar su profesión en una situación de subalternidad y dominación lo determina en su quehacer social, pues no siempre sabrá lo que debe hacer en el contexto comunitario y tratará de dar solución a los asuntos que le lleguen según lo que aprendió en el derecho positivo. 
no sólo el marido aceptó que la maltrataba sino que ella aceptó haberlo abandonado y haber tenido un hijo fuera del matrimonio. También agregué que no era creíble lo que decía el abogado de que en próximos días recibiría la sentencia del Juez donde se le ordenaba recibir los $\$ 600.00$ pesos - lo que se corroboró después, pues nunca llegó el escrito-. Por último, le expresé mi asombro porque yo creía que el abogado de la señora no era mixe y mucho menos no me imaginaba que fuera de Totontepec, que si habían castigado a la mujer que también pensaran hablar con el abogado porque había actuado como si no fuera del pueblo y a la larga les iba a traer más problemas. Después de esto el alcalde reflexionó señalando que el abogado les sería útil a las autoridades municipales - sin abundar en qué sentido.

\section{g) Las deudas económicas y el derecho a la libertad física}

El caso que se narra a continuación expone cómo los límites de la jurisdicción estatal están donde empieza la jurisdicción indígena, definida ésta como un ámbito espacial y territorial, y en torno a la cual se pone en juego un conjunto de valores de lo que la población espera de sus autoridades - su capacidad y sus competencias legales, lo que pueden o no pueden hacer según el sistema jurídico indígena-. A su vez la jurisdicción indígena tiene límites que dependen de su propia legitimidad y de la hegemonía del sistema jurídico mexicano, por ejemplo, cuando uno de los miembros de la comunidad no acepta el resultado o considera que la justicia estatal le puede ayudar mejor. Esto sucede, generalmente, cuando la justicia indígena y el sistema jurídico indígena, como tal, no son tomados en cuenta por la autoridad o agentes del Estado y éstos se imponen.

Llegó una mujer (la señora $\mathrm{X}$ ) con el alcalde a exponerle que su vecina (la señora Y) necesitaba dinero y ella se ofreció a conseguírselo, pero ahora Y no quiere cubrir la deuda y los intereses van en aumento. La señora $(X)$ tuvo que 
pagar los intereses y la señora $Y$ se negaba a pagar porque decía que el hijo de la señora $X$, es decir, Z lo había mal gastado. ${ }^{167}$

Después de que el alcalde estuvo citando varias veces a la señora $Y$ y ésta no se presentaba, la mandó a buscar con un topil a una de las casetas telefónicas de Totontepec pues escuchó por el altavoz que tenía una llamada telefónica. Según el alcalde, el topil estuvo dos horas esperando a que la señora $\mathrm{Y}$ saliera. Al momento en que salió, el topil la llevó a la Alcaldía, ahí el alcalde la interrogó y aceptó su deuda pero argumentó que no tenía dinero y que le hicieran lo que le hicieran ella no pagaba. Ante esta negativa, el alcalde la mandó a la cárcel durante 24 horas. Al salir la señora $Y$ le dijo al alcalde: "hazle como quieras porque no voy a pagar y si me mandas a la cárcel voy a ir". Según el alcalde, la señora Y ya había acudido con un abogado de Derechos Humanos, por eso se sentía tan confiada, de hecho él recibió una llamada de un licenciado de la Comisión de Derechos Humanos de Oaxaca, pidiéndole el licenciado que dejara libre a la señora $Y$ ya que no podía encarcelarla por deudas económicas, y podría incurrir en abuso de autoridad. Así lo relata el alcalde:

Habló el de Derechos Humanos y me dijo: "Sr. alcalde, le suplico que el caso de la señora Y, no es posible que le haga así a ella porque si no tiene, nosotros ¿qué podemos hacer? Hágalo con mucho cuidado de no maltratar a la gente, hay que darles más tiempo [para pagar]". También habló con el presidente municipal (yo no sé por qué), se enojó y le dijo que el alcalde estaba haciendo su trabajo (servicio) pero que si él [el abogado de la Comisión de Derechos Humanos] podía solucionar, que viniera a resolver. [Entrevista con el alcalde de Totontepec, 20 octubre de 2004]

Al conocer la postura de la Comisión de Derechos Humanos, el alcalde mandó que la señora Y saliera de la cárcel y se quedara en el pasillo de las oficinas del Ayuntamiento, así fue hasta que le pidió al alcalde que la dejara ir a comer, a lo

167 Se omiten los nombres ya que se tiene planeado regresar esta tesis al alcalde de Totontepec y considero que esto puede evitar que los conflictos resurjan de otra manera. 
que él respondió "que te traiga tu hija"; la señora $\mathrm{Y}$ aceptó y solicitó al alcalde que la dejará ir a traer el dinero, él le contestó que no, que mandara traer a su hija.

Finalmente se aclaró que el dinero que pidió la señora $X$ para la señora $Y$ era para que ésta se lo diera al hijo de la señora $X$ que estaba en Estados Unidos, sin embargo, la señora $X$ no lo sabía. Por lo que la señora $X$ y la señora $Y$ tuvieron que pagar, la primera por los intereses y la segunda por la deuda; ambas solicitaron que cuando llegara el señor $\mathrm{Z}$ les cubriera a las dos lo gastos hechos para él, quedando así redactada el Acta:

La señora Y paga la cantidad de $\$ X X, 000.00$ (XX mil pesos) ya que fue ella la que pidió directamente dinero prestado para dárselo al señor $Z$. Pide que cuando regrese el ciudadano antes mencionado se le regrese el dinero que ella aportó, por su parte la señora $X$ se compromete a pagar la cantidad de XX,000.00 (XX mil novecientos pesos) que corresponde a los 11 meses de rédito, cantidad que pagará cuando ella pueda, y de igual manera pide que cuando esté en esta población el señor $Z$ le devuelva esta cantidad.

Conforme las partes con el contenido del presente convenio y previa lectura de los expuesto ratifican el mismo, y para constancia ofrecen firmar al calce y margen, por lo que no habiendo otra cosa más que asentar se da por terminada siendo las veintiún horas del día en que se actúa, se expide a las partes copia de la presente constancia, misma que se cierra se autoriza y da fe.

DAMOS FE.-----

[Acta Convenio, 5 de julio de 2004]

Según el alcalde, para la resolución de este asunto tomó en cuenta que la señora $Y$ reconoció su deuda y que a pesar de esto se negaba a pagar, al grado de desafiar su autoridad diciéndole házle como quieras.

En la lógica del derecho positivo, las deudas de carácter económico o el reconocimiento de las mismas por parte del deudor no justifican la privación de la libertad, por ello el abogado de la Comisión de Derechos Humanos, solicitaba al alcalde dejar libre a Y. Para la lógica jurídica del sistema normativo indígena, el que tiene una deuda económica debe hacer lo posible para pagar ya sea dando el 
dinero o alguna cosa equivalente, en esta lógica aceptar la deuda y negarse a pagar resulta un desafío a la autoridad. A esto se agrega que el alcalde argumentaba que él sabía que Y tenía un hijo en Estados Unidos que le manda dinero, por lo que sí estaba en condiciones de pagar.

Por lo anterior, es creíble que el alcalde pensara que el abogado de la Comisión de Derechos Humanos haya asesorado a la señora $Y$ para no pagar, pues le hizo saber que en el derecho positivo mexicano eso no es una causa de encarcelamiento - recuérdese el dicho "debo no niego, pago no tengo" - ${ }^{168} \mathrm{Sin}$ embargo, en el ámbito comunitario los recursos que tiene una autoridad indígena - a diferencia de las autoridades estatales en el sistema jurídico mexicano- para hacer cumplir la ley local son muy reducidos, por lo que el encarcelamiento es usado como mecanismo de presión como la multa o la amonestación para obligar o convencer a una persona a cumplir con sus obligaciones frente a la comunidad o frente a otros miembros.

De esta manera, además del encarcelamiento existen otro tipo de mecanismos para obligar a una persona a cumplir, como se mencionó antes, que pueden llegar a la amonestación pública o la privación temporal o definitiva de derechos, hasta la expulsión; desde la perspectiva del derecho estatal es una violación directa a los derechos humanos.

\subsubsection{Asuntos que llegan de las agencias a la cabecera}

Los asuntos que llegaron en el año 2004, a la cabecera para que el alcalde haga justicia, están registrados en actas de acuerdos, provienen de las siguientes agencias: Chinantequilla, Amatepec, Jareta y Jayacaxtepec. Aunque Móctum es

\footnotetext{
168 En el Artículo 11 de la Constitución Política del Estado de Oaxaca se señala: "Nadie puede ser aprisionado por deudas de carácter puramente civil. Ninguna persona podrá hacerse justicia por sí misma, ni ejercer violencia para reclamar su derecho. Toda persona tiene derecho a que se le administre justicia por los Tribunales que estarán expeditos para impartirla en los plazos y términos que fijen las leyes, emitiendo sus resoluciones de manera pronta, completa e imparcial. Su servicio será gratuito, quedando en consecuencia, prohibidas las costas judiciales". El ArTículo 17 de la Constitución Federal señala lo mismo así como el ARTículo 7 de la Convención Americana sobre Derechos Humanos.
} 
uno de los poblados más cercanos a Totontepec, no tiene registrado ningún caso - tampoco se pudo revisar los años anteriores porque aparentemente no se guardan las actas ni tampoco hay un libro de registro del archivo-. Sin embargo, en Móctum una mujer informó que acudió a Totontepec porque ella era de este lugar y su esposo era de Móctum y que seguramente las autoridades iban a estar de lado de su esposo porque "es su gente".

Al preguntarle al alcalde porqué cree que la gente de otras agencias acude a la cabecera para exponer sus casos, me respondió que a veces en las agencias las autoridades sólo trabajan medio día o que cuando se necesitan están en otras comisiones, o porque la autoridad hizo justicia pero las personas involucradas no aceptaron el arreglo. Finalmente los usuarios de las agencias reconocen la autoridad en las distintas instancias legales.

El procedimiento para que un caso sea llevado ante las autoridades municipales puede variar y depende de los intereses de los usuarios del derecho y de las autoridades indígenas. En ocasiones, los casos pueden ser directamente llevados por los usuarios de las agencias, sin considerar a sus autoridades comunitarias - cuando la justicia a este nivel no tiene los efectos que esperaban-. O bien, las autoridades de las agencias solicitan que la cabecera intervenga mandando topiles para controlar una riña, o remiten sus casos enviando a los usuarios a la cabecera.

\section{a) Disputa sobre solares}

Un caso que llegó de San Francisco Jayacaxtepec se trata de una disputa que el agente en la comunidad no quiso atender, entre familiares (hijo y madrastra) por el terreno que dejó el papá al morir. El hijo del primer matrimonio del finado llegó a la casa de la que fue la segunda esposa (con hijos) queriendo construir. El alcalde citó al hijo y a la madrastra y después de escucharlos les pidió que llevaran testigos. Al siguiente día llegó el vecino quien señaló: 
Yo se lo vendí al finado y ahí vivieron, ahí está su casa todavía. Yo sé bien ese terreno donde se colinda [sic] porque vendi de mi propiedad al finado, y no sé porque ese muchacho se mete ahí.

El muchacho contraargumentó diciendo que el había llegado al terreno porque era de su papá y que lo necesitaba para hacer su casa, el alcalde le increpó diciéndole que lo que había hecho no estaba bien "porque sabes que son tus medios hermanos; no está bien que se amontonen si el terreno es chico".

Finalmente llegaron al acuerdo de que el hijo respetaría la casa de su madrastra y que ésta le pagaría $\$ 500.00$ por 10 días de trabajo para levantar la casa. El acta termina:

Los dos se comprometen a no volverse a meter en la vida del otro. No habiendo más que tratar se levanta la presente siendo las trece horas del mismo día de su inicio, firmando para constancia los que en ella intervinieron. Damos Fe.

En este caso se observa cómo se entretejen las relaciones familiares y que el alcalde aplicó un criterio sobre la disputa de terrenos (véase inciso a.1. del apartado 5.1.1.1) cuando hay dos personas que se creen con derecho, se solicitan testigos para que resulte la verdad, es decir, "quien fue primero". Es probable que la tendencia a oficializar los acuerdos con actas, así como recurrir a testigos, sea producto del contacto con las instituciones oficiales, especialmente en el ámbito agrario, aunque no es el único.

\section{b) ¿"Accidente" o delito de lesiones?}

En el siguiente caso concreto, expuesto por el alcalde, se puede observar la oposición entre el derecho estatal y la justicia aplicada por el alcalde por lo que toca al criterio de gravedad de una conducta. Me narra el asunto que le llega de la agencia municipal de San José Chinantequilla -las autoridades no lo remiten y es más por la iniciativa de las partes involucradas-, me muestra el Acta de Acuerdo que levanta donde se señala que fue un "accidente" ocurrido en la comunidad, quedando la declaración del acusado así: 
Comenta que estaba en estado de ebriedad puesto que había tomado licor, cerveza y tepache por lo que perdió completamente el control de sus actos y dice que le avisaron que traía un machete en la mano, dice también que ya se habían calmado pero alguien le dijo que él no cumplía con lo que dice, por lo que volvió hacia su rival y volvieron a pelear [...] aprovechó y se le fue encima tirándolo a un charco de lodo y empezó a morderle la nariz, arrancándole una parte. [Cfr. Acta de Acuerdo levantada en Totontepec, 12 de mayo de 2004]

Lo anterior, según el Código de Procedimientos Penales (ART. 23) y la Ley Indígena (ART. 38) es un delito grave que se debió exponer al Ministerio Público o que el alcalde como su auxiliar - según el derecho estatal - debió habérselo remitido, ya que hubo lesiones que provocaron deformidad incorregible, y que su sanción es superior a los dos años. Sin embargo, el alcalde logró que las partes llegaran a un acuerdo en el cual el que provocó la lesión aceptó pagar los gastos de traslado al hospital de Villa Alta o de Oaxaca así como las curaciones. Finalmente el culpable aceptó su responsabilidad y no estuvo mucho tiempo en la cárcel pues según señala el alcalde:

[...] tuve que dejarlo libre para conseguir dinero cuando el herido regresó de Villa Alta pues lo enviaron a Oaxaca y como no tenía dinero regresó a Totontepec para que le apoyaran. El que causó el daño dijo que no podía acompañar al herido pero que le daba dinero para que fuera a Oaxaca y que se hacía cargo de los gastos de curación. Sin embargo, el herido regresó porque no le ha pagado X,000 pesos. ¡Quedó feo! [Entrevista al alcalde, 22 de julio de 2004]

Desde la perspectiva del derecho positivo el agresor debería ser encarcelado además de garantizar, con un depósito económico, el pago de la reparación del daño, lo que no se hubiera dado tan rápido por los tiempos de trámite y los traslados - transporte y alimentos - que la persona agredida y los familiares del agresor tendrían que hacer para llegar al Distrito y lograr la reparación del daño, y en su caso la libertad del agresor. 
Finalmente y con gran satisfacción el alcalde pudo dar por terminado este asunto porque el agresor no sólo se hizo cargo de los gastos de cirugía reconstructiva sino que el agredido se dio por satisfecho.

Para dar por terminado con este problema el C. [agresor] liquida todo lo que estaba pendiente respecto a lo económico, haciendo la cuenta de todos los gastos el total fue de $\$ X X, 000.00$ y de esta manera cumple con lo que se comprometió, quedando en total acuerdo y conforme el C. [agredido]

El Alcalde Único Constitucional exhorta a los comparecientes que a partir de hoy en adelante no vuelvan a cometer este tipo de errores, y que esto que les sucedió les sirva de ejemplo, se acuerden que también la familia sufre las consecuencias por los errores de un miembro de la misma, los invita a que desde este momento reine la paz y olviden todo. Les pide a ambos que ninguno de los dos ande por ahí hablando mal del otro.

Los comparecientes se comprometen a respetarse mutuamente y olvidar los rencores y no volver a provocar este tipo de problemas.---_------------------. [Acta de Conformidad, 7 de septiembre del 2004]

En este acuerdo se puede observar una lógica diferente de resolución de conflictos, a diferencia del sistema jurídico mexicano, ya que se privilegia la búsqueda negociada del acuerdo y la relación entre las partes, esto queda ratificado tanto por el ofensor como por el ofendido.

\section{c) Falta de respeto a la autoridad y disparo de arma de fuego}

La imbricación o traslape de lógicas jurídicas distintas también se puede observar en el siguiente caso que se refiere, de acuerdo al Código Penal de Oaxaca, al delito de disparo de arma de fuego. Aunque el Código señala una pena de seis meses a tres años, la Ley Indígena de Oaxaca restringe a las autoridades indígenas el ejercicio de la justicia a delitos que sean sancionados con menos de dos años de prisión (pena corporal), así como a los casos que tengan que ver con: 
tenencia individual de la tierra en la comunidad, faltas administrativas y de policía; atentados en contra de las formas de organización, cultura, servicios comunitarios, trabajos y obras públicas; cuestiones del trato civil y familiar; incumplimiento del deber de las madres y padres de familia consistente en enviar a sus hijos e hijas a la escuela; y en general, todos aquellos casos en los que los ascendientes o los esposos y esposas no se conduzcan como buenos padres y madres de familia [ARTícULO 38]

Los asuntos que describe este artículo de la Ley Indígena de Oaxaca, según lo que se ha planteado que señala esta ley y lo que plantea el Código Penal, son casos que no implican penas corporales, sin embargo, la realidad no es tan simple pues concurren dinámicas diversas en los conflictos o disputas que pueden hacer que estos casos, aparentemente no graves o leves, deriven en asuntos de mayor gravedad, por ejemplo "que los ascendientes o los esposos y esposas no se conduzcan como buenos padres y madres de familia", es un enunciado tan amplio que en él caben los golpes y lesiones - que como hemos visto pueden ser leves o graves-, la violencia intrafamiliar y el abandono que en el derecho positivo ameritan pena corporal a veces superior a los dos años según el perjuicio causado.

El caso llegó de la agencia municipal de Santiago Amatepec remitido por las autoridades locales y trata de que el acusado en estado de ebriedad disparó en el centro de su población, se le encarceló durante 24 horas en la cárcel municipal y aceptó su culpa. Lo interesante además es la manera en que fue redactada el acta en la que se destaca un lenguaje muy formal:

Ante el C.[Y] alcalde Único Constitucional, comparece C.[X-] a quien se le protesta en términos de la ley para que se conduzca con verdad en todo lo que va a manifestar y advertido que fue de las penas en que incurren los que declaran con falsedad ante una autoridad, por sus generales dijo llamarse [X] [...] y examinado que fue con relación a su comparecencia manifiesta: que en base a la demanda girada por la autoridad municipal de Santiago Amatepec de los hechos sucedidos el dia [XX] de los corrientes por la tarde y después de haber sido detenido por esta autoridad, reconoce y acepta que efectivamente tuvo 
culpa por haber disparado en el centro de su población con un arma de fuego con la cual fue sorprendido y encontrándose en estado de ebriedad.

Después de un diálogo muy amplio con dicha persona [el culpable] se compromete en cumplir los siguientes acuerdos:

Primero.- No volver a tomar un arma de fuego o cualquiera que resulte peligroso estando en estado de ebriedad o aún estando en juicio.

Segundo.- Respetar a todo tipo de personas, para no volver a involucrarse en problemas.

Tercero.- Obedecer y respetar a las autoridades de su comunidad.

Cuarto.- Cumplir las sanciones que esta alcaldia municipal le ha impuesto como multa.

Quinto.- De hacer caso omiso al presente convenio se le apercibe que será sancionado doblemente o de lo contrario la autoridad municipal se verá obligado [sic] a actuar conforme a lo dispuesto por el Código de Procedimientos Penales del Estado; ya que su caso quedará como antecedente. [Acta de Acuerdo levantada por el alcalde]

Al final del acta, firma el acusado y las autoridades de Amatepec así como el alcalde de Totontepec. El lenguaje utilizado permite analizar la interrelación e imbricación de lógicas jurídicas, pues por un lado el Derecho Penal desde el cual se definen o califican este tipo de conductas - y es invocado en el Acta de Acuerdo-, es estrictamente punitivo y unilateral. Es decir, se privilegia la imposición de una pena corporal o económica sobre la reparación de un daño o del restablecimiento de las relaciones sociales, tal imposición corresponde única y exclusivamente a una autoridad sin mediar acuerdo o convenio. De esta manera, en el derecho positivo es inaceptable - sobre todo para estos delitos - un CONVENIO o ACUERDO entre la autoridad y quien acepta su error o responsabilidad -como se puede observar en el Acta de Acuerdo antes expuesta-. Por otro lado, en el derecho positivo las sanciones buscan más limitar la libertad del culpable que lograr la reparación de un daño en beneficio del que fue agredido. Sin embargo, el alcalde 
utiliza la formalidad de invocar el Código Penal y de Procedimientos Penales y seguir una forma predeterminada para tomar la declaración del inculpado recuérdense los cursos de capacitación y los formatos que reparte la Procuraduría de Justicia del Estado - apropiándose de esto para dar forma a un acuerdo o convenio de tipo civil - según el derecho estatal -. De igual forma, en el acuerdo quinto es elocuente observar que en caso de que el culpable reincida no se le amenaza con enviarlo al Distrito, simplemente se señala "será sancionado doblemente" y "la autoridad se verá obligada a actuar conforme al Código de Procedimientos Penales [...] ya que su caso quedará como antecedente". Al preguntarle al alcalde qué significa actuar conforme al Código de Procedimientos Penales, me respondió que eso es "para que si la gente quiere seguir, pues sabe que podemos mandar el escrito al Distrito", pero también significa que la persona queda mal con sus autoridades y con las personas de su pueblo, "ya no van a creer en él". Esto se trata de un elemento central del sistema normativo indígena que regula los distintos ámbitos del derecho como el sistema de cargos, los cuales remiten a la obligatoriedad, la reciprocidad y el prestigio.

Finalmente la intervención del alcalde en asuntos que son calificados de delitos graves por el derecho estatal — por lo que su actuación está restringida al resto de los casos con pena corporal menor a dos años- revela que a pesar de la Ley Indígena - que limita el actuar de las autoridades a los asuntos no graves-, del Código Penal y de la intervención de la Procuraduría de Justicia y de la Comisión de Derechos Humanos de Oaxaca - encargados de restringir sus competencias-, las autoridades indígenas hacen justicia por el mandato de la comunidad "por eso los nombraron", de lo contrario y según el alcalde "nos dicen: ¡qué!, ¿no eres autoridad?, ¿no sirves?”. De igual forma, más que una insubordinación contra la norma positiva, se observa cómo entran en juego lógicas jurídicas y valores culturales distintos que la dinámica local y comunitaria determinan, y que influye en el actuar de las autoridades indígenas, como es el caso del alcalde de Totontepec. 


\section{d) La integridad física como bien jurídicamente tutelado: entre la violación sexual y el abuso de autoridad}

Este caso fue narrado en una entrevista, por el agente municipal de Santiago Tepitongo, que es una agencia municipal de Totontepec. Según el agente, en 2004 justo después de asumir su cargo en enero, a él y a otras autoridades de las comunidades del municipio le impartieron un curso - la Procuraduría de Justicia y la Comisión de Derechos Humanos de Oaxaca - sobre derechos humanos, delitos graves, delitos que se persiguen de oficio. Esto muestra las vías a través de las cuales el sistema jurídico mexicano influye y ejerce su predominio sobre el sistema jurídico indígena.

Antes de llegar al caso en cuestión, el alcalde narra otro tipo de asuntos sobre todo disputas familiares por golpes, lesiones, dinero y terrenos, así como de personas que no quieren hacer servicios, semejantes a los que también atienden en Móctum y en la cabecera municipal. La diferencia entre la justicia de la cabecera y la justicia de las agencias es que, en este nivel, los usuarios indígenas tienen una instancia más de justicia, en cambio los de Totontepec sólo tienen ésa antes de recurrir al Distrito.

El caso se trató de una mujer oriunda de Tepitongo que vivía en Amatepec con unos familiares, en esta comunidad-agencia fue violada bajo amenaza de muerte por un hombre. La muchacha se quejó con el alcalde de Totontepec y éste solicitó información al alcalde de Tepitongo porque de ahí era la muchacha.

La mujer recurrió al alcalde de Totontepec por que la violación había ocurrido en Amatepec - otra agencia de Totontepec - y el alcalde de Tepitongo no logró que el agresor llegara voluntariamente cuando lo citó. El alcalde de Totontepec logró que el agresor fuera llevado a la cabecera por los topiles, al momento de la audiencia a la que llegó la muchacha, el agresor aceptó su responsabilidad comprometiéndose a cubrir los gastos del embarazo, el parto y la manutención. 
Sin embargo, el agresor acudió ante la Comisión de Derechos Humanos de Oaxaca para denunciar al alcalde municipal por "abuso de autoridad", por lo cual dicha Comisión solicitó información al alcalde y envió a un visitador acompañado de la policía judicial, para hacer preguntas sobre el estado físico y mental de la muchacha violada. Lo que obligó al alcalde de Totontepec a solicitar, a su vez, información al alcalde de Santiago Tepitongo

[...] en una forma muy confidencial me envíe por escrito datos de la señora [mujer violada] sobre su comportamiento personal en relación a su trabajo, disciplina, seriedad o trato con diferentes muchachos debido a que se requiere por esta Alcaldía información requerida por la Comisión Estatal de Derechos Humanos en la ciudad de Oaxaca, se entiende o se deben entender que este escrito es más o menos como una carta de recomendación. Esta información también le he de agradecer me la envie el día de mañana [X de XX] por conducto del [Sr. Z] ya que requiero que él también me aporte unos datos. No dudando de la fina atención que preste a la presente le reitero mis más sinceros agradecimientos. [Oficio dirigido por el alcalde municipal de Totontepec al alcalde municipal de Tepitongo, 7 junio 2002]

El alcalde de Totontepec fue requerido y acudió a la Comisión Estatal de Derechos Humanos, ahí resultó que le recordaron que como alcalde (o autoridad indígena) no le compete conocer del delito de violación por lo que independientemente de investigarse si efectivamente el agresor resultó ser agredido - porque argumentaba que los topiles y el alcalde lo maltrataron-, el caso tenía que enviarse al Ministerio Público en Zacatepec. Finalmente, la Comisión de Derechos Humanos resolvió que no hubo abuso de autoridad, y el caso de violación fue enviado al Ministerio Público.

En este caso se puede percibir claramente cómo la Comisión Estatal de Derechos Humanos vigila que el derecho mexicano sea respetado y cumplido -y que en su aplicación se respeten los derechos humanos-, lo que presenta como parte de su trabajo de guardia del Estado de Derecho y de los Derechos Humanos, finalmente deja la impresión de que no importa si la muchacha y su futuro hijo 
eran protegidos o no. Esa vigilancia implicó también hacer cumplir y respetar -a como diera lugar - el monopolio del Estado sobre la persecución de los delitos y su castigo, es decir, mantener la idea de que la justicia sólo corresponde al Estado darla.

Éste como los otros casos también muestra que la inclusión de los derechos de los pueblos indígenas, concretamente a tener un derecho propio, genera contradicciones en el sistema jurídico positivista que los quiere abarcar. Esta inclusión crea una confrontación en el sistema jurídico mexicano, de dos lógicas jurídicas distintas que se quieren ver y entender como iguales. Así, desde la perspectiva positivista que reconoce derechos indígenas, los usos y costumbres indígenas y sus autoridades forman parte del derecho mexicano, por tanto sus formas de hacer justicia deberían ser aceptadas como válidas, sin embargo, no es así, porque se considera que no cumplen los requisitos del derecho mexicano.

Lo anterior muestra un punto de contradicción de fondo, pues el cumplimiento de esos requisitos implica que el derecho indígena sea igual o se vuelva como el derecho mexicano, luego entonces aunque existe un reconocimiento formalista unitario, el pluralismo jurídico y la interlegalidad son negados. En las prácticas de las autoridades indígenas siguen haciendo justicia, moviéndose en distintos órdenes jurídicos hasta donde los postulados comunitaristas sean vigentes o fuertes en lo local, y el sistema jurídico mexicano lo permita (por ejemplo, que los agentes del Estado tomen conocimiento o sepan de un asunto y, sin considerar a la autoridad indígena, lo atraigan o lo asuman dentro de su jurisdicción para hacer justicia).

Como se mencionó en la introducción a la tercera parte, se puede decir que las autoridades indígenas tienen un concepto propio de casos relevantes y graves, distinto al que les han querido inculcar desde el sistema jurídico mexicano, por lo que a pesar de esto tratan de cumplir el mandato de su comunidad de hacer justicia. Esto hace pensar que los casos - graves para el derecho positivo-, mientras no 
trasciendan de la jurisdicción comunitaria o local o no sean sacados al Distrito, son competencia de la autoridad comunitaria.

Un mecanismo para lograr un reconocimiento formal del pluralismo jurídico ${ }^{169}$ puede ser que los agentes del Estado tengan como obligación tratar a las autoridades indígenas como pares y no como subordinados o como particulares gobernados - que no tienen poder o jurisdicción sobre los casos. Esta forma de relación agilizaría una investigación que aclare si recurrir a la Comisión de Derechos Humanos o al discurso de los derechos desde el sistema jurídico mexicano funciona eficazmente para denunciar una trasgresión a los derechos humanos o garantías individuales, o más bien se trata de eludir un procedimiento interno de justicia comunitaria. Esto no será posible hasta que se establezcan los mecanismos de coordinación y concurrencia de jurisdicciones entre los sistemas jurídicos, donde el sistema jurídico mexicano acepte al sistema jurídico indígena como otro sistema y no como un nivel suyo, lo que se concretaría -entre otras cosas - en que las autoridades indígenas sean realmente autoridades para el Estado, y que, llegado el caso, también puedan colaborar entre sí.

De la intervención de la Comisión de Derechos Humanos se puede constatar que el discurso de los derechos humanos no es esencialmente liberador, o bien, necesariamente benéfico a los pueblos y comunidades indígenas en la reivindicación de sus derechos. Esto es claro por ejemplo en el caso de las expulsiones por cuestiones religiosas, en las que Fabre (2005) señala que los pueblos indígenas están en desventaja real y jurídica, porque a diferencia de las corporaciones religiosas no están reconocidos como sujetos colectivos y mucho menos con derechos como tales, por lo que al momento en que se dirime una

169 De acuerdo con Esteban Krotz (2006) el diálogo intercultural implica "que personas y comunidades pertenecientes a culturas diferentes (con sus sistemas simbólicos, idiomas, cosmovisiones, costumbres, valores, estilos de vida, concepciones artísticas, prácticas médicas, etc.) tienen que ponerse de acuerdo sobre las modalidades de la convivencia pacífica de diferentes. Pero tal diálogo propiamente dicho es imposible en condiciones de desigualdad evidente y profunda entre las partes. Es, por consiguiente, obligación del más fuerte tender los puentes y asegurar que los más débiles, los dominados durante tanto tiempo, puedan alcanzar una posición de igualdad". 
controversia de ese tipo en las instancias estatales, los pueblos indígenas son acusados de violentar derechos humanos (por ejemplo a la libertad de religión y expresión) sin posibilidad de contrademandar a esas corporaciones por violentar la cultura y organización colectiva. Es decir, el efecto del discurso de los derechos humanos depende de cómo y por quién sea utilizado.

Lo anterior se constata en este capítulo por lo que se refiere al trabajo de hacer justicia de las autoridades indígenas, cuando éstas son coartadas o limitadas por los agentes del Estado bajo la amenaza de acusarlos por abuso de autoridad lo que implica someterse a la justicia penal del Estado - que puede traer como consecuencia desde una amonestación, una multa, hasta el encarcelamiento.

\section{e) Negativa a realizar cargo y cuestionamiento de la autoridad comunal}

El caso se trata de un joven que se niega a respetar a la autoridad. En entrevista, el agente de Santiago Tepitongo narra que el asunto se presentó cuando él era alcalde y tuvo que remitir el caso a Totontepec porque el muchacho no hacía tequio y siempre peleaba con sus compañeros. Según las palabras del agente, demandó al muchacho por el radio de banda civil, ${ }^{170}$ solicitando la intervención del síndico en Totontepec, éste envió a los topiles para agarrarlo. En el Ayuntamiento, el síndico le llamó la atención al muchacho y le instó a ser más participativo y tener cuidado con sus obligaciones. Dice el agente:

Se medio compuso porque antes era más terrible. Lo multaron con dos toneladas de cemento, sólo entregó una. El caso se entregó al siguiente agente porque quedó debiendo una tonelada, pero no sé qué pasó. [Entrevista al agente municipal de Santiago Tepitongo, 18 de octubre de 2004]

Pese a la intervención del síndico de Totontepec, el muchacho confrontó a la autoridad de Santiago Tepitongo amenazando que si el alcalde quería juzgarlo, que él tenía el respaldo de la Comisión de Derechos Humanos. El problema que se

170 Aparentemente estas radios de banda civil las tienen todas las agencias, sin embargo, en las entrevistas realizadas en las oficinas de las agencias no se observaron estos aparatos. 
expresa con éste y otros casos donde interviene la Comisión de Derechos Humanos de Oaxaca como un agente o representante del Estado mexicano, es que a este organismo no le interesa conocer si la persona que recurre a presentar una queja realmente está siendo violentada en sus derechos o más bien busca eludir una responsabilidad ante su comunidad, da por hecho que siempre y en todos los casos existe una violación a los derechos humanos. Esto hace pensar que la Comisión de Derechos Humanos trata los asuntos que llegan contra autoridades indígenas -aquí sí son autoridades - como si se tratara de asuntos contra autoridades estatales, cuando son ámbitos y sistemas jurídicos distintos y, como se ha señalado, precisamente esto hace crisis en el sistema jurídico mexicano pues prevalecen dos referentes conceptuales, axiológicos y culturales traslapados e imbricados que, sin embargo, los funcionarios de derechos humanos ven como un mismo sistema. $\mathrm{Si}$ éste fuera el caso, si la Comisión de Derechos Humanos entendiera que se trata de dos sistemas jurídicos distintos, no hablaría por teléfono con las autoridades indígenas - como si fueran particulares o gobernados -, en todo caso las visitaría o enviaría un oficio con sello y les solicitaría - como par o igual - información del caso no para imponer criterios jurídicos sino para comprender hasta dónde efectivamente se trata de abuso de autoridad o de un recurso de la persona para no cumplir, porque se ha dado cuenta que la justicia del Estado le funciona mejor. Para ilustrar esto, es importante citar textualmente el acta que las autoridades de Santiago Tepitongo dirigieron al Presidente Municipal de Totontepec y que elaboraron para remitirle el caso del joven que no sólo no respeta a la autoridad sino que se niega a realizar servicios y cargos.

Reunidos en la oficina de la agencia municipal todos los integrantes del cabildo de la autoridad municipal, para tratar el asunto de la detención del C. [X], se decide en los términos legales a declarar en forma verdadera y en propia voz de los involucrados a la detención del temido sujeto.

Testimonios en contra del detenido. 
1.- Desde pequeño se ha dedicado a robar en los templos, domicilios particulares y a visitantes.

2.- Desobediencia a la autoridad municipal y acuerdos de la comunidad, debiendo tequios y cuotas de la autoridad y de la escuela.

3.- Desorden en la vía pública en estado de ebriedad y aun en pleno juicio ya que su vocabulario es demasiado pésimo no importando quien esté presente.

4.- Amenazas de muerte cuando menos a todos los integrantes de la autoridad municipal.

5.- Existe una banda de vagos que se dicen cholos o punk al cual este debe pertenecer según como actúa.

6.- Presume ser intocables por ninguna autoridad además es el hermano de uno de la banda de asaltantes de camiones de pasajeros que fue detenido y remitido en la ciudad de Oaxaca quien fue puesto en libertad después de tres meses y quien desde entonces presume no tener miedo a ninguna autoridad ya que también la Comisión Nacional de los Derechos Humanos intervienen [sic] para la pronta liberación de los delincuentes.

7.- Motivo de la detención del sujeto es por haberle apedreado a uno de los policías municipales quien por suerte esquivo el piedrazo el cual apenas pasó rosando [sic] su cabello. Su padre ha intervenido en su defensa amenazando también a los policías en quitarles la vida.

8.- A pesar de que se cuenta con un estatuto comunal en donde se prohíbe los escándalos en altas horas de la noche, a este individuo parece no importarle nada ya que anda mentando la madre a las mismas autoridades en plena puerta del palacio municipal y se ha tratado de capturarlo desde que ha cometido los ilícitos pero siempre ha tenido amenazado a los policías en matarlos o golpearlos en donde los encuentre a uno por uno.

Se ha remitido a este individuo a la autoridad de más capacidad para que se someta a juicio y pague conforme a la ley todo lo que ha hecho y dicho en contra de la sociedad. 
No habiendo otro asunto que tratar se levanta la presente para que los presentes testigos declaren y firmen el contenido del presente al cual se le pide a la autoridad que realice el juicio comunique los resultados del presente caso a esta autoridad municipal. Damos Fe.----

El caso que se apunta es apropiado para explicar cómo finalmente las autoridades indígenas respetando el derecho individual del joven renegado, le han dado varias oportunidades de corregirse e incluso remiten el asunto a la cabecera, apuntando la ineficacia del sistema positivo mexicano para sancionar o en su caso readaptarlo, así como las limitaciones de su sistema normativo interno.

De igual forma, este caso como la mayor parte de los asuntos muestra que, desde la perspectiva del Estado, la falta de profesionalización de la justicia en las comunidades indígenas es un obstáculo para lograr imparcialidad y neutralidad en la resolución de los conflictos que las autoridades indígenas conocen y atienden. Esta profesionalización medida desde el sistema jurídico del Estado no considera requisitos distintos, como el cumplimiento de cargos en la comunidad. Pese a esa falta de profesionalización, el sentido de justicia que aplican las autoridades indígenas -que con su estilo mediador, buscando la reparación del daño, y señalando a los involucrados - resulta ser mucho más adecuado que la justicia del Estado.

El sistema de cargos - que se abordará en el siguiente capítulo - se puede entender desde la visión del sistema jurídico indígena, como ámbito comunitario de profesionalización del servicio, donde el cargo mayor es asignado ya sea para arraigar el sentido de comunalidad y obligatoriedad a los miembros en la localidad o a los migrantes o jóvenes que se encuentran fuera de ella (véase el caso de Móctum en el siguiente capítulo) o bien porque se reconoce que la persona cuenta con el suficiente conocimiento de la comunidad para hacer ese servicio. En ambos casos en mayor o menor medida se hace un reconocimiento a la persona que ha pasado por determinados servicios y cargos que lo hacen candidato a asumir un cargo de ese tipo, aunque eso le signifique mayores gastos y sacrificios, o incluso lo perciba como un castigo. 
Finalmente la profesionalización de la justicia, dentro del sistema jurídico mexicano implicaría pagar mejores salarios o sueldos a los empleados encargados de ello, mientras que en las agencias y las cabeceras municipales indígenas $-\mathrm{y}$ a veces no indígenas rurales - pensar en eso tendría como uno de sus resultados que la lucha municipal por los recursos incluya ese rubro, lo que plantea una posibilidad poco factible. Por tanto, significa un choque de realidades y de valores completamente distintos, es decir, entre la comunalidad y la hegemonía del Estado, pues uno de los pilares de aquélla es la gratuidad del servicio, tanto para usuarios como para los cargueros que no reciben a cambio salario alguno. La vigencia de la comunalidad, como principio y fin de la conducta humana en comunidad, es en definitiva uno de los aspectos centrales del poder comunitario base del ejercicio de la autoridad.

\section{f) Accidente o asesinato: El caso de las maestras de preescolar}

Este caso es lamentable porque resultaron muertas dos maestras de preescolar, sin embargo, es muy interesante porque en su desarrollo desde que desaparecieron las maestras hasta que encontraron sus cuerpos sin vida, se revelaron aspectos que definen la jurisdicción entre las comunidades-agencias y la cabecera.

El caso se refiere a dos maestras de preescolar oriundas de Tlacolula (comunidad-cabecera zapoteca de Valles Centrales) que llevaban por lo menos cinco años trabajando en la comunidad de Tonaguía, municipio de Santo Domingo Roayaga, distrito de Villa Alta, colindante del municipio de Totontepec. Relata el agente:

Esas maestras pasaban por aquí pero nunca se presentaron, yo ni sabía que eran maestras hasta que en una ocasión una de ellas me andaba buscando, ni siquiera me saludó llegó y me dijo que había ido a la Agencia y que me andaba buscando hasta que me encontró. Yo le dije

"bueno ya me encontraste". Me dijo que iba a traer unos muebles para el preescolar y que cuánto le cobraba por dejarlos en la Agencia de Tepitongo, yo le dije "sí tráelos y luego hablamos", fue lo que le dije y se fue. Vi que venía con otra maestra pero no hablaba, como 
que la más civilizada era con la que hablé, porque siempre pasaban y no saludaban a nadie hasta la gente se burlaba. [Entrevista con el agente de Santiago Tepitongo, 18 de octubre 2004]

Este asunto era un tema de plática en las comunidades del municipio, sobre todo porque las personas entrevistadas señalaban que el camino por Tepitongo era el más corto para llegar a Tonaguía y que el camino que tomaron cuando supieron que desaparecieron era mucho más largo. El caso preocupaba mucho más a las autoridades de Tepitongo porque, según les informó un grupo de judiciales que llegó a la zona a investigar, que en la comunidad de Chinantequilla (también agencia de Totontepec), decían que las maestras habían pasado por esa comunidad porque en Tepitongo les cobraban muy caro por guardar los muebles que llevaban para el preescolar, lo cual indignaba mucho al agente y él desmentía esa versión. ${ }^{171}$ Relata el secretario del agente:

Siempre recibimos bien a las maestras aunque nunca se presentaron. Uno de mis hijos es su amigo. En una ocasión sólo les cobraron para el refresco de los topiles, porque tuvieron que bajar todo el material del camión para bajar lo de Tonaguía que estaba hasta el final, volver a meterlo y cuidarlo, como llegó muy tarde el camión, despertaron al alcalde y los del material pidieron de cenar, y no pasaron luego, luego, se tardaron, todavía hay cosas que no han recogido como unos vidrios. [Entrevista al secretario del agente municipal de Tepitongo, 18 de octubre 2004]

171 Pues además aseguran - él y las otras autoridades de Santiago Tepitongo- que tienen buenas relaciones con las autoridades de Tonaguía, por que como no tienen camino para que lleguen carros, siempre que les llega material para las escuelas los de Tepitongo lo han recibido. 


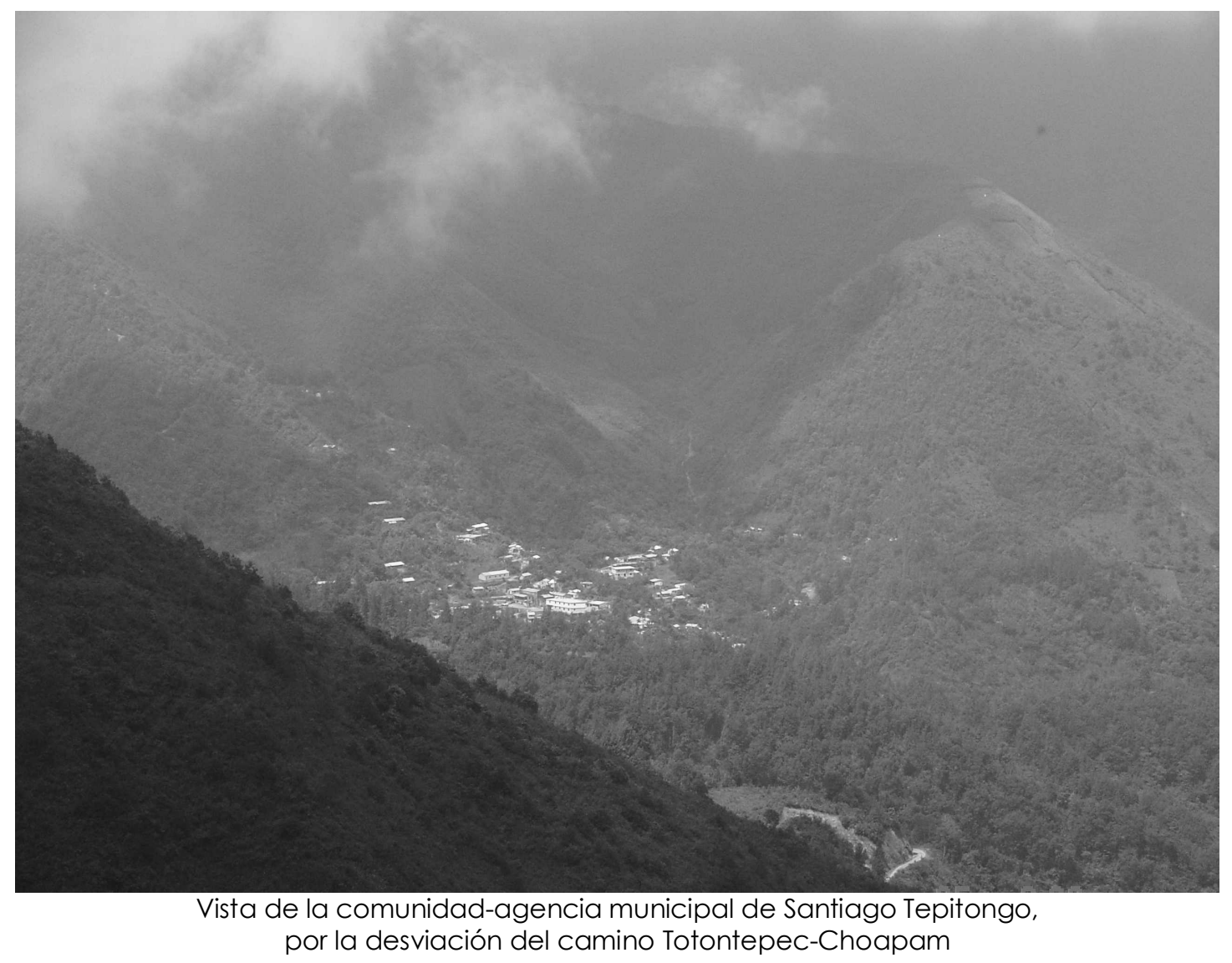

En entrevista al agente municipal de Santiago Tepitongo (24 de octubre de 2004) dijo: "Para cuidar las pertenencias de la CONASUPO, hace 3 años se cobraba $\$ 50$ pesos por noche. Si es para cuidar algo, los topiles cobran. Ya nadie hace algo sin cobrar".

Mientras se realizaba el trabajo de campo, llegaron las autoridades de Tonaguía por las cosas que les llegaron del Instituto Estatal de Educación Pública de Oaxaca (IEEPO) y que faltaba que recogieran, entonces el alcalde de Santiago Tepitongo aprovechó para explicarles cuál había sido el trato de ellos como autoridades de Tepitongo hacia las maestras y que éstas, a diferencia de otras personas -mostrándoles el oficio con el que yo me presenté firmado por la coordinación del doctorado de la UAM-I-, no se presentaron con algún escrito del IEEPO. 
Según la versión de la Delegación Sindical de Preescolar D-357, ubicada en San Pablo Villa de Mitla, que se podía leer en un desplegado que pegaron en varios lugares de la cabecera-comunidad de Totontepec, era que las maestras, después de haber recogido material en el almacén de Zaachila, se trasladaron posteriormente a la comunidad de Ayutla Mixes para recoger la otra parte del mobiliario, contratando una camioneta pick-up que las llevaría a la comunidad de San José Chinantequilla a donde se supone iban a ser esperadas por el comité de padres de familia, al llegar ahí les informaron que el comité ya se había regresado a Tonaguía por lo que las maestras emprendieron la caminata tras ellos para alcanzarlos, "según datos proporcionados por los habitantes del lugar donde fueron vistas por última vez":

[...] hasta el momento se tiene conocimiento de que aparecieron algunas pertenencias de ambas maestras, existen hipótesis y muchas especulaciones que giran en torno a su desaparición, razón por la cual y debido a las condiciones climáticas y geográficas de dichas comunidades es necesario la intervención de personas y equipo especializado para la búsqueda eficaz y oportuna de nuestras compañeras. [Desplegado de la Delegación Sindical D-357, sin fecha ni firmas]

Este asunto conmovió tanto los ánimos de las comunidades de Totontepec porque había muchos policías judiciales revisando camionetas y camiones, y por ejemplo en Móctum se especulaba que seguramente las maestras habían sido asaltadas porque se encontraron unos zapatos y bolsos, pero no a ellas. Esta situación retardó el ritmo del trabajo de campo, dada la preocupación de la gente ante la inseguridad.

La policía judicial solicitó el apoyo de la autoridad de Tepitongo pidiéndole que enviara con ellos a un guía y que formaran un equipo de búsqueda de las maestras. Las autoridades de Tepitongo no aceptaron, pues los pobladores de éste consideraron que las comunidades vecinas pudieran pensar que se están invadiendo sus tierras, también argumentaron que de hecho la búsqueda ponía en 
riesgo a los hombres que participarían, porque ellos a diferencia de la policía no llevan armas por si algún animal peligroso se presenta.

Es el problema de acá porque cuando vino la policía, yo sí iba, pero los demás no porque nos ibamos a meter en terrenos de otros pueblos y la policía no deja que lleve uno un arma, porque pueden salir víboras, tigres o cualquier animal. Los de aquí [Tepitongo] me dijeron que no arriesgue a la gente. Ni los preventivos se meten ahí.

El agente justifica esta decisión porque "por reglamento cada quien [cada comunidad y autoridad] debe hacer lo que le toca. Uno no se debe meter en una investigación, es delicadísimo. Si la policía trajera una orden de la sindicatura [de Totontepec], aquí se convoca a Asamblea y que ella decida quiénes van a ir a buscar o a acompañar a la policía". A pesar que Santiago Tepitongo como agencia municipal cuenta con síndico, alcalde y regidores, con esto se corrobora que pese a las diferencias y relación de tensión por cuestiones agrarias y municipales, el agente reconoce la preeminencia de las autoridades de Totontepec. El caso también muestra la manera en que se da la concurrencia de jurisdicciones entre instancias legales del sistema indígena, y entre éste y el sistema jurídico mexicano. El Estado ejerce su hegemonía para atraer la resolución del caso de las maestras y solicita la intervención de las autoridades comunitarias, al desconocer las formas y los mecanismos internos de relación entre las instancias indígenas, no encuentra eco a su llamado, sobre todo que las autoridades y la comunidad de Tepitongo sentían que eran señalados como responsables, cuando en realidad las maestras desaparecieron el día que no pasaron por ahí.

Los de Chinantequilla le echan la culpa al municipio, pero el síndico de Totontepec dijo que por eso están las Agencias para avisar. El municipio pidió auxilio a la Procuraduría de Justicia del Estado y al Ejército. Aquí [en Tepitongo], no se podía hacer esto porque el síndico [de Totontepec] es el que está capacitado para eso. Como nosotros en 1997, hubo un fallecimiento de Amatepec [otra agencia de Totontepec], en sus terrenos, estaban sacando aguardiente, nosotros estábamos más cerca pero eran terrenos de ellos. 
Finalmente, se encontraron los cuerpos de las maestras en el río a cinco kilómetros de la comunidad donde desaparecieron, y esto no aclaraba la versión de su fallecimiento, unos decían que había sido accidente pero no era creíble porque se encontraron pertenencias lejos del río, otros decían que fue un asalto pero las pertenencias eran bolsos y zapatos, además si ya les habian robado ¿para qué matarlas?, fueron algunas de tantas interrogantes.

\section{g) Problemas familiares o adulterio}

Este caso no provino de algunas de las agencias que integran Totontepec, pero como involucra a personas de otro municipio, se incluye dentro de este tipo de asuntos, para observar los mecanismos de definición de la jurisdicción y la competencia de la autoridad indígena, concretamente del alcalde.

Un señor de Totontepec pidió al alcalde que interviniera en el caso de su hija porque se estaba involucrando con un hombre casado de la comunidadmunicipio de Ayutla. El papá argumentaba que la hija no admitía esto, pero el asunto llegó a tal grado que la esposa del hombre un refresquero llegó a su casa y enfrentó a la hija delante de él:

Se presentó un señor diciendo que como él tiene una hija de 19 años de edad y que se dio cuenta que su hija anda con un señor. La hija no dice nada pero ya se dio cuenta porque recibe llamadas y se va a Ayutla diciendo que debe arreglar papeles de la secundaria. Ya se dio cuenta que cuando llega un señor de Ayutla, que vende refresco, la ven que anda corriendo con él. La esposa de este señor llegó a la casa del papá de la muchacha y agarró a su hija y los asustó. Aquélla le decía a la muchacha: “Qué crees que no sé lo que haces con mi marido?". El padre de ella le dijo a la señora: “¿Por qué haces eso con mi hija?”. La señora le respondió: "Cuida a tu hija, ¿qué no sabes lo que hace? Se anda relacionando con mi marido". [La esposa del refresquero le contó al papá de la muchacha cómo había sorprendido a su hija con su esposo en Ayutla] [Narración del alcalde, 25 y 26 de julio de 2004] 
Con lo anterior, el alcalde mandó llamar a la muchacha para cuestionarla sobre su conducta: “¿Qué andas haciendo con ese señor? ¿Qué sientes, qué tienes? ¿Tienes relación con él?", como no aceptaba que estaba involucrada con un hombre casado, el padre solicitó al alcalde que llamara al señor de Ayutla. El alcalde aprovechó que el refresquero iba periódicamente a Totontepec y cuando estuvo ahí lo llamó, también lo cuestionó sobre su conducta en presencia del padre de la muchacha, a lo que el señor respondió que eran sólo amigos y amenazó al alcalde con demandarlo en Zacatepec (cabecera del distrito), ante esta actitud el alcalde lo metió a la cárcel. No estuvo mucho tiempo porque después llegó la esposa diciendo "vine a aclarar", sin embargo, la mujer no quiso exponer la infidelidad de su esposo. Al narrar esto el alcalde reflexionó: "Ellos decían que no había nada, pero ahora ya entendí que sí había algo". Finalmente el alcalde dejó salir al hombre de la cárcel obligándolo a comprometerse a no seguir buscando a la muchacha.

Acta Compromiso.

[El señor $\mathrm{X}][\ldots]$ y además manifiesta que en su comunidad no le dicen nada por hacer estas cosas [buscarse a otra mujer], el alcalde le aclara que en esta comunidad no es así, después de una larga discusión llegan a los siguientes acuerdos.

"PRIMERA.- [El señor X] se compromete a no volver a molestar a [la muchacha]. [La muchacha] pide que las cosas queden hasta ahí y acepta no volver a verse con el [señor X] y hacer de cuenta que no lo conoce.

SEGUNDO.- Se comprometen a respetar el compromiso, y de no hacerlo así, se les castigará de otra forma.

[El señor X] fue detenido durante 24 horas por el motivo de que se involucró con una jovencita estudiante siendo un hombre casado. [Acta Compromiso, 21 de julio de 2004]

Este caso es interesante porque expone los límites de la justicia y la jurisdicción. Por un lado, el alcalde aprovecha que el refresquero llega a Totontepec a vender y aprovecha para mandarlo a traer, aunque sabe que es persona de otra comunidad, 
también sabe que su pueblo lo reconoce como autoridad, y una persona (el padre de la muchacha) solicitó su intervención. Por otro, cuando llega la mujer del refresquero, ésta prefiere no exponer la infidelidad de su marido, aunque ya había enfrentado en Totontepec a la muchacha en presencia de su papá. Seguramente la mujer del refresquero intuía que dirimir un conflicto conyugal en una comunidad ajena y ante una autoridad distinta a la que existe en la suya, los colocaba a ella y a su marido en una situación de desventaja, porque su condición frente a la comunidad de Ayutla (servicios, prestigio, obligaciones, reciprocidad) es desconocida para el alcalde de Totontepec. Por ello seguramente saldrían más perjudicados que beneficiados, pues el alcade lo único que conocía de su conducta era que habían cometido una mala conducta por su infidelidad.

La justicia solicitada por el señor de Totontepec se centraba en que el alcalde hablara con su hija para convencerla de no seguir a un hombre casado. Este tipo de asuntos, desde la perspectiva del derecho positivo, corresponde a una esfera muy íntima de la familia en la cual no debe entrar autoridad alguna, a menos que se constituya en un delito, por ejemplo, adulterio. Sin embargo, entendiendo que en la lógica comunitaria el alcalde es el mayor de los cargos, como tal, se considera al hombre que lo asume como el padre de la comunidad y sus miembros esperan que siempre escuche —aunque nada más venga a platicar y no pida justicia- y actúe en consecuencia cuando se le solicita, siempre y cuando él lo considere pertinente —como se verá después.

En otro caso el alcalde señala que llegó una mujer a contarle lo que le pasaba con su esposo que al parecer estaba buscándose a otra mujer "la señora sólo vino a platicar, si viniera a pedir justicia lo mando a traer". Sin embargo, el esposo también se fue a quejar con el alcalde diciendo que en su casa amaneció un hombre que no conoce. La esposa le aclaró que era un amigo de sus hijos pero que como su marido ya no vive con ellos no sabe lo que sucede en la casa: "ese señor anda loco, inventando, es una amistad de mis hijos [...] Él ya no sabe qué hacen sus hijos y 
cree que yo ando como él, es una tontería y yo estoy viendo a mis hijos". La actuación del alcalde se concretó a escuchar a los esposos en disputa.

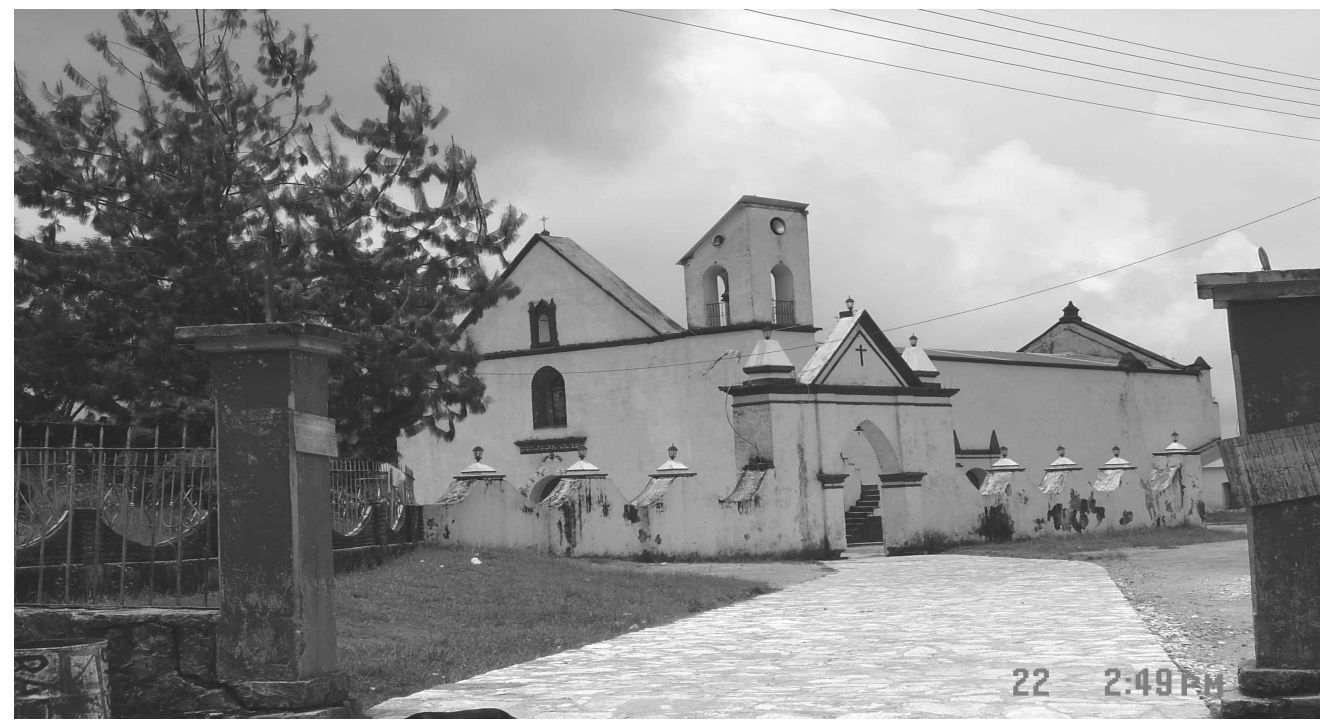

Vista exterior del templo de Totontepec

\section{h) Confrontación entre niveles legales del campo jurídico: Las instancias del Estado y las instancias jurídicas indígenas}

Sin bien desde la perspectiva estatal, el ejercicio de autoridad tiene definidos ámbitos de competencia claros y rígidos, en la práctica la capacidad de los agentes del Estado tiene límites para hacer que esto suceda. En esta definición de los límites jurisdiccionales de cada sistema, algunos de los casos analizados finalmente muestran que las dinámicas, propias de las comunidades en su relación con el Estado, hacen que en la práctica esos límites sean flexibles y no definitivos, y si bien tienen como base lo territorial no están regidas por éste - es decir, depende del caso concreto y de la coyuntura en la correlación de fuerzas-. También se puede constatar en el ejemplo siguiente que se refiere de manera general. Se trata de una disputa entre vecinos de Totontepec por la posesión y propiedad sobre un terreno que se disputan varias personas de Totontepec. Las personas que no se sienten favorecidas por la justicia de la autoridad indígena recurren al Ministerio Público (MP) de Zacatepec, demandando a dos personas que tienen en posesión el 
terreno en disputa. El MP, sin considerar a las autoridades indígenas de la comunidad-cabecera del municipio, cita a esas dos personas -favorecidas por la justicia indígena - señalando: "Se les apercibe si no comparecen en la fecha y hora señaladas, sin causa justificada, se le impondrá a cada uno, el medio de apremio que establece el Artículo 104 de la Ley Orgánica de la Procuraduría General de Justicia del Estado".

Las personas citadas por el Ministerio Público, en lugar de cumplir con el citatorio, recurren a las autoridades de Totontepec quienes a través de un oficio, membretado con el escudo nacional y el nombre del municipio, informan al MP que la disputa por la propiedad del terreno es un asunto resuelto en la comunidad y que la persona que ha pedido la intervención del Agente del MP ha demandado en innumerables ocasiones a las autoridades. Para demostrar la improcedencia de la pretensión de esa persona, las autoridades indígenas municipales anexan un documento del año 1954, donde se demuestra que el terreno no es de ella. Este caso expone, de alguna manera, que las autoridades indígenas municipales -que forman parte del sistema jurídico mexicano pero que son investidas como autoridades indígenas por la comunidad - más que defender a los verdaderos posesionarios del terreno señalan un límite a la jurisdicción del Ministerio Público como autoridad del Estado.

\section{i) Lo aparentemente absurdo de las disputas}

Por lo regular calificamos de absurdos los conflictos que se dirimen por cuestiones u objetos que desde nuestra perspectiva individual o cultural no son claros, válidos o razonablemente justificables, sin embargo, al hacer un estudio en profundidad de las disputas, como se pudo observar en el caso del conflicto madre entre Totontepec y Móctum (CAPítulo 4), que empieza con una "jícara" y continúa con un "mantelito de hilos de oro", el meollo del asunto es el ejercicio del poder y la preeminencia de una parte sobre otra en una relación. 
Lo anterior se expresa también en las formas de entender un asunto como grave desde la perspectiva del derecho positivo o del derecho indígena. Para ilustrar esto y lo antes señalado apuntado se agrega otro caso en el que el alcalde multó a una persona y ésta recurrió al Ministerio Público de Zacatepec (cabecera del distrito Mixe). Éste le dirigió un escrito en el que le hacía saber que imponer multas no es parte de sus funciones y que insistir sobre esa actitud podría considerarse abuso de autoridad. Es decir, pese a que la multa -desde la perspectiva del derecho positivo - no es lesiva de derechos humanos como lo podría ser el encarcelamiento, con una intervención de este tipo por parte de los agentes del Estado, lo único que se promueve es que las autoridades indígenas sean más estrictas o severas en las formas de lograr la justicia y en el tipo de sanciones que imponen, para inhibir que los quejosos recurran al exterior a solicitar la intervención del Estado o de otros actores. Esto es un punto de contacto ríspido entre los sistemas jurídicos donde el desconocimiento de los motivos y razones del actuar de las autoridades indígenas - de su investidura y potestad-, y de la dinámica comunitaria, promueve que las autoridades del Estado movilicen recursos, que en la lógica indígena, es desproporcionado o sin razón de ser, como fueron los casos de la violación o del joven renegado. En el primer caso, se quería inhibir por parte del Estado el actuar de las autoridades indígenas, dándose una gran movilización de recursos materiales y humanos. Por lo que se refiere a la petición de las autoridades de Tepitongo sobre el joven renegado, no hubo reacción del Estado - de movilizar recursos para hacer cumplir las obligaciones comunitarias - y más bien se expresa que las acciones de éste no contribuyen en la legitimación y dignificación del ejercicio de la autoridad comunitaria mermándola, porque el joven, teniendo antecedentes penales y mala conducta, seguía haciendo de las suyas con el pretexto de que la Comisión Estatal de Derechos Humanos lo defendía. Esto seguramente no es así, sin embargo, el papel de esta Comisión - de "perseguir" a las autoridades indígenas y no tanto apoyarlas en el ejercicio de sus 
funciones - no dejaba dudas a las autoridades de Tepitongo de que lo que decía el joven, seguramente, tenía algo de cierto.

\section{CONCLUSIÓN}

El objetivo de este capítulo ha sido dar cuenta de la resolución de disputas en el nivel legal del municipio, concretamente en la alcaldía indígena, con el fin de mostrar varios aspectos del pluralismo jurídico y de la interlegalidad: las prácticas, el sentido de la justicia, el procedimiento de resolución de disputas y los valores que éstas revelan, así como los referentes y lógicas legales a las que se recurre - por los usuarios y autoridades- para resolver controversias. De esta manera hemos visto en las prácticas, a partir de los casos narrados por el alcalde, tres presenciados (el joven que causa daño a la muchacha, la mujer que pide intervención por su esposo que la cela y el abogado indígena que recurre a la instancia del distrito) y otros más revisados en actas, la manera como se imbrican y en ocasiones entran en conflicto referentes y elementos legales provenientes de órdenes jurídicos diferentes: el estatal y el de la comunidad.

También se muestra cómo interactúan los órdenes jurídicos indígena y el mexicano en un mismo campo social y jurídico. El campo jurídico está integrado por el derecho en distintos niveles legales - las instancias legales de la agencia el municipio y el distrito-: las instituciones y las autoridades indígenas y no indígenas, los valores y criterios de resolución de disputas y conflictos así como la historia y los procesos que enmarcan estos elementos.

La resolución de disputas, por parte del alcalde municipal de Totontepec como del alcalde de Santiago Tepitongo y de otras autoridades de las agencias como Huitepec, expone los valores que se ponen en juego a nivel local, como son: mantener la unidad y la armonía entre los habitantes y sobre todo la legitimidad de la autoridad en su ejercicio de hacer justicia, poniendo en práctica sus capacidades individuales, su conocimiento de la dinámica comunitaria, su experiencia y su prestigio, todo esto, sobre la base del principio de la comunalidad. 
Otras agencias fueron visitadas, como la de Tiltepec, Metepec, Amatepec, y Huitepec, sin embargo, en las tres primeras no se encontraba el alcalde o el secretario y las autoridades presentes argumentaban que no sabían responder pero que tampoco sabían con certeza cuándo regresarían el alcalde y/o el secretario o el agente para conversar sobre las formas de hacer justicia y los casos que atendían. Por lo que se refiere a Huitepec fue interesante porque se tuvo acceso a algunos casos escogidos por el agente. Estos casos corroboraron el planteamiento de que los asuntos graves para el Estado o para el derecho positivo - restringidos para las autoridades indígenas por el Código Penal y la Ley Indígena - son atendidos tanto en la cabecera como en las agencias cuando los pobladores exigen intervención de sus autoridades. Estos casos son considerados de competencia interna o local hasta en tanto no salgan o que los afectados lo hacen de conocimiento del Estado o de sus agentes - Procuraduría de Justicia, Comisión de Derechos Humanos, Ministerio Público, Juez de Distrito-, o bien, hasta en tanto éstos no intervengan o exijan respeto al monopolio del Estado sobre la justicia.

Por lo que respecta a la justicia y el sentido de la misma, como se mencionó en el CAṔ́tulo 1, el concepto de justiciabilidad, planteado por Santos (1995), es clave para comprender la distinción así como los puntos de intersección entre el derecho del Estado y el derecho indígena. Tal como lo revela el quehacer del alcalde de Totontepec para administrar la justicia. La definición de la justicia resulta no sólo de la aplicación de normas jurídicas de acuerdo al caso concreto (el individuo o la persona) sino también de la aplicación de principios generales de regulación que en el caso de las comunidades indígenas involucran la comunalidad, la búsqueda del acuerdo, la obligatoriedad, la reciprocidad y el prestigio que definen la relación de una persona o individuo con la comunidad y su autoridad.

A la aplicación de normas al caso concreto subyace el sentido de justicia que se determina por los valores, intereses y principios que cada sociedad o pueblo 
tiene, así como por la lógica o la forma de cómo debe hacerse para lograrlo. ${ }^{172}$ Estos aspectos relevantes para la comunidad, que determinan el sentido de la justicia -en la resolución de conflictos, disputas y atención de asuntos- y los límites del sistema jurídico, se corresponden con los principios generales del derecho (cfr. Cruz 2005). Estos principios son criterios que la conducta humana debe seguir en cierta situación, que emanan, por un lado, del devenir histórico, por ejemplo de la comunidad-cabecera en su relación con cada una de las comunidades-agencias que integran el municipio, y, por otro, de la relación de estas unidades con el pueblo indígena del que forman parte. El principio fundante en el que descansa este cuerpo de principios éticos y axiológicos es el de la comunidad, de ahí también la fuerza que han adquirido los discursos políticos de intelectuales mixes y zapotecos en torno al tema.

Sobre la conformación de un sistema jurídico indígena, es interesante lo que resultó de la visita y la entrevista al agente de Santa María Huitepec porque al igual que en Móctum (capítulo siguiente) se mantiene un discurso de que los casos no salen y sólo son resueltos sin intervención de la cabecera. Aquí se pudo constatar, por lo menos por lo que corresponde al año 2004, que no hubo casos en los que los usuarios recurrieran a una instancia externa aunque sí hubo casos de diverso tipo (graves y leves) en estas comunidades. En este sentido son también significativas las reglas que se han establecido entre instancias legales sobre los límites de la jurisdicción, es decir, de lo que pueden o no pueden hacer y deben o no deben hacer las autoridades de las comunidades-agencias y de la comunidadcabecera. El criterio fundamental es el de territorialidad asociado a la figura de la comunidad agraria, un segundo criterio - no menos importante- es el de las

172 En el caso oaxaqueño la definición de los usos y costumbres establecidos en la constitución estatal y en los códigos penal y electoral (concretamente sobre nombramiento de autoridades municipales) es lineal ya que no dan cuenta de la totalidad del sistema cultural que respalda a ese sentido de justicia, y más bien se refieren a una realidad jurídica acotada a lo electoral. Como contrapunto las autoridades de los pueblos indígenas se refieran a los usos y costumbres como la manera en que resuelven sus conflictos internos y aplican sus sistemas normativos: "la visión desde lo nuestro" (Bautista 2004:17). 
funciones de las agencias y de la cabecera según lo que dice el derecho positivo y lo que demanda la dinámica comunitaria. Ambos aspectos implican la puesta en juego de sistemas jurídicos que son vistos y usados indistintamente por las autoridades como si fueran uno, es decir, sus funciones están marcadas por lo que han hecho siempre (otras autoridades de sus comunidades), lo que creen que les toca por mandato de la Asamblea y lo que saben e intuyen que deben hacer de acuerdo al derecho positivo.

También esto se observa en los usos del derecho por parte de los usuarios indígenas, que a veces recurren y acatan la autoridad de su comunidad, otras recurren a la justicia del Estado, según sus propios intereses haciendo uso del discurso de los derechos y de los derechos humanos, pero también se ven inevitablemente insertos e involucrados en la dinámica comunitaria.

De igual forma, como se apuntó tanto en el caso de la violación como en el del joven renegado, desde la perspectiva de las autoridades indígenas, la justicia del Estado no es suficientemente rápida, fuerte y contundente. En cambio, cuando se trata de inhibir y cuestionar el actuar de las autoridades indígenas de hacer justicia, el Estado, sus autoridades y agentes son expeditas, infalibles, categóricos y determinantes.

Por otro lado, el interés del alcalde de Totontepec sobre el uso y la función del sello, de las Actas de Acuerdo, Convenios o Actas de Conformidad para dar por concluido un caso o para que las partes en un conflicto o disputa limiten sus pretensiones de seguir un pleito, es compartido por la mayoría de las autoridades en las demás agencias. Estos recursos son el resultado de la influencia del sistema jurídico mexicano sobre el sistema jurídico indígena, que las autoridades indígenas no sólo utilizan para dar formalidad a un acuerdo, convenio o conformidad, sino para encauzar una disputa a una solución (véase Sierra 1992). Como se explicó, el valor de lo escrito y de la formalidad que representa el sello puede deberse a los cursos de capacitación jurídica que año con año reciben las autoridades de agencias y de la cabecera por parte de la Procuraduría de Justicia y la Comisión de Derechos 
Humanos de Oaxaca, pero también por el contacto que los habitantes de las distintas comunidades han tenido con los agentes del Estado, sobre todo por la cuestión agraria, como son la Secretaría de la Reforma Agraria, las promotorías, la Procuraduría Agraria, la Junta de Conciliación Agraria de Oaxaca, etc. Finalmente existe una apropiación y refuncionalización de elementos del derecho positivo (como es lo escrito, algunas normas y preceptos, la invocación de leyes, la formalidad de los escritos, el uso del sello, entre otros) que las autoridades indígenas adecuan a las necesidades locales y sobre todo a su responsabilidad de hacer justicia.

Pero además de observar esa influencia del sistema jurídico positivista sobre el sistema jurídico indígena, se observan las contradicciones que se provocan en el seno de aquél por su afán de reconocer unilateral y parcialmente el derecho indígena, así como el choque y la crisis que esto provoca al interior del sistema jurídico mexicano. 


\section{CAPÍTULO 6}

\section{LAS INSTANCIAS LEGALES Y EL SISTEMA JURÍDICO EN SAN MARCOS MÓCTUM 173}

\section{Introducción}

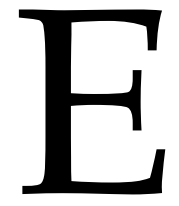

n el capítulo anterior se abordó el nivel legal de la comunidad-cabecera de Totontepec que por sus características territoriales, políticas y culturales tiene preeminencia sobre las demás instancias jurídicas en el municipio de Totontepec. También se definió este campo municipal conformado por relaciones de poder entre campos sociales semiautónomos (a nivel comunitario y a nivel municipal), planteamiento que amplia la visión que asocia cabecera municipal con municipio, pues éste no constituye una unidad homogénea sino un entramado de relaciones sociales y políticas vinculadas por una historia e intereses de poder.

En este capítulo se aborda el nivel legal de la comunidad-agencia de San Marcos Móctum (en adelante Móctum), también, al igual que la comunidadcabecera, tiene el doble estatus jurídico de ser comunidad agraria y agencia de policía y como tal forma parte del municipio de Totontepec. Esta comunidadagencia se seleccionó para este estudio por su historia de tensión con la cabecera

173 En la Enciclopedia de los Municipios de México. Estado de Oaxaca <http://www.elocal.gob.mx/work/templates/enciclo/oaxaca/municipios/20437a.htm>, se señala en la parte que corresponde a Santa María Tlahuitoltepec que Móctum como otros pueblos mixes es un asentamiento donde existen vestigios que pueden explicar el origen de los mixes. "Hipótesis sobre el origen y establecimiento en el territorio de Oaxaca del grupo racial mixe: Por las características de semejanza con los Mesoamericanos entre las que sobresalen el calendario solar y ritual, así como el aspecto lingüístico, se puede proponer que es una descendencia Olmeca; esto parece estar respaldado en la antigüedad peculiar de algunos centros de población como Móctum, Candayoc, Mixistlán y otros, que en el futuro podría ser confirmada por algunas construcciones antiguas". El crédito que se da sobre estos datos, según consta en la parte de créditos de esta ficha, es del $\mathrm{H}$. Ayuntamiento Constitucional de Santa María Tlahuitoltepec. 
municipal, que se remonta hasta mucho antes de la Colonia, según la memoria colectiva (Gómez Bravo 2004). Historia que comparten, de una u otra manera, con las otras comunidades-agencias que conforman el municipio, pero a diferencia de éstas Móctum se ha colocado con mayor fuerza y presencia frente a la cabecera, confrontando los intereses caciquiles de sus élites, logrando mejores resultados, por ejemplo, el respeto a sus límites territoriales

En el estudio del derecho en el ámbito local de Móctum, se recurre a dos perspectivas de análisis dentro de la antropología jurídica: la procesual y la normativa, es decir, se reconstruyen las normas que regulan las dinámicas de la comunidad y sus miembros, fundamentalmente por lo que tiene que ver con el sistema de cargos y la atención y resolución de disputas, para dar cuenta del sentido en que las normas son usadas. A diferencia del capítulo anterior, en el que se expuso la lógica de la justicia a través de casos, en este capítulo se formulan normas a manera de criterios jurídicos resultantes de la resolución de conflictos y disputas que han hecho las autoridades y la comunidad a través de asambleas. Sin embargo, se citan algunos casos para contextualizar la norma escrita y entender los factores implicados en la lógica de hacer justicia.

Para explicar esto, se han dividido - en este nivel legal- las normas en orales y escritas; las primeras son acuerdos tomados por la mayoría de comuneros y ciudadanos en Asamblea, a las que se suele hacer referencia como "el reglamento". Estas normas fueron reconstruidas a partir de las narraciones de casos que las autoridades pasadas y actuales resolvieron y se presentan aquí para facilitar su análisis -más que para formular un reglamento escrito-; en esta redacción de las normas orales se trató de respetar la narrativa de las personas. El segundo tipo de normas se presentan según como fueron escritas en el estatuto de la comunidad que fue elaborado entre la Asamblea de Comuneros y un promotor de la Secretaría de la Reforma Agraria.

Este capítulo consta de dos apartados: 6.1 Las dinámicas comunitarias en su relación con lo agrario y su influencia en el derecho. En este apartado se explica la 
incidencia y determinación que el conflicto agrario ha tenido en las dinámicas de la comunidad. En 6.2 Las influencias de la configuración del derecho en la comunidad donde se explica cómo el sistema jurídico mexicano y, específicamente, la ley y agentes del Estado influyen en la definición y transformación del derecho.

El primer apartado se divide en tres partes: La lógica jurídico-cultural en la comunidad (6.1.1), para exponer los criterios de relevancia y los asuntos que cumplen con éstos según la comunidad; Dimensiones de la norma no escrita (6.1.2), se muestra aquí cómo se gesta y se expresa esta norma y cómo es utilizada por la comunidad y sus miembros; y, finalmente, La adscripción y autoadscripción comunitaria (6.1.3), donde se presenta el sistema de cargos, cómo este sistema sirve como referente para dar cuenta de la membresía de un individuo a su comunidad y cómo a partir de su organización y su funcionamiento se establecen esos criterios de adscripción y autoadscripción.

El siguiente apartado (6.2) se divide en: Dos lógicas jurídicas imbricadas (6.2.1) y Dimensiones de la norma escrita (6.2.2) para explicar las influencias del sistema jurídico mexicano y las implicaciones de la norma escrita.

De acuerdo con la propuesta analítica de Nader (1978) sobre el estudio de caso, la recopilación de normas implicó conocer de manera directa (por observación y participación) e indirecta (por testimonios) la prehistoria e historia de las disputas - sucedidas a través del tiempo-, sus circunstancias y consecuencias, así como el actuar de las autoridades internas y el pueblo en asamblea para resolverlos.

En este capítulo, se profundizó en los asuntos relevantes y sentido de la justicia del sistema jurídico en Móctum y no desde el derecho estatal (como podrían ser el actuar de los juzgados y ministerios públicos, como es el caso del trabajo de Martínez Martínez (2004) que se refiere a las estrategias de litigantes y posturas de jueces cuando aquéllos exigen derechos en los juzgados del Estado).

El análisis que se presenta en este capítulo es diferente al del CAPítulo 5, ya que en el caso de Móctum me planteo el análisis del derecho desde una perspectiva 
más normativa que procesualista, pero sin descartar ésta. Esto se realizó así porque en Móctum existen normas escritas que tienen cierto peso en las decisiones de las autoridades indígenas y de la comunidad, a diferencia de Totontepec que no cuenta con un cuerpo de normas escritas - como lo es el reglamento interno o el estatuto comunal - . Circunstancia que planteó la oportunidad de utilizar las dos perspectivas antropológicas del estudio del derecho (cfr. Commarof y Roberts 1981).

\subsection{Las dinámicas comunitarias en su relación con lo agrario y su influencia en el derecho}

El conflicto agrario de Móctum con Totontepec indudablemente influyó en sus dinámicas internas e intercomunitarias, lo cual se expresa en el derecho vigente en la comunidad. Para comprender cómo se conforma ese derecho, se estudian y muestran las normas contextualizándolas en la realidad de la comunidad y explicándolas según los casos que les dieron origen. El análisis se presenta de esta manera porque las normas abordadas - sean escritas $u$ orales - expresan aspectos formales del derecho en Móctum y, de alguna manera, muestran parcialmente una realidad. Por ello, la norma, como traducción de la conducta humana a un "deber ser" y su mera trascripción o enunciación, tiene limitaciones prácticas para exponer las dinámicas del poder y los usos del derecho en la comunidad.

En este sentido existe un debate en torno a las implicaciones de reconstruir esa norma oral y plasmarla a la manera de la norma escrita. Por un lado la norma escrita tiene cierta garantía de no ser alterada tan fácilmente, y por lo mismo es difícil su manipulación cuando se involucran relaciones y usos de poder por parte de usuarios y autoridades. Por otro, la desventaja que presenta la norma escrita es que puede prestarse a imponer como hechos dados lo que se escribe. Sin embargo, las comunidades indígenas se han apropiado de la norma escrita incorporándola a su sistema jurídico interno como una herramienta más en el ejercicio de sus derechos y regulación de sus dinámicas locales, sin dejar de lado la norma oral; 
Zapata (2004:91) muestra esto en el caso del estatuto comunal de San Juan Tabaá, comunidad zapoteca de la Sierra descrita por el visitador de la Procuraduría Agraria como una comunidad muy arraigada por lo que fue difícil lograr un reglamento de esa naturaleza.

Por su parte, las ventajas de la norma oral están marcadas por las desventajas de la norma escrita, es decir, a diferencia de ésta es flexible pues puede incorporar con mayor facilidad los hechos prácticos de la vida cotidiana, por lo que facilita la resolución de disputas. Sin embargo, partiendo de los criterios que el derecho mexicano tiene para la modificación e interpretación de una norma escrita, en el caso de la norma oral los márgenes de interpretación son más amplios, lo que puede prestarse a manipulación en la aplicación de una norma a un caso concreto, más cuando intervienen relaciones y usos de poder, lo que también se da en el caso de la norma escrita, sin embargo, da lugar a menos ambigüedades porque no depende de la memoria colectiva sino de lo que está por escrito.

En el caso que se estudia, son tres aspectos a destacar de las normas orales: 1) Son normas no escritas que la comunidad se ha dado, se elaboran y actualizan a través del tiempo, la mayoría a partir de casos concretos que son resueltos en asamblea o por las autoridades en turno, tanto agrarias como de la agencia municipal. 2) Son normas que resultan de la atención a los asuntos que presentan los miembros de la comunidad en las oficinas de la agencia de policía de Móctum. 3) Resultan de la atención a diversos casos que revelan la emergencia de nuevos sujetos -como las mujeres - en las dinámicas internas cotidianas. ${ }^{174}$ En la observación de casos, se puede dar cuenta de la influencia del derecho positivo, sobre todo en el discurso y en el lenguaje de los usuarios y autoridades que invocan derechos ya sean constitucionales, indígenas, humanos o de las mujeres.

Esas normas - escritas o no - son el resultado de la atención y resolución de los conflictos y disputas, las cuales hacen referencia a los asuntos relevantes que

174 En otro trabajo (Cruz 2004) hago un análisis del derecho en Móctum y cómo las mujeres se constituyen en un elemento esencial de contestación y transformación del mismo. 
más importan a la comunidad por estar íntimamente relacionadas con su historia y cultura. Es decir, son asuntos que muestran las conductas que se consideran obligatorias, permitidas y prohibidas en y por la comunidad, también expresan los derechos reconocidos y las obligaciones impuestas, por ejemplo, el tequio o el cargo, los criterios de adscripción, a quiénes se considera o se pueden considerar como comuneros, o quiénes pueden llegar a serlo. El derecho en la comunidad está constituido de estas normas que son determinadas por sus formas de organización social, su identidad cultural175 y por su relación con los otros niveles del campo jurídico. Por ello, estas normas son construidas y transformadas en las propias dinámicas sociales, históricas y culturales de la comunidad.

Para exponer la norma escrita en su relación con los procesos y dinámicas de la comunidad, se presentan y explican los asuntos y conflictos relevantes, así como el sistema de cargos que constituye un referente central del derecho indígena. El interés central es mostrar la dinámica del derecho en Móctum, a través de la puesta en marcha de la estructura comunitaria para atender los asuntos, éstos muestran a su vez la oposición de intereses en temas que son considerados por los pobladores como de especial importancia, y que por ello son considerados conflictos relevantes (Krotz 1995).

Para comprender la especificidad del derecho en la comunidad es importante recordar que no se puede hablar de un derecho mixe, pero sí de principios generales de ese derecho que tienen su expresión y aplicación particular en cada comunidad, pues, como se mencionó en la introducción general, los grupos etnolingüísticos no son homogéneos y uniformes, por el contrario manifiestan diversidad interna. En el caso de los mixes, esta diversidad está dada

175 En los asuntos que se presentaron en la agencia de policía, las audiencias eran en idioma mixe y las autoridades siempre señalaban la importancia del cumplimiento de acuerdos y de la voluntad del pueblo pero también invocaban la Constitución y la Ley Agraria. Sin embargo, estos ámbitos del derecho en San Marcos Móctum no son los únicos, pues se dan otros al nivel de los particulares como los consejos que dan las personas mayores (que han pasado por todos los cargos) cuando se los solicitan, o los acuerdos entre los particulares sin llegar con la autoridad, así como los compromisos de ayuda mutua como la mano vuelta y el tequio, aspectos que Adelfo Regino (1996:152) señala como elementos de lo que llama Derecho Mixe. 
por los procesos históricos diferenciados de cada comunidad, en los que han influido aspectos como el ecológico, el demográfico, el geográfico, el económico y el social. Por esta circunstancia, no se puede hablar de un ser mixe sino de distintas maneras de ser mixe, lo que implica entender al sistema jurídico que se estudia como parte de una realidad histórica y cultural determinada con manifestaciones y diversidades concretas. Éstas determinan la construcción y transformación del derecho en la comunidad indígena de que se trate $y$, a la vez, su realidad y las manifestaciones de la misma son influenciadas y determinadas por el mismo derecho.

\section{Derecho y Territorio}

Como parte de esos procesos de transformación son centrales la cuestión agraria y el control municipal en su historia y actualidad (por lo que fue la Reforma Agraria y ahora la crisis de productividad del campo, que ha acelerado la migración), lo que indudablemente ha influido en la construcción y cambios del derecho -o derecho indígena - en la comunidad. De esta manera, los asuntos que involucran la gestión municipal, y sobre todo lo agrario, son relevantes ya que marcan en gran medida la dinámica de los conflictos o disputas al interior de cada poblado y entre la cabecera municipal y sus agencias, sobre todo con Móctum. Lo agrario como una dimensión de lo territorial hace énfasis en el hecho de que la tierra es de suma importancia no sólo para los Estados nacionales ya que representa un espacio de aplicación de su derecho, que conocemos como ámbito jurisdiccional (incluyendo el espacio aéreo, el subsuelo y el mar), que legitima el control de recursos naturales y fuentes de riqueza, sino también lo es para los pueblos indígenas para quienes el vínculo con la tierra y sus territorios es un elemento central de su existencia en cuanto colectividades. La cuestión agraria o lo agrario es todo aquello relacionado con el uso y distribución de la tierra (según extensión, cantidad y calidad). De esta manera, lo agrario en la comunidad se refiere al conjunto de normas y dinámicas vinculadas con la distribución y uso de la tierra (control de ella y sus recursos) y la definición de los sujetos agrarios - la comunidad y los comuneros-, sus 
obligaciones y derechos. Pero el derecho no sólo es esto, sino que incluye los procesos de generación y justificación de esas normas y de las instituciones sociales, unipersonales o colectivas (Krotz 1997:12). Podemos decir que cuando hablamos del uso de la tierra, nos referimos al control que la comunidad tiene sobre ella y las dinámicas y relaciones humanas encaminadas a lograrlo, de esta manera los asuntos, conflictos o disputas que la involucran son relevantes.

Por lo anterior para Totontepec y Móctum la cuestión agraria, que se representa como el uso y control de la tierra $-\mathrm{y}$ sus recursos naturales y biológicos - y como elemento importante para la subsistencia y sobrevivencia de la comunidad, ha determinado en mucho sus dinámicas actuales; por ejemplo, la apropiación de elementos culturales externos que se integran a su orden jurídico, agregados a elementos anteriores al conflicto agrario fundamentalmente, y otros derivados de este proceso. Esto se explica porque, en el momento en que se estudió Móctum, la cuestión agraria seguía siendo un referente central de las relaciones sociales. Por ello, coincidimos con Krotz (1997:9) que define los conflictos jurídicamente relevantes: "[...] al hablar de cuestiones jurídicas se trata [...] de fenómenos sociales clave. Tan clave son estos fenómenos que su examen revela enseguida aspectos centrales de la organización de una sociedad dada".

Es decir, ya que lo agrario es una dimensión de lo territorial (CAPÍtULO 4) no sólo como ámbito de competencia y de ejercicio del poder, sino como base de subsistencia económica y cultural de la comunidad, el conflicto agrario se constituye como el conflicto madre y el referente histórico de varios conflictos en la comunidad, sobre todo los relacionados con la disputa entre Móctum y Totontepec - como núcleos agrarios y entidades político-municipales - , con la definición de la pertenencia como comunero, ciudadano y fundamentalmente, con el uso y disfrute de la tierra. ${ }^{176}$ Esto se muestra claramente cuando al preguntarles a las autoridades

\footnotetext{
${ }^{176}$ Finalmente, es importante recordar que como se mencionó en el CAPítulo 3, la comunidad de San Marcos Móctum es una pequeña comunidad indígena mixe que cuenta con 525 hectáreas de tierra de las cuales aproximadamente 500 son de temporal y el resto son peñascos, según los pobladores, con 211 habitantes distribuidos en 31 familias o núcleos familiares, todos hablantes de la lengua
} 
porqué cuando una bestia está suelta se multa al dueño con diez pesos, la respuesta fue "porque si después un ganado de Móctum se mete en tierras de Totontepec, para que no nos cobren más". Algo similar sucede al reconocer el derecho de las mujeres a ser comuneras, lo que implica que pueden casarse con hombres de otras comunidades sin necesidad de dejar Móctum, esto después de que se les negaba este derecho por temor a que los de Totontepec buscaran casarse con mujeres de la comunidad para volver a invadir terrenos de Móctum.

\section{La influencia del sistema jurídico mexicano en la dinámica comunitaria y en el sistema jurídico indígena}

Como lo planteo en otro trabajo (Cruz 2004), el sistema jurídico mexicano ha influido en la forma en que están divididas las tierras al interior de Móctum (asentamiento humano, uso común y parcelas especiales) así como en la forma de propiedad colectiva o social de la misma - es decir, pertenece al conjunto de comuneros y/o comuneras legalmente reconocidos -. Por ello, estas formas de organización de la tenencia de la tierra no son exclusivas de Móctum o de los mixes debido al predominio que el Estado ha tenido en el medio rural a través de la Secretaría de la Reforma Agraria (SRA) y posteriormente de la Procuraduría Agraria (PA), para hacer que los núcleos ejidales y comunales se apeguen a formas de tenencia y explotación de la tierra fijadas en la Ley Agraria. Tal situación es evidente cuando en el plano general de las tierras de Móctum, que se elaboró como resultado del PROCEDE, se señalan las tierras que se han destinado a la UAIM (Unidad Agrícola e Industrial de la Mujer) como una parcela especial que, sin embargo, en los hechos no existe en Móctum porque las mujeres no están organizadas para producir colectivamente ni tampoco han solicitado las tierras

ayuuk. Esta comunidad y sus pobladores se autoadscriben al pueblo mixe, el cual ocupa un área geográfica relativamente compacta en el estado de Oaxaca representada por el distrito Mixe. Esta demarcación territorial indica que existen límites para darla en explotación para nuevos miembros, así como para vivir exclusivamente de ella, lo que plantea que las reglas sean más o menos rígidas por lo que toca a servicios cargos y cooperaciones como medios para sostener a la comunidad. Esto, indudablemente, impacta en los rumbos de la construcción y transformación del derecho. 
para ese fin. Esto muestra que la constitución de la UAIM fue en cumplimiento a una norma del Estado y que hacerlo así fue para terminar los trabajos de medición del programa citado. Pese a esto Móctum ganó con PROCEDE, pues logró actualizar su plano interno y plano definitivo, lo que implicó el recorrido físico de sus terrenos con la presencia de topógrafos del INEGI y personal de la Procuraduría Agraria junto con los comuneros de Móctum y de los pueblos colindantes, así como la firma de las actas de conformidad de linderos, dando certeza y seguridad de que el conflicto había terminado. Esto demuestra cómo el uso de la ley estatal no es unilateral y no siempre implica una actitud pasiva o sumisa de los que se someten a ella o la usan, pues puede ser utilizada para obtener beneficios - como se expuso en el caso de Totontepec al recurrir los usuarios indígenas a la Comisión Estatal de Derechos Humanos para evitar la justicia comunitaria o bien, el caso del supuesto heredero que perdió el amparo presentado ante el poder judicial federal.

De igual forma, y como se verá a continuación, la forma de tenencia de la tierra dictada desde la ley del estado genera tensiones, sin embargo, las normas que la regulan son apropiadas desde la práctica comunitaria, según la propia historia, percepción e intereses de los miembros de Móctum. Esto se observó en el caso de Totontepec (CAPítUlO 5) por lo que se refiere a la justicia, pues según se vio el alcalde adecua y usa la norma positiva para lograr que los usuarios, que acuden a él, lleguen a acuerdos o convenios, pese al hecho de que las conductas sean consideradas en el derecho mexicano como delitos.

\subsubsection{La lógica jurídico-cultural en la comunidad}

En el caso de Móctum se puede observar que los conflictos están relacionados principalmente con cuatro aspectos de la vida de la comunidad: 1) los cargos y servicios, 2) el uso y tenencia de la tierra, 3) los recursos económicos o apoyos que vienen del municipio o del gobierno estatal, y 4) el papel de la mujer en la vida comunitaria. 
Los asuntos son relevantes cuando evidencian o muestran el interés de la comunidad, los usos del poder y los procedimientos de resolución de sus conflictos. El control de estos asuntos relevantes y otros procesos comunitarios permite que exista una menor ingerencia del exterior por parte de los agentes del Estado, y la ideología armónica (cfr. Nader 1998) ayuda a crear una idea de solidaridad y consenso al interior que sale a relucir en los asuntos cuando la autoridad señala que las decisiones que se toman son por mayoría y acuerdo de todos (cfr. Cruz 2004, el caso de la disputa entre mujeres). De igual forma, podemos decir que son asuntos básicos de los que se derivan otros asuntos y conflictos.

De esta manera, a partir de las narraciones de los habitantes sobre las normas que se han dado, llegué a la conclusión de que los asuntos relevantes y básicos en Móctum son los que conciernen a:

1) Los cargos y servicios a la comunidad, el uso de la tierra y cumplimiento de las obligaciones asignadas por la asamblea, esto es una expresión de la voluntad de continuar siendo parte de la comunidad.

2) El ajuste de la conducta individual a lo que socialmente se espera y que afecta la vida y quehacer de las personas. ${ }^{177}$ Por ejemplo, solicitud y ejercicio de derechos de membresía como comunero o ciudadano, uso de la tierra, propiedad individual sobre los productos de la siembra o la cosecha. También intervienen las autoridades comunitarias, cuando hay riñas y lesiones graves que dejan cicatriz o dejan incapaz a una persona para realizar su trabajo cotidiano, o bien, en caso de chismes y celos. En ninguno de los casos se buscó por parte de los involucrados el arreglo

177 Sin duda los conflictos entre católicos y adventistas son relevantes, pero no los pude documentar. En mis últimas visitas las autoridades cuidaban mucho de que se expusieran o se tratara públicamente los asuntos que les llegaban a la agencia de policía; supe que una vez que yo abandonaba la comunidad hacían asambleas, citaban a las personas involucradas en un asunto o las encarcelaban. Tal vez consideraban que mi presencia, por ser abogada, les causaba problemas en el manejo del conflicto, dato que no he corroborado. Así me enteré de varios asuntos que no pude presenciar, pero que la disputa se daba entre católicos y protestantes por asuntos que aparentemente no tenían que ver con lo religioso. 
privado o entre ellos, más bien se acudió a la autoridad y tampoco se dieron casos de denuncia contra los hombres por chisme.

3) Daños al patrimonio de una persona o familia como daños en la milpa, robos en general, pero sobre todo de gallinas o frutos (café, plátano, limón), o incumplimiento del pago de daños o de un trato o acuerdo. Todos éstos tienen reparación económica o en especie si no se pone en riesgo la vida o la integridad de las personas (homicidio o lesiones graves que pongan en riesgo la vida), o bien si no se hace uso de armas blancas o de fuego, o uso de la violencia física. No se presentó ninguno de estos casos durante mi estancia. No se reportan homicidios pero si decesos por enfermedad o accidente, en este caso se da parte al síndico de Totontepec y éste a su vez al Ministerio Público que se encuentra en el Distrito, en Zacatepec.

4) Vigilancia sobre la autoridad en cuanto al manejo de recursos o apoyos económicos canalizados a través de programas gubernamentales. Se tratan en asamblea o, el agente manda a traer a la persona que está cuestionando su gestión, para "meterlo" en la cárcel o multarlo.

5) Acatamiento de la voluntad de la asamblea, relacionado sobre todo con el uso de la tierra y la inclusión o expulsión de un comunero. Por ejemplo, sucede cuando una mujer se casa con hombre fuereño - antes de 1990 que no se reconocían derechos a las mujeres - cuando una persona nacida en Móctum ha salido de la comunidad para trabajar o estudiar y no coopera, y después quiere regresar y exige respeto a sus derechos de comunero.

A partir de los casos narrados por las personas y las autoridades involucradas, en los siguientes apartados se plantean algunas precisiones analíticas. En total se pudieron documentar 20 asuntos, de los cuales por cuestión de espacio sólo se exponen cuatro casos y criterios generales (que desprendí de esos 20 casos). Este 
trabajo sirvió para tener un panorama del tipo de asuntos que las personas en Móctum disputan. Estos asuntos versan sobre: el uso de la tierra (que incluye una variedad de conductas como la siembra, el pastoreo, construcción de casas, ranchos, daños sobre éstos), ofensas entre las personas (riñas, lesiones, agresiones verbales, chismes, difamación), cuestionamiento de la autoridad, alteración del orden después de las 10 p.m., ${ }^{178}$ trasgresión al acuerdo colectivo o de asamblea, problemas intrafamiliares (abandono de hijos - como el cuidado de los niños es asumido por los abuelos o familiares, la autoridad sólo interviene en caso de que se lo pidan - infidelidad, golpes a la esposa).

\subsubsection{Asuntos relevantes sobre el patrimonio particular: Robos y daños}

En el marco comunalista se reconocen derechos individuales. Así, como parte de la norma interna se hace valer el derecho que tiene una persona sobre cosas o animales; a los comuneros se les reconoce el derecho que tienen sobre su casa, su solar urbano y su parcela o los frutos que cosechan, siempre y cuando cumplan con sus obligaciones y servicios para la comunidad. Frente a la propiedad individual existe la propiedad colectiva sobre la tierra, es decir, es de todos y de nadie en lo individual, sin embargo, todos los miembros pueden disponer de ella para sostenerse.

Tomando en cuenta estas consideraciones y sobre todo el conflicto agrario con Totontepec provocado porque algunos de sus pobladores que invadieron terrenos de Móctum - bajo el argumento de que estaban abandonados o que esas tierras fueron tomadas a cambio del pago de deudas - , a continuación se apuntan algunas circunstancias en las que el patrimonio individual o particular es motivo de disputa al interior de la comunidad, con esto se muestra cómo disputa la gente y sobre qué.

178 Debido a la falta de alumbrado público, en la noche no se distingue quién anda caminando por la comunidad, ya que se han dado robos, para evitarlos todos saben que a esa hora no deben estar fuera de sus casas, por lo que si alguien es visto a esa hora es perseguido por los topiles para ser llevado a la agencia municipal. También en caso de estar ocasionando disturbios, por borrachera u otras circunstancias. 
En los casos en los que se han dado robos pequeños en la comunidad, por lo regular son negados por quien es señalado como responsable o es acusado. Para resolver el asunto o arreglarlo, la autoridad siempre solicita un testigo, aun cuando el afectado tenga la convicción y pruebas fundadas en hechos y momentos de que el responsable fue tal o cual persona.

Por ser un pueblo pequeño, cuando hay daños en parcelas o solares así como riñas los que están involucrados no pueden negarlo, "no se necesitan testigos" aunque la autoridad, según sea la gravedad del asunto, puede solicitar que las personas que presenciaron la pelea o los daños intervengan como testigos, para desalentar al acusado o acusados de su pretensión de recurrir al municipio.

Si la persona que agredió o que es acusada niega su culpa, a pesar de haber testigos, y "si se pone muy confiado de que en el municipio lo van a ayudar", se le multa (esto según una autoridad interna). Si después de haber llegado a un acuerdo la persona que está obligada a pagar o a cumplir no lo hace, se le puede señalar una multa - que va al "ahorro" de la agencia- y obligarlo a pagar. El "ahorro" de la agencia es una especie de "caja chica" que se forma con las aportaciones económicas o "cooperaciones" de los miembros de la comunidad, son fondos que se utilizan para que las autoridades realicen distintas gestiones.

Todos los asuntos entre los ciudadanos (problemas o conflictos) pasan al agente, sin embargo, cuando los que están implicados se "arreglan", ya no es necesario. El agente sólo actúa cuando se presenta una queja y no se quiere reconocer el daño. De igual forma, se dieron asuntos que llegaron con la autoridad o a la agencia y que los particulares involucrados buscaban un posible arreglo o denunciaban el incumplimiento de un arreglo previo.

Cuando el comisariado no puede solucionar un problema, por ejemplo, que se cuestione la propiedad comunal de la tierra, es decir, que uno de los miembros de la comunidad u otra persona externa a ella se ostente como propietario único de todo o parte de las tierras comunales (en 6.1.2 se expone el caso), este tipo de asuntos se plantean y resuelven en asamblea, como en el caso de Totontepec 
(CAPítUlo 5, apartado 5.1.1.1). En casos como éste se puede observar la influencia del derecho positivo estatal, pues según el derecho de propiedad que éste postula una persona es dueña de una cosa mueble o inmueble por usarla durante un tiempo determinado (usucapio o prescriptio, según sea el caso - véase CAPítulo 1 apartado 1.2-, lógica o razonamiento que no impera en el derecho en la comunidad, ya que una persona tiene derecho de usar la tierra por ser miembro del colectivo y no al revés, es decir, usa la tierra: luego entonces es miembro. Si el problema es sobre tierra (uso y posesión) pero hubo daños, golpes o lesiones sobre las personas, se pasa con el agente.

De lo anterior se puede deducir que además de las instancias formales de la comunidad, es decir, la asamblea, el agente o el comisariado de bienes comunales, existen otros ámbitos de resolución de conflictos como el que se da entre particulares o las personas involucradas, así como el nivel legal de las autoridades de la cabecera municipal, como la alcaldía, que funge como juzgado. También se observa que en asuntos de menor gravedad - como el abandono de hijos, desde la perspectiva del derecho positivo- las autoridades sólo intervienen cuando así se les solicita.

\subsubsection{La propiedad comunal como asunto relevante de la comunidad}

El cuestionamiento al sistema de propiedad comunal se considera un atentado a la integridad de las tierras de Móctum, por ello se respeta la propiedad del producto cultivado pero no sobre la tierra. Esto en efecto ha propiciado conflictos con personas que exigen que se respete la propiedad sobre un terreno que ha cultivado o en el que tiene siembra.

En cuanto al uso de la tierra tenemos que se han establecidos varios acuerdos de asamblea, por ejemplo: si una persona ya rozó (limpió y quemó) el lugar que va a sembrar, por ese hecho ya tiene derecho sobre ese pedazo de tierra, y tiene derecho a que se le respete para sembrar y cuando se cosechan los productos (maíz o frijol, principalmente); si ya no se vuelve a rozar o a usar, otra 
persona puede utilizar ese pedazo de tierra. Después de usar una porción o parcela de tierra por uno o dos años, debe dejársele descansar por lo menos un año ya que "así se acordó por la asamblea". Si usa el mismo pedazo dos años consecutivos no puede extenderse "hacia los lados". No se permite cercar, sólo si "se trata de ganados" y siempre y cuando se "pida permiso".

De igual forma el uso de la tierra es un derecho, pero también implica una obligación pues si una persona roza su terreno y el fuego se sale de control, debe pagar los daños aunque haya sido por imprudencia y no intencional.

Cada persona tiene un solar que se le asigna por el comisariado después de cumplir algunos requisitos, como hacer servicio a la comunidad, cargos y tequios y "que se vea o exprese su voluntad" de que se va a quedar a vivir en la comunidad. En todos los casos, cada solar incluye una extensión de tierra que se puede usar para construir una casa y cultivar milpa (maíz) o frijol. A veces se dan casos en que uno de los vecinos se pasa de los límites señalados (mojoneras) y es cuando piden la intervención del comisariado. El consejo de vigilancia se cerciora de esto trasladándose al lugar de los hechos escuchando a las partes y haciendo mediciones para enterarse de lo que sucede, es decir, hace una inspección in situ, en el lugar. En caso de que alguna de las partes en disputa haya movido las mojoneras, se regresan a su lugar, y si el que las movió es renuente se le puede meter a la cárcel o bien se le puede multar por no obedecer lo que ha dispuesto la autoridad.

Otro tipo de daños al patrimonio de las personas se da cuando un ganado (chivos, mulas, burros, bueyes o vacas) entra a una milpa y no existe arreglo entre el dueño del ganado y el dueño de la milpa; el comisariado, por su parte, toma en cuenta los siguientes criterios para determinar el pago del daño: si el ganado se comió la planta pero no el fruto (la mazorca), el dueño del animal debe pagar 50\% (porque la planta puede crecer y producir); si el ganado se come la mazorca, el dueño del ganado debe pagar $100 \%$; en ambos casos el porcentaje se obtiene sobre el trabajo invertido, es decir, los días de trabajo (a \$120 por día, en el año 2006) 
proporcionales al daño cometido entre 10 ó 20 plantas dañadas, o bien en este último caso la entrega del número de mazorcas que el ganado o los ganados se hayan comido o dañado.

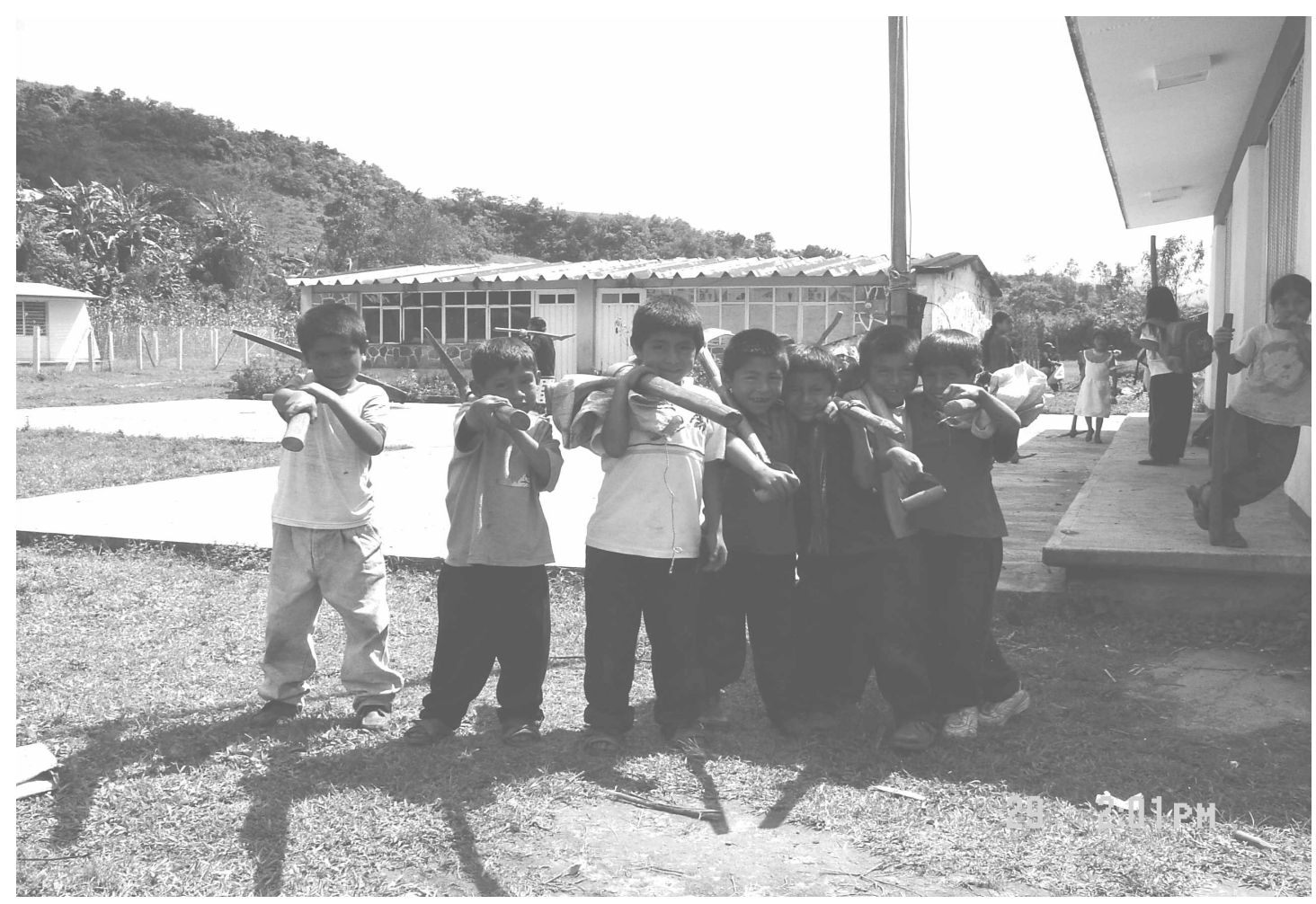

Niños en Móctum después de trabajar en la parcela escolar

\subsubsection{Dimensiones de la norma no escrita}

Se puede afirmar que el proceso de gestación o génesis de una norma empieza en el momento en que un asunto es presentado a las autoridades (asamblea, agente o comisariado), por ejemplo, solicitar un solar no implica la existencia de una parte contraria o adversario - claramente identificado-, aunque se puede presentar alguien argumentando a favor o en contra de la solicitud, revelándose disputas pasadas con el solicitante. La resolución de este tipo de conflictos o casos implica la aplicación de distintos criterios relacionados fundamentalmente con la circunstancia y posición de las personas ante la comunidad, y también si existe un caso similar que oriente a las autoridades y a las partes involucradas a buscar una 
solución. Así, son dimensiones de la norma oral la existencia de casos semejantes anteriores que se toman como referentes, y la norma como criterios surgidos a partir de la resolución de casos que no son similares pero que ayudan en la definición de esos criterios para atender "nuevos" casos. Como ya lo mencioné, uno de los derechos de los miembros de la comunidad es solicitar un solar o usar una parcela, este derecho era exclusivo de los hombres, sin embargo, se ha dado el caso de mujeres que han solicitado este derecho, lo que para las autoridades significa actuar sin casos precedentes porque las mujeres nunca lo habían solicitado -regresaremos sobre esto en el segundo caso de este apartado.

Para explicar la forma en que surge una norma jurídica no escrita, expongo dos casos en los que se establecieron reglas sobre la propiedad colectiva de la tierra y su uso. Para comprender el resultado o resolución de estos casos y el porqué se dio, de una forma u otra, es importante considerarlos en el contexto del conflicto agrario con Totontepec, donde los invasores argumentaban que eran pequeños propietarios (CAPÍTULO 4).

\section{a) Primer caso}

Este primer caso se refiere a la propiedad colectiva de la tierra, es decir, los bienes comunales de Móctum, donde se aplicaron normas no escritas ya existentes y, por esa aplicación, se crearon nuevas.

Según lo que narran algunas personas que fueron autoridades de bienes comunales, hace tiempo un señor hizo su potrero "allá abajo por el río" (en la parte baja de la comunidad), nadie dijo nada y parecía normal, sin embargo, llegó un momento en que cercó y ya no dejó pasar a nadie ni que otros animales pastaran, "se creía propietario" (según las autoridades).

Las autoridades hablaron con esta persona, sin embargo, no hacía caso por lo que el comisariado de bienes comunales recurrió a la asamblea "si ella decide que se reconozca la propiedad, pues se reconoce, si no pues no, pero no es una decisión mía sino de todo el pueblo". Ante la cerrazón del presunto dueño, la gente 
decidió invadir el potrero y "todos sobre el potrero; ahora ese señor ya no vive en Móctum pues se fue a trabajar a Oaxaca o a México, no se sabe con exactitud".

La decisión radical de la asamblea se explica porque antes de que las autoridades agrarias internas hablaran con el señor, éste ya había acudido con el presidente municipal de Totontepec, el cual dirigió un escrito al comisariado de Móctum. Éste respondió señalando que según la “ley [la Ley Agraria], las tierras de comunidad son de todos, no hay 'dueño', además el reglamento [los acuerdos] señala que los asuntos de la comunidad deben arreglarse aquí y si no hay solución pues se pasan al municipio".

Lo anterior significó que el señor que se creía “dueño" en la percepción, de las autoridades de Móctum (del comisariado y del agente de policía) se saltó esta instancia o bien pasó por alto su jurisdicción, por eso y ante la respuesta del comisariado a su citatorio, el presidente municipal no atendió el asunto regresándolo al agente de policía. Además, según las personas que fueron autoridades, también el Presidente o el municipio tienen limitaciones - señaladas por el derecho positivo-, pues no puede conocer de todos los asuntos que le llegan de las comunidades.

Este último razonamiento es clave porque en esta percepción aparentemente de sentido común, se puede observar la influencia del derecho positivo pero también la fuerza del derecho local construido desde la cotidianidad comunitaria - cuando se hace referencia al derecho de propiedad por el uso prolongado de la tierra y al "reglamento" como conjunto de acuerdos sobre los límites de la jurisdicción de Móctum y la competencia de sus autoridades - . Efectivamente en el derecho mexicano los asuntos agrarios no son de la competencia del ayuntamiento o de sus funcionarios municipales como el presidente municipal. Como se refirió en el CAPÍtulo 4 -cuando se menciona la doble calidad de Móctum como agencia y como núcleo agrario, y que con aquella característica está subordinada a la cabecera municipal-, la cuestión agraria es materia federal y corresponde a otro ámbito de competencia o jurisdicción de otro tipo de 
autoridades como el Comisariado de Bienes Comunales de cada comunidad, así como la Procuraduría Agraria y los Tribunales Agrarios como instituciones públicas federales del Estado mexicano.

Finalmente el señor que se creía dueño ya no insistió cuando vio que no tuvo eco su solicitud ante el presidente municipal, ya que entendió que éste al no ayudarlo avalaba las acciones de las autoridades de Móctum; aunque como se dijo arriba, en el sistema jurídico mexicano el presidente municipal no tenía otra opción, de lo contrario las autoridades de Móctum podían reclamarle su intromisión en asuntos internos que la "ley" mexicana les legitima para conocer.

En este caso relucieron los siguientes criterios que en su momento sirvieron como normas que se aplicaron para resolverlo y que constituyen un referente de casos futuros:

$1^{\circ}$ Todos los terrenos de Móctum son comunales por estar así reconocidos en su Resolución Presidencial, ${ }^{179}$ pero también sus habitantes han optado por decir que son "comunes", es decir de todos, para mantener la integridad de sus tierras y evitar invasiones. Planteamiento que nos remite a la ideología armónica analizada por Laura Nader (1998), como un discurso que enfatiza el consenso comunitario para mantener lealtades y la cohesión interna y evitar la intromisión del Estado.

$2^{\circ}$ Existen pedazos de tierra en el área del asentamiento humano (caserío) y en las tierras laborables o en explotación que son propiedad individual. Esto se explica porque antes de 1975 (fecha de la Resolución Presidencial) los de Totontepec las invadieron, y algunos habitantes de Móctum las compraron para recuperarlas. Los documentos que los acreditaban como dueños o propietarios los entregaron a la Secretaría de la Reforma Agraria (SRA), para iniciar el procedimiento de Reconocimiento y Titulación de

179 Este documento, según la actual Ley Agraria, es el título de propiedad o documento que ampara la propiedad del núcleo sobre la tierra, la tenencia o posesión se comprueba por el uso continuo que se haga de ellas. Para darle cumplimiento a la Resolución Presidencial, los topógrafos de la SRA, fueron a Móctum y levantaron un acta que se conoce como Acta de Posesión y Deslinde, reconociendo ese uso o ejercicio del derecho de propiedad sobre las tierras. 
Bienes Comunales (RTBC) y con ello recuperar las tierras de manera colectiva.

$3^{\circ}$ Se reconoce la posesión de un comunero(a) o ciudadano(a) sobre las tierras (parcelas) en las que sembró o cultivan cafetos y árboles en producción. No se permite que otro llegue a sembrar, es decir, las plantas son propiedad de la persona en lo individual y el terreno es comunal.

$4^{\circ}$ Se reconoce la posesión de un comunero, comunera o ciudadano sobre los sembradíos o cultivos desde el momento de la siembra hasta la cosecha. Después de la cosecha, si no se utiliza o prepara para una nueva siembra puede llegar otro comunero o ciudadano a sembrar.

$5^{\circ}$ Las tierras sobre las cuales se construyen las casas de los comuneros, comuneras y ciudadanos son propiedad del núcleo agrario, sin embargo, éste reconoce el derecho de propiedad de quienes compraron el terreno a los de Totontepec (cfr. CAPítUlo 4).

Como se mencionó al principio de la tesis y de este capítulo, en mi trabajo de campo me aboqué a "recuperar" las normas que los habitantes de Móctum se han dado para regular sus dinámicas internas, y ya que no están por escrito, las redacté contextualizándolas y respetando en la medida de lo posible la narrativa de los informantes. Lo anterior es producto de ese trabajo.

\section{b) Segundo caso}

En este caso, se ilustra cómo surge la necesidad de formular una norma, las condiciones en que se aplica y la idea que se tiene de ella.

Entre las mujeres, sobre todo del grupo "Mujeres Olvidadas del Rincón Mixe" (grupo de mujeres formado en Móctum para promover proyectos productivos como un molino, cultivo de hortalizas), se produjo un fuerte malestar o inconformidad porque decían que la asamblea de los comuneros ${ }^{180}$ acordó que 
las mujeres que se casaran con hombres "de fuera" tenían que abandonar Móctum. Tanto las mujeres como las autoridades señalan que esto fue a raíz de que en una ocasión una mujer se casó con un hombre que no era de la comunidad - que "era de fuera" - y éste solicitó ser comunero, la asamblea y las autoridades lo aceptaron sin condición. Pasando el tiempo ya no quiso cumplir con los servicios, entonces le exigieron a la esposa que cumpliera en lugar de su esposo, pero ella también se rehusó por lo que "prácticamente les pidieron que se fueran".

El trasfondo de lo anterior es mantener la idea de unidad en torno a la comunidad y garantizar la protección de la integridad de la tierra como un bien económico y de pervivencia de la comunidad, así como de cada uno de sus miembros. Esto se entiende si se toma en cuenta que en la visión y versión de los habitantes de Móctum sobre el conflicto agrario, fueron perdiendo sus tierras por deudas contraídas con comerciantes de Totontepec, y también porque al ser pocos habitantes, los de esta comunidad aprovecharon para trabajarlas y apropiarse de ellas (véase CAṔ́TULO 4) dando algunas las en arrendamiento y/o a medias.

En las entrevistas realizadas para indagar más sobre este caso, una de las autoridades agrarias señaló que las mujeres siempre han tenido derechos sobre las tierras, pero para eso tienen que cumplir obligaciones con la comunidad, sin embargo, otros reconocen que el derecho de las mujeres como comuneras es reciente. Según lo dicho por esta autoridad, ${ }^{181}$ antes no se exigían obligaciones para ser comunero o vivir en Móctum y lo único que hizo el pueblo y las autoridades es ser más estrictos, justificando esto con "el reglamento" o los acuerdos de la asamblea. Se puede deducir entonces, que el reglamento sintetiza normas del derecho positivo y las que resultan de su aplicación en la comunidad a casos

jóvenes pueden ser comuneras si lo solicitan y cumplen proporcionalmente como los hombres con los tequios y cuotas, esto gracias al trabajo de las mujeres del grupo con el apoyo de Servicios de Apoyo Intercultural, A. C. (SAIAC).

${ }^{181}$ Sobre el caso que sucedió con el hombre que no quería hacer servicio la autoridad señaló: "nadie lo obligó a irse, él se fue primero y su esposa después, y según el reglamento como ya se fueron por más de dos años ya perdieron sus derechos, si quieren regresar tienen que cumplir con los requisitos". Esto dicho por el comisariado parece ser un argumento que se opone a la idea de que en realidad hubo una expulsión. 
concretos, es decir, el derecho en la comunidad o derecho indígena. El reglamento que menciona esta autoridad, como otras personas que ya han ejercido cargos, no es un texto escrito sino un referente normativo que comparten los vecinos de Móctum.

Por su parte, una de las mujeres del grupo “Mujeres Olvidadas del Rincón Mixe" argumentó que es difícil que una mujer tenga los mismos derechos de un hombre comunero: "no puede tener los mismos derechos de comunero porque las mujeres por lo general no se quedan en un lugar [en su comunidad], si se casan con hombres de fuera se tienen que ir porque el hombre es muy difícil que se quede en un lugar que no es su comunidad". A esto se agrega la regla comunitaria de que las mujeres viudas que son comuneras, al casarse nuevamente, sus derechos pasan al hombre. Sin embargo, en 2006 se dio el caso de una mujer que siendo soltera era comunera y cumplía sus obligaciones económicas, en trabajo y de tequio, al casarse solicitó se le respetara este derecho (a seguir colaborando y a mantener a su nombre un solar - para construir su casa - que se le dio cuando era soltera) ya que su esposo también es comunero (con su propio solar). Después de una discusión en la que hubo mujeres y hombres en contra, se aceptó pero ahora ella sabe que los gastos para la familia, que formó con su marido, son dobles porque los dos deben cumplir sus obligaciones de comuneros.

El caso de esta mujer de nueva cuenta nos remite al debate sobre la norma oral, porque revela que las normas se redefinen y no son códigos estáticos sin ser ajenos a intereses y poderes locales, sino que se adecuan a las realidades y necesidades humanas de establecer un control y un orden. Finalmente esto marca una diferencia fundamental entre la norma oral y la escrita.

\subsubsection{La adscripción y autoadscripción comunitaria: El sistema de cargos en Móctum y Totontepec}

Como se mencionaba el sistema de cargos es uno de los pilares de la dinámica comunitaria - en la que se implica la cohesión comunitaria, los conflictos y 
disputas y por tanto, los usos del poder-. De acuerdo con Barabas (2004:340) los sistemas de cargos:

[...] son instituciones politicas perdurables, que pueden considerarse como pilares de la estructura social local, pero sumamente dinámicas y flexibles, capaces de adecuarse a situaciones cambiantes internas y externas y de apropiarse y reestructurar diferentes aportes e imposiciones culturales.

En el caso oaxaqueño, los sistemas de cargos han resurgido con mayor fuerza a propósito de la reforma electoral sobre elección de autoridades por "usos y costumbres". 182

Cuando hablamos del sistema de cargos nos referimos a un entramado complejo de relaciones sociales al interior de una comunidad articuladas con lo político y el uso del poder, involucrando los grados de edad, el género, las relaciones parentales, el ejercicio de la justicia, el uso de la tierra, las formas de intercambio recíproco interfamiliares e intercomunitarias.

En este trabajo me interesa destacar las normas que rigen el sistema de cargos, definido como el conjunto de puestos y servicios que se dan a la comunidad organizados en orden de importancia y de responsabilidades, y que hombres o mujeres deben cumplir para poder vivir en ella, tener derechos y obligaciones y trabajar la tierra. Considero que el sistema de cargos forma parte del derecho que se construye en la comunidad, pues en él confluyen un conjunto de normas jurídicas y sus usos, que describen y señalan derechos y obligaciones así como requisitos de ciudadanía y de membresía definitorios de la relación del individuo con la comunidad.

Como se apuntó en la introduccióna la tercera parte de esta tesis, diferentes trabajos antropológicos han documentado la importancia central del sistema de

${ }^{182}$ Cfr. Comisión Permanente de Asuntos Indígenas, LVI Legislatura del Estado (1998:iii): “En 1995 se reformó el Código de Instituciones Políticas y Procedimientos Electorales de Oaxaca; por primera vez en la historia del país fueron reconocidas las elecciones de las autoridades municipales mediante las tradicionales prácticas comunitarias". Posteriormente, el capítulo relativo a este sistema es reformado en 1997. 
cargos para la organización de la vida social y religiosa de las comunidades indígenas mesoamericanas (Cancian 1965, 1990; Medina Hernández 1995; Korsbaek 1996; Dehouve 2001; Barabas 2004), postulándose ya sea el origen prehispánico ${ }^{183}$ y en otros el origen colonial de esta estructura (sobre todo a finales del siglo XIX - cfr. Chance y Taylor 1987), y la manera en que las comunidades indígenas se han apropiado del sistema para la gestión de su vida comunitaria y de alguna manera como resistencia a las influencias del exterior. ${ }^{184}$

Desde la perspectiva apuntada, el sistema de cargos, como normas de conducta esperadas por los miembros de una comunidad, es una parte del derecho que se construye localmente, pero también representa un eje importante de la vida política, como sucede en la mayoría de las comunidades y los municipios de Oaxaca (Velásquez 2000; Maldonado 2003:33). De igual forma, en el sistema de cargos confluyen distintas dinámicas y órdenes de la vida comunitaria que involucran lo social, político, religioso y cultural. El propio sistema de cargos presenta distintas tensiones entre lo nacional y lo local, sobre todo por lo que se refiere al sistema jurídico. Tales tensiones están dadas, en algunos casos, por la penetración de religiones distintas a la católica que en varias comunidades indígenas de Oaxaca han provocado que el sistema de cargos cívico-religioso por tradición se transforme y termine expresándose a través de los cargos civiles. De esta manera el sistema de cargos no necesariamente está asociado a los cargos religiosos, según sucede en Móctum. Pero no sólo los cambios en el sistema de

183 Así, Medina Hernández (1995:9) señala: “El sistema de cargos se inscribe fundamentalmente en la matriz comunitaria india, y si bien es cierto que la estructura político-religiosa es impuesta por los colonizadores españoles, y vigilada muy de cerca por el clero regular - responsable y mediador entre la población india y las autoridades coloniales-, la base del modo de vida del campesino indio permanece inalterable [...] Con este planteamiento trato de definir la dialéctica que habría de establecerse - desde el principio de la colonización hispana -, entre la comunidad agraria de raíz mesoamericana y las autoridades políticas y religiosas novohispanas. Por una parte encontraremos la imposición de las instituciones coloniales, orientada hacia la explotación y el dominio, y por la otra, la resistencia y el desarrollo de estrategias comunitarias para mantener la integridad y la reproducción del modo de vida y la cultura de las comunidades indias".

${ }_{184}$ En su obra, María Teresa Rodríguez (2003) dedica un capítulo al sistema de cargos y a la comunidad indígena, en donde presenta las principales vertientes de la discusión teórica relativa a los sistemas de cargos o jerarquías cívico-religiosas, sintetizando el desarrollo del debate. 
creencias representan una tensión y provocan cambios en el sistema de cargos, también la migración y los cambios económicos que se dan a nivel nacional impactan en él y en su estructura.

Respecto al sistema jurídico, la tensión se presenta porque en el sistema interaccionan y se sobreponen elementos formales propios de la institución municipal - como institución del Estado mexicano-, con elementos de la lógica cultural y las dinámicas comunitarias. Esta conjunción de elementos culturales diversos hacen del sistema de cargos una entidad híbrida según Velásquez (2000 107):

[...] el sistema se convierte en una entidad híbrida, cuyas normas establecen una frontera jurídica, que regula su reproducción. La frontera existe porque se trata de dos territorios en el que los contenidos se separan pero en donde existe una adherencia a formalidades; porque históricamente tanto la legislación como la política, primero colonial y después estatal, permitió su reproducción diferenciada como estrategia de subordinación, porque la condición propia de vasallaje, el colonialismo y la discriminación crearon condiciones para formar una barrera, un límite y una resistencia a la disolución de la identidad cultural en lo nacional

En este proceso de subordinación y discriminación y a la vez de subalternidad, contestación y resistencia de los pueblos indígenas, el sistema de cargos se ha transformando, distinguiéndose en muchas comunidades la tendencia a una separación entre el aspecto civil y el religioso (Sierra 2002). Ésta es una diferencia fundamental entre Totontepec y Móctum, porque mientras en el primero se mantienen los cargos religiosos (dado que los adventistas son una minoría) en el caso de Móctum se puede observar justamente el proceso en el cual el sistema se transforma y se vuelve más cívico, mientras los cargos religiosos pierden fuerza dentro del sistema comunitario en general, lo que indudablemente puede mostrar un trastrocamiento de la cosmovisión indígena asociada al sincretismo católico (Fabre 2005). 
De acuerdo con la información del Alcalde Único Constitucional de Totontepec (de 2004) como la de los adventistas residentes en este poblado, éstos tienen la obligación de participar en las fiestas religiosas como mayordomos o bien capillos que atienden a las bandas del pueblo o de otros pueblos, o a realizar cualquier otro cargo civil o religioso si así lo asigna la asamblea. En las agencias de Totontepec que pude visitar, los cargos religiosos se mantienen separados dada la presencia cada vez más fuerte de adventistas. Como muestra de esto, en Santa María Tiltepec en el año 2002, se dio el caso de expulsión de varias familias por no cumplir con el trabajo colectivo y cargos religiosos, el asunto se resolvió porque algunas familias adventistas accedieron a realizar aportaciones (económicas o en especie), tequios y trabajos colectivos para la comunidad, pero no participan en los cargos religiosos o relacionados con la iglesia católica. Esto parece marcar una constante en las otras agencias, donde los adventistas participan en los cargos que no son religiosos (católicos). En Tlahuitoltepec, otro municipio cercano a Totontepec, también hubo expulsión de adventistas en 1982, pese a esto, sigue habiendo adventistas no en la cabecera pero sí en las rancherías y agencias como Yacochi, mostrando que las tendencias cambian. Frente a las decisiones impuestas por la mayoría de católicos sobre el cumplimiento de los cargos religiosos y cumplimiento de trabajos comunitarios, los adventistas se negaban a acatarlas usando el discurso legal del Estado (libertad de creencias). Ahora, por lo menos en la cabecera del municipio de Totontepec, la penetración del discurso sobre derechos en materia de libertad religiosa (Fabre 2005), así como un mayor conocimiento del derecho positivo, ha provocado que se establezcan reglas de tolerancia o aceptación para que los correligionarios de las distintas religiones, miembros de una misma comunidad, convivan de otra manera, lo que no ha significado una igualdad a tabla rasa pues la religión católica sigue siendo predominante.

La conversión religiosa de Móctum al adventismo en la década de 1970 significó que el sistema cívico-religioso de los cargos, identificado en la literatura 
antropológica con la religión católica y como referente central del "ser mixe" (Korsbaek 1996; Münch 1996; Regino 1996), fuera rebasado; por el contrario los cargos civiles cobraron una renovada fuerza y hasta hoy son el eje central de la organización comunitaria, como veremos más adelante, y un aspecto clave de las dinámicas jurídicas de Móctum. Esto muestra que los rasgos objetivos no son los que definen una identidad sino los procesos de autoadscripción que remiten a procesos y matrices históricas y culturales expuestas a ser transformadas y redefinidas.

\section{Cargos y servicios en Totontepec}

Para comprender el sistema y estructura de cargos como parte del derecho en Móctum y en Totontepec y como un elemento importante del sistema jurídico que se estudia, a continuación se describen los tipos de cargos y servicios voluntarios vigentes en la comunidad. Esta relación se hace también para comprender la lógica cultural que subyace al sistema y el porqué de las sanciones que se aplican en caso de que algún miembro de la comunidad no quiera cumplir.

En el sistema de cargos de Totontepec, a diferencia de Móctum, existe una amalgama de servicios o cargos que corresponde al ayuntamiento (regidores, síndico, alcalde, presidente municipal), con la tierra (comisariado de bienes comunales) o con los servicios de salud y educativos (comités de la clínica y de la escuela, promotores de salud). Todos estos cargos se han establecido de acuerdo a la estructura o a las exigencias de las instancias del Estado mexicano, sin embargo, son adoptados, adecuados y utilizados de acuerdo a las necesidades del pueblo. Es decir, cada uno de los cargos del sistema tiene sus propias funciones, pero a su vez están en íntima relación unos con otros. Existen también otro tipo de cargos que responden al sistema de creencias dominante en la comunidad como son los mayordomos de las fiestas, los encargados de la iglesia, los que atienden a la banda (capillos). 
Según las entrevistas hechas al Alcalde Único Constitucional y al presidente municipal, "la cabeza de todo el servicio es el presidente municipal". Para llegar a ser Presidente Municipal se debe pasar por los escalafones del sistema de cargos que, de acuerdo con Honorio Alcántara Nuñez (2004), oriundo de Totontepec, son 12 si se consideran sólo los civiles y el servicio de topil como un cargo introductorio al sistema (véase DiAGRAMA 1).

El primer cargo es el de topil, en mixe se le dice el que hace los mandados. Los topiles fungen como policías y realizan los trabajos más rudos y pesados, cargan arena (para las construcciones y caminos), hacen mezcla, "deben ser diestros para usar el pico y la pala más que la pistola" (Presidente Municipal del 2004). Acompañan al síndico y junto con él resguardan el orden público, su servicio es de 24 horas. En el día hacen trabajos y en la noche vigilan. "Hay muchachos que no hacen caso y siempre se quedan como topiles hasta los 40 [años de edad] o hasta que fallecen" (Alcalde de 2004).

Los topiles están organizados en grupos de trabajo que se turnan por mes, en cada grupo cada topil se turna por una semana. Cuando son las elecciones de los miembros del cabildo, se consideran a los 40 topiles que hayan prestado su servicio para elegir a los regidores o tex, que quiere decir "plato" ("porque se encargan de servir cuando son las fiestas a todos los que son de Totontepec, los invitados y visitantes, a la banda, y a todos los que participan"). Los regidores deben encabezar los trabajos comunitarios y también los trabajos en las festividades sociales, cívicas y religiosas.

Si bien cada uno de los regidores tiene una actividad, es decir, existe un regidor por cada asunto según los requisitos del Estado: hacienda, educación, deportes, cultura o recreación, salud y obras, esto es sólo de membrete - según las autoridades entrevistadas -, "porque en realidad todos deben entrarle a todos los trabajos, por ejemplo, ahorita todos andan en las obras que se están haciendo de colado y revestimiento. Los regidores se turnan dos por semana (se les llama regidores de semana)". La interrelación entre las funciones de cada cargo giran en 
torno a lo que se llama servicio al pueblo, de esta manera lo expone el presidente municipal (2004):

Aunque los regidores se turnan cuando hay que hacer por ejemplo un colado, todos deben ir para dar el ejemplo a todo el pueblo. Si para una obra se acabó las piedras, todos debemos ir a romper piedras. Los regidores auxilian al sindico, cuando por el caso se tiene que agarrar a alguien, que los topiles por ser menores de edad no pueden, pues van los regidores. También, aunque cada uno, síndico, alcalde y presidente tenemos funciones determinadas, en realidad, si no está uno, el otro debe responder. Cuando el alcalde está solo debe atender a todos, si son cosas particulares como proyectos o gestiones, entonces esperan que llegue el presidente. Cuando son cuestiones de justicia el alcalde interviene en asuntos que no le tocan o que le tocan al síndico, o se dejan hasta que éste llegue si no son urgentes.

De esta manera, puede verse cómo el pueblo y sus autoridades adecuan las exigencias legales del Estado - sobre el tipo de cargos en el ayuntamiento- a las dinámicas propias de la zona (la cabecera y las diez agencias) y a sus necesidades. El siguiente cargo es el de síndico (el que limpia y abre las calles) y es el que se encarga de hacer justicia ("para el Estado es el auxiliar del Ministerio Público"), cuando esto sucede los topiles deben estar presentes para aprender ya que "se están formando".

Para nosotros, el sindico hace la justicia sobre problemas de tierras, riñas, limpieza de las calles, porque además encabeza todas las obras. De seis a ocho de la mañana imparte justicia. En la tarde de seis a nueve de la noche, regresa a hacer justicia, el resto del tiempo está coordinando y trabajando en las obras. Después de las diez de la noche ya nadie puede estar afuera. Por último el sindico junto con los topiles hace un rondín, cerca de las once de la noche se va a dormir. [Presidente Municipal de 2004] 
DiAgRAMA 1

Sistema de Cargos de Totontepec

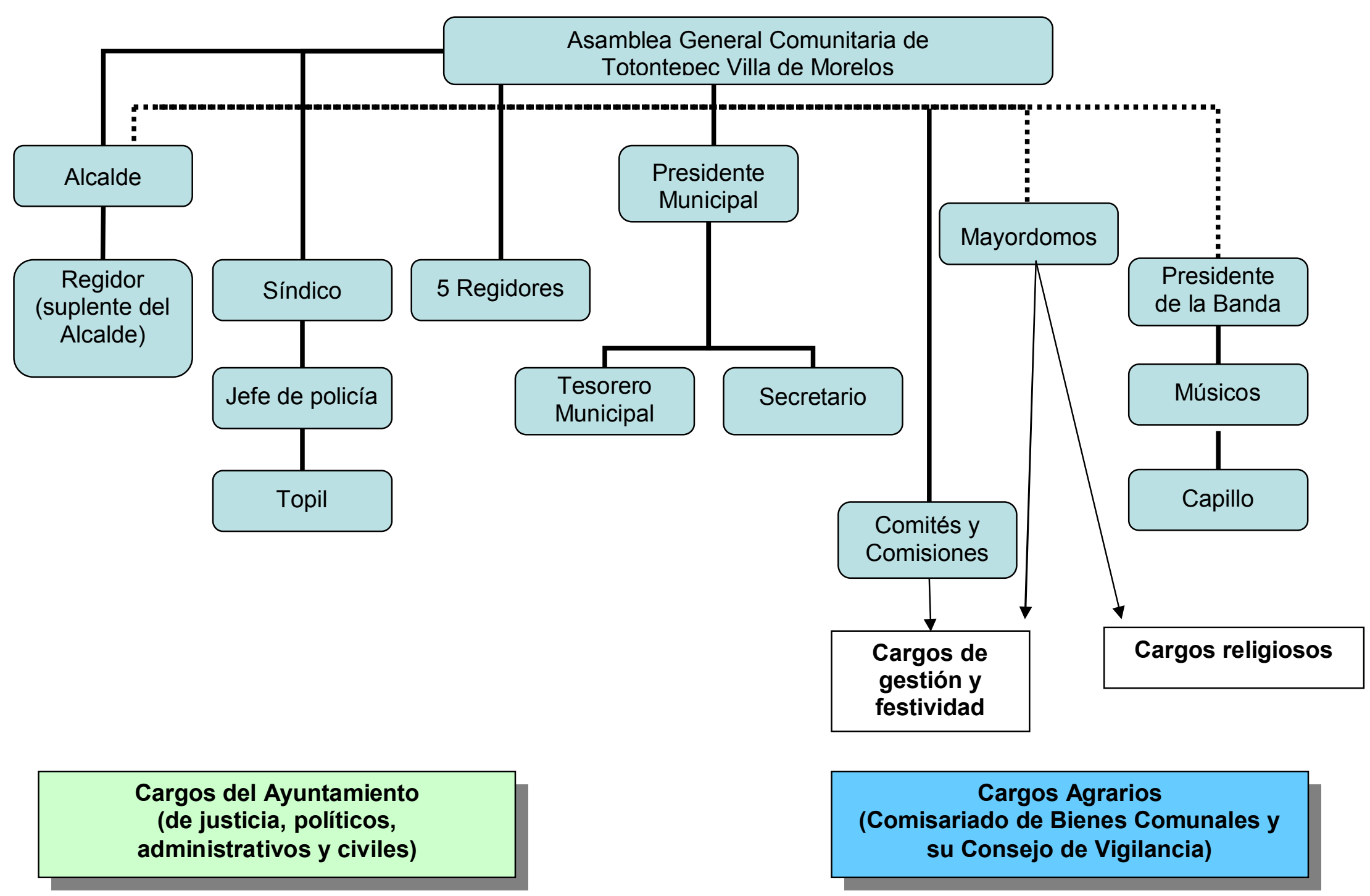


De acuerdo con la información proporcionada por el presidente municipal, existen dos cargos de los que se está discutiendo su incorporación al sistema de cargos, “pues no están completamente reconocidos como servicio, éstos son los de tesorero (contador) y secretario", esto es porque reciben una remuneración simbólica y tienen formación profesional. La discusión resultó porque después la asamblea nombra a las personas que dan estos servicios como regidores, entonces existe malestar en ellas porque sienten que el trabajo que hicieron como contador o secretario no cuenta o "no valió", o bien, se han dado casos que se nombran regidores pero no pasaron por el cargo de tesorero y secretario y los que sí lo hicieron se quejan, "lo que buscamos es que estos cargos valgan igual, es decir, se consideren al mismo nivel que el de regidor, porque de todas formas el pueblo los nombra".

Al cargo del presidente municipal, como se verá más adelante, es considerado la cabeza de la comunidad; le sigue el cargo del alcalde, aunque esto no exime al que lo ha ocupado de seguir participando en otros servicios, como de comité de la escuela, si sus hijos o nietos están ahí (según el alcalde de 2004). El alcalde es el auxiliar del juez que está en Zacatepec.

En lo interno lo llamamos gran bastón ya que cumplió con todos los cargos, es como el consejero, quien da "palabras de sabiduría". El alcalde propone [en el cabildo], cuida la casa [el pueblo], hace justicia, es diferente a lo que hace el síndico, porque los casos que le tocan son materia civil. Por ejemplo, entre matrimonios, él trata de unirlos, que se concilien. También conoce de deudas y de hechos de sangre, lesiones por riñas. Se puede tener sustituto para topil pero no para regidor, sindico, alcalde o presidente municipal. La asamblea no acepta sustituto. [Alcalde de 2004]

Otro ejemplo de cómo los cargos del ayuntamiento tienen relación con el aspecto religioso se da cuando los integrantes del cabildo (autoridades) tienen que conseguir a los mayordomos (para el cuidado de la iglesia o para alguna de las festividades). Así lo señala Alcántara Núñez (2004:40): 
Como son personas voluntarias ya se tienen ciertas referencias aunque no ocurre así todos los años, hay ocasiones en que se debe pensar [por las autoridades] quienes pueden serlo e incluso se debe convencerlos [...] primero se envía a un regidor para verificar si el posible mayordomo se encuentra en su casa [...] Una vez confirmado esto, los doce [cabildo] nos dirigimos a su hogar [...] Cuando se presentó la persona indicada y algunos familiares, ceremoniosamente les ofrecimos el Dios Yakyj. ${ }^{185}$

También en los Días de Muertos o Todos Santos, las autoridades deben encabezar y apoyar en las actividades religiosas, por ejemplo, la iglesia católica en coordinación con el presidente municipal organiza rezos y manda a los niños a las casas a rezar, después por la noche van las autoridades.

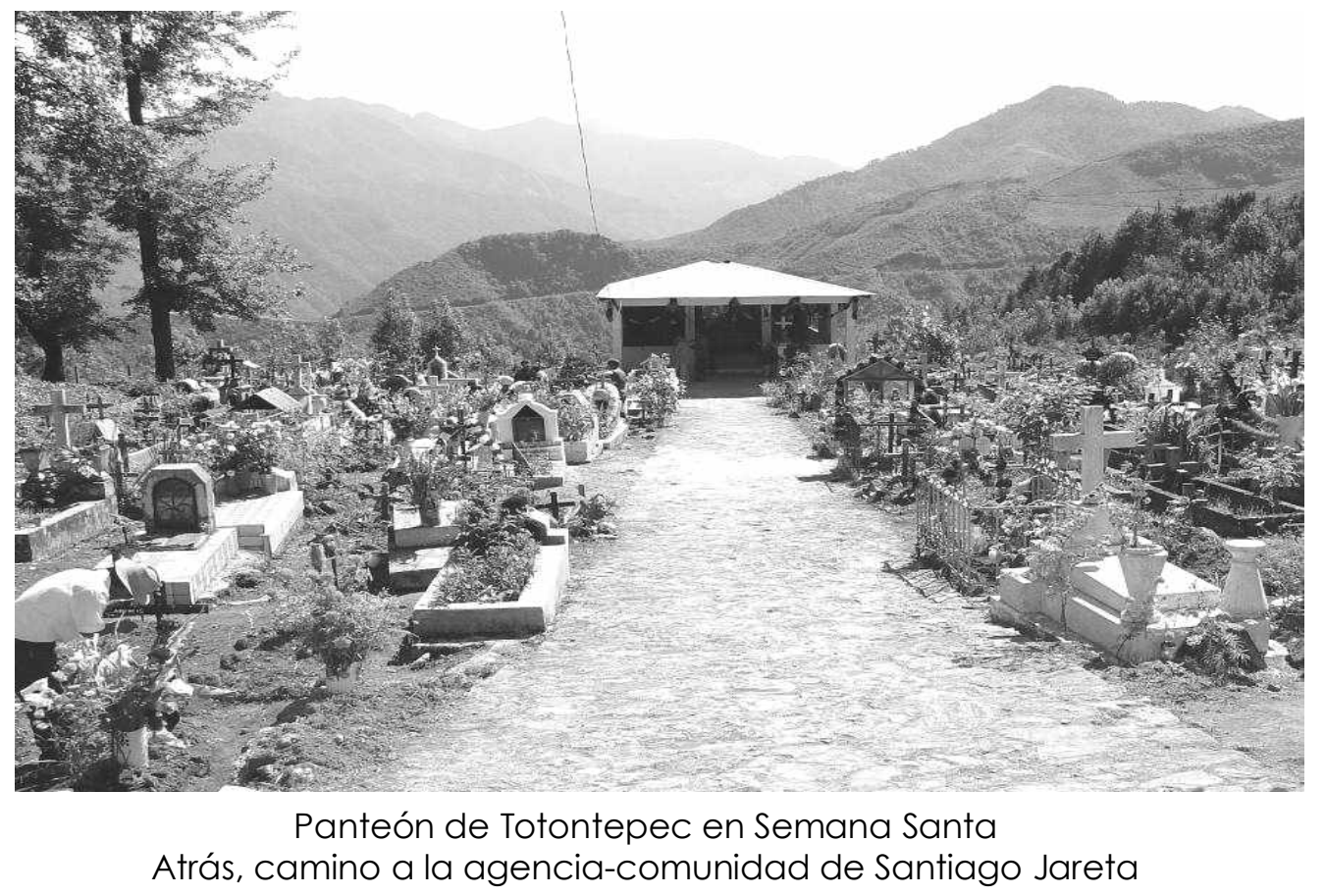

185 Honorio Alcántara Nuñez (2004:37) apunta: “En la comunidad de Anyukojm Totontepec existe una forma especial de saludar que se llama en mixe Dios Yakyj, que traducido literalmente es 'dar a Dios', pero debido a su importancia y profundidad lo hemos llamado 'saludo ritual y ceremonial'. Las personas más aptas para dar este saludo son las autoridades y ancianos de gran respeto y prestigio social, usándolo sólo en ocasiones muy especiales. Cuando es usado por autoridades municipales, en primer lugar es para dar un saludo de bienestar y prosperidad en todos los hogares al inicio de cada año; también es utilizado para solicitar la ayuda persona de algún ciudadano para ocupar cargos en el municipio o en la iglesia, o para colaborar en las fiestas patronales. Cuando los ancianos son los encargados de darlo, es cuando se formaliza una boda, es decir, cuando los papás de la novia y el novio han aceptado ya el compromiso matrimonial". 
El presidente municipal es la cabeza de la comunidad y es el que tiene como obligación realizar gestiones, no sólo para el poblado donde reside la cabecera, sino también para las agencias que integran el municipio. Se encarga de las relaciones intercomunitarias en el campo municipal, sobre todo respecto a las obras públicas y a los recursos económicos provenientes de la federación y del estado.

Los cargos relacionados con el comisariado de bienes comunales están dentro del sistema de cargos, sin embargo, no son escalafonarios, pues no es necesario haber tenido antes un cargo y pueden o no tomarse en cuenta para cumplir otros cargos, dependen exclusivamente de la asamblea de comuneros, mientras los demás dependen de la asamblea general comunitaria (Valdivia 2003:499,503). Existen otros cargos, pero me limito a exponerlos en el DIAGRAMA 1, basado en el trabajo de Valdivia (2003:503) sobre el sistema de cargos en 17 de los 19 municipios de la región mixe. A diferencia del sistema de cargos de Totontepec antes expuesto, en Móctum es necesario haber cumplido en principio el servicio de topil para llegar a ser comisariado o agente, para ser secretario es necesario saber leer y escribir, no es necesario que tenga formación profesional, si bien no recibe un salario se le otorga una remuneración simbólica. Dada la población tan reducida y a que los jóvenes en edad de cumplir un cargo son pocos, pues muchos de ellos migran como sucede en la mayor parte de las comunidades indígenas de Oaxaca, sucede que personas consideradas mayores porque cumplieron todos los cargos del sistema, pueden ser elegidos para otros cargos "más bajos" o anteriores (excepto el de topil) - por lo que se da una especie de reciclaje de los cargos.

Finalmente es importante subrayar que en el caso del cargo de presidente como de alcalde municipal, las personas que son elegidas se consideran padres de la comunidad, a lo que Barabas (2004:347) se refiere de la siguiente manera :

Con frecuencia el lenguaje metafórico alude a las autoridades como "padres" e incluso como "padres-madres" comunales, destacando que deben desempeñarse como reguladores de la vida en ese ámbito doméstico ampliado que es la comunidad. Una característica distintiva 
del sistema es que no se basa en la "representación" sino en la "regulación": los cargueros no son líderes o representantes colectivos, pues no pueden decidir por sus paisanos, especialmente respecto a cuestiones que atañen a la articulación de la comunidad con el medio exterior. Los cargueros contribuyen a que la vida colectiva transite por los cauces del sistema normativo, pero no tienen capacidad delegada por la comunidad para imponer cambios.

Lo anterior clarifica el sentido en el actuar del alcalde de Totontepec para resolver un conflicto o disputa, pues en él se han depositado por la comunidad exigencias y expectativas de cuidar y regular la vida de la colectividad. El significado metafórico que menciona Barabas también deja en claro cómo el alcalde tiene capacidad de convocar a dos partes en conflicto aunque una de ellas de antemano no esté de acuerdo con él como instancia para hacer justicia (véanse los casos sobre el cuestionamiento a la autoridad comunitaria en el CAPítULO 5).

\section{Cargos y servicios en Móctum}

Los pobladores de Móctum organizan la vida comunitaria con base en la definición de cargos identificados con el "servicio y la autoridad". Los cargos son de carácter civil, por el predominio del adventismo - aunque en el templo adventista también se realizan servicios y cargos propios de esta religión.

En el DIAGRAMA 2 podemos observar los cargos que integran el sistema en Móctum, todos ellos asignados y derivados de las decisiones de la asamblea, algunos cargos corresponden a comités formados para responder exigencias de instancias de gobierno o según las necesidades que se presenten por la propia comunidad.

Sólo enunciaré los cargos empezando por los primeros servicios o cargos que la asamblea asigna a una persona, ya sea por su edad o porque es un nuevo integrante aunque sea mayor de edad o de edad avanzada (lo que concuerda con el sistema de cargos en Totontepec), así el último cargo es el de mayor responsabilidad o jerarquía. 
El servicio empieza a partir de los 16 años de edad, cuando se considera que los hombres y mujeres están listos para cumplir sus obligaciones y ejercer sus derechos de comuneros. En ninguno de los cargos hay suplentes, primero, porque son pocos los habitantes de Móctum en edad de realizar cargos y, segundo, porque se toma en cuenta la trayectoria personal. Todos duran un año, excepto el cargo del comisariado de bienes comunales que es de tres años.

Cuando un hombre o una mujer cumple los 16 años de edad el agente, a solicitud del comisariado ${ }^{186}$ o por su propia iniciativa, los llama y les señala sus obligaciones.

Al igual que en Móctum en Totontepec las mujeres también hacen cargos aunque en ninguno de los dos se han elegido mujeres como topil ni para los cargos mayores (comisariado de bienes comunales, agente, síndico, etc.). En Móctum sólo existen dos cargos para las mujeres: promotora de salud y encargada de la tienda. En Totontepec: comité de la clínica, comité del DIF, promotoras y molino. En

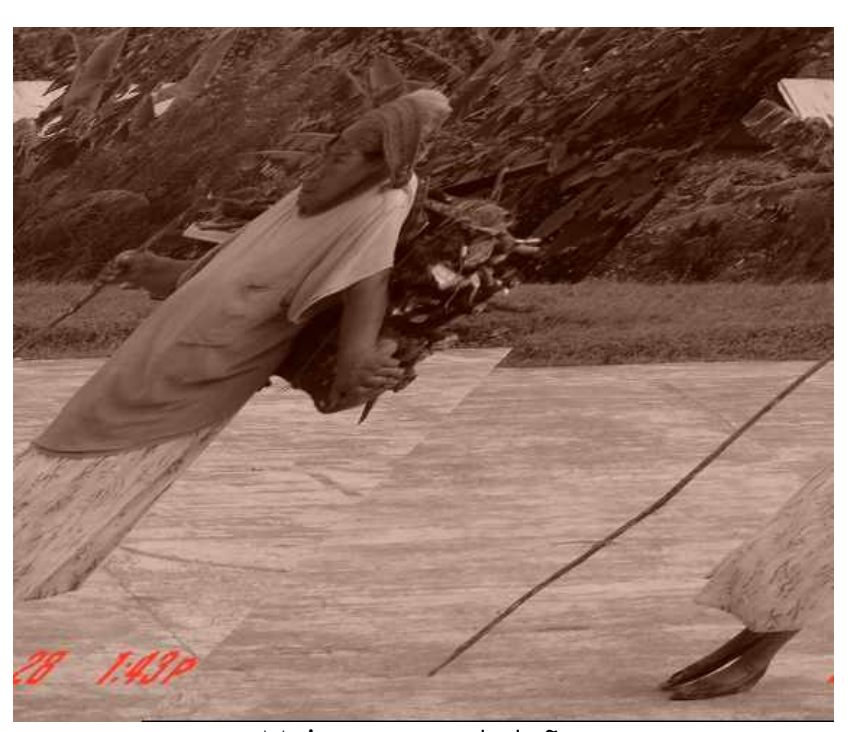

Mujer cargando leña,

atravesando la cancha de basketball de Móctum
Móctum el molino es del grupo de "Mujeres Olvidadas del Rincón Mixe", ya que las autoridades de la época cuando se tramitó no apoyaron que se consiguiera y más bien dejaron la responsabilidad en las mujeres. $\mathrm{Al}$ parecer en Totontepec el molino se consiguió a través de la autoridad municipal por eso se integra como cargo para las mujeres.

186 En algunos casos se utiliza para referirse más al Presidente del Comisariado de Bienes Comunales que al colectivo, pues aquél representa al órgano colegiado del Comisariado de Bienes Comunales. 


\section{LOS CARGOS EN SAN MARCOS MÓCTUM}

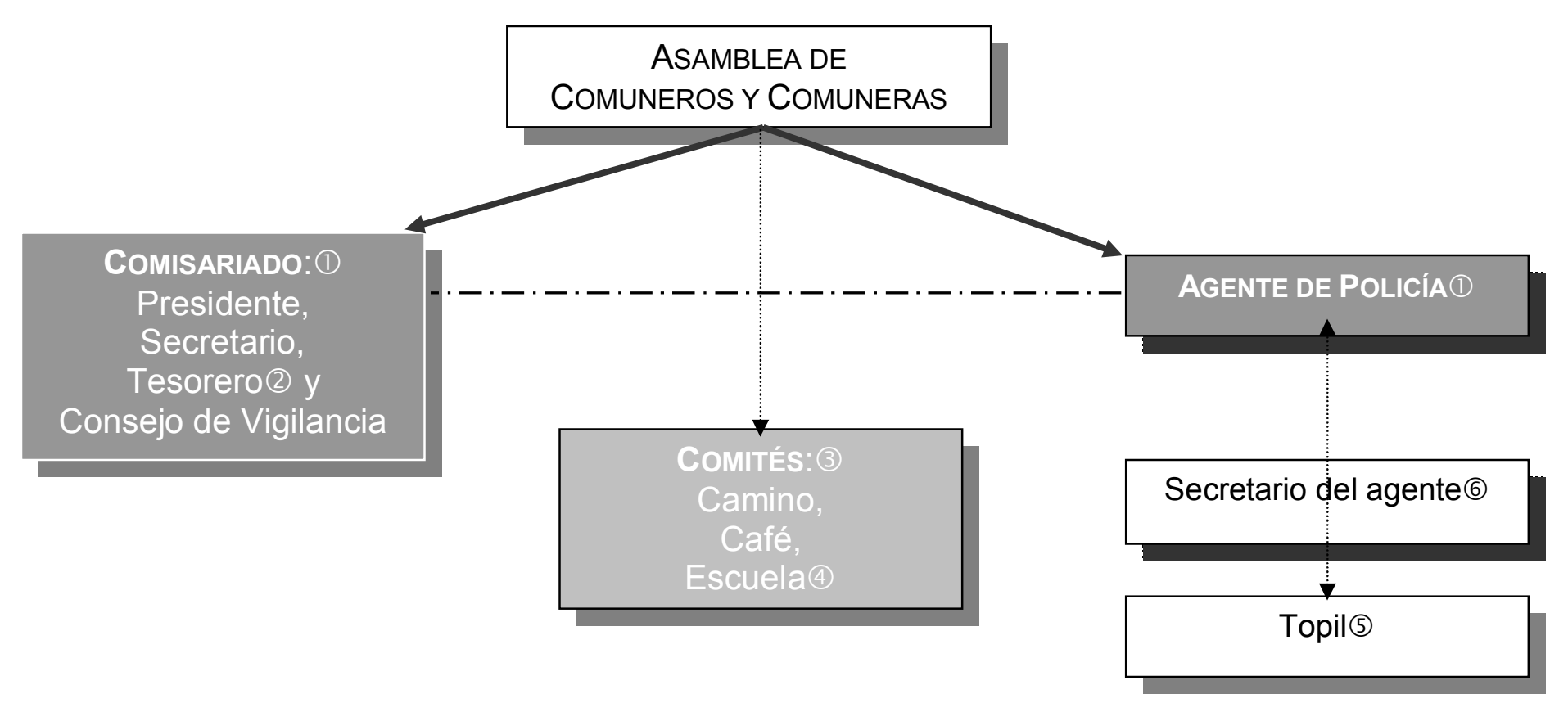

Cargos agrarios

(1) Cargos superiores o más importantes "de sello".

(2) El secretario y tesorero son ayudantes del presidente del comisariado.

(3) Secretarios y tesoreros de cada comité ayudan al presidente respectivo.

(4) Este comité es nombrado por los padres de familia.

(5) Cargo de iniciación, asignado por la asamblea, depende del agente.

(6) Asignado por el Agente, sólo depende de él. 
El topil ${ }^{187}$ es el primero de los cargos, por lo que los hombres que ingresan al sistema deben empezar a cumplir sus obligaciones como topiles aunque no trabajen "su" tierra - pues los niños desde los diez años de edad o menos, acompañan a su papá a trabajar la tierra y le ayudan a sembrar o a cosechar-. El ser topil les da la oportunidad a los jóvenes de ser considerados a futuro para usar la tierra de la comunidad y con eso sostener a su futura familia, o bien recibir un pedazo de terreno como solar para construir su casa independiente a la de sus padres. ${ }^{188}$ Si un joven está estudiando, esto lo exime de ser topil - la mayoría sólo estudia la primaria, por lo que después se espera que se integre al sistema de cargos como topil, a menos que siga estudiando y así lo compruebe para eximirlo de realizar servicios-. Por ejemplo, el caso de un joven músico que a muy temprana edad salió de Móctum para estudiar música en Zoogocho, comunidad indígena zapoteca; se casa en Móctum con una mujer de otra comunidad y pretende regresar para radicar en Móctum, sin embargo, durante el tiempo que se fue no respondió a la comunidad, pues no hizo tequio ni cumplió con cargos. Según su padre, el muchacho estaba estudiando por lo que no podía asumir sus responsabilidades como topil, ni tampoco dar aportaciones económicas a la comunidad; para algunas personas - sobre todo los que tienen más influencia en el templo adventista - esto no es significativo pues argumentan que varias personas

187 De acuerdo con el planteamiento de Victor Turner (1993:518) sobre el estado liminal y la comunitas, el estatus previo a ser topil es ser "hijo de familia", el o la menor de 16 años de edad es considerado todavía un niño o niña que depende de una cabeza de familia (en la mayoría de los casos es hombre, aunque no siempre; puede ser su familiar por afinidad o consanguinidad y que en la comunidad tiene estatus de comunero y, por tanto, un cargo superior al de topil) que tiene toda la autoridad y responsabilidad sobre él/ella. El limen o fase del umbral es la situación del joven como topil; la reagrupación del individuo en un nuevo estatus sería su estado de comunero, con plenos derechos pero además con reconocimiento moral de su trayectoria en la comunidad. En efecto, la etapa del ser topil, prepara al sujeto para formarlo como parte de la comunidad y para que él reafirme su voluntad de ser parte de ella.

188 El topil es el ayudante del agente y del secretario del agente de policía, hace mandados y lleva recados que tengan que ver con las funciones de la agencia, trae a las personas que están citadas, o a las que se manda a aprehender, a veces debe hacer labor de limpieza en la oficina de la agencia, como son cuatro jóvenes, cada uno se turna una semana para estar de guardia en la agencia y cuando el agente los necesite. Los topiles son siempre hombres de 16 años o más, se dice que antes empezaban a los 13 años de edad pues había pocos habitantes. 
que se han ido, incluso fuera de la región y del país, han enviado sus aportaciones y han respondido a los cargos.

Vale decir que los cargos que se consideran de mayor responsabilidad o jerarquía son aquellos que corresponden al tipo de trabajo como es la gestión y manejo de recursos, hacer justicia y la representación del pueblo para hablar en su nombre ante distintas instancias federales y estatales. Para este fin se utiliza un sello el cual queda impreso en sus escritos. A este tipo de cargos la gente los conoce o llama como "cargos de sello". ${ }^{189}$

El cargo de topil no entra en la categoría de los "cargos de sello", es un cargo en el que la asamblea puede nombrar nuevamente a un joven como topil aunque ya haya cumplido con el cargo. Se podría decir que es tomado en cuenta (se le reconocen derechos y sobre todo se le imponen obligaciones) pero que todavía no tiene el mismo peso — ex experiencia y frente a los demás—, que los que ya han pasado por los "cargos de sello" o bien, más aún, por todos los cargos.

El hecho de que algunos cargos son de sello ha coincidido con su importancia o jerarquía, pues si no tienen sello deben solicitarle al agente o al presidente del comisariado que selle los escritos que se hagan. El valor simbólico del sello si bien es un producto del derecho colonial y republicano ha sido adoptado tanto en Móctum como en Totontepec. Esta importancia queda plasmada en palabras del Alcalde Único Constitucional de Totontepec: “este documento [mostrándome un acta de acuerdo elaborada por él y firmada por las partes en un caso] vale, tiene sello, no lo ha hecho cualquiera, si no tuviera [sello], podrían decir que no vale, que otro lo hizo, pero tiene sello". 190 Sin embargo, aunque el cargo de topil no es de sello es uno de los más importantes ya que tiene la importancia de

189 Finalmente y a manera de reflexión, podemos decir que los cargos de sello se dan en la medida en que tienen un valor de importancia para la comunidad, es decir, que le significan un beneficio - sobre todo material - , pero también responsabilidades, por ejemplo, en la solicitud de créditos.

190 En 2006 durante el conflicto magisterial que exigía rezonificación y la renuncia del gobernador Ulises Ruiz, según Noemí Gómez, las autoridades de Totontepec recibieron un escrito donde se les invitaba a ellos y a su pueblo a participar en la marcha pacífica a favor del gobernador, sin embargo, no llevaba sello por lo que argumentaron "no trae sello, no sabemos si es del gobierno o no, entonces nadie va". 
introducir a los jóvenes y a los avecindados —que solicitan vivir en la comunidad y tener derechos - en el sistema de cargos y, por tanto, en la organización interna.

En el siguiente nivel están varios comités, con varios servicios y cargos: comité de la escuela (vocales, secretario, tesorero) y después el de presidente de padres de familia de la escuela, así como otros comités que se integran por funciones diversas. En un tercer nivel están los cargos de ayudantía a la agencia de policía y al comisariado de bienes comunales: secretario y tesorero del agente $y$, secretario y tesorero del consejo de vigilancia del comisariado de bienes comunales (tampoco son "cargos de sello"). Por último, en el cuarto nivel encontramos los cargos de presidente del comisariado de bienes comunales y el de agente de policía. Éstos son los "cargos de sello". El cargo de agente es de los cargos más importantes porque es el que ejecuta la mayor parte de las decisiones de la asamblea y mantiene la relación con la cabecera municipal además que organiza los trabajos colectivos de los ciudadanos. El agente es el equivalente del agente de policía en Móctum, pues éste hace justicia. Las personas que llegan a este nivel tienen en promedio entre 25 (si están casados) y 50 años de edad. Este cargo, como todos los demás, es asignado por la asamblea según el derecho en la comunidad, pero requiere además de la ratificación del presidente municipal — según el derecho positivo.

En suma, el sistema de cargos es la parte medular de la organización social, política y cultural tanto de Totontepec como de Móctum como campos sociales semiautónomos. En el sistema confluyen mecanismos, procedimientos y normas de incorporación de nuevos miembros o de cambio de estatus para los ya existentes - como el topil y los hombres de más edad o mayores, como dos extremos en el sistema-; de esta manera las normas incluyen requisitos para aceptar a una persona en la comunidad, para que exprese su voluntad de integrarse a ella consintiendo o expresando su acuerdo sobre las normas o reglas y formas de organización para resolver conflictos, para mantenerla, para cambiar su estatus de hijo de comunero a comunero con plenos derechos, entre otros. 
De igual forma, en el sistema de cargos se puede observar y dar cuenta de la imbricación de los sistemas jurídicos —el del estado y el comunitario-. En una escala amplia el sistema jurídico indígena no es distinguido en su especificidad, sino sólo como parte del sistema jurídico mexicano, es decir, como uno de sus niveles. En una escala menos amplia pero más detallada, se observa que el sistema jurídico indígena existe $-\mathrm{y}$ tiene una simbología distinta - y puede ser visto como mapa (tomando esto como una metáfora) con sus características y simbología, distintas del sistema jurídico mexicano. Esto es claro, cuando en el ejemplo de Totontepec las autoridades saben que el cargo que ocupan tiene funciones especifícas señaladas por el derecho mexicano y como tales son reconocidos por éste, pero también existe una dinámica social y cultural a la cual deben responder y por la que sus funciones se adecuan y diversifican. La imbricación de sistemas jurídicos como mapas se observa en el discurso de las autoridades mismas, cuando se reconocen como parte del aparato del Estado pero a la vez como autoridades independientes de él, por ejemplo cuando el Alcalde Único Constitucional de Totontepec señala por un lado "yo soy auxiliar del juez de Distrito" y por otro "él no conoce a mi gente, si él sabe que venga a ser justicia, por algo la asamblea me eligió como autoridad". Esta imbricación de referentes legales en el discurso de los actores también se observa en el caso de Móctum que se reconoce independiente de Totontepec, pero a la vez sus autoridades y miembros reconocen que ahí se encuentra una instancia de justicia superior a las que se acude en caso de que en la comunidad no se pueda llegar a un acuerdo sobre un conflicto o disputa local.

\section{Móctum y Totontepec: Dos formas de sistema de cargos}

El sistema de cargos es una expresión del dinamismo de las comunidades indígenas y su derecho (interno o comunitario), por ello, no se puede decir que exista un modelo de sistema de cargos prototípico para los mixes, dada su diversidad cultural. El caso de estudio es un ejemplo de esto, donde estamos ante unidades políticas con puntos de convergencia pero con características distintas. 
Si se observan los diagramas presentados antes, la estructura de cargos en ambos poblados, se puede concluir que si bien el sistema existe en ambas comunidades, tienen diferentes formas de componerse y funcionar, esto de acuerdo a las necesidades de la población, a los procesos históricos, políticos y sociales de las comunidades, así como al estatus mismo de éstas, es decir, si son cabeceras o agencias.

Por ejemplo, en Móctum el comisariado de bienes comunales forma parte del sistema y es un cargo igualmente importante que el de agente, por lo menos hasta antes de finiquitado el conflicto agrario (1999), en cambio en Totontepec no se incluye y más bien los cargos municipales son más afines al sistema de cargos donde también están los cargos religiosos asociados a la iglesia católica -a diferencia de Móctum. ${ }^{191}$

En Móctum el cargo de comisariado, como lo expuse, es un cargo de gran responsabilidad y aparece en el diagrama al mismo nivel que el cargo de agente, sin embargo, la resolución del conflicto agrario así como el surgimiento de otras fuentes económicas, está provocando hoy en día que la cuestión agraria pierda peso como estructuradora del sistema normativo. Seguramente esto propiciará que las normas que se empiecen a formular referirán otro tipo de asuntos, como es el hecho mismo de la migración, sin que pierda su importancia la tierra y el territorio como espacio de reproducción cultural y de aplicación del derecho (como se apuntó en la conclusión del CAPítULO 4).

191 En el caso de Móctum (Diagrama 2), se puede observar que los cargos religiosos o vinculados a la iglesia católica o adventista tampoco se consideran dentro del sistema de cargos. Un ejemplo, de que los cargos religiosos (adventistas o católicos) están separados de la estructura civil, es el hecho de que a finales de 2004 Noemí Gómez Bravo pidió al agente de policía de Móctum convocara a los señores principales (líderes morales) para pedirles permiso para presentar su libro La Antigua Grandeza de Móctum en la comunidad. Estos líderes son personas, que sin distingo de su preferencia religiosa (son católicos y adventistas), se han caracterizado por su participación en los cargos y servicios a la comunidad y, sobre todo, por su intervención activa para resolver el conflicto agrario con Totontepec. Aceptaron escuchar a Noemí Gómez, le expusieron sus opiniones y le plantearon la necesidad de escribir la historia del conflicto. Después de todo, Noemí Gómez presentó su libro (asistiendo sobre todo mujeres y niños), los principales no han insistido sobre su planteamiento, lo que no descarta que después la llamen para cumplir. 
Tal situación se vuelve significativa cuando se comenta por algunos que las autoridades actuales no son muy competentes, pero como ya no hay tanto que gestionar y sobre todo, el problema de la tierra ya está resuelto "lo que viene ya no es tan importante". 192

\subsection{Influencias del derecho estatal en la configuración del derecho en la comunidad}

El reglamento interno es uno de los aspectos en los que se permite observar las dinámicas jurídicas de Móctum como campo semiautónomo, porque el establecimiento de cada norma revela los recursos y aspectos relevantes sobre los que la comunidad, autoridades y líderes están preocupados de controlar. Desde la Ley Federal de Reforma Agraria, ejidos y comunidades estaban obligados a regular su funcionamiento a través de un Reglamento Interno que debía registrarse en el Registro Agrario Nacional (RAN), sin embargo, muchos núcleos agrarios no contaban con él. Con las modificaciones de 1992 al ARTículo 27 Constitucional en materia de ejidos y comunidades agrarias, esa obligación no cambió aunque la "obligatoriedad" de contar con un reglamento se hizo más imperativa a propósito del llamado PROCEDE (Programa de Certificación de Derechos Ejidales y Titulación de Solares Urbanos), pues el reglamento de la Ley Agraria en esta materia señala como requisito indispensable que los núcleos agrarios que se integran al programa deben contar con su Reglamento Interno entre otros documentos. ${ }^{193}$

192 Esta expresión guarda cierto sentido de disminución o menosprecio de las tareas de la autoridad y quizá de su legitimidad (Swartz, Turner y Tuden 1994) pues las expectativas de la población sobre el actuar y la importancia del quehacer del cargo de Comisariado ha disminuido, lo que trae aparejado que los pobladores no lo tomen en cuenta o bien que se consideren que puede ser fácilmente manipulable por los que sean más fuertes económica o políticamente (Cruz 2005). Sin embargo, el Comisariado sigue siendo un nivel del sistema de cargos importante para el cual se sigue llamando a las personas para ejercer servicio voluntario.

193 Sin embargo, podría entenderse que el requisito de tener un reglamento interno/estatuto comunal es más una opción que una obligación, pues en caso de no existir se aplicará la Ley Agraria, es decir, cuando surja algún problema o asunto al interior del núcleo agrario, y a falta de reglamento o estatuto, la autoridad interna o representante se auxiliará o aplicará la Ley Agraria o sus usos y costumbres. Cuando el asunto o problema llegué a los Tribunales Agrarios y a falta de reglamento (ejidos) o estatuto (comunidades), los jueces atenderán lo que diga la Ley Agraria, y en caso de comunidades indígenas además sus usos y costumbres. Pese a lo anterior, la Ley Agraria 
Desde la perspectiva del derecho positivo mexicano — según la Ley Agraria del 26 de febrero de 1992 — ${ }^{194}$ se conoce como reglamento interno — para el caso de los núcleos agrarios ejidales - o estatuto comunal — para los núcleos agrarios de bienes comunales o comunidades - al conjunto de reglas escritas que se refieren a distintos temas como: derechos de ejidatarios y/o comuneros, delimitación y aprovechamiento de las tierras, derechos de los avecindados (si los hubiera), formas de organización, etc. Tanto uno como el otro tienen que estar registrados en el Registro Agrario Nacional, y los ejidatarios o comuneros u otras personas (según sea el caso) deben cumplirlo siempre y cuando ese Reglamento no contradiga la Ley Agraria -esto, desde la lógica jurídica del derecho positivo mexicano, ARTículos 10 y 107 de la Ley Agraria. ${ }^{195}$

Como se había apuntado, la necesidad de contar con normas escritas ha sido parte de una exigencia del Estado, pero también las comunidades indígenas lo han retomado como una manera de defender sus derechos a tener una forma de organización interna propia y a un sistema de justicia basado en los usos y costumbres - el caso de Móctum como de otros poblados es representativo de estos procesos.

\subsubsection{Dos lógicas jurídicas imbricadas}

En el ejercicio de mostrar la norma escrita, se corre el riesgo de no reconocer su dinamismo por lo que resulta necesario abordar las prácticas de justicia para

menciona aspectos que no regula, para ello remite al reglamento o estatuto, en donde deben regularse por la comunidad de acuerdo a sus circunstancias.

194 Diario Oficial de la Federación (DOF) del 26 de febrero de 1992.

195 “ARTículo 10.- Los ejidos operan de acuerdo con su reglamento interno, sin más limitaciones en sus actividades que las que dispone la ley. Su reglamento se inscribirá en el Registro Agrario Nacional, y deberá contener las bases generales para la organización económica y social del ejido que se adopten libremente, los requisitos para admitir nuevos ejidatarios, las reglas para el aprovechamiento de las tierras de uso común, así como las demás disposiciones que conforme a esta ley deban ser incluidas en el reglamento y las demás que cada ejido considere pertinentes. [...] ARTículo 107.- Son aplicables a las comunidades todas las disposiciones que para los ejidos prevé esta ley, en lo que no contravengan lo dispuesto en este Capítulo [De las comunidades, Atículos 98 a 107]. [...] ARTículo 99.- Los efectos jurídicos del reconocimiento de la comunidad son: IV. Los derechos y las obligaciones de los comuneros conforme a la ley y el estatuto comunal". 
observar cómo se actualizan. En el caso que ahora se aborda, se puede destacar que la simple trascripción de la norma no representa las dinámicas sociales y usos del derecho y del poder, esta descontextualización de la norma hace difícil comprender las razones y motivos involucrados en su redacción. Pese a esto, es interesante destacar que en el Estatuto Comunal de Móctum (en 1995) quedaron plasmadas las normas de la expulsión de comuneros y la de privación o suspensión de derechos, aun cuando éstas, en el sistema jurídico mexicano, pueden considerarse violatorias de derechos humanos, pese a que fue un agente del Estado quien estuvo presente en la redacción del documento final.

Como se ha apuntado, el reglamento interno o estatuto comunal es un ejemplo palpable de la influencia del derecho mexicano en la dinámica interna de la comunidad y su sistema jurídico. Con la finalidad de observar esta influencia a continuación expongo a grandes rasgos el capitulado y contenido del reglamento interno de Móctum que fue elaborado con la intervención de un representante de la Promotoría Agraria de la Secretaría de la Reforma Agraria. Este documento resultó de una actualización realizada el 26 de agosto de 1995 después de que se declara finiquitado el conflicto agrario entre Móctum y Totontepec, aunque fue hasta 1999 que se consideró del todo resuelto. En esa fecha los comuneros de Móctum aprobaron la "actualización"196 de su Estatuto Comunal,197 en el cual

196 Primera hoja supra, parte inicial. Aunque se dice actualización, nadie de los que fueron y son autoridades pudo darme razón de un anterior estatuto. El párrafo introductorio del estatuto comunal señala: ACTUALIZACIÓN DEL ESTATUTO COMUNAL DEL POBLADO DENOMINADO SAN MARCOS MÓCTUM, MUNICIPIO DE Totontepec VILLA DE MORELOS, DISTRITO DE SANTIAGO Zacatepec MIXE, ESTADO DE OAXACA, EN ASAMBLEA GENERAL DE COMUNEROS CELEBRADA POR PRIMERA CONVOCATORIA DEL DÍA 26 DE AGOSTO DE 1995.

197 El estatuto comunal cuenta de cinco páginas tamaño oficio, cada una de ellas presenta cuatro sellos: "Comisariado de Bienes Comunales", "Consejo de Vigilancia" y "Agencia de policía" de San Marcos Móctum, y de la Secretaría de la Reforma Agraria (SRA) "Promotoría Agraria, Mixe, Oax." (No tiene número de folio o de registro en el Registro Agrario Nacional). Se compone de cuarenta artículos numerados con números arábigos y tres capítulos titulados y señalados con números romanos, así como una parte de artículos transitorios marcados con números ordinarios en letras mayúsculas. 
señalaron algunos derechos y obligaciones. ${ }^{198}$

\section{Capitulado del estatuto comunal}

El CAPÍtulo i de DisPOSICIONES GENERALES, contiene seis Artículos del 01 al 06, de los cuales son de destacarse el 01, 03 y el 06. El ArTículo 01 señala la necesidad de aplicar el derecho estatal según su nivel jerárquico:

ARTíCULO 01.- En lo no previsto en este (estatuto comunal) se aplicará supletoriamente en la siguiente base, en su caso la carta magna, el código penal del Estado Libre y Soberano de Oaxaca, y la Ley Reglamentaria, es decir, la Nueva Legislación Agraria.

Visto desde un análisis del poder, en este artículo se muestra cómo el derecho estatal se sobrepone y sus agentes se encargan de que impere sobre cualquier otra forma de derecho. En el ARTículo 03 se describe a la comunidad de Móctum, sus características agrarias geográficas y categoría política y, en el ARTículo 06 se señala que el compromiso que contraen los comuneros es luchar por conservar su condición de bienes comunales.

\section{Capítulo II de los comuneros}

Consta de ocho ARTículos del 07 al 14, en éstos se señalan algunos de los derechos de los comuneros así como sus obligaciones, por ejemplo, cómo las mujeres pueden ser comuneras, la edad máxima para ser comunero, los requisitos para ocupar "cargos mayores", la pérdida de la calidad de comunero y los casos de expulsión - si bien la Ley Agraria habla de separación.

198 Es importante precisar que existe otro estatuto comunal aprobado por la Asamblea de comuneros de Móctum, del 9 de septiembre de 1998, sin embargo, cuando yo empecé a investigar el estatuto, las autoridades no tenían copia y sólo me entregaron el documento que es objeto de análisis en esta tesis. Sabía que con PROCEDE el estatuto debía inscribirse en el Registro Agrario Nacional (RAN) por lo que mi intención fue cotejar el que yo tenía y el que quedó inscrito para saber si era el mismo. Sin embargo, desde enero de 1999 lo solicité a la delegación del RAN en Oaxaca y me dieron largas. En septiembre del 2003, y a duras penas (pagando los respectivos derechos en el banco, y esperando varios meses) conseguí copia certificada de la carpeta básica, así como del estatuto comunal registrado. 


\section{Capítulo III de los órganos internos de la comunidad}

Se integra de 26 ARTículos del 15 al 40, en los que se señalan los órganos de representación de Móctum así como sus funciones (15 al 22 y del 32 a 34). Sin embargo, no se menciona al agente de policía aunque en el ARTículo 16 se señala que los comuneros se coordinarán con la autoridad municipal para las gestiones relacionadas con los servicios comunitarios.

Este capítulo es el más extenso de todos, pues a pesar de su título también se señalan sanciones (23 a 31) que posteriormente comentaré. Si se asumiera una postura estrictamente legalista, según el derecho estatal, hubiera sido conveniente un capítulo de sanciones. También se menciona otros derechos de la comunidad y de los comuneros $(36,37,39)$ así como una solicitud-compromiso de la comunidad frente a la Promotoría Agraria para recibir su orientación, ${ }^{199}$ lo que también muestra el afán de control del Estado a través de sus agentes.

\section{Un compromiso con la Secretaría de la Reforma Agraria}

Ese afán de control del Estado sobre las dinámicas comunitarias es una constante que se expresa a lo largo del estatuto. En este sentido, lo que a continuación se asienta en el estatuto comunal es convincente, pues acudir o no a las instancias de gobierno es una potestad o derecho y no una obligación de los núcleos agrarios, más si es sólo por asesorías.

ARTículo 40.- La Asamblea general de comuneros pide y manifiesta de que cuando se tenga algún caso que sea tratado en una Asamblea se pida orientación necesaria de la Coordinación de la Secretaría de la Reforma Agraria o en su caso a la Promotoría Agraria, a efecto de realizar la orientación correspondiente y sean aclarados todas las dudas.

199 En 1992 entra en vigor la nueva Ley Agraria, en la cual se establecía la creación de la Procuraduría Agraria (PA), a la cual, en lugar de la SRA, le toca asesorar y orientar a los sujetos agrarios o campesinos. Así cuando se elabora este estatuto comunal ya existía la PA y la sRA se estaba descentralizando, incluso se impulsó el retiro voluntario para sus funcionarios, por lo que desde otro punto de vista, muchos trabajadores (sobre todo los de la estructura territorial o de campo) se dedicaron a tratar de asegurar su trabajo, o bien aprovechar todos los medios para que los campesinos los siguieran requiriendo. 
Es importante comentar que en la fecha que resultó este estatuto, por ley la Secretaría de la Reforma Agraria ya no tenía obligación ni facultad de elaborar el estatuto o prestar asesoría para ello, en todo caso le corresponde a la Procuraduría Agraria, siempre y cuando lo solicite el núcleo agrario comunidad o ejido (Artículos 135 y 136 de la Ley Agraria).

Por lo demás en este CAPítUlo III, se señalan aspectos que la Ley Agraria marca y que lo único que se hace en el estatuto comunal es transcribirlos con algunas modificaciones.

\section{TRANSITORIOS}

Son tres los artículos en este capítulo y se refieren a la vigencia del estatuto comunal, es decir, desde qué fecha empieza a ser obligatorio o a aplicarse, así como la obligación del comisariado de hacer los trámites para que el estatuto se inscriba en el Registro Agrario Nacional (RAN), y el "derecho irrenunciable" de la Asamblea para modificarlo.

Hasta aquí se ha expuesto el contenido del estatuto comunal de Móctum, a continuación se exponen algunos artículos sobre los derechos y obligaciones de los comuneros, sistema de cargos, privación de derechos y expulsión, con la intención de mostrar los aspectos y normas relevantes para la comunidad y, cómo a pesar de la influencia del sistema jurídico mexicano, prevaleció en cierta medida una lógica jurídica comunitaria en este Estatuto Comunal, elaborado con anterioridad al PROCEDE.

\section{Derechos y obligaciones de los comuneros}

En el ARTículo 08, se señalan los derechos de los comuneros y prácticamente se apunta lo que la Ley Agraria señala:

a) ejercer plenamente o trasmitir en los términos que la Ley establece sus derechos sobre la parcela comunal o solar urbano, b) participar de los servicios, concesiones y permisos obtenidos por la comunidad; c) recibir de la comunidad, al alcance de sus posibilidades, 
apoyo para desarrollar sus actividades productivas; d) participar con voz y voto en las asambleas de la comunidad. ${ }^{200}$

En cuanto a las obligaciones de los comuneros se menciona en el Estatuto Comunal:

ARTículo 09.- Cumplir cabalmente las disposiciones de lo dispuesto en el estatuto comunal y los acuerdos que surjan de las asambleas de la comunidad. Acudir puntualmente a las asambleas y participar activamente en todas las actividades de la comunidad. Aportar su colaboración o tequio en los trabajos y obras de beneficio comunitario en las condiciones aprobadas por la Asamblea General. Desempeñar con responsabilidad de las comisiones y servicios encomendadas por la asamblea general de comuneros. Para abrir brechas o colindancias del bien comunal, es obligación de los comuneros y comuneras que aparecen en la lista. Para mujeres comuneras tendrán la obligación de aportar dinero de acuerdo a los días que trabajen los comuneros.

Es de destacarse que se habla de las comuneras, sin embargo, si se toma en cuenta que el estatuto comunal es de 1995 y el reconocimiento de derechos a las mujeres fue en 1999, este artículo se refiere a las viudas que heredaron el derecho de sus maridos fallecidos. Por ello, la lucha por ser reconocidas como comuneras por las mujeres jóvenes solteras y sus madres, se contrapuso al acuerdo tomado por los hombres y otras mujeres de obligarlas a no casarse con hombres de fuera o dejar Móctum. Esto es un aspecto importante pues después de unirse y lograr un molino de nixtamal, las mujeres del grupo "Mujeres Olvidadas del Rincón Mixe" organizaron talleres de capacitación y difusión sobre sus derechos, por lo que con ello lograron que formalmente se les diera la opción de decidir ser comuneras o no.

En cuanto a la integración de una persona como comunero, se establece en el “ARTículo 10.- La obligación de los comuneros es a partir de los 16 años para los hombres, y para las mujeres, si desea tener derechos, aportará su cooperación

200 En cuanto al inciso a) de este artículo del estatuto comunal, en la Ley Agraria se establece: “ARTículo 17.- El ejidatario tiene la facultad de designar a quien deba sucederle en sus derechos sobre la parcela y en los demás inherentes a su calidad de ejidatario". 
económica de comuneros, por si lo desea". Sin embargo, no se señala si se refieren a las mujeres solteras, casadas o viudas, pero se podría entender que es optativo para ellas ser o no ser comuneras, en cambio para los hombres es obligatorio si quieren mantener a su familia en la comunidad. ${ }^{201}$

\section{Sistema de cargos}

Lo que se señala en el siguiente artículo del estatuto comunal es por un lado, una alusión al sistema de cargos y, por otro, la excepción para los estudiantes de no cumplir con cargos y servicios cuando llegan a la edad de 16 años. Es decir, se suspende temporalmente el riesgo de ser multado o, peor aún, expulsado de la comunidad por no cumplir. Así, en el ARTícUlo 11, se señala:

En el caso de los hijos de los comuneros de 16 años, que estén estudiando hasta la educación secundaria no se tomará por negligencia y presentará su constancia de estudios, de acuerdo al ARTíCULO $3^{\circ}$ de la Constitución Política de los Estados Unidos Mexicanos.

Esta alusión al sistema de cargos está explícita en el siguiente artículo, en el que además se aborda la jerarquía que debe seguirse.

ARTículo 12.- Para llegar a ocupar cargos mayores, se empezará desde los cargos más pequeños, como topil y vocal de la escuela, hasta llegar a los puestos más grandes de esta comunidad.

Sin embargo, lo que expuse sobre el sistema de cargos - en 6.1.3 - no se expresa en su amplitud en esta norma escrita, lo que evidencia sus límites.

\section{Privación de derechos}

En el ARTículo 13, se señala:

Los comuneros pierden su calidad como tal, por cesión, renuncia o prescripción negativa de sus derechos agrarios, en los términos establecidos por el ARTícULO 20 de la Ley Agraria en

201 La idea de que sólo los hombres pueden ser comuneros o en su caso mujeres viudas de comuneros se remonta a la anterior Ley Federal de Reforma Agraria (LFRA), que señalaba que los hombres cabeza de familia eran los beneficiados como ejidatarios y las mujeres, sólo si enviudaban. 
vigor, además por dedicarse a la siembra de estupefacientes o a cualquier otra actividad ilícita que ponga en entredicho la seguridad y tranquilidad de la comunidad.

Según este artículo del estatuto comunal, la renuncia se da cuando el comunero quiere dejar de serlo sin dejar la comunidad o deja de sembrar o usufructuar la tierra, sin anunciarlo o hacerlo explícito al comisariado de bienes comunales. La Ley Agraria define la pérdida de derechos por prescripción negativa (ARTícUlO 48) como inactividad, es decir, dejar de cumplir obligaciones frente a la comunidad (dejar de usar la tierra), en contraposición a esto, la prescripción positiva es la adquisición de un derecho por que se ha ejercido de manera continua, por ejemplo, usufructuar la tierra aun cuando no se hacen cargos pero las autoridades y la asamblea lo permiten.

De igual forma, se puede observar en la lectura de este estatuto comunal que hay una referencia a las parcelas en general sin especificar el tipo de explotación y de posesión, por lo que aplicado a la realidad o a la dinámica de la comunidad el ARTículo 13 del reglamento o estatuto es inexacto. Esto porque el ARTíCUlo 20 de la Ley Agraria se refiere a los ejidos parcelados y, en Móctum no hay parcelas definitivas (salvo la escolar y la UAIM, constituidas por el derecho positivo), aunque sí se respeta el derecho de la persona que siembra primero en un terreno que se ha dejado descansar por lo menos un año. En cuanto a los supuestos para la pérdida de los derechos fueron establecidos en la anterior Ley Federal de Reforma Agraria.

Por otro lado, el ARTículo 13 del reglamento o estatuto de Móctum es tal vez el precepto que daría lugar o justificaría la expulsión, sin embargo, no es así porque en ningún caso se dice que el comunero deba abandonar el núcleo agrario si dejan de usufructuar la tierra. ${ }^{202}$

202 Como se ha apuntado, el ARTículo 20 de la Ley Agraria se refiere a los derechos que pierde una persona (prescripción negativa) a favor de otra, porque abandonó la tierra que tenía usufructuando (no pierde los derechos sobre la cosecha). 
Si bien se puede llegar a expulsar a una persona por no cumplir servicios y cargos, esto — según las autoridades - no es una práctica común pues si una persona no cumple, por lo general tiene familiares que pueden estar dispuestas a cumplir por el renuente. Sin embargo, es importante recordar que los cargos mayores no aceptan sustituto, por lo que la persona que fue elegida debe cumplir. En 2005 se dio el caso de un emigrante en Estados Unidos que fue llamado para hacer el cargo de agente, sin embargo, solicitó que no se le diera un cargo mayor o que en su caso se le permitiera nombrar a otra persona. La asamblea y los mayores - personas, sobre todo hombres, que han cumplido con todos los cargostomaron en cuenta esto. Sin embargo, al analizar su caso resultó que no era la primera vez que el emigrante en Estados Unidos planteaba una solicitud así, pues en años anteriores lo había hecho cuando lo llamaron para el cargo de secretario del agente. En esa ocasión se tomó en cuenta su solicitud y se le permitió que otra persona lo hiciera en su lugar, pues no era un cargo mayor. En este caso, el emigrante tuvo que pagar a su sustituto para realizar su trabajo como secretario del agente.

Lo anterior hizo que la asamblea y sobre todo los mayores fueran más estrictos con el emigrante. Para obligarlo a regresar lo amenazaron con expulsarlo si no cumplía con el cargo. La presión llegó a tal punto de tensión que se rumoraba que si el emigrante no llegaba, sacarían a su mujer y a sus hijas de su casa, y a ésta la usarían de bodega. Aun cuando los padres y hermanos del emigrante solicitaban hacer el cargo en su lugar, las autoridades, la asamblea y los mayores no aceptaron señalando que el papá ya había hecho todos los cargos y por sus hijos volvía hacer los cargos menores; también se argumentó que los hombres que ya habían hecho todos los cargos ya estaban grandes de edad y cansados, que era necesario que los jóvenes empezaran a cumplir con su comunidad. Finalmente, el emigrante aceptó no sin antes considerar la posibilidad de demandar a las autoridades "con un abogado", sin embargo, desistió de esto porque al consultarlo con sus padres y hermanos le hicieron ver que hacer algo así empeoraría su situación y rompería 
cualquier posibilidad de negociar con el pueblo, ya que lo verían como una afrenta y desafío a su decisión y a sus autoridades "pues ni un abogado ni un juez de fuera te podrán defender adentro y frente a tu comunidad". ${ }^{203} \mathrm{Al}$ terminar su año como agente el emigrante regresó a Estados Unidos, su esposa e hijas siguen viviendo en Móctum con la seguridad de que no serán expulsadas. Esta situación sin duda revela las estrategias de la comunidad para presionar a los migrantes ante la dificultad de organizar la comunidad cuando no se cuenta con sus miembros; efecto bastante extendido de la migración.

Se observa una oposición de concepciones sobre los derechos individuales y colectivos, cuando el emigrante opone un derecho individual que dice tener, porque al contar con dinero que manda a su esposa, ofrece a la comunidad pagar a otro que haga el cargo en su lugar, desde su perspectiva, no se niega a hacerlo. Frente a esto, está el derecho colectivo que apunta que los cargos mayores no pueden ser cumplidos a través de otro, además que el interés de las personas que han pasado por todos los cargos es hacer que los jóvenes se involucren en la vida y organización de la comunidad para que ésta perviva. Esto, finalmente, pone en el centro de la disputa el derecho individual frente al principio de pertenencia y adscripción colectivo-individual: si aceptas el cargo, aceptas seguir en la comunidad, aceptas seguir siendo comunero y que tu familia siga viviendo y aprovechando sus recursos. Visto desde la perspectiva de la comunidad, un derecho individual ejecutado dentro de la jurisdicción de la comunidad y principios comunitarios no puede existir o no puede darse si la comunidad o comunalidad no es respetada. Es de notar que durante la elaboración de las normas del Estatuto Comunal el emigrante del caso antes expuesto estuvo presente - todavía no decidía irse a Estados

${ }^{203}$ El emigrante es hermano de Noemí Gómez Bravo quien como se ha mencionado, realizó un trabajo de rescate histórico de su comunidad que plasmó en su obra La antigua grandeza de Móctum (2004), también ha realizado varios cursos de capacitación jurídica sobre derechos humanos y derechos de los pueblos indígenas. Cuando Noemí me cuenta su versión de los hechos me plantea que se sintió entre la espada y la pared, porque su hermano le reclamó que no lo defendiera frente a la comunidad que sólo se preocupa por otros. A esto Noemí respondió a su hermano que la comprendiera porque ella después de estudiar y hacer su libro, entendía porque las autoridades actuaban así, de lo contrario la comunidad moriría porque ya nadie iba a querer hacer cargos. 
Unidos-, por lo que él junto con los demás comuneros lo aprobaron en asamblea, mostrando de alguna manera su conformidad con las normas que se plasmaron, como la suspensión de derechos y la expulsión.

La actitud renuente del migrante - según las autoridades de Móctumdesconocía no sólo el reglamento si no el acuerdo comunitario sobre las sanciones en caso de no cumplir los cargos, comportamiento que la comunidad interpretó como la decisión del migrante de ya no formar parte de la comunidad, según el principio de pertenencia: te reconozco como miembro y te puedes decir parte de, siempre y cuando cumplas servicios y cargos. Este principio se estaba vulnerando o trastocando por el migrante; visto desde la perspectiva de éste su derecho a tener y conservar un trabajo digno (en Estados Unidos) y de alguna manera un modo de vida estaban amenazados por la posición de la comunidad y de sus autoridades de llamarlo a hacer cargo, sin darle nuevamente la oportunidad de hacerlo a través de otro.

Lo anterior revela, por un lado, el sentido de la justicia desde la perspectiva individual y la perspectiva colectiva que impera, porque es el terreno en el que se definen y ejercitan los derechos individuales. También se puede observar cómo el sistema de cargos establece parámetros de pertenencia y autoadscripción a la comunidad, tanto individuales como colectivos: soy miembro en tanto se me reconoce como tal, puedo opinar y refutar porque soy miembro de, es decir, y como lo apunta Maldonado (2003):

Cumplir con estos trabajos expresa la voluntad del individuo por ser parte de la comunidad, involucrándolo en las redes de reciprocidad que generan. Por ello, quienes no cumplen con sus servicios, o se niegan a darlos, están oponiéndose a la tradición y, al mismo tiempo, expresan su voluntad de no formar parte de la comunidad; quienes rechazan las obligaciones y la cultura comunales, son llamados a rectificar su actitud; la reincidencia puede implicar, además de desprestigio, pérdida de derechos e incluso expulsión de la comunidad, como sucede con los convertidos al protestantismo, que se niegan definitivamente a dar cargos, tequios y asistir a fiestas. 
Sin embargo, es importante no perder de vista que en el sistema de cargos están involucrados un entramado de relaciones sociales y políticas de los miembros de la comunidad. Por tanto, la reciprocidad no siempre implica que las relaciones interpersonales, que motivan la elección de determinadas personas a un cargo, no estén exentas de los usos del poder, pues, como veremos más adelante, otro comunero que tenía una deuda económica muy alta con la comunidad fue perdonado por las autoridades, pese a que no hubo consenso de la asamblea; se dice por algunos que era pariente del agente en turno.

\section{Expulsión de un comunero}

El ARTículo 14 del estatuto comunal de Móctum señala:

El ciudadano o comunero que no acepte o abandone las comisiones encomendadas por la asamblea como Comisariado de bienes comunales o consejo de vigilancia, agente de policía, comité de la escuela, la asamblea tomará medidas al respecto si lo consiente o se expulsa de acuerdo a sus antecedentes, es decir si es por su costumbre.

Es importante subrayar que la Ley Agraria habla de separación y no de expulsión (véase ARtículo 23 Fracción II de la Ley Agraria). La separación tiene como consecuencia la pérdida del derecho a participar en la asamblea y de tener acceso a los apoyos que se adquieren a través del comisariado o de la agencia, pero no significa que el comunero sea sacado de la comunidad. ${ }^{204}$ Asumiendo una postura formalista, legalista o de estricto apego a la ley estatal, la expulsión planteada en el ARTículo 14 de este estatuto no sólo se puede argumentar de atentatoria de los derechos humanos sino de ilegal. Seguramente de esto están enterados algunos líderes y autoridades de Móctum, por eso matizan los hechos y señalan que nadie

\footnotetext{
204 Se establece en los Artículos 20 y 48 de la Ley Agraria los supuestos para perder la calidad de ejidatario o comunero. "ARTículo 20.- La calidad de ejidatario se pierde: I. Por la cesión legal de sus derechos parcelarios y comunes; II. Por renuncia a sus derechos, en cuyo caso se entenderán cedidos en favor del núcleo de población; Por prescripción negativa, en su caso, cuando otra persona adquiera sus derechos en los términos del ARTículo 48 de esta ley".
} 
ha sido expulsado, sino que se van porque no aguantan o no quieren seguir viviendo en la comunidad. 205

Sin embargo, y si bien no se ha expulsado a una persona que no quiere acatar la decisión de las autoridades o de la Asamblea, existen métodos de presión para obligarla a cumplir, o exigirle más servicios y cargos, por ejemplo, nombrarlo como autoridad o en varios cargos y comisiones, imponerle mayores multas que las normales, exigirle más trabajo.

En 2006 se dio el caso de un comunero que no quiso pagar una deuda que tenía por no haber cumplido cargos y tequios, él argumentaba que había pedido permiso a la autoridad de años anteriores, sin embargo, la persona que fue autoridad negó esto. Después de varias discusiones y reuniones se decidió que el comunero debía irse de la comunidad ya que además de no aceptar su deuda, amenazaba con ir a la cabecera a denunciar a las autoridades, sin embargo, no todos estuvieron de acuerdo con una expulsión. Los argumentos expuestos a favor y en contra del comunero fueron tanto desde la lógica de la ley del Estado como desde la lógica comunitaria. Unos plantearon que se respetara el Estatuto Comunal y "el reglamento", de lo contrario otros harían lo mismo y nadie después iba a querer cumplir sus deudas y cargos con la comunidad - esto lo señalaban entre otros el secretario del agente en turno-, otros argumentaron que la Ley Indígena de Oaxaca prohibía las expulsiones. Aunque no se citaron artículos de la ley o el texto de la misma donde se señala que están prohibidas las expulsiones en las comunidades, es evidente la influencia del derecho mexicano y su discurso sobre los derechos en la dinámica comunitaria y en la construcción y transformación del

\footnotetext{
${ }^{205}$ Los casos más sonados de expulsión en la región han sido más por cuestiones religiosas que por problemas agrarios internos, aunque aquéllos pueden dar lugar a éstos o estar interrelacionados (Montes 1995:35). De esta manera, queda en la mente de algunas personas que son adventistas (sobre todo los líderes que habían estado vinculados con la Asamblea de Autoridades Mixes, ASAM) la expulsión de varias familias de evangélicos de la comunidad de Tlahuitoltepec, precisamente cuando fue autoridad Floriberto Díaz líder de SER e impulsor de ASAM, por lo que a pesar de lo señalado en el Artículo 14 del estatuto ellos dicen que en el caso de San Marcos Móctum se da de baja a un comunero por abandono de la comunidad y por incumplimiento de las obligaciones encomendadas.
} 
derecho. Finalmente el comunero se quedó en Móctum con la condición de cumplir todos los cargos empezando como topil y pagar parte de su deuda, aunque no todos estuvieron de acuerdo. Un dato importante sobre la definición de la jurisdicción y las competencias es que el agente que conoció de este caso, efectivamente era pariente del comunero a ser expulsado, por esta circunstancia y al parecer, debido a que la Asamblea estaba dispuesta a la expulsión, remitió el asunto a la comunidad-cabecera, lo que le mereció el repudio y la increpación de las otras autoridades y del pueblo de Móctum. En última instancia, la comunidadagencia retomó el asunto y lo resolvió, aunque algunos mayores han dicho que "otros llegarán a ser autoridades y se retomará el reglamento". Indudablemente el hecho de que la posible expulsión saliera y se hiciera del conocimiento de una autoridad municipal, inhibió el actuar de las autoridades en turno y del pueblo, lo que significó un cuestionamiento al principio de comunalidad y al control interno sobre ésta.

El ejercicio de la jurisdicción y las competencias de las autoridades indígenas - lo que pueden o no hacer y/o deben hacer - implica una constante lucha por el poder y el control de las dinámicas internas, entre las instancias legales indígenas y del derecho positivo, lo que se debe fundamentalmente a que el sistema jurídico mexicano insiste en ver al sistema jurídico indígena como un nivel subordinado - lo que no significa que esté reconocido en todas sus dinámicas e implicaciones-. De esta manera, la autoridad municipal de la comunidadcabecera desde la perspectiva del sistema jurídico mexicano es jerárquicamente superior, pero vista dentro de la dinámica municipal entre instancias del sistema jurídico indígena, es un símbolo de poder y control centralizado que provoca de manera recurrente la contestación de las comunidades-agencias. El caso de la expulsión es una muestra de cómo se da esa lucha por el control y el poder, pero también cómo se interrelacionan e imbrican dos sistemas jurídicos que definen las jerarquías y la dinámica municipal de manera diferente. 
Lo expuesto en este capítulo del estatuto comunal de Móctum es una muestra de los aspectos que para sus pobladores son de tal importancia que decidieron ponerlos por escrito - como una manera de tener el aval de las autoridades del Estado mexicano y garantizar mayor control interno-: el cumplimiento e incumplimiento de obligaciones, los cargos y sobre todo la expulsión. También muestra la limitación de la norma escrita al no expresar las dinámicas del poder y los usos del derecho.

\section{Otros asuntos:}

\section{Robos, incumplimiento del tequio y disparo de arma de fuego}

El siguiente artículo del estatuto comunal es una muestra de algunos de los asuntos que se consideran relevantes, pues independientemente de que pueden ser frecuentes, marcan el ámbito de jurisdicción y plantean la posibilidad de que la comunidad pueda resolver a su interior sus propios problemas, es decir, tener control de su dinámica.

ARTículo 26.- Para al que [sic] se le sorprenda robando leña cortada, o esté cometiendo robos en los ranchos, se castigará con cárcel y multa de acuerdo al monto de lo robado.

Las autoridades de Móctum se han quejado de que muchas veces el Ministerio Público considera que estos robos son pequeños por lo que no amerita iniciar una averiguación o meter a la cárcel a una persona, por ello en este artículo se establece que esos robos serán sancionados por las autoridades internas.

En el ARTículo 28 se sanciona el disparo que una persona haga con arma de fuego:

El que dispare con armas de fuego en plena calle o en estado de ebriedad, la autoridad tendrá la facultad de citar al que comete tal cosa ilícita, se le dará advertencia por primera vez y la segunda será con multa.

En este caso el agente de policía aplica la sanción. En Móctum, según este artículo, el disparo con arma de fuego no es sancionado tan gravemente como en el derecho 
mexicano o estatal, que lo tipifica como delito y amerita prisión o cárcel. También es relevante el hecho de que los agentes municipales y de policía son, por disposición de la Ley Orgánica Municipal de Oaxaca, auxiliares de la autoridad municipal -y ésta a su vez del Ministerio Público y del juez-, por lo que sólo pueden conocer de los asuntos para después remitirlos al municipio, sin embargo, esto no sucede, tal como se ha expuesto en el capítulo anterior y en éste.

\section{Disputas sobre la tierra}

El siguiente artículo se refiere a los asuntos, disputas o conflictos que se dan por el uso de la tierra al interior de la comunidad.

ARTículo 29.- Cuando entre comuneros o ciudadanos surja algún problema como de solares o tierras agrícolas, se resolverá en asamblea, de acuerdo al ARTícuLO 21, Fracción primera de la nueva ley agraria, pero si el problema es de otro asunto, la autoridad municipal investigará primero si no está dentro de su competencia lo turnará a la siguiente instancia correspondiente. 206

Lo anterior muestra que se trata de una norma escrita discutida y no impuesta, por lo que recoge las necesidades de la gente, o por lo menos de quienes participaron en su elaboración y aprobación. De igual forma, se puede afirmar que la norma escrita tiene ventajas y desventajas, por un lado representa estabilidad y permanencia en los derechos y obligaciones, y deja la sensación de que todos los que se comporten de una manera u otra serán tratados igual, pero por el otro no siempre resulta adecuada para responder a las exigencias de las dinámicas y realidad comunitarias.

Lo que se observa en Móctum es que la norma escrita siempre se aplica e interpreta de acuerdo a los casos pasados que ya fueron resueltos y tomando en cuenta las circunstancias del caso que se quiere resolver en la actualidad. Otro

\footnotetext{
${ }^{206}$ Hay un error en este artículo cuando se cita el ArTículo 21 de la Ley Agraria, pues éste se refiere a los órganos del ejido, en todo caso será el Artículo 23 que se refiere a las facultades de la asamblea.
} 
principio es el tomar en cuenta la circunstancia de la persona o individuo ante la comunidad, si ha respetado a la autoridad y a la asamblea, si realmente está imposibilitada para ejercer los cargos. Finalmente, la aplicación del principio de interpretación, según los casos pasados y el caso actual, da lugar a una norma oral de hecho, también se puede afirmar que la norma oral (acuerdos, criterios o "reglamento") es finalmente el origen de la norma escrita del estatuto comunal de Móctum.

\section{El conflicto agrario con Totontepec en el estatuto comunal}

En el estatuto comunal también se revela lo que fue el conflicto agrario entre Móctum y Totontepec, como uno de los aspectos relevantes. Esto queda expresado en el siguiente artículo:

ARTículo 30.- Queda prohibido estrictamente la detención de comuneros y ciudadanos, por otra autoridad de otra comunidad en caso de que surja la necesidad, la autoridad local lo tiene que saber primero previo comunicado, la detención se manejará como secuestro.

Este artículo se explica porque durante el conflicto agrario con Totontepec, el presidente municipal de ese entonces mandó a aprehender a los hombres de Móctum para obligarlos a desistir de continuar su lucha. Por lo que se puede observar una necesidad de delimitar y reafirmar la jurisdicción de Móctum y, a la vez de poner límites a otras jurisdicciones, como la del Estado mexicano en general y del municipio como parte de él. Esto plantea una lógica jurídica distinta de la del derecho positivo porque según éste un reglamento interno o estatuto comunal, según sea el caso, es obligatorio para las personas que lo suscriben o los miembros de una comunidad. En el estatuto no se pueden establecer obligaciones o prohibiciones a otras entidades o personas que se encuentran fuera de su ámbito territorial o jurisdiccional, por ejemplo, otra comunidad; la policía judicial, los jueces del distrito judicial, el ministerio público o el presidente municipal, éstos se rigen por sus propios reglamentos y leyes. Lo cierto es que el sistema jurídico mexicano y su derecho ponen límites y regulan la intervención de las distintas 
autoridades y agentes del Estado (incluyendo las municipales), según la materia de que se trate. Las autoridades de Móctum y el pueblo han podido respaldarse en él para regular su vida interna y limitar las pretensiones de Totontepec como comunidad-cabecera del municipio.

El ámbito territorial como jurisdicción queda plasmado en el siguiente artículo:

ARtículo 31.- La Asamblea ha determinado prohibir la venta de leña y arenas que se encuentran en la jurisdicción, ni la autoridad ni ningún particular, sino que todos los comuneros y ciudadanos estamos obligados de vigilar nuestros recursos propios de la comunidad.

Es interesante esta redacción del artículo, por el uso de la palabra "jurisdicción", seguramente introducido por el promotor de la SRA o por uno de los comuneros que han tomado cursos de derechos humanos en Oaxaca, pero que expresa claramente los límites y alcances de lo que pueden o no hacer las autoridades indígenas y las no indígenas, como se observó en el caso de Totontepec (véanse conclusión del Capítulo 5). También esto es alusivo de las relaciones que Móctum tiene no sólo con la comunidad cabecera sino con otras comunidades-agencias, recuérdese el caso de la luz eléctrica con Santa María Ocotepec (CAPítulo 4, apartado 4.3) y también que ésta agencia ha pedido permiso para explotar arena de terrenos de Móctum.

\section{Organización interna para la producción}

El derecho de los comuneros y de la comunidad a adoptar distintas formas de organización para la producción ha quedado asentado en los ARTículos 05 y 06, plasmándose de nueva cuenta en el ARTículo 37, todos del estatuto comunal, por lo que el ARTículo 36 es redundante. ${ }^{207}$

207 “ARtículo 36.- La comunidad reclamará para mi mismo su derecho a adoptar las formas de organización que aseguren y garanticen el pleno dominio administrativo de sus recursos y la autoridad necesaria para regir su organización económica interna, respetando el derecho de sus integrantes a darse las formas de organización que deseen en la producción". 
De igual forma, lo que se señala en el ARTículo 37 del estatuto comunal, se refiere a los grupos u organizaciones de producción agrícola que se llegaran a constituir al interior de la comunidad. ${ }^{208}$

\subsubsection{Dimensiones de la norma escrita}

La norma escrita en Móctum responde a las exigencias del Estado y su derecho que marca como necesario que esta comunidad deba ser reconocida por él como comunidad agraria. Después de la elaboración del Reglamento Interno por escrito, para integrarse a PROCEDE la comunidad elaboró otro reglamento, ahora con la presencia de la Procuraduría Agraria que sigue al pie de la letra lo que señala la Ley Agraria - para ser aceptado por el Registro Agrario Nacional-, por lo que no muestra aspectos relevantes para la comunidad como la expulsión. Pese a esto, los comuneros y comuneras saben que el Estatuto Comunal anterior a PROCEDE es válido y se remiten a él cuando surgen conflictos o disputas.

El hecho de existir dos estatutos comunales, uno expuesto en este capítulo y elaborado con el promotor agrario justo al momento de las modificaciones al ARTículo 27 Constitucional, el otro elaborado con la Procuraduría Agraria propiamente en el procedimiento del PROCEDE, ambos con funciones distintas, muestra cómo la comunidad se adecua a las exigencias del Estado y construye y transforma su propio derecho. También muestra la imbricación de sistemas y lógicas distintas, así como la subalternidad de las comunidades indígenas que son partícipes, en alguna medida, de las transformaciones de campos sociales más amplios como el municipal. De esta manera, se tiene por un lado que para Móctum

208 Del estatuto comunal: “ARTículo 37.- La comunidad compromete a cambio su apoyo y su respaldo sobre todo a aquellos grupos que al organizarse para tales fines prevén desde sus propias normas, sin afectar su independencia de acción, operar en estricta coordinación con el núcleo agrario, a fin de fortalecer su integridad y su unidad [...] ARTículo 38.- En atención a los ARTículos 63, 70, 71 y 72 de la Ley Agraria, la comunidad destinará dentro de las mejores tierras un predio para el funcionamiento de la parcela escolar. ARTículo 39.- Compete a los comuneros la plena responsabilidad de mantener productiva su parcela él con su familia." A éste último se aplica el comentario que expusimos para el ArTículo 08 del estatuto comunal, que se refiere a las obligaciones de los comuneros. 
era cumplir un requisito formal que le permitió integrarse a PROCEDE y con ello dar por concluido su conflicto agrario con Totontepec - lo que ha significado para aquel poblado recibir más apoyos económicos municipales -, por otro el estatuto elaborado antes de PROCEDE da a los miembros de la comunidad y a sus autoridades la seguridad de que normas como la expulsión fueron avaladas por autoridades del Estado.

Esta doble dimensión de la norma escrita como ley del Estado y como Estatuto Comunal, se puede observar cuando las autoridades resuelven disputas o conflictos e invocan la ley del Estado, como el Código Penal y la Constitución para legitimar su actuar - aunque no citan artículos-. Por ello, la norma escrita en Móctum tiene una doble dimensión pues no sólo es el Reglamento Interno o Estatuto Comunal, como lo llama la Ley Agraria, sino también el derecho positivo mexicano interpretado y aplicado por las autoridades según su propio entendimiento. Sin embargo, algunas veces esta percepción de dos formas de derechos no es tan clara, precisamente porque los sistemas jurídicos son vistos por los actores como un solo referente legal (por ejemplo en materia agraria, el criterio de dos años de abandono de la tierra por el que se considera que un comunero ya no tiene derechos, es citado por el comisariado pero también fue una norma de la Ley Federal de Reforma Agraria), por lo que para el observador (sobre todo si no es abogado o especialista) es difícil distinguir hasta dónde se trata de una práctica comunitaria tradicional o de la aplicación del derecho mexicano a las dinámicas locales, adecuaciones que pueden incluso tergiversarlo o trasgredirlo, sin embargo, los actores y sobre todo las autoridades indígenas tienen la firme convicción de que es su derecho y de que se está haciendo justicia. 


\section{A MANERA DE CONCLUSIÓN}

El Reglamento Interno o Estatuto Comunal como norma escrita de Móctum no abarca todas las conductas posibles que pudieran adoptar los comuneros o comuneras de Móctum es, en todo caso, la puesta en papel de las normas no escritas, lo que resultó de la participación de agentes del Estado, cuya tarea prioritaria era implementar un programa gubernamental llamado PROCEDE. Esta actitud exhibe la intervención del Estado en la vida de las comunidades indígenas, a través de la política agraria de dotar de tierra y reconocer la que han tenido en posesión ancestralmente (los llamados procedimientos agrarios), lo que finalmente marca un continuo con la política colonial hacia estos pueblos.

Algunas de las normas expuestas como no escritas tuvieron origen durante el conflicto con Totontepec, como el hecho de establecer la prohibición impuesta a las autoridades externas de detener a cualquier comunero de Móctum; que las mujeres que se casaran con hombres de otra comunidad se fueran - norma, que confiesan algunos que fueron autoridades, fue la "estrategia", para que los de Totontepec no quisieran retomar las tierras que Móctum había recuperado-. El cultivo de caña y la cría de ganado también entran en ese tipo de normas. Esta situación no se exponen en el estatuto comunal (que es de 1995), por lo que es limitado frente a las normas no escritas vigentes. En este sentido, la norma no escrita expresa con mayor nitidez la dinámica de la comunidad, sus asuntos y conflictos relevantes contemporáneos, así como las respuestas que la comunidad da para enfrentarlos.

Aunque se señala que el Estatuto Comunal o Reglamento Interno elaborado con la intervención del funcionario de la Promotoría Agraria era una actualización de otro existente con anterioridad, ni el agente ni el comisariado lo conocía. En el estatuto de Móctum no se anotan qué artículos se modifican y cuáles quedan sin alteración (lo que se tendría que especificar en los artículos transitorios). 
Los aspectos más importantes que determinan la creación y aplicación de las normas en Móctum -y por tanto, la dinámica de su orden jurídico - están relacionados con el ámbito agrario de la comunidad: tierra, trabajo colectivo, adscripción o reconocimiento de comuneros. La confrontación de la norma escrita con las prácticas de resolución de conflictos y sus normas no escritas exhibe las limitaciones de aquélla fundamentalmente porque no muestran los casos de excepción - que son los que se dan en la cotidianidad, como en el caso del emigrante o del comunero que incumple sus deudas económicas-, sino que se presentan como postulados categóricos inamovibles. Por tanto, en el caso de Móctum la exposición y puesta en marcha de su sistema jurídico (creación y aplicación de normas, autoridades y mecanismos de resolución de disputas) no se puede reducir a lo escrito en el Estatuto Comunal o en el Reglamento Interno, en el que se pretendió por parte de los agentes del Estado transcribir, transponer o traducir todo o parte de la Ley Agraria, evadiendo las condiciones reales de la comunidad.

Tal situación salta a la vista cuando observamos que uno de los elementos fundamentales de la comunidad es la tierra, sin embargo, en el estatuto no se establece nada más que generalidades como ámbito territorial de la jurisdicción de las autoridades y respecto a su posesión y tipo de usufructo, pese al proceso histórico de reivindicación y de que los conflictos más relevantes están estrechamente relacionados con ella y con la aceptación de nuevos comuneros (cumplimiento de obligaciones y ejercicio de derechos).

También se podrá observar que los acuerdos actualizan a la norma escrita. De esta manera, una norma no sólo es un breve enunciado de una conducta sino la regla que resulta de tomar en cuenta un hecho y sus circunstancias, por ello, la actualización de la norma se da a través de la exposición del asunto ante la Asamblea, o bien cuando el agente hace justicia. Así, tanto las normas escritas como las no escritas están rodeadas de situaciones y antecedentes que les dan sentido, lo 
cual está en la memoria de las autoridades dando legitimidad a un acuerdo de que tal norma debe ser aplicada.

Las limitaciones de la norma escrita, es decir, del estatuto comunal se deben en parte a lo antes apuntado pero también a la intervención de la promotoría de la SRA, ya que su interés era más el cumplir un programa de gobierno que el apoyar a Móctum, por ejemplo, a recuperar y sistematizar su sistema jurídico. Esto es evidente cuando al conocer de un asunto, la autoridad se refiere al "reglamento" más como el conjunto de acuerdos y precedentes que a la norma escrita. Si los de Móctum aceptaron hacer el Reglamento Interno fue porque les convenía incorporarse a PROCEDE (aun cuando son comunidad y no ejido) por el conflicto agrario con Totontepec, pues el deslinde, ubicación de mojoneras o marcas de límites, así como la delimitación de sus tierras para tener "seguridad jurídica" debió hacerse desde 1975, sin embargo, lo lograrían con este procedimiento en los umbrales del siglo XxI. El finiquito del conflicto agrario marcó la posibilidad de Móctum de establecer otro tipo de relación con Totontepec, lo que se expresa en la "cooperación" entre autoridades, que observamos recurrentemente como en el caso de la expulsión y también en la inyección de recursos municipales para obras de infraestructura comunitaria, como la electrificación trifásica y el entubado del agua potable, antes referidos.

Finalmente el control del Estado es cada vez mayor sobre las formas comunitarias de hacer justicia, debido entre otros aspectos al desarrollo de los medios de transporte y comunicación. De esta manera, las autoridades de Móctum no son ajenas a la intervención de los agentes del Estado mexicano como la Procuraduría de Justicia del Estado, la Procuraduría Agraria y, sobre todo, la Comisión de Derechos Humanos de Oaxaca. En esta interacción se da una lucha de poder entre sistemas jurídicos en que los protagonistas - las autoridades indígenas, las no indígenas y los usuarios en las comunidades - tratan de hacer que uno impere sobre el otro, o bien que subsista reforzando la práctica comunitaria del trabajo colectivo y de los cargos, así como en la reafirmación del 
comunitarismo basado en una ideología de la "armonía". Dicho discurso comunitarista puede ser usado con el fin de promover la solidaridad local convirtiéndose en una estrategia para resistir la hegemonía del Estado, buscando reinstalar el balance entre las partes en disputa (véase la justicia que el alcalde quiere lograr en los asuntos). Esto puede verse como la intención de establecer el equilibrio de las relaciones sociales que se había visto alterado por el conflicto. De esta manera, los valores culturales que predominan en el proceso de impartición de justicia son los de ayuda mutua, balance, armonía e igualdad. Con todo ello, se pretende inhibir tanto la intervención de agentes externos como los intentos de los habitantes de la comunidad para acudir a la justicia del Estado y, que eludan sus obligaciones ante el colectivo, o para realmente defenderse. Pero también es importante advertir, que en el ejercicio de hacer justicia intervienen otros factores que pueden suponer un abuso de las autoridades indígenas y del colectivo comunitario sobre el individuo; sin embargo, no se puede afirmar esto de manera categórica y generalizada sin hacer un conocimiento y estudio profundo de los casos - sus circunstancias y usos del poder que los enmarcan - así como el contexto comunitario en el que se dan y con los que se pretende ejemplificar y respaldar tal afirmación.

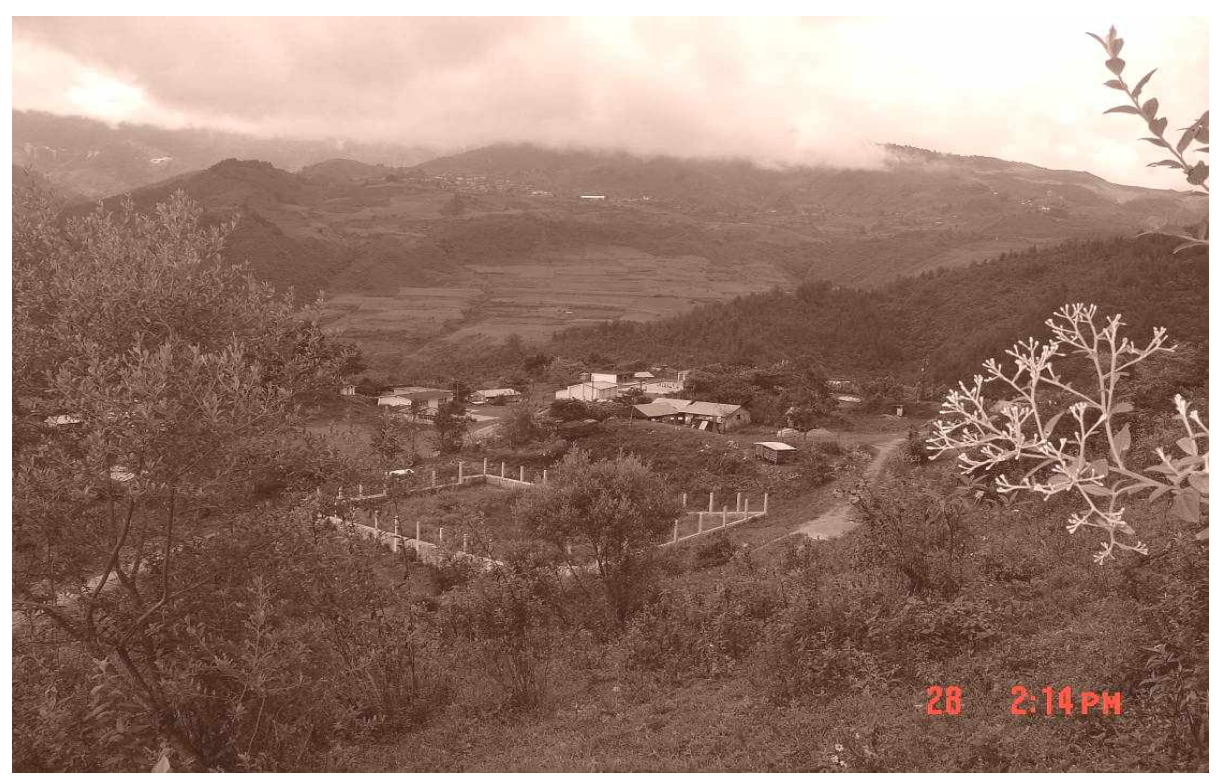

Móctum visto desde el panteón comunitario

Al fondo Totontepec Villa de Morelos 
Tal vez de este trabajo se desprende una defensa al sistema comunitario de hacer justicia, sin embargo, lo que se ha pretendido es mostrar la lógica, motivación, circunstancias y contexto sobre los cuales las autoridades indígenas y la comunidad elaboran y aplican la comunalidad y sus normas para la defensa de su jurisdicción. De igual forma, se han expuesto los puntos de contacto más ríspidos entre sistemas jurídicos, para dar cuenta del porqué de esos encuentros y desencuentros, y abonar a un verdadero reconocimiento del pluralismo jurídico, la interculturalidad y la interlegalidad más allá de lo que actualmente las leyes mexicanas señalan. 


\section{CONCLUSIONES FINALES}

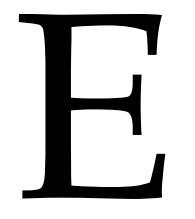

$\mathrm{n}$ este trabajo me propuse investigar el derecho vigente en comunidades mixes del municipio de Totontepec, con el fin de comprender en qué sentido comunidades pequeñas, como San Marcos Móctum, construyen sus normas y dirimen sus conflictos en el marco de una continua tensión y relación con unidades mayores con las cuales han estado históricamente vinculadas. Esto me llevó a abordar el estudio del campo jurídico desde el ámbito municipal, lo que me permitió entender las dinámicas de Móctum como parte de ordenamientos jurídicos más amplios a los cuales se encuentra subordinada. Me llamó la atención constatar las energías invertidas por los vecinos de Móctum a lo largo de su historia para mantenerse como comunidad aparte, reivindicando su autonomía ante la cabecera municipal de Totontepec. Un eje central de las tensiones que marcan la relación entre estas dos comunidades ha sido la defensa del territorio y el reclamo de sus derechos. En este proceso ha sido clave la participación del Estado y sus agentes, especialmente a través de la reforma agraria que, finalmente después de largos años, otorgó el reconocimiento de Móctum como comunidad agraria, y por tanto como entidad de derecho público, es decir, con la capacidad de tomar decisiones y regular su vida interna, bajo sus propias autoridades. Esto significó la oficialización y legalización de su territorio, garantizando así el control de sus tierras. La historia de tensión entre agencias y cabeceras, o entre anexos y cabeceras - de lo cual Móctum y Totontepec es un ejemplo-, ha sido la historia de las comunidades indígenas y sus pueblos en diferentes regiones del país, como lo muestra el estado de Guerrero (Dehouve 2001) y el estado de Chiapas (Burguete 2002). El caso de Oaxaca es especialmente revelador de esta problemática, cuyos orígenes se remontan a la Colonia cuando se reorganizó el territorio de las comunidades y unas, por razones diversas, quedaron sujetas a otras. En muchos casos, dichas divisiones no correspondieron a las 
jurisdicciones antiguas y por el contrario propiciaron que antiguos pueblos perdieran su autoridad y quedaran sometidos a otros. Tal parece ser el caso de Móctum que hasta la fecha sigue reivindicando su pasado como referente de grandeza, lo que, sin embargo, es desconocido por los habitantes de Totontepec.

La disputa por el territorio, y sobre todo por la "soberanía" de la comunidad, ha provocado dos principales procesos que me interesó documentar en esta tesis, y que resultan claves para comprender el derecho vigente en comunidades mixes: la historia de la lucha y el reclamo por la tierra, y la comunidad; y por otra parte, el sentido en que este proceso significa también una disputa por la identidad, disputa que ha fomentado los localismos y el arraigo comunitario, más que identidades regionales, lo cual también ha incidido en los procesos recientes de reivindicación étnica. La mirada desde el derecho resulta clave para comprender el papel de la ley estatal en la legitimación de los reclamos, en el caso estudiado lo agrario, y por otra parte el papel del derecho propio en la construcción de las normas y su regulación.

En este sentido, el estudio incorpora una visión sincrónica y diacrónica de los procesos jurídicos tomando en cuenta dos puntos de tensión -que identifiqué como ejes analíticos -, entre Totontepec Villa de Morelos y San Marcos Móctum: lo territorial, en su dimensión municipal y agraria, y la justicia y la jurisdicción, éstos últimos considerados como partes de un mismo eje. En este sentido mi trabajo apunta a considerar que el derecho como fenómeno social y cultural, estructurador de las dinámicas comunitarias, no puede ser explicado exclusivamente por los acontecimientos cotidianos (usos del derecho y relaciones de poder), sino que deben tomarse en cuenta los procesos históricos que determinan la conformación de un pueblo indígena. Este conocimiento histórico de la relación entre comunidades -como unidades políticas jerárquicamente disímiles- hace comprensible el porqué determinados asuntos como la membresía y el uso de la tierra son tan relevantes y se reflejan en la construcción del derecho, concretamente en las normas internas (orales y escritas) - véase el caso del grupo de "Mujeres Olvidadas del Rincón Mixe", en Móctum, que pedían se les permitiera a sus hijas y 
a las mujeres jóvenes casarse con hombres de "fuera", lo que contravenía la idea arraigada de mantener el control interno de la tierra.

De esta manera, no sólo me propuse estudiar las prácticas de la justicia como referente central para documentar el ejercicio y uso del derecho, desde los casos atendidos en las instancias legales del campo jurídico municipal, ni sólo me concentré exclusivamente en el análisis de los criterios y las norma escrita y oral, per se, sino que incorporé la perspectiva histórica de los procesos de construcción comunitaria.

Mi intención en el CAṔ́tULO 1 fue el de presentar un marco teórico desde la perspectiva antropológica del derecho, sobre los debates en torno al pluralismo jurídico y al campo jurídico, como referente para comprender las dinámicas legales y la construcción del derecho en las comunidades mixes, marcadas por una continua relación de tensión e imbricación con el derecho del Estado. Esto confirma que la interlegalidad es una característica central de las dinámicas jurídicas en las regiones indígenas. Dicha interlegalidad, sin embargo, sienta sus raíces en los procesos históricos y de poder que han hecho que el derecho indígena, el derecho vigente en las comunidades indígenas, cristalice y se construya en esa tensión y desde ella genere sus respuestas. Para profundizar en estos procesos, en el CAPítulo 2 retomo el contexto histórico, dando cuenta de los factores y dinámicas que determinan la situación contemporánea de las comunidades indígenas de Oaxaca, y el hecho que sus conflictos internos e intercomunitarios no pueden ser comprendidos si no se toma en cuenta esas disputas históricas entre comunidades. En el caso de estudio dichas disputas remiten a lo agrario y lo territorial, por lo cual las denomino conflicto madre. Así, ubiqué dos elementos centrales que consideré intervienen directamente en la configuración comunitaria e influyen eventualmente en la conformación de las dinámicas del derecho: lo territorial y la justicia. Estas comunidades, Totontepec y Móctum, como muchas en el estado de Oaxaca, históricamente han vivido ciclos de encuentros y 
desencuentros, en los que son recurrentes esos dos elementos centrales, que necesariamente han incidido en el desarrollo del derecho en lo local.

La revisión histórica de los usos del derecho dominante, el derecho del Estado, y la conflictividad territorial en periodos amplios (Romero 1996, 2005) muestra la importancia de entender el derecho en comunidades indígenas, como resultado de procesos históricos de construcción comunitaria. En el caso de estudio, Móctum reivindica su derecho de ser reconocida como unidad política aparte, con tierras propias, ante la tendencia de Totontepec, como unidad mayor, de tratar de dominarla e invadir sus tierras. En esta relación, está presente el referente comunalista tan arraigado en Oaxaca y su vínculo estructural con lo agrario y lo territorial.

Otra propuesta, que se deriva de este estudio, es entender que el municipio no puede comprenderse sólo desde las dinámicas que se dan en la cabecera municipal, sino que es necesario contemplarlo en su complejidad considerando el papel de las agencias o anexos, y las relaciones entre las unidades políticas y sus autoridades; así como la historia de estas relaciones y sus tensiones, lo cual suele ser desconocido por los trabajos municipalistas. También, es relevante señalar que el derecho, en su sentido amplio como sistema de normas, valores y procedimientos, se concibe como parte de un campo social semiautónomo, a su vez inserto en un campo jurídico más amplio, esto le otorga al derecho una dimensión dinámica que desde la disciplina jurídica no suele contemplarse. En este sentido el concepto de pluralismo jurídico y, sobre todo, el de campo jurídico visto como arena de confluencia de diferentes instancias, autoridades y órdenes jurídicos ofrece un panorama mucho más amplio y rico que si sólo se considera al derecho como un conjunto de normas que dictan derechos y obligaciones. Esta forma de pensar el derecho, por ejemplo, puede ayudar a sentar las bases para comprender el derecho indígena y establecer relaciones de coordinación de las autoridades indígenas con el Estado, y sus agentes, es decir, éstos deben de entenderlo con una 
lógica propia, concibiendo al derecho como fenómeno y no como postulados escritos o sólo normas, más allá de la lógica del derecho mexicano.

Como lo he señalado, el derecho indígena es el resultado de tensiones históricas y de una realidad que dista mucho de ser armónica, pero que tiene sus propias dinámicas de conflictividad y de establecimiento de un status quo. Como expuse en los CAPÍtulos 2 y 3, los mixes, como muchos otros pueblos indígenas, viven a su interior tensiones, encuentros y desencuentros, pero también son un ejemplo de como tratan de construir la unidad (territorial y étnica) partiendo de la diversidad del ser mixe

\section{El eje de lo territorial}

Lo territorial y la justicia fueron los dos ejes de análisis escogidos para abordar las dinámicas del derecho y su construcción. Primero, porque como lo señalé en el CAPítulo 2, lo territorial, en el caso que se aborda, conjunta dos aspectos fundamentales: la propiedad de la tierra (lo agrario) y el ejercicio del poder municipal (jurisdicción y límites de las autoridades indígenas) en distintos niveles (la cabecera y las agencias). Segundo, porque la justicia es uno de los puntos de mayor confrontación entre el derecho positivo y las dinámicas locales -que dictan los criterios para que las autoridades indígenas hagan justicia-; pero también, ha sido una de las arenas más importantes en la que los pueblos indígenas y el Estado se han relacionado, pues a pesar de que aquéllos lo contestan y confrontan, también han hecho uso del derecho dominante para reivindicar sus derechos como colectividades; así se muestra en el expediente colonial en el que Móctum demanda, vía civil, a Totontepec por invasión de sus terrenos. Es de suponerse, de acuerdo con lo que señala Chance (1998), que en la Colonia Totontepec era un pueblo cabecera y Móctum estaba subordinado a él, posteriormente, Móctum lograría en la misma época su reconocimiento como pueblo con tierras aparte. Más adelante la disputa por esa pretensión se reaviva en el siglo XIX cuando Móctum vuelve a quedar subordinado a Totontepec. Es hasta fines del siglo xx que 
Móctum, amparado en la reforma agraria y su nueva legislación, consigue su reconocimiento con tierras independientes. Esto motiva a pensar que en los distintos momentos históricos de México la promulgación y vigencia de nuevas leyes, reactiva viejos conflictos.

Por lo que toca a la dimensión municipal, lo territorial ha sido una de las arenas de conflicto más recurrentes en muchos estados de la República, pero en Oaxaca es especialmente característico por la composición pluriétnica y el número y diversidad de municipios existentes que, en su mayoría, guardan un doble carácter: o son cabeceras y a la vez comunidad-agraria, o son agencias y al mismo tiempo comunidad-agraria. Me referí a la proliferación de municipios en el caso oaxaqueño en el CAṔ́tulo 2, por el establecimiento frecuente de nuevos asentamientos humanos en la Sierra Juárez desde la época colonial, particularmente en la zona en la que se ubica el caso de estudio, en la que "nuevos" pueblos desplazan a los antiguos, con la subsiguiente pérdida de control de éstos sobre aquéllos (König 1993). Esto aunado a los procesos políticos, sociales y agrarios que vincularon al municipio y a los cacicazgos rurales, como medios de control del Estado mexicano, y que le dieron cierta presencia en las zonas indígenas del estado de Oaxaca. Esos procesos explican cómo la preeminencia política de un pueblo sobre otro - primero con el municipio colonial (República y cabildo de indios, cfr. Romero 1996, Aguirre 1991) y después con el municipio libre - ha provocado una arena de disputa constante cuya manifestación varía, pero suele intensificarse cuando se le reconoce al municipio como ámbito de gobierno (ya que con anterioridad se consideraba una unidad administrativa) y se le dan más facultades para obtener y administrar recursos.

Así, las reformas más importantes sobre el municipio se dan durante el gobierno del presidente Ernesto Zedillo sexenio (1994-2000) ${ }^{209}$ abriendo paso a dos

\footnotetext{
${ }^{209}$ En este sexenio se reforma el IFE y se establece la elección directa proporcional. Una de las reformas más importantes fue la del ARTículo 115 Constitucional (en 1999) en la que se reconoce al municipio como verdadero ámbito de gobierno, ampliando sus facultades. Ya en la reforma de 1983 se
} 
fenómenos vinculados: la reforma política con la adopción del multipartidismo (que se gesta con el presidente Salinas de Gortari, sexenio 1988-1994) y el proceso de remunicipalización. Así, en 1995 se le concede al municipio capacidad de controversia constitucional entre poderes, por el manejo de recursos (y por tanto como órgano de gobierno). En 1999, esto se explicita en el texto constitucional lo que conlleva a reconocer la importancia del municipio, no sólo como unidad primordial de la división territorial del Estado, y como marco jerárquico que señala competencias desiguales entre las unidades políticas que lo conforman (por ejemplo, entre cabecera y agencias), sino como órgano fundamental del poder local. Ya que el municipio suele cumplir funciones administrativas (recursos), ejecutivas (gestiones y ejercicio del gobierno) y legislativas (establecimiento de bandos o leyes), la cabecera ejerce con fuerza su poder sobre las localidades de categoría inferior, como las agencias, por lo que se refiere a las contribuciones que puede cobrar (impuesto predial), impartición de justicia y gestión de apoyos financieros del gobierno estatal y federal.

La dimensión agraria plantea una arena particular de confrontación entre dos poblados del mismo pueblo indígena, de los cuales uno de ellos, Totontepec, como cabecera municipal, tiene mejores niveles de vida en su población, además de que su ubicación geográfica y su propia historia, lo ubican como un poblado con un fuerte proceso de amestización, señalado como descaracterizado por algunos autores (Kuroda 1993), que ha ejercido su supremacía con ciertos visos de discriminación y racismo sobre el resto de las comunidades-agencias (como se expuso en el CAPítulo 3). Esa desigualdad económica y política, aunada a la jerarquía desigual que el ámbito municipal implica, y que hereda de la historia colonial, se ve contrastada y confrontada con el ámbito agrario, regulado por la legislación federal -que establece una organización y órganos de autoridad

establecía y ampliaba el principio de representación proporcional de los cabildos independientementede supoblación.Cfr. <http://www.monografias.com/trabajos7/vimu/vimu.shtml> 
independientes de la cabecera municipal-, a diferencia del ámbito municipal que se rige por la legislación estatal (esto se explica en el CAPÍtULO 4).

De esta manera, aunque se reconoce a la cabecera municipal la facultad de impartir justicia, y de manera auxiliar a las agencias, su condición de comunidades agrarias les ha permitido fortalecer su jurisdicción y el ejercicio de la justicia. Como hemos visto en este proceso domina un sentido arraigado de comunidad, de control interno de los procesos, lo que al ser usado como recurso discursivo da lugar a lo que Laura Nader (1998) ha llamado ideología armónica; el concepto busca dar cuenta de las estrategias desarrolladas por autoridades zapotecas para evitar ingerencias del Estado, lo que en el caso analizado se produce también con relación a las cabeceras. Estas características muestran que las comunidadesagencias frente a la comunidad-cabecera no acatan inermes y pasivas sus mandatos, sino que en esa desigualdad también actúan y ejercen control dentro de sus propios límites territoriales y jurisdiccionales, lo que las coloca como campos sociales semiautónomos (Moore 1990) y subalternos (Mallon 2003). Situación que se reproduce - con sus propias características, dimensiones y dinámicas - ante el Estado. Esto se puede observar claramente con el análisis que presenté del Estatuto Comunal de Móctum (véase CAPítulo 5), que revela los usos del derecho dominante a nivel local, pero además, muestra un punto de transición crucial para este pueblo: de ser una comunidad sojuzgada, pasa a ser una comunidad reconocida en sus límites territoriales y jurisdiccionales.

\section{El eje de la justicia}

Una de las críticas que se le ha hecho al derecho indígena o a los sistemas normativos de los indígenas es que sobreponen el derecho colectivo al derecho individual, lo que para el pensamiento jurídico positivista es aberrante porque puede prestarse a imposiciones y abusos del poder. Podemos decir que el derecho mexicano, eminentemente liberal y respetuoso de los derechos y garantías individuales, no está exento de una crítica parecida ya que en aras de la aplicación 
estricta de la ley pasa sobre derechos colectivos e individuales. A esto se agrega que el Estado no acepta que los derechos humanos a nivel internacional han cambiado e incorporado nuevos derechos que en 1948 - año de la Declaración Universal de Derechos Humanos - eran insospechados; algunos de ellos son los derechos de los pueblos indígenas - no como minorías ni como sindicatos ni como corporaciones civiles -, el conocimiento tradicional - que revoluciona el concepto de propiedad intelectual -, el medio ambiente, el derecho al desarrollo.

Dada la influencia de los discursos y reivindicaciones de los derechos humanos que las comunidades indígenas han experimentado, se puede observar el manejo de ese lenguaje por parte de las autoridades y vecinos de los pueblos al dirimir disputas, pero también modificaciones en su proceder y en sus mecanismos de sanción. El problema se presenta cuando los indígenas han tratado de acoplar sus sistemas jurídicos a los requerimientos nacionales e internacionales en materia de derechos humanos - incluyendo los derechos colectivos -, pero el Estado y sus agentes no hacen lo propio de incorporar en su práctica lo que en el marco jurídico mexicano ya existe $-\mathrm{y}$ lo que a nivel internacional los obliga (véase la discusión y decisión más reciente de la Corte de Justicia de la Nación sobre la aplicación de los Tratados Internacionales, que limita su aplicación sobre todo en materia de derechos humanos) - ${ }^{210}$ Considero que una crítica al sistema normativo indígena debe considerar tanto la tarea del Estado de establecer otro tipo de relación con los pueblos indígenas y sus autoridades, como comprender la historia de los conflictos y disputas, las dinámicas internas, las motivaciones y razones que las autoridades comunitarias aplican en sus resoluciones; sobre todo, en los casos en los que desde la perspectiva positivista se están dañando derechos e intereses individuales - por

210 En nota del periódico La Jornada (15 de febrero de 2007) Laura Poy y Víctor Ballinas reportan: “Con la decisión de la Suprema Corte de Justicia de la Nación (SCJN) de aplicar un criterio por el cual los tratados internacionales están por encima de las leyes federales y estatales, pero no de la Constitución, se incurre en una visión 'piramidal' del sistema de protección de derechos, pues se coloca un "dique que limita la posibilidad de que un ciudadano pueda invocar un tratado o acuerdo internacional que le brinda más protección", aseguró Miguel Ángel Eraña, especialista en derecho constitucional de la Universidad Iberoamericana". 
lo regular los afectados, generalmente miembros de esas comunidades, previamente han roto con normas internas que anteriormente aceptaron como válidas y participaron en su formulación e imposición.

Por otro lado, lo territorial representa un ámbito espacial de la acción humana sobre todo de las autoridades indígenas, ya que les marca un límite en su actuar y su poder (o potestad jurisdiccional) para resolver asuntos - véase el CAPÍTULO 6-, por ejemplo, cuando el presidente municipal intentó intervenir en un asunto agrario, exclusivo de Móctum; o en el caso del migrante que pretendía acudir con un abogado para demandar a las autoridades de Móctum, sin embargo, su familia le hizo desistir ante el efecto negativo que esa acción tendría para su vida en la comunidad, pues después nadie lo podría ayudar. También, la territorialidad del municipio representa un límite en la intervención de los agentes del Estado sobre las dinámicas internas de las comunidades, como se pudo demostrar en el CAPítulo 5 -véase el caso del amparo y de la intervención del Ministerio Público, en un caso que las autoridades consideraban resuelto; o en el caso de las maestras, donde los agentes del Estado necesitaban a las comunidades y sus autoridades para realizar las indagaciones sobre el paradero de los cuerpos y, posteriormente, para conocer las causas de su deceso.

Como lo he anotado, lo territorial constituye un referente central en la disputa por la afirmación comunitaria tal como se mostró en los CAPítulos 2, el contexto histórico; 3, el caciquismo regional; y 4, la cuestión agraria como estructuradora del derecho. Esto indudablemente plantea un cambio estructural importante para Móctum, ya que en ese proceso de reivindicación de la tierra logró la constitución de sus órganos de autoridad agraria (el Comisariado de Bienes Comunales y el Consejo de Vigilancia) reconocidos por la Ley Federal de Reforma Agraria y la actual Ley Agraria y, por consiguiente, el establecimiento de sus propias normas internas. Así, el territorio, como ámbito de competencia y posibilidad de acción para las autoridades indígenas, es una expresión más de la 
disputa sobre la justicia, pues Móctum tuvo que recurrir a las instancias del distrito Mixe y del estado de Oaxaca para hacer efectiva esa reivindicación.

En la actualidad, después de finiquitado el conflicto agrario, la tensión territorial se ha transformado en una disputa de competencia y jurisdicción, ya que recurrir a las instancias jurídicas del nivel legal superior (por ejemplo, pasar de la agencia a la cabecera, o de ésta al distrito) representa un cuestionamiento de la autoridad comunitaria, más cuando el asunto se considera resuelto en la primera instancia - véase en el CAPÍtulo 5, el caso de la mujer que demandó a su esposo ante el juez en el distrito y causó el enojo del Alcalde Único Constitucional de Totontepec-. Quizá las autoridades indígenas no percibirían como un desacato o afrenta que los particulares o usuarios indígenas acudan a otra instancia, si en ésta, por ejemplo, el juez de distrito o el Ministerio Público tomará en cuenta la justicia hecha en las comunidades. La experiencia ha sido que las autoridades del Estado se han preocupado más en señalar los "errores" de las autoridades indígenas y obligar a que éstas sigan los preceptos y formalidades del derecho positivo, que en entender la lógica y la dinámica comunitaria, que explica tal o cual acuerdo o sanción.

La justicia guarda estrecha relación con lo territorial - sobre todo en su dimensión agraria - porque a través del sistema jurídico del Estado, éste establece categorías jurídicas y formas de organización para designarlos, como la comunidad y el ejido, y ha dictado las formas y procedimientos para que los pueblos indígenas pueden acceder a la tierra, sin tomar en cuenta los procesos históricos y los fraccionamientos territoriales que las demarcaciones estatales y municipales han impuesto a la integridad de los territorios indígenas. Esto ha sido una constante en las dinámicas agrarias y políticas del estado de Oaxaca - véase la historia de las reivindicaciones agrarias (Zafra 1980; Arellanes 1999; el caso de Jaltepec de Candayoc, Cruz 1992) citado en este trabajo.

Otro aspecto a destacar ha sido la confrontación en el campo jurídico entre sistemas legales distintos o formas de derecho diversas, por lo que se refiere a las 
formas de hacer justicia en las tres vertientes antes apuntadas: la competencia, la materia y las sanciones. La primera se refiere a los asuntos que le tocan o no resolver a la autoridad indígena; la segunda valora si se trata, por ejemplo, de terrenos comunales o no, si los asuntos son graves o no; y, por último, la tercera, si la sanción es multa, amonestación, encarcelamiento o expulsión.

Estamos ante una confrontación de formas distintas de derecho y sobre el objeto de la justicia. Por ejemplo, en el caso del alcalde de Totontepec, le queda claro que no puede conocer de asuntos calificados como graves por el Estado -como las lesiones, la violación y el homicidio-, pero desde su perspectiva los asuntos graves no incluyen las lesiones que desfiguran el rostro o bien, que pueden dejar incapacitado de la vista a una persona (que en el derecho del Estado sí son graves). También en el caso de las sanciones, para el alcalde, como para muchas autoridades en comunidades indígenas, es correcto aplicar multas y encarcelar, sin embargo, aunque el derecho positivo no lo permite, lo siguen haciendo.

El estudio del campo jurídico en zonas indígenas revela que, a pesar de la situación de subalternidad de los pueblos indígenas frente al Estado, es posible apreciar un derecho propio, que si bien tiene influencias fuertes del derecho positivo no sigue al pie de la letra o en rigor su lógica. Más bien, desde las comunidades y pueblos indígenas se dan usos propios del derecho positivo (de acuerdo a su cultura y a su historia), y reformulaciones del mismo para ser aplicados a las necesidades cotidianas.

Pese al afán que el Estado tiene de influir y de controlar las maneras de hacer justicia en las comunidades, las autoridades indígenas han encontrado las formas de poner límites a esa injerencia, con mayor o menor éxito, lo que les ha permitido reformular y transformar su propio derecho, que finalmente responde a la cultura de la cual provienen.

Como parte de la influencia del derecho positivo en las dinámicas internas de comunidades indígenas y en su derecho interno, expuse el ejemplo de la justicia en la alcaldía de Totontepec y en la agencia municipal de Móctum. En Totontepec 
la ley del Estado está presente a través de los agentes estatales y de organizaciones sociales como las proétnicas y de derechos humanos, o profesionistas como los abogados y maestros indígenas. En Móctum, el diseño del estatuto comunal revela cómo el Estado ejerce su hegemonía y aplica un control institucional sobre las dinámicas de la comunidad, al mismo tiempo que define las normas que debe seguir para regular su vida interna.

Por último, debo señalar que no pude profundizar en los referentes culturales que intervienen en un conflicto y su resolución, tal como lo planté en la introducción, fundamentalmente por mi falta de dominio del idioma mixe. No obstante sí fue posible dar cuenta de expresiones relativas a la organización comunitaria y el trabajo colectivo y solidario - como el tequio, la mano vuelta y la gozona, así como los sistemas de cargo - vigentes también en otras comunidades del pueblo ayuuk, lo que revela el fuerte sentido de comunalidad que manifiestan. Dicho arraigo comunitario e identitario al pueblo mixe si bien abre opciones para construir discursos colectivos de reivindicación étnica, también puede significar el exacerbamiento de localismos en momentos de conflicto, tal como se expresó en las etapas más ríspidas del conflicto agrario entre Totontepec y Móctum (donde las mujeres tuvieron que actuar, ya que los hombres de la comunidad habían sido apresados, solicitando a través de los maestros indígenas la intervención de la ASAM).

De igual forma, no abordé otros aspectos que indudablemente están marcando hoy en día el campo jurídico, como la religión y la migración. Respecto al primer aspecto tuve la oportunidad de constatar el importante papel que jugó la conversión religiosa al adventismo de la mayoría de los habitantes de Móctum, lo que sin duda influyó en la construcción de las diferencias y distancias entre la cabecera y la agencia, en fortalecer el arraigo comunitario y en la reivindicación de la tierra. 


\section{Perspectivas de investigación}

Considero que este trabajo deja pendientes varias líneas de investigación que me interesa indagar en un futuro:

1) El derecho indígena y las relaciones inter e intraétnicas, tomando en cuenta la relación desigual que involucra el ámbito municipal. En el caso de análisis, destaca la descaracterización de la cabecera y sus pretensiones de superioridad sobre las agencias, lo que lleva a plantearse: ¿se puede hablar de un racismo interno entre comunidades de un mismo pueblo indígena?; ¿cómo se refleja esto en el derecho y en las dinámicas del campo jurídico?; ¿en qué puede contribuir este estudio al debate sobre el pluralismo jurídico?

2) El estudio del derecho indígena con una cobertura más amplia tomando en cuenta los elementos metodológicos y de análisis vertidos en este trabajo, aplicándose a una selección representativa de los 19 municipios que integran el territorio mixe (véase MAPA 2), con el fin de reconstruir aspectos recurrentes y contrastantes en la construcción del derecho en comunidades mixes: ¿En qué sentido una perspectiva de este tipo puede apoyar la reconstrucción del derecho mixe?; ¿cuáles son las expresiones diferenciadas del derecho mixe?; ¿cómo el contacto cultural con otros pueblos indígenas aporta nuevos elementos a la justicia de las comunidades mixes?

3) En qué sentido las nuevas legislaciones nacionales y estatales relativas al reconocimiento del derecho indígena han impactado en las jurisdicciones indígenas y en las prácticas mismas de la justicia.

4) Estudiar el impacto de fenómenos como la migración y la conversión religiosa, en la redefinición de los sistemas normativos y en las formas de hacer justicia en las comunidades indígenas.

5) El estudio de la vinculación entre las formas de propiedad y tenencia de la tierra, con la configuración territorial étnica, es decir, el tipo de tenencia de la tierra -privada o colectiva-, en una comunidad indígena ¿es 
determinante en sus formas de justicia y de derecho?, ¿cómo esas formas de tenencia de la tierra configuran un discurso sobre la territorialidad?, ¿varía las formas de ejercer la jurisdicción indígena, según esos tipos de tenencia?

Finalmente, quería señalar que para mi práctica profesional esta experiencia de investigación me ha permitido incursionar en temas tradicionalmente considerados "impensables" en mi disciplina de origen, desde una perspectiva novedosa, conjuntando la antropología y el derecho, lo que sin duda me ha abierto nuevos senderos y alternativas de investigación. Tal es por ejemplo, el estudio del conocimiento tradicional como parte de los derechos colectivos, analizado desde la legislación sobre propiedad intelectual; 211 o la interacción entre antropólogos y juristas, concretamente con jueces en zonas indígenas ${ }^{212}$ así como con abogados y abogadas indígenas. ${ }^{213}$ Considero que el campo de investigación de la antropología jurídica abre espacios diversos de debate en los que interactuamos profesionistas de distintas disciplinas y desde nuevas ópticas, para encontrar respuestas prácticas a viejos problemas en torno a la justicia, el derecho y la cultura.

211 En los años 2006 y 2007, participé en el Programa de Recursos Colectivos de la Comisión Nacional para el Conocimiento de la Biodiversidad en México (CONABIO), como consultora en materia jurídica para realizar un análisis sobre la legislación mexicana en materia de derechos colectivos y conocimiento tradicional, en su relación con los recursos naturales y biológicos, y la propiedad intelectual. En el marco de esta consultoría pude aplicar mis conocimientos antropológicos para explicar cómo los pueblos indígenas han transformado su conocimiento sobre recursos naturales y biológicos que se encuentran en sus territorios, lo que me permitió hacer propuestas para llegar a un sistema sui generis de reconocimiento del conocimiento tradicional en México, que a nivel internacional se está discutiendo, sobre todo, en espacios de la ONU como la Organización Internacional de la Propiedad Intelectual (OMPI).

${ }^{212}$ Quiero aprovechar para agradecer a la Dra. María Teresa Valdivia Dounce por su invitación para incorporarme como docente en el programa de la maestría en Administración de Justicia en la Universidad Autónoma de Veracruz, que año con año se realiza, congregando a jueces y magistrados que atienden asuntos en zonas indígenas de ese estado, sobre todo, en materia penal. También agradezco a la Dra. Artemia Fabre Zarandona por invitarme a participar como ponente en los distintos diplomados sobre peritaje antropológico que ha organizado junto con la Coordinación Nacional de Antropología del INAH.

${ }^{213}$ En la oficina del Alto Comisionado de Naciones Unidas para los Derechos Humanos en Oaxaca (OACNUDH). En esta experiencia con mis colegas indígenas, pudimos compartir conocimientos diversos sobre el derecho y el derecho indígena, lo que indudablemente me ha ayudado en otros proyectos laborales. 


\section{BiBLIOGRAFÍA}

\section{A}

S/f Acevedo Conde, María Luisa, y María Teresa Pardo. Proyecto etnográfico sobre los municipios oaxaqueños. Centro de Investigaciones y Estudios Superiores en Antropología Social-Pacífico Sur. Oaxaca.

1998 Adame Goddard, Jorge. "Principios Generales del Derecho", en: Diccionario Jurídico Mexicano. Instituto de Investigaciones Jurídicas-Porrúa. México.

1978 Adams Newbold, Richard. La red de la expansión humana. Centro de Investigaciones Superiores del INAH. México.

1983 Energía y Estructura. Una teoría del Poder Social. Fondo de Cultura Económica. México.

1992 Aguilar Domingo, Martín. Zacatepec, Mixe. Círculo Fraternal de Zacatepec, Mixe- Casa de la Cultura Oaxaqueña. Oaxaca.

1991 Aguirre Beltrán, Gonzalo. Formas de gobierno indígena, Fondo de Cultura Económica (Obra Antropológica: IX). (Primera edición, 1953). México.

2003 Alcántara Bernal, Juan Arelí, y Noemí Ortiga Rivera. Mook jyööjtsykin ax jö'n ayuuk jayu di izada. El ciclo de vida del maíz según los mixes. Instituto Estatal de Educación Pública de Oaxaca. Oaxaca.

2004 Alcántara Núñez, Honorio. Usos y costumbres. Vivencias y convivencias de un alcalde mixe. Consejo Nacional para la Cultura y las Artes-Dirección General de Culturas Populares e Indígenas. México.

1998 Arcos García, María de los Ángeles. Las velas tateikietari... invocando la lluvia y la lucha de un pueblo. (Tesis de maestría en Desarrollo Rural). Universidad Autónoma Metropolitana Xochimilco. México.

2007 _. Enraizar al mundo por sus cinco vértices. La estrategia de lucha territorial de los indígenas huicholes (1991-2005), Sierra Madre Occidental de México. Departamento de Geografía de la Universidad Autónoma de Barcelona.

1999 Arellanes Meixueiro, Anselmo. Oaxaca. Reparto de la tierra, alcances, limitaciones y respuestas. Universidad Autónoma "Benito Juárez" de Oaxaca-Universidad Nacional Autónoma de México. (Segunda edición). Oaxaca.

\section{B}

1999 Bailón Corres, Jaime. Pueblos indios, élites y territorio. El Colegio de México. México. 
2001Bailón Vásquez, Fabiola. La conformación del territorio huave durante el periodo colonial (s. XVI-XVIII): la lucha por el acceso y control económico y político de los recursos naturales en la costa del Istmo de Tehuantepec, Oaxaca. (Tesis de licenciatura en Etnohistoria). Escuela Nacional de Antropología e Historia. México.

1998Barabas, Alicia Mabel. "Reorganización etnopolítica y territorial: caminos oaxaqueños para la autonomía", en Miguel A. Bartolomé y Alicia M. Barabas, coords. Autonomías étnicas y Estados nacionales, pp. 343-366. Instituto Nacional de Antropología e Historia. México.

2004

"Estructuras políticas indígenas en Oaxaca: Un acercamiento etnográfico", en Robles García, ed. Estructuras políticas en el Oaxaca antiguo, pp. 339-370. Instituto Nacional de Antropología e Historia. México.

1999aBarabas, Alicia Mabel, y Miguel Alberto Bartolomé. “Los protagonistas de las alternativas autonómicas", en Alicia M. Barabas y Miguel A. Bartolomé, coords. Configuraciones étnicas en Oaxaca. Perspectivas etnográficas para las autonomías, Vol. I., pp. 14-56. Instituto Nacional Indigenista-Instituto Nacional de Antropología e Historia, 3 volúmenes. México.

$1999 \mathrm{~b}$ coords. "A manera de Prólogo", en: Configuraciones étnicas en Oaxaca. Perspectivas etnográficas para las autonomías, pp. 9-13. Instituto Nacional Indigenista-Instituto Nacional de Antropología e Historia, 3 volúmenes. México.

2004 Barabas, Alicia M., Miguel Bartolomé y Benjamín Maldonado. “Los pueblos indios de Oaxaca", en Alicia Barabas, et al. Los pueblos indígenas de Oaxaca. Atlas etnográfico, pp. 11-17. Fondo de Cultura EconómicaSecretaría de Asuntos Indígenas Gobierno del Estado de Oaxaca. México.

1997 Bartolomé, Miguel Alberto. Gente de costumbre y gente de razón. Siglo Veintiuno-Instituto Nacional Indigenista. México.

2001_. "Las palabras de los otros: la antropología escrita por indígenas en Oaxaca", en Inventario antropológico. Anuario de la revista Alteridades, Vol. 7, pp. 43-87.

2005 _ "Una lectura comunitaria de la etnicidad en Oaxaca”, en Miguel Lisbona Guillén, La comunidad a debate. Reflexiones sobre el concepto de comunidad en el México contemporáneo, pp. 101-119. El Colegio de Michoacán-Universidad de Ciencias y Artes de Chiapas. Michoacán.

1998 Bartolomé, Miguel A., y Alicia M. Barabas. "Introducción”, en Miguel A. Bartolomé y Alicia M. Barabas, coords. Autonomías étnicas y Estados nacionales, pp. 15-28. Instituto Nacional de Antropología e Historia. México.

1976 Bartra, Roger. "Campesinado y poder político en México", en Caciquismo y poder político en el México rural, pp. 5-30. Siglo Veintiuno-Instituto de Investigaciones Sociales-Universidad Nacional Autónoma de México. México. 
2004 Bautista Cruz, Melitón. Normas de convivencia a través de acuerdos comunitarios. Consejo Nacional para la Cultura y las Artes-Dirección General de Culturas Populares e Indígenas-Instituto Oaxaqueño de las Culturas. Oaxaca.

1979Beulink, Anne Marie. Quítame un retrato. Una etnografía de la región mixe, Oaxaca. (Manuscrito sujeto a revisión). Instituto Nacional Indigenista (mimeografiado). México.

1993 Bohannan, Paul, y Mark Glazer, comps. Antropología: lecturas McGraw-Hill. (Segunda edición). Madrid.

2002 Burguete Cal y Mayor, Araceli. “Remunicipación en Chiapas: reorganización territorial inconclusa", en: CEMOS-Memoria, número 157, versión electrónica <http://memoria.com.mx/157/Burguete.htm> [consultado el 27 de febrero 2007]. México.

\section{C}

2000Campos Orozco, Jesús. “Finanzas públicas para el desarrollo municipal: reformas y recursos para 2000", en Instituto de Desarrollo Municipal, Partido de la Revolución Democrática. $A B C$ del gobierno municipal, pp. 143-177. Grupo parlamentario del PRD-Cámara de Diputados LVII Legislatura-Congreso de la Unión. México.

1965 Cancian, Frank. Economics and prestige in a Maya community: The religious cargo system in Zinacantan. Stanford University Press. Stanford

1990 Economía y prestigio en una comunidad maya. El sistema religioso de cargos en Zinacantán. Instituto Nacional Indigenista. México.

2000 Carrithers, Michael. "Cultura", en Thomas Barfield, ed. Diccionario de antropología, pp. 138-141. Siglo Veintiuno. México.

2000 Castellanos Guerrero, Alicia. "Racismo, multietnicidad y democracia en América Latina", en Nueva Antropología. [Núm. monográfico sobre "Racismo y pueblos indios en América Latina"], Vol. XVII, núm. 58, pp. 9-25.

2001 Centro de Derechos Humanos Tepeyac del Istmo de Tehuantepec. Los derechos humanos en el Istmo en época de... ¿cambio político? IX informe. Centro de Derechos Humanos Tepeyac del Istmo de Tehuantepec. Santo Domingo Tehuantepec.

1998 Chance, John. La conquista de la Sierra. Españoles e indígenas de Oaxaca en la época de la Colonia. Instituto Oaxaqueño de las Culturas-Fondo Estatal para la Cultura y las Artes-Centro de Investigaciones y Estudios Superiores en Antropología Social. Oaxaca.

1987 Chance, John K., y William B. Taylor "Cofradías y cargos: una perspectiva histórica de la jerarquía cívico-religiosa mesoamericana", en Antropología 
(Boletín Oficial del Instituto Nacional de Antropología e Historia), Suplemento, Núm. 14, mayo-junio.

1984 Chávez Chávez, Jorge. Legalización de un sistema de colonialismo interno en el México del siglo XIX: las leyes de desamortización de 1856, culminación de un proceso. (Tesis de licenciatura en Antropología Social). Escuela Nacional de Antropología e Historia. México.

1999 Chenaut González-Lelong, María Victoria. Honor, disputas y usos del derecho entre los totonacas del distrito judicial de Papantla. (Tesis de doctorado en Ciencias Sociales). El Colegio de Michoacán. Zamora.

1995aChenaut González-Lelong, María Victoria, y María Teresa Sierra. "Introducción: La antropología jurídica en México: Temas y perspectivas de investigación", en: Victoria Chenaut y María Teresa Sierra, coords. Pueblos Indígenas ante el derecho, pp. 13-41. Centro de Investigaciones y Estudios Superiores en Antropología Social-Centro Francés de Estudios Mexicanos y Centroamericanos. México.

1995bChenaut González-Lelong, María Victoria y María Teresa Sierra, coords. Pueblos Indígenas ante el derecho. Centro de Investigaciones y Estudios Superiores en Antropología Social-Centro Francés de Estudios Mexicanos y Centroamericanos. México.

1995a Collier, Jane F. El derecho zinacanteco. Procesos de disputar en un pueblo indígena de Chiapas. Centro de Investigaciones y Estudios Superiores en Antropología Social-Universidad de Ciencias y Artes del Estado de Chiapas. México.

$1995 b$ "Problemas teórico-metodológicos en la antropología jurídica", en Victoria Chenaut González-Lelong y María Teresa Sierra, coords. Pueblos Indígenas ante el derecho. Centro de Investigaciones y Estudios Superiores en Antropología Social - Centro Francés de Estudios Mexicanos y Centroamericanos. México.

1981 Comaroff, John, y Simon Roberts. Rules and Processes. The Cultural Logic of Dispute in an African Context. The University of Chicago Press. Chicago

1991aComisión Nacional de Derechos Humanos (CNDH). Memoria de la zona mixe en el estado de Oaxaca. Comisión Nacional de Derechos Humanos. México.

$1991 b$ Recomendación Núm. 103/91. Recomendación sobre el caso de la comunidad de San Juan Jaltepec de Candayoc, Municipio de Cotzocón, Distrito Mixe, Oaxaca. Comisión Nacional de Derechos Humanos. México.

1998 Comisión Permanente de Asuntos Indígenas, LVI Legislatura del Estado. Derechos indígenas en la Legislación Oaxaqueña. LVI Legislatura del Estado de Oaxaca. Oaxaca.

1994 Correas, Óscar. "Teoría general del derecho y derecho indígena", en Crítica Jurídica, Núm. 14, pp. 15-31. 
1992 Cruz Rueda, Elisa. El derecho de los pueblos indios como un derecho alternativo. (Tesis de licenciatura en Derecho, seminario de sociología). Facultad de Derecho-Universidad Nacional Autónoma de México. México.

1995 “El EZLN: ¿Un doble poder?”, en Gerardo Gómez González y José Emilio R. Ordóñez Cifuentes, coords. Derecho y poder: la cuestión de la tierra y los pueblos indios, pp. 139-149. Universidad Autónoma de Chapingo. México.

1997 _ El sistema normativo indígena frente al derecho mexicano: el sistema normativo en San Marcos Móctum, Mixe, Oaxaca, como expresión de la Autonomía Indígena. (Tesina de maestría en Ciencias Antropológicas). Universidad Autónoma Metropolitana Iztapalapa. México.

2000 _ .El sistema de seguridad pública indígena comunitaria", en José Emilio Rolando Ordóñez Cifuentes, coord. Análisis interdisciplinario del Convenio 169 de la OIT. IX Jornadas Lascasianas, pp. 15-25. Universidad Nacional Autónoma de México. México.

2004 _ "Normas y procesos en San Marcos Móctum: expresiones del derecho mixe", en María Teresa Sierra Camacho, ed. Haciendo justicia. Interlegalidad, derecho y género en regiones indígenas, pp. 299-357. Cámara de Diputados LIX Legislatura-Centro de Investigaciones y Estudios Superiores en Antropología Social-Miguel Ángel Porrúa. México.

2005 _ "Los principios generales del derecho en Totontepec Mixe, Oaxaca", ponencia presentada en el Encuentro Pueblos y Fronteras, PreCongreso de la Red Latinoamericana de Antropología Jurídica, San Cristóbal de las Casa, Chiapas (5-9 de octubre), PROIMMSE-UNAM.

\section{D}

2001 Dehouve, Danielle. Ensayo de geopolítica indígena. Los municipios tlapanecos. Centro de Investigaciones y Estudios Superiores en Antropología SocialCentro Francés de Estudios Mexicanos y Centroamericanos-Miguel Angel Porrúa. México.

1998 De la Cruz, Luis. Manual de Autoridades Auxiliares. Centro de Servicios Municipales "Heriberto Jara", A.C. México.

1994 Díaz Gómez, Floriberto. “El caciquismo y la violación de los derechos humanos del pueblo mixe", en Salomón Nahmad Sittón, coord. Fuentes etnológicas para el estudio de los pueblos ayuuk (mixes) del estado de Oaxaca, pp. 553-570. Centro de Investigaciones y Estudios Superiores en Antropología Social del Istmo-Instituto Oaxaqueño de las Culturas. Oaxaca.

1992 Díaz Montes, Fausto. Los municipios. La disputa por el poder en Oaxaca. Universidad Autónoma "Benito Juárez" de Oaxaca-Instituto de Investigaciones Sociológicas-Gobierno del Estado de Oaxaca. Oaxaca. 
1994 Durand Alcántara, Carlos. Derechos indios en México... derechos pendientes. Universidad Autónoma de Chapingo. México.

\section{$\mathbf{E}$}

2002 Escalante Betancourt, Yuri. "Luces y sombras en el reconocimiento constitucional de los sistemas normativos de los pueblos indígenas", en: México Indígena, Vol. 1, núm. 3, pp. 59-67.

\section{$\mathbf{F}$}

1985 Fabre Zarandona, Artemia. Continuidad o ruptura. Relaciones de poder: un conflicto político-religioso. (Tesis de licenciatura en Antropología Social). Universidad Autónoma Metropolitana Unidad Iztapalapa. México.

2005 _. Libertad religiosa y colisión de sistemas jurídicos. Los pueblos indígenas y el Estado mexicano. (Tesis de doctorado en Ciencias Antropológicas). Universidad Autónoma Metropolitana Unidad Iztapalapa. México.

2003 Falcón, Román. "Prólogo. Invitación al diálogo", en Florencia Mallon. Campesino y nación. La construcción de México y Perú poscoloniales, pp. 3750. El Colegio de San Luis-El Colegio de Michoacán-Centro de Investigaciones y Estudios Superiores en Antropología Social. México.

1998 Fitzpatrick, Meter. La mitología del derecho moderno. Siglo XXI. México.

1997 Florescano, Enrique. Etnia, Estado y Nación. Ensayo sobre las identidades colectivas en México. Aguilar. México.

\section{G}

2004 García Arreola, Ana María, J. Dionisio B. Córdova Tello, Gelacio Morga Cruz y Alejandro Sandoval Torres. Autoridades locales en municipios indígenas. Centro de Servicios Municipales "Heriberto Jara", A.C. México.

1987 Garma Navarro, Carlos. Protestantismo en una comunidad totonaca de Puebla, México. Instituto Nacional Indigenista. México.

1986 Gerhard, Peter. Geografía histórica de la Nueva España. 1519-1821. Universidad Nacional Autónoma de México. México.

1978 González Casanova, Pablo. Sociología de la explotación. Siglo Veintiuno. (Novena edición). México.

1995 González Galván, Jorge A. El Estado y las etnias nacionales en México: la relación entre el derecho estatal y el derecho consuetudinario. Universidad Nacional Autónoma de México. México.

2004 Gómez Bravo, Noemí. Móctum: Antigua grandeza de un pueblo mixe. Fondo para la Cultura y las Artes-Gobierno del Estado de Oaxaca. Oaxaca.

1990 Gómez Rivera, Magdalena. “La defensoría jurídica de presos indígenas”, en Rodolfo Stavenhagen y Diego Iturralde, comps. Entre la ley y la costumbre: 
el derecho consuetudinario indígena en América Latina, pp. 371-388. Instituto Indigenista Interamericano-Instituto Interamericano de Derechos Humanos. México-San José.

1997 Gómez Rivera, Magdalena, coord. Derecho indígena. Instituto Nacional Indigenista-Asociación Mexicana para las Naciones Unidas. México.

2001 Gutiérrez Chong, Natividad. Mitos nacionalistas e identidades étnicas: los intelectuales indígenas y el estado mexicano. Instituto de Investigaciones SocialesPlaza y Valdés. México.

\section{H}

1996 Hernández Díaz, Jorge, y Jesús Lizama Quijano. Cultura e identidad étnica en la región huave. Instituto de Investigaciones Sociológicas-Universidad Autónoma "Benito Juárez" de Oaxaca. Oaxaca.

2001 Hernández Díaz. Reclamos de la identidad: formación de las organizaciones indígenas en Oaxaca. Universidad Autónoma "Benito Juárez" de OaxacaMiguel Ángel Porrúa. México.

2000 Instituto Nacional de Estadística, Geografía e Informática (INEGI). (2001). "Tabulados Básicos Estados Unidos Mexicanos". Tomo I (tres tomos) en XII Censo General de Población y Vivienda 2000. México.

1997 Iturralde, Diego. "Desarrollo indígena: los retos de final de siglo", en Magdalena Gómez, coord. Derecho Indígena, pp. 381-406. Instituto Nacional Indigenista-Asociación Mexicana para las Naciones Unidas. México.

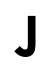

2003 Juan Martínez, Víctor Leonel. "Reforma municipal, ¿fortalecimiento o violación de la autonomía?", en En Marcha, pp. 4-6, Núm. 50.

\section{K}

2000 Keyes, Charles. "Etnicidad, grupos étnicos", en Thomas Barfield, ed. Diccionario de antropología, pp. 203-206. Siglo Veintiuno. México.

1993 König, Viola. "Mapa antiguo de Tiltepec mixes". (Lienzo de San Miguel Metepec), en König, Viola. Die Schlacht bei Sieben Blumen. Konquistadoren, Kaziken und Konflikte aufalten Landkarten der Indianer Südmexikos, pp. 175205. Temmen. Bremen. 
1996 Korsbaek, Leif. "Introducción al sistema de cargos", en Leif Korsbaek. Introducción al sistema de cargos, pp. 31-52. Universidad Autónoma del Estado de México. Estado de México.

1995 Krotz, Esteban. “Órdenes jurídicos, antropología del derecho, utopía. Elementos para el estudio antropológico de lo jurídico", en Victoria Chenaut y Teresa Sierra, coords. Pueblos Indígenas ante el derecho, pp. 345353. Centro de Investigaciones y Estudios Superiores en Antropología Social-Centro Francés de Estudios Mexicanos y Centroamericanos. México.

1997 _. "Aproximaciones a la cultura jurídica en Yucatán", en Esteban Krotz, coord. Aspectos de la cultura jurídica en Yucatán, pp. 9-29. Maldonado. Mérida.

$2002 \mathrm{a}$ . La Otredad Cultural entre la utopía y ciencia. Un estudio sobre el origen, el desarrollo y la reorientación de la antropología. Universidad Autónoma Metropolitana Unidad Iztapalapa-Fondo de Cultura Económica.

$2002 b$ "Sociedades, conflictos, cultura y derecho desde una perspectiva antropológica", en: Esteban Krotz, ed. Antropología jurídica: perspectivas socioculturales en el estudio del derecho, pp. 13-49. AnthroposUniversidad Autónoma Metropolitana Iztapalapa. Barcelona-México.

2006 _ "Yucatán, identidad y cultura maya: Reforma legislativa y diálogo intercultural: consideraciones y propuestas relativas a la idea de promover una legislación sobre los derechos y la cultura del pueblo maya en el Estado de Yucatán". <http://www.uady.mx/sitios/mayas/articulos/reforma.html> [consultado el 16 de mayo de 2006]

1993 Kuroda, Etzuko. Bajo el Zempoaltepetl. La sociedad mixe de las tierras altas y sus rituales. Centro de Investigaciones y Estudios Superiores en Antropología Social-Instituto Oaxaqueño de las Culturas. Oaxaca

1978 Laviada, Iñigo. Los caciques de la sierra. Jus. México.

1994 Lazarus-Black, Mindie, y Susan Hirsch, eds. Contested States: Law, Hegemony and Resistance, Routledge. Nueva York.

2005. Lisbona Guillén, Miguel. La comunidad a debate. Reflexiones sobre el concepto de comunidad en el México contemporáneo. El Colegio de MichoacánUniversidad de Ciencias y Artes de Chiapas. Michoacán.

2007 López Bárcenas, Francisco. Constitucionalismo y derechos indígenas en Oaxaca, en $<$ www.laneta.apc.org/fiob/estudiosoaxacalifornia/francisco.html> [febrero 2007]. 


\section{M}

1998 Mair, Lucy. Introducción a la antropología social. Alianza (Décimo segunda ed). Madrid.

1998 Maldonado Alvarado, Benjamín. “Obstáculos internos para la construcción de autonomías indias: una perspectiva desde Oaxaca", en Miguel A. Bartolomé y Alicia M. Barabas, coords. Autonomías étnicas y Estados nacionales, pp. 367-384. Instituto Nacional de Antropología e Historia. México.

2003 "Organización social y política", en: Alicia M. Barabas, Miguel A. Bartolomé y Benjamín Maldonado, coords. Los pueblos indígenas de Oaxaca. Atlas etnográfico, pp. 21-49. Fondo de Cultura Económica-Secretaría de Asuntos Indígenas-Gobierno del Estado de Oaxaca-CONACULTA-Instituto Nacional de Antropología e Historia. México

1999 Maldonado Alvarado, Benjamín, y Margarita M. Cortés Márquez. “La gente de la palabra sagrada. El grupo etnolingüístico ayuuk jáay (mixe)", en Alicia M. Barabas y Bartolomé, Miguel A., coords. Configuraciones étnicas en Oaxaca. Perspectivas etnográficas para las autonomías, pp. 95-145. Instituto Nacional Indigenista-Instituto Nacional de Antropología e Historia, Vol. II. México.

2003 Mallon, Florencia E. Campesino y nación. La construcción de México y Perú poscoloniales. El Colegio de San Luis-El Colegio de Michoacán- Centro de Investigaciones y Estudios Superiores en Antropología Social. México.

1883 Martínez Gracida, Manuel, ed. Cuadros sinópticos de los pueblos, haciendas y ranchos del estado libre y soberano de Oaxaca. Congreso del estado de Oaxaca. (Colección anexo Núm. 50 A: La memoria Administrativa al H. Congreso del mismo, 17 de septiembre 1883, Vol. II). Oaxaca.

2003 Martínez Luna, Jaime. Comunalidad y Desarrollo. Centro de Apoyo al Movimiento Popular Oaxaqueño, A.C. Oaxaca.

2004 Martínez Martínez, Juan Carlos. Derechos Indígenas en los juzgados. (Tesis de maestría en Antropología Social). Centro de Investigaciones y Estudios Superiores en Antropología Social Unidad Occidente. Guadalajara.

2006 Martínez Martínez, Juan Carlos. La nueva justicia tradicional: Interlegalidad y ajustes en los campos jurídicos de Santa María Tlahuitoltepec y Santiago Ixtayutla. (Tesis de doctorado en Antropología Social). Centro de Investigaciones y Estudios Superiores en Antropología Social. México.

1987 Medina Cervantes, José Ramón. Derecho Agrario. Harla. México.

1989 . Ley Federal de Reforma Agraria comentada. Harla, México. 
1995 Medina Hernández, Andrés. “Los sistemas de cargos en la Cuenca de México: una primera aproximación a su trasfondo histórico", en: Alteridades, Núm. 9, pp. 7-23.

1988 Merry, Sally Engle. “Legal Pluralism”, en Law and society, Vol. 22, Núm. 5, pp. 869-896.

1956 Miller, Walter S. Cuentos Mixes. Instituto Nacional Indigenista. México.

1995 Montes, Olga. "Los conflictos religiosos en Oaxaca: una aproximación a su estudio", en: Enrique Marroquín Z., coord. ¿Persecución religiosa en Oaxaca?, pp. 25-70. Instituto Oaxaqueño de las Culturas-Instituto de Investigaciones Sociológicas de la Universidad Autónoma "Benito Juárez" de Oaxaca. Oaxaca.

1990 Moore, Sally Falk. Social facts and fabrications. Customary law on Kilimanjaro (1880-1980). Cambridge University Press. Nueva York.

1996 Münch Galindo, Guido. Historia y Cultura de los Mixes. Instituto de Investigaciones Antropológicas-Universidad Nacional Autónoma de México. México.

1978 Nader, Laura. "Introduction: The Disputing process", en Laura Nader y Harry F. Todd, eds. The Disputing Process: Law in Ten Societies. Columbia University Press. Nueva York.

1998 _. Ideología armónica: justicia y control en un pueblo de la montaña zapoteca. Instituto Oaxaqueño de las Culturas-Centro de Investigaciones y Estudios Superiores en Antropología Social del Istmo. Oaxaca.

1965 Nahmad Sittón, Salomón. Los mixes: estudio social y cultural de la región del Zampoaltepetl y del istmo de Tehuantepec. Instituto Nacional Indigenista. (Memorias del Instituto Nacional Indigenista, Vol. XI). México.

1990 _. "Ayuuk-Mixe: El primer centro de investigación indígena", en América Indígena, Vol. L, Núms. 2-3, pp. 35-61.

2003 _. Fronteras étnicas. Análisis y diagnóstico de dos sistemas de desarrollo: Proyecto nacional vs. proyecto étnico. Consejo Nacional de Ciencia y Tecnología-Centro de Investigaciones y Estudios Superiores en Antropología Social. México.

\section{$\mathbf{P}$}

1994 Pardo, María Teresa. "El territorio, la demografía y la lengua de los ayuuk”, en: Salomón Nahmad Sittón, ed., y comp. Fuentes etnológicas para el estudio de los pueblos ayuuk (mixes) del estado de Oaxaca, pp. 571-614. Centro de Investigaciones y Estudios Superiores en Antropología Social del Istmo-Instituto Oaxaqueño de las Culturas. Oaxaca. 
2005 Pérez Ruiz, Maya Lorena. “La comunidad indígena contemporánea. Límites, fronteras y relaciones interétnicas", enMiguel Lisbona Guillén. La comunidad a debate. Reflexiones sobre el concepto de comunidad en el México contemporáneo, pp. 87-100. El Colegio de Michoacán-Universidad de Ciencias y Artes de Chiapas. Michoacán.

1965 Pospíšil, Leopold. The Kapauku Papuans of West New Guinea. Nueva York.

1985 Pozas, Ricardo e Isabel Horcasitas de Pozas, Los indios en las clases sociales de México. Siglo Veintiuno (Décimo cuarta edición). México.

\section{$\mathbf{R}$}

1982 Ramírez Castañeda, Elisa, coord. Ap ayuuk. Cuentos mixes. Tradición oral indígena. Secretaría de Educación Pública-Comisión Nacional de Fomento Educativo. México

2002 Recondo, David. État et coustumes électorales dans l'Oaxaca (Mexique). Réflexions sur les enjeux politiques du multiculturalisme. (Thèse pour le doctorat en Science Politique). Droit, sciences sociales et politiques, sciences économiques et de gestion. Université Montesquieu-Bordeaux IV. Francia.

1996 Regino Montes, Adelfo. “Autonomía y derecho indígena", en Instituto Oaxaqueño de las Culturas, ed. Coloquio sobre derechos indígenas, pp. 130173. Instituto Oaxaqueño de las Culturas. Oaxaca.

1998 _ "La reconstitución de los pueblos indígenas", en Miguel A. Bartolomé y Alicia M. Barabas, coords. Autonomías étnicas y Estados nacionales, pp. 415-424. Instituto Nacional de Antropología e Historia. México.

2002 _ "La comunalidad. Raíz, pensamiento, acción y horizonte de los pueblos indígenas", en México indígena (nueva época), Vol. 1, Núm. 2, pp. 7-14.

1982 Romer, Marta. Comunidad, migración y desarrollo: el caso de los mixes de Totontepec. Instituto Nacional Indigenista. México.

1996 Romero Frizzi, María de los Ángeles. El sol y la cruz. Los pueblos indios de Oaxaca colonial. Centro de Investigaciones y Estudios Superiores en Antropología Social-Instituto Nacional Indigenista. México.

2005 "Peritaje Etnohistórico" (Conferencia dictada el $1^{\circ}$ febrero de 2005), en Diplomado Peritaje en Ciencias Antropológicas organizado por la Coordinación Nacional de Antropología del Instituto Nacional de Antropología Historia. México. 


\section{S}

1992 Sánchez Botero, Esther (comp). Antropología Jurídica. Normas formales: costumbres legales en Colombia. Comité Internacional para el Desarrollo de los Pueblos-Sociedad Antropológica de Colombia.

1998 Justicia y pueblos indígenas en Colombia. Universidad Nacional de Colombia-UNIJUS, Bogotá.

1991 Santos, Boaventura de Sousa. Estado, Derecho y Luchas Sociales. Instituto Latinoamericano de Servicios Legales Alternativos. Bogotá.

1995 Toward a New Common Sense: Law, Science and Politics in the Paradigmatic Transition. Routledge. Nueva Cork-Londres.

1998 - La globalización del derecho: los nuevos caminos de la regulación y la emancipación. ILSA-Universidad Nacional de Colombia. Bogotá.

1987 Sierra Camacho, María Teresa. El ejercicio discursivo de la autoridad en asambleas comunales. Metodología y análisis del discurso oral. Cuadernos de la Casa Chata. México.

1992 . "Conflictos entre la ley y la costumbre indígena", en Crítica Jurídica, Núm. 11, pp. 97-103.

1993 "Usos y desusos del derecho consuetudinario", en Nueva Antropología [núm. monográfico sobre "derechos de los pueblos indios"], Vol. XIII, Núm. 44, pp. 17-26.

1995 _. "Articulaciones entre la ley y la costumbre: estrategias jurídicas de los nahuas", en Victoria Chenaut y María Teresa Sierra. Pueblos Indígenas ante el derecho, pp. 101-124. Centro de Investigaciones y Estudios Superiores en Antropología Social-Centro Francés de Estudios Mexicanos y Centroamericanos. México.

2002

"Derecho indígena: herencias, construcciones y rupturas", en: Guillermo de la Peña y Luis Vásquez León, coords. La antropología sociocultural en el México del milenio. Búsquedas, encuentros y transiciones, pp. 247-294. Instituto Nacional Indigenista-Consejo Nacional para la Cultura y las Artes-Fondo de Cultura Económica.

$2004 a$ ed. Haciendo justicia. Interlegalidad, derecho y género en regiones indígenas. Cámara de Diputados LIX Legislatura-Centro de Investgaciones y Estudios Superiores en Antropología Social-Miguel Ángel Porrúa. México.

$2004 b$

"Introducción. Hacia una interpretación comprensiva de la relación entre justicia, derecho y género: los procesos interlegales en regiones indígenas", en María Teresa Sierra Camacho, ed. Haciendo justicia. Interlegalidad, derecho y género en regiones indígenas, pp. 11-56. Cámara de Diputados LIX Legislatura-Centro de Investigaciones y 
Estudios Superiores en Antropología Social-Miguel Ángel Porrúa. México.

2005 - "Debates antropológicos en torno a la interlegalidad y el pluralismo jurídico y sus aportes para pensar los derechos indígenas y las políticas del reconocimiento", ponencia presentada en el Encuentro Pueblos y Fronteras, Pre-Congreso de la Red Latinoamericana de Antropología Jurídica, San Cristóbal de las Casa, Chiapas (5-9 de octubre), PROIMMSE-UNAM

2006 Sierra Camacho, María Teresa. "La renovación de la justicia indígena en tiempos de derechos: etnicidad, género y diversidad", en Ruth Stanley, (comp.) Estado, Violencia, Ciudadanía en América Latina. Vervuert. Frankfurt-Madrid.

2002 Sierra Camacho, María Teresa, y Victoria Chenaut. "Los debates recientes y actuales en la antropología jurídica: las corrientes anglosajonas", en Esteban Krotz, ed. Antropología Jurídica: perspectivas socioculturales en el estudio del derecho, pp. 132-170. Anthropos-Universidad Autónoma Metropolitana Iztapalapa. Barcelona-México.

1987 Soberanes Fernández, José Luis. "Distrito judicial", en: Diccionario jurídico mexicano, pp. 1172-1173. Porrúa-Instituto de Investigaciones JurídicasUniversidad Nacional Autónoma de México. (Segunda edición), tomo II. México.

1982 Stavenhagen, Rodolfo, coord. Derecho indígena y derechos humanos. Colegio de México. México

1990 . "Derecho consuetudinario indígena en América Latina", en Rodolfo Stavenhagen y Diego Iturralde, comps. Entre la ley y la costumbre: el derecho consuetudinario indígena en América Latina, pp. 27-46. Instituto Indigenista Interamericano-Instituto Interamericano de Derechos Humanos. México-San José.

1992 "La cuestión étnica: algunos problemas teóricometodológicos", en Estudios sociológicos de El Colegio de México. [Núm. monográfico sobre "etnicidad y sus representaciones. Problemas teóricometodológicos"], Vol. 10, Núm. 28, pp. 53-76.

1990 Stavenhagen, Rodolfo, y Diego Iturralde, comps. Entre la ley y la costumbre: el derecho consuetudinario indígena en América Latina. Instituto Indigenista Interamericano-Instituto Interamericano de Derechos Humanos. MéxicoSan José.

1994 Swartz, Marc, Victor W. Turner, y Arthur Tuden. “Antropología política: una introducción", en Alteridades, año 4, Núm. 8, pp. 101-126. 


\section{$\mathbf{T}$}

1993 Turner, Victor. "Pasos, márgenes y pobreza: símbolos religiosos de la comunitas", en: Paul Bohannan y Mark Glazer, comps. Antropología: lecturas, pp. 515-544. McGraw-Hill (Segunda edición). Madrid.

2003 Tutino, John, "Presentación", en Mallon, Florencia. Campesino y nación. La construcción de México y Perú poscoloniales, pp. 29-36. El Colegio de San Luis-El Colegio de Michoacán-Centro de Investigaciones y Estudios Superiores en Antropología Social. México.

2001 Valdivia Dounce, María Teresa. "En torno al sistema jurídico indígena", en Anales de Antropología, Núm. 35, pp. 63-77.

2003 . Normas jurídicas en los sistemas de cargos mixes. Zonas alta y media (materiales etnográficos). (Mimeografiado). Universidad Nacional Autónoma de México-Instituto de Investigaciones Antropológicas. México.

2004 Vallejo, Ivette. "Relaciones de género, mujeres nahuas y usos de la legalidad en Cuetzalan", en María Teresa Sierra, ed. Haciendo justicia. Interlegalidad, derecho y género en regiones indígenas, pp. 187-236. CIESAS-Miguel Ángel Porrúa.

2002 Varela, Roberto. “Naturaleza/cultura, poder/política, autoridad/legalidad/ legitimidad", en Esteban Krotz, ed. Antropología jurídica: perspectivas socioculturales en el estudio del derecho, pp. 69-111. Anthropos-Universidad Autónoma Metropolitana Iztapalapa. Barcelona-México.

1999 Velásquez, María Cristina. "Fronteras de gobernabilidad en Oaxaca", en Willem Assies, Gemma Van der Haar y André Hoekema, eds. El reto de la diversidad, pp.289-313. Colegio de Michoacán. México.

2000 - El nombramiento: las elecciones por usos y costumbres en Oaxaca. Instituto Estatal Electoral. Oaxaca.

1999 Villoro, Luis. Estado plural, pluralidad de culturas. Paidós-Facultad de Filosofía y Letras-Universidad Nacional Autónoma de México. México.

\section{Z}

1980 Zafra, Gloria. "Problemática agraria en Oaxaca: 1971-1975", en Raúl Benítez Zenteno, comp. Sociedad y Política en Oaxaca 1980, 15 estudios de caso, pp. 331-349. Universidad Autónoma "Benito Juárez" de Oaxaca-Instituto de Investigaciones Sociológicas. Oaxaca.

2004 Zapata Tarrés, Clara. ¿La gente de la palabra? Identidad, tierra, escritura y costumbre en la Sierra Juárez de Oaxaca. (Tesis de maestría en Antropología 
Social). Centro de Investigaciones y Estudios Superiores en Antropología Social. México.

\section{LEGISLACIÓN}

1990 Constitución Política de los Estados Unidos Mexicanos. Porrúa (Octogésima novena edición). México.

1990 Constitución Política del Estado Libre y Soberano de Oaxaca, en: Periódico Oficial del Estado de Oaxaca, 29 de octubre.

1993 Ley Orgánica Municipal en: http://www.elocal.gob.mx/wb2/ELOCAL/ELOC_Ley_Organica_Municipal_15 [27 de febrero de 2000]

1995 Código de Instituciones Políticas y Procedimientos Electorales de Oaxaca. Instituto Estatal Electoral. Oaxaca.

2007 Código de Procedimientos Penales de Oaxaca, en <http://www.ordenjuridico.gob.mx/Estatal/OAXACA/Codigos/OAX COD04.pdf $>$ [consultado el 17 de julio de 2007]

1998 Decreto número 258, aprobado por la LVI legislatura constitucional del Estado, mediante el cual se reforman y adicionan diversos artículos en materia indígena de la Constitución Política del Estado Libre y Soberano del Estado de Oaxaca, en Periódico Oficial del Estado, Núm. 23, tomo LXXX, Oaxaca de Juárez, Oaxaca, 6 de junio.

1998 Ley de Derechos de los pueblos y comunidades indígenas del Estado de Oaxaca (conocida como Ley Indígena del Estado de Oaxaca) en: www.ordenjuridico.gob.mx/Estatal/OAXACA/Leyes/OAXLEY017.pdf.

2003 Ley Agraria, en Agenda Agraria. Compendio de leyes, reglamentos y otras disposiciones conexas sobre la materia. Ediciones Fiscales ISEF. México.

\section{Expedientes agrarios}

Ordenados cronológicamente

Núm. 20 del año 1583, con el resumen: "Testimonio de Convenio Celebrado para la posesión de tierras, entre los pueblos de Ocotepec, Jayacaxtepec y Móctum". Archivo Histórico del Poder Judicial del estado de Oaxaca.

Núm. 46 del año 1694: "Diligencias hechas para que los naturales y especialmente los del pueblo mixe ocurran a reparar las casas de los vecinos de villa 
Alta según Real Provisión". Archivo Histórico del Poder Judicial del Estado de Oaxaca.

Núm. 138 del año 1694: "Acuerdo Celebrado entre pueblos de Totontepec, Amatepec, Móctum y Tiltepec, sobre la forma de abastecer de leña, zacate y otros". Archivo Histórico del Poder Judicial del Estado de Oaxaca.

Núm. 229 del año 1755: “Los principales y el común del pueblo de Móctum contra los del Pueblo de Totontepec sobre tierra". Archivo Histórico del Poder Judicial del Estado de Oaxaca.

Núm. 482 del año 1793: "Convenio celebrado entre el común del pueblo de Móctum y el de Jayacaxtepec sobre tierras". Archivo Histórico del Poder Judicial del Estado de Oaxaca.

Núm. 739-TC: “Confirmación y Titulación de Terrenos Comunales del poblado de Totontepec Villa de Morelos, Municipio mismo nombre (m/n), Distrito Mixe, Oaxaca". Archivo General de la Secretaría de la Reforma AgrariaOaxaca.

Núm. 276.../807 (General y Ejecución): “Confirmación y Titulación de Terrenos Comunales. San Marcos Móctum, Municipio de Totontepec, Distrito Mixe, Oaxaca". Archivo General de la Secretaría de la Reforma AgrariaOaxaca.

Carpeta Básica de San Marcos Móctum: Resolución Presidencial (2 de septiembre de 1975), Acta de Ejecución y Deslinde (2 de agosto de 1980) y Plano Definitivo (10 de diciembre de 1990). Archivo del Comisariado de Bienes Comunales de San Marcos Móctum.

Dictamen que recae sobre la acción agraria de Reconocimiento y Titulación de Bienes Comunales de San Marcos Móctum. Fechado y firmado por el Consejero Agrario del Cuerpo Consultivo Agrario, en: México, D.F. 9 agosto de 1974. 11 fojas (expediente 2761/167). Archivo General de la Secretaría de la Reforma Agraria-Oaxaca.

\section{Páginas electrónicas}

<http://es.encarta.msn.com/encyclopedia_761586289_2/Bulas_Alejandrinas.html> [3 de mayo de 2006]

<http://es.wikipedia.org/wiki/Reducciones_de_indios> [3 de mayo de 2006]

<http: //www.redindigena.net/ser/pueblomixe/localizacion.html $>[25$ de noviembre 2006]

<http://www.ilo.org/ilolex/gbs/ceacr2006.htm> [25 de noviembre de 2006]

<http://www.e-local.gob.mx/work/templates/enciclo/oaxaca> [6 de abril de 2007]

$<$ http:/ / www.inegi.gob.mx> [6 de abril de 2007]

$<$ http://www.laneta.apc.org/rci/organinteg/mixe.html>[consultado el 12 de febrero 2007]

<http://www.e-local.gob.mx/work/templates/enciclo/oaxaca/index.html> [6 de 
abril de 2007]

<http://www.ilsa.org.co> [Consulta 25 de febrero 2007]

<http://www.ilsa.org.co/recherche.php3?recherche=Pluralismo $>$ [Consulta 25 de febrero 2007]

<http://www.monografias.com/trabajos7/vimu/vimu.shtm> [27 defebrero 2007]

>http://www.e-local.gob.mx/work/templates/enciclo/oaxaca/index.html> [15

de julio de 2007]

<http://www.e-local.gob.mx/wb2/ELOCAL/ELOC_Ley_Organica_Municipal_15> [15 de julio de 2007]

\section{Acrónimos}

ASAM Asamblea de Autoridades Mixes.

ADHIASAM Academia de Derechos Humanos y Derechos Indígenas de la ASAM.

CECAFE Consejo Estatal del Café.

CIESAS Centro de Investigaciones y Estudios Superiores en Antropología Social.

CONAFE Comisión Nacional de Fomento Educativo.

CONASUPO Compañía Nacional de Subsistencia Popular.

CTBC Confirmación y Titulación de Bienes Comunales.

DIF Desarrollo Integral de la Familia.

DOF Diario Oficial de la Federación.

IMSS Instituto Mexicano del Seguro Social.

INAH Instituto Nacional de Antropología e Historia.

INEGI Instituto Nacional de Estadística Geografía e Informática.

INI Instituto Nacional Indigenista.

LFRA Ley Federal de Reforma Agraria.

OACNUDH Oficina del Alto Comisionado de Naciones Unidas para los Derechos Humanos.

OIT Organización Internacional del Trabajo.

OMIZACH Organización Mixe, Zapoteca, Chinanteca.

PA Procuraduría Agraria.

SAGARH Secretaría de Agricultura, Ganadería y Recursos Hidráulicos.

SAIAC Servicios de Apoyo Intercultural, A.C.

SER Servicios del Pueblo Mixe.

PROCAMPO Programa de Apoyo a los Productores del Campo.

PROCEDE Programa de Certificación de Derechos Ejidales y Titulación de Solares Urbanos.

PROGRESAPrograma Nacional de Educación, Salud y Alimentación.

SCT Secretaría de Comunicaciones y Transportes.

SEDESOL Secretaría de Desarrollo Social.

SER Servicios del Pueblo Mixe.

SRA Secretaría de la Reforma Agraria. 
TELECOM Telecomunicaciones de México.

TUDH Taller Universitario de Derechos Humanos.

UAM-I Universidad Autónoma Metropolitana Unidad Iztapalapa.

UNAM Universidad Nacional Autónoma de México. 


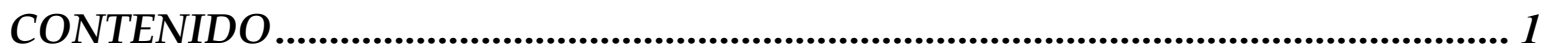

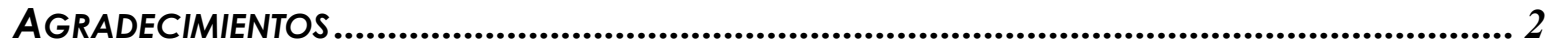

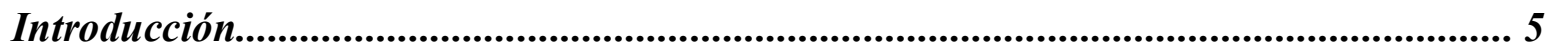

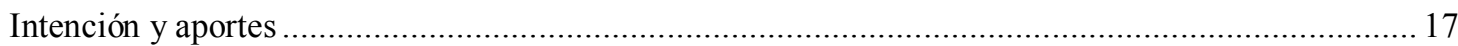

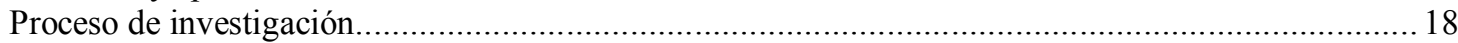

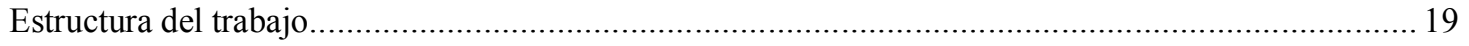

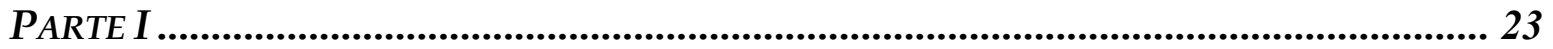

TRANSFORMACIÓN Y PROCESOS DE CAMBIO EN EL CAMPO JURÍDICO: RELACIÓN ENTRE EL ESTADO Y LOS PUEBLOS INDÍGENAS ....................................................................................... 23

Introducción........................................................................................................................... 23

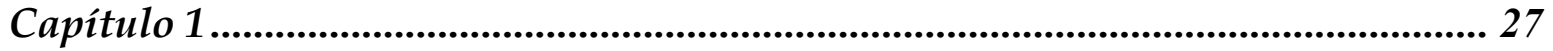

La Tensión en la Relación del Estado con los Pueblos Indígenas. Alteridad y Derecho. 27

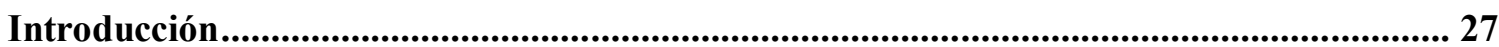

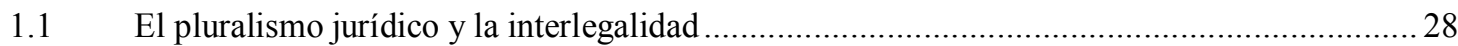

1.2 Influencia del derecho estatal en las dinámicas locales y el sistema jurídico indígena como

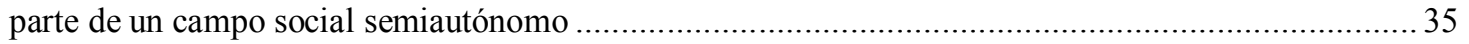

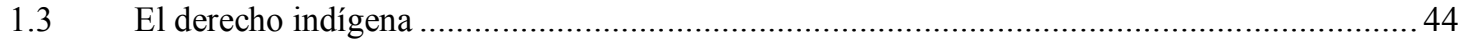

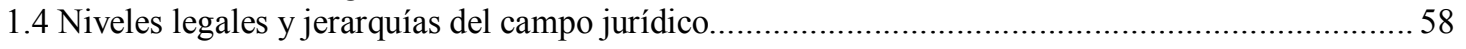

Capitulo 2 .............................................................................................. 61

Las Tensiones en el Campo Jurídico: Lo Territorial .................................................... 61

Introducción ............................................................................................................................................... 61

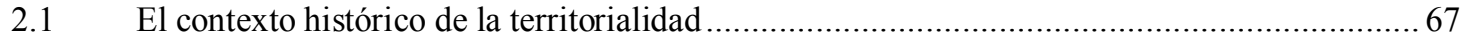

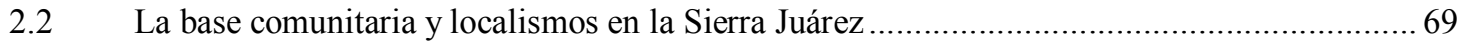

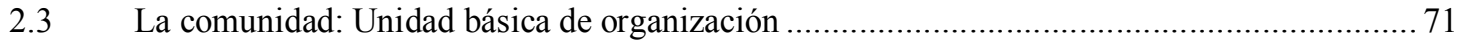

2.4 La comunidad como unidad político-territorial: El reparto agrario ...................................... 72

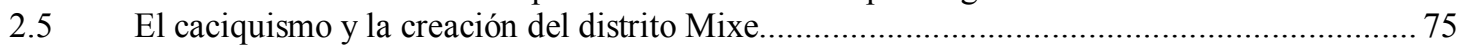

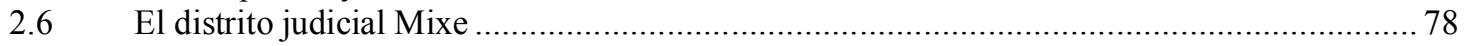

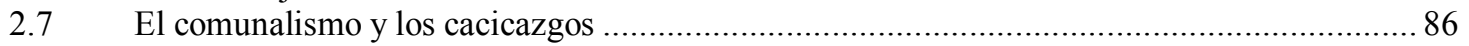

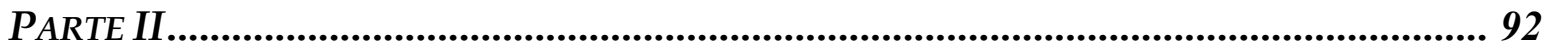

Niveles Legales del Campo Jurídico y sus Tensiones: El caso de Totontepec y San

Marcos Móctum ................................................................................................................ 92

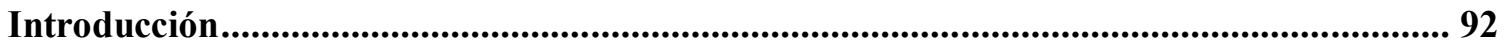

Capitulo 3 ................................................................................................ 99

La relación entre el Distrito, el Municipio y la Localidad como Demarcaciones Territoriales del Campo Jurídico ................................................................................. 99

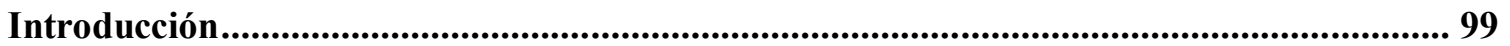

3.1 Aspecto cultural en la relación de los campos sociales ............................................. 102

3.1.1 El comunitarismo y el sentido de unidad étnica ..................................................... 102

3.1.2 Totontepec y Móctum: Un ejemplo de diversidad cultural entre los mixes....................... 105

3.2 Totontepec Villa de Morelos y San Marcos Móctum: Las identidades compartidas ............ 109

3.2.2 El campo social semiautónomo de la cabecera municipal de Totontepec Villa de Morelos.. 113 
Agencias de Totontepec Villa de Morelos

3.2.3 El campo social semiautónomo de San Marcos Móctum, agencia de policía......................... 116

3.3 La descaracterización étnica en la configuración municipal como una tensión en el campo jurídico 119

3.3.1 Tensión entre cabecera y agencia: Totontepec como pueblo descaracterizado.

Conclusión

La Cuestión Agraria como Estructuradora del Derecho y la Autonomía Comunitaria 132

Introducción.

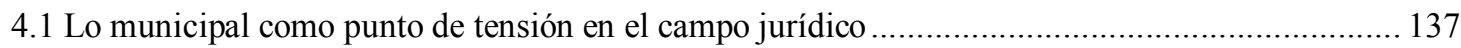

4.2 El conflicto agrario y su relación con las dinámicas comunitarias: El expediente agrario .... 146

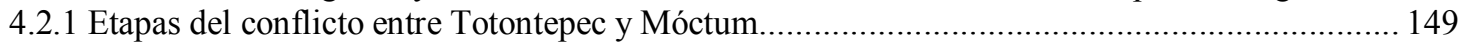

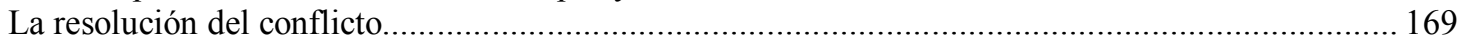

4.3 Lo municipal como punto de tensión en la relación entre Móctum y Totontepec..................... 174

Disputa por los recursos: Reivindicación de derechos de las agencias frente a la cabecera................... 175

La hacienda municipal......................................................................................................................176

Participación y aportaciones federales........................................................................................176

La tensión entre Totontepec y sus agencias...........................................................................178

Obras municipales en Totontepec ......................................................................................180

Móctum y su reivindicación de derechos frente a la cabecera..........................................182

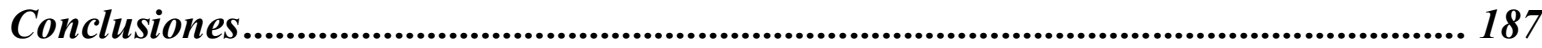

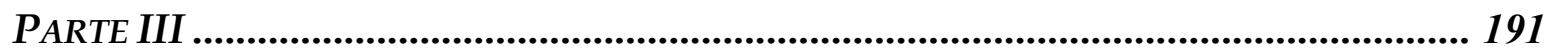

Las Dinámicas del Campo Jurídico y la Confrontación entre Instancias....................... 191

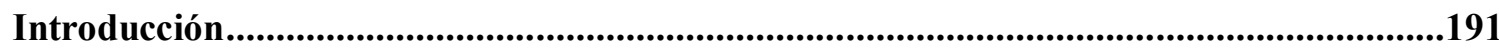

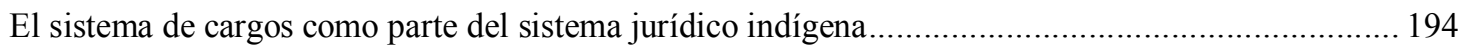

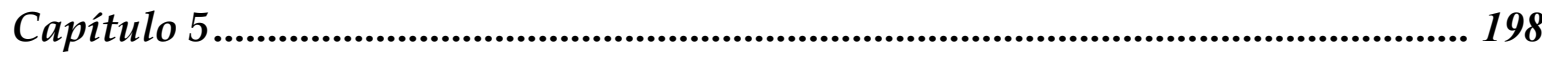

El Sistema Jurídico y la Resolución de Conflictos en Totontepec................................... 198

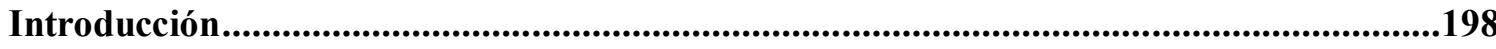

5.1 La justicia y el derecho en las dinámicas locales y municipales................................................. 202

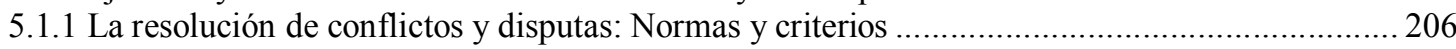

5.1.1.1 Asuntos que se presentan y resuelven en la cabecera municipal: Imbricación de sistemas legales

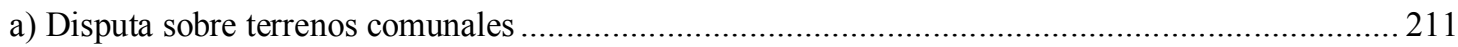

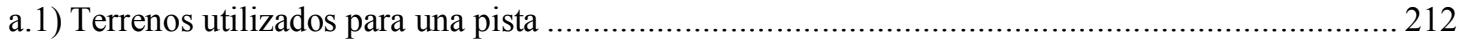

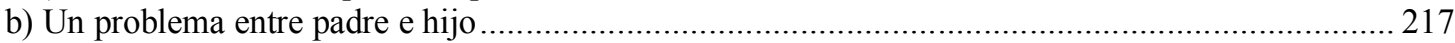

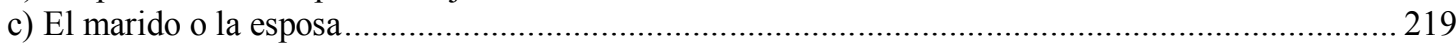

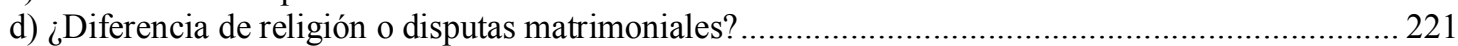

e) El error y la reparación del daño: ¿Crimen y castigo? .............................................................. 222

f) Cuestionamiento a la justicia comunitaria: ¿El abogado indígena o la mujer como cliente?............224

g) Las deudas económicas y el derecho a la libertad física .................................................................22

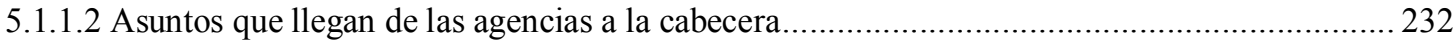

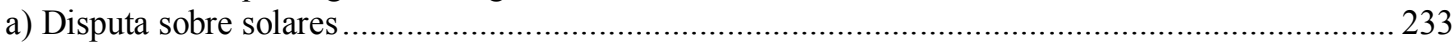

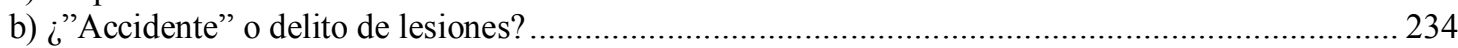

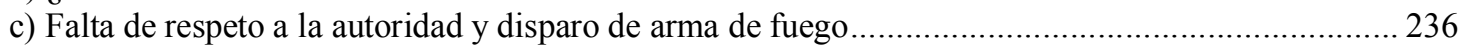


d) La integridad física como bien jurídicamente tutelado: entre la violación sexual y el abuso de a

e) Negativa a realizar cargo y cuestionamiento de la autoridad comunal ..................................... 244

h) Confrontación entre niveles legales del campo jurídico: Las instancias del Estado y las instancias

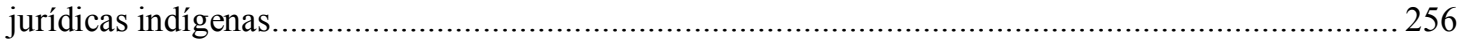

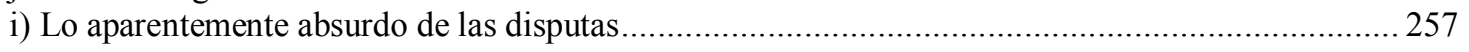

Conclusión ........................................................................................................................... 259

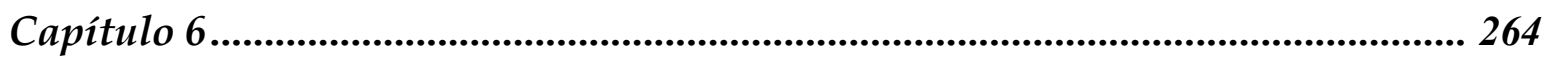

Las Instancias Legales y el Sistema Jurídico en San Marcos Móctum .......................... 264

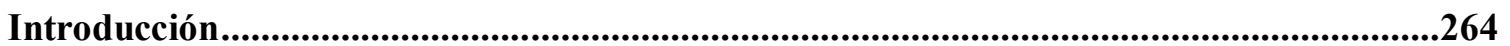

6.1 Las dinámicas comunitarias en su relación con lo agrario y su influencia en el derecho ....... 267

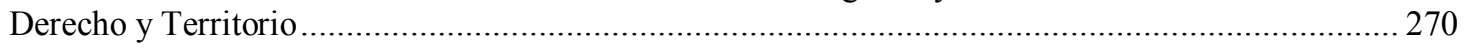

La influencia del sistema jurídico mexicano en la dinámica comunitaria y en el sistema jurídico

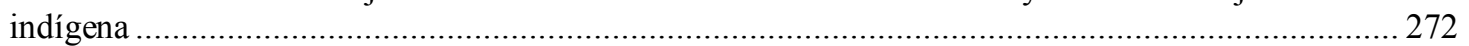

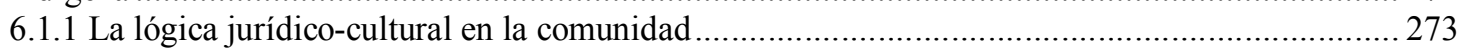

6.1.1.1 Asuntos relevantes sobre el patrimonio particular: Robos y daños .................................2276

6.1.1.2 La propiedad comunal como asunto relevante de la comunidad...................................... 278

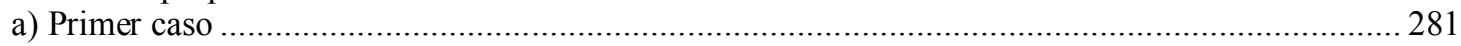

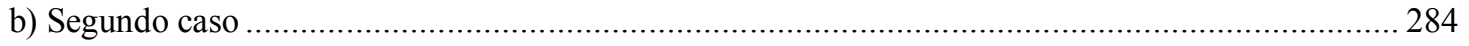

6.1.3 La adscripción y autoadscripción comunitaria: El sistema de cargos en Móctum y Totontepec . 286

Cargos y servicios en Totontepec................................................................................ 291

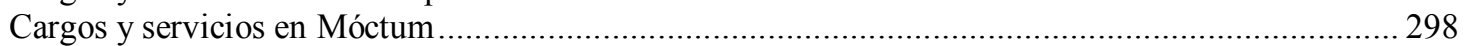

Móctum y Totontepec: Dos formas de sistema de cargos .................................................. 304

6.2 Influencias del derecho estatal en la configuración del derecho en la comunidad ................306

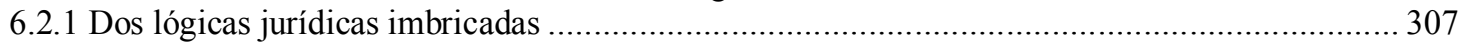

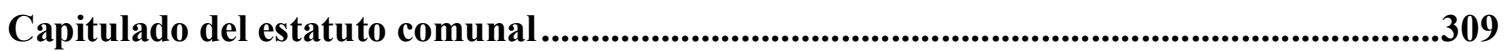

Capítulo II de los comuneros ..........................................................................................................309

Capítulo III de los órganos internos de la comunidad ................................................................310

Un compromiso con la Secretaría de la Reforma Agraria.......................................................310

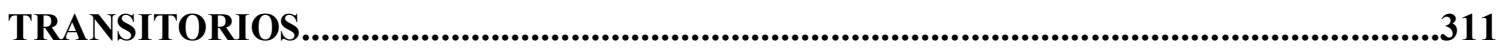

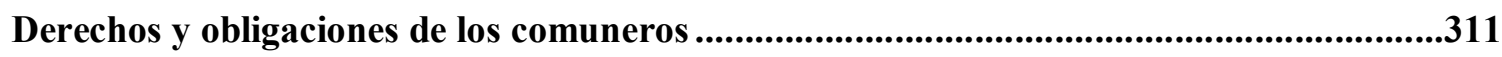

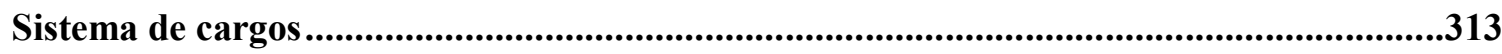

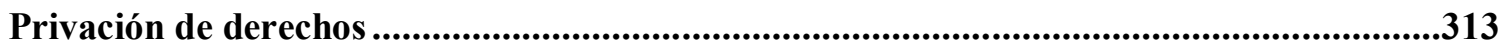

Expulsión de un comunero ..........................................................................................................318

Otros asuntos: Robos, incumplimiento del tequio y disparo de arma de fuego ...................321

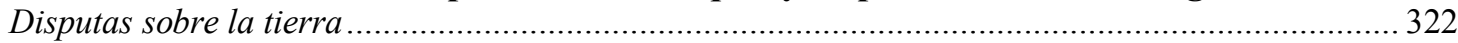

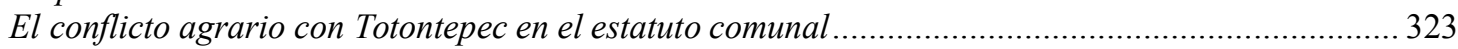

Organización interna para la producción ............................................................................. 324

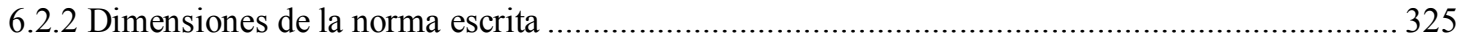

A manera de conclusión.............................................................................. 327

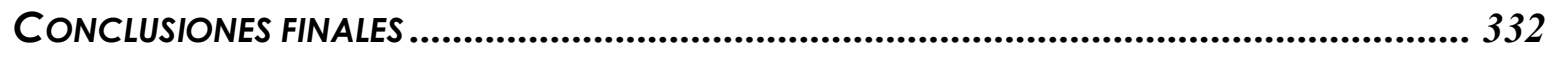

Bibliografía ............................................................................................................ 347

A 


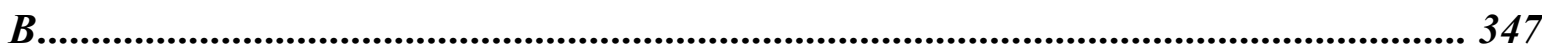

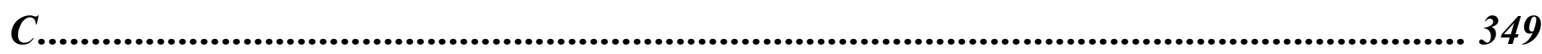

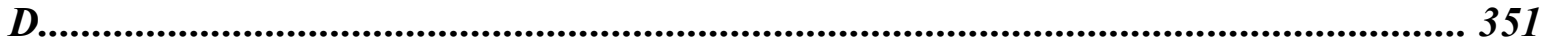

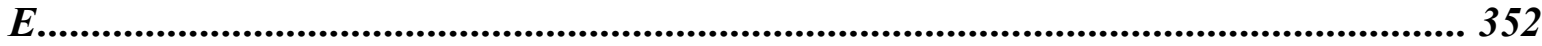

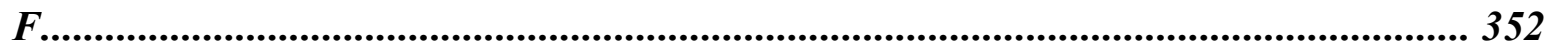

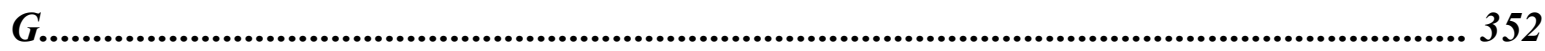

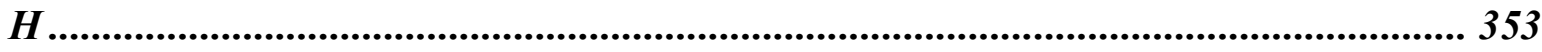

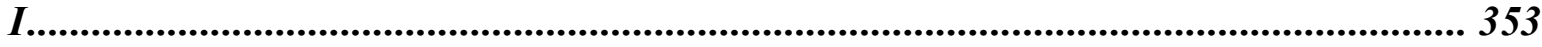

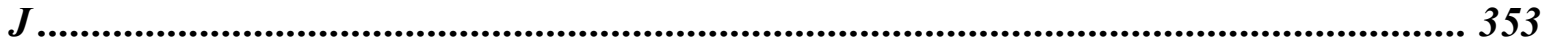

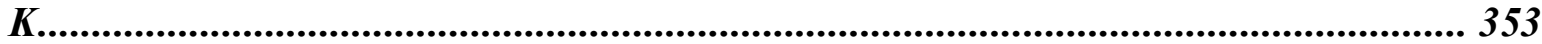

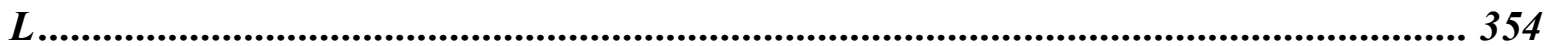

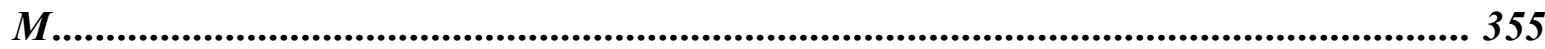

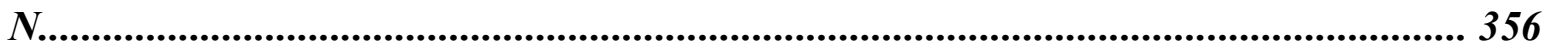

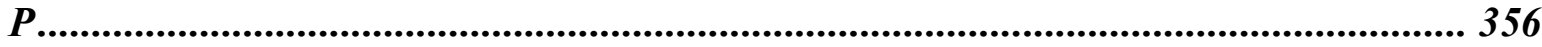

R

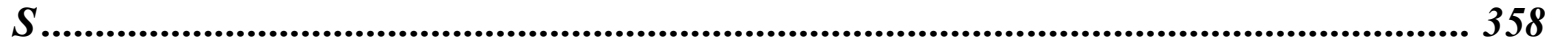

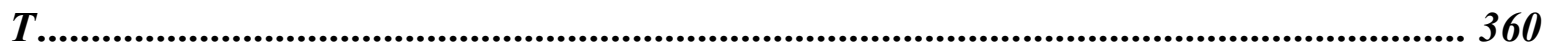

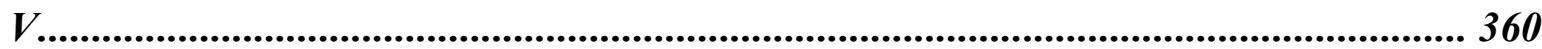

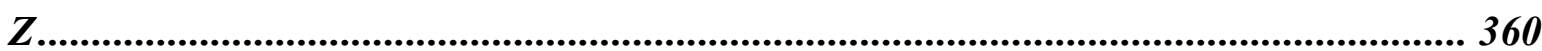

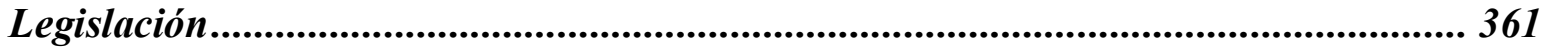

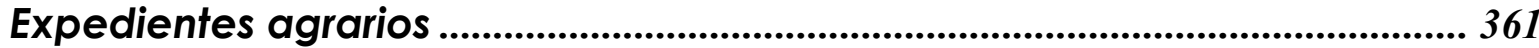

Páginas electrónicas ....................................................................................... 362

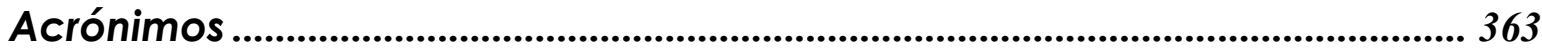

\section{Mapas}

Mapa 1 El distrito Mixe

Mapa 2 El territorio (región)

Mixe

Mapa 3 Areas Culturales Colindantes y Centros ¡Error! Marcador no definido.5 Rectores

Mapa 4 Camino a Móctum

Diagramas

Diagrama 1. "Sistema de Cargos deTotontepec" 294

Diagrama 2. "Los cargos en San Marcos Móctum" 300 


\section{Cuadros}

Agencias de Totontepec Villa de Morelos

113

\section{Tablas.}

TABLA 1. Población de 5 años y más que habla lengua indígena por municipio y tipo de lengua, y su distribución según condición de habla española y sexo (Municipio de Totontepec)

TABLA 2. Población de 5 años y más que habla lengua indígena por municipio y tipo de lengua, y su distribución según condición de habla española y sexo (Dto. Mixe)

TABLA 3 Población de 5 años y más por municipio, sexo y religión, y su distribución según grupos quinquenales de edad (en el Dto. Mixe)

TABLA 4. Población de 5 años y más por municipio, sexo y religión, y su distribución según grupos quinquenales de edad (en Totontepec)

\section{Fotografías}

Santiago Zacatepec $\quad 83$

Edificio del Ayuntamiento de Totontepec $\quad 91$

Comunidad-agencia municipal de Santa María Huitepec $\quad 101$

Móctum y el Cerro del Zempoaltépetl 104

Vista de la cabecera-comunidad de Totontepec 105

Escudo de Totontepec 107

Don Cipriano Gómez Gómez $\quad 172$

Eificio de la Agencia Municipal de San Marcos Móctum 183

Maíces mixes $\quad 190$

Día de mercado en Totontepec 201

Don Guillermo Gómez Reyes Alcalde Único Constitucional de 204

Totontepec durante el año 2004

Vista de la comunidad-agencia municipal de Santiago Tepitongo 250

Vista exterior de la Iglesia de Totontepec 256

Niños en Móctum después de trabajar en la parcela escolar 280

Panteón de Totontepec en Semana Santa 296

Mujer llevando leña $\quad 299$

Móctum visto desde el panteón comunitario 330 